Felix Knappertsbusch

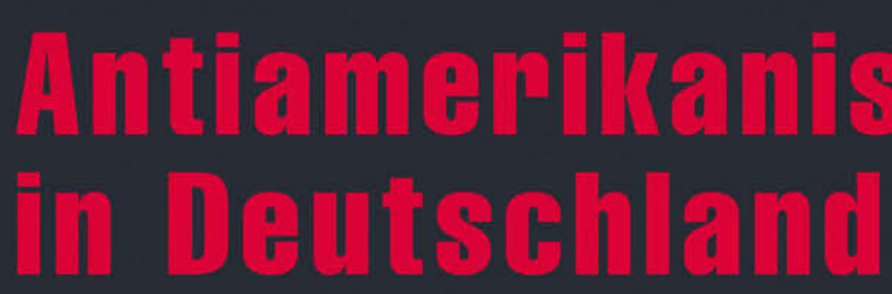

Über die Funktion von Amerikabildern in nationalistischer und ethnozentrischer Rhetorik 
Felix Knappertsbusch

Antiamerikanismus in Deutschland

Kulturen der Gesellschaft | Band 2I 
Felix Knappertsbusch, geb. I98I, ist wissenschaftlicher Mitarbeiter am Institut für Soziologie der Justus-Liebig-Universität Gießen. Zu seinen Arbeitsschwerpunkten zählen die Vorurteils- und Diskriminierungsforschung sowie Methoden und Methodologie empirischer Sozialforschung. 
Felix KNAPpertsbusch

\section{Antiamerikanismus in Deutschland}

Über die Funktion von Amerikabildern in nationalistischer und ethnozentrischer Rhetorik

[transcript $]$ 
Die Publikation dieses Bandes wurde unterstützt durch Druckkostenzuschüsse der Wilhelm Hahn und Erben-Stiftung, Bad Homburg sowie der UniversitätsStiftung der Philipps-Universität Marburg.

\section{(c) $(1) \Theta \Theta$}

Dieses Werk ist lizenziert unter der Creative Commons Attribution-NonCommercial-NoDerivs 4.0 Lizenz (BY-NC-ND). Diese Lizenz erlaubt die private Nutzung, gestattet aber keine Bearbeitung und keine kommerzielle Nutzung. Weitere Informationen finden Sie unter https://creativecommons.org/licenses/by-nc-nd/4.o/deed.de/. Um Genehmigungen für Adaptionen, Übersetzungen, Derivate oder Wiederverwendung zu kommerziellen Zwecken einzuholen, wenden Sie sich bitte an rights@transcript-verlag.de

\section{(C) 2016 transcript Verlag, Bielefeld}

Die Verwertung der Texte und Bilder ist ohne Zustimmung des Verlages urheberrechtswidrig und strafbar. Das gilt auch für Vervielfältigungen, Übersetzungen, Mikroverfilmungen und für die Verarbeitung mit elektronischen Systemen.

\section{Bibliografische Information der Deutschen Nationalbibliothek}

Die Deutsche Nationalbibliothek verzeichnet diese Publikation in der Deutschen Nationalbibliografie; detaillierte bibliografische Daten sind im Internet über http://dnb.d-nb.de abrufbar.

Umschlagkonzept: Kordula Röckenhaus, Bielefeld

Druck: Majuskel Medienproduktion GmbH, Wetzlar

Print-ISBN 978-3-8376-3388-7

PDF-ISBN 978-3-8394-3388-1

Gedruckt auf alterungsbeständigem Papier mit chlorfrei gebleichtem Zellstoff. Besuchen Sie uns im Internet: http://www.transcript-verlag.de Bitte fordern Sie unser Gesamtverzeichnis und andere Broschüren an unter: info@transcript-verlag.de 


\section{Inhalt}

\section{Danksagung | 9}

1. Einleitung: Antiamerikanische Vorurteile als gesellschaftliches und theoretisches Problem | 11

1.1 Die historische und aktuelle Relevanz antiamerikanischer Vorurteile | 19

1.2 Fragestellung und Forschungsdesign der Studie I 24

1.3 Die normative Verortung der Vorurteilskritik I 28

1.4 Aufbau der Arbeit I 32

2. Was ist falsch am Antiamerikanismus? Forschungsgegenstand und Stand der Forschung | 39

2.1 Aufgeklärter Antiamerikanismus? Widerstände gegen eine anti-antiamerikanische Vorurteilskritik | 41

2.2 Die Problematisierung des Antiamerikanismusbegriffes in der Forschungsliteratur $\mid 47$

2.3 Probleme des Prejudice-as-Attitude Ansatzes I 54

2.4 Zwischenfazit: Ein performativer Antiamerikanismusbegriff I 77

3. Vorurteilskritik und Sprachpraxis | 83

3.1 Praxistheorie der Bedeutung und Vorurteilskritik: Performativität | 84

3.2 Die Sozialität sprachlicher Bedeutung -

Zur Flexibilität und Kontextabhängigkeit vorurteiligen Sprechens | 90

3.3 Die Normativität sprachlicher Bedeutung und die Teilnehmerinnenperspektive soziologischer Theorie 195

3.4 ,No formula will help to solve this problem“ -

Familienähnlichkeit als Modell der Begriffsbildung I 99

3.5 Zwischenfazit: Ein performativer Antiamerikanismusbegriff II | 106

4. Gesellschaftstheoretische Einordnung: Vorurteile als Ungleichheitssemantiken Vorurteilsforschung als erschließende Kritik | 109

4.1 Ungleichheit und Diskriminierung | 112

4.2 Ungleichheitssemantiken und die symbolische Ordnung sozialer Ungleichheit I 115

4.3 Zwischenfazit: Vorurteile als Ungleichheitssemantiken I 121 
4.4 Der immanente Widerspruch der egalitären Norm und die Rechtfertigung kategorialer Differenzkonstruktionen I 123

4.5 Vorurteil als Ideologie,

Vorurteilsforschung als ,erschließende Kritik“| 131

4.6 Vorurteil und Nationale Identität: Ethnozentrismus, Antisemitismus, Antiamerikanismus | 152

4.7 Zwischenfazit: Ein performativer Antiamerikanismusbegriff III | 164

\section{Empirische Methode und Methodologie | 169}

5.1 Das Wechselverhältnis von Theorie und Empirie und die Bedeutung qualitativer Methoden I 170

5.2 Vorurteilskritik als ,empirisch begründete Theoriebildung“| 174

5.3 Die Integration qualitativer und quantitativer Methoden in der empirisch begründeten Theoriebildung | 182

5.4 Fallauswahl und Feldzugang | 189

5.5 Erhebung des qualitativen Materials I 194

5.6 Auswertung des qualitativen Materials I 196

5.7 Zwischenfazit | 202

6. Statistische Ergebnisse: Antiamerikanismus in den Surveydaten | 205

6.1 Beschreibung der Antiamerikanismus-Indikatoren I 206

6.2 Dimensionalität und Verteilung der Antiamerikanismus-Skala | 210

6.3 Die Verbreitung von Antiamerikanismus in der Bevölkerung Deutschlands | 214

6.4 Korrelationen von Antiamerikanismus und Gruppenbezogener Menschenfeindlichkeit I 223

6.5 Zusammenfassung der statistischen Ergebnisse I 227

\section{Ergebnisdarstellung der qualitativen Empirie | 231}

7.1 Einleitung | 231

7.2 Antiamerikanismus in Funktionskontexten nationaler Identität I 240

7.3 Antiamerikanismus im Funktionskontext von Erinnerungspolitik, Schuldabwehr und Antisemitismus | 268

7.4 Antiamerikanismus im Funktionskontext von Ethnozentrismus und Rassismus | 292

7.5 Die unscharfen Ränder des Antiamerikanismusbegriffes Ambivalenzen, Fragmentierung und verschobene Funktionskontexte | 316

7.6 Zusammenfassung und Diskussion der qualitativ-empirischen Analysen I 348 


\section{Schluss $\mid 375$}

8.1 Fazit der Theoriebildung I 376

8.2 Fazit der methodenintegrativen Empirie | 383

8.3 Mögliche theoretische und empirische Perspektivenerweiterungen der Antiamerikanismusforschung | 388

8.4 Geltungsreichweite der Ergebnisse und empirisch-methodische Anknüpfungspunkte I 394

8.5 Resümee und Ausblick | 395

Literatur | 401 



\section{Danksagung}

Bei dem vorliegenden Band handelt es sich um die geringfügig überarbeitete Fassung meiner Dissertationsschrift, die am 6. Februar 2015 vom Fachbereich Gesellschaftswissenschaften und Philosophie der Philipps-Universität Marburg angenommen wurde. Ohne all die Menschen aufzählen zu können, die die Entstehung dieser Arbeit mit ermöglicht haben, möchte ich doch einige hier namentlich erwähnen und ihnen meinen ganz besonderen Dank aussprechen. Danken möchte ich dem Betreuer meiner Dissertation, Udo Kelle, für treffende methodologische Kritik, seinen theoretischen Liberalismus sowie sein lebhaftes soziologisches Interesse; Thorsten Bonacker, Elmar Schlüter und Sighard Neckel für ihre großzügige Unterstützung und wertvollen Ratschläge; den Mitgliedern des Graduiertenkollegs Gruppenbezogene Menschenfeindlichkeit, insbesondere Mathias Bös, Manuela Freiheit, Mathias Kauff, Andrea Newerla, Veronika Schmid, Peter Schmidt, Kristina Seidelsohn, Stefan Thörner, Ulrich Wagner und Corinna Zakikhani, für methodische wie theoretische Horizonterweiterungen und kollegiale Unterstützung; meinen Eltern, Helga und Christoph Knappertsbusch, für die bedingungslose Förderung meines Studiums, ihre Gelassenheit und ihren bruchlosen Glauben an meine Tätigkeit; Monika und Cornelius Gutenbrunner für ihre großzügige Hilfe; Michael Höttemann, Frank Rüthrich, Matti Traußneck, Katharina Madl, Björn Milbradt, Tim Williams, Dirk Schröder und Sebastian Schreull für anregende Gespräche, freundliche Anteilnahme, unentbehrliche Kritik und tatkräftige Unterstützung; Lisa Gutenbrunner für die unzähligen, wunderbaren Spiegelungen, ihre grenzenlose Solidarität und den bodenlosen Halt unseres gemeinsamen Zuhauses.

Marburg, im Dezember 2015

Felix Knappertsbusch 



\section{Einleitung: Antiamerikanische Vorurteile als gesellschaftliches und theoretisches Problem}

Antiamerikanische Vorurteile sind ein gesellschaftliches Problem. Spätestens seit den Anschlägen des 11. September 2001 hat das Thema einen prominenten Platz in öffentlichen Diskursen eingenommen. Das Ausmaß der terroristischen Gewalt, der an diesem Tag nahezu 3000 Menschen zum Opfer fielen, machte den Zusammenhang von antiamerikanischem Vorurteil und menschenfeindlicher Gewalt schlagartig klar. Doch die Diskussionen um Antiamerikanismus, die auf die Anschläge folgten, beschäftigten sich nicht nur mit den Taten der Terroristen. Als antiamerikanisch wurden auch bestimmte Erklärungen und Rechtfertigungen der Anschläge sowie Proteste gegen die von den USA geführten Militäreinsätze in Afghanistan und Irak oder das amerikanische Gefangenenlager in Guantanamo Bay bezeichnet.

Unabhängig davon, ob diese Antiamerikanismusvorwürfe im Einzelnen berechtigt waren, lässt sich zunächst festhalten: Um als antiamerikanisch gelten zu können, muss eine Handlung offenbar nicht Amerikanerinnen und Amerikaner ${ }^{1}$ mit dem Leben bedrohen. Es besteht vielmehr, wie bei vielen anderen Vorurteilsformen, ein stärker vermitteltes Verhältnis zwischen Gewalt und Vorurteil. Die Art dieser Vermittlung ist aber alles andere als klar und konsensuell festgelegt, wie auch das folgende Beispiel nahelegt: Als im Sommer 2013 wöchentlich neue Meldungen über die Überwachungsmethoden des amerikanischen Geheimdienstes NSA erschienen, wies der damalige Innenminister Hans-Peter Friedrich die Skandalisierung der Vorfälle als „Mischung aus Antiamerikanismus und Naivität“ zurück (vgl. Zahn 2013). Diejenigen, gegen die er sich damit wandte, hatten freilich keine amerikanischen Staatsangehörigen bedroht, sondern die USA pauschalisierend bspw.

1 Mit Amerika bzw. Amerikanerinnen und Amerikanern sind in dieser Arbeit immer die USA und deren Bevölkerung gemeint bzw. deren Wahrnehmung in den Augen der Untersuchungsteilnehmenden. 
als „digitale Besatzungsmacht“ (F.A.Z. 2013) bezeichnet. Dass sich in diesen Sprechhandlungen nicht dieselbe Amerikafeindschaft ausdrückte, die die Täter des 11. September motivierte, dürfte Friedrich durchaus bewusst gewesen sein. Worauf bezog er sich dann aber mit seinem Antiamerikanismusvorwurf? Was hatten die gegen amerikanische Geheimdienstpraktiken Protestierenden getan, das diese Klassifikation begründete und, umgekehrt betrachtet, was tat Friedrich, als er den Terminus Antiamerikanismus in dieser Weise gebrauchte?

Nach gängiger Auffassung wird als Antiamerikanismus eine feindselige Haltung gegenüber den USA verstanden, die auf einem undifferenzierten Amerikabild beruht. In diesem Sinne verwendete wahrscheinlich auch Innenminister Friedrich den Terminus. Angesichts mancher Protestausdrücke mag man dies als gerechtfertigt ansehen. Zugleich ist aber auch die Empörung Vieler nachvollziehbar, die ihre Kritik amerikanischer Abhörmethoden zu Unrecht als Vorurteil klassifiziert fanden. Die populäre Auffassung von Antiamerikanismus als feindseliger, irrationaler Haltung gegenüber den USA scheint bei der Vermittlung dieser beiden Positionen jedenfalls wenig hilfreich. Was für die einen legitime und notwendige Kritik an den USA ist, kommt für andere bereits als antiamerikanisches Ressentiment in Betracht. Insbesondere die gängigen Kriterien ,Irrationalität ${ }^{2}$ und ,Feindseligkeit ${ }^{2}$ scheinen zur Lösung des Disputs nur bedingt geeignet, da i.d.R. alle Beteiligten gleichermaßen beanspruchen, weder feindselig noch irrational zu handeln.

Antiamerikanismus ist also nicht nur ein gesellschaftliches Problem im Sinne menschenfeindlicher Gewalt bzw. deren Legitimation, sondern auch ein (alltags-) theoretisches. Umso wichtiger scheint es, diesem Problem mit einer sozialwissenschaftlich begründeten Kritik zu begegnen, zumal aktuelle Ergebnisse der Surveyforschung nahelegen, dass antiamerikanische Vorurteile in Deutschland weit verbreitet sind (Beyer 2014, S. 94; Beyer und Liebe 2014, S. 137; Decker et al. 2010, S. 125; Knappertsbusch und Kelle 2010, S. 150 ff.; vgl. auch Kap. 6.2). Demnach stimmt in repräsentativen Bevölkerungsstichproben rund ein Zehntel der Befragten abwertenden oder feindseligen Aussagen über ,die Amerikaner‘ zu. Bei weniger drastischen Item-Formulierungen steigt der Anteil zustimmender Antworten teilweise auf über $50 \%$.

Für eine sozialwissenschaftliche Antiamerikanismuskritik bildet die soziologische und sozialpsychologische Forschung, die sich um den Begriff des Vorurteils etabliert hat, einen naheliegenden Ansatzpunkt. Insofern ist es begrüßenswert, dass eine wachsende Zahl von Publikationen Antiamerikanismus im theoretischen Rahmen des Vorurteilsbegriffes bearbeitet (Berman 2008; Beyer 2014; Beyer und Liebe 2014; Ceaser 1997; Markovits 2007; O’Connor 2007b; Katzenstein und Keohane

2 Rationalität wird hierbei i.d.R. in einem sehr allgemeinen, repräsentationalistischen Sinn verstanden als Fähigkeit, reale Sachverhalte in jeweiligen Urteilen angemessen zu berücksichtigen. 
2007b; Knappertsbusch 2013; Knappertsbusch und Kelle 2010). Dies gilt umso mehr, da Antiamerikanismus auch in der Forschungslandschaft zu Vorurteilen und Diskriminierung ein umstrittenes Konzept darstellt. Es gibt kaum eine Studie zu diesem Thema, die nicht mit einer Diskussion von „Definitionsproblem[en]“ einsetzt (Baethge et al. 2010, S. 367; vgl. Gulddal 2011; O’Connor 2007b). Das gesellschaftliche Problem des Antiamerikanismus ist somit zugleich ein Theorieproblem der Antiamerikanismusforschung.

Problematisch erscheint indessen die Weise, in der die existierende Literatur sich auf den Vorurteilsbegriff bezieht. Die vorurteilskritische Antiamerikanismusforschung gebraucht, so wird im Folgenden argumentiert, ein verengtes und reduktionistisches Vorurteilskonzept (vgl. Knappertsbusch et al. 2013; Dixon und Levine 2012a). Zu eng sind dessen Grenzen, weil mit den klassischen Kriterien von Feindschaft, Irrationalität und kognitivem Schematismus nur weltanschaulich konsistente, explizit feindselige Vorurteilsausdrücke erfasst werden. Reduktionistisch ist der Begriff, weil keines der darin benannten Kriterien an sich spezifische sozialtheoretische Gründe dafür gibt, warum bestimmte Verhaltensweisen als Vorurteil kategorisiert werden, andere hingegen, trotz vergleichbarer Ausprägung der genannten Merkmale, nicht. Diese Probleme eines ,prejudice as attitude“-Ansatzes (Nelson 2002, S. 8) treten in der Diskussion um das „Definitionsproblem“ des Antiamerikanismusbegriffes bzw. dessen richtigen Gebrauch besonders deutlich hervor. Dennoch stellen sie keine lokale Verirrung der Antiamerikanismusforschung dar, sondern sie betreffen die begrifflichen Traditionslinien der etablierten Vorurteilsforschung insgesamt. In diesem Sinne richtet sich die vorliegende Arbeit einerseits gegen die Auffassung, Antiamerikanismus könne prinzipiell nicht zum Gegenstand der Vorurteilskritik werden, sei also mit Phänomenen wie Rassismus, Fremdenfeindlichkeit, Antisemitismus grundsätzlich nicht vergleichbar; sie argumentiert, mit einer polemischen Zuspitzung Brendon O'Connors gesprochen, gegen ,the prejudice against seeing anti-Americanism as a form of prejudice" (O'Connor 2007b, S. 19).

Zugleich ist die hier entwickelte Kritik des Antiamerikanismusbegriffes aber auch eine Kritik des Vorurteilsbegriffes insgesamt bzw. seiner konventionellen Verwendung. Ich plädiere somit für die verstärkte Berücksichtigung von Antiamerikanismus als Gegenstand der Vorurteilsforschung, möchte aber gleichzeitig eine Modifikation der theoretischen Bedingungen vorschlagen, unter denen diese Forschung operiert. Diese Modifikation betrifft in erster Linie den rhetorischfunktionalen Aspekt vorurteiligen Sprechens (Billig 1991; Graumann und Wintermantel 2007; Wetherell und Potter 1992). Dies bedeutet zunächst, dass der analytische Fokus der Antiamerikanismuskritik sich von der Kategorisierung antiamerikanischer Dispositionen bzw. Personen hin zur Rekonstruktion antiamerikanischer Sprechakte verschiebt. Dabei wird der vorurteilige Charakter bzw. die Bedeutung solcher Sprechhandlungen von deren rhetorischer Funktion bei der Reproduktion 
von Ungleichheit und Diskriminierung abhängig gemacht. Nicht die im antiamerikanischen Sprechen ausgedrückte Feindseligkeit, nicht die Stereotypie der gezeichneten Amerikabilder und nicht deren mangelnde Korrespondenz mit ,der Realität ${ }^{*}$ Amerikas machen es zum Gegenstand sozialwissenschaftlicher Kritik, sondern, dass die betreffenden Sprechweisen an der Benachteiligung und Verfolgung gesellschaftlicher Gruppen mitwirken. Mit einem Begriff Peter Bergers sind antiamerikanische Vorurteile als „Ungleichheitssemantiken“ (Berger 1989) bzw. „Ungleichheitspragmatiken" (Sutterlüty 2004, S. 1, Herv. F.K.; vgl. auch Neckel und Sutterlüty 2005, S. 421) aufzufassen. Die diskriminierende Wirkung antiamerikanischer Vorurteilsäußerungen kann allerdings nicht direkt beobachtet werden, v.a. nicht im Rahmen der hier untersuchten Survey- und Interviewdaten. Wenn im Verlauf dieser Arbeit also von rhetorischen Funktionen, Effekten oder Wirkungen die Rede ist, so ist dies nicht in einem kausalanalytischen Sinne zu verstehen. Die hier analysierte Wirkung vorurteiligen Sprechens bezeichnet keine Relation des ,Wenn-Dann“, sondern eine des ,Indem“: Sie führt nicht unmittelbar den Nachweis, dass als Konsequenz aus den beobachteten Sprechweisen konkrete Personen benachteiligt oder geschädigt werden; sie deutet vielmehr antiamerikanisches Sprechen als Reproduktion der Differenzkonstruktionen, die solche Diskriminierung möglich machen. Der Bezug auf Diskriminierungspraxen bleibt also im Rahmen der hier durchgeführten Analysen immer eine theoretische Investition: Die vorurteilige Wirkung oder Funktion antiamerikanischen Sprechens ist eine performative, d.h. sie bezieht sich nicht auf ein aus den jeweiligen Sinnkonstruktionen kausal folgendes Handeln, sondern auf eine zusätzliche Bedeutungsebene des Gesprochenen als Handeln. Empirisch gezeigt wird etwa, wie ein stereotypes Sprechen über Amerika dazu gebraucht wird, eine essentialistische ethno-nationale Identität rhetorisch zu stabilisieren; ob und inwiefern diese Differenzkonstruktion in anderen sozialen Kontexten wiederum zur manifesten Benachteiligung oder Schädigung von Personen bzw. Gruppen führt, liegt außerhalb des Blickfeldes der vorliegenden Arbeit.

Dieser Bezug auf Antiamerikanismus als Moment einer „symbolische[n] Ordnung sozialer Ungleichheit“" (Sutterlüty et al. 2008, S. 28; vgl. auch Weiß et al. 2001) entsteht aber nicht aus Verlegenheit um bessere Möglichkeiten der empirischen Kausalanalyse, sondern er ist im Begriff des Vorurteils logisch angelegt: Dieser ist durch eine Spannung zwischen manifester, letztendlich leiblicher Gewalt ${ }^{3}$

3 Der Begriff der Leiblichkeit, der phänomenologischen und pragmatistischen Theorieströmungen entstammt, weist darauf hin, dass mit der besagten Gewalt kein ,rein körperlicher" Vorgang gemeint ist (vgl. Demmerling 2011, S. 12 ff.; eine Übersicht zum Leibbegriff bzw. zur „Philosophie der Verkörperung“ bieten Alloa et al. 2012 und Fingerhut et al. 2013). Denn einerseits werden gewalttätige und vergewaltigte Körper immer in sprachlichen Bedeutungszusammenhängen erfahren; und andererseits verweist auch das Phänomen sprachlicher Gewalt, die ohne physische Einwirkung im engeren Sinne 
und deren rhetorisch-diskursiven Bedingungen gekennzeichnet. Bevor Türen und Grenzen geschlossen, Menschen gequält und ausgebeutet werden, sagen die Verantwortlichen: ,Sie verdienen es nicht anders, es hat seinen guten Grund'. Zwar sind beide Momente, die diskursive Rechtfertigung und der gewaltvolle Abbruch der Diskursivität, analytisch zu trennen. Aber ohne die schädigende Tat könnten die Differenzkonstruktionen des rechtfertigenden Sprechens nicht als Vorurteil, ohne die gesprochene Rechtfertigung die Taten nicht als Diskriminierung oder Verfolgung gefasst werden. Vorurteiliges Sprechen bedeutet somit gewissermaßen ein Brechen mit der Diskursivität in der Diskursivität. D.h. innerhalb der Prinzipien von Dialog und Rechtfertigung wird eine Aufhebung dieser Prinzipien legitimiert oder performativ vollzogen. Deswegen impliziert zwar das Phänomen des Vorurteils ein ,Wenn-Dann“, d.h. es ist ohne die potentielle Kausalität von symbolischer Klassifikation und Verletzung nicht denkbar; aber es wird nicht erst in dem Moment zum Vorurteil, in dem tatsächlich unmittelbar verletzt wird. Gerade aufgrund dieser immanenten Spannung des Vorurteilskonzeptes kann sinnvoll von performativen Effekten antiamerikanischer Rede gesprochen werden, ohne zugleich auch einen kausalen Effekt in Form von leiblicher Gewalt nachweisen zu müssen. Die Kriterien des konventionellen Vorurteilsbegriffes (Feindschaft/Aversion, faktische Falschheit/Irrationalität, kognitiver Schematismus) nähern sich zwar diesem Zusammenspiel von rhetorischer Praxis und gewalttätiger Diskriminierung an und können für viele Fälle vorurteiligen Sprechens als valide Proxy-Variablen gelten. Aber sie übergehen das Problem einer gesellschaftstheoretischen Grundlage des Vorurteilsbegriffes und blenden zudem eine beträchtliche Menge von Vorurteilsausdrücken aus, die nicht den genannten Kriterien entsprechen. Dieses Versäumnis ist meines Erachtens mitverantwortlich dafür, dass die häufig beklagten ,Definitionsprobleme" des Antiamerikanismus sich so hartnäckig fortschreiben.

Die Frage, auf die einstellungstheoretische Vorurteilskonzepte keine befriedigende Antwort geben, lautet: Was ist eigentlich das Problem, wenn jemand , die USA“ oder , die Amerikaner' nicht mag? Genauer: Was ist das spezifisch vorurteilige Problem daran, im Vergleich bspw. zu jemandem, der die Deutsche Bahn bzw. , die Bahner' nicht mag? Diese Frage ist mitnichten als Verharmlosung stereotyper Aversionen gemeint, sondern zielt auf eine genauere Analyse des rhetorischpraktischen Aspekts antiamerikanischer Ausdrücke: Was tut jemand, der sich antiamerikanisch äußert? Welche praktische Bedeutung hat es, wenn jemand Amerika ,ablehnt" oder gar ,hasst"? Aus einer praxis- bzw. sprechakttheoretisch informierten Perspektive wird die Frage nach der Bedeutung antiamerikanischer Ausdrücke zur Frage nach der rhetorischen Funktion von Amerikabildern in bestimmten Äuße-

verletzen kann, und deren beschädigende Wirkung zudem in aller Regel in körperlichen Metaphern ausgedrückt wird, auf dieses Wechselverhältnis von Körper und Sprache (vgl. Butler 2006 S. 13 ff.; Herrmann et al. 2007, S. 17 ff.). 
rungskontexten (vgl. Billig 1991; Graumann und Wintermantel 2007; Wetherell und Potter 1992). Gleichzeitig rücken feindselige oder aversive Affekte, stereotype und schematische Kognitionen, sowie die faktische Wahrheit der jeweiligen Äußerungen als Definiens antiamerikanischer Vorurteile in den Hintergrund. Entscheidend für die Kritik eines Ausdrucks als Vorurteil wird vielmehr, welcher rhetorische Akt mit ihm vollzogen wird. Anstatt die Frage nach einer ,more precise definition of the term" (O'Connor 2007b, S. 6) mit immer neuen Variationen über das Thema einer einstellungstheoretischen Vorurteilskonzeption $\mathrm{zu}$ beantworten, sollte eine qualitativ-empirisch fundierte ,Kartierung ' (vgl. Wetherell und Potter 1992) der verschiedenen rhetorischen Funktionen und Funktionskontexte antiamerikanischen Sprechens verfolgt werden, die zugleich ein Ausloten der gesellschaftstheoretischen Grundlagen dieser Kritik beinhaltet. Die vorliegende Arbeit versteht sich als „Landschaftsskizze[n]“ (Wittgenstein 2006, S. 231), die zu solch einer Kartierung beiträgt.

Mit der konzeptuellen Kritik des vorurteilstheoretischen Antiamerikanismusbegriffes verbindet sich aber auch eine Kritik des Antiamerikanismus selbst. Schließlich bliebe der Sinn der begrifflichen Modifikation fraglich, hätte sie keinen erkennbaren Effekt auf die empirische Beobachtung des Gegenstandes. Dementsprechend erhebt meine begriffliche Neufassung des Antiamerikanismus als „Unleichheitssemantik“ bzw. ,-pragmatik“ nicht nur den Anspruch, bestehende Befunde der Antiamerikanismusforschung auf ein neues theoretisches Fundament zu stellen, sondern auch bislang unbekannte Facetten antiamerikanischer Vorurteile sichtbar zu machen. Diese anhand von Interviewmaterial rekonstruierten Sprechweisen betreffen - ohne jeden Anspruch auf Vollständigkeit - drei maßgebliche Funktionen antiamerikanischer Rede: So dient Antiamerikanismus erstens auf spezifische Weise der Konturierung und Stabilisierung nationalistischer Identitätskonstruktionen. Zweitens kann mittels antiamerikanischer Rhetorik eine Normalisierung des Holocaust bzw. des nationalsozialistischen Erbes deutscher Nationalidentität geleistet werden. Und drittens fungiert Antiamerikanismus als Mittel zur Rechtfertigung rassistischer und ethnozentrischer Differenzkonstruktionen im Kontext egalitärer Normen.

Mit keinem dieser drei Funktionskontexte betritt die Antiamerikanismuskritik völliges Neuland. ${ }^{4}$ Jedoch können die spezifischen Funktionsweisen, die im Ergebnis der hier durchgeführten qualitativen Empirie gezeigt werden, als bislang weit-

4 Sowohl nationale Identitätsfunktionen von Antiamerikanismus (Markovits 2007; Gulddal 2011) als auch dessen Zusammenhang mit Antisemitismus (Markovits 2005; Markovits und Rensmann 2007; Beyer und Liebe 2010; Knappertsbusch und Kelle 2010) sind bereits mehrfach diskutiert worden. Das Verhältnis von Antiamerikanismus zu rassistischen oder fremdenfeindlichen Konstruktionen beschränkt sich hingegen bislang auf wenige Anmerkungen (z.B. Berman 2008, S. 40 f.). 
gehend unbeschrieben gelten. Im Licht eines performativen Antiamerikanismusbegriffes werden die vorurteiligen Funktionen antiamerikanischer Rede jenseits der gängigen Kriterien obsessiver Feindschaft, faktischer Unwahrheit und geschlossener Weltanschaulichkeit erkennbar. Diese Funktionen antiamerikanischen Sprechhandelns liegen insbesondere im Bereich der ideologischen Bearbeitung von Widersprüchen in Identitätskonstruktionen und normativen Orientierungen. Dabei wird unter Ideologie nicht ein deskriptiv oder moralisch schlechthin falsches Denksystem verstanden - eine solche kategorische Zurückweisung des Antiamerikanismus ließe sich überhaupt nicht als Kritik im engeren Sinne verstehen, wie in Kapitel 4.5 erörtert wird. Ideologie meint hier vielmehr das latente Bearbeiten von Widersprüchen in den Identitätskonstruktionen und normativen Orientierungen der antiamerikanisch Sprechhandelnden. So können Amerikastereotype etwa dazu gebraucht werden, eigene rassistische oder fremdenfeindliche Differenzkonstruktionen mit egalitären Normen in Einklang zu bringen. Hierbei wird der Widerspruch zwischen ethnozentrischer Diskriminierung und dem Ideal ,ethnischer Gleichheit“ (Sutterlüty 2011) ideologisch aufgehoben, indem man sich bspw. von ,amerikanischem Rassismus' distanziert. Der Protest gegen den Rassismus der ,kultur- und wurzellosen Amerikaner" wird so zum Ausdruck einer ethno-nationalen Weltsicht, in der ,Kultur' als Code für eine ursprüngliche, nationale Abstammungsgemeinschaft fungiert (vgl. Kap. 7.4).

Die vorliegende empirische Studie verdankt ihre Ergebnisse zu einem guten Teil der Adaption von Erkenntnissen der rhetorischen bzw. diskursiven Psychologie (Billig 2012; Billig 1991; Martin 2013; Martin 2010; Wetherell 2012; Wetherell und Potter 1992), einer wissenssoziologisch bzw. praxistheoretisch orientierten Theorie des Ethnozentrismus und Rassismus (Nassehi 1997b; Nassehi und Richter 1996; Neckel und Soeffner 2008; Neckel und Sutterlüty 2005; Sutterlüty und Neckel 2012; Sutterlüty 2010; Weiß 2013; Weiß et al. 2001) sowie des Antisemitismus (Holz 2005; Holz 2001; Schäuble 2012; Scherr und Schäuble 2006). Diese Anknüpfungspunkte ergeben sich nicht nur aus der theoretisch-methodologischen Nähe der genannten Ansätze zum hier gebrauchten Begriffsmodell, sondern sie hängen auch eng mit einer der zentralen Fragestellungen der vorliegenden Arbeit zusammen: Worin besteht bzw. wie funktioniert der Zusammenhang von Antiamerikanismus und anderen Vorurteilsformen, insbesondere Antisemitismus, Rassismus und Fremdenfeindlichkeit? Nicht zuletzt in den Surveydaten der vorliegenden Arbeit sticht der Zusammenhang von Antiamerikanismus, Antisemitismus, Fremdenfeindlichkeit und Rassismus deutlich hervor. Im Kontext der hier eingenommenen rhetorisch-performativen Theorieperspektive wird der „Syndromcharakter" des Vorurteils (Heitmeyer 2002b; Zick et al. 2012; Zick et al. 2008; kritisch dazu Milbradt 2013) als rhetorisches Phänomen aufgefasst. Ein zentrales Ergebnis der Interviewstudie ist, dass antiamerikanische Rhetorik zur ideologischen Rechtfertigung bzw. Normalisierung revisionistisch-nationalistischer, rassistischer und frem- 
denfeindlicher Differenzkonstruktionen gebraucht werden kann. Der Zusammenhang zwischen den genannten Vorurteilsformen wird somit als argumentatives Zusammenspiel verstehbar. Die „Ideologie der Ungleichwertigkeit“ (Neckel und Sutterlüty 2005, S. 415; Heitmeyer 2008), die verschiedene Vorurteilsausdrücke vereint, wird nicht als psychische Disposition gefasst, die das gemeinsame Auftreten verschiedener Vorurteilsformen kausal erklärt, sondern als rhetorisch-funktionale ,Arbeitsteilung ' bei der Reproduktion einer ,,symbolische[n] Ordnung sozialer Ungleichheit" (Sutterlüty et al. 2008, S. 28).

In der vorliegenden Arbeit werden also zwei zentrale Konzepte der Antiamerikanismusforschung aufgegriffen und sprechakttheoretisch gewendet: Vorurteil und Ideologie (vgl. Friedman 2012, S. 7 f.). Die Bestimmung der vorurteiligen Bedeutung amerikabezogener Ausdrücke verlässt sich dabei aber nicht auf definierte Kriterien des Vorurteils als Einstellung. Sie wird vielmehr über deren Funktion als „Ungleichheitssemantiken“, d.h. deren rhetorische Wirkung im Kontext von Ungleichheit und Diskriminierung bestimmt. Der Diskriminierungsbegriff bietet den theoretischen Rahmen, in dem Funktionskontexte antiamerikanischen Sprechens rekonstruktiv erschlossen werden können, ohne deren Merkmale im Vorhinein definieren zu müssen. Der Ideologiebegriff wird, entgegen der generellen Tendenz in der Antiamerikanismusliteratur, nicht als Bezeichnung für die weltanschauliche Geschlossenheit eines ,generalized hatred of the United States“ (Friedman 2012, S. 5) gebraucht. Ideologie bezeichnet stattdessen eine bestimmte Form der Reflexion auf Widersprüche und Kontingenzen in den Identitätskonstruktionen und normativen Orientierungen der Teilnehmenden. Diese spezifische Reflexionsform besteht, mit Luhmann gesprochen, in einer doppelten ,,Invisibilisierung “ - sowohl der Operation selbst als auch ihres Problems“ (Luhmann 1987b, S. 163). Sie deckt nicht nur ein Begründungsproblem oder einen Widerspruch zu, sondern lässt zugleich auch dieses Verdecken selbst verschwinden. Als weiteres Beispiel hierfür kann eine antiamerikanische Normalisierungsrhetorik gelten, in der, analog dem sekundären Antisemitismus (Holz 2007; Bergmann 2007), mittels des Stereotyps eines , amerikanischen Genozids“ der Holocaust latent thematisiert und relativiert wird. Die Vernichtung der europäischen Jüdinnen und Juden kann damit als Begründungsproblem deutscher Nationalidentität beseitigt und zugleich diese Beseitigung selbst antiamerikanisch invisibilisiert werden (vgl. Kap. 7.3).

Die beschriebene Skepsis gegenüber einer Definition antiamerikanischer Vorurteile qua Einstellungsmerkmalen sowie gemäß eines ,totalen Ideologiebegriffs“ (Adorno 2003a, S. 472; Adorno 2003e, S. 558 f.) spiegelt zudem einen weiteren Kernaspekt der hier bearbeiteten Fragestellung wider: Forschungsgegenstand der vorliegenden Arbeit sind antiamerikanische Ausdrücke im alltäglichen, nicht politischprogrammatisch ausformulierten Sprechen. Angesichts solcher spontanen Sprechweisen bekommt das Problem eines sinnvollen Gebrauchs des Antiamerikanismuskonzeptes eine zusätzliche empirische Komponente. Denn das fragmentierte und 
flexible Auftreten von Vorurteilen in Alltagsdiskursen lässt deren Klassifikation als „generalized and comprehensive normative dislike of America“ (Markovits 2007, S. 17) zusätzlich fragwürdig erscheinen. Um den rhetorischen Funktionen antiamerikanischen Sprechens gerade auch in seinen fragmentierten und inkonsistenten Gebräuchen im Interviewmaterial nachspüren zu können, wurden die starken Vorannahmen einer weltanschaulichen Geschlossenheit sowie einer antiamerikanischen Einstellung im Verlauf dieser Arbeit bewusst fallengelassen.

Die Problematik einer begrifflichen Fassung von Antiamerikanismus im Alltagsdiskurs wird im folgenden Abschnitt anhand eines Interviewbeispiels verdeutlicht. Um einen einführenden Eindruck vom Phänomen antiamerikanischer Vorurteile insgesamt zu vermitteln, wird zuvor ein drastisches Beispiel antiamerikanischer Propaganda vorgestellt.

\subsection{Die historische Und AKTUELle ReleVANZ ANTIAMERIKANISCHER VORURTEILE}

1944 veröffentlichte die „Germaanse SS in Nederland“, eine nationalsozialistische paramilitärische Gruppe in den besetzten Niederlanden (vgl. Hoffmann 1972, S. 42 f.), ein antiamerikanisches Propagandaplakat, das unter dem ironischen Titel „Liberators“ die USA als katastrophale Bedrohung Europas darstellt (vgl. Abbildung 1). Was an dieser Phantasie amerikanischer Übermächtigung besonders ins Auge sticht, ist nicht nur die Obszönität der monströsen Feindbildkonstruktion, sondern auch deren kompositorische Komplexität. Es wird nicht ein Stereotyp ,des Amerikaners` gezeichnet, sondern ,das Amerikanische' tritt als ein vielgestaltiges Wesen auf.

Die Zusammenstellung der dabei gebrauchten Motive vereinigt eine Vielzahl traditioneller antiamerikanischer Topoi: So finden sich Bilder korrupter Verhältnisse, in denen Gewaltverbrechen (der rechte, untere Arm ist der eines ausgebrochenen Verbrechers) und bürgerliche Gesellschaft (der linke, untere Arm in Anzug- und Hemdärmel) sich wechselseitig ergänzen. Die vom rechten oberen Arm geschwungene Schallplatte symbolisiert einen bedrohlichen Einfluss amerikanischer Kulturindustrie, während der Geldsack in der linken Hand den vermeintlichen Materialismus und die ,Herrschaft des Geldes“ in den USA symbolisiert. Das rechte Bein des Monstrums, umwunden von Maßbändern und einer Schleife mit der Aufschrift „World's Most Beautiful Leg“, versinnbildlicht einen oberflächlich-instrumentellen Schönheitskult und eine ,übersexualisierte“ Gesellschaft, ebenso wie die beiden Schönheitsköniginnen, die auf den Schultern der Figur reiten (,Miss America“ und „Miss Victory“). Die Schwingen sowie das linke Bein des Monstrums verweisen 
auf die Technologie des Bombenkrieges (auch die Überschrift „Liberators“ spielt auf einen amerikanischen Bomber-Typ an: die Consolidated B-24 ,Liberator").

Neben diesen traditionellen Stereotypen eines korrupten, gewalttätigen, lasterhaften und allein von Profitgier getriebenen Amerika finden sich in der Zeichnung Hinweise auf ein charakteristisches Zusammenspiel von Antiamerikanismus und anderen Vorurteilsformen, insbesondere Rassismus und Antisemitismus. So klammert am Beutel in der linken Faust des Monstrums ein ,Geldjude“, der den ,jüdisch kontrollierten' Finanzkapitalismus der USA symbolisiert. Zudem trägt der , amerikanische Moloch' Maurerschurz - eine zeremonielle Kleidung der Freimaurer dessen Markierung mit einem Davidstern auf den vermeintlichen verschwörerischen Einfluss ,der Juden“ in den USA verweist. Parallel zu diesen antisemitischen Darstellungen finden sich rassistische Motive, am prominentesten wohl verbildlicht in den tanzenden ,Wilden“, deren Käfig die ironische Aufschrift „Jitterbug - Triumph of Culture“ trägt. ${ }^{5}$ Die muskulösen ,Neger-Arme“ vermitteln zudem das Bild einer ,unzivilisierten Gewalt‘, die die USA durch ihre schwarze Bevölkerung gewinnen.

Im Zusammenhang dieser rassistischen Bilder ist zudem bemerkenswert, dass die Darstellung selbst Rassismus zu den verderblichen Eigenschaften ,der Amerikaner‘ zählt: Den Kopf des Monstrums bildet eine Ku-Klux-Klan Maske, die Tanzenden ,Wilden' werden im Käfig zur Schau gestellt und der Galgenstrang zur Rechten der Figur erinnert an rassistische Lynchmorde. ,Die Amerikaner“ werden hier also gleichermaßen für ihren gewalttätigen Rassismus wie für ihre ,rassische Unreinheit‘ angefeindet. Diese Konstellation, die gerade im Kontext von NaziPropaganda zunächst widersprüchlich erscheint, wird sich im Verlauf dieser Arbeit als ein zentrales Moment antiamerikanischer Rhetorik herausstellen: Wie im vorigen Abschnitt bereits angesprochen, verknüpfen antiamerikanische Darstellungen auf ideologische Weise ethnozentrischen Nationalismus mit antirassistischen Motiven, und dienen somit dem Ausdruck eines gemäß egalitärer Normen gerechtfertigten Ethnozentrismus. In eine ähnliche Richtung verweist der von „Miss America“ getragene Federschmuck: Auch das Bild amerikanischer Ureinwohner als Opfer eines rücksichtslosen ,weißen Profitstrebens“ in den USA ist teil des semantischen Repertoires antiamerikanischer Rhetorik und kann ähnliche Legitimationsfunktionen erfüllen, wie das des , amerikanischen Rassismus‘ (vgl. Kap. 7.3).

Insgesamt zeichnet die Graphik ein amerikanisches Feindbild, das sich aus Motiven ethnischer Heterogenität und kultureller Oberflächlichkeit bzw. Substanzlosigkeit zusammensetzt. Der von der Figur im unteren linken Bildrand präsentierte Text besagt: „De U.S.A. zullen de Europeesche Kultuur van den ondergang redde“ (niederländisch: „Die U.S.A. sollen die europäische Kultur vor dem Untergang retten“). Dieser Kommentar unterstreicht auf ironische Weise die zerstörerische Wir- 
kung des ,amerikanischen Monsters‘. Implizit wird hier ein Wir-Gruppenbild der Homogenität, Traditionalität und Moral der europäischen ,Kulturen ‘ bzw. ,Völker gezeichnet. ,Die Amerikaner' werden demgegenüber als ,falsche Befreier` dargestellt, die tatsächlich im Begriff sind, die ,europäische Kultur' mit brutaler Gewalt zu zerstören bzw. durch eine groteske ,Un-Kultur' zu ersetzen. In diese Feindbildkonstruktion mischen sich rassistische Ideale ethnischer Homogenität sowie antisemitische Vorstellungen von Autonomie und Freiheit. Gleichzeitig ist die Illustration aber darum bemüht, ihre eigenen menschenfeindlichen Darstellungen gegen einen ,amerikanischen' Rassismus bzw. Antisemitismus abzugrenzen und so die eigene Friedfertigkeit und Vernunft zu betonen.

Abbildung 1: Propagandaplakat der niederländischen SS aus dem Jahr 1944 (Illustrator: Harald Damsleth)

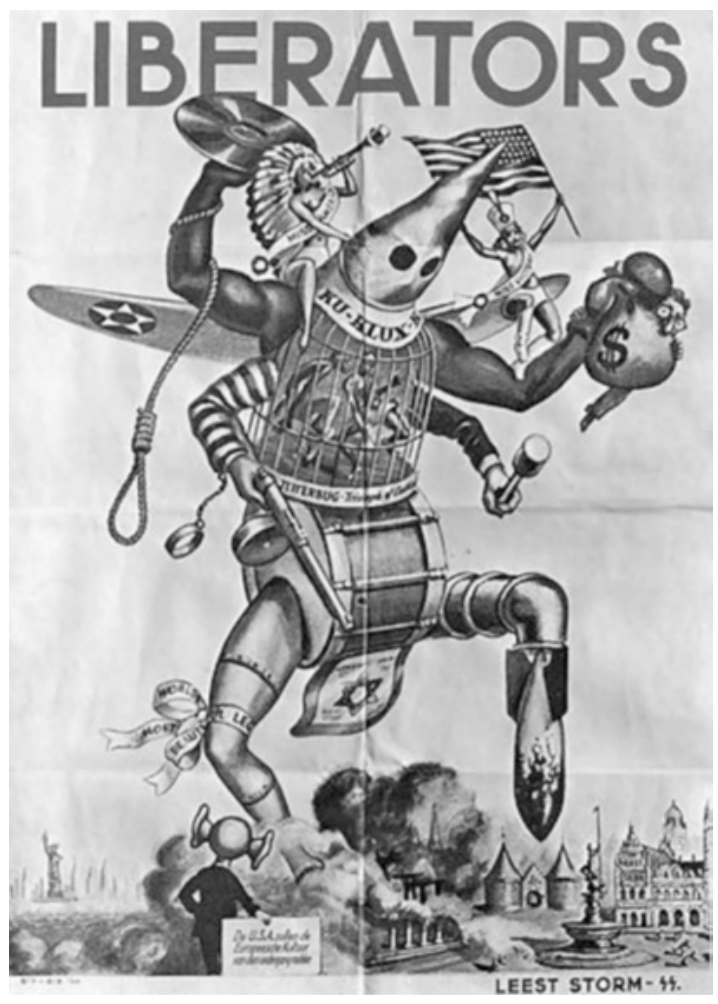

Quelle: http://en.wikipedia.org/wiki/File:Liberators-Kultur-

Terror-Anti-Americanism-1944Nazi-Propaganda-Poster.jpg (zuletzt geprüft: 3.9.2015) @ C VG Bild-Kunst, Bonn 2015 
Wie ich im Verlauf der Arbeit zeigen werde, lassen sich viele der skizzierten antiamerikanischen Motive im Material der vorliegenden Interviewstudie wiederfinden. Sie sind bis heute Teil des aktiven argumentativen Repertoires antiamerikanischer Rede. Doch der analytische Brückenschlag von NS-Propaganda zu aktuellem, alltäglichem Antiamerikanismus ist nicht selbstevident. Während erstere aufgrund des historisch-politischen Kontextes problemlos als Moment einer diskriminierenden, menschenfeindlichen Praxis kategorisiert werden kann, ist dies bei antiamerikanischer Rede heute häufig nicht der Fall. Obwohl sich darin bestimmte historische Motive des Antiamerikanismus wiederholen, bleibt doch der Gebrauchsaspekt aktueller Ausdrücke oftmals vergleichsweise vage.

In der Konfrontation mit nicht standardisiertem empirischem Material treten somit Leerstellen der gängigen Vorurteilsdefinition zu Tage, die in standardisierter Vorurteilsempirie in der Regel unbemerkt bleiben. Diese Leerstellen betreffen in erster Linie den Gebrauchskontext vorurteiliger Sprechweisen: Der Antiamerikanismus des SS-Plakates ist nicht deswegen so eindeutig und fraglos gegeben, weil die Bilder so obszön, die ausgedrückte Feindseligkeit so intensiv oder die Stereotypie so bruchlos ist, sondern, weil es sich um ein Nazi-Propagandaplakat handelt. Man weiß, welchen rhetorischen Zweck es verfolgt und welchen menschenfeindlichen Taten diese Rhetorik zugearbeitet hat. Im spontanen, nicht politischprogrammatisch verorteten Alltagsgespräch oder in der beiläufigen Bemerkung über , die Amerikaner' ist diese Klarheit des Funktionskontextes gerade nicht gegeben.

Indem der klassische Vorurteilsbegriff sich auf Stereotyp, Affekt und kognitive Prozesse fokussiert, setzt er aber implizit genau dies voraus: zu wissen, was die vorurteilig Handelnden tun, indem sie entsprechende Äußerungen machen. Ein wichtiger Ausgangspunkt der vorliegenden Arbeit ist die Annahme, dass diese impliziten Selbstverständlichkeiten der Vorurteilskritik in zweifacher Hinsicht hinterfragt und besser expliziert werden müssen: Die Frage, was vorurteilig Handelnde eigentlich tun, indem sie bestimmte stereotype Gruppenkonstruktionen reproduzieren, muss aus einer praxistheoretisch-hermeneutischen Blickrichtung empirisch bearbeitet werden, anstatt sie immer wieder voreilig mit Konzepten wie ,Feindschaft", ,Hass“, ,Ressentiment', etc. zu beantworten. Dies ist reziprok mit der reflexiven Frage verbunden, was eigentlich ,das Problem“ am antiamerikanischen Sprechen ist, d.h. aus welcher sozialtheoretischen, auch normativen Perspektive die Vorurteilsforschung ihren Gegenstand rekonstruiert.

Zur Veranschaulichung dieser Problemstellung möchte ich noch einmal auf das oben bereits zitierte Beispiel einer antiamerikanischen Normalisierung des Holocaust eingehen. Der Interviewteilnehmer Herr B ${ }^{6}$, dessen Fall in Kapitel 7.3 aus-

6 Das Interviewmaterial wurde vollständig anonymisiert. Orts- und Personennamen sowie andere Bezeichnungen, die einen Rückschluss auf die personale Identität der Interview- 
führlich dargestellt wird, zeichnet wiederholt negative Bilder einer undemokratischen und manipulativen amerikanischen Supermacht. Nach dem Grund für seine Abneigung gegen ,die US-Amerikaner“ befragt, nimmt er auf den globalpolitischen Einfluss der USA Bezug:

Herr B: Die US-Amerikaner, äh, spiegeln ja so was wie die Weltpolizei wider. Also die mischen sich praktisch, äh, überall ein, äh, in die politischen, wirtschaftlichen, äh, meist auch dann mit militärischer Gewalt, äh, oder sonstigen Mitteln, halt andere Regierungen, andere Staatengemeinschaften praktisch, ähm - ich sage das mal so unverblümt - auf diesen amerikanischen Kurs, äh, dieses amerikanische Weltbild drauf hin einzulenken, und das finde ich halt, ähm ja, finde ich halt persönlich nicht ganz so demokratisch, wie man im Allgemeinen Demokratie verstehen würde.

Versucht man Herrn Bs Rede mit der oben gegebenen Antiamerikanismusdefinition zu kategorisieren, werden verschiedene Unschärfen in der Verwendung dieses Begriffes, bzw. seiner drei Komponenten Feindseligkeit, Stereotypie und faktische Falschheit, erkennbar. So mag man zwar sagen, dass der Teilnehmer gegenüber ,den Amerikanern' eine ablehnende Haltung einnimmt. Aber kann seine Position als Feindschaft oder Aversion gewertet werden? Und selbst wenn man Herrn B eine solche aggressive Abneigung gegen die USA unterstellte, wäre das Anlass genug, seine Rede als antiamerikanisches Vorurteil zu kritisieren? Was ist eigentlich problematisch daran, dass jemand , die USA' nicht mag? Sind Vorurteile eine besonders intensive Art der Aversion?

Weiterhin zeichnet der Teilnehmer mit seiner Darstellung der USA ein stark pauschalisierendes, stereotypes Bild, der Amerikaner'. Aber auch hier kann als fraglich gelten, ob dies Grund genug ist, von einem Vorurteil zu sprechen. Immerhin gebrauchen wir tagtäglich in unzähligen Kontexten grobe Verallgemeinerungen und rhetorische Zuspitzungen, ohne dabei vorurteilig zu handeln.

Und schließlich: So grob Herrn Bs Verallgemeinerungen bzgl. amerikanischer Politik auch sein mögen, als schlechthin faktisch falsch wird man sie nicht einstufen können. Kaum jemand wird bestreiten wollen, dass die USA einen - wie auch immer prekären - Supermachtstatus besitzen, der mit weltweitem ökonomischen Einfluss, zahlreichen militärischen Interventionen und einem oftmals chauvinistischen Sendungsbewusstsein einhergeht. Und auch hier gilt: Selbst wenn Herrn B faktisch falsche Aussagen über Amerika getroffen hätte, wäre diese faktische Falschheit Grund genug, seine Rede als Vorurteil zu kategorisieren? Sind Vorurteile lediglich eine Art Denkfehler oder Irrtum?

teilnehmenden zulassen, wurden durch entsprechende Codes ersetzt. Im Falle der Personennamen bestehen diese aus der Anrede „Frau“ bzw. „Herr“ und einem willkürlich gewählten Buchstaben. 
Möchte man nun aus dieser Beobachtung nicht den Schluss ziehen, dass Herr B ganz einfach nicht antiamerikanisch gesprochen hat - und ich werde in Kapitel 7.3 zeigen, dass dies tatsächlich eine Fehleinschätzung wäre - so werden die obengenannten Kriterien des Vorurteilsbegriffes in zweifacher Weise problematisch: Einerseits scheinen zumindest zwei von ihnen (Feindschaft/Aversion, faktische Unwahrheit) nicht notwendig zu sein. Es steht zu vermuten, dass man antiamerikanisch sprechen kann, ohne sich dabei feindselig zu äußern oder propositional falsche Sätze über die USA zu formulieren. Andererseits scheinen alle drei Kriterien für sich genommen nicht hinreichend $\mathrm{zu}$ sein, um den Gegenstand genau einzugrenzen. Sind antiamerikanische Vorurteile wirklich als eine Art von Irrtum oder falschem Faktenwissen, eine Art von Feindschaft oder eine Art von pauschalisierender Darstellung zu bestimmen? Und wenn ja, welche spezifische Art dieser Handlungsweisen wäre dies? Welche Arten von Irrtümern, Feindseligkeiten und Pauschalisierungen werden als Vorurteil problematisch? ${ }^{7}$ In der etablierten Vorurteilsforschung sind diese Fragen bislang vergleichsweise randständig behandelt worden. ${ }^{8}$ Die vorliegende Arbeit versteht sich als Beitrag zu einer theoretischen Schärfung und besseren empirischen Fundierung der sozialwissenschaftlichen Vorurteilskritik jenseits der genannten definitorischen Kriterien.

\subsection{Fragestellung UND Forschungsdesign DER STUDIE}

Wie in den vorigen Abschnitten dargestellt, nimmt die vorliegende Arbeit ihren Ausgangspunkt von zwei distinkten aber eng verknüpften Problemstellungen. Sie fragt einerseits empirisch nach Formen, Funktionen und Tragweite antiamerikanischer Vorurteile in Deutschland heute. Die Beantwortung dieser Frage impliziert aber andererseits die Problematik einer genauen theoretischen Bestimmung des Antiamerikanismus: Die Frage nach Formen und Funktionen antiamerikanischen Spre-

7 Als Alternative könnte man eine Konjunktion aller drei Merkmale zu einem komplexen hinreichenden Kriterium vorschlagen. Diese Variante scheint mir allerdings zu einer übermäßig restriktiven Definition des Vorurteilsbegriffes zu führen. Wenn allein noch eine stereotype Feindseligkeit gegen alles Amerikanische, die zudem auf faktisch falschen Annahmen beruht, als Antiamerikanismus gelten kann, würde man den Gegenstandsbereich unzulässig einengen. Es käme nur noch der fanatischste Amerikahass als Antiamerikanismus in Frage.

8 Ähnliche Schwerpunktsetzungen finden sich in der Forschung zu benevolentem Sexismus und paternalistischem Rassismus (vgl. Glick und Fiske 2012; Dixon et al. 2012; Dixon und Levine 2012b; Billig 2012; Jackman 1994). Diese werden in Kapitel 2.3 detaillierter diskutiert. 
chens ist immer auch die Frage danach, auf welcher sozialtheoretischen Basis diese als antiamerikanische bestimmt werden können. Hierzu werden zwei häufig gebrauchte Konzepte aus den Kontroversen um eine angemessene Antiamerikanismusbestimmung aufgegriffen und in praxis- bzw. sprechakttheoretischer Weise modifiziert: Vorurteil und Ideologie.

Antiamerikanische Vorurteile werden als Ungleichheitssemantiken bzw. -pragmatiken aufgefasst, d.h. als Differenzkonstruktionen und Argumentationsmuster, die an der rhetorischen Reproduktion einer symbolischen Ordnung sozialer Ungleichheit mitwirken. Der Ideologiebegriff wird entsprechend dieser Theorieperspektive nicht als Bezeichnung für eine geschlossene Weltanschauung oder einen irrationalen, kognitiven Schematismus gebraucht; sondern Ideologie bezeichnet eine bestimmte Form der rhetorischen Bearbeitung von Begründungs- und Kontingenzproblemen in vorurteiligen Differenz- und Identitätskonstruktionen.

Einen dritten Eckpfeiler des Gegenstandsbereichs dieser Arbeit bildet die Konzentration auf spontane, alltägliche Formen antiamerikanischen Sprechens, die insbesondere hinsichtlich ihrer Inkonsistenzen und Flexibilität untersucht werden. In Frage steht also nicht nur, welche Formen und Funktionen Antiamerikanismus in Deutschland heute annimmt und auf welcher begrifflichen Grundlage diese als vorurteilige ausgewiesen werden können. Es ist zugleich zu berücksichtigen, wie antiamerikanischer Ausdrücke im alltäglichen Sprechen trotz ihrer Heterogenität und Inkonsistenz unter einem Antiamerikanismusbegriff zusammengefasst werden können.

Hiermit ist der theoretische Rahmen umrissen, innerhalb dessen eine systematische hypothesengenerierende Empirie erfolgen kann. Denn mit der Bestimmung von Antiamerikanismus als Sprechhandeln bzw. Ungleichheitssemantik und der vorgeschlagenen rhetorischen Fassung des Ideologiebegriffes ist über die konkreten Formen und Funktionen tatsächlichen antiamerikanischen Sprechens in Deutschland ja noch nichts gesagt. Es sind lediglich die zentralen ,heuristischen Rahmenkonzepte“ (Kelle und Kluge 2008, S. 63) gegeben, die eine ,empirisch begründete Theoriebildung“ (Kelle 1997) bzgl. antiamerikanischer Vorurteile anleiten. Den Schwerpunkt der vorliegenden Arbeit bildet daher eine qualitativ-empirische Interviewstudie.

Die dabei bearbeiteten Forschungsfragen lassen sich wie folgt zusammenfassen:

1. Welche Antiamerikanismen lassen sich in alltäglichem Sprechen in Deutschland heute feststellen und welche rhetorischen Funktionen erfüllen diese?

2. Welche Arten des Zusammenspiels von Antiamerikanismus mit rassistischen, fremdenfeindlichen und antisemitischen Differenzkonstruktionen lassen sich beobachten? 
3. Inwieweit lässt sich Antiamerikanismus als kognitiver Schematismus bzw. geschlossene Weltanschauung bestimmen? Welche Formen flexiblen und fragmentierten antiamerikanischen Sprechens lassen sich feststellen?

Anschluss an die Vorurteilsforschung nimmt die vorliegende Arbeit aber nicht nur in theoretischer, sondern auch in empirisch methodischer Hinsicht. So bilden nicht nur die Potentiale und Grenzen des einstellungstheoretischen Vorurteilsbegriffs in der Antiamerikanismusforschung den Ausgangspunkt für die Begriffsentwicklung, sondern auch deren etablierte empirische Forschungsinstrumente. In einem sequentiellen quantitativ-qualitativen Mixed Methods Design bildet die standardisierte Erhebung von Antiamerikanismus mittels Surveyinstrumenten den Startpunkt der vorliegenden Empirie. Die mittels Antiamerikanismusskalen ermittelten Surveyergebnisse liefern einerseits statistische Explananda in Form von Korrelationen zwischen Antiamerikanismus, Antisemitismus, Fremdenfeindlichkeit und Rassismus. Der qualitative Strang des methodenintegrativen Designs dient anschließend der Entwicklung von Erklärungshypothesen. Zugleich fungieren die Surveyergebnisse als Auswahlkriterium für die Ziehung der qualitativen Stichprobe. Auf diese Weise konnte ein effizienter Feldzugang sowie eine möglichst enge Korrespondenz des zu erklärenden statistischen und des erklärenden qualitativen Materials gewährleistet werden.

Dieses Forschungsdesign reagiert auch auf eine zentrale Leerstelle in der gegenwärtigen empirischen Antiamerikanismusforschung: „das Fehlen sozialwissenschaftlicher Untersuchungen zum Antiamerikanismus im Alltag“ (Baethge et al. 2010, S. 366), d.h. der Mangel an empirischen Studien zu flexiblen und fragmentierten Äußerungsformen von Antiamerikanismus. Bisherige Untersuchungen lassen - mit wenigen Ausnahmen (Baethge et al. 2010; Jaecker 2014) - die empirische Frage offen, welche Formen antiamerikanische Sprechweisen im heutigen Alltagsdiskurs annehmen, welche Funktionen sie erfüllen und mit welcher Geschlossenheit oder Flexibilität sie auftreten. Dabei ist auf die Flexibilität und Inkonsistenz des Antiamerikanismus im Zuge von Diskussionen um Definitionsprobleme vielfach hingewiesen worden (Baethge et al. 2010; Chiozza 2009, S. 45 ff.; Diner 2003, S. 8; Jaecker 2014, S. 289 ff.; O'Connor 2007b, S. 16). Weiterhin wurde die Variabilität der politischen Kontexte aufgezeigt, in denen Antiamerikanismus auftritt, und die ein pluralistisches Konzept von „Anti-Americanisms“ nahelegen (Katzenstein und Keohane 2007a).

Bislang sind aus diesen Hinweisen aber selten theoretische Konsequenzen gezogen worden. Auch diejenigen Studien, die auf die Flexibilität und Inkonsistenz antiamerikanischer Ausdrücke hinweisen, halten zum Großteil an einer einstellungstheoretischen Definition von Antiamerikanismus anhand der etablierten Kriterien fest. Ebenso wenig lässt sich ein Wandel in den angewendeten empirischen Methoden feststellen. Standardisierte Verfahren, insbesondere der Surveyfor- 
schung, stellen die überwiegende Mehrheit der gebrauchten empirischen Forschungsmethoden dar (Beyer 2014; Beyer und Liebe 2014; Beyer und Liebe 2010; Chiozza 2009; Decker et al. 2010; Johnston 2006; Katzenstein und Keohane 2007a; Knappertsbusch und Kelle 2010). Qualitative Untersuchungen zum Thema sind vergleichsweise selten zu finden (Baethge et al. 2010; Birkenkämper 2006; Fried 2014; Jaecker 2014; Srp 2005). ${ }^{9}$

Angesichts des bestehenden Klärungsbedarfs bzgl. der alltäglichen Ausdrucksweisen von Antiamerikanismus ist dieses Ungleichgewicht als besonders unglücklich zu bewerten. Denn es sind gerade qualitative Methoden, die systematisch Möglichkeiten einer „empirisch begründete[n] Theoriebildung“ eröffnen (Kelle 1997). So scheint der derzeitige Stand der Antiamerikanismustheorie ein paradigmatischer Fall jener Forschungssituation zu sein, in der den Forschenden „lokales Wissen über Handlungsbedingungen (Handlungsregeln, Handlungsziele und Optionen) in spezifischen kulturellen Kontexten“ fehlt (Kelle 2008a, S. 230), nämlich Wissen darüber, in welchen Kontexten welche rhetorischen Zwecke mittels welcher antiamerikanischen Argumentationsmuster verfolgt werden. Solch lokales und kontextuelles Wissen ist für eine empirisch gehaltvolle und theoretisch überzeugende Begriffsbildung unverzichtbar. Methodologisch gesprochen fehlen dem Antiamerikanismusbegriff die „Brückenhypothesen“ (ebd.), die das empirisch weitgehend gehaltlose Konzept antiamerikanischer Vorurteile überzeugend mit spezifischen antiamerikanischen Ausdrücken verbinden. Aus allgemeinen theoretischen Überlegungen über die Beschaffenheit von Vorurteil und Ressentiment allein, werden sich diese Brückenhypothesen nicht ableiten lassen (vgl. ebd.). Sie müssen aus einer empirischen Beobachtung des Sprachgebrauchs antiamerikanischer Rede entwickelt werden.

Das Definitionsproblem der Antiamerikanismusforschung erweist sich in dieser Perspektive weniger als eines der theoretischen Definition, sondern vielmehr als eines der empirischen Anwendung des Antiamerikanismusbegriffes. In eine für diesen Gebrauchsaspekt sensible „theoretische Empirie“ (Kalthoff 2008, S. 9) des Antiamerikanismus fließen antiamerikanisches Sprechen und das Sprechen über Antiamerikanismus gleichermaßen ein. Eine Weiterentwicklung des Antiamerikanismusbegriffes wird daher beides zugleich leisten müssen: eine Rekonstruktion des antiamerikanischen Sprachgebrauchs und eine Reflexion des vorurteilskritischen Sprachgebrauchs der Antiamerikanismusforschung.

Da das dazu gebrauchte Material aus teilstandardisierten, stark narrativ fundierten Interviews stammt, trägt die hier präsentierte qualitative Empirie außerdem zur

9 Daneben existieren zahlreiche ideengeschichtlich oder literaturwissenschaftlich angelegte Arbeiten zum Thema (Ceaser 1997; Diner 2003; Gulddal 2011; Hollyday 1977; Markovits 2007; Roger 2005), die aber aufgrund ihres theoretischen und methodologischen Aufbaus nicht als empirische Sozialforschung im engeren Sinne gelten können. 
Schließung eine weiteren Lücke im Bereich der Antiamerikanismusforschung bei: Die existierenden qualitativ-empirischen Studien konzentrieren sich, mit Ausnahme der Arbeit von Baethge und KollegInnen, sämtlich auf publizierte Medieninhalte, insbesondere Zeitungs- und Zeitschriftenpublikationen. Wenngleich solche Medienanalysen ohne Frage einen wichtigen Teil öffentlicher Diskurse, und damit des Antiamerikanismus in Deutschland, abdecken, stellen sie doch zur Beobachtung von Antiamerikanismus im alltäglichen Sprechen eine suboptimale Materialquelle dar. Insbesondere wenn antiamerikanische Sprechweisen unter Berücksichtigung von deren Flexibilität und Fragmentierung beobachtet werden sollen, stellen programmatisch weniger reflektierte, spontanere Sprachausdrücke, die in nichtstandardisierten Interviewgesprächen beobachtet werden können, eine besonders fruchtbare Materialquelle dar.

\subsection{Die nORMATIVE Verortung DER VORURTEILSKRITIK}

Die normative Verortung des Antiamerikanismusbegriffes ist vielfach nachdrücklich in Frage gestellt worden. Demnach diene das Konzept in erster Linie als politischer Kampfbegriff um Protest gegen US-Politiken zum schweigen zu bringen (vgl. z.B. Altvater et al. 1989; F.A.Z. 2001; Misik 2003). Und tatsächlich ist nicht von der Hand zu weisen, dass der Antiamerikanismusvorwurf immer wieder zur Legitimation auch fragwürdiger US-Politiken gebraucht wurde. Der Politikwissenschaftler Max Paul Friedman hat in seiner Studie Rethinking Anti-Americanism diese problematische Begriffsgeschichte nachgezeichnet. Er kommt zu dem Schluss, dass die Idee antiamerikanischer Vorurteile ein langhin gepflegter Mythos amerikanischer Außenpolitik sei, dessen primäre Funktion in einer „constriction of political discourse about U.S. society and especially about U.S. foreign relations" bestehe (Friedman 2012, S. 4):

„If anti-American myths have offered some foreigners an unproductive way to explain the relative decline of their own societies in the face of growing American power, the myth of anti-Americanism has also had a damaging effect. In the United States, it has worked its own logic in a comparable process of sedimentation through repetition, and it now risks hardening into a scholarly consensus that has had profound and regrettable effects on policy makers and the American public. I have undertaken to write this book because those who are unaware of the history of the term [...] contribute to its proliferation as an explanatory category even though it does less to illuminate than to obscure.“ (Ebd.)

Die historischen Beispiele, die Friedman für den Gebrauch des Antiamerikanismusbegriffs als Polemik und Propagandavokabel bringt, sind vielgestaltig und überzeu- 
gend. So steht außer Frage, dass der Begriff oftmals als Ausdruck eines chauvinistischen Nationalismus gebraucht wurde, der auf die politische Vormachtstellung eines ethnisch homogenen, religiös-konservativen Amerika zielte. Insbesondere im frühen zwanzigsten Jahrhundert entwickelte sich der Begriff zu einem zentralen Schlagwort der amerikanischen politischen Rechten, wo er sich mit fremdenfeindlichen, rassistischen und antisemitischen Argumentationsmustern verband (vgl. ebd., S. 52 ff.). Die anti-kommunistische Repression der McCarthy Ära (ebd., S. 88 ff.) sowie reaktionäre Widerstände gegen die Bürgerrechtsbewegung (ebd., S. 107 ff.) und Anti-Vietnamkriegs Proteste (ebd., S. 172 ff.) geben weitere Beispiele für die Kontinuität dieses Begriffsgebrauchs.

Bis heute findet sich in der politischen Literatur eine starke rechtskonservative Strömung, deren Antiamerikanismusbegriff häufig eng verknüpft ist mit nationalistischen, ethnozentrischen und heteronormativen Positionen (vgl. z.B. D'Souza 2008; Hollander 1995; Krauthammer 2003). Als antiamerikanisch gilt in dieser Perspektive nicht zuletzt die ,kulturelle Linke“ Amerikas, deren Engagement für wohlfahrtsstaatliche Politik, legale Abtreibung, die rechtliche Gleichstellung gleichgeschlechtlicher Partnerschaften, etc. als Bedrohung ,amerikanischer Werte' erscheint. Die vermeintliche moralische Überlegenheit jener Werte wird in konservativen Antiamerikanismuskonzepten zur Grundlage des anti-antiamerikanischen Protestes (vgl. Friedman 2012, S. 3). So beschreibt beispielsweise Paul Hollander Antiamerikanismus als Symptom eines moralischen Verfalls, in dessen Zuge ,antisocial behavior, especially criminal violence and mental illness" zunehmen ebenso wie ,the decay of sustaining values, loss of national purpose, decline of collective self esteem“ (Hollander 1995, S. 459). Ironischerweise übernimmt dieser AntiAntiamerikanismus weite Teile der moralischen Verfallserzählung, die auch für antiamerikanische Vorurteile selbst charakteristisch ist: Anti-Antiamerikanismus bedeutet hier reaktionären Nationalismus.

Angesichts solcher Positionen mag es naheliegend erscheinen, Antiamerikanismus in erster Linie als Mythos und Instrument reaktionärer Politik zu bewerten. Problematisch ist an Friedmans Position - stellvertretend für viele andere - jedoch, dass er die begriffshistorische Reflexion des Antiamerikanismuskonzeptes weitestgehend vom Gegenstand antiamerikanischer Vorurteile trennt. Ein vorurteilskritischer Gebrauch des Begriffes, abseits der von ihm zu Recht kritisierten politischen Instrumentalisierungen, kommt in seiner Begriffsgeschichte allenfalls als Randerscheinung vor. Dadurch leistet seine treffende Kritik bestimmter Traditionslinien des Anti-Antiamerikanismus bedauerlicherweise der weit verbreiteten Skepsis gegenüber einem vorurteilskritischen Antiamerikanismusbegriff insgesamt Vorschub. Was Friedman und mit ihm viele GegnerInnen eines kritischen Antiamerikanismusbegriffes nicht sehen, ist, dass die Engführungen gängiger Definitionen von Antiamerikanismus als ,particularized and generalized hatred of the United States“ (ebd., S. 6) nicht nur ein Problem amerikanischer Politik darstellt, sondern auch ei- 
nes der Kritik antiamerikanischer Vorurteile. In diesem Sinne teilt die vorliegende Arbeit zwar den theoretischen Ausgangspunkt Friedmans, dass der Streit über konkurrierende Definitionen des Phänomens durch eine Reflexion auf den Gebrauch des Antiamerikanismusbegriffs ergänzt werden sollte (vgl. Friedman 2012, S. 6 f.). Sie betont dabei aber, im Gegensatz zu Friedman, die Bedeutung eines vorurteilskritischen Begriffsgebrauchs.

Wie ist nun aber ein solcher Anti-Antiamerikanismus, der kein reaktionärer ,Amerikanismus“ ist, normativ zu verorten? Zunächst sei festgehalten, dass eine wertneutrale, „nominalistische“ Definition (Schwark 2008, S. 9) keine Lösung des Problems bietet. Die Idee einer rein „sachliche[n] Untersuchung“ des Gegenstands (ebd.) kommt dem Versuch gleich, den spezifischen normativen Gehalt sozialwissenschaftlicher Antiamerikanismuskritik schlichtweg zu ignorieren. Wie in den Kapiteln 3 und 4 dieser Arbeit anhand von sprechakttheoretischen und erkenntniskritischen Überlegungen gezeigt wird, ist ein normativer Bezug sozialwissenschaftlicher Theoriebildung unumgänglich: ,The formulation of critical theory is not an option" (Giddens 1984, S. XXXV). Das kann damit begründet werden, dass soziologische Begriffe gewissermaßen performativ in ihren Gegenstandsbereich hineinreichen. Jede sozialwissenschaftliche Beschreibung stellt selbst ein performatives Sprechhandeln dar, das nur durch seine Einbettung in einen Äußerungskontext Sinn macht; als Teil einer „Lebensform“ (Jaeggi 2005b, S. 116), deren gesellschaftspolitische Aspekte von denen des Gegenstandes nicht unabhängig sind.

Dies ist einerseits als Möglichkeitsbedingung jeder ,erklärend verstehenden ‘ (Weber 1988, S. 550; vgl. auch Eberle 1999) Sozialwissenschaft anzusehen, die sich das implizite Handlungswissen in ihrem Gegenstandsbereich ,zu eigen“ machen muss, um darin überhaupt bestimmte Handlungen beobachten zu können:

„Soziale Realität konstituiert sich durch aktive Handlungen der Gesellschaftsmitglieder, die hierzu - weitgehend routinemäßig - auf sozial vermittelte alltagsweltliche Wissensbestände zurückgreifen, welche ihnen helfen, die Bedeutung und den Anforderungscharakter sozialer Situationen zu verstehen. Der soziologische Untersucher kann Hypothesen weder formulieren noch operationalisieren, ohne auf diesen Wissenshintergrund wenigstens implizit Bezug zu nehmen“ (Kelle 1997, S. 53; vgl. auch Giddens 1993, S. 84 ff.)

Diese Teilnehmerinnenposition hat andererseits zur Konsequenz, dass sozialwissenschaftliche Theoreme nie ,reine Beschreibungen“ sind, ,weil jede Theorie in einem gesellschaftlichen Kontext formuliert wird, der die gesellschaftlichen Verwendungsweisen der theoretischen Beschreibung bestimmt“ (Bonacker 2000, S. 34), und ihr damit eine normative Komponente gibt.

Wenn aber Wertneutralität keine methodologisch haltbare Option darstellt und Kritik tatsächlich ein zentrales Moment soziologischer Theoriebildung ist, so muss sie sich dennoch von jener Art von ,Kritik' unterscheiden lassen, wie sie bspw. 
durch den oben zitierten anti-antiamerikanischen Konservativismus vertreten wird. Und dieser Unterschied kann nicht einfach darin bestehen, dass sie einen ,besseren “ normativen Standpunkt bezieht. Stattdessen wird hier vorgeschlagen, Kritik anhand der Struktur ihres Verhältnisses zum Gegenstand zu bestimmen. Für die Form einer „immanente[n] Kritik“ (Honneth 2007c, S. 68) ist charakteristisch, dass sie von einer (teilweisen) Übereinstimmung ihrer eigenen normativen Orientierung mit derjenigen des kritisierten Gegenstands ausgeht. Kritik stellt sich ihrem Gegenstand nicht vom Standpunkt einer überlegenen Normativität aus entgegen, sondern mit der „normativen Kraft der Kontingenz“ (Bonacker 2000). Sie bildet stets einen unvollständigen Gegensatz zum Kritisierten, kann kein rein äußerliches Verhältnis zu ihm einnehmen, denn „Kritik wird unhaltbar und tendenziell autoritär, wenn sie ihren Bezug zum Kritisierten aufgibt und ihr Fundament, ihr Entscheidungskriterium, ihre Wertvorstellungen außerhalb ihres Gegenstandes ansiedelt“ (ebd., S. 28).

In der vorliegenden Arbeit bilden die egalitäre Norm bzw. die oben angerissenen Konzepte sozialer Ungleichheit und Diskriminierung den Ausgangspunkt der Kritik. Antiamerikanisches Sprechen wird zu deren Gegenstand nicht durch den Nachweis, dass es rundheraus antiegalitär ist, sondern durch das Aufzeigen einer normativen Ambivalenz: Die kritisierten antiamerikanischen Sprechweisen sind überwiegend damit beschäftigt, vorurteilige Positionen unter dem Vorzeichen der Vorurteilsfreiheit zu rechtfertigen, ethnozentrische Diskriminierung unter dem Vorzeichen egalitärer Prinzipien zu vollziehen. Mit diesen ideologischen Konstruktionen richten sie sich gerade nicht explizit gegen die demokratisch-egalitäre Ordnung moderner Gesellschaften, sondern sie versuchen kategoriale Differenzkonstruktionen innerhalb dieser Ordnung zu reproduzieren, abzusichern und mit dem Gleichheitsgrundsatz in Einklang zu bringen. Im Sinne von Theodor W. Adornos Einschätzung, dass ,das Nachleben des Nationalsozialismus in der Demokratie potentiell bedrohlicher ist, als das Nachleben faschistischer Tendenzen gegen die Demokratie“ (Adorno 2003d, S. 555 f.), richtet sich Antiamerikanismuskritik gegen die ideologische Rechtfertigung anti-egalitärer Tendenzen in der egalitären Ordnung.

Die normative Grundlage der hier vorgebrachten Kritik bildet dementsprechend auch kein ,überlegenes ' Prinzip absoluter Gerechtigkeit, sondern vielmehr die Einsicht, dass die egalitäre Norm durch einen immanenten Widerspruch gekennzeichnet ist und ihre normative Kraft gerade aus der Kontingenz und Problematisierbarkeit jeweils erreichter Modelle der Gleichberücksichtigung bezieht (vgl. Menke 2004, S. 28). Es ist dieser Vollzugscharakter der egalitären Norm, den antiamerikanische Vorurteile abzubrechen versuchen, ohne ihn explizit negieren zu müssen. Vor dem Hintergrund dieses normativen Theoriefundaments „ohne Normativität“ (Bonacker 2000), begreift die hier entwickelte Antiamerikanismuskritik ihren Gegenstand gerade nicht als individuelle Pathologie, als paranoiden Wahn oder moralische Verderbtheit, sondern als „soziale Pathologie“ (Honneth 2007a; vgl. auch Wetherell 2012, S. 165), d.h. als „Unfähigkeit von Gesellschaften [...], ein in ihnen 
bereits angelegtes Vernunftpotential in den Institutionen, Praktiken und Alltagsroutinen angemessen zum Ausdruck zu bringen“" (Honneth 2007a, S. 33).

\subsection{Aufbau der Arbeit}

Kapitel 2 liefert einen Überblick über die aktuelle Forschungsliteratur zu Antiamerikanismus. Im Fokus stehen hierbei vorurteilstheoretische Konzepte, die Antiamerikanismus als negative Einstellung gegenüber den USA auffassen. Wenngleich diese Theorielinie sich durch konzeptuelle Klarheit auszeichnet und zudem die Anschlussfähigkeit der Antiamerikanismusforschung für die sozialwissenschaftliche Vorurteilsforschung steigert, bildet eine Kritik ihrer Definitionskriterien den Ausgangspunkt für die hier entwickelte Begriffsbildung. Hierbei werden vier Kernkriterien einstellungstheoretischer Antiamerikanismusdefinitionen problematisiert: Die propositionale Falschheit, die Feindseligkeit sowie die weltanschauliche Geschlossenheit antiamerikanischer Ausdrücke und die Bestimmung von Antiamerikanismus als individualpsychische Disposition. Ausgehend von der These, dass keines dieser Kriterien eine notwendige und hinreichende Bedingung antiamerikanischen Sprechens bietet, wird stattdessen ein performativer Antiamerikanismusbegriff entwickelt. Die Kernannahme dieses Modells ist, dass sich der Sinngehalt antiamerikanischer Ausdrücke weder an dessen semantischen Komponenten (negatives Amerikabild, stereotype Darstellung), noch an der Korrespondenz der formulierten Propositionen mit ,der Realität' Amerikas festmachen lässt. Stattdessen wird vorgeschlagen, die antiamerikanische Qualität solcher Ausdrücke als deren praktische oder performative Bedeutung zu bestimmen, d.h. als deren rhetorische Funktion in einem jeweiligen Äußerungskontext. Entscheidend ist dann nicht, was jemand sagt, sondern was diese Person tut, indem sie etwas sagt.

Im Anschluss an diesen Begriffsentwurf besteht Klärungsbedarf hinsichtlich zweier Aspekte: Zum einen muss geklärt werden, was mit ,Performativität‘ gemeint ist, wie also die praxistheoretischen Grundlagen dieses Konzeptes verstanden werden. Diese Frage wird in Kapitel 3 im Anschluss an sprechakttheoretische Überlegungen John L. Austins und Ludwig Wittgensteins bzw. deren Adaptionen bei Albrecht Wellmer und Peter Winch erörtert.

Zum anderen stellt sich die Frage, welche Sprachgebräuche in welchen Funktionskontexten als antiamerikanisches Sprechen gelten können. Dies ist wesentlich eine empirische Frage, zu deren Bearbeitung das bislang entwickelte Begriffskonzept lediglich eine gehaltlose Forschungsheuristik bietet. Um diese am Material sinnvoll einsetzen zu können, braucht es aber konkretere theoretische Anhaltspunkte, die die Rekonstruktion antiamerikanischer Sprachgebräuche gesellschaftstheoretisch verorten. Als Ausgangspunkt hierzu werden die Konzepte soziale Ungleich- 
heit und Diskriminierung gewählt. Ein amerikabezogenes Sprechen kann dann als antiamerikanisches Vorurteil betrachtet werden, wenn es an der rhetorischen Reproduktion diskriminierender sozialer Klassifikationen mitwirkt. Da sich aber die Unterscheidung von sozialer Ungleichheit und Diskriminierung selbst als unscharf bzw. als Gegenstand gesellschaftlicher Konflikte und Aushandlungsprozesse erweist (Menke 2004; Kreckel 2004), kann auch der Diskriminierungsbegriff nur bedingt zur Konkretisierung der Unterscheidung zwischen Vorurteil und vorurteilsfreiem Sprechen dienen.

Um dennoch Orientierungspunkte für die theoretische Bestimmung vorurteiliger Differenzkonstruktionen ausmachen zu können, rücken kategoriale Klassifikationen in den Fokus der Überlegung, d.h. solche Differenzkonstruktionen, die sich gegen die eigene Kontingenz und historische Wandelbarkeit abschirmen (Neckel und Sutterlüty 2005; Giesen 1987). Diese Form der selbststabilisierenden reflexiven Bearbeitung normativer Dilemmata wird im Anschluss an Überlegungen Luhmanns und Adornos als Ideologie bezeichnet. Mit dieser Perspektivverschiebung geht zudem eine Verschiebung der methodologischen Grundlage der Vorurteilskritik einher. Wenn egalitäre Normen nicht als Standard einer absoluten Gerechtigkeit, sondern als Aushandlungsprozess je und je problematisierter Gleichheitsvorstellungen aufgefasst werden, dann können diese einer Kritik an antiegalitären, vorurteiligen Sprechweisen nicht als gesicherter normativer Ausgangspunkt dienen. Unter „nachessentialistischen Bedingungen“" (Bonacker 2000, S. 14) herrscht zwischen Vorurteil und Nicht-Vorurteil keine strikte Äußerlichkeit. Vorurteilskritik muss, so wird im Anschluss an aktuelle Entwicklungen kritischer Theorie gezeigt, genau an dieser Unschärfe ihren Ausgangspunkt nehmen. Eine solche erschließende oder immanente Kritik (Bonacker 2008; Honneth 2007c) verurteilt ihren Gegenstand nicht als absolut falschen, sondern zeigt die ideologische Vermittlung von egalitären Normen und antiegalitärer Klassifikation deutend auf.

Um die Theoriegrundlage der empirischen Analysen genauer zu explizieren, wird das Konzept nationaler Identifikation eingeführt. Im Rückgriff auf wissenssoziologisch-hermeneutische Begriffe von Ethnozentrismus, Rassismus und Antisemitismus wird der funktionale Zusammenhang nationaler Identitätskonstruktionen mit vorurteiligem Sprechen aufgezeigt. Vorstellungen nationaler Zugehörigkeit, Homogenität und Ursprünglichkeit stehen häufig im Zentrum kategorialer Differenzkonstruktionen. Wie sich im Zuge der empirischen Ergebnisdarstellung zeigen wird, arbeiten hierbei antiamerikanische Sprechweisen eng zusammen mit antisemitischen, fremdenfeindlichen und rassistischen.

In Kapitel 5 werden Methodologie und Methoden des empirischen Vorgehens dargestellt und $\mathrm{zu}$ den vorherigen theoretischen Überlegungen in Bezug gesetzt. Hierbei wird vor allem die methodologische Nähe von qualitativ-interpretativer Sozialforschung, erschließender Kritik und Praxistheorie der Bedeutung erörtert. Dies betrifft zunächst die Reziprozität von Theorie und Empirie als Momente einer über- 
greifenden sozialwissenschaftlichen Erkenntnispraxis, die unter dem Begriff einer „theoretische[n] Empirie“ (Kalthoff 2008, S. 9) verhandelt wird. Im Anschluss an Udo Kelles Arbeiten zur Methodologie theoriegenerativer Sozialforschung kann dann gezeigt werden, inwiefern sich das Vorgehen einer erschließenden Vorurteilskritik als „empirisch begründete Theoriebildung“ (Kelle 1997) beschreiben lässt. Hierbei erweisen sich die von Kelle hervorgehobenen Konzepte des empirischen Gehalts sowie der hypothetischen Schlussfolgerung als nützliche Anknüpfungspunkte, um beide methodologischen Modelle zu verbinden. Im Anschluss daran kann das hier verwendete methodenintegrative Design methodologisch in den Theoriekontext eines performativen Antiamerikanismusbegriffes eingeordnet werden. Die vermeintlich widersprüchliche Kombination von praxistheoretischem Vorurteilsverständnis und quantitativer Empirie lässt sich hierbei als kritischer Anschluss an die etablierten Methoden der Vorurteilsempirie begründen.

Die abschließende Dokumentation der empirischen Ergebnisse erfolgt gegliedert in zwei Hauptteile. In Kapitel 6 wird zunächst gezeigt, dass sich mit der im Survey (geschichtete Zufallsstichprobe der deutschen Telefonhaushalte, $\mathrm{N}=808$ ) erhobenen Antiamerikanismusskala zwei Subdimensionen antiamerikanischer Vorurteile konsistent und trennscharf erfassen lassen: Die kulturkonservative Antiamerikanismusdimension beinhaltet Stereotype eines kulturell oberflächlichen, von Egoismus geprägten Amerika, während in der antiimperialistischen Dimension den USA die Schuld an weltweiten Konflikten zugeschrieben und das Bedrohungsszenario eines ,amerikanischen Imperialismus‘ beschworen wird. Auf beiden Dimensionen stimmen $15 \%$ respektive $9 \%$ der Teilnehmenden überdurchschnittlich stark $\mathrm{zu}\left(\mathrm{x}_{\mathrm{i}}>1\right.$ Standardabweichung über dem Skalenmittel). Unter Berücksichtigung der hohen Korrelation zwischen beiden Dimensionen $(r=, 77)$ kann somit von einer konsistenten Reproduktion (potentiell) antiamerikanischer Sprechweisen durch rund ein Zehntel der deutschen Bevölkerung ausgegangen werden. Überdies lassen sich moderate bis hohe Korrelationen $(, 22 \leq \mathrm{r} \leq, 55)$ mit acht weiteren Vorurteilsmaßen nachweisen, wobei insbesondere Antisemitismus, Fremdenfeindlichkeit und Rassismus herausstechen. Diese korrelativen Befunde bilden die Explananda der anschließenden qualitativen Interviewstudie.

Kapitel 7 gliedert sich in 4 Hauptabschnitte, in denen jeweils ein spezifischer Funktionskontext antiamerikanischen Sprechens im Fokus steht. So werden in Kapitel 7.2 zwei Beispiele für eine antiamerikanische Stabilisierung und Konturierung ethno-nationaler Identität gegeben. Die antiamerikanische Rhetorik von Herrn C zeichnet sich zunächst durch seinen umfassenden Gebrauch des Motivs der ,Amerikanisierung' aus, mit dessen Hilfe er diverse als bedrohlich oder problematisch erachtete Aspekte der Eigengruppe (irrationale Konsumkultur, soziale Ungleichheit, moralischer und kultureller Verfall) als amerikanische Einflüsse externalisiert. Zusätzlich dient aber das Motiv dazu, einen inneren Widerspruch der nationalen WirGruppenkonstruktion zu bearbeiten: den Konflikt zwischen einer ost- und einer 
westdeutschen Subgruppe. Herr C, der sich mit der ostdeutschen Hälfte identifiziert, konturiert und ,reinigt' mittels des Motivs der ,Amerikanisierung ' nicht nur ,Gesamtdeutschland', sondern er nutzt diesen Topos zugleich, um die Ost-West Unterscheidung innerhalb der antiamerikanisch geeinten Wir-Gruppe aufrechtzuhalten. Seine Wut auf arrogante, ausbeuterische ,Wessis“ äußert sich stets als Aggression gegen ,amerikanisierte Wessis“, so dass auch die beklagte Spaltung Deutschlands letztendlich amerikanischen Einflüssen zugeschrieben werden kann.

Im Interview mit Herrn F findet sich eine antiamerikanische „Figur des Dritten“ (Holz 2010, S. 296), die der Stabilisierung seiner ethno-nationalistischen Weltsicht dient, indem sie eine latente Bearbeitung der Kontingenz dieses Ordnungsmusters ermöglicht. Mit ,Amerika‘, dem Staat, der nur aus immigrierten Menschen besteht, kann an einem weit entlegenen und klar abgegrenzten Ort die Möglichkeit thematisiert werden, dass zwischen eingewanderter und , autochthoner' Bevölkerung kein essentieller Unterschied bestehen könnte, d.h. dass die nationale Identität nicht ethnisch-essentiell gesichert ist.

In Kapitel 7.3 werden antiamerikanische Sprechweisen im Funktionskontext von Erinnerungspolitik und Antisemitismus dargestellt. Im Zentrum dieses Abschnitts steht eine Rhetorik, die sich in großer Nähe zu sekundär antisemitischen Argumentationsmustern befindet. Mittels des Bildes einer , amerikanischen Manipulation" des europäischen Bildungssystems, durch die angeblich ein falsches, antideutsches Bild der zwei Weltkriege vermittelt wird, vollzieht der Interviewteilnehmer Herr B zunächst eine teilweise Täter-Opfer Umkehr. In der Gruppe der deutschen Opfer ,amerikanischer Willkür' können die Täter des Nationalsozialismus mit den nachgeborenen Generationen zu einer geschlossenen nationalen WirGruppe verbunden werden. Bilder eines , amerikanischen Genozid ‘ an der indigenen Bevölkerung ermöglichen dabei, den Holocaust zu einem Genozid unter vielen zu relativieren, ohne ihn jemals explizit ansprechen zu müssen. Als antiamerikanische Variation einer klassischen antisemitischen Rhetorik kann hingegen die Rede von Frau K gelten. Von ihr werden ,die USA“ und ,die Israelis ' für weltweite Kriege und Konflikte verantwortlich gemacht, die vermeintlich von diesen aus Profitinteressen angezettelt werden. ,Die Amerikaner' erscheinen dabei als Instrument und Komplizen eines schädlichen Einflusses ,der Israelis ‘, die durch ,Gier" und ,Streitlust` getrieben werden. In diesem Fall ist Antiamerikanismus also tatsächlich Element eines nur notdürftig mit antizionistischer "Camouflage“ (Holz 2001, S. 440 ff.) verdeckten weltanschaulichen Antisemitismus.

Kapitel 7.4 wendet sich dem Zusammenhang von Rassismus, Ethnozentrismus und Antiamerikanismus zu. Im Fokus steht hierbei zunächst das Beispiel Herrn As, in dessen Interview eine vergleichsweise drastische, explizit fremdenfeindliche Rhetorik neben der Empörung über ,amerikanischen Rassismus`steht. Während ein türkischstämmiger Bundeskanzler in Deutschland aufgrund seiner,ethnischen Fremdheit' undenkbar wäre, erscheinen ihm rassistische Anfeindungen Barack 
Obamas in den USA als verwerflich und unverständlich. Es wird argumentiert, dass die Abgrenzung gegen ,amerikanischen Rassismus“ hier rhetorisch ein Ausklammern der Rassismusproblematik aus dem Bereich der Wir-Gruppe bewirkt. Dies hat den ideologischen Effekt, dass Herr A sich nicht nur präventiv gegen Rassismusvorwürfe abschirmen kann, sondern ihm selbst der Widerspruch in seiner Rede überhaupt nicht mehr bewusst wird. Anhand drei weiterer Interviewbeispiele kann die These zusätzlich untermauert werden, dass die Motive eines ,amerikanischen Rassismus 'bzw. ,amerikanischer Fremdenfeindlichkeit' als rhetorische Stütze rassistischer und ethnozentrischer Identitätskonstruktionen gebraucht werden.

Nachdem anhand des Interviewmaterials die Funktionsweise antiamerikanischer Ungleichheitssemantiken exemplarisch rekonstruiert und auf diesem Wege zugleich Thesen zu deren Zusammenhang mit anderen Vorurteilsformen formuliert wurden, widmet sich Kapitel 7.5 inkonsistenten und fragmentierten Sprachgebräuchen. Ausgehend von der These, dass eine kritische Antiamerikanismusforschung sich gerade dadurch auszeichnet, dass sie auf die Grenzen der eigenen Begriffe reflektiert, werden anhand zweier Beispiele die Grenzbereiche antiamerikanischer Rede beleuchtet. So zeichnen sich Herr I und Frau H zunächst durch eine starke Ambivalenz und Unsicherheit hinsichtlich ihrer Darstellung ,der Amerikaner' aus: Beide betonen im Verlauf des Interviews immer wieder, dass sie ,eigentlich' kaum etwas über Amerika wissen und auf keinen Fall als amerikafeindlich eingestuft werden wollen. Darüber hinaus kann das Interview mit Frau $\mathrm{H}$ als anschauliches Beispiel für die Fragmentierung antiamerikanischer Rede gelten. So gebraucht sie in einer späten Sequenz des Gespräches eine relativ drastische ethno-nationalistische Rhetorik, in der die vermeintliche Wurzellosigkeit der USA gegen die Homogenität und Ursprünglichkeit des ,deutschen Volkes ' ausgespielt wird. Im Rest des Interviews findet sich hingegen keinerlei Anklang an ethnozentrische Identitätskonstruktionen. Frau H ist vielmehr bemüht, sich als ohnmächtige und letztendlich unpolitische ,Normalbürgerin‘ zu präsentieren. Am Beispiel von Herrn I lässt sich hingegen eine Verschiebung des Funktionskontextes beobachten: Zwar wird das Fremdbild der ,Amerikaner' von ihm gebraucht, um die eigene Wir-Gruppe zu konturieren, homogenisieren und relativ aufzuwerten. Jedoch ist diese Wir-Gruppe weder ethnisch noch national bestimmt, sondern bezieht sich auf die Identifikation mit einem Viertel einer deutschen Großstadt. Da sich Herr I zudem von ethnozentrischen und nationalistischen Identitätskonstruktionen explizit distanziert, bleibt in diesem Fall unklar, inwiefern es sich um eine Rhetorik handelt, die zur Reproduktion diskriminierender Verhältnisse beiträgt.

An den Beispielen von Herrn I und Frau $\mathrm{H}$ wird also ersichtlich, dass Antiamerikanismus auch jenseits geschlossener Weltanschauungen und amerikafeindlicher ,Obsessionen“ auftritt und dass auch die Ränder eines performativen Antiamerikanismusbegriffs in der empirischen Anwendung unscharf bleiben. 
Die Arbeit schließt mit einer Überblicksdarstellung des entwickelten Antiamerikanismuskonzepts und dessen sozialtheoretischer Rahmung. Die rekonstruierten antiamerikanischen Sprechweisen werden nach dem Begriffsmodell der „Familienähnlichkeit“ (Wittgenstein 2006, S. 278) zusammengeführt, anhand dessen sowohl die Flexibilität und Kontextabhängigkeit des Antiamerikanismus im alltäglichen Sprachgebrauch, sowie die theoretisch-begriffliche Konsistenz eines performativen Antiamerikanismusbegriffs erkennbar werden. 



\section{Was ist falsch am Antiamerikanismus? Forschungsgegenstand und Stand der Forschung}

Nachdem im vorigen Kapitel ein allgemeiner Aufriss des gesellschaftlichen Problems Antiamerikanismus gegeben wurde, beginne ich meine theoretische Betrachtung dieses Phänomens mit einem Überblick über die Forschungsliteratur zum Thema. Dieser Überblick markiert einerseits die Anknüpfungspunkte meiner Vorurteilskritik an den bestehenden Forschungsansätzen, berücksichtigt andererseits aber auch den Gebrauch des Antiamerikanismusbegriffes in außerwissenschaftlichen Diskursen. Dem Konzept Antiamerikanismus wird häufig mit Skepsis begegnet; man vermutet dahinter ein Propagandainstrument mithilfe dessen KritikerInnen von US-Politik delegitimiert werden sollen. Darüber hinaus wird die Auffassung, dass antiamerikanische Vorurteile ein gesellschaftliches Problem darstellen, häufig generell zurückgewiesen: Solchen Positionen zufolge ist das Problem nicht Antiamerikanismus, sondern Amerika selbst. Insgesamt ist also die Kritik antiamerikanischer Vorurteile weit entfernt davon, Common Sense zu sein; weiter zumindest, als etwa die des Rassismus oder Antisemitismus.

Diese Skepsis bzw. Unsicherheit im Umgang mit dem Begriff setzt sich auch in wissenschaftlichen Arbeiten zum Thema fort. Kaum eine Studie über Antiamerikanismus präsentiert ihre Ergebnisse ohne zuvor auf „Definitionsproblem[e]“ der Antiamerikanismusforschung hinzuweisen (Baethge et al. 2010, S. 367; vgl. auch Beyer 2014, S 9 ff.; Gulddal 2011, S. 3; Haury 2004, S. 65 f.; O’Connor 2007b, S. 7). Das Problem einer mangelnden Präzision der Begriffsdefinition wird in der Regel in direkten Zusammenhang gestellt mit möglichen Missbräuchen des Konzeptes, und greift damit die oben genannten Bedenken außerwissenschaftlicher Diskurse auf.

Ein aussichtsreicher Vorschlag zur Lösung der besagten Definitionsprobleme besteht in der Eingemeindung des Antiamerikanismusbegriffes in den Gegenstandsbereich der etablierten Vorurteilsforschung. Diese Antiamerikanismus-als- 
Vorurteil-Perspektive übernimmt die drei wesentlichen Kriterien eines ,klassischen ‘ Vorurteilsbegriffes (vgl. Dovidio et al. 2010, S. 6 f.): Sie definiert Antiamerikanismus als irrationale bzw. auf faktisch falschen Prämissen beruhende, feindselige und weltanschaulich geschlossene Einstellung gegenüber den USA.

Wie ich im Verlauf des Abschnittes 2.3 zeigen werde, bleiben diese drei Kriterien aber unbefriedigend: Einerseits lässt sich zeigen, dass sie keine notwendigen Kriterien zur Bestimmung von Antiamerikanismus darstellen, es also antiamerikanische Ausdrücke gibt, die nicht feindselig, irrational und weltanschaulich geschlossen sind. Andererseits geben sie auch in den Fällen, in denen sie erfüllt sind, keine hinreichenden Kriterien zur Kategorisierung von Ausdrücken als Antiamerikanismus ab; anders gesagt: das Problem, das die Vorurteilskritik in den Blick nimmt, ist als irrationale Generalisierung, Feindschaft oder Weltanschauung unterbestimmt.

Mein Alternativvorschlag eines Antiamerikanismusbegriffes beruht auf einer grundlegenden methodologischen Skepsis gegenüber Begriffsmodellen, die sich ausschließlich auf die Definition notwendiger und hinreichender Kriterien verlassen. Eine kriterielle Bestimmung von Vorurteilen, so mein Argument, kann der Flexibilität und Fragmentierung antiamerikanischer (und im Prinzip aller) Vorurteile im alltäglichen Sprechen begrifflich nicht gerecht werden, so lang sie nicht auch ihren eigenen flexiblen Gebrauch der Kriterien, d.h. die flexible Realisierung von Merkmalen wie Feindschaft, Aversion, etc. im vorurteiligen Sprechen reflektiert: Wann wird eine abwertende oder faktisch falsche Aussage als Vorurteil relevant? Begriffsbildungen, die sich allein auf die Definition von Kriterien verlassen, verfehlen die rhetorische Kontextbezogenheit antiamerikanischer Ausdrücke. Dieser situierte, funktionale Gebrauch bestimmter Amerikabilder und Argumentationsmuster lässt sich nicht durch eine Definition universaler Merkmale erschöpfen. Es liegt näher, eine empirische ,Kartierung' (vgl. Wetherell und Potter 1992) der verschiedenen Gebrauchsweisen zu versuchen: In welchen Funktionskontexten werden welche Amerikastereotype in welcher Weise gebraucht, und inwiefern lassen sich diese Gebräuche jeweils als vorurteilige bestimmen?

Um dieser Aufgabe besser gerecht werden zu können, schlage ich ein sprechaktbzw. praxistheoretisch informiertes Modell der Begriffsbildung vor, das ich als performativen Antiamerikanismusbegriff bezeichne. Dieses Modell unterscheidet sich von existierenden Antiamerikanismusdefinitionen nicht allein darin, dass andere oder zusätzliche Kriterien in das Definiens aufgenommen werden - es verwirft vielmehr den Anspruch, Antiamerikanismus durch die Definition notwendiger und hinreichender Kriterien erschöpfend bestimmen zu können. Stattdessen schlage ich eine am Modell der „Familienähnlichkeiten“ (Wittgenstein 2006, S. 278) orientierte Begriffsbildung vor, in der die genaue empirische Analyse von Ähnlichkeiten zwischen verschiedenen amerikabezogenen Sprechakten zur Grundlage der Vorur- 
teilskritik wird. In Kapitel 3 werden die sprechakttheoretischen Grundlagen dieses Konzeptes genauer expliziert.

Das Modell eines performativen Antiamerikanismusbegriffes wird im Folgenden aus einer Kritik existierender Antiamerikanismusdefinitionen entwickelt. Hierbei gehe ich in drei Schritten vor: Abschnitt 2.1 beschreibt die grundlegenden Vorbehalte, die gegen einen kritischen Antiamerikanismusbegriff sowohl in der Forschungsliteratur, als auch in außerwissenschaftlichen Diskursen geäußert werden. Abschnitt 2.2 fasst die Bemühungen der Antiamerikanismusforschung zusammen, diesen Vorbehalten mit einem Vorurteilskonzept zu begegnen, in dem Antiamerikanismus mithilfe des sozialpsychologischen Begriffs der Einstellung gefasst wird. In Abschnitt 2.3 werden die Definitionskriterien dieses Ansatzes systematisch auf ihre Grenzen hin befragt. Die dabei gewonnenen Einsichten in die Engführungen und Reduktionismen bestehender Vorurteilskonzepte bilden die Grundlage für das anschließend entwickelte performative Antiamerikanismuskonzept.

\subsection{AUFGEKLÄRTER ANTIAMERIKANISMUS? WIDERSTÄNDE GEGEN EINE ANTI-ANTIAMERIKANISCHE VORURTEILSKRITIK}

Antiamerikanismus ist ein umstrittenes Konzept. Häufig wird Antiamerikanismus als vorurteilskritischer Begriff in Frage gestellt, während diejenigen Ausdrücke und Handlungen, gegen die er sich kritisch wendet, als legitime Formen politischen Protestes bestärkt werden. Man begegnet der Kritik antiamerikanischer Vorurteile mit dem Einwand, der Antiamerikanismusbegriff sei ein politisches Machtmittel, eine Waffe der „Political Correctness“ (Auer 2002), erschaffen, um die Kritiker der USA und ihrer Politik zum Schweigen zu bringen (vgl. Gulddal 2011, S. 3 f.; Hahn 2003, S. 20 ff.; O’Connor 2007b, S. 5; Roger 2005, S. xii). Diese Umdeutung der anti-antiamerikanischen Vorurteilskritik zum Vorurteil, der zufolge nicht der Gegenstand der Antiamerikanismuskritik problematisch ist, sondern der Antiamerikanismusbegriff selbst, ist der Form nach aus Debatten um Antisemitismus und Israelkritik bekannt, in Deutschland beispielsweise jüngst aus denjenigen um Günther Grass' im April 2012 veröffentlichtes Gedicht Was gesagt werden muss (Grass 2012; vgl. Joffe 2012) oder die ,israelkritischen“ Äußerungen Jakob Augsteins (vgl. Kuhn 2013; Pokatzky 2013). Von Günter Grass stammt auch die folgende Äußerung, die er im Kontext der politischen Debatten um Reaktionen auf die Anschläge des 11. September 2001 machte: 
Der einzelne Intellektuelle, der in der Gruppe mitgescholten wird, wird das überleben, aber diese Art, demokratische Grundrechte einzuschränken, Maulkörbe verpassen zu wollen, ist vom Ergebnis her jedesmal ein Triumph der Terroristen.“ (F.A.Z. 2001)

Hier findet sich die oben skizzierte Position in exemplarisch verdichteter Form wieder: Die Antiamerikanismuskritik richtet sich Grass zufolge in erster Linie gegen legitimen Protest und ist daher ein „Wortungeheuer“, das „demokratische Grundrechte“ einschränkt bzw. „Maulkörbe“ verteilt. Da der Antiamerikanismusbegriff kein aufklärerisches, emanzipatorisches Interesse verfolge, sondern ein Instrument der Unterdrückung sei, beförderten diejenigen, die ihn gebrauchen, bewusst oder unbewusst die Ziele ,,der Terroristen“.

Diese Form der Umkehrung eines kritischen Antiamerikanismusbegriffes ist geläufig. Das, wogegen er sich richtet, wird gerechtfertigt, der Begriff selbst aber zum Vorurteil und Zensurinstrument erklärt. ${ }^{1}$ Im Gegensatz zu den in argumentativer Hinsicht ähnlich verlaufenden Antisemitismus-Debatten, scheint der Sanktionsdruck des Antiamerikanismus-Vorwurfs aber weitaus geringer zu sein. Tatsächlich finden sich immer wieder Fälle einer affirmativen Aneignung des Antiamerikanismusbegriffes, in denen die eigene Position positiv als antiamerikanisch markiert wird, teilweise verbunden mit der Forderung nach einem, aufgeklärten Antiamerikanismus‘ (Altvater et al. 1989; Misik 2003; vgl. auch Schwark 2008, S. 10). Solche Argumentationen implizieren wiederum, dass ein Begriff zur genauen Beschreibung und Kritik von Vorurteilen gegenüber den USA bzw. Amerikanern gegenstandslos sei. Antiamerikanische Vorurteile sind demnach entweder gar nicht existent, oder aber politisch unbedeutend, nicht der kritischen Rekonstruktion wert. Dies muss die Implikation solcher Forderungen sein, denn akzeptierte man Antiamerikanismus grundsätzlich als einen Begriff der Vorurteilskritik, wäre die Forderung nach einem , aufgeklärten Antiamerikanismus' ungefähr so absurd, wie wenn ,Israelkritiker' einen , aufgeklärten Antisemitismus ‘ für sich reklamierten. Wo diese

1 Gerade vor dem Hintergrund der in der vorliegenden Arbeit unternommenen theoretischen Schärfung des Antiamerikanismusbegriffes muss man zugestehen, dass der damalige Bundesinnenminister Otto Schily, ebenso wie Hans-Peter Friedrich im Juni 2013 (vgl. Kap. 1), den Begriff sicherlich nicht in einer sozialwissenschaftlich-reflektierten Weise verwendete. Für den hiesigen argumentativen Zusammenhang ist dies aber von nachrangigem Belang. Entscheidend ist vielmehr, dass Grass aus der Feststellung eines vermeintlichen Missbrauchs des Antiamerikanismusbegriffes den Schluss zieht, dieser sei insgesamt als antidemokratischer „Maulkorb“ zu verwerfen. Er argumentiert z.B. gerade nicht, dass ein solcher Missbrauch auch deshalb problematisch sei, weil dadurch die Kritik eines tatsächlich existierenden Antiamerikanismus verwässert würde, o.ä. Seine Rhetorik negiert - gewollt oder ungewollt - die Existenz antiamerikanischer Vorurteile. Antiamerikanismus ist für ihn insgesamt „one word too many“ (Roger 2005, S. xii). 
aber eine Nähe zu antisemitischer Rhetorik stets vehement bestreiten und damit die Existenz von Antisemitismus als Problem prinzipiell anerkennen, richtet sich Kritik am Antiamerikanismusbegriff häufig nicht nur gegen eine falsche Anwendung des Konzepts, sondern gegen die Sinnhaftigkeit bzw. kritische Relevanz des Begriffes überhaupt.

In einigen Beispielen solcher Ablehnung anti-antiamerikanischer Vorurteilskritik werden gar jene Aspekte des Antiamerikanismus affirmativ gewendet, die gemeinhin als vorurteilig verurteilt werden: Es wird dann behauptet, dass gegen Ressentiment, und stereotype Abwertung nichts einzuwenden sei, gerade dann, wenn sich diese allgemein gegen die USA bzw. die amerikanische Gesellschaft richten (vgl. dazu Gitlin 2003; Markovits 2007, S. 25; O’Connor 2007b, S. 13 f.). Bei solchen Positionen, wie etwa derjenigen des Theaterregisseurs Peter Zadek, dem „Amerika zutiefst zuwider“ ist, weswegen er sich explizit zum „Kulturkampf“ gegen die USA bekenne, da man „,heute durchaus gegen die Amerikaner sein“ dürfe, ,so wie im zweiten Weltkrieg der größte Teil der Welt gegen die Deutschen war" (zit. n. Markovits 2004, S. 34 f.; vgl. auch Hahn 2003, S. 24), geht es nicht mehr um die Zurückweisung des Antiamerikanismusvorwurfes. Es handelt sich vielmehr um einen offenen und selbstbewussten Antiamerikanismus (vgl. Hahn 2003, S. 22 f. für weitere Beispiele). ${ }^{2}$ Darin unterscheidet sich diese Form vorurteiliger Rede von den rhetorisch behutsameren Relativierungen, wie sie am Beispiel von Grass gezeigt wurden.

Es ist insgesamt also auffällig, wie sehr die Idee einer anti-antiamerikanischen Vorurteilskritik auf öffentliche Ablehnung stößt. Dieser Umstand wirkt umso bedenklicher, da die Ablehnung des Antiamerikanismusbegriffes selbst häufig mit ei-

2 Tatsächlich lassen solche selbstbewussten antiamerikanischen Ausdrücke ein zentrales Manko einstellungstheoretischer Antiamerikanismusbegriffe erkennen: Gegen Abneigung oder Hass ist ja ,an sich“, d.h. ohne nähere Bestimmung von deren Sinnzusammenhang, tatsächlich erst einmal nichts einzuwenden - zumindest nicht im Sinne einer Vorurteilskritik. Dass manche Menschen die USA oder ,die Amerikaner' nicht mögen, u.U. sogar hassen, konstituiert noch nicht das gesellschaftliche Problem, dass die Vorurteilskritik als Antiamerikanismus in den Blick nimmt (wenngleich solche Aversionen natürlich ein relevanter Aspekt dieses Gegenstands sein können). Erst durch ihre funktionale Verknüpfung mit Diskriminierung, Exklusion und Verfolgung werden solche Aversionen für die Antiamerikanismusforschung relevant, wie ich in Kapitel 4 detailliert zeige. D.h. ein Vorurteilsbegriff, der sich definitorisch auf negative Einstellungen oder affektive Komponenten beschränkt, läuft Gefahr, seinen Gegenstand zu verfehlen und vorzeitig in bloße moralische Setzungen zu verfallen. Ein geeigneter Ansatzpunkt der Vorurteilskritik scheint mir viel eher in der rhetorisch-ideologischen Stoßrichtung zu liegen, die in Zadeks Vergleich der USA mit dem nationalsozialistischen Deutschland anklingt. Ähnliche normalisierende Rhetoriken werden in Kapitel 7.3 eingehend empirisch beleuchtet. 
ner stereotypen Abwertung oder Anfeindung der USA einhergeht, also genau den Tatbestand reproduziert, dessen Existenz bzw. politische Relevanz bestritten wird. Damit ist nicht gesagt, dass jede Zurückweisung des Antiamerikanismusbegriffes selbst als antiamerikanisches Sprechen zu werten ist. Es zeigt aber, dass Antiamerikanismus zu denjenigen Vorurteilen zählt, die auch im öffentlichen Raum weithin als zutreffend oder legitim akzeptiert werden. Andrei Markovits hat antiamerikanische Rhetoriken aufgrund dieser Hoffähigkeit als eine „European lingua franca“ bezeichnet (Markovits 2007, S. 11).

Warum aber ist Antiamerikanismus so salonfähig und dessen Kritik vielerorts ungern gesehen? Es sollten bezüglich dieser Frage drei Punkte berücksichtigt werden, die sich zumindest auf den ersten Blick als Erklärung oder gar Rechtfertigung solcher Widerstände anzubieten scheinen.

(1) Die im Antiamerikanismus konstruierte Fremd- bzw. Feindgruppe ist, im Gegensatz zu den meisten allgemein anerkannten, ,klassischen' Vorurteilsformen, weder eine Minderheit, noch schwach oder benachteiligt (sofern sich dies in solcher Allgemeinheit überhaupt sagen lässt). Es ist daher vermutet worden, dass Antiamerikanismus als quasi natürlicher Neid bzw. als Ressentiment gegenüber Mächtigeren zu verstehen sei (vgl. Markovits 2007, S. 32). Wenngleich der relativ mächtige Status der USA durchaus eine Rolle für den Ausdruck von Antiamerikanismus spielen mag, so wäre es doch verfehlt, die antiamerikanische Konstruktion einer (über-)mächtigen Outgroup sogleich mit korrespondenzlogischen Erklärungen zu verbinden (vgl. Holz 2001, S. 62; Wetherell und Potter 1992, S. 67 ff.; siehe zu korrespondenztheoretischen Ansätzen auch Kap. 2.3.1). Dieser Fehler beruht auf einer in der Vorurteilsforschung weit verbreiteten Annahme, der zufolge Vorurteile durch einen Abgleich mit ,der Realität‘ einer jeweils bezeichneten Outgroup kritisiert, oder sogar durch deren Eigenschaften ursächlich erklärt werden könnten. Wie ich zeigen werde, kann die Macht ,der Amerikaner' und die korrespondierende Unterlegenheit der Wir-Gruppe in antiamerikanischen Konstruktionen durchaus unterschiedliche Funktionen erfüllen, die nicht unbedingt auf Neid oder Kränkung der ,Kleineren“ schließen lassen. Motive einer , amerikanischen Einflussnahme“ auf Medien und Politik können z.B. im Rahmen einer schuldabwehrenden Rhetorik gebraucht werden, die sich der eigenen nationalsozialistischen Vergangenheit zu entledigen sucht (vgl. Kap. 7.3). Bilder einer universal verbreiteten , amerikanischen Kulturindustrie' können der Konturierung und Aufwertung einer durchaus sehr selbstbewussten nationalistischen Wir-Gruppenkonstruktion dienen (vgl. Kap. 7.2). Geht man davon aus, dass erst solche funktionalen Gebräuche den vorurteiligen Charakter antiamerikanischer Ausdrücke konstituieren, nicht der semantische Inhalt oder die Faktizität der darin gemachten Propositionen, so kann prinzipiell nicht von 
der tatsächlichen Macht der USA auf die Gestalt des Antiamerikanismus geschlossen werden. ${ }^{3}$

(2) Weiterhin beinhalten antiamerikanische Fremd- oder Feindbildkonstruktionen - zumindest auf den ersten Blick - meist keine ethnisierende Zuschreibung. Antiamerikanismus richtet sich, im Gegensatz zu vielen anderen ,klassischen “ Vorurteilen wie Rassismus oder Antisemitismus, nicht gegen ein ,Volk' im Sinne einer ethnischen Abstammungsgemeinschaft, sondern gegen eine staatlich verfasste Gruppe. Jenes biologisierende Moment, das übrigens heute auch für die genannten ,klassischen' Vorurteilsvarianten nicht immer ausschlaggebend ist (Martin 2010, S. 71 ff.), fungiert häufig als Kernkriterium eines Common-Sense-Begriffes des Vorurteils, der dieses mit Rassismus mehr oder weniger gleichsetzt. Das zumindest vordergründige Fehlen dieser biologisierenden Komponente im Antiamerikanismus erleichtert dessen Legitimation als vorurteilsfreie ,Meinung'. So würde ein selbstbewusster Antiamerikanismus sich wahrscheinlich darauf beziehen, dass er sich gegen eine ethnisch völlig heterogene Gruppe richtet, deren Staatspolitik zudem noch demokratisch legitimiert sei, was das eigene verallgemeinernde Sprechen dann von jedem Vorurteil unterscheiden soll, da es mit Rassismus ja offensichtlich nichts zu tun habe. Diesen Argumenten liegt aber ein Selbstmissverständnis zugrunde - in manchen Fällen vielleicht auch eine bewusste Täuschung -, das von der (wissenschaftlichen) Antiamerikanismuskritik bislang kaum behandelt wurde: Alle oben umrissenen Rechtfertigungsmuster, der Verweis auf die ethnische Heterogenität der

3 Auch teile ich Max Friedmans Einschätzung nicht, dass Antiamerikanismus sich darin von anderen Vorurteilsformen, wie etwa Antisemitismus, prinzipiell unterscheide, dass es ,die Amerikaner' als Gruppe tatsächlich gibt, während ,die Juden` eine rein antisemitische Konstruktion sind: „It is never legitimate to hold ,the jews“ responsible for anything, because there is no such collectivity that behaves as a unit. [...] There is, however, a collectivity called ,the Americans" who jointly elect their leaders and fund their nation's activities through their tax payments." (Friedman 2012, S. 12) Wenn auch die staatliche Verfasstheit der USA einer pauschalisierenden Gruppenzuschreibung auf ,die Amerikaner` ein gewisse Grundlage verleiht, so ist Friedmans Argumentation doch in zweifacher Hinsicht problematisch. Erstens erscheint es aus einer hermeneutisch-wissenssoziologischen Perspektive fraglich, inwiefern Nationalstereotype sich von stereotypen Konstruktionen ethnischer Gruppen prinzipiell unterscheiden. Dass es einen amerikanischen Staat gibt dessen demokratische Basis ja übrigens gerade keinen monolithischen Block darstellt ändert in dieser Blickrichtung zunächst nichts daran, dass pauschale Gruppenstereotype in erster Linie als Konstruktionen der jeweiligen Sprecher anzusehen sind. Zweitens sind auch bzgl. generalisierender Aussagen über ,die Juden' durchaus Kontexte denkbar, in denen eine verallgemeinernde Kategorie nicht allein aufgrund ihrer Verallgemeinerung schon als vorurteilige Konstruktion zu werten ist - bspw. wenn von der Verfolgung der europäischen Juden während des zweiten Weltkrieges die Rede ist. 
USA, die Eingrenzung des Vorurteils auf biologistischen Rassismus, vermeiden nicht eine ethno-nationalistische Semantik oder stehen dieser entgegen, sondern sie implizieren gerade Nationalismus und Ethnozentrismus. Wie insbesondere in Kapitel 7.2 und 7.4 gezeigt wird, kann Antiamerikanismus als entschärfter Ausdruck bzw. Camouflage ethnozentrischer, nationalistischer und rassistischer Positionen dienen, gerade weil er keine unmittelbar ,rassischen' Zuschreibungen enthält. Nur weil ein Fremd- oder Feindbild nicht als ,Volk' konstruiert wird, bedeutet dies nicht, dass es nicht der Konstruktion und Stabilisierung ethno-nationalistischer Identitätskonstruktionen dienen kann.

(3) Abschließend ist noch zu bemerken, dass der Terminus Antiamerikanismus selbstverständlich auch missbraucht werden kann - genauer: dass er zu Zwecken gebraucht werden kann, die mit einer sozialwissenschaftlichen Vorurteilskritik nicht vereinbar sind. Dies ist historisch mit dem Antiamerikanismusbegriff sicherlich häufiger und folgenreicher geschehen, als mit anderen heute etablierten Vorurteilsbegriffen (vgl. Kap. 1.3 sowie Sablowski 2004; O'Connor 2007b, S. 5). Bis heute schreiben sich chauvinistisch-nationalistische, reaktionäre Gebrauchsweisen des Antiamerikanismusbegriffes fort, wie in der Einleitung zu dieser Arbeit bereits erwähnt wurde. Daraus kann aber nur dann der Schluss gezogen werden, dass solche reaktionären Gebräuche das Wesentliche des Antiamerikanismusbegriffes ausmachen und dieser daher insgesamt zu verwerfen sei, wenn man jegliche anderen Referenzpunkte einer Antiamerikanismuskritik entweder für irrelevant oder gar unterstützenswert hält. Jesper Gulddal fasst dies bzgl. der Debatten um den Irak-Krieg 2003 zusammen:

„The suspicion was not entirely unfounded: in the heated debates over Iraq the concept of anti-Americanism was in fact frequently employed, by Europeans as well as Americans, as a way of ,gagging the sceptics'. However, this misuse of the concept does not mean, that antiAmericanism is not real.“ (Gulddal 2011, S. 3)

Die genannten drei Aspekte können also insgesamt nicht als Erklärung oder gar Rechtfertigung dafür gelten, dass Antiamerikanismus ein vergleichsweise wenig sanktioniertes Vorurteil darstellt, dessen Kritik mit Skepsis und Ablehnung begegnet wird. Vielmehr sollten alle drei Aspekte als Teil des Gegenstands einer rekonstruktiven Antiamerikanismuskritik aufgenommen werden: Die (Über-)Macht und Bedrohlichkeit ,der Amerikaner' oder deren ethnische Heterogenität sind nicht als Ursache oder Legitimation für die Akzeptabilität antiamerikanischer Äußerungen zu fassen, sondern als ein funktionales Moment derselben. 


\subsection{Die Problematisierung DES ANTIAMERIKANISMUSBEGRIFFES IN DER FORSCHUNGSLITERATUR}

Nachdem im vorigen Abschnitt populäre Einwände gegen einen vorurteilskritischen Antiamerikanismusbegriff beschrieben wurden, stehen im Folgenden begriffliche Überlegungen der Antiamerikanismusforschung im Fokus, die auf diese Problematik reagieren. Hierbei zeigt sich, dass auch wenn man die oben geschilderten prinzipiellen Einwände gegen eine Antiamerikanismuskritik hinter sich gelassen hat, die Konzeption antiamerikanischer Vorurteile alles andere als einvernehmlich und klar ist. Dies mag einerseits kein Wunder, sondern eher eine Selbstverständlichkeit sozial- und geisteswissenschaftlicher Forschungsdiskurse sein, leben diese doch von theoretischer Vielfalt und Debatte (vgl. Bonacker 2001). Andererseits fällt aber gerade an der Antiamerikanismusliteratur eine besondere Betonung der begrifflichen Unschärfen und Probleme des Kernbegriffes auf. Im Verlauf dieses Kapitels werde ich auf einige Hauptmotive der Diskussion um den Antiamerikanismusbegriff eingehen und die darin behandelten Probleme bündeln. Dabei werden in Abschnitt 2.2.1 zunächst die zwei am häufigsten diskutierten Probleme der Theoriebildung zum Antiamerikanismus aufgegriffen: Eine mangelnde theoretische Präzision der Definitionen und das Fehlen eines klaren Abgrenzungskriteriums gegenüber legitimer Amerika-Kritik.

Als wichtiger Referenzpunkt für Lösungsvorschläge zu diesen Problemen wird in der Forschungsliteratur zunehmend auf den Begriff des Vorurteils Bezug genommen (Berman 2008; Beyer 2014; Beyer und Liebe 2014; Ceaser 1997; Chiozza 2009; Katzenstein und Keohane 2007b; Knappertsbusch 2013; Knappertsbusch und Kelle 2010; Markovits 2007; O'Connor 2007b), wie er in einer vornehmlich sozialpsychologisch geprägten Vorurteilsforschung seit den 50er Jahren etabliert wurde (vgl. Billig 2012; Dixon et al. 2012; S. 411 f.; Dovidio et al. 2005). Dieser Anschluss an die Vorurteilsforschung wird hier zunächst als begrüßenswert beurteilt, da er eine größere theoretische Stringenz in der Antiamerikanismuskritik sowie deren Einbettung in die etablierten Forschungsdiskurse zu Vorurteil und Diskriminierung befördert. Allerdings bringt der traditionelle Vorurteilsbegriff zugleich einige theoretische Probleme mit sich, die in Abschnitt 2.3 genauer analysiert werden. In den beiden Abschnitten 2.2.1 und 2.2.2 werden nun aber zunächst die in der Antiamerikanismusliteratur weithin geteilte Auffassung des ,Definitionsproblems “ sowie die daraufhin formulierten einstellungstheoretischen Lösungsvorschläge beschrieben. 


\subsubsection{Ungenügende Definitionen und die Unterscheidung von Antiamerikanismus und Amerika-Kritik}

Wie eingangs bereits erwähnt, existiert nicht nur in öffentlichen Debatten, sondern auch in wissenschaftlichen Spezialdiskursen eine gewisse Unsicherheit im Umgang mit dem Konzept Antiamerikanismus:

„The exact meaning of the concept of anti-Americanism is a large and controversial problem that has been debated endlessly in recent years without having found a definitive, universally accepted solution.“ (Gulddal 2011, S. 3)

So wird hier immer wieder Klärungsbedarf hinsichtlich eines Definitionsproblems sowie eines, meist als daraus resultierend betrachteten, mangelnden Kriteriums zur Abgrenzung von antiamerikanischem Vorurteil und vorurteilsfreier Amerikakritik geäußert. Der australische Politikwissenschaftler Brendon O'Connor schreibt in der Einleitung zur von ihm herausgegebenen Sammelpublikation Anti-Americanism: History, Causes, Themes:

„The existing academic literature provides endless devisions between different so-called sources of anti-Americanism but there is too little scholarship on what anti-Americanism conceptually is and thus how anti-Americanism can effectively be differentiated from criticism.“ (O’Connor 2007b, S. 7)

Eine ähnliche, zweigliedrig argumentierende Kritik am Forschungsstand äußert Gregory Johnston in seiner Dissertation:

„Despite its currency in popular discourse, anti-Americanism is a topic that has received limited attention by academics. This lack of attention is probably due to two factors. First, antiAmericanism is a term that is difficult to conceptualize. Second, it easily lends itself to (mis)use as a pejorative.“ (Johnston 2006, S. 2 f.)

In beiden Problembestimmungen wird eine mangelnde Genauigkeit des Antiamerikanismusbegriffes in engem Zusammenhang mit dem Problem eines politischen Missbrauchs dieses Konzeptes gesehen. Mit einer ähnlichen argumentativen Zielsetzung schreibt Sebastian Schwark, die Problematik des Antiamerikanismusbegriffes beginne bei dessen politischer Aufladung (Schwark 2008, S. 9 vgl. auch Chiozza 2009, S. 34). Der Begriff entstamme der politischen Sprache und werde in erster Linie polemisch-pejorativ gebraucht. Ein wissenschaftlicher Antiamerikanismusbegriff habe diese Problematik zu überwinden, indem ein ,,performativer“ Antiamerikanismusbegriff durch einen ,nominalistischen“ ersetzt werde (Schwark 2008, 
S. 9). ${ }^{4}$ Eine solche „more precise definition of the term“ (O'Connor 2007b, S. 6) soll dementsprechend nicht nur die Validität empirischer Instrumente zur Erhebung von Antiamerikanismus stärken, sondern perspektivisch auch das Problem eines ,Missbrauchs‘ des Begriffes lösen.

In Kapitel 3 wird ausführlich auf die Probleme eingegangen, die durch eine solche einseitige Fixierung der Forschungsliteratur auf Nominaldefinitionen entstehen, und ein alternatives, sprachpragmatisch informiertes Modell der Begriffsbildung vorgeschlagen. Was an dieser Stelle zunächst hervorgehoben werden soll, ist, dass es ein regelmäßig beklagtes Definitionsproblem der Antiamerikanismusforschung gibt, dass dieses Problem meist in engem Zusammenhang mit der Unterscheidung von Antiamerikanismus und Kritik diskutiert wird, und dass die Lösung dieses Problems meist in einer Präzisierung der Antiamerikanismusdefinition gesucht wird. Den theoretischen Rahmen, in dem eine (zumindest vorläufige) Lösung des Definitionsproblems formuliert wird, stellt dabei häufig der Begriff des Vorurteils dar.

\subsubsection{Anti-Americanism as Prejudice - Prejudice as Attitude}

Die Adaption des Vorurteilsbegriffes als Lösungsstrategie für die Definitionsprobleme der Antiamerikanismusforschung wird explizit von Brendon O'Connor gefordert. Von den fünf von ihm herausgearbeiteten Definitionsansätzen (O'Connor 2007b, S. 8 f.) betrachtet er ein Anknüpfen an die Vorurteilsforschung als die produktivste Lösung:

„The markers of prejudice include: undifferentiated attacks, assumption of inferiority or an $a$ priori belief that only bad intentions drive one's ideas and actions. Prejudice encompasses negative stereotyping, but goes beyond this to include more direct forms of hatred and vitriol. [...] These generally recognised signs of prejudice are all too familiar in discussions about America, and it seems high time to honestly acknowledge them as prejudice." (O'Connor 2007b, S. 13)

Mit einem solchen Begriffsverständnis verbinden sich für O'Connor zwei maßgebliche Vorteile: Erstens ermöglicht es den Anschluss an eine umfangreiche und sozialwissenschaftlich gut etablierte Vorurteilsforschung mit erprobten Begriffen und empirischen Instrumenten. Und zweitens verhilft es dem Antiamerikanismusbegriff $\mathrm{zu}$ einer klareren normativen Verortung mit ,significant cultural and political resonance in the fight against racism and discrimination“" (ebd., S. 13):

4 Da die vorliegende Arbeit explizit für einen performativen Antiamerikanismusbegriff plädiert, wenngleich vor einem von Schwarks Konzept stark abweichenden Theoriehintergrund, wird in Abschnitt 2.3.1 auf dessen Thesen noch einmal genauer eingegangen. 
,$[\ldots .$.$] to ask whether these actions or attitudes [i.e. die als antiamerikanisch kritisierten, F.K.]$ are prejudiced, or not, is a relatively straight-forward question that helps us get to the heart of people's views about America in a way that is widely understood and allows for necessary debate on this issue." (Ebd., S. 15)

Diese theoriestrategische Argumentation ist überzeugend, und dem entspricht, dass in weiten Teilen der Forschungsliteratur Antiamerikanismus als Vorurteilsphänomen bestimmt wird - übrigens nicht erst seit O'Connors explizitem Vorschlag. So resümiert beispielsweise Andrei Markovits in seiner umfassenden Studie zu antiamerikanischen Diskursen in Europa unter Rückgriff auf Definitionen von Paul Hollander (,,a predisposition to hostility“), Alvin Rubinstein und Donald Smith (,,an undifferentiated attack“) und Todd Gitlin (,,an emotion masquerading as an analysis"; alle zit. n. Markovits 2007, S. 17 ):

„Agreeing with all three of these definitions, I see anti-Americanism as a generalized and comprehensive normative dislike of America and things American that often lacks distinct reasons or concrete causes.“ (Ebd.)

In Markovits Definition spiegelt sich das bereits bei O'Connor explizierte Grundmuster eines anti-Americanism-as-prejudice-Ansatzes wider: Antiamerikanismus ist eine Feindseligkeit oder Aversion gegenüber Amerika, die sich undifferenziert und ohne konkrete Gründe äußert, d.h. nicht (ausreichend) mit der Realität der USA korrespondiert. Dieser Versuch, ,to separate , argument based' critiques of the United States from prejudicial or racist preconceptions", baut also einerseits auf starken Annahmen über die propositionale Wahrheit bzw. die Rationalität von Urteilen über Amerika auf: „A key controversial issue in defining what constitutes antiAmericanism relates to the role that rationality, or irrationality, should have in the definition." (Chiozza 2009, S. 34)

Andererseits wird die Unterscheidung von Urteil und Vorurteil maßgeblich in psychologischen Termini als „predisposition“, „emotion“ oder „,dislike“ beschrieben. Die Antiamerikanismus-als-Vorurteil-Perspektive knüpft also auch dahingehend an die Konzepte einer (sozial-)psychologisch aufgestellten Vorurteilsforschung an, dass sie eine individuelle Disposition zum Kern ihrer Bestimmung macht (vgl. Wetherell 2012, S. 165). Häufig wird zusätzlich davon ausgegangen, dass diese Disposition als ,generalized and comprehensive“ auftritt, ein mehr oder weniger geschlossenes kognitives und affektives Schema, das sich als dichtes, selbstreferentielles Gewebe über die ,eigentliche Realität‘ der USA legt (vgl. auch Friedman 2012, S. 5).

In einigen Arbeiten werden solche Gegenstandsbestimmungen zusätzlich mit klinischem Vokabular aufgeladen um die eigene Position durch Pathologisierung des Gegenstandes zusätzlich zu untermauern. Ein einschlägiges Beispiel hierfür ist 
die folgende Erörterung Russel Bermans, dessen Verständnis von Anti-Americanism in Europe einen stark vereinfachenden, klinischen Begriff von Rationalität ins Feld führt:

„Anti-Americanism is indicated precisely when reasoned argument gives way to sweeping generalizations and hostile innuendo, and the obsessive thought structures of prejudice and stereotype prevail. Although a particular policy dispute may serve as a pretext, antiAmericanism is driven by a deeper and more expansive fixation on an image or idea of America, burdened with multiple negative associations that extend far beyond a bone of contention about any particular policy.“ (Berman 2008, S. 40)

Die dichotomisierende Abgrenzung von „fixation“ und „obsessive thought structures“ gegen ein „reasoned argument“ wird hier nicht nur auf individuelle Dispositionen zurückgeführt, sondern als quasi-pathologisches Phänomen markiert. Abgesehen davon finden sich auch in dieser Definition die oben beschriebenen Kernmerkmale des anti-Americanism-as-prejudice-Ansatzes: Feindschaft, unzulässige Generalisierung und grundlose Abwertung, der konkrete politische Streitfragen lediglich als Vorwand dienen. Zwar basiert die gegenwärtige Antiamerikanismusliteratur, wie im Folgenden argumentiert wird, generell auf starken Annahmen über die Unterscheidung einer, wahren ' Realität der USA und der verzerrten Sicht der vorurteilig Eingestellten. Nicht alle Ansätze gehen aber auch soweit, dieses korrespondenzlogische Fundament zusätzlich psychopathologisch aufzuladen und in frühaufklärerisch-patriarchaler Geste Antiamerikanismus zu einer Form von Wahnsinn zu erklären. In Abschnitt 2.3.1 wird anhand von Überlegungen Michael Billigs deutlich werden, dass Vorurteile häufig gerade nicht das Gegenteil eines ,reasoned argument" darstellen, sondern vielmehr selbst als „reasoned discourse“ verstanden werden müssen (Billig 1991, S. 44).

Eine nüchternere und theoretisch enger an aktuellen sozialpsychologischen Forschungsdiskursen geführte Definition bieten die Ansätze von Heiko Beyer (Beyer 2014; Beyer und Liebe 2014) sowie Robert Keohane und Peter Katzenstein (Katzenstein und Keohane 2007b). Sie können als Beispiele einer umfassenden und expliziten Adaption eines einstellungstheoretischen Vorurteilsbegriffes in der Antiamerikanismusforschung dienen. Heiko Beyer knüpft mit seiner Antiamerikanismusdefinition unmittelbar an den prejudice-as-attidude-Ansatz an:

„Antiamerikanische Einstellungen definiere ich im Anschluss an Eagly und Chaiken als Tendenz der Psyche, die sich in der Abwertung von Personen, Institutionen oder Sachen, die als ,amerikanisch' wahrgenommenen werden, ausdrückt. [...] Die negative Einstellung kann sowohl politische und ökonomische als auch kulturelle Objekte betreffen. Zudem kann sie affektiver oder kognitiver Natur sein, das heißt, sie kann entweder wesentlich auf Gefühlen oder auf Überzeugungen beruhen. [...] Der hier verwendete Einstellungsbegriff unterstellt 
darüber hinaus, dass es so etwas wie eine verfestigte psychische Struktur gibt." (Beyer 2014, S. $21 \mathrm{f}$.)

Die pathologisierende Rhetorik, die man in Russel Bermans Konzeption findet, fällt hier weg. Jedoch ist es auch in Beyers Ansatz die Idee einer ,verfestigte[n] psychische[n] Struktur“, anhand der die definitorische Grenzziehung zwischen antiamerikanischem Vorurteil und legitimierter Amerikakritik unternommen wird:

„Antiamerikanische Einstellungen zeichnen sich gerade durch einen spezifischen Schematismus aus, der die Realitätswahrnehmung grundlegend beeinflusst: Die Tatsache zum Beispiel, dass Amokläufe, Kino oder ,Big Brother' keineswegs in den USA erfunden worden sind, wird das Bewusstsein, dem jene Phänomene ,typisch amerikanisch'scheinen, kaum eines Besseren belehren. Diese nichtsituative und essenzialistische Bewertung unterscheidet antiamerikanische Einstellungen von kritischen Positionen zu einzelnen Sachverhalten.“ (Ebd.)

Auch hier finden sich also die zentralen Komponenten einer Antiamerikanismusals-Vorurteil-Perspektive: Abwertung/Aversion, Irrationalität/propositionale Unwahrheit, psychologischer Schematismus. Eine besondere Betonung liegt bei Beyer auf der psychologischen Konsistenz, dem Schematismus antiamerikanischer Einstellungen. Wo Antiamerikanismus beginnt und „kritische[n] Positionen“ enden, ist also eine Frage der kontextbezogenen Flexibilität der Wahrnehmung:

„In general, although there might be an empirical overlap of anti-Americanism and criticism of policies of the United States, empirical studies have to aim for a clear distinction between both phenomena. The main criterion is that of coherence: an individual is to be labelled , antiAmerican“ only if we find a coherent attitude structure." (Beyer und Liebe 2014, S. 2)

Auch Peter Katzenstein und Robert Keohane schlagen im einleitenden Artikel des von ihnen herausgegebenen Bandes Anti-Americanisms in World Politics einen „framework for analysis“ vor, dessen Kernstück das Konzept der Einstellung bildet:

„We view anti-Americanism as a psychological tendency to hold negative views of the United States and of American society in general. Such views draw on cognitive, emotional, and normative elements. Using the language of psychology, anti-Americanism could be viewed as an attitude.“ (Katzenstein und Keohane 2007b, S. 12)

Die antiamerikanische Einstellung wird weiter differenziert hinsichtlich ihres kognitiven Gehaltes sowie der affektiven Intensität der Ablehnung. Ersterer wird anhand des Begriffes des „,cognitive schema“ präzisiert, einer „,ognitive structure that relies on specific metaphors, analogies, symbols, and narratives of specific events and general historical developments to make sense of the world" (ebd., S. 13). Al- 
lerdings ist diese inhaltliche Komponente in Katzensteins und Keohanes Konzeption weniger entscheidend für die Bestimmung antiamerikanischer Einstellungen, als die affektive und emotionale Intensität mit der sie ausagiert werden. Anhand dieser Intensitäts-Dimension unterscheiden die Autoren antiamerikanischen „bias“ von einer bloßen antiamerikanischen „opinion“ (ebd., S. 11).

Antiamerikanische Einstellungen bilden hier also ein Kontinuum von bloßen Meinungen bis hin zum manifesten Vorurteil. In dieser Variante wird ein klares Kriterium für die Unterscheidung von Antiamerikanismus und legitimer Kritik umgangen, indem auch Amerika-Kritik prinzipiell in das Spektrum antiamerikanischer Einstellungen mit einbezogen wird. Der normative Gehalt der Antiamerikanismuskritik, den die zuvor zitierten Definitionen vergleichsweise streng anhand korrespondezlogischer und psychischer Kriterien formulieren, wird somit an die jeweiligen historisch-situativen Kontextbedingungen delegiert: Ob eine abwertende oder feindselige Einstellung gegenüber den USA als antiamerikanisches Vorurteil zu kritisieren ist, oder aber ein Moment eines als legitim erachteten Protestes darstellt, kommt auf den historischen Kontext an. Zumindest vordergründig werden somit die Theorieprobleme eines korrespondenzlogisch-realistischen Vorurteilsbegriffes umgangen. Die Forschenden befindet sich nicht in der misslichen Lage, propositional wahre und falsche Urteile über die USA zu unterscheiden und sind scheinbar auch von der Problematik befreit, einen normativen Standpunkt für die eigene Kritik zu formulieren. Bei genauerer Betrachtung wird die Flexibilität und Offenheit dieser Antiamerikanismusdefintion aber zum Problem, denn Keohane und Katzenstein formulieren keinerlei Kriterium, um diejenigen Kontexte, in denen eine Abneigung als Antiamerikanismus in Betracht kommt, weiter einzugrenzen. Damit verbleibt letztendlich die Intensität der Abneigung als einziges Definitionskriterium. Ist Antiamerikanismus aber schon dadurch hinreichend bestimmt, dass jemand die USA besonders nachdrücklich ablehnt? Wie im folgenden Abschnitt 2.3.2 gezeigt wird, stellt ein aversiver oder abwertender Gehalt weder ein notwendiges, noch ein hinreichendes Kriterium für den vorurteiligen Charakter einer Äußerung dar. ${ }^{5}$

5 Man muss Keohane und Katzenstein zugestehen, dass die inhaltliche und normative Offenheit ihres Konzeptes auch dem Umstand geschuldet ist, dass sie einen Rahmen für die international vergleichende Analyse von Antiamerikanismus zu geben versuchen. Angesichts so verschiedener Phänomene wie etwa jihadistischem Antiamerikanismus in Afghanistan, kulturkonservativem Antiamerikanismus in Frankreich oder linkem Antiamerikanismus in den USA wird man zu Recht vorsichtig mit der Formulierung einer universellen Definition sein. Das von den Autoren formulierte Intensitäts-Kriterium ist aber als Hilfskonstruktion wenig informativ. Keohanes und Katzensteins „,framework for analysis" scheint mir hingegen an den Stellen am stärksten, an denen es doch inhaltliche Unterscheidungen vorschlägt, etwa im Falle ihrer Typologie von Antiamerikanismen nach Bedrohungsempfinden gegenüber den USA und der Bewertung von US-Politiken (ebd., 


\subsection{Probleme des Prejudice-as-Attitude Ansatzes}

Im vorigen Abschnitt wurde ein Überblick über die Adaption des Vorurteilsbegriffs in der Antiamerikanismusforschung gegeben. Dabei wurde zunächst Brendon O'Connors Einschätzung bekräftigt, dass diese begriffliche Annäherung sowohl im Bereich der theoretischen Klärung, als auch für eine genauere Verortung der Antiamerikanismusforschung im sozialwissenschaftlichen Diskurs förderlich ist. Darüber hinaus könnte der Anschluss an die Vorurteilsforschung prospektiv zu einer klareren normativen Verortung des Antiamerikanismusbegriffes in politischen Diskursen auch jenseits der Sozialwissenschaften verhelfen.

Eine solche Eingliederung des Antiamerikanismusbegriffes in die sozialwissenschaftliche Vorurteilskritik ist sicherlich wünschenswert. In dieser Hinsicht möchte ich mich also dem Antiamerikanismus-als-Vorurteil-Ansatz anschließen und dementsprechend für die hier unternommene begriffliche und empirische Elaboration des Antiamerikanismuskonzeptes den Terminus ,Vorurteil' beibehalten. Zugleich aber möchte ich im Folgenden auf einige theoretische Probleme hinweisen, die die Antiamerikanismuskritik mit dem traditionellen Vorurteilsbegriff mit übernommen zu haben scheint. Ich verstehe meine Kritik am Antiamerikanismusbzw. Vorurteilsbegriff aber nicht als Gegenentwurf zur etablierten Vorurteilsforschung, sondern als Versuch, einige Selbstmissverständnisse und Ungenauigkeiten in diesem Forschungsstrang aufzuzeigen. Diese bestehen meiner Ansicht nach wesentlich darin, zu übersehen, dass die definitorischen Bemühungen des Vorurteilsbegriffes immer schon eine gesellschaftlich-politische (d.h. auch normative) Problembestimmung voraussetzen, die weder in den vermeintlich wertneutralen Kategorien von Kognition und Emotion, noch durch einen realistischen ,Faktencheck angemessen reflektiert wird (vgl. Blumer 1971). Der traditionelle Vorurteilsbegriff setzt also zumindest implizit immer schon voraus, was er in seinen Definitionen ausklammert: dass antiamerikanische Vorurteile nur in ihrer Funktion innerhalb gesellschaftlicher Konflikte um Ungleichheit, Diskriminierung und Exklusion bestimmt werden können, als Vollzugsformen eines fortlaufenden Streits um Gleichheitsvorstellungen, die auf eine spezifische Weise problematisiert werden (vgl. dazu ausführlich Kap. 4).

In der traditionellen Vorurteilsforschung wird diesem Umstand durchaus Rechnung getragen, allerdings i.d.R. gemäß eines kausalistischen Modells: Vorurteile

S. 29). Weiterhin ließe sich einwenden, dass Keohanes und Katzensteins Definition nur scheinbar normativ abstinent ist: Die Unterscheidung von „bias“ (i.e. Voreingenommenheit oder Verzerrung) und bloßer „opinion“ impliziert notwendig einen Normalzustand, von dem das als Antiamerikanismus Problematisierte abweicht. Sie drängt auf die Frage: Abweichung von was bzw. von welcher ,normalen', angemessenen Haltung gegenüber den USA? 
werden als Kausalursachen oder Wirkungen von gesellschaftlichen Konflikten oder Gruppenbildungsprozessen analysiert, jedoch unabhängig von diesen definiert. Ich möchte dagegen darauf hinweisen, dass nicht erst das Vorurteil , da ist', und dann der daraus folgende Konflikt erklärt werden kann (oder umgekehrt), sondern dass Vorurteile unabhängig von ihrem Gebrauch in solchen gesellschaftspolitischen Konstellationen überhaupt nicht bestimmt werden können. Vorurteile sind, mit Adorno, „Problem im emphatischen Sinne“ (Adorno 2003e, S. 551): nicht losgelöst von den gesellschaftlichen Problemzusammenhängen zu definieren, als deren Teil sie auftreten.

\subsubsection{Antiamerikanismus ist nicht propositional falsch - Vorurteile als performatives Sprechen}

Ist man als ForscherIn genötigt, ein Urteil über den antiamerikanischen oder vorurteilsfreien Charakter bestimmter Redeweisen zu fällen, so schlägt einem die gängige Forschungsliteratur hierzu als ein zentrales Kriterium den propositionalen Gehalt des Gesagten bzw. dessen faktische Geltung vor. ${ }^{6}$ Demnach mögen zwar auch faktisch zutreffende Aussagen in die antiamerikanische Konstruktion eingewoben sein oder ein ,tatsächlicher' politischer Disput als Vorwand für deren Ausdruck dienen: Im Wesentlichen zeichnet sich Antiamerikanismus aber dadurch aus, dass ihm ein ,realistischer' und ,rationaler' Weltbezug fehlt, d.h. die von ihm präsentierten Bilder sind entweder grundlegend falsch oder zumindest verzerrt, logisch inkonsistent, o.ä. So wird Antiamerikanismus bspw. als „Schematismus“ bestimmt, „,der die Realitätswahrnehmung grundlegend beeinflusst“ (Beyer 2014, S. 21; vgl. auch Katzenstein und Keohane 2007b, S. 13), als Abneigung gegen Amerika ,that often lacks distinct reasons or concrete causes“ (Markovits 2007, S. 17) bzw. als Gegnerschaft gegenüber einem ,,imaginierten Amerikanismus“, der ,gerade nicht in einer tatsächlichen und empirisch nachweisbaren Qualität der Vereinigten Staaten von Amerika“ begründet sei (Schwark 2008, S.20). Antiamerikanismus, so wird also immer wieder betont, zeichnet ein faktisch unwahres Bild der USA oder zumindest ,,an undifferentiated view of America and the Americans“ (O'Connor 2007b, S. 8).

6 Als Propositionen bezeichnet man die „Inhalte und Objekte von mentalen Akten wie Wollen, Glauben, Hoffen [...] bzw. von Sprechakten wie Behaupten [...] oder Versprechen [...] wobei Sätze mit verschiedener Illokution denselben propositionalen Gehalt haben können“ (Bäuerle 1995). D.h. die Proposition ist derjenige Sinngehalt eines Ausdrucks, der unabhängig davon definiert werden kann, was mit diesem Gehalt in einem bestimmten Äußerungskontext getan wird. So ließe sich bspw. der propositionale Gehalt „ein Glas Wasser“ unabhängig von Äußerungs- und Handlungskontext (Wird eine Bestellung aufgegeben, eine Bitte formuliert, eine Tatsachenfeststellung gemacht?) lexikalischsemantisch definieren und ggf. auf seine angemessene Verwendung prüfen. 
Alle diese Bestimmungen setzen somit implizit voraus, dass die Wahrheit bzw. Unwahrheit antiamerikanischer Aussagen wesentlich im Bereich der faktischen Gültigkeit jeweiliger Propositionen zu suchen ist. Sprechakttheoretisch gesprochen, gehen diese Autoren implizit davon aus, dass Antiamerikanismus in erster Linie als konstatives Sprechen (vgl. Austin 2010, S. 27) zu behandeln sei, mit Referenz und Prädikation als zentralen Funktionen: als stellten antiamerikanische Sprechakte vor allem Faktenbehauptungen über Amerika auf, und die Aufgabe der Vorurteilsforschung sei es, diese auf ihre Übereinstimmung mit einer empirischen Realität zu prüfen.

Diese Auffassung soll hier in zweifacher Hinsicht als reduktionistisch problematisiert werden: Zum einen werde ich zeigen, dass propositionale Unwahrheit kein notwendiges Merkmal vorurteiliger Rede darstellt. Zum anderen werde ich argumentieren, dass auch in denjenigen Fällen, in denen antiamerikanische Ausdrücke faktisch falsche Aussagen enthalten, dies kein hinreichendes Kriterium zur Bestimmung von Antiamerikanismus bietet, sondern die Kategorisierung der jeweiligen Aussage als Vorurteil sich an deren rhetorischer Wirkung orientieren muss.

Bzgl. des ersten Arguments ist zunächst festzuhalten, dass die Unterscheidung zwischen falscher oder verzerrter und exakter Darstellungen der USA spätestens dann äußerst schwierig wird, wenn man es mit dem lebendigen Text alltäglicher Rede zu tun bekommt. Dieses Problem, wenngleich im Prinzip unabhängig von der untersuchten Textgattung, intensiviert sich, wenn man nicht mit bewusst ausformulierten, reflektiert argumentierenden Medieninhalten konfrontiert ist, sondern mit den spontan vorgebrachten Rhetoriken, die sich bspw. in Interviewprotokollen finden lassen: ,speech acts of ordinary people who don't hold political office, who are unlikely to have more than the average fifteen minutes of fame in their lives, and who haven't made a profession out of writing or speaking." (Martin 2010, S. 40; vgl. auch Schäuble 2012, S. 87 ff.). Denn zwischen exakter Repräsentation und verzerrter Darstellung verläuft keine klare Trennlinie (vgl. Martin 2010, S. 104; Austin 2010, S. 161 ff.). Zwar gibt es offenkundig faktisch falsche Darstellungen, wie beispielsweise die Behauptung, , die Juden' kontrollierten die Wirtschaft und Politik der USA. Ebenso mag es Aussagen über die USA geben, die relativ unproblematisch als faktisch zutreffend gelten können, bspw. die Feststellung, dass weite Teile der US-Bevölkerung starke Vorbehalte gegenüber wohlfahrtsstaatlichen Politiken haben (vgl. O'Connor 2003). Zwischen diesen beiden Polen befindet sich aber eine Menge von Aussagen mit maßgeblich rhetorischem Charakter, die also mit Stilmitteln wie Pauschalisierungen, Metaphern, Vergleichen etc. für oder gegen eine Position Argumentieren und so eine normative Zielsetzung verfolgen, die gerade nicht durch Faktenwissen allgemein und unzweifelhaft begründet ist.

Solche normativ-politischen Debatten stellen nun aber keine Ausnahme oder gar Anomalie menschlicher Kommunikation dar, sondern vielmehr den Regelfall. Ja, selbst die oben angeführten Beispiele für faktisch gültige bzw. ungültige Propo- 
sitionen werden notgedrungen, sobald sie kommuniziert werden, einen rhetorischen Aspekt bekommen - ich selbst habe sie etwa gerade als Beispiele genutzt. Der rhetorisch-performative Charakter menschlicher Interaktion bildet den übergreifenden Rahmen, in dem auch Faktenaussagen erst bedeutsam werden. Die Vorurteilsforschung hat zu lange ihren Begriff maßgeblich auf den Annahmen der faktischen Falschheit und logischen Inkonsistenz aufgebaut und dabei ignoriert, ,that most debates among human beings [...] are made in situations of uncertainty of evidence“ (Martin 2010, S. 69) und dass, wie zu ergänzen wäre, selbst das anführen von ,evidence" immer in einem politisch-normativen Kontext geschieht. Innerhalb solcher Diskurse, die nicht allein mit dem befasst sind, was ist, sondern mit dem, was sein sollte, können rhetorische Strategien sowohl mit faktisch zutreffenden wie unzutreffenden Propositionen arbeiten. Dementsprechend wird man im Material immer wieder auch auf Darstellungen der USA treffen, die offenkundig nicht faktisch falsch sind, und dennoch als Teil einer antiamerikanischen Argumentation funktionieren. Dies ist die erste Problematik, für die eine solche rhetorische Perspektive auf vorurteilige Rede sensibilisieren kann: Die Möglichkeit vorurteiliger Gebräuche faktisch wahrer Propositionen.

Soweit wurde argumentiert, dass propositionale Unwahrheit kein notwendiges Kriterium vorurteiligen Sprechens darstellt. Aus den dazu angestellten Überlegungen folgt aber zudem, dass selbst wenn die empirische Unwahrheit einer Proposition festgestellt werden kann, dies noch kein hinreichendes Kriterium für den vorurteiligen Charakter der jeweiligen Aussage abgibt. Zum Vorurteil (d.h. zum Gegenstand der Vorurteilskritik) wird eine Aussage nicht, weil sie propositional unwahr ist, sondern weil sie rhetorisch auf ein bestimmtes normativ-politisches Ziel hinarbeitet. Den vorurteiligen Gehalt an der propositionalen Wahrheit einer Aussage festzumachen, ist reduktionistisch. Fasst man Antiamerikanismus als eine Art kognitiven Fehler oder eine irrationale Schlussfolgerung, so sagt man letztendlich vor allem etwas darüber aus, welche Form solche kognitiven Fehler annehmen können, aber kaum etwas über Antiamerikanismus. Anders gesagt: Das Problem am Antiamerikanismus ist nicht, dass Menschen sich irren oder logisch inkonsistent schlussfolgern. Die vorurteilskritische Frage ist grundsätzlich nicht, ob im Antiamerikanismus Amerika falsch beschrieben wird, sondern was mit dieser Darstellung Amerikas außer bloßen Beschreibungen noch getan wird.

Der rhetorisch-performative Charakter vorurteiliger Rede wurde in der Vorurteilsforschung vor allem in der rhetorischen Psychologie Michael Billigs diskutiert. In seinem Band Ideology and Opinions fasst er diesen wie folgt zusammen:

„The problems of rhetoric are of a very different order, for there is no single right answer, whose correctness can be contrasted with the incorrect reasoning lying behind other answers. The problems of rhetoric are not to be solved, or dissolved, decisively by an application of logical procedures. For example, a political disagreement between a left- and a right-winger 
does not arise because one side has correctly applied the laws of logic and the other has not. Both sides can argue their case with equal logic consistency, for the difference between them has not arisen from errors of reasoning. Their disagreement will be more basic than that It will have emerged from genuine social problems or dilemmas, for which opposing solutions can be proposed.“ (Billig 1991, S. 39)

Irrationalität oder faktische Unwahrheit sind also deswegen nicht der richtige Ansatzpunkt für eine Vorurteilskritik, weil das, was als vorurteilige Rede kritisiert werden soll, gerade keine individuelle Abweichung von geltendem Faktenwissen und der Logik des common sense darstellt, sondern vielmehr Ausdruck gesellschaftlicher Probleme und Debatten ist. ${ }^{7}$ Ihre (antiamerikanische) Bedeutung gewinnen Vorurteile demnach erst im Kontext weiterer Diskurse bzw. durch die Weise, wie in Vorurteilsausdrücken auf bestimmte Problemstellungen Bezug genommen wird:

„From this, it could be suggested that we cannot understand the meaning of a piece of reasoned discourse, unless we know what counter-positions are being implicitly or explicitly rejected. In the same way, we cannot understand the attitudes of an individual, if we are ignorant of the wider controversy in which the attitudes are located. In other words, the meaning of a piece of reasoned discourse, or of an expressed attitude, does not merely reside in the aggregation of dictionary definitions of the words used to express the position: it also resides in the argumentative context.“" (Billig 1991, S. 44)

Der vorurteilige Gehalt bestimmter Ausdrücke lässt sich also prinzipiell nicht allein an lexikalisch-grammatischen Inhalten, etwa im Sinne einer Checkliste von Stereotypen, festmachen. ${ }^{8}$ Die Rekonstruktion der Bedeutung antiamerikanischer Sätze schließt in dieser Perspektive immer eine Deutung von dessen Funktion im jeweiligen Äußerungskontext ein.

Ein ähnliches Verständnis der Bedeutung von Vorurteilsausdrücken legt Klaus Holz seiner Antisemitismusanalyse zugrunde: Er kritisiert Nicoline Hortzitz Analyse des Wortschatzes antisemitischer Texte, in der zunächst einzelne Lexeme aus den Texten gesammelt werden, um diese anschließend gemäß allgemeiner Wort-

7 Das bedeutet nicht, dass Vorurteile nicht als ein spezifischer Ausdruck gesellschaftlicher Debatten und Probleme aufzufassen sind. Es heißt aber, dass diese Spezifizität nicht durch faktische Unwahrheit oder logische Inkonsistenz bestimmt werden kann.

8 Als , lexikalisch-grammatische" werden solche Bedeutungserklärungen verstanden, die weitestgehend kontextunabhängig eine typisch-allgemeine Bedeutung von Wörtern und Sätzen festhalten (vgl. Kambartel und Stekeler-Weithofer 2005, S. 48 f.). Die lexikalischgrammatische Bedeutung eines Satzes ist also diejenige, die wir mithilfe eines Lexikons und einer Grammatik weitgehend unabhängig vom Ausdruckskontext bestimmen können. 
bzw. Merkmalsfelder zu gliedern und somit die Grundstruktur der antisemitischen Semantik herauszufiltern. Holz weist diesen Ansatz als „,subsumtionslogische Interpretation“ zurück, da die vermeintlich allgemeine lexikalische Semantik der Wortfelder den antisemitischen Texten äußerlich bleibt: „Ob und wie die antisemitischen Texte selbst Ordnungsmuster oder Sinnstrukturen konstituieren, kann nicht aufgezeigt werden, wenn die Texte einem vorgegebenen Ordnungsmuster subsumiert werden.“ (Holz 2001, S. 121 f.) Die Ansätze Holz' und Billigs betonen also, dass die Analyse vorurteiliger Ausdrücke immer eine Interpretation in deren jeweiligem Kontext nötig macht, und dass eine solche Interpretation prinzipiell nicht deduktivistisch konzipiert werden kann.

In ihrer konversationsanalytischen Studie zum Rassismus weißer Neuseeländer (Pakeha) gegenüber indigenen Maori, positionieren sich Margaret Wetherell und Jonathan Potter ebenfalls kritisch gegen die „emphasis on propositions“ (Wetherell und Potter 1992, S. 69) der etablierten Vorurteilsforschung. In großer theoretischer Nähe zu Billigs rhetorischer Psychologie schlagen sie eine funktionalistische Perspektive auf vorurteilige Praxis vor. Wenn Rassismus (und damit Vorurteile überhaupt) weder nach lexikalisch-grammatischen Inhalten, noch nach psychologischen Kriterien bestimmt werden kann, muss die Vorurteilsbestimmung sich an der Wirkung rhetorischer Praxen im Kontext weiterer politischer Streits festmachen:

„None the less, it is possible to hold a distinctive conception of racism - not as an intrinsic property of certain forms of discourse - but as one effect of discursive practice and other social practices. Racist discourse, in our view, should be seen as discourse (of whatever content) which has the effect of establishing, sustaining and reinforcing oppressive power relations between those defined, in the New Zealand case, as Maori and those defined as Pakeha." (Wetherell und Potter 1992, S. 70)

Wetherell und Potter Unterscheiden dementsprechend zwischen ,interpretative resources" (ebd.), also bestimmten semantischen Gehalten, z.B. Gruppenstereotypen, und deren Gebrauch in einer jeweiligen rhetorischen Praxis. Rassistische Rede ist dann solche, ,which has the effect of categorizing, allocating, and discriminating between certain groups and, in the context of New Zealand, it is discourse which justifies, sustains and legitimates those practices which maintain the power and dominance of Pakeha New Zealanders“ (ebd.). ${ }^{9}$ In dieser rhetorischen oder performa-

9 Es muss an dieser Stelle angemerkt werden, dass die von Wetherell und Potter vorgenommene Bestimmung dahingehend ungenau ist, dass sie „discourse (of whatever content)“ als potentiell rassistisch bestimmen. Es macht hier den Eindruck, als würden die AutorInnen den rassistischen Charakter entsprechender Ausdrücke allein an deren Funktion bzw. Wirkung festmachen wollen. Diese Überbetonung des funktionalen Kontextes würde allerdings ein Problem bei der Unterscheidung unterschiedlicher Vorurteilstypen 
tiven Perspektive werden Vorurteile also über den Gebrauch bestimmter Semantischer Konstruktionen bestimmt, nicht über deren propositionalen Gehalt. Eine performative Antiamerikanismuskritik zielt dementsprechend weder auf das Lexikon antiamerikanischer Stereotype an sich, noch auf deren Korrespondenz mit einer vom Kritiker zertifizierten ,Wahrheit über Amerika‘, sondern auf Sprechhandlungen und deren rhetorische Funktionen im Kontext bestimmter politisch-normativer Diskurse. $^{10}$

Diese Argumentation greift übrigens auch gegenüber solchen Antiamerikanismusbegriffen, die das Kriterium der faktischen Unwahrheit antiamerikanischer Ausdrücke mit psychopathologischen Begriffen ergänzen. Die Bestimmung von Antiamerikanismus als „obsession“ (Berman 2008, S. 40; Hollander 2004, S. 8; Joffe 2006; Revel 2003), „hysteria“ (Zeldin zit. n. O’Connor und Griffiths 2006, S. 2) oder ,paranoid fantasy“ (Berman 2008, S. 41) baut letztendlich genauso auf der Idee einer ungetrübten Wahrnehmung des ,realen Amerika' auf, wie andere korrespondenzlogische Ansätze. Sie fügt dieser Bestimmung lediglich eine psychopathologische Erklärungshypothese hinzu, manchmal vielleicht auch nur eine polemische Spitze. Ein solcher Ansatz ist damit ebenso reduktionistisch wie die zuvor kritisierten und dementsprechend mit denselben zwei grundlegenden Problemen konfrontiert. Er schränkt einerseits den Gegenstandsbereich des Antiamerikanismusbegriffes zu stark ein, indem er nur die „most fanatical haters of America“ (O'Connor 2007b, S. 13) in den Blick nimmt, von denen mit guten Gründen angenommen werden kann, dass sie lediglich eine Teilmenge der antiamerikanisch (sprech-) handelnden Akteure darstellen. Darüber hinaus ist aber eine psychopathologische Bestimmung von Antiamerikanismus gerade auch gegenüber jenen „fanatical haters" ungenau: Sie fasst das Problem des Antiamerikanismus nicht in seiner politisch-rhetorischen Spezifik, sondern lediglich als Ausdruck einer psychopathologischen Abweichung von einer objektivistisch verbrieften Wahrheit. Es mag zwar in

mit sich bringen. Was eine Aussage antiamerikanisch macht, und nicht etwa sexistisch oder antisemitisch, ist ja gerade das Zusammenspiel bestimmter Amerikabilder mit deren rhetorischer Funktion. An anderer Stelle reflektiert Wetherell die Relevanz von Stereotypeninhalten allerdings sehr wohl (vgl. Wetherell 2012, S. 171).

10 Eine wichtige Konsequenz dieser performativen Theorieperspektive ist eine verschärfte Reflexion auf die normative Verortung der Vorurteilskritik: Wenn Vorurteile als rhetorisches Problem bestimmt werden, es also nicht um Wahrheit in einem rein propositionalen, faktischen Sinne geht, muss man die eigene normative Position ebenfalls im Kontext politischer Debatten verorten. Die Frage, ab wann ein bestimmtes Sprechen über Amerika als vorurteilige Rhetorik gewertet wird, geht über in die Frage, von welcher (auch normativen) Warte aus man dieses Sprechen problematisiert. Die methodologischen Schwierigkeiten und Chancen einer solchen Perspektive werden in den Kapiteln 3.3 und 4.5 unter sprechakttheoretischen bzw. ideologiekritischen Aspekten beleuchtet. 
mancherlei Hinsicht produktiv sein, den Gegenstand antiamerikanischer Vorurteile aus der Perspektive der klinischen Psychologie zu betrachten, dies setzt aber eine genaue Beschreibung des diskursiv-rhetorischen Phänomens Antiamerikanismus begrifflich immer schon voraus. ${ }^{11}$

Wenn es der Vorurteilskritik nicht um den Nachweis einer Korrespondenz oder Nicht-Korrespondenz von vorurteiligen Propositionen und ,der Realität' gehen kann, so folgt daraus ebenso eine Kritik dessen, was Klaus Holz in seiner Antisemitismusanalyse als „Korrespondenztheorien“ vorurteiligen Verhaltens bezeichnet (Holz 2001, S. 62 ff.): Demzufolge können Vorurteile nicht nur nicht als Abweichung von propositionaler Wahrheit bestimmt werden, sie können auch nur sehr bedingt durch die wirklichen Eigenschaften der jeweils im Vorurteil referierten Gruppe (hier: ,der Amerikaner') erklärt werden. Holz beschreibt einen solchen Erklärungsansatz wie folgt: „Korrespondenztheoretische Ansätze [...] versuchen, antisemitische Vorurteile aus der Interaktion zwischen ingroup und outgroup, Mehrheit und Minderheit oder aus angeblich tatsächlichen Besonderheiten der Juden, ihrer Berufsstruktur, Religion usw. abzuleiten." (Ebd.)

Dennoch sind solche Theorieansätze in der Antiamerikanismusforschung relativ gängig (vgl. kritisch dazu Beyer und Liebe 2014, S. 90 f.; Jaecker 2014, S. 18 f.; O'Connor 2007b, S. 17 ff.). So findet sich immer wieder der Verweis, dass um Antiamerikanismus $\mathrm{zu}$ verstehen, man zunächst den existierenden ,Amerikanismus erfassen und dessen Einfluss auf die Welt prüfen müsse (z.B. Birkenkämper 2006, S. 18 ff.; Crockatt 2003; Johnston 2006; Katzenstein und Keohane 2007b, S. 3; Srp 2005, S. 32 ff.). ${ }^{12}$ Antiamerikanismus wird hier als Gegnerschaft gegenüber dem verstanden, was Amerikanismus bzw. Amerika selbst sei: „One cannot have anti-

11 Man könnte an dieser Stelle einwenden, dass Autoren wie Berman oder Joffe pathologisierende Begriffe nicht im strengen Sinne klinischer Psychologie, sondern vielmehr metaphorisch gebrauchen. Dieser Einwand ist plausibel angesichts der Tatsache, dass z.B. Berman Antiamerikanismus schon im Titel seines Buches als „cultural problem“ beschreibt, und nicht etwa als psychopathologisches Problem. Aber auch ein solcher metaphorischer Gebrauch dient bei Berman und Joffe maßgeblich zur Unterstützung einer vereinfachenden Unterscheidung von wahrem und falschem bzw. vorurteiligem und vorurteilsfreiem Sprechen, die, wie ich gezeigt habe, längst problematisch geworden ist.

12 Die lexikalisch-semantische Ableitung des Antiamerikanismusbegriffes durch Kombination eines vermeintlich real existierenden ,Amerikanismus ' mit der Vorsilbe ,Anti- “ weist eine gewisse Verwandtschaft mit bestimmten Missverständnissen des Antisemitismusbegriffes auf. Diese verweisen darauf, dass die Sprachgruppe der ,Semiten " neben Juden noch viele andere ethnische Gruppen umfasse und der Begriff als Bezeichnung für Judenfeindlichkeit daher ungenau sei - wahlweise auch darauf, dass es einen arabischen Antisemitismus nicht geben könne, da , die Araber' schließlich selbst ,Semiten“ seien (vgl. Hahn 2003, S. 21 f.). 
Americanism without America.“ (Johnston 2006, S. 9) Dies mag bei oberflächlicher Betrachtung zunächst einleuchtend erscheinen, da Antiamerikanismus natürlich Teil einer Welt ist, in der Amerika existiert und wirkt - ich selbst habe ja gerade dafür plädiert, Antiamerikanismus nicht als bloßen individuellen Wahn zu fassen. Dennoch wird vor dem Hintergrund der oben entwickelten rhetorisch-diskursiven Perspektive eine tiefgreifende Problematik solcher Ansätze erkenntlich. Diese sehen sich zunächst einmal vor die Aufgabe gestellt, ,die Realität' Amerikas oder ,des Amerikanismus' explizieren zu müssen, was sich angesichts der Heterogenität dieser Gegenstände als äußerst schwierige Aufgabe erweisen dürfte (vgl. O'Connor 2007b, S. 17 ff.). ${ }^{13}$ Vor allem aber verfehlen solche Ansätze den rhetorischen Charakter antiamerikanischen Sprechens. Sie vernachlässigen die argumentativen Funktionen des Antiamerikanismus, indem sie diese von vornherein auf die Repräsentation einer , amerikanischen Realität' festlegen. Klaus Holz fasst diese methodische Problematik hinsichtlich einer Analyse des Antisemitismus wie folgt zusammen:

„Gemäß dem korrespondenztheoretischen Ansatz müßte man den Wahrheitsgehalt der Belege [des Antisemitismus, F.K.] im einzelnen prüfen. Damit aber würde man einem ,notwendigen Schein“ aufsitzen und bestenfalls eine Widerlegung des Antisemitismus schreiben. Die Scheinhaftigkeit der Belege wäre reduziert auf ihre Unwahrheit, anstatt zu erklären, welchen Sinn gerade diese Belege, seien sie wahr oder unwahr, haben.“ (Holz 2001, S. 65)

Auch Wetherell und Potter weisen darauf hin, dass korrespondenztheoretische Ansätze den ideologischen Gehalt ihres Gegenstandes verfehlen und somit Gefahr laufen, der Selbstdarstellung des Vorurteils als konstativem Sprechen auf den Leim zu gehen:

„One of the dangers with a focus on representation and reality and on truth and falsity, in our view, is that it can sometimes lead to a neglect of the actuality of ideological practice and often to an obsessive concern with defining the content of racism in an a priori fashion." (Wetherell und Potter 1992, S. 69)

Das bedeutet nicht, dass die USA, ihre Politik, ihr kultureller und ökonomischer Einfluss, keinerlei Bedeutung für die Analyse antiamerikanischer Sprechakte hätten, aber: „Die Frage nach Korrespondenzen kann erst angemessen gestellt werden,

13 In dieser realistischen Epistemologie von Korrespondenztheorien kündigt sich auch eine Tendenz zu mangelnder Reflexivität bzgl. der rhetorischen bzw. normativen Aspekte ihrer eigenen Sprechakte an (vgl. (Martin 2010, S. 68): Wenn es keine Darstellung der Wirklichkeit gibt, deren Bedeutung nicht auch in rhetorische Zusammenhänge eingebunden ist, so wird die Gegenüberstellung von antiamerikanischem Vorurteil und ,wissenschaftlicher Realitätsprüfung ' problematisch. 
wenn man sich des Sinnzusammenhangs versichert, in dem Scheinbelege stehen." (Holz 2001, S. 66)

Zum Abschluss dieses Abschnitts soll nun noch auf drei Forschungsbeiträge eingegangen werden, die ebenfalls auf einen rhetorisch-performativen Gehalt antiamerikanischer Rede abzielen, diesen jedoch theoretisch eher randständig behandeln. So verweist Andrei Markovits in seinen Studien zum Antiamerikanismus in Europa darauf, dass sich der antiamerikanische Gehalt bestimmter Aussagen nicht allein an inhaltlichen Kriterien festmachen lasse: ,[...] the important insight that form matters at least as much as substance, indeed that form is often the same as substance.“ (Markovits 2007, S. 16). Neben der inhaltlichen „substance“ spiele ebenso der „tone“ (ebd.) einer Äußerung eine wichtige Rolle, der dieser in einer jeweiligen Situation erst Bedeutung verleihe: „The content defines, but the context lends meaning." (Ebd.) Eine weiterführende theoretische Ausführung dieser Unterscheidung sowie der rhetorischen Kategorie des ,Tons' bleibt bei Markovits allerdings aus. Gleiches gilt für seine These, dass im antiamerikanischen Sprechen typischerweise eine undurchsichtige Vermischung von „what America is“ und „what America does" stattfinde (ebd., S. 13): Wenngleich sich Antiamerikanismus an der Wirklichkeit amerikanischer Taten orientiere, liege ihm doch eigentlich eine Feindschaft gegen das zugrunde, was als wesenhafte Essenz Amerikas wahrgenommen wird. Die Unterscheidung von „,is“ und „,does“ läuft parallel zu derjenigen von propositionalem Gehalt und Gebrauch in antiamerikanischen Äußerungen. Diese greifen demnach Fakten über Amerika auf (,what America does“), verwenden sie aber in einer dämonisierenden, essenzialisierenden Argumentation (,what America is“). Die praxistheoretischen Anklänge dieser Unterscheidung werden bei Markovits aber nicht weiter ausgeführt, so dass unklar bleibt, in welchem Verhältnis sie zur Annahme einer propositionalen Falschheit des Antiamerikanismus stehen (vgl. die oben zitierte Definition: Antiamerikanismus als „,normative dislike of America [...] that often lacks distinct reasons or concrete causes").

Ein ähnlicher Anklang an praxistheoretische Überlegungen findet sich in Dan Diners Arbeit zum Feindbild Amerika:

„Tradition und Wirkung amerikafeindlicher Ressentiments und Befindlichkeiten aufzuzeigen ist ein undankbares Unterfangen. Schließlich sind nicht alle kruden Äußerungen über die USA Ausdruck blinder Phantasie. [...] Die Unterscheidung zwischen amerikanischer Realität und Antiamerikanischer Phantasie wird allein schon dadurch erschwert, dass sich die weltanschauliche Verzerrung an die Fährte durchaus realer Phänomene zu heften weiß. Auch beim kritischen Beobachter führen die Verschränkungen von Ressentiment und Wirklichkeit zu verblüffenden Irritationen - so, als enthalte die ideologische Imagination im Kern doch so manche Wahrheit, eine verstellte Wahrheit sozusagen, die als Trophäe der Entlarvung begierig aufgegriffen und triumphierend vor sich her getragen wird.“ (Diner 2003, S. 24) 
Diner trifft implizit eine sprechakttheoretische Unterscheidung von ,Fakten“ und dem, was man mit diesen anfangen kann: Die ,amerikanische[r] Realität“ wird antiamerikanisch als „Trophäe der Entlarvung“ gebraucht. Am Beispiel des Schriftstellers Leo L. Mathias bringt Diner diese rhetorische Verbindung von propositionaler Wahrheit und ,ideologischer Imagination“ auf die folgende Formel: „Der Erfolgsautor des Antiamerikanismus lügt mit der Wahrheit." (Ebd., S. 26). Diese widersprüchliche Figur bewegt sich in großer Nähe zu einem performativen Verständnis vorurteiligen Sprechens: Wenn man die Wahrheit spricht, und dennoch lügt, so kann sich der Akt des Lügens bzw. dessen Falschheit, nicht auf den propositionalen Gehalt der Aussage beziehen, sondern man muss in einem anderen Sinne unwahr sprechen. $^{14}$

Es liegt nahe, diese Unwahrheit des antiamerikanischen ,Lügens mit der Wahrheit' in dessen rhetorischem Zweck, die Wirkung in einem gegebenen Äußerungskontext aufzufassen. Es wird also auch von Diner angedeutet, dass es der Antiamerikanismuskritik nicht allein um propositionale Wahrheit und konstative Sprechakte gehen kann. In gewisser Weise wird diese Perspektive in Diners historischen Analysen auch eingelöst: Antiamerikanische Stereotype werde hier in verschiedenen historischen Kontexten hinsichtlich ihres funktionalen Gebrauches interpretiert. Die rekonstruierten Funktionen verbleiben dabei aber immer sehr nah an der Grundthese, Antiamerikanismus als „Ressentiment“ zu lesen, in dem die „Entfremdungserfahrungen der Moderne“" verarbeitet werden (ebd., S. 62 f.): Amerika als „Projektionsfläche für die Abspaltung eigener Negativität“ (ebd., S. 129).

Eine besonders interessante Referenz auf die rhetorischen Aspekte des Vorurteils findet sich in Sebastian Schwarks Studie zur Genealogie des modernen Antiamerikanismus in Deutschland (Schwark 2008). Sie ist deshalb von besonderem Interesse, weil Schwark einerseits Antiamerikanismus explizit als „Sprechakt, als sprachliche Handlung“ (ebd., 17) bestimmt und auch den Antiamerikanismusbegriff als ,performativ[en]“ Begriff fasst. Jedoch verbindet sich bei Schwark mit diesen Begriffen ein vollkommen anderes Theorieverständnis, als das in der vorliegenden Arbeit explizierte. Unter performativen Begriffen versteht er ,politische Kampfbegriff[e]“, die ,die empirische Welt in Pole unterschiedlicher Wertigkeit gemäß der Zweckmäßigkeit für politische Ziele“ einteilen (ebd., S. 9 f.). Dementsprechend zielt Schwarks Begriffsbildung darauf ab, den Antiamerikanismusbegriff seines performativen Charakters zu entledigen und stattdessen eine ,sachliche[n] Untersuchung“ des Gegenstands zu leisten, die mithilfe eines ,nominalistische[n]“ Antiamerikanismusbegriffes operiert:

14 Diner gebraucht das Wort ,lügen" hier also metaphorisch, denn normalerweise impliziert es die bewusste Täuschung darüber, dass eine behauptete Proposition propositional falsch ist. 
„Die Wissenschaft - auch die Politische Wissenschaft - hingegen macht sich die sachliche Diskussion der empirischen Welt mit Hilfe von wissenschaftlichen Begriffen oder die sachliche Diskussion der Begriffe selbst zum Ziel. Ihre Aufgabe ist die Kritik. Wissenschaftliche Begriffe sind in der Nachfolge Max Webers daher nominalistische Begriffe.“ (Ebd., S. 10)

Bemerkenswerterweise greift Schwark trotz seiner Bestimmung des Antiamerikanismus als „sprachliche Handlung“ und des Selbstverständnisses eines Kritikers keinen der oben zitierten Aspekte einer rhetorisch-diskursiven Perspektive auf. Vielmehr hält er an einer strikten Unterscheidung von wertneutraler wissenschaftlicher Beschreibung und rhetorischem Sprechen fest und bezeichnet seine Begriffsbildung als ,nominalistisch“. Wie ich, im Vorgriff auf Argumentationen der Kapitel 3 und 4, kurz darlegen möchte, befindet sich Schwark hiermit auf mehreren Ebenen im Widerspruch zu seiner eigenen Feststellung, es handele sich beim Antiamerikanismus um „Sprechakte““. 15

Hierzu muss man sich zunächst vor Augen führen, was eine nominalistische Theorie der Bedeutung impliziert: Ihre Grundannahme ist, dass die zur Bezeichnung verwendeten Sprachzeichen (hier: ,Antiamerikanismus') mit dem jeweils Bezeichneten in einer ,zweistellige[n] Namensrelation“ stehen (Wellmer 2004, S. 32): Begriffe werden einem Gegenstand angeheftet wie Namenstäfelchen. Dabei muss jenes nominalistische Bedeutungsverständnis eine prinzipielle Unabhängigkeit von Zeichen und Bezeichnetem annehmen. Die Dinge, Bilder, Vorstellungen, etc., die in Sprache Bezeichnet werden, existieren diesem Modell zufolge zunächst als außersprachliche. Mit dieser strengen Trennung von Sprache und Ding unterschlägt der Nominalismus in verschiedener Hinsicht, dass sprachliche Bedeutung immer eine Sprachpraxis voraussetzt, die weder an einer außersprachlich gegebenen Realität unmittelbar abgeglichen, noch als unabhängig von gesellschaftlichen Praxen insgesamt aufgefasst werden kann. Dies betrifft v.a. den normativen Charakter des (wissenschaftlichen) Sprechens, zu dessen Reflexion es „keinen Archimedischen Punkt“ außerhalb von Sprache gibt, ,,von dem aus man über ,richtig' und ,falsch“ urteilen könnte“ (Wellmer 2004, S. 81). Schwarks Begriffsbildung tut aber letztendlich genau das: Sie arbeitet mit einer strikten Unterscheidung von „performativen“ Sprechakten und den ,reinen Konstruktionen“ wissenschaftlicher Beschreibung. Das von Schwark durchaus gesehene „Problem, dass das Verständnis der politischen Probleme, mit denen sie [die Politikwissenschaft, F.K.] sich auseinandersetzt,

15 Dabei scheint mir die methodologische Anlage seiner Arbeit weit weniger von der meinen entfernt, als deren nominalistisches Selbstverständnis vermuten lassen könnte. Tatsächlich tut Schwark methodisch etwas sehr ähnliches, wie die vorliegende Arbeit: Er nimmt seinen Ausgangspunkt bei bestehenden antiamerikanischen Motiven bzw. Antiamerikanismusbegriffen, die er dann anhand von Dokumentenanalysen in ihren flexiblen und verschiedenartigen Gebräuchen untersucht. 
durch politische Begriffe vorstrukturiert ist“" (Schwark 2008, S. 10), lässt sich aber nicht durch eine ,Ausschaltung' der performativen Aspekte des eigenen Sprechens lösen, sondern nur durch deren kritische Reflexion (vgl. dazu ausführlich die Kap. 3.3 und 4.5).

Wenngleich also Markovits, Diner und Schwark den rhetorisch-performativen Gehalt antiamerikanischer Vorurteile thematisieren, wird dieser von ihnen theoretisch nicht ausgearbeitet. Die performative bzw. praxistheoretische Grundlage der Antiamerikanismuskritik weiter auszuarbeiten, ist eines der Kernanliegen der vorliegenden Arbeit. Dies ist deswegen ein zentraler Aspekt der Begriffsbildung, und keine theoretische Pedanterie, weil hiermit das Wechselverhältnis von Gegenstand und Beobachtung, von antiamerikanischem Sprechen und Sprechen über Antiamerikanismus, als methodologische Grundlage der Vorurteilskritik klarer hervortritt. Wie die Ergebnisse der qualitativen Empirie in Kapitel 7 zeigen, eröffnet eine solche methodologische Selbstverständigung auch empirisch neue Perspektiven.

\subsubsection{Antiamerikanismus ist nicht gleich Feindschaft oder Aversion}

Das zweite wichtige Kriterium, das in der Forschungsliteratur zur Bestimmung von Antiamerikanismus genannt wird, ist dessen abwertende oder feindselige Haltung. Im vorigen Abschnitt wurde gezeigt, dass der Sinngehalt antiamerikanischen Handelns nicht losgelöst von dessen performativer Komponente zu fassen ist und somit auch eine normative Bestimmung des funktionalen Gebrauches bestimmter Amerikastereotype erfordert: Wenn antiamerikanisches Sprechen nicht primär aus konstativen Akten besteht und deren Unwahrheit somit nicht an der faktischen Geltung der Propositionen festgemacht werden kann, muss die Vorurteilskritik an anderen Formen der Performanz und deren normativem Gehalt ansetzen. Was also tut Antiamerikanismus und warum richten wir unsere Kritik gegen dieses Tun?

Die Abwertung oder Anfeindung einer amerikanischen Outgroup scheint auf den ersten Blick eine einfache Antwort auf diesen Frage zu geben: Wer andere abwertet oder anfeindet, verhält sich in einer zumindest potentiell verletzenden Weise und die Kritik eines solchen Verhaltens scheint allein dadurch schon gerechtfertigt. Genauere Betrachtungen der negativen Valenz von Vorurteilen haben aber ergeben, dass es sich auch mit diesem Aspekt nicht so eindeutig verhält, wie häufig angenommen (Dixon et al. 2012; Glick und Fiske 2012; Jackman 1994; Rudman 2005).

Wie im Folgenden gezeigt wird, lassen sich auch gegen das Kriterium der Feindseligkeit die beiden oben entwickelten Einwände in Stellung bringen: Weder muss antiamerikanisches Sprechen notwendig abwertend oder gar feindselig sein, noch gibt die bloße Feststellung einer solchen negativen Haltung bereits ein überzeugendes Kriterium für die Vorurteiligkeit antiamerikanischer Rede ab. Zumindest 
der erste dieser beiden Einwände ist in der Antiamerikanismusliteratur bereits wiederholt zum Thema geworden. So betonen einige AutorInnen, dass Antiamerikanismus häufig durch eine Gleichzeitigkeit von positiven und negativen Haltungen gegenüber den USA geprägt ist (vgl. Chiozza 2009, S. 59 ff.; Diner 2003, S. 66 ff.; Jaecker 2014, S. 146 ff.; Kane 2006). Dennoch folgt daraus in der Regel keine grundlegende Neujustierung der Antiamerikanismusdefinition. Es bleibt bei der ,klassischen“ Bestimmung des Vorurteils als einer ablehnenden oder feindlichen Haltung. Die Antiamerikanismus-als-Vorurteil Perspektive weicht insofern nicht von dem theoretischen Standard ab, den die Sozialpsychologen John Dixon und Mark Levine für die Vorurteilsforschung insgesamt feststellen:

„For much of the history of prejudice research [...] prejudice has been defined as a kind of generic affective response towards members of other groups, which varies in intensity from low to high and is in practice defined by its negative valence (even if textbook discussions dutifully remind readers that prejudice can, in principle, involve warm as well as hostile feelings). [...] In a nutshell, prejudice occurs when, we ' dislike ,them ‘ and don't have a sensible reason for doing so.“ (Dixon und Levine 2012b, S. 10)

So wird auch in der Antiamerikanismusforschung neben dem propositionalen Gehalt antiamerikanischer Aussagen deren negative Valenz zu einem zentralen Stützpfeiler des Konzeptes. Dies gilt häufig gerade auch für diejenigen Ansätze, die zugleich auf die Ambivalenz antiamerikanischer Zuschreibungen hinweisen. So hält Dan Diner fest, ,das Element einer ambivalenten, vornehmlich aber feindseligen und durch Angst bestimmten Reaktion auf die Moderne" sei in verschiedenen historischen Formen antiamerikanischer Ausdrücke fortlaufend zu finden (Diner 2003, S. 9). Giacomo Chiozza betont zwar, dass die öffentliche Meinung gegenüber Amerika ,takes a loose and multi-faceted form in which negative and positive elements coexist with no apparent tensions“ (Chiozza 2009, S. 4), definiert dann aber Antiamerikanismus als „low opinions“ bzgl. der USA. Der Literaturwissenschaftler Jesper Gulddal betont in seiner Studie zu literarischem Antiamerikanismus zwar die Wichtigkeit, das empirische Material nicht allein auf die ,extreme and unambiguous [...] examples“ zu reduzieren, bleibt aber bei der Einschätzung, dass ,even in its less radical forms, anti-Americanism involves an undifferentiated hostility directed not at specific aspects of the country, but generalized into an all-encompassing attack on American civilization." (Gulddal 2011, S. 5 f.). Der Politikwissenschaftler Gregory Johnston ersetzt die Frage nach einem Abgrenzungskriterium von antiamerikanischem Vorurteil und Amerika-Kritik durch einen fließenden Gradunterschied zwischen beiden, und setzt die negative Valenz als einziges Unterscheidungsmerkmal ein: „According to the theory presented, the only thing separating anti-Americanism from pro-Americanism is valence. They are not fundamentally different." (Johnston 2006, S. 30) Dementsprechend konzentriert sich auch seine 
Definition auf den Aspekt negativer Bewertung: ,anti-Americanism represents a broad disposition toward negative evaluations of that which is perceived as ,American'." (Ebd., S. 41)

Es geht mir an dieser Stelle nicht darum, in Zweifel zu ziehen, dass antiamerikanische Äußerungen häufig abwertende oder feindliche Stereotype beinhalten werden. Auch die Antiamerikanismen, die im Interviewmaterial der vorliegenden Studie rekonstruiert wurden, zeichnen sich überwiegend durch eine abwertende oder zumindest skeptisch-distanzierte Haltung aus. Worauf ich hinweisen möchte ist aber, dass die Konzentration des vorurteilskritischen Blicks auf abwertende Stereotype dessen Sicht auf die Funktionsweisen antiamerikanischer Rede eher verstellt als schärft. Wie bereits angerissen, gilt dies wiederum in zweifacher Hinsicht: Einerseits geraten antiamerikanische Sprachgebräuche aus dem Blickfeld, die nicht als Abwertung oder Feindschaft bestimmt werden können. Bspw. bleibt die stabilisierende Funktion, die Amerikaklischees für eine nationalistische Weltsicht haben können, mit der aber nicht notwendig eine Abwertung von Amerikanerinnen und Amerikanern einhergehen muss, unterbelichtet (vgl. Kap. 7.2.2). Andererseits scheint mir die Konzentration auf Feindschaft und Abwertung eine genauere Auseinandersetzung mit der Frage nach dem (normativen) sozialtheoretischen Ansatzpunkt der Vorurteilskritik zu behindern. Sie fungieren oft als handlicher Ersatz für eine differenzierte theoretische Bestimmung dessen, was (antiamerikanische) Vorurteile überhaupt zum Gegenstand der Kritik werden lässt. Zwar werden empirische Analysen antiamerikanischer Äußerungen meist auch mit funktionalen Deutungen verknüpft, bspw. deren Funktion für eine europäische Identitätskonstruktion oder der Bearbeitung erinnerungspolitischer Probleme (z.B. Markovits 2007; Markovits und Rensmann 2007). Dennoch gehen die diesen Analysen zugrunde gelegten Definitionen in der Regel von einer Aversion gegen die USA aus. Der Tatbestand aber, dass jemand eine Aversion gegenüber einem Objekt oder einer Gruppe hat, ist an sich noch kein Kriterium für vorurteiliges Handeln.

John Dixon und Kollegen haben kürzlich in einer vielbeachteten Publikation zum Vorurteilsbegriff auf dieses Defizit der klassischen Theorieansätze der Vorurteilsforschung hingewiesen: Zwar habe diese in ihrer bis ins frühe 20. Jahrhundert zurückreichenden Tradition zahlreiche ausgefeilte Kategorisierungsschemata und

16 Dies funktioniert bei Johnston unter der Prämisse, dass er Antiamerikanismus rein formal als jegliche gegen Amerika gewandte Position definiert: „We define anti-Americanism as ,a systematic negative normative evaluation of the United States'. This definition does not preclude either anti-Amnerican prejudice or nuanced evaluation reflecting measured policy disagreements. It encompasses both.“ (Ebd., S. 19) Antiamerikanismus ist in diesem Fall also nicht unbedingt als Vorurteil bestimmt. Der theoretische Nutzen eines solchen Antiamerikanismusbegriffs jenseits der Unterscheidung von vorurteiligem und nicht vorurteiligem Sprechen erscheint indessen äußerst fragwürdig. 
Erklärungsansätze in verschiedensten Disziplinen von der Soziologie bis zur Neurophysiologie entwickelt, die Konzeption des gesellschaftlichen Problems, von dem die Vorurteilsforschung ausgeht, sei hingegen kaum jemals revidiert worden: „Notwithstanding this historical and conceptual complexity, at the heart of most prejudice research is a deceptively simple question: Why don't we like one another?" (Dixon et al. 2012, S. 413) Und auch in den Interventionsprogrammen die aus der Vorurteilsforschung hervorgegangen sind, sei über unterschiedliche Ansätze hinweg ein Konsens zu erkennen, demzufolge es um eine Reduktion von Vorurteilen gehen müsse, nach der Grundfrage: „How can we get individuals to think more positive thoughts about, and hold more positive feelings towards, members of other groups? In short, how can we get people to like each other?" (Ebd.)

Die Autoren zeigen daraufhin am Beispiel von interethnischen und Geschlechterverhältnissen, dass hierarchisierende und unterdrückende Praxen keineswegs notwendig mit abwertenden Stereotypen einhergehen müssen sowie, dass auch benevolente Handlungen, etwa Hilfeleistungen, ,,may service relations of domination in varying ways, depending on the prevailing ideological conditions" (ebd., S. 416). Entscheidend für die Vorurteilsbestimmung ist für Dixon und Kollegen also nicht die (negative) Valenz vorurteiliger Ausdrücke, sondern die ,ideological conditions“, in deren Kontext bestimmte Gruppenstereotype diskriminierende Effekte zeitigen. Damit verschiebt sich auch der begriffliche Fokus der Vorurteilsbestimmung von einer psychologischen Definition der kognitiven oder affektiven Komponenten bestimmter Praxen, hin zu deren Effekten hinsichtlich der Strukturen von Ungleichheit und Herrschaft einer Gesellschaft. Damit verweisen die Autoren indirekt auf Diskriminierung und Ungleichheit als Grundlage des Vorurteilsbegriffs. Sie bewegen sich also, ähnlich wie die vorliegende Arbeit, im Rahmen einer Vorurteilsforschung mit einer „functionalist emphasis on the social and psychological processes that serve to reproduce unequal social relations" (ebd., S. 421). ${ }^{17}$

\subsubsection{Antiamerikanismus ist nicht notwendig eine geschlossene Weltanschauung}

In den vorigen beiden Abschnitten wurden der propositionale Gehalt bzw. die faktische Geltung von Aussagen über Amerika sowie deren negative Valenz als Kriterien für deren vorurteiligen Charakter aus theoretischen sowie empirischen Gründen zurückgewiesen. Neben faktischer Unwahrheit und negativer Valenz findet sich als

17 Wenn auch vor einem anderen theoretischen Hintergrund, nehmen Dixon und Kollegen damit eine Perspektive auf Vorurteile ein, die dem diskurstheoretischen Ansatz von Wetherell und Potter sehr nahe kommt. Diese haben Rassismus aufgefasst als "discourse (of whatever content) which has the effect of establishing, sustaining and reinforcing oppressive power relations“ (Wetherell und Potter 1992, S. 70). 
drittes zentrales Kriterium vieler Antiamerikanismusdefinitionen eine weltanschauliche Geschlossenheit antiamerikanischer Vorurteile. Es wird angenommen, dass es sich beim Antiamerikanismus um ein konsistentes Schema von Wahrnehmungsund Deutungsmustern handelt, das den Blick der antiamerikanisch Handelnden auf das Weltgeschehen umfassend prägt.

Markovits zufolge ist Antiamerikanismus nicht nur hinsichtlich des darin gezeichneten Amerikabildes als ,generalized and comprehensive normative dislike“ (Markovits 2007, S. 17) zu bezeichnen, sondern nimmt auch in seiner weltanschaulichen Funktion die Geschlossenheit eines „Ismus“ an, „den Institutionalisierung und Nutzung zu einer modernen Ideologie machen." (Markovits 2004, S. 17). Russel Berman sieht im Antiamerikanismus ebenfalls ein totalisierendes Denksystem, welches ,involves a global judgment, an enormous stereotype, driven by fears regarding democracy and capitalism.“ (Berman 2008, S. 63). Auch Jesper Gulddal attestiert dem Antiamerikanismus jenen weltanschaulich geschlossenen Charakter und bestimmt ihn als ,a chauvinistic denunciation of America as a whole, raised to the status of an ideology" (Gulddal 2011, S. 4). Nach diesen Beschreibungen tritt Antiamerikanismus als ein konsistentes Schema in den Wahrnehmungen und Urteilen von antiamerikanisch handelnden Akteuren auf, das relativ unabhängig von situativen Ausdruckskontexten ist. Diese Eigenschaft wird häufig mit den Begriffen „Weltanschauung“ oder „Ideologie“ bezeichnet (vgl. Friedman 2012, S. 7 f.; Jaecker 2014, S. 287 ff.; O'Connor 2007b, S. 15 ff.). Aber auch in den in Abschnitt 2.2.2 beschriebenen explizit vorurteilstheoretischen Ansätzen finden sich ähnliche Konzeptionen von Antiamerikanismus als „Schematismus“ der Wahrnehmung, der eine „nichtsituative und essenzialistische Bewertung“ verschiedenster Sachverhalte bedingt (Beyer 2014, S. 21 f.; vgl. auch Katzenstein und Keohane 2007b, S. 13).

Diese These der weltanschaulichen Geschlossenheit stellt jedoch eine unzulässige Vereinfachung der vorurteiligen Sprachpraxis dar. Es gilt also auch hier, was Margaret Wetherell für die sozialpsychologische Vorurteilsforschung insgesamt feststellt:

„The most integrated form of prejudice talk appears, of course, within the texts of social psychology. The ,lived ideology ${ }^{`}$ is, as usual, much more fragmented, piecemeal and contradictory, caught up as it is in the kaleidoscope of common sense." (Wetherell 2012, S. 158)

Ähnliche Positionen wurden zuletzt vermehrt in der Forschung zu antisemitischer Alltagskommunikation stark gemacht (Mansel und Spaiser 2012; Schäuble 2012; Scherr und Schäuble 2006). Aber auch in der Antiamerikanismusliteratur selbst ist die Idee einer konsistenten antiamerikanischen Weltanschauung nicht unwidersprochen geblieben. So stellt Dan Diner bspw. fest: 
„Antiamerikanismus tritt nicht als geschlossene und sich auf den ersten Blick als solche zu erkennen gebende Weltanschauung auf, sondern legt sich als Schleier unterschiedlicher Konsistenz auf in den Vereinigten Staaten tatsächlich anzutreffende oder ihnen auch nur zugeschriebene Phänomene von Politik, Kultur und Alltagsleben.“ (Diner 2003, S. 8)

Tobias Jaecker verweist auf Inkonsistenzen im antiamerikanischen Diskurs und empfiehlt eine dementsprechende Skepsis vor universalisierenden Bestimmungen dessen als umfassende „Weltanschauung“ oder „Ideologie“. Demzufolge

,sind derart geschlossene antiamerikanische Weltbilder im medialen Diskurs nur vereinzelt zu finden. Wie die Analysen ergeben haben, überwiegt insgesamt die fragmentarische Form des Antiamerikanismus. Einzig im wirtschaftlichen Diskursbereich sind wiederholt Aussagen und Texte zu finden, die geschlossenen Charakter haben und den ganzen wirtschaftlichen Lauf der Welt mit Amerika erklären. In den Debatten zur Politik wiederum ist eine annähernd geschlossene Deutungsweise allenfalls im Zusammenhang mit außenpolitischen Themen festzustellen.“ (Jaecker 2014, S. 289)

Die Wahrnehmungs- und Bewertungsschemata antiamerikanischer Vorurteile zeichnen sich demnach also weniger durch einen strikten Schematismus, sondern eher durch eine Art „flexible coherence“ aus, wie O'Connor im Anschluss an den Politikwissenscahftler Michael Freeden formuliert (O'Connor 2007b, S. 16). Ähnlich urteilt Giacomo Chiozza, Antiamerikanismus sei ,a loosely constrained belief system“, das maßgeblich durch eine Ambivalenz von Einstellungen und variable politische Kontextbedingungen geprägt ist (Chiozza 2009, S. 199).

Eine systematische Einbindung dieses Befundes in die Theoretisierung und empirische Analyse von Antiamerikanismus bleibt in der Regel aber aus. Klaus Baethge und KollegInnen bilden hier mit ihrer Studie zu Antiamerikanismus in der Krise eine Ausnahme, indem sie eine funktionalistische Theorieperspektive vorschlagen, die die Fragmentierung und Flexibilität antiamerikanischer Vorurteile ins Zentrum der Analyse rückt. Ihr Ansatz ist zusätzlich mit einer methodischen bzw. methodologischen Kritik verknüpft, die maßgeblich auf einen Mangel qualitativ-interpretativer Studien zum Thema abzielt. So beklagen die AutorInnen „das Fehlen sozialwissenschaftlicher Untersuchungen zum Antiamerikanismus im Alltag“" (Baethge et al. 2010, S. 366). Empirische Forschung zum Antiamerikanismus arbeite nahezu ausnahmslos entweder mit standardisierten Instrumenten, meist im Rahmen von Surveys, oder konzentriere sich, sofern qualitative Analysemethoden zum Einsatz kommen, auf massenmediale Debatten. Durch diese Empirie- bzw. Materialarten könne aber die Frage nicht beantwortet werden, ,ob, und wenn ja, wie antiamerikanische Wahrnehmungsmuster sich den Teilnehmern als subjektiv funktionale Deutungen ihrer sozialen Erfahrung anbieten und wie die bestehenden Deutungsangebote aufgegriffen und umgearbeitet werden“ (ebd., 368). Stattdessen setze die For- 
schung in der Regel eine weltanschauliche Konsistenz und Funktionsweise antiamerikanischer Vorurteile voraus, ohne deren Funktionieren jenseits von SurveyItems, Presseartikeln und Politikeräußerungen jemals systematisch empirisch zu beobachten. So ist „die sozialwissenschaftliche Antiamerikanismus-Forschung von einer kanonisierten Begriffsbestimmung geprägt [...], die sich allein auf die antiamerikanischen Inhalte konzentriert und eine darüber hinausgehende funktionale Bestimmung des Antiamerikanismus vernachlässigt“ (ebd., S. 367).

Dem setzen Baethge und KollegInnen ein Verständnis von Antiamerikanismus entgegen, in dem dieser nicht als isoliertes Phänomen, sondern als „Element eines Sets alltagspraktischer Bewusstseinsformen der Welterklärung und Handlungsorientierung" begriffen wird (ebd.). Diese Theorieanlage, die sich an Detlev Claussens Begriff der „Alltagsreligion“ orientiert, entspricht in vielerlei Hinsicht der oben umrissenen funktionalen Perspektive auf Vorurteile. Auch dort wird die Frage nach dem Sinngehalt antiamerikanischer Ausdrücke nicht an Stereotypeninhalten, deren negativer Valenz oder weltanschaulicher Geschlossenheit festgemacht, sondern am Gebrauch, den bestimmte Stereotype in einem jeweiligen Funktionskontext finden.

Ein zentrales Ergebnis der von den AutorInnen durchgeführten Gruppendiskussions-Studie ist, dass sich antiamerikanische Redeweisen in alltäglichen Gesprächen kaum je zu geschlossenen Welterklärungen verdichten:

„Für die Alltagskommunikation muss eher von einem stark fragmentarischen, lediglich stichwortartigen Abrufen oder Einwerfen von Antiamerikanismen ausgegangen werden. Die pauschal abwertende Erwähnung der USA dient dabei häufig lediglich zur Konsensbildung und wird nicht zum Welterklärungsmodell ausgeweitet.“ (Ebd. 382)

Demzufolge lassen sich in den von Baethge und KollegInnen erhobenen Gruppendiskussionen zwar spezifische Funktionen antiamerikanischer Rede rekonstruieren; zugleich jedoch scheinen die Gebräuche gängiger Amerikastereotype ,weitaus offener für subjektive und situative Umschriftungen [...], als dies die bisherige Forschung vermuten ließe“ (ebd.). Die Funktionen antiamerikanischer Rede sind also, wie Baethge und KollegInnen argumentieren, ein unverzichtbares Moment der Bestimmung antiamerikanischer Sinngehalte.

Ein weiterer Aspekt, der im Rahmen der Inkonsistenz antiamerikanischer Vorurteile von Baethge und Kollegen diskutiert wird, ist eine gewisse normative Ambivalenz oder negative Selbstbezüglichkeit, die mit dem Gebrauch antiamerikanischer Stereotype einhergeht. In den Gruppendiskussionen wurde beobachtet, dass antiamerikanische Sprechweisen häufig in Form eines Witzes oder einer ironischen Bemerkung eingebracht werden, so dass das gebrauchte Amerikaklischee durch die Art seines Vortrages gleichzeitig in Frage gestellt wird. Auf diese Weise gelingt es den SprecherInnen, gleichzeitig eine vorurteilige Funktion zu erfüllen, etwa die per- 
sonalisierende Erklärung der Finanzkrise, und sich dennoch von vorurteiligem Sprechen zu distanzieren (vgl. Baethge et al. 2010, S. 275 ff.).

„Es scheint, als wären die Witze auch Ausdruck einer Hilflosigkeit der Teilnehmer: Zwar glauben sie selbst nicht so recht an die antiamerikanischen Stereotype, aber andere Erklärungen haben sie auch nicht. Anscheinend kann auf die stereotype Reduktion nicht verzichtet werden, obwohl man sich als über derartige Simplifizierungen überlegen präsentieren muss. [...] Die Komplexitätsreduktion der Wirklichkeit, die Attraktivität einer klaren Aussage und Position zu einem verwickelten Sachverhalt, die gleichzeitig die eigene Wir-Gruppe von negativen Aspekten entlastet - all diese attraktiven Momente des Antiamerikanismus können erhalten bleiben, ohne dass man sich dem Vorwurf des antiamerikanischen Ressentiments aussetzt.“ (Ebd., S. 376)

Das rhetorische Manöver, das hier am Beispiel des Witzes bzw. der Ironie diskutiert wird, ist in der rhetorischen Psychologie Michael Billigs ausführlich beschrieben worden. Wie oben in Abschnitt 2.3.1 bereits ausgeführt, besteht ein zentrales Argument Billigs darin, dass Vorurteile nicht als individuelle Einstellungen aufgefasst und auf ihre faktische Gültigkeit und logische Konsistenz hin beurteilt werden können, sondern dass diese als Ausdruck politisch-normativer Diskurse aufgefasst werden sollten, auf die vorurteiliges Sprechen sich rhetorisch bezieht. Die Struktur solcher Diskurse ist grundsätzlich ,dilemmatic“, und durch ,contrary themes“ geprägt (Billig 1991, S. 21; vgl. auch Martin 2010, S. 76 ff.). In diesem Sinne weisen auch Vorurteile bzw. die Probleme, die auf vorurteilige Weise verhandelt werden, eine widersprüchliche Struktur auf. Vorurteiliges Sprechen ist nach Billig also Ausdruck einer widersprüchlichen normativen Konstellation des gesellschaftlichen Common Sense, in dem es doppelt sanktioniert wird: „It is sanctioned to the extent that it is allowed and it is sanctioned to the extent that it is penalized." (Billig 2012, S. 144) Dies führt dazu, dass vorurteiliges Sprechen widersprüchliche Normen zu vereinen sucht, indem es sich selbst gleichzeitig als vorurteilsfrei präsentiert: ,The attitudes held by the modern racists are deracialized in that the attitudes are justified by traditional values, such as equality and fairness, and not by overt racial themes." (Billig 2012, S. 140 f. $)^{18}$

Entscheidend ist für die rhetorische Perspektive, dass die Beteuerung der eigenen Vorurteilsfreiheit nicht als bewusstes ,impression management“ gedeutet wird, um von einer tiefer liegenden, , eigentlichen' Einstellung abzulenken (ebd., S. 142 ff.): „In some instances, this manoeuvre might be made to save face - but more commonly, it may express a sincere conviction that what one has to say is not ra-

18 In der sozialpsychologischen Vorurteilsforschung wird diese normative Ambivalenz des Vorurteils als „motivation to control prejudice“ diskutiert (Dunton und Fazio 1997; vgl. auch Plant und Devine 2009; Sommers und Norton 2006). 
cism, despite the possibility of it being construed as such." (Martin 2010, S. 108) Nicht nur liegen vorurteiligem Sprechen also widersprüchliche normative Konstellationen zugrunde, sondern diese drücken sich im vorurteiligen Sprechen auch aus: Dieses ist demnach typischerweise durch eine negative Reflexivität gekennzeichnet, durch die es sein eigenes vorurteiliges Potential zugleich anerkennt und zu negieren sucht. Diese selbstrechtfertigende Struktur vorurteiligen Sprechens wird in Kapitel 4.5 und 4.6 mit den Begriffen der Ideologie und der Kommunikationslatenz genauer gefasst. An dieser Stelle sei zunächst nur festgehalten, dass antiamerikanische Vorurteile auch durch negative Selbstbezüglichkeit von einer konsistenten Weltanschauung abweichen können.

Wenn also so etwas wie eine weltanschauliche Funktion des Antiamerikanismus existiert, dann nicht im Sinne von Eindimensionalität und Universalität eines negativen Gesamtbildes der USA, sondern als flexibles ideologisches Navigieren widersprüchlicher normativer Orientierungen. Weltanschauliche Erklärungsfunktionen des Antiamerikanismus mögen in einem Äußerungskontext oder thematischen Zusammenhang auftreten, in anderen aber ausbleiben. Wenn sie aber auftreten, so wird ihre welterklärende oder orientierungssichernde Funktion sich oftmals zugleich dagegen absichern, als vorurteilige Weltanschauung zu erscheinen - und zwar nicht nur nach außen hin, vor den jeweiligen Gesprächspartnern, sondern häufig auch vor sich selbst: ,the speaker, in a real sense, is literally engaging in selfjustification: the self is being justified by the self to the self." (Billig 2012, S. 146).

Es kann also festgehalten werden, dass antiamerikanische Vorurteilsäußerungen in dreifacher Weise von der Form einer konsistenten Weltanschauung oder eines geschlossenen Denksystems abweichen: Einerseits treten sie fragmentiert auf, d.h. wenn in einer Situation eines Kommunikationszusammenhanges antiamerikanische Rhetoriken gebraucht werden, geht damit nicht notwendig auch ein solcher Sprachgebrauch in anderen Kommunikationssituationen einher (vgl. Kap. 7.5.1). Andererseits tauchen in den qualitativen Analysen der vorliegenden Studie häufig ambivalente antiamerikanische Äußerungen auf. So verweisen viele Interviewteilnehmende im unmittelbaren Zusammenhang mit abwertenden Haltungen gegenüber , den Amerikanern" darauf, dass sie bestimmte Aspekte an den USA durchaus als positiv empfinden (vgl. Kap. 7.2.2 und 7.5.2). Und schließlich kann für die Gebräuche antiamerikanischer Rhetorik eine größere Flexibilität der funktionalen Einbettung festgestellt werden, als in der Forschung häufig angenommen. So können antiamerikanische Sprechweisen bspw. nicht nur mit der Funktion einer Konturierung und Aufwertung nationaler oder ethnischer Identität einhergehen, sondern auch im Kontext lokalpatriotischer Identitätskonstruktionen auftreten (vgl. Kap. 7.5.2). In der Antiamerikanismusliteratur finden derartige Befunde bislang aber wenig Berücksichtigung, was immer wieder zu einer ,problematischen Vereindeutlichung“ des Antiamerikanismusbegriffes führt, wie Albert Scherr sie für den Antisemitismusbegriff konstatiert (Scherr und Schäuble 2006, S. 56). 


\subsubsection{Antiamerikanismus ist als individualpsychische Disposition unterbestimmt}

In ihrem Artikel Anti-Americanism in Europe: Theoretical Mechanisms and Epirical Evidence (Beyer und Liebe 2014) verweisen Heiko Beyer und Ulf Liebe nachdrücklich auf die Relevanz einer klaren Unterscheidung von Antiamerikanismus und legitimer Amerikakritik. Sie verstehen ihr Antiamerikanismuskonzept als Beitrag zur Überwindung eines „,political reductionism“ in der Antiamerikanismusliteratur (ebd., S. 91), demzufolge Antiamerikanismus in erster Linie eine „response to actions performed by the United States" darstellt (ebd., S. 90). Um eine klare Trennlinie zwischen Vorurteil und ,bloßer Meinung ' ziehen zu können, formulieren sie als Kriterium die Konsistenz der antiamerikanischen Einstellung: „We therefore advocate using the term ,anti-Americanism" solely for coherent negative attitudes.“ (Ebd., S. 91) Die Frage nach der Bedeutung des Antiamerikanismusbegriffes wird hier gleichbedeutend mit der Frage, ab wann man eine Person als ,Antiamerikanerin“ bzw. ,Antiamerikaner' einstufen kann. Beyer und Liebes Antwort lautet: „an individual is to be labelled , anti-American' only if we find a coherent attitude structure." (Ebd.) Ist aber diese Eingrenzung des Antiamerikanismusbegriffes auf den Einstellungsbegriff ein geeignetes Kriterium, um Vorurteil von ,bloßer Meinung $\mathrm{zu}$ unterscheiden?

Ich möchte zeigen, dass ein zu enger psychologischer Fokus dazu führt, dass die Vorurteilskritik wichtige Aspekte ihres Gegenstandes ausblendet. In gewissem Sinne kann man sagen, dass Beyer und Liebe mit ihrem Vorschlag, einen politischen Reduktionismus zu überwinden, diesen durch einen psychologischen Reduktionismus ersetzen. Demgegenüber möchte ich im Sinne eines performativen Antiamerikanismusbegriffes ein Primat der Praxis stark machen. Nicht erst die Unterscheidung konsistenter und inkonsistenter psychologischer Dispositionen ermöglicht die Trennung von Antiamerikanismus und nicht-Antiamerikanismus; sondern die psychologische Unterscheidung hat die letztere vielmehr schon zur Bedingung. Erst wenn wir wissen, was eine antiamerikanische Äußerung ist, können wir sagen, dass jemand mehr oder weniger häufig bzw. konsistent solche Äußerungen tätigt, und somit auf dessen kohärente Einstellung schließen. Genau darin besteht der Reduktionismus psychologischer Vorurteilskonzepte: Sie versuchen das Phänomen ,Vorurteil ' als spezifische Form eines allgemeineren Phänomens ,Einstellung' zu erörtern, verlieren dabei aber die Spezifika des jeweiligen Vorurteils aus dem Blick. Anders formuliert: Vorurteile als Einstellung zu definieren, sagt mehr darüber aus, welche Formen Einstellungen annehmen können, als darüber, was das jeweilige Vorurteil charakterisiert.

Implizit wird diese Problematik im Artikel von Beyer und Liebe selbst thematisiert: So erkennen die Autoren die Verbreitung von „ambivalent rather than outright 
negative attitudes" durchaus an, beharren aber darauf, dass solche ambivalenten oder nicht eindeutig negativen Äußerungen ,,should not be labelled, (manifest) antiAmerican“"(ebd.). Dies bedeute jedoch wiederum nicht, dass

„such individuals do not participate in an anti-American discourse with certain utterances. But on a conceptual level, one has to keep in mind the analytical distinction between attitudes and discourse.“ (Ebd.)

Damit stehen nun aber zwei konkurrierende Bestimmungen von Antiamerikanismus nebeneinander, die einstellungspsychologische und die diskursive. Einerseits soll als Antiamerikanismus nur gelten, was als konsistente Einstellungsstruktur ausgewiesen werden kann; andererseits kann aber auch außerhalb solcher Strukturen, in Form von Diskursbeiträgen, schon Antiamerikanismus beobachtet werden. Akteure können also antiamerikanisch handeln, ohne antiamerikanisch zu sein. Der umgekehrte Fall einer antiamerikanischen Person, die niemals antiamerikanisch handelt, scheint hingegen kaum denkbar. ${ }^{19}$ Man kann dies so lesen, dass auch im strikt einstellungspsychologisch formulierten Ansatz von Beyer und Liebe das Primat der Praxis implizit anerkannt wird. Das, was von der Vorurteilsforschung grundlegend als individuelle Einstellung aufgefasst wird, ist demnach zunächst als Sprechakt zu bestimmen. $^{20}$

Die hier formulierte Kritik schmälert den Nutzen psychologischer Vorurteilskonzepte im Übrigen keineswegs. Diese können insbesondere als kausale Erklärungsgrößen für individuelle Differenzen im vorurteiligen Verhalten wichtige theoretische Funktionen erfüllen. Da dieser explanatorische Gebrauch aber eine theoretische Bestimmung antiamerikanischer (Sprach-)Praxen schon voraussetzt, sollten psychologische Konstrukte wie das der Einstellung nicht im Zentrum eines Antiamerikanismusbegriffes stehen. Andernfalls führt dies tendenziell dazu, dass der Gebrauchsaspekt vorurteiligen Sprechens, wie er in Abschnitt 2.3.1 umrissen wurde, vernachlässigt wird. Die Frage nach den Funktionen antiamerikanischen Sprechens wird überblendet mit der vermeintlich klarer fassbaren Klassifikation psychischer Dispositionen. Ähnliches gilt auch für Fragen nach der Fragmentierung und Flexibilität im vorurteiligen Sprechen, die in einer einstellungstheoretischen Perspektive zwar anerkannt werden, meist aber nur eine Nebenrolle spielen. Und schließlich, so

19 Vgl. zum Verhältnis von (sprach-)praktischem Ausdruck und innerpsychischem Vorgang auch Milbradt 2013, S. $102 \mathrm{ff}$.

20 Vgl. auch die Forderung Klaus Holz’, ,systematisch zwischen einer (Sozial)Psychologie von Antisemiten und einer Soziologie des Antisemitismus“ zu unterscheiden (Holz 2001, S. 16), sowie den radikaleren Vorschlag der diskursiven Psychologie, Einstellungen generell nicht als einen „mental or neural state of readiness“ zu begreifen, sondern als eine „,internal action in the medium of language“ (Martin 2010, S. $106 \mathrm{f}$.). 
kann mit Margaret Wetherell argumentiert werden, lässt eine psychologische Vorurteilskonzeption Fragen nach der gesellschaftlichen Wirkung vorurteiligen Verhaltens sowie nach den normativen Grundlagen von deren Kritik in den Hintergrund treten:

„Prejudice remains a personal pathology, a failure of inner-directed empathy and intellect, rather than a social pathology, shaped by power relations and the conflicting vested interests of groups." (Wetherell 2012, S. 165)

Ausgehend von diesen Überlegungen wird in der vorliegenden Arbeit Antiamerikanismus als sprachliche Praxis bestimmt, deren Äußerungen anhand bestimmter Amerikabilder und deren antiamerikanischem Gebrauch bestimmt werden können.

\subsection{ZWISCHENFAZIT: EIN PERFORMATIVER ANTIAMERIKANISMUSBEGRIFF}

Das vorliegende Kapitel hat einen Überblick über die existierende Antiamerikanismusliteratur gegeben, wobei ein besonderer Fokus auf solchen Beiträgen lag, die Antiamerikanismus als Vorurteil theoretisieren. Seinen Ausgangspunkt nahm dieser Überblick aber nicht bei der Forschungsliteratur allein, sondern auch bei der öffentlichen Wahrnehmung des Antiamerikanismus bzw. den Vorbehalten gegenüber diesem Konzept: Es wurde gezeigt, dass es sich beim Antiamerikanismus um ein vergleichsweise wenig sanktioniertes Vorurteil handelt, dessen Kritik regelmäßig auf Widerstand stößt. So wird häufig die Existenz antiamerikanischer Vorurteile zwar eingestanden, deren Begriff aber auf extreme Fälle eingeschränkt, während ein Großteil antiamerikanischer Äußerungen als legitime politische Kritik anerkannt wird. In extremeren Formen wird dabei der Begriff Antiamerikanismus als positive Markierung der eigenen politischen Position umgewertet.

Als Gründe für diese Widerstände gegen einen kritischen Antiamerikanismusbegriff werden häufig die tatsächliche Macht der USA, der politische, nicht ,ethnische' Charakter der als Amerikaner bezeichneten Gruppe sowie polemische Missbräuche des Antiamerikanismusbegriffes vorgebracht. So könne Antiamerikanismus kein Vorurteil sein, da es sich bei ,den Amerikanern“ nicht um eine unterdrückte Minderheit handele, sondern um eine globale Supermacht. Außerdem habe Antiamerikanismus nichts mit Rassismus zu tun (der häufig als synonym mit Vorurteilen überhaupt angesehen wird), da die Amerikaner schließlich keine ,Rasse“ seien, sondern eine politische Gruppe, deren Politik zudem demokratisch legitimiert ist. Schließlich, so ein weiterer häufiger Einwand, sei der Antiamerikanismusbegriff nicht als Mittel der Vorurteilskritik zu gebrauchen, weil er zu oft als politisches 
Propagandainstrument verwendet werde, um Kritiker der US-Politik mundtot zu machen.

Entgegen dieser Einwände konnte gezeigt werden, dass (1) eine korrespondenzlogische Perspektive als Grundlage der Vorurteilskritik problematisch ist: Dass die USA tatsächlich mächtig sind, tut der Kritik des Antiamerikanismus keinen Abbruch, weil ihr Ausgangspunkt nicht ,die Realität' Amerikas ist, sondern die Konstruktionen und Funktionen des antiamerikanischen Sprechhandelns. Darüber hinaus wurde (2) im Vorgriff auf die Analysen der Kapitel 6 und 7 nahegelegt, dass Antiamerikanismus durchaus in einem engen Zusammenhang mit ethnozentrischen und rassistischen Identitätskonstruktionen steht. Die ethnische Heterogenität und ,Wurzellosigkeit‘ der USA kann als Kontrastfolie zu einem Ideal homogener ethnonationaler Identität gebraucht werden, wobei die Tatsache, dass ,die Amerikaner selbst nicht als ,Rasse“ angefeindet werden, gerade der Legitimation solcher Gebräuche dient. Schließlich wurde (3) eingewandt, dass Missbräuche des Antiamerikanismusbegriffs dessen generelle Ablehnung nicht rechtfertigen können: Vielmehr sind alle diese Einsprüche als Momente einer Antiamerikanismuskritik zu inkorporieren, die über die Mängel der bisherigen Antiamerikanismuskritik hinausweist. Somit scheint mir die öffentliche Skepsis gegenüber dieser Kritik insgesamt vor allem ein Indiz für die Ungenauigkeiten der bisherigen Begriffsverwendung zu sein, nicht für die Sinnlosigkeit oder Irrelevanz des mit diesem Begriff begonnenen theoretischen und politischen Unternehmens. ${ }^{21}$

Nimmt man die wissenschaftliche Begriffsverwendung genauer in den Blick, so zeigt sich auch hier ein Hadern mit dem Antiamerikanismus: Definitionsprobleme plagen die Antiamerikanismusforschung. Dass auch in diesen Diskursen hauptsächlich Probleme der Unterscheidung von antiamerikanischem Vorurteil und legitimer Amerika-Kritik diskutiert werden, zeigt, wie nah auch die wissenschaftliche Antiamerikanismusdebatte, trotz aller Bemühungen um definitorische Neutralität, an den öffentlichen Diskursen zum Thema orientiert bleibt: Die Skepsis gegen den Antiamerikanismusbegriff resoniert auch in der Forschung. Dabei ist, wie ich im weiteren Verlauf der Arbeit (vgl. Kap. 3 und 4) argumentieren werde, die Einbindung sozialwissenschaftlicher Forschung in eine politische Öffentlichkeit nicht als zu behebendes Problem, sondern als eine Notwendigkeit zu betrachten. Problematisch scheint mir dementsprechend vielmehr die bislang in der Forschungsliteratur favo-

21 Wie in der Einleitung zu dieser Arbeit bereits nahegelegt wurde, betrachte ich die Arbeit am Antiamerikanismusbegriff auch als Erbe eines emanzipatorisch-kritischen Projektes, dass seinen Ausgang in den frühen antifaschistischen und anti-antisemitischen Arbeiten u.a. Hannah Arendts (Arendt 1986), Max Horkheimers (Horkheimer 1988; Horkheimer 1989), Ludwig Marcuses (Marcuse 1953b; Marcuse 1953a) und Golo Manns (Mann 1954) nahm. 
risierte Lösungsperspektive zu sein, das Definitionsproblem des Antiamerikanismusbegriffes durch präzisere Nominaldefinitionen zu lösen.

Ich werde im folgenden Kapitel argumentieren, dass die Definitionsprobleme der Antiamerikanismusforschung als Probleme des Sprachgebrauches aufgefasst werden müssen. Heiko Beyer und Ulf Liebe formulieren in einer aktuellen Publikation zu Anti-Americanism in Europe eine ähnliche Problembestimmung. Demzufolge existiert in der Antiamerikanismusforschung bereits weitreichende Übereinstimmung hinsichtlich der Definition von Antiamerikanismus als Vorurteil: „The problem lies more in the application of the concept." (Beyer und Liebe 2014, S. 91) Im Gegensatz zum Lösungsvorschlag Beyers und Liebes allerdings, der auf eine präzisere operationale Definition des Konzeptes hinausläuft, werde ich argumentieren, dass sich dieser Gebrauchsaspekt des Antiamerikanismusbegriffes nicht durch eine Formel wird einhegen lassen. Ich möchte daher eine Methodologie gebrauchssensitiver Vorurteilsempirie vorschlagen, die auf sprechakttheoretischen Prämissen und dem Wittgensteinschen Konzept der Familienähnlichkeit aufbaut.

Die Probleme einer Antiamerikanismusdefinition lassen sich, wie ich im vorliegenden Kapitel gezeigt habe, zunächst anhand ihrer eigenen Kriterien kritisieren. Als Ansatzpunkt für diese Kritik habe ich Arbeiten gewählt, die Antiamerikanismus als Vorurteil begreifen, weil mir diese Ansätze, einer Idee Brendon O'Connors folgend, theoretisch am besten ausgearbeitet und am anschlussfähigsten für den breiteren Forschungsdiskurs zu Vorurteilen und Diskriminierung erscheinen. Ich habe vier zentrale Merkmale der einstellungspsychologischen Antiamerikanismusdefinition herausgearbeitet: propositionale Falschheit, Feindschaft bzw. Aversion, weltanschauliche Geschlossenheit und eine Konzentration auf individuelle psychische Dispositionen. Im Anschluss an Arbeiten aus der rhetorischen bzw. diskursiven Psychologie sowie aktuelle Strömungen einer funktionalistisch-rhetorisch orientierten Soziologie und Sozialpsychologie habe ich sodann argumentiert, dass alle vier Kriterien als Definiens des Antiamerikanismus unbefriedigend bleiben. Sie können jeweils weder als hinreichende, noch als notwendige Kriterien einer Antiamerikanismusdefinition gelten. Eine logische Verknüpfung aller vier Aspekte würde den Begriff hingegen zu stark eingrenzen, d.h. zu viele antiamerikanische Sprechweisen aus dem Gegenstandsbereich der Kritik ausschließen.

Als alternative Begriffsbildung habe ich vorgeschlagen, Antiamerikanismus als Sprechakte zu fassen, d.h. als Handlungen, in denen ,man etwas tut, indem man etwas sagt“ bzw. ,dadurch, daß man etwas sagt, etwas tut“ (Austin 2010, S. 112). Eine solche rhetorische oder performative Perspektive nimmt sozusagen eine Zwischenposition zwischen Antiamerikanismus als Tun und Antiamerikanismus als sprachlicher Äußerung ein: Sie fragt einerseits nach den semantischen Gehalten antiamerikanischer Sprechakte, andererseits aber auch danach, wofür und in welchem Handlungskontext sie mobilisiert werden. 
Diese Theorieperspektive ist in dreifacher Hinsicht ein Resultat der oben vorgebrachten Kritik am traditionellen Vorurteilsbegriff. Sie lässt die korrespondenzlogischen Probleme des Kriteriums propositionaler Wahrheit hinter sich, da sie ihr Augenmerk zu allererst darauf richtet, was Akteure mit ihrem Sprechen über Amerika bezwecken. Eine performative Perspektive ist darüber hinaus besonders geeignet, um der Flexibilität und den Inkonsistenzen antiamerikanischen Sprechens nachzuspüren. Die Annahmen einer geschlossenen Weltanschauung oder eines psychischen Syndroms entfallen, und die Forschungsperspektive öffnet sich gerade auch für inkonsistente und fragmentierte Ausdrucksweisen. Nicht zuletzt verweist ein performativer Antiamerikanismusbegriff auf die Kontextabhängigkeit antiamerikanischen Sprechhandelns. Die Feststellung, dass ein bestimmtes Amerikabild auf antiamerikanische Weise gebraucht wird, macht eine interpretative Verortung des jeweiligen Sprechaktes in seinem Äußerungskontext nötig. Was am antiamerikanischen Sprechen antiamerikanisch ist, liegt gewissermaßen nicht in diesem Sprechen allein, sondern in seiner Funktion in einem übergreifenden Praxiszusammenhang.

Den für eine Antiamerikanismuskritik relevanten rhetorischen Kontexten nähert sich diese Arbeit, wie in Kapitel 4 expliziert wird, mittels der Konzepte der sozialen Ungleichheit und Diskriminierung. Unabhängig von dieser konkreteren sozialtheoretischen Einbettung lässt sich der vorgeschlagene performative Antiamerikanismusbegriff als Analyseheuristik zunächst wie folgt bestimmen:

Antiamerikanismus bezeichnet die performative Bedeutung von Sprechakten, in denen bestimmte Amerikabilder in bestimmten Funktionskontexten rhetorisch gebraucht werden.

In Anlehnung an Wetherells und Potters Begriffe der ,,interpretative resource“ und der ,flexible application of that resource in practice“ (Wetherell 2012, S. 171) trifft diese Heuristik eine analytische Unterscheidung von Semantiken (bestimmte Amerikabilder) und Gebrauch (rhetorische Funktion im Äußerungskontext), und bestimmt Antiamerikanismus daraufhin als den performativen Effekt, der dem Zusammenspiel dieser beiden Aspekte entspringt. Tabelle 1 veranschaulicht diesen Zusammenhang anhand einiger Ergebnisse aus dem Interviewmaterial.

Anhand dieser Darstellung lässt sich noch einmal veranschaulichen, inwiefern der performative Antiamerikanismusbegriff ein Ergebnis der Kritik am traditionellen Vorurteilsbegriff ist: Zum einen wird hier klar, was damit gemeint ist, dass propositionale Wahrheit kein hinreichendes Kriterium der Vorurteilsbestimmung sein kann. Dass z.B. die amerikanische Gesellschaft vergleichsweise heterogen ist, lässt sich auf der Ebene faktischer Wahrheit kaum bezweifeln. Wenn ich aber im Kontext einer Äußerung dieses Motivs zeigen kann, dass es als negative Kontrastfolie zur Konturierung einer ethnisch homogenen Nationalidentität gebraucht wird, 
kann dies als antiamerikanischer Sprachgebrauch gelten: Ein Amerikastereotyp wird gebraucht, um ein ethno-nationalistisches Weltbild zu reproduzieren.

Tabelle 1: Typische Amerikabilder und Gebräuche in antiamerikanischen Sprechakten $^{22}$

\begin{tabular}{|c|c|}
\hline & iche/Rhetorische Funktionen \\
\hline $\begin{array}{ll}\text { - } & \text { Heterogenität der amerikanischen } \\
& \text { Gesellschaft } \\
\text { - } & \text { Rassismus in den USA } \\
\text { - } & \text { Mangelnde Solidarität in der } \\
& \text { amerikanischen Gesellschaft } \\
\text { - } & \text { Oberflächlichkeit der amerikanischen } \\
\text { Kultur } \\
\text { - } \ldots\end{array}$ & 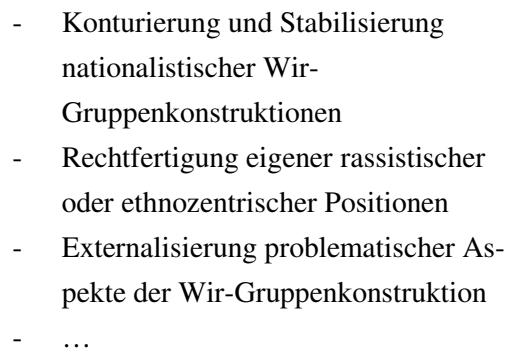 \\
\hline
\end{tabular}

Daran zeigt sich zweitens, dass ohne die funktionale Einbettung eines bestimmten Amerikabildes in einen bestimmten Kontext, ein Sprechakt nicht als antiamerikanisch zu fassen ist: Weder die aufgelisteten Amerikabilder, noch die nebenstehenden Gebräuche sind , an sich“ antiamerikanisch. Man kann offenkundig von amerikanischem Rassismus sprechen, ohne damit antiamerikanisch zu handeln, ebenso wie man seine nationalistische Wir-Gruppenkonstruktion konturieren kann, ohne dabei jemals auf Amerika Bezug nehmen zu müssen. Erst die jeweilige Kombination von Semantik und Gebrauch kennzeichnet die rhetorische Praxis antiamerikanischen Sprechens.

Die Explikation von Funktionskontexten veranschaulicht zudem noch einmal, dass eine negative Valenz, Abwertung oder Feindschaft, nicht als notwendiges Kriterium für Vorurteilsäußerungen gelten kann. So muss z.B. die Feststellung ethnischer Heterogenität in den USA nicht abwertend konnotiert sein. Sie kann aber dennoch der Konturierung und Stabilisierung einer homogenen ethno-nationalen Wir-Gruppenkonstruktion dienen, und auf diese Weise zum Gegenstand der Vorurteilskritik werden (vgl. Kap. 7.2.2).

Und schließlich wird anhand dieser Beispiele deutlich, dass die Bestimmung von antiamerikanischen Vorurteilen als Sprechakten ohne die Annahme einer weltanschaulichen Geschlossenheit oder Konsistenz, einer psychischen Disposition oder gar Pathologie („Obsession“, „Hysterie“) auskommt. Damit soll nicht bestritten werden, dass diese Phänomene existieren und wichtige Forschungsbereiche darstellen. Psychologisch zu beantworten wäre nicht zuletzt etwa die Frage, inwiefern sich

22 Die Stereotype und Gebräuche sind in keiner besonderen Reihenfolge angeordnet; nebeneinanderstehende Semantiken und Gebräuche bilden also keine Paare. 
individuelle Differenzen in der Neigung zu antiamerikanischen Handlungen erklären lassen. Fragen dieses Typs setzen aber eine Bestimmung der Handlungsweise, die psychologisch erklärt werden soll, bereits voraus.

In einem solchen performativen Antiamerikanismusverständnis hängt die Unterscheidung von vorurteiligem und vorurteilsfreiem Sprechen also maßgeblich davon ab, welche Funktionskontexte man in den Fokus seiner Analyse rückt. Bevor diese sozialtheoretische und normative Verortung der Vorurteilskritik in Kapitel 4 weiter ausgearbeitet wird, werden im nächsten Kapitel zunächst die sprechakt- bzw. praxistheoretischen Grundlagen eines performativen Antiamerikanismusbegriffes näher erläutert. 


\section{Vorurteilskritik und Sprachpraxis}

Im vorigen Kapitel wurde dargestellt, dass in der aktuellen Antiamerikanismusforschung noch immer um eine genaue begriffliche Bestimmung des Antiamerikanismus und dessen Abgrenzung zur Amerika-Kritik gerungen wird. Die von mir kritisierten Ansätze begegnen diesem Problem, indem sie Antiamerikanismus als Vorurteil definieren. Sie bauen dabei maßgeblich auf die Kriterien der propositionalen Unwahrheit, der Feindseligkeit sowie der weltanschaulichen Geschlossenheit antiamerikanischer Ausdrücke. Dagegen habe ich eingewandt, dass diese Kriterien des Vorurteilsbegriffes jeweils weder als notwendig noch als hinreichend gelten können.

Innerhalb des etablierten methodologischen Rahmens einer Nominaldefinition antiamerikanischer Vorurteile lassen sich also einige theoretische Ungenauigkeiten feststellen, die eine unzulässige Engführung des Konzeptes zur Folge haben. Meine Kritik richtet sich aber nicht nur im Einzelnen gegen die Definitionskriterien, die bei der Adaption eines traditionellen Vorurteilsbegriffes übernommen werden. Vielmehr werde ich zusätzlich das metatheoretische Argument entwickeln, dass die Konzentration auf eine kriterielle Bestimmung an sich eine problematische Schwerpunktsetzung darstellt: Nicht nur erfassen die gewählten Definitionskriterien (propositionale Falschheit, Aversion, Schematismus) den Gegenstand ungenau, sondern die Suche nach notwendigen und hinreichenden Kriterien selbst ist problematisch, solange sie nicht durch eine systematische Reflexion auf den Gebrauchsaspekt des Antiamerikanismusbegriffes ergänzt wird.

Die Definitionsprobleme der Antiamerikanismusforschung sind demnach nicht nur im Sinne eines genitivus obiectivus als Definitionsprobleme zu verstehen (d.h. als Probleme, die beim Formulieren einer Definition entstehen), sondern ebenso im Sinne eines genitivus subiektivus als Definitionsproblem (d.h. als ein Problem, das durch die Methode des Definierens entsteht). Da es sich, so wird aus sprachpragmatisch informierter Perspektive argumentiert, bei der Frage nach der Abgrenzung von Antiamerikanismus und Amerika-Kritik um ein Problem des Sprachgebrauchs, also der Verwendung von Ausdrücken, handelt und nicht um die Frage ihrer lexikalisch- 
semantischen Bedeutung, wird es durch keine noch so präzise definitorische Formel gelöst werden können.

In diesem Kapitel werden die grundlegenden sprechakttheoretischen Begriffe eingeführt, auf denen mein Vorurteilsbegriff aufbaut. Den Einstieg hierzu bildet das Konzept der Performativität, das in Abschnitt 3.1 im Anschluss an die Arbeiten John L. Austins vorgestellt wird. Es verdeutlicht die basale Überlegung einer pragmatischen Bedeutungstheorie, dass die Bedeutung eines Sprachausdrucks nicht unabhängig von dessen Einbettung in einen jeweiligen Handlungskontext erfasst werden kann. Die somit aufgeworfenen Fragen der Kontextabhängigkeit und Flexibilität sprachlicher Bedeutung werden anschließend in Abschnitt 3.2 genauer expliziert. Dies geschieht im Rückgriff auf Elemente von Ludwig Wittgensteins Praxistheorie der Bedeutung, nämlich die „Differentialität“, ,Sozialität“ und „Normativität" sprachlicher Bedeutung (Wellmer 2004, S. 27).

In Abschnitt 3.3 wird im Anschluss an die wissenschaftstheoretischen Arbeiten Peter Winchs der Aspekt der Normativität jeglicher Sprachpraxis auf den wissenschaftlichen Sprachgebrauch selbst angewendet: Demnach müssen die theoretischen Prämissen einer pragmatischen Bedeutungstheorie nicht nur auf antiamerikanisches Sprechen, sondern auch auf das Sprechen über Antiamerikanismus Anwendung finden. Für eine gebrauchssensible Antiamerikanismuskritik bedeutet dies, dass sie ihren eigenen Sprachgebrauch auf die Aspekte der Kontextabhängigkeit, Flexibilität und Normativität hin befragen muss. Das Medium dieser Selbstreflexion ist einerseits die soziologische Theoriebildung, durch die der Gebrauch des Antiamerikanismusbegriffes sozialtheoretisch und normativ genauer verortet wird (vgl. Kap. 4). Andererseits stellt sich mit dem Aspekt der Flexibilität wissenschaftlichen Sprechens auch die Frage nach der methodologischen Anlage der Begriffsbildung: Wie muss ein Antiamerikanismusbegriff beschaffen sein, der den Gebrauchsaspekt antiamerikanischer sowie antiamerikanismuskritischer Sprechakte, d.h. deren Flexibilität und Kontextabhängigkeit, systematisch miteinbezieht? Mit Wittgensteins Konzept der Familienähnlichkeit wird in Kapitel 3.4 ein Modell der Begriffsbildung vorgeschlagen, das diesen Anforderungen besser gerecht wird, als nominaldefinitorische Konzepte.

\subsection{Praxistheorie der Bedeutung Und VoruRteilskritik: PERformativitÄT}

In Abschnitt 2.3 des vorigen Kapitels wurde unter Verweis auf Überlegungen aus der rhetorischen bzw. diskursiven Psychologie argumentiert, dass der vorurteilige Gehalt antiamerikanischer Sprechweisen nicht auf der Ebene lexikalischgrammatischer Inhalte bzw. deren Repräsentationsfunktion zu suchen sei, sondern 
in der praktischen Bedeutung, die sie durch ihren rhetorischen Gebrauch erlangen. Doch was ist mit dieser praktischen Bedeutung gemeint? Im Folgenden wird unter Rückgriff auf sprachtheoretische Überlegungen John L. Austins ein theoretischer Rahmen für die Analyse des Praxisaspektes antiamerikanischer Bedeutung ausgearbeitet, in dessen Zentrum der Begriff der Performativität steht. Diese Theorieperspektive nimmt antiamerikanische Vorurteilsäußerungen als Sprechhandlungen in den Blick und zielt somit auf die Doppelstruktur menschlichen Handelns als Konstruktion von Sinn und über bloße Semantik hinausweisende Tätigkeit.

Der Begriff der Performativität setzt an der Schnittstelle dieser beiden Handlungsaspekte an, indem er die Wirkung bezeichnet, die durch das Zusammenspiel von bestimmten semantischen Motiven und deren funktionalen Gebräuchen entsteht: Wenn, wie im vorigen Kapitel argumentiert, weder auf der Ebene der Semantik, noch durch bestimmte Funktionen hinreichende und notwendige Kriterien für Antiamerikanismus benannt werden können, so lassen sich doch möglicherweise Kriterien für deren Zusammenspiel finden. Dabei ist unter Wirkung in diesem Zusammenhang nicht ein kausaler Effekt im Sinne eines analytisch vom Sprechakt zu trennenden Ereignisses zu verstehen, sondern die praktische Bedeutung des Sprechaktes selbst: Nur insofern eine sprachliche Äußerung in einen weiterreichenden praktischen Kontext eingebunden ist, kommt ihr überhaupt Bedeutung zu.

Das Problem einer angemessenen Bestimmung von Antiamerikanismus verbleibt somit auf sprach- und bedeutungstheoretischer Ebene; es bleibt die Frage nach der Bedeutung des Antiamerikanismusbegriffes bzw. spiegelbildlich nach der Bedeutung antiamerikanischer Sprechweisen. Unter Bedeutung wird hierbei aber nicht allein ein formalisierbares, lexikalisch-grammatisches Regelsystem verstanden, sondern die funktionale Einbindung bestimmter Bilder und Motive in bestimmte rhetorische Funktionskontexte. Entgegen Befürchtungen, ein solcher sprachtheoretischer Vorurteilsbegriff reduziere seinen Gegenstand zu einer „bloß falschen Denkweise“ und verharmlose damit dessen ,gewalttätige Praxis in Wort und Tat" (Claussen 2010), zielt er also gerade auf die wechselseitige Verflechtung von Sprechen und Handeln, auf die ,performativ-propositionale[n] Doppelstruktur unserer Sprache“ (Wellmer 2004, S. 47). D.h. sprachliche Bedeutung ist hier nicht ein irgendwie dem Handeln Äußerliches, Hinzutretendes, sondern wird gerade hinsichtlich der unhintergehbaren Reziprozität von Sprechen und Handeln beleuchtet.

Spätestens seit den einflussreichen Arbeiten zur Sprach- und Bedeutungstheorie, die Mitte der 50er Jahre mit Wittgensteins Philosophischen Untersuchungen und Austins How to do Things with Words erschienen, kann hinsichtlich der Bedeutung sprachlicher Ausdrücke nicht mehr von einer solchen praxistheoretischen Perspektive abgesehen werden. „Die Philosophen haben jetzt lange genug angenommen, das Geschäft von ,Feststellungen“ oder ,Aussagen“ sei einzig und allein, einen Sachverhalt zu ,beschreiben' oder ,eine Tatsache zu behaupten`, und zwar entweder zutreffend oder unzutreffend“, stellt Austin in seiner berühmten Vorlesung fest. Im 
Anschluss daran beginnt er, genauer nach den vielfältigen Möglichkeiten sprachlichen Tuns jenseits dieser beiden Optionen zu fragen (Austin 2010, S. 26). Er hat damit sein Augenmerk auf jene Bereiche der Sprache gerichtet, in denen sich Sprechen nicht auf das äußern konstativer Sätze beschränkt, sondern in denen neben „etwas feststellen“ (ebd., S. 35) noch ganz andere sprachliche Tätigkeiten vollzogen werden.

Ausdrücke wie ,Ich verspreche, morgen da zu sein', ,Ich erkläre Sie hiermit zu Mann und Frau', ,Ich taufe dieses Boot auf den Namen Orca' scheinen nicht lediglich außersprachliche Tatbestände zu beschreiben, sondern selbst Tatbestände hervorzubringen, ohne dabei aber den Bereich sprachlicher Handlungen zu verlassen. Für diesen Typus der Sprechhandlung, in dem sprachliche Bedeutung und praktisches Tun sich auf besondere Weise verbinden, prägte Austin den Begriff ,performative Äußerungen“:

„Jeder würde sagen, daß ich mit diesen Äußerungen etwas Bestimmtes tue (natürlich nur unter passenden Umständen); dabei ist klar, daß ich mit ihnen nicht beschreibe, was ich tue, oder feststelle, daß ich es tue; den Satz äußern heißt: es tun.“ (Ebd., S. 29)

Dies hat die Konsequenz, dass die Bedeutung solcher Sätze nicht in einem repräsentationalistischen Sinne aufgefasst, ihr Gehalt also nicht durch den Verweis auf einen außersprachlichen Gegenstand erklärt werden kann. Daraus folgt wiederum, dass jene Sätze nicht in einem korrespondenzlogischen Sinne auf ihre Wahrheit oder Falschheit befragt werden können: Der Ausdruck ,Dieser Satz ist unwahr!', wäre kein gelungener Anschluss an die Aussage ,Ich taufe dieses Boot auf den Namen Orca', weil derartige Sätze (zumindest in ihrer konventionellen Verwendung) gar nicht die Funktion haben, eine zutreffende Beschreibung der Welt zu geben, sondern vielmehr selbst einen sozialen Tatbestand erzeugen. Dieser Tatbestand kann dann in verschiedener Hinsicht beurteilt (,Eine glückliche Namensgebung!‘) oder die Angemessenheit der Bedingungen seiner Hervorbringung bzw. das Gelingen des Aktes in Zweifel gezogen werden (,Dazu sind Sie nicht befugt!'). ${ }^{1}$ Er ist aber als sprachlicher Ausdruck nicht in derselben Weise wahr oder falsch, wie etwa theoretische Sätze der Art ,Die Erde ist eine Scheibe‘ wahr oder falsch sind.

Diese Überlegungen schärfen den Blick für das zuvor kritisierte Problem einer übermäßigen Konzentration der Vorurteilsforschung auf propositionale Wahrheit: Wenn gilt, dass Vorurteile in erster Linie dadurch zu kennzeichnen sind, dass sie bestimmte rhetorische Funktionen erfüllen, also performativ an der (Re-)Produktion bestimmter sozialer Tatbestände mitwirken, können sie nicht allein als „faulty and inflexible generalizations“" und ,factually wrong“ (Martin 2010, S. 67 ff. sowie S.

1 Austin spricht davon, dass solche Sprechakte nicht wahr oder falsch sind, sondern ihr Vollzug ,,verunglücken“, „nichtig“ oder „unwirksam“ sein kann (ebd., S. 45 f.). 
104; vgl. auch Wetherell und Potter 1992, S. 67 ff.) kritisiert werden. Wenngleich sich vorurteilige Rede oftmals als bloßes konstatives Sprechen, als reiner Faktenbericht präsentieren mag, so muss die Vorurteilskritik primär mit deren performativer, rhetorischer Bedeutung befasst sein. Der traditionelle Ansatz der Vorurteilsforschung neigt dazu, den performativen Charakter vorurteiliger Rede zu verfehlen, weil er eine zu große Konzentration auf „konstative Äußerungen“ (Austin 2010, S. 27) legt, und damit gewissermaßen unkritisch das Selbstverständnis des vorurteiligen Sprechens übernimmt.

Nun könnte man gegenüber dieser Perspektive auf Vorurteile ${ }^{2}$ einwenden, dass Austin bei seiner Unterscheidung von performativen und konstativen Äußerungen eine spezielle Klasse von Sprechhandlungen im Sinn hatte, in denen das Sprechen bestimmter Sätze mit konventionellen oder rituellen Handlungen verknüpft ist (vgl. Austin 2010, S. 37), und dass die in der vorliegenden Arbeit analysierten Vorurteilsäußerungen wohl kaum in diese Klasse fallen (vgl. Herrmann und Kuch 2007, S. 10). Tatsächlich kann ein performativer Antiamerikanismusbegriff nicht speziell auf so etwas wie antiamerikanische Versprechen oder Taufen abzielen - sofern solche Sprechakte überhaupt möglich sind. Der performative Funktionskontext, sozusagen die konventionelle Einbettung des Sprechaktes, ist hier in einem weiteren Sinne zu verstehen. Dies stellt aber insofern keinen Widerspruch zu Austins Überlegungen dar, als er selbst im Verlauf seiner Vorlesung die Unterscheidung von performativen und konstativen Äußerungen problematisiert hat. Wie er feststellt, markieren die von ihm formulierten Kriterien für performative und konstative Akte keine scharfe Trennlinie:

„Wir haben [...] hinreichende Anzeichen dafür gefunden, daß Äußerungen beider Typen, nicht nur die performativen, verunglücken können; weiter, daß auch die performativen Äußerungen nicht nur glücken müssen, sondern der Forderung unterliegen, den Tatsachen zu entsprechen oder doch in einer je nach Fall verschiedenen Beziehung zu den Tatsachen zu stehen, ganz wie das für allem Anschein nach konstative Äußerungen typisch ist.“ (Ebd., S. 109, vgl. auch S. 153 ff.)

Austin erweitert bzw. spezifiziert nun seinen Blick auf den Praxisaspekt sprachlicher Bedeutung dahingehend, dass er jeglichem Sprechakt prinzipiell eine performative Komponente zuspricht. Er verwirft „die Differenz von konstatie-

2 Eine ähnliche Argumentation wurde im vorigen Kapitel anhand der Arbeiten von Michael Billig sowie Margaret Wetherell und Jonathan Potter aufgezeigt, die vorurteiliges Sprechen auf der Ebene rhetorischer Argumentationen verorten. Insbesondere Wetherell und Potters Unterscheidung von ,interpretative resources“ (Wetherell und Potter 1992, S. 70) und deren funktionaler Anwendung in sprachlichen Äußerungen spiegelt den sprechakttheoretischen Ansatz Austins wider. 
rend/performativ zugunsten einer Trias unterschiedlicher Handlungsdimensionen, die jeder Äußerung zukommen: ,Lokution“ meint die Hervorbringung des sprachlichen Ausdrucks selbst, die ,Illokution ' das, was man tut, indem man etwas sagt und die ,Perlokution" das, was bewirkt wird dadurch dass man etwas sagt." (Krämer 2010, S. 1920) Man könnte also, um ein Beispiel Austins aufzugreifen, an dem Ausdruck ,Das kannst du nicht tun!' die Hervorbringung einer lexikalischgrammatikalisch korrekten Zeichenkette (Lokution), den vollzogenen Akt des Protestierens gegen eine Tat (Illokution) und die dadurch erzielte Wirkung des Einhalt Gebietens (Perlokution) unterscheiden (vgl. Austin 2010, S. 119). Die konkrete Bedeutung des Ausdrucks geht nur aus dem Zusammenspiel aller drei Aspekte hervor, also immer auch aus dem illokutiven und perlokutiven Gehalt im jeweiligen Äußerungskontext.

Im Zuge der achten sowie der folgenden Vorlesungen von How to do Things with Words ist Austin dann maßgeblich damit beschäftigt, klare Unterscheidungsmerkmale von lokutiven, illokutiven und perlokutiven Rollen auszumachen und deren Erklärungskraft hinsichtlich des ursprünglich anvisierten Phänomens performativer Äußerungen auszuloten. Er stößt dabei aber wiederum auf diverse Mischformen und Unschärfen, so dass auch auf diese Weise das Projekt einer kategorischen Unterscheidung von performativen und konstativen Äußerungen in seiner anfänglichen Form nicht gerettet werden kann (vgl. ebd., S. 118 ff.). Da es für die Zwecke der vorliegenden Arbeit nicht entscheidend ist, vorurteilige Sprechakte eindeutig einer der Austinschen Ebenen sprachlicher Praxis zuzuordnen, werde ich Austins Bemühungen hier nicht weiter im Detail auslegen. ${ }^{3}$

3 Der hier vorgeschlagene performative Antiamerikanismusbegriff geht in Austins Terminologie nicht exakt auf, d.h. er zielt auf Akte, die ,nicht so recht in eine dieser grob definierten Klassen fallen, oder die recht unbestimmt zu mehreren zu gehören scheinen“ (ebd., S. 122). Austin selbst hat solche Grenzfälle in Betracht gezogen und den Akt „Etwas zu verstehen geben" als Beispiel hierfür angeführt (ebd., S. 121 f.). Dieser folge einerseits einer Konvention, wie illokutionäre Akte es tun, aber es sei dennoch nicht möglich, den in der Äußerung vollzogenen Akt zu explizieren, wie dies beim „konventionalen Benutzen“ (ebd., S. 121) anderer illokutionärer Akte der Fall ist: „,wir können nicht sagen: ,Ich gebe zu verstehen... ““ und damit den Akt zugleich vollziehen, so wie wir etwa sagen könnten ,Ich warne Sie...' (ebd., S. 122). Insofern scheint bei solchen Akten doch eher eine perlokutive Rolle zu dominieren: ,Etwas zu verstehen geben 'stellt „eher eine klug berechnete Wirkung als eine bloße Handlung“ dar. Ebenso verhält es sich mit den vorurteiligen Sprechakten in meiner Analyse: Wenn Herr B sagt, „Da sind 500 indianische, äh, Ureinwohner, Völker, ganze Stammesgruppen sind vernichtet worden“, und damit einer Normalisierung des Holocaust bzw. einer Rehabilitierung deutscher Nationalidentität zuarbeitet, so greift er einerseits auf konventionale Sprechweisen zurück, insofern diese Form der ,Vergangenheitsbewältigung' einem etablierten Muster entspricht. 
Entscheidend ist für meine Zwecke vielmehr, dass während Austins Analyse damit eingesetzt hatte, eine bestimmte, eigentümliche Klasse sprachlicher Ausdrücke zu beschreiben, die Perspektive nun auf die praktische Komponente jedweder sprachlicher Äußerungen ausgeweitet wurde. Das Performative, so könnte man vereinfachend sagen, bezeichnet nun keine spezifische Klasse von Sprechweisen mehr, sondern ist der Problemtitel für die Untersuchung eines Aspektes von Sprache überhaupt: „daß man etwas tut, indem man etwas sagt; ja daß man dadurch, daß man etwas sagt, etwas tut" (ebd., S. 112). ${ }^{4}$ Dies aber, wie gesagt, nicht in jenem banalen Sinn, dass jede sprachliche Äußerung auch eine Handlung darstellt, sondern auf den Punkt zielend, an dem sprachliche Bedeutung und Handeln als Momente einer Praxis zusammenzulaufen scheinen - der Punkt, an dem deutlich wird, dass Handeln nicht ohne Referenz auf sprachliche Bedeutung, und sprachliche Bedeutung nicht ohne Referenz auf ihren Handlungsaspekt begriffen werden kann.

Bis hierher haben wir also zwei zentrale Punkte des Performativitätsbegriffs festgehalten: Wenn wir Sprachausdrücke in performativer Perspektive betrachten, untersuchen wir ,nicht den Satz, sondern die Äußerung in einer Sprechsituation“ (ebd., S. 158), d.h. die Bedeutung eines jeweiligen Satzes umfasst in dieser Perspektive mehr bzw. anderes, als die wörtliche Bedeutung der Sprachzeichen selbst.

Andererseits ist dieser Sprechakt als antiamerikanisch sicherlich nicht in erster Linie anhand seiner illokutiven Rolle (im strengen Sinne einer konventionalen Handlung wie Taufen, Versprechen, Warnen, etc.) zu bestimmen. Auch hier scheint es eher um eine (wenn auch nicht unbedingt bewusste) „klug berechnete Wirkung“ zu gehen. An anderer Stelle habe ich diese Zwischenform von konventionalem Akt und perlokutionärer Wirkung als ,potentielle“ bzw. „mögliche Perlokutionen“ bezeichnet (Knappertsbusch 2013, S. 96).

4 Austin vollzieht damit auch eine reflexive Wendung seines Ansatzes: Wenn allem sprachlichen Ausdruck ein performativer Aspekt zukommt, so gilt dies auch für Austins eigenes Sprechen über Performativität. Damit rückt der Unterschied von performativen und konstativen Akten ebenso sehr als Merkmal der Unterscheidungspraxis Austins in den Blick, wie als Merkmal des Untersuchungsgegenstands. In entsprechender Weise beschreibt Austin in seiner elften Vorlesung diese Unterscheidungspraxis als begriffliche Abstraktionen, deren Grenzen nicht eindeutig am Gegenstand ausgemacht werden können, sondern ,zugunsten von größeren Familien verwandter und einander überlappender Sprechakte fallengelassen“ werden müssen (ebd., S. 168). Im Vorgriff auf die folgenden Abschnitte sei hier schon angemerkt, dass Austin damit im Prinzip dieselbe reflexive Bewegung vollzieht, die Wittgensteins Bedeutungstheorie sowie deren Adaption durch Peter Winch auszeichnen. Eine solche reflexive Wendung wird in der vorliegenden Arbeit auch für den Antiamerikanismusbegriff vorgeschlagen: eine spiegelbildliche Reflexion der Praxis antiamerikanischen Sprechens und der Praxis des Sprechens über Antiamerikanismus. 
Daraus folgt auch, dass man mit sprachlichen Äußerungen desselben lexikalischgrammatischen Gehalts sehr unterschiedliche Handlungen vollziehen kann. Fernerhin, so der zweite wichtige Punkt, ist dieser Handlungsaspekt der Bedeutung, d.h. deren praktische Einbettung in weitere Handlungszusammenhänge, nichts Zusätzliches, dem sprachlichen Sinn Äußerliches, sondern integraler Bestandteil jeden Sinns und unverzichtbares Moment jeder Sinndeutung: Wir können nicht interpretieren, was jemand sagt, ohne auch zu beurteilen, was er oder sie in einer bestimmten Situation tut, indem er oder sie dies sagt.

Im Hinblick auf Vorurteile bedeutet eine solche performative Theorieperspektive, dass man nach dem Bedeutungsgehalt von Vorurteilen fragt, diesen aber weder auf der Ebene lexikalisch-grammatischer Merkmale, noch auf der Ebene der Repräsentationsfunktion propositionaler Sätze sucht, sondern in der illokutionären bzw. perlokutionären „Rolle“ (Austin 2010, S. 118) oder „Kraft“ (Butler 2006, S. 11), die bestimmte Gruppenstereotype in bestimmten rhetorisch-weltanschaulichen Kontexten gewinnen (ohne, an sich“ schon vorurteilig zu sein). Die Vorurteilskritik muss auf die Rekonstruktion dieser ,praktischen Bedeutung' von Vorurteilsäußerungen abzielen, um ihren Gegenstand und dessen gesellschaftliche Relevanz theoretisch trennscharf $\mathrm{zu}$ bestimmen.

\subsection{Die Sozialität SPRACHLicher Bedeutung - ZUR FLEXIBILITÄT UND KONTEXTABHÄNGIGKEIT VORURTEILIGEN SPRECHENS}

Einen ähnlichen, wenn auch im Vergleich zu Austin ungleich radikaleren Begriff des Praxisaspekts der Sprache hat Ludwig Wittgenstein in seinem Spätwerk entfaltet. Es ist an dieser Stelle weder möglich noch nötig, die Tragweite von Wittgensteins Argumentation umfassend zu beschreiben; es sollen vielmehr einzelne Momente daraus für den hiesigen argumentativen Zusammenhang aufgegriffen werden. Im Mittelpunkt seiner Analyse „,des Wortfeldes ,Bedeuten“, ,Meinen“, ,Verstehen“" (Wellmer 2004, S. 46) steht der Gebrauch von Sprachzeichen, wie einem der bekanntesten Zitate aus den Philosophischen Untersuchungen zu entnehmen ist: „Man kann für eine große Klasse von Fällen der Benützung des Wortes ,Bedeutung ' - wenn auch nicht für alle Fälle seiner Benützung - dies Wort so erklären: Die Bedeutung eines Wortes ist sein Gebrauch in der Sprache." (Wittgenstein 2006, S. 262) Der besagte Gebrauch von Sprachzeichen wird im Folgenden als Anknüpfungsstelle von Performativitätsbegriff und Wittgensteins Sprachtheorie dienen.

Diesen Gebrauch kann man zunächst knapp als dasjenige bestimmen, was am Sinngehalt sprachlicher Äußerungen über deren lexikalisch-grammatische Bedeutung hinausweist. Denn Sprachzeichen weisen prinzipiell eine ,systematische[r] 
Ambiguität“ auf (Winch 1966, S. 39), die ihren Sinn erst in einem jeweiligen Äußerungskontext konkret werden lässt. Der Satz, Wir brauchen Wasser 'bspw. lässt sich erst verstehen, wenn die situativen Bedingungen seiner Äußerung bekannt sind. Ohne diesen Kontext bleibt unklar, ob dieser eine (unhöfliche) Bestellung, einen Hilferuf, einen Befehl oder eine bloße Feststellung artikuliert. Man kann also sagen, dass im hier entwickelten Performativitätsverständnis der Gebrauchsaspekt zunächst die Kontextabhängigkeit sprachlicher Bedeutung bezeichnet. ${ }^{5}$

Ich erinnere an dieser Stelle an die sehr ähnliche Feststellung Michael Billigs, dass ,the meaning of a piece of reasoned discourse, or of an expressed attitude, does not merely reside in the aggregation of dictionary definitions of the words used to express the position: it also resides in the argumentative context" (Billig 1991, S. 44). Wittgenstein formuliert eine radikalisierte Variante dieses Argumentes, wenn er schreibt: „Einen Satz verstehen, heißt, eine Sprache verstehen. Eine Sprache verstehen, heißt, eine Technik beherrschen.“ (Wittgenstein 2006, S. 344) Wie Albrecht Wellmer erläutert, ist „Technik“ hier „eher im Sinne des griechischen techneBegriffes“ zu verstehen und bezeichnet somit „das für das Verstehen einer Sprache konstitutive Moment des praktischen Wissens, des Könnens“ (Wellmer 2004, S. 28; vgl. auch Giddens 1984, S. 20 f.). Damit verweist er auf die Reichweite des Praxisaspektes in Wittgensteins Bedeutungstheorie: Die Kontextabhängigkeit der Bedeutung bleibt demzufolge nicht bei der „Differentialität“ (Wellmer 2004, S. 47) von Sprachzeichen stehen, im Sinne von Ferdinand de Saussures strukturalistischer Einsicht, dass Worte allein im Zusammenhang von Sätzen Bedeutung haben; sondern diese Differentialität wächst sich zu einer konstitutiven „Sozialität“ (ebd., S. 28) der Sprache aus: nur im Zusammenspiel der (auch nicht-sprachlichen) Alltagspraxen kann diese demnach überhaupt als bedeutsam gedacht werden, in ,einer sozialen Praxis, in der Sprechen und Handeln immer schon in einem unauflösbaren Zusammenhang miteinander stehen“ (ebd.). Wie durch konzentrische Kreise ist in Wittgensteins Modell die Bedeutung eines Wortes eingebettet in den Satz, die Bedeutung des Satzes in die jeweilige Einzelsprache, bis hin zum sprachlichen Handeln überhaupt, das nur als Moment einer ganzen Lebensform Sinn ergibt: ,eine Sprache vorstellen heißt, sich eine Lebensform vorstellen.“ (Wittgenstein 2006, S. 246)

Wittgenstein richtet sich damit gegen eine sprachtheoretische Tradition, die Wellmer als „semantischen und hermeneutischen Objektivismus“ bezeichnet (Wellmer 2004, S. 22). Die Kernannahme dieser Tradition „betrifft den Zei-

5 Wie wir sehen werden, ist ,Kontextabhängigkeit ‘ eine ungenaue Bezeichnung, da sie die Reziprozität von Sprachzeichen und Praxis unterbelichtet: In Wittgensteins Verständnis ist nicht erst das sprachliche Zeichen als irgendwie bedeutsames schon vorhanden und kann dann in einen Kontext gestellt und entsprechend in seiner Bedeutung modifiziert werden. Sprachzeichen und Sinnzusammenhang sind unterschiedene Aspekte einer Sprachpraxis. 
chencharakter der sprachlichen Zeichen selbst, nämlich die Annahme, daß sie für etwas stehen, etwas zum Ausdruck bringen, etwas bedeuten, was schon unabhängig von den Zeichen für ein Subjekt ,da' ist: Dinge oder Gedanken, Vorstellungen, Wünsche oder Absichten usw." (ebd.). Dagegen zeigt Wittgenstein, dass Sprachzeichen (1) nur im situativen Zusammenhang ihres praktischen Gebrauchs bedeutsam werden, und dass (2) deren Bedeutungsweisen nicht auf die einfache Formel einer „zweistelligen Namensrelation“ gebracht werden können, sondern Worte und Sätze je nach praktischem Kontext ganz unterschiedliche Bedeutungsweisen haben (vgl. ebd., S. 32). Diese beiden Einsichten finden im Rahmen eines performativen Antiamerikanismusbegriffes als Grundannahmen der Sozialität und der Flexibilität von Vorurteilsäußerungen Berücksichtigung: Die vorurteilige Bedeutung von Sprechakten zeigt sich in deren situativem Gebrauch, und in diesem Gebrauch können Vorurteile sehr unterschiedliche Funktionen erfüllen. Zum besseren Verständnis dieser Grundannahmen wird im Folgenden Wittgensteins bedeutungstheoretische Begründung für das beschriebene Wechselverhältnis von Sprache und sozialer Praxis erörtert.

Wittgenstein entwickelt ein Verständnis des Sprechhandelns, d.h. der Sprache als Handeln und des Handelns als sprachlich vermitteltem, in dem eine Immanenz der Sprache (es gibt keine Wirklichkeit außerhalb sprachlicher Deutungsprozesse) und eine Transzendenz der Sprache (die Bedeutungsfunktion der Sprache setzt etwas Sprachäußerliches voraus) in ein dialektisches Spannungsverhältnis gesetzt werden. Ein Hauptargument Wittgensteins für die Nicht-Abgeleitetheit, die Immanenz der Sprache basiert auf der oben bereits angesprochenen Differentialität von Sprachzeichen: „die Brücke, die ich in Worten, d.h. nur scheinbar zwischen Sprache und Welt, schlage, ist eine Brücke zwischen den Worten." (Wellmer 2004, S. 41) Dies ist unmittelbar plausibel für „,verbale Definitionen“ (ebd., S. 33 f.), also die Erläuterung einer Zeichenbedeutung durch eine sprachliche Erklärung: Schlägt man ein Wort in einem Lexikon nach, so finden sich zu dessen Erklärung weitere Worte bzw. Sätze, die selbst wiederum erklärungsbedürftig sind. Am Beispiel ostensiver Definitionen zeigt Wittgenstein aber, dass diese Problematik auch für nicht-verbale, ja prinzipiell für alle Bedeutungserklärungen gilt. So erscheinen ostensive Definitionen, also Erklärungen eines Zeichens mittels gestischen Zeigens auf das Bezeichnete, auf den ersten Blick als unhintergehbar eindeutig, als müsse mit der gestischen Verknüpfung von bezeichnetem Ding und Sprachausdruck die Bedeutungsrelation unmittelbar verständlich sein. Bei genauerem Hinsehen stellt sich die ostensive Definition aber als petitio principii heraus, da die Zeigegeste selbst ein zu deutendes Zeichen darstellt. Dass sie als Erklärung sprachlicher Bedeutung funktionieren kann, setzt schon eine funktionierende Sprache voraus. Um bspw. das Wort „Grün“ zu definieren, indem man auf eine grünen Apfel zeigt, muss schon gewiss sein, dass eine „Farbe“ definiert werden soll, da sonst unklar bliebe, ob mit „Grün“ die Form, das Gewicht, der Geschmack oder eben die Farbe des Gegenstandes bezeichnet 
wird (vgl. Wellmer 2004, S. 34 f.). Wenn die deutende Erklärung eines jeden Sprachzeichens wiederum nur auf andere Sprachzeichen verweist, so kann sprachliche Bedeutung nicht einfach durch Verweis auf ein der Sprache Äußerliches begründet werden - es ist überhaupt kein solcher Verweis denkbar, der nicht durch Sprache vermittelt wäre: „Jede Deutung hängt, mitsamt dem Gedeuteten, in der Luft; sie kann ihm nicht als Stütze dienen." (Wittgenstein 2006, S. 344) - soweit das Argument für die Immanenz der Sprache.

Andererseits aber, und hierin unterscheidet sich Wittgensteins Theorie von radikal sprachskeptischen Positionen, kann dies nicht das Ganze der Sprache sein, da sonst Bedeutung als intersubjektiv verstehbare überhaupt unmöglich bzw. lediglich eine subjektive Einbildung wäre. Sprache wäre dann nicht mehr sinnvoll als Regelfolgen aufzufassen. Wenn jede Regel, die den Gebrauch eines Zeichens kontrollieren soll, selbst wieder gedeutet werden muss, wäre durch eine entsprechende Deutung ,jede Handlungsweise mit der Regel in Übereinstimmung zu bringen“ und Regelfolgen würde zum bloßen Selbstwiderspruch: „Ist jede mit der Regel in Übereinstimmung zu bringen, dann auch zum Widerspruch. Daher gäbe es hier weder Übereinstimmung noch Widerspruch.“ (Ebd., S. 345) Dass es aber eine Möglichkeit der Unterscheidung von richtigen und falschen Anwendungen der Regel gibt, ist für einen sinnvollen Begriff von Sprache als Regelfolgen unverzichtbar: Ohne die Möglichkeit des Fehlermachens, kann vom Befolgen einer Regel nicht gesprochen werden. Es muss also, damit sprachliche Bedeutung möglich ist, die Deutung durch mehr als bloße Sprachregeln bestimmt sein, oder genauer: Die Regeln der Sprache müssen mehr als ,bloße Sprache" sein und ihre Befolgung muss in mehr als bloßer Deutung bestehen: „Die Deutungen allein bestimmen die Bedeutung nicht.“ (Ebd., S. 344) - soweit das Argument für eine Wirklichkeit, die Sprache transzendiert.

Es ist genau jenes Spannungsverhältnis von Sprachimmanenz und -transzendenz, das Wittgensteins Begriff des Gebrauchs bzw. der Praxis erfasst: Es besteht ein Unterschied zwischen „Deuten“ (d.h. einen Regelausdruck durch einen anderen ersetzen) und „Regelfolgen“, und da ersteres die Bedeutungsfunktion von Sprache nicht erklären kann, ,ist ,der Regel folgen“ eine Praxis“ (ebd., S. 345). Praxis meint dann ein Übergreifendes von Sprachlichem und Nicht-Sprachlichem, einen Handlungsvollzug, der immer schon passiert sein muss, bevor Sprache in expliziten Regeln rekonstruiert werden kann, der aber zugleich nur als sprachlicher überhaupt rekonstruiert werden kann. Wittgenstein konstatiert also einerseits, „daß der in Sprache ausgedrückte Sinn nur als sprachlicher Sinn existiert und daß er sein Sein nur in einem Prozeß der Kommunikation und Interpretation hat." (Wellmer 2004, S. 22) Sprache ist also notwendig Interpretation bzw. Deutung. Diese Deutung muss aber, um verstehbar zu sein, als ein Regelfolgen gedacht werden, und solches Regelfolgen wird nur dadurch möglich, „daß es eine Auffassung einer Regel gibt, die nicht eine Deutung ist; sondern sich, von Fall zu Fall der Anwendung, in dem äu- 
Bert was wir ,der Regel folgen“, und was wir ,ihr entgegenhandeln“ nennen“ (ebd., S. 345).

Sprache ist also zugleich immanente Regeldeutung und über bloße Sprache hinausweisendes Regelfolgen. Wittgenstein erweitert somit den Widerspruch, in den die radikale Immanenz sprachlicher Regeln geführt hatte, zur Paradoxie: Bedeutsamer Sprachgebrauch als Regelfolgen ist gerade dann möglich, wenn den Regeln eine „konstitutive Offenheit“ (Wellmer 2004, S. 71) zukommt, d.h. sie die Bedeutung nicht vollkommen bestimmen. Damit ist die Grenze der Deutung, die Praxis des (blinden) Regelfolgens, zugleich ihre Ermöglichungsbedingung.

Für den Zusammenhang einer performativen Antiamerikanismuskritik ist an diesen Überlegungen zunächst relevant, dass sprachliche Bedeutung notwendig als Moment einer Praxis verstanden werden muss, die über bloß sprachliches Handeln hinausweist. Im Anschluss an den im vorigen Abschnitt entwickelten Performativitätsbegriff kann man auch sagen: Der performative Charakter der Sprache macht den weiteren lebensweltlichen Zusammenhang von sprachlichen Äußerungen zu einem integralen Bestandteil ihrer, praktischen Bedeutung'. Sprachtheorie ist in diesem Sinne Gesellschaftstheorie und vice versa. Damit soll nicht behauptet werden, dass mit der Analyse sprachlicher Äußerungen - d.h. in der vorliegenden Arbeit: mit der Analyse von Interviewpassagen - auch schon eine Erkenntnis über deren alltagspraktische Bedeutung gesichert wäre. Die Analyse einzelner Ausdrücke im Kontext des Interviewmaterials lässt keine direkten, sondern nur hypothetische Schlussfolgerungen auf die performative „Kraft“ (Butler 2006, S. 11) des Gedeuteten zu. Aus der performativen Perspektive wird aber ersichtlich, dass eine vorurteilskritische Analyse des Interviewmaterials die darin zu findenden Äußerungen als Ausdruck lebensweltlicher Praxen lesen muss, um sie überhaupt als Vorurteile verstehen zu können. Die sozial- und gesellschaftstheoretische Rekonstruktion dieser Praxen ist wesentlicher Bestandteil der Bildung eines nicht-reduktionistischen Vorurteilsbegriffes. ${ }^{6}$ In Kapitel 4 wird der Versuch unternommen, mittels Ansätzen der Ungleichheits- und Diskriminierungsforschung sowie soziologischen Konzepten von Nationalismus und Ethnozentrismus einen solchen Theoriehorizont zu umreißen.

Für die Beschreibung antiamerikanischer Sprechakte in ihren Äußerungskontexten ist weiterhin der Aspekt der Flexibilität sprachlicher Bedeutung entscheidend: Die Flexibilität des Antiamerikanismus besteht nicht zuletzt darin, dass bestimmte Amerikamotive in verschiedenen Kontexten verschiedene Funktionen erfüllen kön-

6 Eine ähnliche Analyseperspektive, wenngleich von einem sehr verschiedenen theoretischen Standpunkt aus, liefert Gesine Schwans ideengeschichtliche Untersuchung von Antiamerikanismus und Antikommunismus in Deutschland: „Ziel der Untersuchung ist die Ermittlung der normativen und dispositiven Basis, von der her die jeweilige Gegnerschaft sich begründet.“ (Schwan 1999, S. 19) 
nen, jenseits eines kohärenten weltanschaulichen Zusammenhangs „,raised to the status of an ideology“ (Gulddal 2011, S. 4). Man kann also in der Analyse von Vorurteilen nicht einfach von kohärenten Netzwerken der „Feindschaft“ oder ,,systematic opposition“" ausgehen, wenngleich es solche auch geben mag. Der Funktionskontext antiamerikanischer Sprechakte muss mit größerer empirischer Offenheit gerade auch hinsichtlich seiner Flexibilität und Fragmentierung rekonstruiert werden.

Im Folgenden Abschnitt werden nun die genannten Topoi einer Praxistheorie der Bedeutung reflexiv auf das wissenschaftliche Sprechen über Antiamerikanismus angewendet: Es lässt sich zeigen, dass die Attribute performativen Sprechens, Flexibilität und Sozialität, auch in den Sprechakten der Antiamerikanismuskritik selbst zu finden sind. Dies hat Konsequenzen für das methodologische Selbstverständnis der soziologischen Begriffsbildung sowie für dessen normative Verortung.

\subsection{Die Normativität SPRachlicher Bedeutung UND DIE TEILNEHMERINNENPERSPEKTIVE SOZIOLOGISCHER THEORIE}

Der Wissenschaftstheoretiker und Methodologe Peter Winch hat in seiner 1958 erschienenen Abhandlung über Die Idee der Sozialwissenschaft und ihr Verhältnis zur Philosophie Wittgensteins praxistheoretische Überlegungen zu Sprache und Bedeutung auf die Methodologie der Sozialwissenschaften übertragen. Winch erörtert hierbei die bisher präsentierten Argumente gewissermaßen aus umgekehrter Blickrichtung: Während Wittgenstein und Austin zeigen, dass Sprache nur verstehbar ist, wenn sie als Sprechhandeln aufgefasst wird, geht Winch vom Begriff der Handlung aus, um deren sprachliche Vermitteltheit zu erläutern, d.h. inwiefern jedes Handeln auch als Sprechhandeln aufgefasst werden muss.

Winch knüpft dazu an Max Webers Handlungsbegriff und dessen Bezug auf „subjektiv gemeinten Sinn“ an und verknüpft diesen mit der Wittgenstein“schen Analyse der Sprache als sozialer und differentialer Praxis. Die mit einer Handlung, sei es durch deren Interpreten oder den Akteur selbst, verknüpfte Idee, d.h. die Reflexion des Handelns im Medium der Sprache, ist demnach integraler Teil jeder soziologischen Handlungserklärung. Sofern der sprachlich reflektierte Sinngehalt des Handelns im Sinne der praxistheoretischen Überlegungen Wittgensteins aufgefasst wird, bedeutet dies keinen wissenssoziologisch-hermeneutischen Reduktionismus: Handeln und Sprechen sind demnach keine geschiedenen Gegenstände, sondern verschiedene Sichtweisen auf eine übergreifende Praxis.

Winch generalisiert diese These im Laufe seiner Untersuchung dahingehend, „daß die sozialen Beziehungen zwischen Menschen und den in den Handlungen der Menschen verkörperten Ideen in Wahrheit dieselbe Sache seien, nur unter verschie- 
denen Gesichtspunkten betrachtet [...]“ (Winch 1966, S. 154). Die Ideen, die in den Handlungen Ausdruck finden, spiegeln also zugleich die gesellschaftlichen Verhältnisse zwischen den Akteuren wider. Nicht nur ist jedes Handeln allein unter Bezug auf die darin ausgedrückte sprachlich-sinnhafte Komponente zu verstehen, sondern qua der Performativität sprachlichen Bedeutens ist jede Handlung zugleich in einen weiteren Kontext sinnhaft eingebunden. Winch versucht also die Methodologie der sozialwissenschaftlichen Handlungserklärung ${ }^{7}$ durch die Erkenntnisse einer Praxistheorie der Bedeutung zu bereichern indem er zeigt, dass beide analytischen Perspektiven, Sprachverstehen und Handlungsverstehen, ineinander übergehen: „Die Bedeutung eines Wortes darlegen heißt beschreiben, wie es gebraucht wird, und das wiederum heißt, die sozialen Wechselbeziehungen beschreiben, in die es eingeht.“ (Ebd., S. 157) Umgekehrt ließe sich dann formulieren: Soziale Wechselwirkungen zu beschreiben, heißt die Bedeutung der Konzepte darzulegen, die in ihnen zur Anwendung kommen.

Wie im Folgenden gezeigt wird, ist diese performative Perspektive auf die Bedeutung sozialen Handelns in doppelter Hinsicht zu berücksichtigen: Sie betrifft sowohl das sozialwissenschaftlich beobachtete, als auch das sozialwissenschaftlich beobachtende Handeln. Auch das Sprechhandeln soziologischer Begriffsbildung ist durch Sozialität und Flexibilität gekennzeichnet und reicht qua dieser Eigenschaften in den lebensweltlichen Zusammenhang der beobachteten Praxen hinein. Diese Teilnehmerinnenperspektive der Soziologie ist einerseits als Ermöglichungsbedingung sozialwissenschaftlichen Sinnverstehens zu betrachten; andererseits erwachsen daraus aber auch Konsequenzen für deren normative Verortung.

Während er Wittgensteins sprachpragmatische Thesen in den oben zitierten Passagen auf das sozialwissenschaftlich beobachtete Handeln angewandt hatte, bezieht Winch sie im weiteren Verlauf seiner Argumentation auf das sozialwissenschaftliche Handeln selbst. Wissenschaftliche wie außerwissenschaftliche Begriffe sind „mit Theorie imprägniert“ (Winch 1966, S. 158), wie Winch im Anschluss an eine Formulierung Gilbert Ryles feststellt. Das bedeutet, dass „,,die Idee, die wir uns von einem Objekt bilden', nicht nur aus Elementen besteht, die der Beobachtung dieses Objekts in völliger Isolierung entnommen sind, sondern die Idee eines Zusammenhangs zwischen ihm und anderen Objekten einschließt" (Winch 1966, S. 158). Damit ist zunächst wiederum die Differentialität und Sozialität auch wissenschaftlicher Ausdrücke angesprochen, der zufolge ein jeweiliges Sprechhandeln erst in seinem Gebrauchskontext praktische Bedeutung gewinnt. Dies macht die Bedeutung wissenschaftlicher Begriffe ebenso flexibel und kontextabhängig, wie es im vorigen Abschnitt für sprachliche Ausdrücke generell festgehalten wurde. Der je-

7 Mit ,Erklärung“ ist hier wiederum ein ,erklärendes Verstehen“ gemeint, in dem kausales Erklären und sinnhaftes Verstehen wechselseitig aufeinander bezogen sind (Weber 1988, S. 547, 550). 
weilige Ausdruckskontext ist aber nicht nur durch die Regeln strukturiert, nach denen sich die beobachteten AkteurInnen verhalten, sondern auch durch diejenigen der BeobachterInnen:

„Infolgedessen bedeutet die Untersuchung des jeweiligen Typs von Regelhaftigkeit, der mittels einer bestimmten Forschungsweise studiert wird, eine Prüfung der Wesensart der Regel, nach welcher innerhalb der betreffenden Forschung Identitätsurteile gefällt werden. “ (Ebd., S. 108)

Wissenschaftliche Theoriebildung muss also, indem sie Aussagen über die Struktur und Regelhaftigkeit ihrer Gegenstände trifft, auch Aussagen über die methodologische Struktur und Regelhaftigkeit ihrer eigenen Begriffe treffen. Die Identitätsurteile wissenschaftlicher Beobachtung hängen nicht nur von der Regelhaftigkeit ihres Gegenstands ab, sondern auch von der „Partizipation“ des Beobachters ,,an einer etablierten Form der Tätigkeit in Gesellschaft seiner wissenschaftlichen Kollegen“ (ebd., S. 111). Im Fall sozialwissenschaftlicher Beobachtung gewinnt diese Struktur eine zusätzliche Komplexität, da hier nicht nur die Regeln der Beobachtungsbegriffe sozial und flexibel sind, sondern auch die des beobachteten Gegenstandsbereichs.

„Die Begriffe und Kriterien, denen zufolge der Soziologe das Urteil fällt, daß in zwei verschiedenen Situationen das gleiche sich ereignet hat oder die gleiche Handlung vollzogen worden ist, müssen verstanden werden unter Bezugnahme auf die Regeln, welche die soziologische Forschung beherrschen. Aber hier stoßen wir auf eine Schwierigkeit: während wir es im Falle des Naturwissenschaftlers nur mit einer Gruppe von Regeln zu tun haben, nämlich denen, die sein Forschen selbst beherrschen, ist im Falle des Soziologen das, was er erforscht, ebenso wie sein Forschen selbst ein menschliches Verhalten und daher seinerseits von Regeln geleitet. Und es sind gerade diese Regeln, mehr als die der Forschung selbst, die im einzelnen bestimmen, was im Hinblick auf jenes Verhalten als ,das gleiche tun“ gelten soll.“ (Ebd., S. 112; Herv. i. O.)

Die Soziologie kann also gegenüber ihrem Gegenstand keinen äußerlichen Standpunkt einnehmen, weil sich die generativen Regeln ihres Gegenstandsbereiches mit denen ihres eigenen Tuns überschneiden. Sie muss sich die Selbstwahrnehmungen, Begründungen, Rechtfertigungen der beobachteten Akteure ,zu eigen " machen, um ein „erklärendes Verstehen“ des Gegenstandes zu ermöglichen. Winch bemüht zur Veranschaulichung dieses Zusammenhangs die biblische Parabel vom Pharisäer und Zöllner, die im Jerusalemer Tempel beten, und schließt hieran die Frage an:

„Tat der Pharisäer, der sagte ,Ich danke dir, Gott, daß ich nicht bin wie die anderen Leute', etwas von der gleichen Art wie der Zöllner, der betete ,Gott, sei mir Sünder gnädig'? Um die- 
se Frage zu beantworten, müßte man zunächst die Implikationen der Idee des Gebetes erwägen; und das ist eine religiöse Frage.“ (Ebd., S. 113)

Die beiden Figuren der Parabel werden hier natürlich als Beispiele für beobachtete Akteure gebraucht, während die Frage nach der Gleichartigkeit von deren Verhalten als Beispiel für eine soziologische Fragestellung bzw. Begriffsbildung fungiert. Was Winch damit veranschaulichen will, ist, dass die Soziologie ihre Konzepte nicht durch reine Beobachtung ,experimentelle[r] Tatsachen“ (ebd., S. 140) gewinnt, sondern vielmehr an die in ihrem Untersuchungsfeld selbst gebrauchten Begriffe reflektierend anknüpft. Im übertragenen Sinne kann man sagen: Die Frage, ob zwei Äußerungen als antiamerikanische klassifiziert werden können, ist eine normative Frage - sie kann nicht außerhalb der normativ-politischen Zusammenhänge beantwortet werden, in denen antiamerikanische Äußerungen wirksam werden.

Die notwendige Partizipation der Soziologie an ihrem Gegenstand hat also auch Implikationen für den normativen Charakter des soziologischen Handelns selbst: Wenn soziologische Theoriebildung immer schon Teilnehmerin einer jeweils untersuchten Lebensform sein muss, um überhaupt Handeln verstehen zu können, dann kann ihre Perspektive auf Gesellschaft keine ,wertneutrale' sein, sondern bestenfalls eine reflektiert normative. Das heißt in erster Linie, dass sie ihre Problemstellungen und Fragen aus außerwissenschaftlichen gesellschaftspolitischen Diskursen aufgreift und diese mit formt und gestaltet.

Winch fasst diese Verquickung von Erkenntnis und Praxis so, „daß eine neue Redeweise, die wichtig genug ist, um als eine neue Idee zu gelten, ein neues Arrangement sozialer Beziehungen impliziert.“(Winch 1966, S. 156) Das kann sicherlich nicht bedeuten, dass ein gelingender sozialwissenschaftlicher Verstehensprozess notwendig zu gesellschaftlichem Wandel führt - jedenfalls nicht in einem größeren Umfang. Es bedeutet aber, dass jede sozialwissenschaftliche Deutungspraxis zumindest implizit ein Verständnis gesellschaftlicher Probleme oder Missstände sowie ein Modell möglichen gesellschaftlichen Wandels vorrausetzt (vgl. Dixon et al. 2012, S. 417 ff.): „Zur Verständigung über die Sprache gehört nicht nur eine Übereinstimmung in den Definitionen, sondern (so seltsam dies klingen mag) eine Übereinstimmung in den Urteilen.“ (Wittgenstein 2006, S. 356) ${ }^{8}$ Diese „Übereinstim-

8 Wie Wittgenstein an anderer Stelle schreibt, lässt sich das praktische Fundament unserer Sprache und damit der Sinn unserer Handlungen letztendlich nicht ursächlich begründen, sondern lediglich rechtfertigen: ,'Wie kann ich einer Regel folgen?' - wenn das nicht eine Frage nach den Ursachen ist, so ist es eine nach der Rechtfertigung dafür, daß ich so nach ihr handle. Habe ich die Begründungen erschöpft, so bin ich nun auf dem harten Felsen angelangt, und mein Spaten biegt sich zurück. Ich bin dann geneigt zu sagen: ,So handle ich eben. ““ (Wittgenstein 2006, S. 350) Auf diesen Aspekt von Normativität als Rechtfertigungszusammenhang werde ich in Kapitel 4 zurückkommen. 
mung in den Urteilen“" hat als Moment einer gesellschaftlichen Lebensform auch ethischen Charakter.

Ob bewusst oder unbewusst, Sprechhandeln hat immer auch einen generativen Aspekt. Durch Sprache reproduzieren Akteure die soziale Welt, wenn auch nicht vollständig nach ihren eigenen Vorstellungen. Soziologie beschreibt dementsprechend, wie Menschen die Welt unter Kontingenzbedingungen erzeugen. Qua ihrer Teilnahme am gesellschaftlichen Leben bekommen die Sozialwissenschaften dabei aber selbst einen normativen Aspekt: Die Beschreibung performativer Praxen ist selbst eine performative Praxis, inklusive aller Merkmale, die damit einhergehen: Sozialität, Flexibilität, Normativität. Inwiefern sich die reflektiert normative Position wissenschaftlichen Sprechens dennoch gegen eine bloß moralische Standpunktkritik abgrenzen lässt, wird in Kapitel 4 unter der Überschrift einer ,,normative[n] Theorie ohne Normativität“ (Bonacker 2000, S. 15) näher erläutert.

\section{4 „NO FORMULA WILL HELP TO SOLVE THIS PROBLEM“ - FAMILIENÄHNLICHKEIT ALS MODELL DER BEGRIFFSBILDUNG}

Die vorigen Abschnitte haben für eine Theorieperspektive argumentiert, in der der Gebrauchsaspekt bzw. die Performanz von Begriffen in den Fokus rückt. Die Frage nach dem performativen Gehalt des Antiamerikanismus wurde gefasst als die Frage danach, in welchem rhetorischen bzw. Handlungspraktischen Zusammenhang antiamerikanisches Sprechen funktional wird. Darüber hinaus wurde gezeigt, dass eine performative Perspektive auf antiamerikanische Vorurteile nicht nur die Beschreibung des beobachteten Sprechhandelns betrifft, sondern auch die methodologische Selbstbeobachtung ebenjener Beschreibung. Wie in Abschnitt 3.2 bereits angerissen, folgt aus dieser Theorieperspektive eine tiefgreifende Skepsis gegenüber Nominaldefinitionen als alleinigem Mittel zur Bestimmung von Antiamerikanismus. Nimmt man die Wittgenstein'schen Analysen des Praxisaspekts sprachlicher Bedeutung, deren Sozialität und Flexibilität, ernst, so muss eine Nominaldefinition von Antiamerikanismus unbefriedigend bleiben, weil eine solche Definition selbst wiederum ein Zeichen ist, das erst im Gebrauch bedeutsam wird: Eine Definition ist nur so informativ wie ihre Anwendung. Diese Anwendung der Definition wird aber von den bestehenden Ansätzen entweder nicht methodisch reflektiert, oder es wird versucht die Anwendung selbst formal zu regeln, sei es durch die Variation von Definitionskriterien oder eine standardisierte empirische Operationalisierung. Gemäß der in Abschnitt 3.2 explizierten Bedeutungstheorie führt der Versuch, die Anwendung der Definition selbst in einer weiteren Definition festzuschreiben, in einen endlosen Regelregress. Denn hinter jeder neuen Regeldefinition steht nur wiederum 
die Frage nach deren Anwendung. Winch hat diese Problematik - im Zuge einer Beschreibung der Unzulänglichkeiten ostensiver Definitionen am Beispiel des Wortes „Everest“ - treffend zusammengefasst:

„Ich mag noch so nachdrücklich auf diesen Berg hier vor mir hindeuten und noch so nachdrücklich die Wörter , dieser Berg' aussprechen, meine Entscheidung muß doch immer noch auch in Zukunft angewendet werden, und die Implikationen einer solchen Anwendung sind gerade das, was hier in Frage steht. Das Problem wird darum nicht mit Hilfe einer Formel gelöst werden können; wir werden immer zu einem Punkt gelangen, an dem wir über die Anwendung der Formel Rechenschaft abgeben müssen.“ (Winch 1966, S. 41 f.)

Der Gebrauch des Sprachzeichens „Everest“ (im übertragenen Sinne: des Antiamerikanismusbegriffes), und damit seine praktische Bedeutung, kann demnach nicht durch eine weitere Formel festgeschrieben werden: „No formula will help to solve this Problem“, wie es prägnant im englischen Original heißt (Winch 2008, S. 27). Mein Alternativvorschlag zur begrifflichen Bestimmung von Antiamerikanismus wird dementsprechend nicht in der Ergänzung bestehender Definitionen durch andere oder zusätzliche Kriterien bestehen, sondern in einer Begriffsbildung, die die Praxis der Begriffsanwendung mit reflektiert. ${ }^{9}$ In Kapitel 2 wurden existierende Antiamerikanismusdefinitionen auf der Grundlage ihrer eigenen begrifflichen Logik hinreichender und notwendiger Kriterien kritisiert. Es wurde argumentiert, dass diese Definitionen keine notwendigen Merkmale oder Merkmalskombinationen antiamerikanischen Sprechens aufzeigen können, die zugleich auch theoretisch hinreichend sind. Vor dem Hintergrund der in den vorigen Abschnitten getroffenen Bestimmungen zum performativen Charakter antiamerikanischer Rede kann die Kritik an jenen Antiamerikanismusdefinitionen nun aber auf einer anderen Ebene ansetzen: Eine Lösung des Definitionsproblems der Antiamerikanismusforschung, insbesondere hinsichtlich der Frage nach der Unterscheidung von Amerika-Kritik und Vorurteil, wird in der vorliegenden Arbeit gerade nicht über eine ,more precise definition of the term“ (O'Connor 2007b, S. 6) angestrebt, sondern durch eine Reflexion auf die flexible und soziale Anwendung des Begriffes.

Die vorausgegangenen Abschnitte 3.1 bis 3.3 waren hauptsächlich damit beschäftigt, aus performativer Perspektive die Flexibilität und Kontextabhängigkeit antiamerikanischer Vorurteile sowie der Instrumente zu deren Beobachtung theoretisch zu erschließen. Um in einen brauchbaren Antiamerikanismusbegriff zu münden, muss sich zu dieser Dekonstruktion definitiver Konzepte aber auch ein Moment der Schließung bzw. begrifflichen Abstraktion finden: Auch ein performativer

9 Im Vorgriff auf den in Kapitel 4.5 entwickelten Kritikbegriff könnte man ergänzen: Erst wenn die Kritik einer Definition dieser nicht bloß eine andere Definition gegenüberstellt, wird sie überhaupt im engeren Sinne zur Kritik. 
Antiamerikanismusbegriff muss sich der Anforderung stellen, die verschiedenen flexiblen und fragmentierten Antiamerikanismen als Ausdrücke eines gemeinsamen Phänomens ,Antiamerikanismus ‘ zu bezeichnen.

An dieser Stelle des Theoriegebäudes kommt das Konzept der Familienähnlichkeit zum Tragen. Es wird im Folgenden als eine Möglichkeit vorgestellt, Antiamerikanismus anhand typischer Merkmale begrifflich zu identifizieren und zugleich auf den Gebrauchsaspekt (und damit die Flexibilität und Kontextabhängigkeit) der so gewonnenen Bestimmungen zu reflektieren. Diese Reflexion des Gebrauchsaspektes beseitigt zwar nicht den Regelregress begrifflichen Sprechens, denn auch die Rekonstruktion einer ,Familie" antiamerikanischer Sprechakte bedeutet das Anwenden von Begriffen; sie zielt aber, im Gegensatz zu selbstgenügsamen Nominaldefinitionen, darauf ab, ,über die Anwendung der Formel Rechenschaft“ abzugeben (Winch 1966, S. 42). Das Familienähnlichkeitskonzept nimmt gewissermaßen die Unabgeschlossenheit des Begriffsgebrauches in den gebildeten Begriff mit auf und zwingt sich dadurch selbst immer wieder zur Rechenschaft über dessen Anwendung.

Dieses Rechenschaft-Abgeben über die Anwendung des Antiamerikanismusbegriffes lässt sich, wie ich in Kapitel 5 argumentieren werde, im Zuge empirischer Forschung qualitativ-interpretativer Art realisieren. Zugleich verweist das Konzept der Rechenschaft auf die normative Komponente des Antiamerikanismusbegriffes, die im folgenden Kapitel 4 aufgegriffen wird: Da es sich bei Antiamerikanismuskritik selbst um eine bestimmte Art der Rhetorik handelt, ist auch diese letztendlich auf eine Rechtfertigung ihrer Methoden und Begriffe angewiesen und kann sich nicht auf eine Begründung nach dem Modell unverzerrter Repräsentation von Realität beschränken.

Wittgensteins Konzept der Familienähnlichkeit lässt sich anhand seiner berühmten Analyse der unterschiedlichen Gebräuche des Wortes „Spiel“ in den Philosophischen Untersuchungen veranschaulichen. Er fragt hier nach einer definitiven Erklärung der Wortbedeutung und kommt zu dem Schluss, dass, obwohl es offenkundig ein intersubjektiv geteiltes, praktisches Verständnis des Wortes in seinen alltäglichen Gebräuchen gibt, sich kein einziges notwendiges Kriterium finden lässt, das allen diesen Gebräuchen gemeinsam wäre (vgl. Wittgenstein 2006, S. 277). Er vergleicht hierzu verschiedene Arten von Spielen, u.a. Schach, Tennis, Patience, aber auch das vergleichsweise freie Ballspiel eines Kindes, und schließt: „Wir sehen ein kompliziertes Netz von Ähnlichkeiten, die einander übergreifen und kreuzen. Ähnlichkeiten im Großen und Kleinen.“ (Ebd., S. 278) Die Relationen innerhalb eines solchen Netzwerks von Fällen mit einander ähnlichen oder überlappenden Merkmalen bezeichnet er sodann als „Familienähnlichkeiten“(ebd.).

Im 67. Aphorismus fährt Wittgenstein wie folgt mit der Beschreibung dieser Ähnlichkeitsrelation fort: 
„Und ebenso bilden z.B. die Zahlenarten eine Familie. Warum nennen wir etwas ,Zahl“? Nun etwa, weil es eine - direkte - Verwandtschaft mit manchem hat, was man bisher Zahl genannt hat; und dadurch, kann man sagen, erhält es eine indirekte Verwandtschaft zu anderem, was wir auch so nennen. Und wir dehnen unseren Begriff der Zahl aus, wie wir beim Spinnen eines Fadens Faser an Faser drehen. Und die Stärke des Fadens liegt nicht darin, daß irgend eine Faser durch seine ganze Länge läuft, sondern darin, daß viele Fasern einander übergreifen." (Ebd.)

Anstelle eines universellen Merkmales (oder Sets von Merkmalen), dass sich in allen unter eine Kategorie gefassten Fällen findet (die metaphorische Faser, die „durch seine ganze Länge läuft"), werden die Mitglieder eines Familienbegriffes durch indirekte Verwandtschaften verbunden. Die einfachste Variante einer solchen Ähnlichkeitsrelation ließe sich bspw. durch die Reihe ,AB, BC, CD, DE, EF, ... veranschaulichen (vgl. Rosch und Mervis 1975, S. 575).

Im Sinne einer solchen Ähnlichkeits-Struktur wird in der vorliegenden Arbeit der Antiamerikanismusbegriff konzipiert: Als Familie von Sprechakten, die sich sowohl hinsichtlich ihres funktionalen Gebrauchs als auch hinsichtlich der dabei zur Anwendung kommenden Amerikastereotype und Argumentationsmuster ähneln bzw. überschneiden, für die aber kein universell geteiltes Merkmal zu finden ist, das zugleich als hinreichend für die theoretische Bestimmung von Antiamerikanismus gelten kann. Abbildung 2 veranschaulicht diese Familienähnlichkeitsrelation antiamerikanischer Sprechakte (vgl. auch die Tabelle typischer Amerikamotive und deren funktionaler Gebräuche in Kap. 2.4 sowie die Ergebnisdarstellung in Kap. 7.6).

Anhand dieser vereinfachten grafischen Darstellung der Familienähnlichkeitsrelation werden zwei wesentliche Unterschiede gegenüber einer Nominaldefinition mittels notwendiger und hinreichender Kriterien deutlich: Zum einen ist kein allgemein geteiltes Merkmal auszumachen, das alle fünf aufgezeichneten Sprechakte (a1 bis a5) vereint: a1 und a3 sind hinsichtlich ihres Gebrauchsaspektes vergleichbar, der aber über verschiedene Stereotype realisiert wird, während a3 und a4 unterschiedliche Funktionen durch den Gebrauch desselben Stereotyps realisieren. Durch ,indirekte Verwandtschaft“ (über a3) ist somit a1 mit a4 verbunden, während a2 durch eine indirekte Verbindung mit a5 in die Familie eingebunden ist. Eine direkte Verbindung aller 5 Elemente der Gruppe existiert nicht, d.h. sie sind als antiamerikanische Sprechakte nur über ihre Verwandtschaft mit anderen Sprechakten derselben Familie zu klassifizieren. Was sie also zu antiamerikanischen Sprechakten macht, ist nicht unmittelbar in den Sprechakten selbst zu finden, sondern in ihrem vermittelten Verhältnis zu anderen antiamerikanischen Äußerungen. Die Bestimmung eines Sprechaktes als antiamerikanisch setzt somit einen Begriff des Antiamerikanismus, genauer: eine Praxis des als-antiamerikanisch-Begreifens, schon voraus. 
Abbildung 2: Antiamerikanismus als Familie von Sprechakten

(vgl. Knappertsbusch 2013)

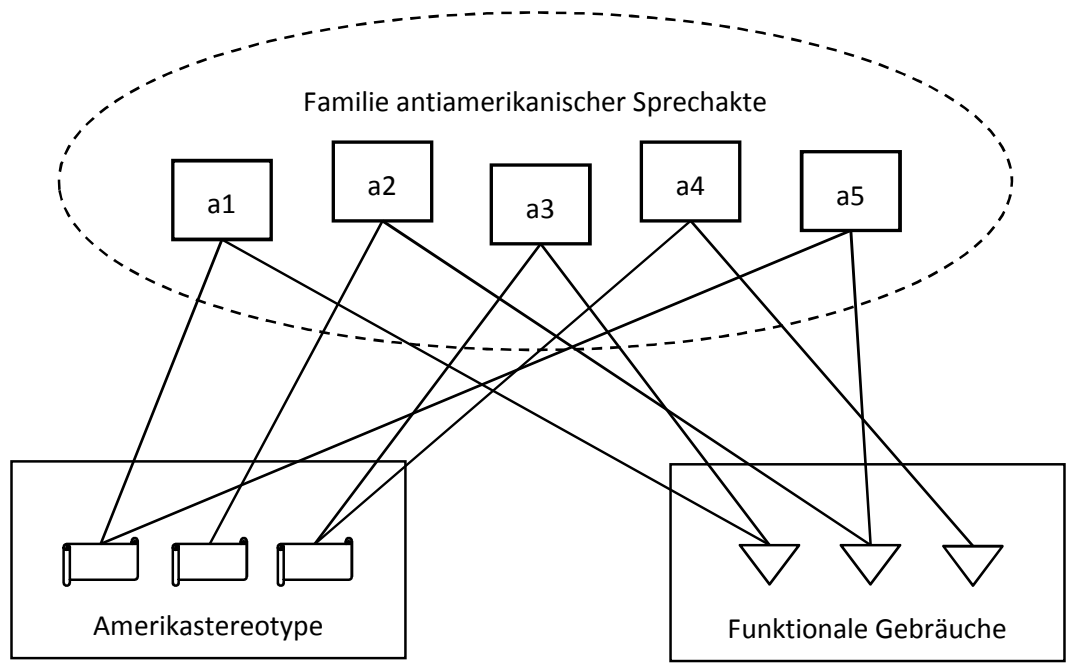

Dieser Begriff kann nicht dadurch begründet werden, dass man vor der Kategorisierung entsprechende Merkmale identifiziert, da diese ja gerade nicht als identische Merkmale des einen oder anderen Sprechaktes, sondern nur als Merkmale der Familie Sinn ergeben. ${ }^{10}$

Hierin liegt der zweite entscheidende Unterschied gegenüber Antiamerikanismusdefinitionen, nämlich die Reziprozität von theoretischer Deutung und empirischer Beobachtung: Nicht nur setzt die Kategorisierung jedes spezifischen Sprechaktes als antiamerikanisch eine bereits begrifflich gefasste Familie voraus, sondern auch die theoretisch-abstrakte Bestimmung der Familie kommt nicht ohne Verweis auf die jeweils spezifischen Merkmale der einzelnen Sprechakte aus. Die Bestimmung des Antiamerikanismus wird damit, in den Worten des Erkenntnis- und Wissenschaftstheoretikers Norwood Hanson, zu einer Operation des ,seeing as“ (Hanson 1972, S. 19), in der theoretische und empirische Aspekte immer schon reziprok verbunden sind. Auf die methodischen Implikationen einer solchen ,theoretischen Empirie" (Kalthoff 2008) in qualitativ-interpretativer Sozialforschung werde ich in Kapitel 5.1 zurückkommen.

10 Ich erinnere an die im vorigen Abschnitt erörterte Feststellung Winchs, dass „, die Ideen, die wir uns von einem Objekt bilden', nicht nur aus Elementen bestehen, die der Beobachtung dieses Objekts in völliger Isolierung entnommen sind, sondern die Idee eines Zusammenhangs zwischen ihm und anderen Objekten einschließt.“ (Winch 1966, S. 158) 
Es gibt einen naheliegenden Einwand, der von AnhängerInnen einer nominaldefinitorischen Vorgehensweise gegen die Begriffsstruktur der Familienähnlichkeit vorgebracht werden könnte. Er betrifft die Logik der Verknüpfung der einzelnen Mitglieder durch ,indirekte Verwandtschaft“. Man könnte vermuten, dass es sich bei Familienbegriffen lediglich um einen bestimmten Typus von Definition handelt, nämlich die Disjunktion einer Reihe hinreichender Kriterien: Antiamerikanismus wäre dann definiert als ,a1 oder a 2 oder $\ldots$ oder $\mathrm{aN}^{\star}$. Wittgenstein selbst hat diesen Einwand antizipiert. Wie häufig in den Philosophischen Untersuchungen, lässt er eine zweite, rhetorische Stimme das Argument führen, die Begriffsfamilie der „Zahl“ sei „erklärt als die logische Summe jener einzelnen miteinander verwandten Begriffe $[\ldots]$ und gleicherweise der Begriff des Spiels als logische Summe entsprechender Teilbegriffe“ (Wittgenstein 2006, S. 278). Wittgenstein wendet gegen seinen rhetorischen Gegenspieler ein:

„Dies muss nicht sein. Denn ich kann so dem Begriff ,Zahl“ feste Grenzen geben, d.h. das Wort ,Zahl` zur Bezeichnung eines fest begrenzten Begriffs gebrauchen, aber ich kann es auch so gebrauchen, daß der Umfang des Begriffs nicht durch eine Grenze abgeschlossen ist. Und so verwenden wir ja das Wort ,Spiel'. Wie ist denn der Begriff des Spiels abgeschlossen? Was ist noch ein Spiel und was ist keines mehr? Kannst du die Grenzen angeben? Nein. Du kannst welche ziehen: denn es sind noch keine gezogen. (Aber das hat dich noch nie gestört, wenn du das Wort ,Spiel“ angewendet hast.)“ (Ebd.)

Wittgenstein beharrt also auf der Unabgeschlossenheit sprachlicher Kategorien indem er, gewissermaßen auf einer höheren Reflexionsebene, wiederum auf die Pluralität möglicher Bedeutungsweisen verweist: Es gibt auch Definitionen, aber diese können kein Primat gegenüber anderen Formen der Begrifflichkeit beanspruchen bzw. sie setzen selbst eine existierende Sprachpraxis voraus, deren Regeln sich nicht definitorisch fassen lassen. Übertragen auf die Problematik des Antiamerikanismusbegriffes bedeutet dies: Man kann Antiamerikanismus definieren, aber die Definition kann jederzeit mit anderen möglichen Definitionen konfrontiert werden, die ihre Geltung in Frage stellen (gerade darin besteht ja das „Definitionsproblem“ der Antiamerikanismusforschung). Die Güte einer Definition, bzw. deren Überlegenheit gegenüber anderen Definitionen, wird sich nur im Gebrauch der Definition, d.h. in deren Anwendung auf empirisches Material zeigen lassen. In diesem Moment wäre sie aber wiederum damit konfrontiert, dass es keine ,natürliche' Grenze der Kategorie Antiamerikanismus gibt, und auf ihre eigenen Setzungen zurückgeworfen. Die Begründung eines Antiamerikanismusbegriffes wird daher auch in der Rechtfertigung dieser Setzungen bestehen müssen.

Hier wird die oben explizierte normative Komponente der Begriffsbestimmung erneut ersichtlich: Die Praxis der eigenen Begriffsbildung kann letztendlich nur gerechtfertigt, nicht abschließend bewiesen werden. Nimmt man dies an, so wird klar, 
dass die Güte eines Begriffes nicht von dessen exakter Begrenzung abhängt, nach dem Kriterium der bestmöglichen Korrespondenz mit einer externen Realität, sondern letztendlich von den Zwecken, die man mit seinem Gebrauch verfolgt - und d.h. von der Weise, in der diese Zwecke mit der sozialen Wirklichkeit des Gegenstandes verwoben sind und selbst als soziale Praxis bedeutsam werden. ${ }^{11}$

Wittgenstein plädiert dementsprechend noch einmal für den Gebrauch unabgeschlossener Begriffe, indem er zeigt, dass deren Unschärfe keine Fehlbildung, sondern eine Reflexion der Unschärfe der begriffenen gesellschaftlichen Praxen ist. Gegenüber dem Pochen auf exakte Definitionen macht er geltend, dass auch die Exaktheit ein besonderer, zu rechtfertigender Zweck ist, und stellt damit die unhintergehbare Teilnehmerinnenperspektive jeder Begriffsbildung heraus:

„Wie würden wir denn jemandem erklären, was ein Spiel ist? Ich glaube, wir werden ihm Spiele beschreiben, und wir könnten der Beschreibung hinzufügen: ,das, und Ähnliches, nennt man »Spiele«`. Und wissen wir denn selbst mehr? Können wir etwa nur dem Anderen nicht genau sagen, was ein Spiel ist? - Aber das ist nicht Unwissenheit. Wir kennen die Grenzen nicht, weil keine gezogen sind. Wie gesagt, wir können - für einen besonderen Zweck - eine Grenze ziehen. Machen wir dadurch den Begriff erst brauchbar? Durchaus nicht! Es sei denn, für diesen besonderen Zweck. So wenig, wie der das Längenmaß ,1 Schritt‘ brauchbar machte, der die Definition gab: 1 Schritt $=75 \mathrm{~cm}$. Und wenn du sagen willst ,Aber vorher war es doch kein exaktes Längenmaß', so antworte ich: gut, dann was es ein unexaktes. - Obgleich du mir noch die Definition der Exaktheit schuldig bist.“ (Ebd., S. 279)

Die Konsequenz hieraus ist sicherlich nicht, dass wissenschaftliche Definitionen (in der Vorurteilsforschung oder anderswo) sinnlos seien. Es wird aber gezeigt, dass definitorische Begriffe (1) ihre Exaktheit nicht in einem korrespondenzlogischen Sinne als überlegene Beschreibung sozialer Tatbestände auffassen und (2) nicht als Wertneutralität missverstehen sollten, da auch die jeweilige definitorische Präzision eine zu rechtfertigende Zwecksetzung ist. Ein auf Familienähnlichkeit beruhender Begriff betont demgegenüber die Flexibilität und Kontextabhängigkeit des Begriffenen und verpflichtet sich zugleich zu einer sozialtheoretischen Rechtfertigung der angelegten Vergleichskriterien. Aus dieser Rechtfertigung spricht dabei auch das selbstreflexive Verständnis der Performativität bzw. Sozialität der eigenen Begriffe.

11 Anders Formuliert: Begriffliche Exaktheit und Präzision sind nur dann ein wertfreier ,Wert an sich“, wenn man einen „semantischen und hermeneutischen Objektivismus“ vertritt, also davon ausgeht, dass die eigenen Begriffe als Namenstäfelchen für sprachunabhängig existierende Gegenständen funktionieren. Andernfalls wird man sich immer der Frage stellen müssen: Exaktheit wozu? 


\subsection{ZWISCHENFAZIT: EIN PERFORMATIVER ANTIAMERIKANISMUSBEGRIFF II}

Antiamerikanismus wird in der vorliegenden Arbeit als Sprechhandeln bestimmt, das sowohl hinsichtlich seiner semantischen als auch seiner praktisch-rhetorischen Komponente erfasst werden muss. Der Begriff der Performativität wurde gewählt, um diese eigentümliche ,performativ-propositionale Doppelstruktur“ (Wellmer) des antiamerikanischen Sprechens theoretisch zu erfassen, dass man ,etwas tut, indem man etwas sagt“" (Austin). Damit wird der im vorigen Kapitel entwickelten Kritik des traditionellen Vorurteilsbegriffs eine sprechakt- bzw. praxistheoretische Grundlage gegeben.

Drei Hauptaspekte eines performativen Vorurteilsverständnisses wurden expliziert: Flexibilität, Sozialität und Normativität. Als Flexibilität wurde die Möglichkeit in Rechnung gestellt, dass antiamerikanische Sprechakte (1) nicht als Ausdruck einer geschlossenen weltanschaulichen Struktur auftreten müssen, und (2) prinzipiell in unterschiedlicher Weise praktisch bedeutsam werden können. Man kann die antiamerikanische Bedeutung eines Sprechhandelns daher weder als Fehldarstellung der USA, noch als Anfeindung oder Abwertung eindeutig festschreiben. Vielmehr ist eine Vielzahl antiamerikanischer Sprachgebräuche denkbar, die in verschiedenen Äußerungskontexten verschiedene Funktionen erfüllen. Mit einem bestimmten Amerika-Stereotyp (z.B. ,Weltpolizei', ,Amerikanisierung', , amerikanischer Rassismus') können also vielfache rhetorische Funktionen erfüllt werden (z.B. relative Aufwertung der Eigengruppe, Rechtfertigung ethnozentrischer Positionen), und der antiamerikanische Gehalt eines Sprechaktes besteht gerade in dem Zusammenspiel dieser beiden analytisch geschiedenen Komponenten.

Das Moment der Flexibilität verweist somit zugleich auf die Sozialität bzw. Kontextabhängigkeit des vorurteiligen Handelns: Ohne eine Deutung eines Sprechaktes in dessen funktionalem Bezug zu einem Äußerungskontext, kann er nicht als antiamerikanisch eingestuft werden. Dies geht aus der Annahme der prinzipiellen Differentialität sprachlicher Bedeutung hervor, dass jedes Sprachzeichen nur im Zusammenhang anderer Sprachzeichen Sinn ergibt, der letztendlich auf die Einbettung des Sprachzeichens in den sozialen Zusammenhang einer Lebensform verweist.

Aus dieser methodologischen Überlegung erwächst einerseits die empirische Frage, welche Stereotype in welchen Äußerungskontexten wozu rhetorisch gebraucht werden. Andererseits setzt die empirische Analyse dieser Frage auch die heuristische Setzung eines Theorierahmens voraus: Für welche Funktionskontexte und Gebräuche von Amerikabildern ist meine Vorurteilskritik sensibel? Zur Beantwortung dieser Frage ist es naheliegend, an bestehende Vorurteilsdiskurse anzuknüpfen und Themenbereiche herauszuarbeiten, hinsichtlich derer Sprechakte im 
öffentlichen und wissenschaftlichen Diskurs als vorurteilige problematisiert werden. In Kapitel 4 werden hierzu, ohne jeden Anspruch auf Vollständigkeit, Konzepte sozialer Ungleichheit und Diskriminierung sowie Ansätze der Nationalismusund Ethnozentrismusforschung aufgegriffen.

Eine solche über den traditionellen Vorurteilsbegriff hinausweisende theoretische und normative Verortung der Vorurteilskritik ist deswegen von entscheidender Bedeutung, weil die unter dem Begriff der Performativität explizierten Eigenschaften von Sprechhandlungen in einem doppelten Sinne methodologisch relevant sind: Sie gelten für die beobachteten vorurteiligen Sprechakte ebenso wie für die Sprechakte der Vorurteilskritik. Nicht nur ist der Antiamerikanismus auf seinen Gebrauchsaspekt hin zu beleuchten, sondern auch der Gebrauch des Antiamerikanismusbegriffes ist durch Flexibilität, Sozialität und Normativität gekennzeichnet. Der analytische Akt des ,seeing as“ (Hanson), den die Antiamerikanismuskritik vollzieht, ist also letztendlich als Teilnahme an übergreifenden gesellschaftlichen Diskursen zu rechtfertigen. Diese vorurteilskritische Praxis unterscheidet sich nicht prinzipiell von dem sozialen Handeln, das sie untersucht. Die besondere reflexive Struktur dieser Begründung, durch die sich die wissenschaftliche Perspektive dennoch von den Handlungsweisen im Gegenstandsbereich abgrenzt, wird in Kapitel 4 im Zusammenhang des Kritikbegriffs diskutiert.

Der performative Charakter der Vorurteilskritik hat darüber hinaus Konsequenzen für deren begriffliche Struktur. Ein nominaldefinitorisches Vorgehen steht, so wurde in Abschnitt 3.4 argumentiert, in Widerspruch $\mathrm{zu}$ den praxistheoretischen Überlegungen Wittgensteins, die hier zugrunde gelegt werden. Die Regeln, nach denen sprachliche Bedeutung (re-)produziert wird, lassen sich nicht formalisieren, weil sie stets einen Gebrauchsaspekt beinhalten: Da jede Regel über ihre Anwendung „Rechenschaft abgeben“ (Winch) muss, führt der Versuch die Anwendung zu formalisieren in einen unendlichen Regelregress. Da dennoch aber eine Regelhaftigkeit sprachlicher Bedeutung angenommen werden muss, spannt sich Wittgensteins Bedeutungsverständnis zwischen den Polen der Sprachimmanenz und Transzendenz auf. Jede Bedeutungserklärung, d.h. jede Rekonstruktion einer sprachlichen Regel, muss einerseits auf definierbare Merkmale der untersuchten Sprechweisen abzielen, zugleich aber auch deren nicht abschließend definierbare Anwendung in die Begriffsbildung miteinbeziehen.

Als Modell für eine solche ,gebrauchssensible“ Begriffsbildung hat Wittgenstein das Konzept der Familienähnlichkeit vorgeschlagen. Anstelle der Definition von notwendigen und hinreichenden Kriterien werden hier auch mittelbare Verbindungen der Mitglieder einer Kategorie, d.h. deren ,indirekte Verwandtschaften“, berücksichtigt. Auf diese Weise können Elemente unter einen Begriff gefasst werden, ohne dass ein theoretisch hinreichendes Merkmal oder Set von Merkmalen identifizierbar wäre, das alle Elemente Teilen. Durch die Mittelbarkeit der Verwandtschaftsbeziehungen ist eine solche Begriffsstruktur besonders geeignet, den 
flexiblen und fragmentierten Gebräuchen antiamerikanischen Sprechens nachzuspüren: Das Definitionsproblem wird gewissermaßen nicht durch eine ,überlegene ‘ Definition gelöst, sondern dadurch, dass man vom fragwürdigen Ideal definitorischer Eindeutigkeit ablässt. Paradoxerweise, so könnte man sagen, wird durch das Zulassen familiärer Unschärfe der Antiamerikanismusbegriff nicht unschärfer, sondern präziser. Er Wird präziser, insofern die Bestimmung von Antiamerikanismus als Familie sowohl zum Bezug auf konkretes empirisches Material, als auch zu einer sozialtheoretischen Fundierung des Antiamerikanismuskonzeptes zwingt. Auf dieses Spiegelungsverhältnis von Empirie und Theorie werde ich in Kapitel 5 mit dem Begriff der ,theoretischen Empirie‘ (Kalthoff et al. 2008) zurückkommen. 


\section{Gesellschaftstheoretische Einordnung: Vorurteile als Ungleichheitssemantiken - Vorurteilsforschung als erschließende Kritik}

Die vorurteilige Bedeutung antiamerikanischer Ausdrücke, so wurde in Kapitel 2 nahegelegt, lässt sich weder anhand von semantischen Merkmalen noch anhand propositionaler Kriterien hinreichend bestimmen. Genauer wird der antiamerikanische Charakter solcher Sprechweisen als die ,praktische Bedeutung' aufgefasst, die diese in bestimmten Äußerungskontexten erlangen. Diese performative Wirkung, so wurde in Anknüpfung an Margaret Wetherell und Jonathan Potter vorgeschlagen, kann als die rhetorische Funktion bestimmt werden, die bestimmte Amerikabilder in bestimmten Äußerungskontexten erfüllen. Fasst man antiamerikanische Vorurteile auf diese Weise, so ist die Frage von entscheidender Bedeutung, um welche Funktionskontexte es sich dabei handelt. Welche rhetorischen Tätigkeiten können als vorurteilige Tätigkeiten beschrieben werden, und auf welcher sozialtheoretischen Grundlage?

Das vorliegende Kapitel schlägt Theorien sozialer Ungleichheit und Diskriminierung als Rahmen vor, innerhalb dessen die Funktionskontexte und Funktionsweisen antiamerikanischer Rede bestimmt werden können: Vorurteile sind demnach „Ungleichheitssemantiken“ (Berger 1989) bzw. „Ungleichheitspragmatiken“ (Sutterlüty 2004; Neckel und Sutterlüty 2005, S. 421), die zur Reproduktion diskriminierender gesellschaftlicher Verhältnisse beitragen. Zwar ist die Frage nach den konkreten rhetorischen Funktionen antiamerikanischen Sprechens in erster Linie eine empirische, die in der vorliegenden Arbeit mithilfe qualitativ-interpretativer Methoden beantwortet wird. Aber Empirie und Theorie bilden keine strikt getrennten Arbeitsbereiche, wie im folgenden Kapitel 5 noch einmal ausführlich aufgegriffen wird. Vielmehr ist jede empirische Beobachtung als „,theory-laden“ undertaking“ 
(Hanson 1972, S. 19) abhängig von einer angemessenen Reflexion ihrer theoretischen Prämissen. ${ }^{1}$

Den Startpunkt dieser Reflexion bilden Überlegungen zum Verhältnis von Ungleichheit und Diskriminierung, wie sie im Rahmen einer hermeneutisch-wissenssoziologischen bzw. praxistheoretischen Diskriminierungsforschung entwickelt wurden (Hormel und Scherr 2010; Kreckel 2004; Neckel und Soeffner 2008; Weiß et al. 2001). Zwischen Ungleichheit und Diskriminierung lässt sich diesen Arbeiten zufolge allerdings keine scharfe Grenze ziehen, weil die egalitäre Norm moderner Gesellschaften jede Differenzkonstruktion unter potentiellen Begründungs- und Rechtfertigungsdruck setzt. Rassistische oder eben antiamerikanische Ungleichheitssemantiken erfüllen in dieser Perspektive zunächst genauso eine Funktion im alltäglichen „Kampf[es] um Klassifizierungen“ (Berger 1989, S. 48), wie andere Differenzkonstruktionen auch (z.B. Bildungsgrad oder Einkommen). Was macht sie dann aber zu Vorurteilen? Wie lässt sich ihre spezifische rhetorische Funktion von der anderer Ungleichheitssemantiken unterscheiden?

Im Anschluss an Christoph Menke wird gezeigt, dass moderne Gleichheitsnormen durch einen immanenten Widerspruch gekennzeichnet sind: Sie zielen auf universelle Gleichheit um individueller Besonderheit Willen. Auf die Frage nach der Grenze zwischen legitimer Ungleichheit und illegitimer Diskriminierung kann es somit keine abschließende Antwort geben, sondern die Normativität der egalitären Einstellung speist sich aus dem konflikthaften Vollzug dieser Paradoxie: Moderne Egalität bedeutet, dass etablierte „Personenauffassungen“ (Menke 2004, S. 41), die die gesellschaftlich wirkmächtigen Maßstäbe zum Vergleich von Individuen geben, je und je im Interesse individueller Bedürfnisse problematisiert und verändert werden können. Anti-egalitär ist in diesem Sinne nicht die Infragestellung etablierter Personenauffassungen und Verteilungsregeln, sondern der systematische Abbruch des konflikthaften Vollzugs der Gleichheitsnorm. Der Gegenstand der Vorurteilskritik sind damit solche Ungleichheitssemantiken, die zwar Gleichheit als politisches Ideal für sich in Anspruch nehmen, zugleich aber die Gemachtheit und Kontingenz ihrer eigenen Gleichheitsvorstellungen systematisch ausblenden. Genauer noch: Vorurteile sind Ungleichheitssemantiken, die bereits gesellschaftlich problematisiert werden, die aber den dadurch entstehenden Rechtfertigungsdruck entschärfend in ihre eigene Rhetorik aufnehmen. Es ist dieser Aspekt vorurteiligen Sprechens, der im Anschluss an Überlegungen der älteren und neueren Kritischen

1 Dies gilt freilich auch in dem umgekehrten Sinne, dass jede Theoriebildung immer schon mit Erfahrung durchsetzt ist. Die hier dargestellten theoretischen ,Prämissen` empirischer Arbeit sind somit in gewisser Weise selbst schon Ergebnis der Empirie. In Kapitel 5.2 wird auf das paradoxe Wechselverhältnis von theoretischem Vorwissen und empirischer Ergebnisoffenheit anhand der Konzepte der „,theoretischen Sensibilität“ sowie der „Nachträglichkeit“" eingegangen. 
Theorie sowie der Systemtheorie Niklas Luhmanns als ,Ideologie‘ bezeichnet werden kann.

Diese Bestimmung der ,prejudice problematic“ (Wetherell 2012) als ideologisches Phänomen leitet über zum Problem einer normativen Verortung der Vorurteilskritik. Ein zentrales Ergebnis der Klärung des Performanzbegriffes in Kapitel 3 war, dass sich die Bedeutung von Sprachausdrücken nicht unabhängig von deren Gebrauchskontext, d.h. den praktischen Interaktionsregeln einer jeweiligen „Lebensform“ (Wittgenstein), begreifen lässt. Diese Sozialität der Bedeutung muss auch für wissenschaftliches Sprechen angenommen werden und führt daher in das methodologische Problem einer ,double hermeneutic“ (Giddens 1993, S. 170). Wertneutralität ist vor diesem Hintergrund keine sozialtheoretisch überzeugende Antwort auf die Frage der Normativität sozialwissenschaftlicher Theoriebildung. Freilich ist der Bezug einer starken normativen Position für eine Gesellschaftstheorie „unter nachessentialistischen Bedingungen“ (Bonacker 2000, S. 14) ebenso wenig akzeptabel. Sie würde zu einem Standpunkt neben vielen, dessen Gültigkeit sich rational-diskursiv nicht mehr einlösen ließe.

Unter Bezug auf das Erbe der Frankfurter Schule (Bonacker 2000; Honneth 2007b; Menke 1997) wird stattdessen ein Kritikbegriff vorgeschlagen, der die Spannung zwischen normativer Teilnehmerposition und wissenschaftlicher Differenzsetzung reflexiv in die Methodologie der Begriffsbildung aufnimmt. Eine solche „erschließende Kritik“ (Bonacker 2008) versucht an ihrem Gegenstand performative Selbstwidersprüche aufzuzeigen, d.h. die praktischen Bedingungen eines jeweiligen Sprechhandelns auszuweisen, die in diesem nicht bzw. nur auf ideologische Weise reflektiert werden. Ein zentrales Moment dieser kritischen Neuerschließung des Gegenstandes ist die Reflexion auf die Unabgeschlossenheit der eigenen Deutungen: Sie kann die gesellschaftliche Bedingtheit ihrer Interpretation, die Sozialität ihrer Sprachgebräuche, zwar reflektieren, aber nie ganz ausschalten, und bleibt daher selbst immer ein stückweit Teilnehmerin an ihrem Gegenstand. Diese Unabgeschlossenheit, die unscharfe Grenze zwischen Beobachtung und Beobachtetem, ist zugleich aber Möglichkeitsbedingung einer erschließenden Kritik und begründet deren spezifisches Potential, wie im Anschluss an Thorsten Bonacker erkenntniskritisch rekonstruiert wird.

Nachdem die sozialtheoretischen und methodologischen Grundlagen einer erschließenden Vorurteilskritik umrissen sind, erfolgt in Abschnitt 4.6 schließlich noch eine weitere thematische Konkretisierung des ungleichheitstheoretischen Vorurteilsbegriffes. So wird in Vorbereitung auf die empirische Ergebnispräsentation in Kapitel 7 das Konzept nationaler Identität und dessen Verhältnis zu vorurteiligem Sprechen theoretisch eingekreist. Im Rekurs auf wissenssoziologisch-hermeneutisch orientierte Konzepte des Ethnozentrismus (Nassehi 1997a; Rieker 1997) und des Antisemitismus (Holz 2001; Schäuble 2012) rücken hierbei insbesondere Fragen einer Durchdringung multikulturalistischer und ethnozentrischer Differenz- 
konstruktionen, sowie eines kommunikationslatenten Schuldabwehrantisemitismus nach 1945 in den Blick. Der Kulturbegriff kann demnach neben seinen soziologisch-reflexiven Gebräuchen auch als Ausdruck rigider ethno-nationaler Identitätskonstruktionen bzw. Weltsichten gebraucht werden. Er erfüllt dabei eine ähnliche ideologische Funktion wie die Codes der Kommunikationslatenz im sekundären Antisemitismus: Rechtfertigungsdrücke gegenüber ethnozentrischen oder antisemitischen Konstruktionen zu umgehen bzw. abzuleiten.

\subsection{UNGLEICHHEIT UND DISKRIMINIERUNG}

Die Beschreibung und Analyse sozialer Ungleichheit ist traditionell eine Kerndisziplin soziologischer Theoriebildung. Gegenstand der Ungleichheitsforschung ist dabei freilich nicht jeglicher Unterschied zwischen sozialen Gruppen oder gar Individuen, sondern, so kann man in einer ersten Annäherung sagen, die ,ungleiche Verteilung von Lebenschancen“ (Burzan 2011, S. 7). Anhand welcher Merkmale sich Gesellschaften in Strukturelemente einteilen lassen, welche Merkmale oder Merkmalskombinationen also so wirkmächtig sind, dass sie die gesamte Lebensform jeweiliger Gruppen zu bestimmen vermögen, ist dabei eine dauerhaft umstrittene Frage. Eine Vielzahl sozialstruktureller Theorien, die Gesellschaften in Klassen, Schichten, Milieus, Felder oder Lebensstile einteilen, gibt hierauf eine ebenso große Zahl unterschiedlicher Antworten. Sie unterscheiden sich vor allem in der Weise, in der sie das Verhältnis zwischen , objektiven' materiell-ökonomischen Kategorien, wie Einkommen oder Bildung, und zugeschriebenen Kategorien, wie Geschlecht oder ethnischer Zugehörigkeit, bestimmen. Eine weitere sehr unterschiedlich beantwortete Frage lautet, inwieweit Ungleichheit als normatives Konzept aufzufassen ist, also im Zusammenhang mit Fragen der Legitimität und letztendlich der Gerechtigkeit zu behandeln ist. In weiten Teilen der etablierten Ungleichheitsforschung wird dabei prinzipiell legitime Ungleichheit begrifflich von illegitimer Diskriminierung geschieden, wie Albert Scherr feststellt:

„Als Diskriminierung wurden und werden [...] solche Formen der Benachteiligung thematisiert, die sich nicht zureichend als Bestandteil oder Effekt von Klassenlage, Schicht- oder Milieuzugehörigkeit bestimmen und erklären lassen. In den Blick genommen werden dabei vor allem Benachteiligungen, die sich auf sog. zugeschriebene Merkmale, d.h. durch eigene Leistung nicht erwerbbare bzw. veränderbare ,soziale oder physische Attribute (Hautfarbe, Alter, Geschlecht, usw.)‘ beziehen.“ (Scherr 2010, S. 38 f.)

Diese analytische Trennung ist zunächst plausibel, da ansonsten jede Form sozialer Differenzierung als zu behebendes Unrecht erscheinen müsste. Selbst wenn man die 
Vergleichsdimension bspw. auf berufliche Differenzierung eingrenzt, also die unzähligen subkulturellen Unterscheidungen außen vor lässt, die potentiell ebenfalls als Kriterien sozialer Ungleichheit herangezogen werden könnten, ist klar, dass gegen eine ausdifferenzierte Arbeitsteilung inklusive der damit einhergehenden Gruppenunterschiede in Anforderung, Qualifikation und Entlohnung nicht prinzipiell etwas einzuwenden ist (vgl. Walzer 2000). Ungleichheit erscheint somit also zunächst als legitim, oder vielmehr: als eine nicht-normative Kategorie, der gegenüber sich die Frage der Legitimität überhaupt nicht stellt. Erst dann, wenn die im obigen Zitat benannten askriptiven Merkmale als Kriterien für eine Ungleichbehandlung oder Exklusion von Gruppen ins Spiel kommen, werden normative Aspekte von Gerechtigkeit und Legitimität relevant. Eine solche strikte Trennung von Ungleichheit und Diskriminierung entspricht auch aktuellen politischen Diskursen, die auf ein ,meritokratische[s] Prinzip des Konkurrenzindividualismus“ rekurrieren (Scherr 2011, S. 34). Unter Bedingungen der „Chancengleichheit“, d.h. ausgehend von gleichen gesellschaftlichen ,Startbedingungen“, jedoch unterschiedlichen individuellen Talenten und Präferenzen, ist dann die resultierende Ungleichheit einfach Ausdruck von individuell begründeten, weder natürlich noch gesellschaftlich diktierten Differenzen.

Wo aber liegen die Grenzen dessen, was noch als gesellschaftlich ,gemacht ${ }^{\text {' }}$ der naturwüchsig, d.h. als gesellschaftlich zu verantworten gilt, und wo beginnt die individuelle Verantwortung der Handelnden? Diese Grenzziehungen müssen historisch und kulturell als durchaus variabel angesehen werden. Wenn zudem davon ausgegangen wird, dass auch innerhalb einer historischen Gesellschaftsformation zu einem gegebenen Zeitpunkt keineswegs Einigkeit über besagte Grenzziehungen herrscht (Kreckel 2004, S. 20), stellt sich die Frage, auf welcher autoritativen Grundlage über die Geltung der Grenzverläufe entschieden werden soll? ${ }^{2}$

Tatsächlich ist gegenüber der beschriebenen ,konkurrenzindividualistischen“ Perspektive auf soziale Ungleichheit wiederholt eingewandt worden, dass soziale Ungleichheit grundsätzlich als menschengemachter und somit historisch kontingenter Tatbestand aufzufassen sei, als „Produkt von bewußtem menschlichen Handeln“ (ebd., S. 14). Aus der Annahme einer Kontingenz der Ungleichheit folgt dann auch die Kontingenz der Grenzziehung zwischen Ungleichheit und Diskriminierung: Die Unterscheidung von Ungleichheit und Diskriminierung ist demnach immer Gegenstand gesellschaftlicher Konflikte, hat prinzipiell eine normative Komponente und

2 Zudem muss die strikte Unterscheidung von quasi-natürlichen individuellen Dispositionen und gesellschaftlich gemachten Rahmenbedingungen, die das Modell der Chancengleichheit impliziert, aus soziologischer Perspektive problematisch erscheinen: Ist das vermeintlich unabhängig von seinen (gleich zu verteilenden) Lebenschancen bestimmbare Individuum in Genese und Sozialisation nicht schon durch gesellschaftliche Verteilungs- und Kräfteverhältnisse bestimmt? 
ist demzufolge auch von der Forschung „keineswegs trennscharf“" zu ziehen (Scherr 2010, S. 40). Auch die vermeintlich ,objektiven“ Kriterien der Klassen- oder Schichtzugehörigkeit sind in ihrer Realisierung immer schon durchzogen von „Differenzkonstruktionen“ (Weiß 2001, S. 80) wie etwa Geschlecht, ethnischer Gruppenzugehörigkeit, politischer Orientierung, etc., die sich im Kampf um soziale Positionierung zu einer spezifischen Sorte „symbolischer Gewalt“ (ebd., S. 86) verfestigen können. Eine Ungleichheitsforschung, die einen abgesicherten Bereich nichtnormativer Ungleichheit zu begründen versucht, läuft dementsprechend Gefahr, selbst zur ideologischen Rechtfertigung bzw. Naturalisierung der jeweils geltenden Ungleichheitsvorstellungen zu geraten (vgl. Kreckel 2004, S. 14). Albert Scherr wirft in diesem Sinne der konkurrenzindividualistischen Ungleichheits- und Diskriminierungsforschung vor, sie operiere auf der Grundlage eines „Gesellschaftsverständnis[ses], das als Normalfall von Ungleichheiten zwischen sozialen Gruppen ausgeht, die sich aus physisch und psychisch gesunden, strafrechtlich unbescholtenen männlichen Staatsangehörigen und ihren Familienangehörigen zusammensetzen" (Scherr 2010, S. 39). Diese Forschung ignoriere, dass die Annahme dieses Normalzustandes selbst schon ein kontingentes Ungleichheitsverständnis beinhaltet, d.h. eine Annahme darüber, welche Kriterien ein Individuum erfüllen muss, um als ,gleicher' Konkurrent um Positionierung im Feld einer vermeintlich nichtnormativen Ungleichheitsstruktur gelten zu können. In diesem Sinne, so hält Kreckel fest, sind Ungleichheitstheorien (soziologische sowie außerwissenschaftliche) nie ,unschuldig“, sondern „mischen sich unweigerlich ein in die symbolisch strukturierte Realität, die sie zu erfassen versuchen“ (Kreckel zit. n. Berger 1989, 48 f.). Eine Ungleichheitsforschung, die derart auf die Kontingenz bestehender sozialer Ungleichheit und damit auf den normativen Charakter wissenschaftlicher und auBerwissenschaftlicher Ungleichheitsvorstellungen reflektiert, kann nicht mehr strikt zwischen Ungleichheit und Diskriminierung unterscheiden, zumindest nicht mehr in dem Sinne, dass Diskriminierung als normatives Problem, Ungleichheit hingegen als wertneutrale Notwendigkeit erscheint. Das bedeutet freilich nicht, dass jede Form von Ungleichheit prinzipiell falsch ist und abgeschafft werden soll oder kann - der mit den Begriffen Ungleichheit und Diskriminierung anvisierte Unterschied fällt durch die Problematisierung der traditionellen Unterscheidung also nicht einfach in eins. Es bedeutet aber, dass Fragen der Ungleichheit immer mit Fragen der Legitimität und letztendlich der Gerechtigkeit verbunden sind. Der normative Gehalt der Ungleichheit, den die traditionelle Ungleichheitsforschung im Begriff der Diskriminierung auslagert, wird somit als Problem vermittelter Herrschaft beschreibbar, das sowohl Ungleichheit wie Diskriminierung einschließt. Diese normative und generative Kraft der gesellschaftlichen Normalität erkennbar zu machen, ist die zentrale Aufgabe einer kritischen Ungleichheitsforschung (vgl. Kreckel 2004, S. 14). 
Im Folgenden werden mit Pierre Bourdieus Begriff der symbolischen Macht und Peter Bergers Begriff der Ungleichheitssemantik zwei Ungleichheitstheoretische Konzepte vorgestellt, die eine solche Herrschaftskritische Perspektive erschließen. Mit den Arbeiten von Anja Weiß, Ferdinand Sutterlüty und Sighard Neckel, die im Anschluss an Bourdieus bzw. Bergers Ungleichheitsverständnis eine Rassismusbzw. Xenophobiekritik formulieren, wird dann der Bogen zurück zur Vorurteilsforschung geschlagen: Zwei ,klassische‘ Gegenstände der Vorurteilsforschung, rassistische und fremdenfeindliche Fremd- und Feindbildkonstruktionen, werden hier als funktionale Momente der Reproduktion einer symbolischen Ordnung sozialer Ungleichheit begriffen.

\subsection{UNGLEICHHEITSSEMANTIKEN UND DIE SYMBOLISCHE ORDNUNG SOZIALER UNGLEICHHEIT}

Die Tatsache der Gemachtheit und Kontingenz sozialstruktureller Unterteilungen lässt sich mit Pierre Bourdieus Konzept der „,symbolische[n] Ordnung sozialer Ungleichheit“ fassen (Sutterlüty et al. 2008, S. 28). Die „Sozialstruktur moderner Gesellschaften“ ist in dieser Perspektive das Ergebnis eines andauernden „dynamischen Spiels von Kräften und Gegenkräften, die - jede für sich alleine genommen in völlig unterschiedliche Richtungen zielen können“ (Kreckel 2004, S. 21). Somit ist die Analyse der Sozialstruktur nicht zu trennen von der Analyse eines „Kampfes um Klassifizierungen“, dessen Medium nicht nur die traditionellen vertikalen Dimensionen sozialer Ungleichheit (Bildung, Einkommen, Berufsprestige), sondern auch horizontale Unterscheidungen, d.h. „kulturelle Differenzkonstruktionen“ (Ethnizität, Geschlecht, ästhetische Präferenzen) sind (vgl. Weiß 2001, S. 79 f.). Dieser ständige „Kampf um Klassifizierungen“ wird freilich auch in Gesellschaften mit demokratischem Selbstverständnis nicht zu jedem Zeitpunkt explizit bzw. reflektiert ausgetragen: Die meiste Zeit verlaufen solche Konflikte entlang der Bahnen institutionalisierter Gruppenkonstruktionen und Verteilungsregeln, die als selbstverständliche Grundlage der Vergesellschaftung, als „,zweite Natur“ (Adorno 1973b; Menke 2012), den Streit um gesellschaftliche Positionierung einhegen. In Bourdieus Terminologie kann man von diesen institutionalisierten Ungleichheiten als „symbolische Gewalt“" sprechen, die von denjenigen ausgeübt wird, deren Wahrnehmungs- und Bewertungsmuster sich ideal an die bestehenden gesellschaftlichen Strukturen anpassen, so dass sie als unhintergehbar und natürlich gegeben erscheinen (Weiß 2001, S. 85 f.). Erst wenn eine bestehende Struktur symbolischer Gewalt in eine Legitimationskrise gerät, tritt der Konflikt offen zu Tage und die Wirkung symbolischer Macht wird in Form von „symbolischen Kämpfen“ sichtbar (Weiß 2001, S. 96). Diese mögen etwa die Gestalt von Arbeitskämpfen oder sozialen Be- 
wegungen annehmen, wie z.B. im Kampf um die rechtliche Gleichstellung gleichgeschlechtlicher Beziehungen. Ausgehend von einem Konzept symbolischer Macht werden kulturelle Differenzkonstruktionen aber nicht erst dort zum Medium eines Herrschaftsverhältnisses, wo explizit Gruppen abgewertet, exkludiert oder verfolgt werden bzw. sich gegen solche Herrschaftspraxen auflehnen. Machtverhältnisse herrschen auch dort schon, wo etablierte Gruppenkonstruktionen (Geschlecht, Ethnizität, Alter) und Verteilungsregeln (Leistungsprinzip, Privateigentum) als nicht problematisierte Bedingungen der Reproduktion gesellschaftlicher Besitz- und Machtverhältnisse fungieren.

Anja Weiß legt einen solchen Ungleichheitsbegriff ihrer Analyse der diskriminierenden Funktion rassistischer Zuschreibungen zugrunde, indem sie „Rassismus als symbolisch vermittelte Dimension sozialer Ungleichheit" deutet (Weiß 2001; Weiß 2013). In Analogie zu Bourdieus Modell männlicher Herrschaft bestimmt Weiß Rassismus als „eine sich selbst stabilisierende Praxis der symbolischen Delegitimierung“ (Weiß 2001, S. 87): Durch den Verweis auf ihren möglichen Ausschluss werden rassistisch Klassifizierte tatsächlich aus diversen gesellschaftlichen Märkten ausgeschlossen bzw. in ihren Handlungsspielräumen eingeschränkt. Insofern sich die symbolische Klassifikation von „Rassen“ oder „Ethnien“ institutionell verfestigt und das Handeln auf verschiedenen Märkten beeinflusst, wird sie zu einer Ressource, zu einer Art negativem symbolischem Kapital (ebd., S. 88 ff.). Im Gegensatz zu weiten Teilen der existierenden Rassismusforschung nimmt Weiß mit dieser Herangehensweise vor allem diejenigen Formen rassistischer Diskriminierung in den Blick, die nicht im Rahmen symbolischer Kämpfe explizit verhandelt werden, in denen sozusagen nicht offen um den Wert der Ressource ,rassistisches symbolisches Kapital ' gestritten wird (ebd., S. 96): „Die Aspekte des Rassismus, die im Modus der symbolischen Gewalt vorliegen, werden [...] nicht im Rahmen von Meinungskämpfen reproduziert, sondern sind selbstverständlicher Bestandteil einer Weltsicht, eines Habitus.“ (Ebd., 97) Dieser „klassenspezifische[n] Habitus“, den rassistische dominierte wie dominante Akteurinnen und Akteure ausbilden, ist gemäß Bourdieus Habitus-Begriff weder „Produkt eines unbewussten Programms“ noch „Ausfluss eines bewussten rationalen Kalküls“. „Die Strategie“, mit der rassistische Klassifikationen angewandt werden,

„,ist vielmehr das Produkt des praktischen Sinns als eines ,Spiel-Sinns', eines Sinns für ein historisch bestimmtes, besonderes soziales Spiel, der in frühester Kindheit durch Teilnahme an den sozialen Aktivitäten ... erworben wird. Der gute Spieler, gewissermaßen das Mensch gewordene Spiel, tut in jedem Augenblick das, was zu tun ist, was das Spiel verlangt und erfordert.“ (Bourdieu zit. n. ebd.)

Mit der Bestimmung von Rassismus als einer Form symbolischer Gewalt nimmt Weiß also gerade solche Differenzkonstruktionen in den Blick, die als unhinterfrag- 
te (wenngleich potentiell problematisierbare) Grundlage der Reproduktion sozialer Ungleichheit funktionieren. Anhand dieser Funktionalität, so Weiß`Argument, lassen sich solche kulturellen Differenzkonstruktionen jenseits expliziter moralischer und politischer Verhaltensregeln als rassistische bestimmen. Die Theorieanlage von Weiß‘ Rassismuskritik schlägt somit eine Brücke zwischen Ungleichheits- bzw. Diskriminierungsforschung und Vorurteilbegriff. ${ }^{3}$

Einen ähnlichen Ansatz der Analyse sozialer Ungleichheit hat Peter Berger aus wissenssoziologischer Perspektive vorgelegt. Die institutionalisierten Ungleichheitstheorien (von Laien sowohl als von Sozialwissenschaftlern) fasst er unter dem Begriff der „Ungleichheitssemantiken“ zusammen (Berger 1989). Ebenfalls ausgehend von der Annahme einer fortlaufenden Macht- und Ressourcenkonkurrenz unterschiedlicher Gruppen und ihrer jeweiligen Ungleichheitskonstruktionen, definiert Berger im Anschluss an Niklas Luhmanns Semantikbegriff Ungleichheitssemantiken als ,höherstufig generalisierte, relativ situationsunabhängig verfügbare, aber doch historisch variable Regeln der Sinnverarbeitung und Wirklichkeitsdeutung, die Ungleichheit zum Thema haben“ (ebd., S. 49). Ähnlich der symbolischen Gewalt Bourdieus, die noch vor jeder selbstbewussten Strategie der Unterwerfung, Ausbeutung oder Exklusion die gesellschaftliche Struktur und deren Wahrnehmung hervorbringt, schreibt Berger den Ungleichheitssemantiken einen Doppelcharakter zu: Sie sind demnach nicht nur aggregiertes Resultat von „Orientierungsbestrebungen, Typisierungen, Klassifizierungen“ individueller Akteurinnen und Akteure, sondern

3 Es muss an dieser Stelle darauf hingewiesen werden, dass keiner der hier zitierten Ansätze den Begriff „Vorurteil“ explizit gebraucht. Im Gegenteil: Insbesondere die Arbeiten von Albert Scherr (Scherr 2011) und Anja Weiß (Weiß 2001, S. 81) grenzen ihr Diskriminierungs- bzw. Rassismuskonzept dezidiert vom Vorurteilsbegriff ab, den sie mit einer psychologischen Forschungstradition gleichsetzen. Ich möchte die funktionalistischherrschaftskritische Perspektive, die solche Ansätze bieten aber gerade mit dem Vorurteilsbegriff zusammenbringen, da mir die Trennung der beiden Bereiche eher durch disziplinäre Distinktionsbedürfnisse denn sachliche Differenzen begründet scheint. Zwar stimmt es, dass die sozialpsychologisch dominierte Vorurteilsforschung einen gesellschaftstheoretisch funktionalen Bezug auf Diskriminierung und Ungleichheit häufig allzu sehr vernachlässigt. In ähnlicher Weise aber, so könnte man sagen, verhält sich eine funktionale oder organisationale Diskriminierungsforschung, die die Phänomene Vorurteil und Diskriminierung in allzu separierten Sphären verortet. Sie tendiert dazu, zu übersehen, dass der Gegenstand der Vorurteilsforschung nahezu deckungsgleich ist mit jenen „Gruppenkonstruktionen“, die in diskriminierenden Praxen funktional werden (Hormel und Scherr 2006, S. 184). In der hier vorgeschlagenen Perspektive erscheinen also Diskriminierung und Vorurteil als zwei Hinsichten, die sich in der Betrachtung des Gegenstands wechselseitig bedingen: Keine Diskriminierung ohne vorurteilige Ungleichheitssemantiken, keine Vorurteile ohne diskriminierende Praxis. 
sie sind „,zugleich immer auch Voraussetzungen der Wahrnehmung und Beschreibung gesellschaftlicher Strukturen und Wirklichkeitsdeutungen“ (ebd., S. 49; Herv. F. K.). Die Semantik der sozialen Ungleichheit besitzt also ein Eigenleben, insofern sie sozusagen die weithin als Common Sense etablierte Grundlage bildet, auf der Ungleichheiten und deren Legitimität verhandelt werden. Ungleichheitssemantiken, die „Gesellschaften nach dem Modell von ,Großgruppen“ vorstellen“ und dabei „häufig auf askriptive, durch eigene ,Leistung“ in der Regel nicht veränderbare Merkmale“ zugreifen, konstituieren somit „Annahmen und Vermutungen über Zugehörigkeiten und Mitgliedschaften“ (ebd., S. 49). Sie bilden das unhinterfragte Regelwerk, nach dem im alltäglichen „Kampf um Klassifizierungen“ Ressourcenansprüche, Mitgliedschaften und Exklusionen ausgefochten werden.

Ferdinand Sutterlüty und Sighard Neckel haben in ihren Studien zu ethnozentrischer Diskriminierung den Begriff der Ungleichheitssemantik aufgegriffen (Neckel und Sutterlüty 2005; Sutterlüty 2010; Sutterlüty und Neckel 2012). Mit ihrem Konzept der

„,negativen“ Klassifikationen [...] wird die Aufmerksamkeit auf die diskriminierenden Aspekte der symbolischen Ordnung sozialer Ungleichheit gelenkt - auf jene Bewertungsmuster also, die einen restriktiven Einfluss auf die materiellen und kulturellen Aneignungschancen von Sozialgruppen haben“ (Neckel und Sutterlüty 2005, S. 410).

Indem die Autoren anhand ethnographischer Fallstudien zweier sozial benachteiligter Stadtteile nach dem Zusammenspiel ethnischer und soziostruktureller Gruppenzuschreibungen fragen, verknüpfen sie eine vorurteilstheoretische Perspektive mit der Analyse sozialer Ungleichheit: Welche Rolle spielen ethnische Grenzziehungen zwischen ,Deutschen“ und ,Ausländern“ (vornehmlich türkischer Herkunft) im Umgang der Stadtteilbewohner untereinander und inwiefern werden sie zum Mittel der Austragung alltäglicher „Klassifikationskämpfe“ (Sutterlüty und Neckel 2012, S. 145 ff.)? Die Autoren zeigen, wie kulturelle sich mit soziostrukturellen Differenzkonstruktionen verbinden, und wie sich aus dieser Mischung verfestigte Muster der Diskriminierung ergeben. Hierbei legen sie besonderes Gewicht auf die von Berger vorgeschlagene Unterscheidung von ,graduell-quantitativen“ und ,kategorial-exklusiven“ Semantiken (Berger 1989, S. 54; Neckel und Sutterlüty 2005, S. 414 ff.). Durch erstere werden Personengruppen ,,unter dem Gesichtspunkt von quantitativen Differenzen“ beurteilt und in eine Rangfolge horizontaler Hierarchie gebracht (Neckel und Sutterlüty 2005, S. 414). Zugleich ist aber die „Logik der Differenz“ gradueller Klassifikationen ,über alle Rangstufen hinweg ,konjunktiv“ (Mannheim) organisiert, weil sie auf der Annahme intersubjektiv geteilter Erfahrungsräume und gemeinsamer Eigenschaften beruht“" (ebd.). Dementsprechend haben graduelle Klassifikationen ,eine Affinität zu erworbenen Merkmalen wie Einkommen, Bildung und beruflichem Status, da diese Merkmale in sich veränderlich 
und in ihrer sozialen Wertigkeit verhandelbar sind“ (ebd.). Kategoriale Klassifikationen hingegen strukturieren keine Rangordnung prinzipiell vergleichbarer und potentiell statusmobiler Gruppen, sondern ,ein Nebeneinander sich wechselseitig ausschließender Kategorien“ (ebd.). Sie haben daher eine besondere Affinität zu askriptiven Merkmalen wie „Ethnizität, Religion und Geschlecht“ die ,als unveränderlich gelten und als Gegensatzpaare [...] auftreten“ (ebd.). Während die symbolische Ordnung nach graduellen Unterscheidungen also zwischen denen ausgefochten wird, die entweder schon distinguiert oder zumindest Aspiranten auf Distinktion sind, konstruiert die „Ideologie der Ungleichwertigkeit“ kategorialer Klassifikationen einen Gegensatz „kultureller Unwürdigkeit“ (Neckel und Sutterlüty 2005, S. 415). Damit haben kategoriale Klassifikationen ein besonders ausgeprägtes Potential zur „Naturalisierung“ (Giesen 1993, S. 52) sozialer Ungleichheiten, indem sie sozusagen die Grenze zwischen der Teilhabe an den legitimen Ungleichheitsverhältnissen und einem außergesellschaftlichen Anderen markieren. Bernard Giesen, auf den Sutterlüty und Neckel verweisen, fasst dies wie folgt zusammen:

„Die Auswirkungen sozialen Handelns auf die Genese der fraglichen Ungleichheiten werden in diesem Falle für neutral erklärt und die Unterschiede natürlicher Faktoren für die Entwicklung von Ungleichheit verantwortlich gemacht. ,Soziale Ungleichheit“ wird hier gleichsam dem Geltungsbereich des Gleichheitsideals entzogen und vom Begründungs- und Veränderungsdruck befreit.“ (Giesen 1987, S. 326)

Der Effekt einer Naturalisierung sozialer Ungleichheit ist allerdings nicht auf den Bereich kategorialer Klassifikationen begrenzt. Wie oben bereits argumentiert wurde, beginnt die Problematik als natürlich institutionalisierter Ungleichheiten nicht erst mit dem radikalen Ausschluss gesellschaftlicher Gruppen von jeglicher Teilhabe, sondern auch und gerade die alltäglichen Distinktionspraxen innerhalb sozialer Gefüge basieren auf solchen naturalisierenden Differenzkonstruktionen. Dementsprechend betonen Neckel und Sutterlüty, dass die Unterscheidung von kategorialen und graduellen Klassifikationen als analytische Heuristik zu verstehen sei, nicht als strikte begriffliche Unterscheidung: „In der sozialen Praxis werden graduelle und kategoriale Ungleichheitssemantiken auf mannigfaltige Weise miteinander verwoben." (Neckel und Sutterlüty 2005, S. 416) Auch ein Umschlag von graduellen in kategoriale Unterscheidungsmuster sei häufig zu beobachten, wozu die Autoren den kategorisierenden Gebrauch von gewöhnlich als graduell konzipierten Merkmalen wie Intelligenz oder Reichtum bzw. Armut als Beispiele anführen. In der Praxis der Distinktion und Exklusion sind Ungleichheitssemantiken also grundsätzlich flexibel zu gebrauchen, d.h. sie sind nicht als ,rein semantische‘ Kategorien zu verstehen: 
Struktur jeweils nur am konkreten Gebrauch ablesen lässt. Man muss die sozialen Verwendungsweisen negativer Kategorisierungen in Erfahrung bringen, um ihren graduellen oder kategorialen Gehalt bestimmen zu können. [...] Wenn sich Semantik und Pragmatik negativer Klassifikationen ohne einander gar nicht explizieren lassen, müssen die Handlungskontexte untersucht werden, in denen sie ihren sozialen Sitz haben, wenn man ihre Sinnstruktur erfassen will." (Sutterlüty 2010, S. 75 f. $)^{4}$

Darüber hinaus ist $\mathrm{zu}$ beachten, dass stets verschiedene Ungleichheitssemantiken gemeinsam auftreten und sich in ihrer Bedeutung bzw. ihrem Gebrauch wechselseitig beeinflussen. So hat die Studie von Sutterlüty und Neckel etwa ergeben, dass sich in den untersuchten Stadtteilen ein spezifisches Zusammenspiel kategorialer und gradueller Semantiken beobachten lässt. Zwar spielen „Merkmale vertikaler Ungleichheiten durchaus eine große Rolle“, aber „,der Bewertung aller Unterschiede hinsichtlich Bildung, Einkommen und beruflichem Status ist [...] eine Sortierung nach ethnischen Kriterien vorgelagert“, die wiederum einer kategorialen Logik folgt (ebd., S. 78). Durch diesen kategorialen Filter werden graduelle Variablen, wie z.B. beruflicher Erfolg oder Einkommen, in einen anderen Modus der Bewertung überführt: Arbeitslose Mitglieder der ethnisch klassifizierten Outgroup werden somit zu „Schmarotzern“, die den Sozialstaat ausnutzen, während gegenüber Mitgliedern der Eigengruppe viel eher ökonomische Gründe für Erwerbslosigkeit zur Geltung kommen und Anspruch auf wohlfahrtsstaatliche Hilfe zugestanden wird. Ebenso werden erfolgreiche Outgroup-Mitglieder als „dubiose Geschäftemacher“ beargwöhnt, die nur durch unlautere Geschäftspraxen zu ihrem Reichtum gekommen sein können (vgl. ebd.), wogegen ähnliche Praxen und Erfolge bei Mitgliedern der Eigengruppe Respekt abnötigen. Ein wichtiger Aspekt des Gebrauches negativer Klassifikationen ist also deren Zusammenspiel mit anderen, häufig , an sich “ nicht diskriminierenden Klassifikationsmustern. Sutterlüty und Neckel weisen damit, ähnlich wie Albert Scherr (vgl. Kap. 4.1), auf die theoretische Unzulänglichkeit einer klaren Unterscheidung von normativ-politischer Diskriminierung und wertneutraler Ungleichheit hin. ${ }^{5}$ Ihr Hinweis auf das Zusammenspiel kategorialer und gra-

4 Sutterlüty hat dementsprechend vorgeschlagen, den Begriff der Ungleichheitssemantik durch den der „Ungleichheitspragmatik“ (Sutterlüty 2004; Neckel und Sutterlüty 2005, S. 421) zu ergänzen, um die Perspektive einer Praxistheorie der Bedeutung, das reziproke Verhältnis von Semantik und Gebrauch, stärker in der Analyse symbolischer Ordnungen sozialer Ungleichheit zu verankern. In ähnlicher Weise stellt übrigens Anja Weiß bzgl. der semantischen Gehalte rassistischer Klassifikationen fest, dass diese prinzipiell kontingent seien (vgl. Weiß 2001, S. 88).

5 Auf vergleichbare Weise argumentiert auch Anja Weiß, wenn sie beschreibt, wie die diskriminierenden Effekte rassistischen symbolischen Kapitals nicht zuletzt durch dessen Interaktion mit anderen Formen symbolischen, sozialen und ökonomischen Kapitals entste- 
dueller Klassifikationen bedeutet weiterhin, dass die naturalisierende Abschirmung von Ungleichheitssemantiken gegen den „Begründungs- und Veränderungsdruck“ egalitärer Normen durch Institutionalisierung, kein alleiniges Merkmal kategorischer Klassifikationsmuster ist. Die Verselbständigung zu Formen symbolischer Gewalt, d.h. zu fraglos akzeptierten und reproduzierten Deutungsmustern, ist vielmehr eine grundlegende Tendenz von Ungleichheitssemantiken.

\subsection{ZWISCHENFAZIT: VORURTEILE ALS UNGLEICHHEITSSEMANTIKEN}

Wie die erläuterten Theorieansätze von Weiß, Kreckel, Sutterlüty und Neckel gezeigt haben, kann vor dem Hintergrund der Idee einer symbolischen Ordnung sozialer Ungleichheit die Unterscheidung zwischen normativ-problematischer Diskriminierung und objektiver bzw. wertneutraler Ungleichheit nicht aufrechterhalten werden. Vielmehr muss jede Form sozialer Ungleichheit als kontingente gesellschaftliche Praxis betrachtet werden, und unterliegt somit prinzipiell einem Legitimationsdruck. Mit den Begriffen der Ungleichheitssemantik bzw. der symbolischen Gewalt wurden die Handlungs- und Wahrnehmungsmuster bezeichnet, die die Reproduktion sozialer Ungleichheit gegen bestehende Legitimationsdrücke aufrechterhalten und tendenziell als quasi-natürliche, unhinterfragte Normalität institutionalisieren. Für eine funktionalistische Perspektive auf Vorurteile wird damit eine Brücke zwischen Diskriminierungs- und Vorurteilsbegriff geschlagen, wie die Arbeiten von Weiß, Neckel und Sutterlüty verdeutlichen: Rassismus und Fremdenfeindlichkeit, die klassischen Gegenstände der Vorurteilsforschung, können als Ungleichheitssemantiken bzw. Formen symbolischen Kapitals betrachtet werden, d.h. als kulturelle Differenzkonstruktionen, die der Reproduktion legitimationsbedürftiger Ungleichheiten dienen.

Aufgrund der festgestellten Unschärfe der Unterscheidung von Ungleichheit und Diskriminierung folgt aus diesem Brückenschlag zwischen Diskriminierungsund Vorurteilsbegriff allerdings noch kein genaueres Kriterium für die Bestimmung von Vorurteilen. Das zum Schluss von Kapitel 2 formulierte Ausgangsproblem, die Unzulänglichkeit einer kriteriellen Bestimmung von Vorurteilen, wiederholt sich hier gewissermaßen in einem anderen begrifflichen Register. Wenn man Vorurteile über ihre Funktionalität für die Reproduktion von Diskriminierung begreift, d.h. als bestimmte Ungleichheitssemantiken, stellt sich sogleich die Anschlussfrage, welche

hen: Für rassistisch Dominierte sinkt der Tauschwert verfügbarer anderer Kapitalien, so dass ein ansonsten gleichwertiger Bildungsabschluss eines als ,Ausländer' Markierten sich bspw. auf dem Arbeitsmarkt zu deutlich schlechteren Konditionen eintauschen lässt, als derjenige eines ,Autochthonen“ (Weiß 2001, S. 91). 
Formen sozialer Ungleichheit hierbei relevant werden. Zwar mag man eine Funktionalität bestimmter Stereotype in Praxen der Diskriminierung als notwendiges und hinreichendes Kriterium einer Vorurteilsdefinition annehmen; vor dem Hintergrund der Einsicht, dass prinzipiell jedes Ungleichheitsverständnis auf seine normativen, herrschaftskonstitutiven Aspekte hin zu befragen ist, wird dieses Definitionskriterium jedoch wiederum unscharf. Auch die Unterscheidung kategorialer und gradueller Klassifikationen, die in den Arbeiten Neckels und Sutterlütys besondere Berücksichtigung findet, leistet hier nur bedingt Abhilfe. Die Autoren selbst weisen auf die semantisch-inhaltliche Kontingenz der kategorialen ebenso wie der negativen Bedeutung von Klassifikationen hin: Sie kommen damit zu dem Schluss, den ähnlich die vorliegende Arbeit in Kapitel 2 und 3 formuliert hat, dass es keine streng definierbaren formalen Kriterien für negative, diskriminierende Differenzkonstruktionen geben kann, jenseits von deren negativem und diskriminierendem Gebrauch.

Um eine genauere Verwendung des Vorurteilskonzeptes zu gewährleisten, scheint also, wie in Kapitel 3.4 bereits erörtert, die Explikation der Hinsicht (vgl. Müller 2012) entscheidend, in der einem Gegenstand das Prädikat , antiamerikanisch“ zugewiesen wird. Dies bedeutet einerseits eine genaue empirische Beschreibung der Tätigkeiten antiamerikanisch sprechhandelnder Akteurinnen und Akteure, sowie andererseits eine möglichst weitreichende Reflexion der Tätigkeit dieser (anti-antiamerikanischen) Beobachtung selbst.

Wenngleich also durch die skizzierte ungleichheitstheoretische Ergänzung kein striktes Kriterium zur Bestimmung von Vorurteilen in praxistheoretischer Perspektive gewonnen werden kann, so scheint mir dennoch ein wichtiger theoretischer Gewinn aus dieser sozialtheoretischen Einordnung zu erwachsen: Das Verschwimmen von normativ-problematischer Diskriminierung und nicht-normativer Ungleichheit verweist die Vorurteilsforschung mit Nachdruck auf den Rechtfertigungsaspekt moderner vorurteiliger Rhetorik. Wenn Ungleichheit potentiell nahtlos übergeht in Diskriminierung, d.h. jede Ungleichheit ein diskriminierendes Potential hat, so muss im Umkehrschluss jedes Vorurteil sich potentiell in ,normale', nicht problematisierte Ungleichheitsdiskurse verlängern. Was wir als Vorurteil kritisieren, sind dann nicht (nur) Differenzkonstruktionen, die sich eindeutig außerhalb des Bereiches normaler kultureller und soziostruktureller Grenzziehungen verorten ließen, sondern es sind solche, die in die normalen alltäglichen Distinktionspraxen eingebettet sind und als Teil dieser Normalität beständig sich rechtfertigen und legitimieren. In der Terminologie Bourdieus könnte man sagen, dass sich das Vorurteil gewissermaßen in der Grauzone zwischen (impliziter) symbolischer Gewalt und (explizitem) symbolischem Kampf bewegt: Vorurteilig ist solches Handeln, das einerseits die aktuell geltenden Regeln des egalitären Normvollzuges verletzt (durch ethnozentrische Exklusion, homophobe Diskriminierung, etc.) und in dieser Hinsicht klar Teil symbolischer Kämpfe ist; es wurde als Muster der Reproduktion sozialer Ungleichheit bereits problematisiert und gilt nicht mehr uneingeschränkt als 
selbstverständlicher Common Sense. Andererseits versuchen Vorurteile ihre eigene Position gewissermaßen in den Bereich symbolischer Gewalt zurückzuverlegen, die eigenen Grenzziehungen, Forderungen etc. als Ausdruck genau jenes egalitären Common Sense zu markieren, als dessen Verletzung sie kritisiert werden.

Die Vorurteilskritik hätte dementsprechend an ihrem Gegenstand nicht nur zu zeigen, wie dieser als rhetorisches Mittel der Reproduktion von Herrschaftsverhältnissen bzw. einer systematischen Ungleichverteilung von Lebenschancen dient; sondern es wäre insbesondere auch zu untersuchen, inwiefern es dem Vorurteil gelingt, diese Herrschaftsfunktion als Common Sense, und d.h. hier: als egalitär, auszuflaggen. Um besser zu verstehen, wie vorurteiliges Verhalten mit egalitären Normen in Einklang zu bringen ist, lohnt ein genauerer Blick auf die Struktur der modernen Gleichheitsidee. Wie wir im folgenden Abschnitt sehen werden, ist diese durch einen immanenten Widerspruch zwischen individuellen Bedürfnissen und allgemeiner Gleichbehandlung gekennzeichnet, der eine Regelung ihres Vollzuges durch universelle Gesetzmäßigkeiten verhindert. Der Vollzug der Gleichheitsnorm ist vielmehr abhängig von einem kontingenten ,deskriptiven Gehalt“ der Gleichheit (Menke 2004, S. 39) der eine je historische Antwort auf die Frage gibt: Welche Personengruppen können in welcher Hinsicht Gleichheit beanspruchen? Dabei ist für die moderne Gleichheitsidee entscheidend, dass nicht nur das Prinzip einer universellen Gleichheit der Menschen (im Gegensatz zu universell gesetzten Gruppendifferenzen) als Norm etabliert wird, sondern ebenso die Kontingenz des Vollzuges dieser Gleichheit reflektiert wird. Wenn dies zutrifft, also Gleichheit nur in einem andauernden Streit bzw. Aushandlungsprozess besteht, so lassen sich als problematisch im Sinne von antiegalitär nicht nur solche Handlungspraxen ausweisen, die sich explizit gegen das Prinzip der Gleichbehandlung richten, sondern auch ,schon* solche, die die Kontingenz der normativen Grundlagen solcher Gleichbehandlung nicht anerkennen. Der Gegenstand einer ungleichheitstheoretisch informierten Vorurteilskritik wären somit solche Praxen, die zwar Gleichheit als politisches Ideal für sich in Anspruch nehmen, zugleich aber die prinzipielle Variabilität und historische Gemachtheit der von ihnen verwendeten Differenzkonstruktionen und Verteilungsregeln durch Naturalisierung verdecken.

\subsection{DER IMMANENTE WIDERSPRUCH DER EGALITÄREN NORM UND DIE RECHTFERTIGUNG KATEGORIALER DIFFERENZKONSTRUKTIONEN}

Um die Funktionsweise von Vorurteilen als rhetorische Reproduktion kategorialer Ungleichheit zu verdeutlichen, kann erneut auf die oben zitierte Studie von Sutterlüty und Neckel verwiesen werden. Deren Beschreibung des Zusammenspiels „,ka- 
tegorialer“ und „gradueller Klassifikationen“ kann als eine Form der Naturalisierung von Ungleichheitssemantiken gelten, wobei die graduellen Klassifikationen eine legitimierende Funktion für kategoriale Grenzziehungen einnehmen, indem sie diese an ,beobachtbaren Fakten' (geringer ökonomischer Erfolg, moralische Minderwertigkeit, etc.) vermeintlich belegen. Ausgangspunkt hierbei ist auch für Sutterlüty und Neckel der Widerspruch kategorialer Klassifikationen - insbesondere ethnischer bzw. rassistischer und nationalistischer, die nach wie vor eine zentrale Funktion in der symbolischen Ordnung sozialer Ungleichheit übernehmen (vgl. Sutterlüty 2010 \#418\}, S. 78 ff.) - mit dem normativem Ideal der Gleichheit, das in Einwanderungsgesellschaften mit demokratisch-egalitärem Selbstverständnis zugleich vorherrscht. So stellen die Autoren fest, dass sich die kategorial klassifizierenden und exkludierenden Personen in ihrem Forschungsfeld keineswegs als fremdenfeindlich, rassistisch oder auf sonst irgendeine Weise antiegalitär wahrnehmen:

„Vielmehr ist zu beobachten, dass die meisten Einheimischen in Barren-Ost und IderstadtSüd diesen deterministischen und kollektivierenden Modus negativer Klassifizierung als Zeugnis illegitimer Vorurteilsbeladenheit zurückweisen. Die Norm, jeden Menschen unabhängig von seiner ethnischen Zugehörigkeit zu sehen und zu bewerten, ist sehr präsent. Sie ist dafür verantwortlich, dass die deutschen Stadtteilbewohner ihre negativen Zuschreibungen auf beobachtbare Verhaltensmerkmale ihrer türkischstämmigen Nachbarn beziehen - um nicht zu sagen: Sie suchen und finden diese Merkmale.“ (Sutterlüty 2010, S. 78 f.)

Ich möchte an dieser Stelle auf die große Nähe dieser Beobachtungen zu den Überlegungen Michael Billigs zu „,ideological dilemmas“ in vorurteiliger Rhetorik hinweisen (Billig 1988; vgl. auch Kap. 2.3.1 und 2.3.3). Auch die Teilnehmer der Studie von Neckel und Sutterlüty scheinen einer doppelten Sanktionierung zu unterliegen, der zufolge sie einerseits kategoriale Abwertungen vollziehen, andererseits aber auch egalitären Ansprüchen genügen wollen, die in Widerspruch zu solchen kategorialen Klassifikationen stehen. Die negativ Klassifizierenden begeben sich bei der Lösung dieses Dilemmas allerdings in einen performativen Selbstwiderspruch: Indem sie ihre rassistische oder ehtnozentrische Klassifikation durch ,Fakten' rechtfertigen, tun sie genau das, wogegen sich diese Rechtfertigung abgrenzen will - sie stabilisieren die von ihnen reproduzierten Muster kategorialer Ungleichheit. Vermeintlich wertneutrale, objektive Unterscheidungen werden zum Ausdruck einer kategorial-diskriminierenden Differenzsetzung.

Diesen paradoxen Effekt moderner Ungleichheitssemantiken, das Nebeneinander von egalitärer Orientierung und kategorial ethnifizierender Exklusion, hat Sutterlüty in historisch-genealogischer Perspektive als ,,paradoxale Folgen ethnischer Gleichheit“" beschrieben (Sutterlüty 2011). Das Paradox ethnischer Gleichheit besteht demzufolge darin, dass die Angehörigen der Mehrheitsgesellschaft einerseits den Grundsatz der Gleichberechtigung unabhängig von ethnischen Klassifikationen 
befürworten; und das in einem Maße, das zu einer politischen Implementierung in Staatsbürgerrecht und anderer Gesetzgebung führt (ebd., S. 104 f.). Andererseits scheinen sie zugleich eine Vorstellung von Differenz gegenüber den neuerdings gleichberechtigten ,Fremden“ durchsetzen zu wollen, vor deren Hintergrund diese Gleichberechtigung als ein ,Zuviel“" und letztendlich als Bedrohung wahrgenommen wird (ebd., S. 109). Sutterlüty stellt nun fest, dass dieser Befund nur begrenzt durch ein „competitive threat model“ (ebd., S. 110) begriffen werden kann, demzufolge die Gleichheitsideale der Mehrheit sozusagen von Statusängsten situativ ,übertrumpft‘ würden, denn es erklärt nicht, warum fast ausschließlich die ,ethnischen' Konkurrenten abgewertet werden, nicht aber die Aufsteiger und Konkurrenten aus der Eigengruppe. Er folgert, dass neben dem Gleichheitsgrundsatz und dem ökonomischen Bedrohungsempfinden ,primordialistische Vorstellungen“ einer „ethnischen Differenz“ bzw. eines ,ethnischen ,Verwandtschaftsglaubens“" existieren (ebd., S. 111; vgl. auch Giesen 1993, S. 49 ff.), die als zusätzliche Erklärungsgröße herangezogen werden müssen. Diese ,symbolische Tiefendimension ethnischer Ungleichheit“" (ebd., S. 113) fungiert dann in Kombination mit dem ökonomischen Bedrohungsempfinden, als vermittelnder gesellschaftlicher Prozess, der die paradoxe Wirkung des Gleichheitsgrundsatzes begründet: dass die Teilnehmenden der Studie dem Ideal der Gleichberechtigung verpflichtet scheinen und doch gerade die avancierenden Nachbarn mit Migrationshintergrund als ,Türken' stigmatisieren und abwerten, deren Aufstieg die Befürwortung der Gleichheit befördert.

Jenseits genealogisch-historischer Nachvollzüge solcher Paradoxien verhilft es zu einem klareren Verständnis der von Sutterlüty beschriebenen und ähnlichen Rhetoriken, wenn man sich vor Augen führt, dass die moderne Gleichheitsidee keinen prinzipiellen Einwand gegen solche widersprüchlichen Normvollzüge formuliert. Sie ist vielmehr selbst durch einen immanenten Widerspruch zwischen der Berücksichtigung individueller Bedürfnisse und einem Imperativ der Gleichbehandlung gekennzeichnet. Daraus folgt freilich keine Erklärung dafür, dass sich Akteurinnen und Akteure zugleich auf egalitäre und antiegalitäre Prinzipien berufen. Aus der Feststellung, dass die Gleichheitsnorm sowohl vergleichende wie differenzierende Momente beinhaltet, lässt sich nicht ableiten, dass diese sich auf irgendeine bestimmte weise oder in einem bestimmten Verhältnis realisieren müssen. Es eröffnet aber eine Theorieperspektive, in der die Normalität und damit zugleich die spezifisch ideologische Problematik (vgl. Kap. 4.5.1) solcher egalitär-antiegalitären Normvollzüge erschlossen werden kann.

Christoph Menke betont in seiner Kritik der modernen Gleichheitsidee zunächst deren unangefochtenes Primat als normatives Ideal moderner Vergesellschaftung:

„Fragen wir nach den Pflichten und Rechten, die wir einander gegenüber haben, so ist die erste Antwort der Moderne, dass es Pflichten und Rechte der Gleichheit sind: Gleichheit ist die vorrangige normative Idee der Moderne.“ (Menke 2004, S. 22) 
Die Frage nach einer gerechten gesellschaftlichen Ordnung ist demnach im politischen Diskurs der Moderne untrennbar verknüpft mit der Idee einer Gleichheit der Gesellschaftsmitglieder: Gleichheit ist die moderne Bedingung von Gerechtigkeit. Die Verwirklichung solcher Gleichheit ist aber, wie Menke betont, nicht als Herstellung von Unterschiedslosigkeit zu verstehen, sondern im praktischen Sinn einer gleichen Berücksichtigung ungleicher Individuen:

„Der Ausdruck ,Gleichheit“ meint in der genannten Ausgangsformulierung die gleiche Berücksichtigung aller. Die moderne Idee der Gleichheit meint nicht Gleichsein, erst recht nicht Gleichmachen, aber auch nicht Gleichverteilung. [...] Gleichheit hat hier nicht den theoretischen Sinn, dass sich zwischen den betrachteten Elementen keine Unterschiede feststellen lassen, sondern einen praktischen Sinn: dass zwischen ihnen keine Unterschiede gemacht werden.“ (Ebd.)

Damit kommt der modernen Idee der Gleichheit einerseits ein Vorrang gegenüber anderen rechtlichen und moralischen „Arten der Verbindlichkeit“ zu (ebd., S. 25); dies impliziert aber zugleich, dass es neben der Gleichheit noch andere Arten normativer Verbindlichkeit gibt, und dass auch diese nicht-egalitären Verbindlichkeiten in Recht und Moral anerkannt und berücksichtigt werden: Als Beispiele nennt Menke Gnade und Amnestie im Recht sowie Treue, Freundschaft und Mitleid in der Moral. Bei diesen normativen Verbindlichkeiten handelt es sich gerade um solche „Verpflichtungen, in denen es nicht um die Gleichheit, sondern die Eigentümlichkeit der Beteiligten geht. [...], Eigentümlichkeit‘ ist hier ein anderes Wort für Individualität, sei es die Individualität einer gemeinsamen Lebensform oder eines einzelnen Lebens“ (ebd.). Im Vollzug der egalitären Norm in Recht und Moral treten also Verbindlichkeiten der Individualität neben solchen der Gleichheit auf, und es ist gerade das Spannungsverhältnis zwischen diesen beiden Orientierungen, das für die egalitäre Haltung charakteristisch ist: Die moderne Idee der Gleichheit ist dialektisch verfasst, d.h. sie beinhaltet ihre Negation als Bedingung. Menke formuliert diesen immanenten Widerspruch im Hinblick auf die Kontroverse zwischen egalitären und anti-egalitären Positionen in der praktischen Philosophie:

\footnotetext{
„Denn die normative Orientierung an Individualität, von der aus die Idee der Gleichheit von außen befragt wird, tritt im inneren Vollzug der Gleichheit selbst schon auf; wir beziehen uns auf sie, genauer: wir übernehmen diese andere normative Orientierung gerade auch dann, wenn es uns um Gleichheit geht. [...] Die moderne Idee der Gleichheit und die normative Verpflichtung aus Individualität unterliegen einer unauflöslichen Dialektik: Sie bestehen nur in ihrem Übergehen in ihren Gegensatz.“ (Ebd., S. 28)
}

Mit dieser Spannung zwischen individuellen Bedürfnissen und Lebensvorstellungen und deren allgemeiner Gleichberücksichtigung lässt sich die Kontingenz des Voll- 
zuges der egalitären Norm begründen. Diese existiert in einem fortlaufenden, unabgeschlossenen und nicht zu allen Seiten hin durch Regeln begrenzten Prozess der Aushandlung bzw. des Streits darum, welche Gruppen hinsichtlich welcher Merkmale gleich zu behandeln sind. ${ }^{6}$ Es ist dieser ,deskriptive Gehalt“ der Gleichheit, die den historischen Vollzügen der egalitären Norm ihre Gestalt gibt:

„Gleichheit ist nicht Gleichverteilung, und das gleiche Maß an Berücksichtigung verlangt nicht die gleiche Menge an Verteilbarem. Vielmehr heißt Gleichbehandlung häufig, einen anderen anders zu behandeln als andere: weil er in einer relevanten Hinsicht ,bedürftiger ‘ ist. [...] Das zeigt: Gleichheit und Ungleichheit sind hier - auch hier - perspektivenrelative, oder genauer: sie sind beschreibungsrelative Ausdrücke. [...] Zeichnen wir eine bestimmte Handlungsweise normativ als gleiche Berücksichtigung eines anderen aus, so hat das stets einen deskriptiven Gehalt: Es impliziert zu sagen, als wer, in welcher Bestimmung der andere durch diese Handlungsweise gleichermaßen berücksichtigt wird. Den anderen gleich zu behandeln setzt voraus, den anderen als in bestimmten Hinsichten Gleichen zu beschreiben; Gleichbehandlung bedarf Gleichbeschreibung. “ (Ebd., S. 39 f.)

Die Gleichberücksichtigung von Individuen hat also prinzipiell eine als-Struktur, insofern wir um diese als Gleiche zu behandeln, sie entsprechenden Gruppenkategorien zuordnen, sozusagen einen Vergleichsmaßstab anlegen müssen. Zur begrifflichen Fassung dieser gesellschaftlich wirksamen Vergleichsmaßstäbe der egalitären Norm gebraucht Menke den Terminus „Personenauffassungen“:

„Die Person, die wir gleichermaßen berücksichtigen, ist der einzelne, aber der einzelne nicht als je besonderer, sondern der einzelne, sofern er unter eine allgemeine Beschreibung ge-

6 Eine ähnliche These formuliert Niklas Luhmann in seiner kommunikationstheoretischen Beschreibung der Ko-Evolution von Gesellschaftsstruktur und Semantik. Während in stratifizierten und segmentierten Gesellschaften Personen einer Gruppe bzw. einem Teilsystem zugeordnet waren und das Gleichheitspostulat sich somit gewissermaßen an „Gattungsmerkmalen“ festmachte, orientiert sich die Gleichheitsidee funktional differenzierter Gesellschaften paradoxerweise an der Individualität der zu inkludierenden Personen: „Gerade im Hinblick auf ihre Einzigartigkeit gelten dann die Menschen als gleich [...]. Gleichheit wird sozusagen das soziale Regulativ für die Verwendung von Einzigartigkeiten.“ (Luhmann 1980, S. 31) Die Inklusion der Gesellschaft nach modernen Gleichheitsmaßstäben ist umso größer, je mehr die Individualität der einzelnen Personen dabei realisiert wird. Vgl. hierzu auch Michael Walzers Konzept der „Komplexe[n] Gleichheit“, das ebenfalls auf die Wandelbarkeit und „Vielfalt von Distributionsverfahren, Distributionsagenten und Distributionskriterien“ sozialer Ungleichheit und die damit zusammenhängende Problematik von Gerechtigkeitsurteilen verweist, die auf der Grundlage von Gleichheitspostulaten getroffen werden (Walzer 2000, S. 172 f.). 
bracht werden kann. Nur Personen, die in bestimmten allgemeinen Hinsichten gleich sind oder gleich beschrieben worden sind, können normativ als Gleiche gelten. Die Person ist die Maske der Gleichheit, unter der die einzelnen in das Blickfeld der egalitären Einstellung treten.“ (Ebd., S. 41)

Die von Menke beschriebenen „Masken der Gleichheit“ stehen in großer theoretischer Nähe zu Bergers Ungleichheitssemantiken, insofern sie ebenfalls den allgemein verfügbaren, relativ stabilen Sinn der Gleichheitsnorm in einer bestimmten Gesellschaftsformation beschreiben. Personenauffassungen machen also einen entscheidenden Teil jener symbolischen Ordnung sozialer Ungleichheit aus, indem sie die prinzipiell kontingente Anwendung der egalitären Norm konkret regeln. Aber auch bei Menke wird dieser Prozess nicht als bruch- und reibungsloser Ablauf etablierter Interaktionsformen gedacht, wie seine dialektische Konzeption der Gleichheitsidee bereits nahelegt. So wie es bei Bourdieu einen Wechsel zwischen dem ,alltäglichen Klassenkampf“" der symbolischen Gewalt und den explizit politisierten symbolischen Kämpfen gibt, geht auch Menke davon aus, dass die institutionalisierten Personenauffassungen stets drohen, in Legitimationskrisen zu geraten:

„[...] wir verlassen uns auf ein bestimmtes Vorverständnis der abstrakt beschriebenen Züge von Personen, die in der Einstellung der Gleichheit bedeutsam sind. Gelegentlich jedoch [...] wird dieser deskriptive Gehalt unserer normativen Einstellung ausdrücklich und thematisch: dann nämlich (aber gewöhnlich auch nur dann), wenn ein Problem auftaucht. Dann erst erscheint die unproblematisch vorausgesetzte Personenauffassung als ein ,Vorurteil' (Gadamer) und die mit ihrer Hilfe gewonnene Formulierung der Einstellung der Gleichheit in einer (rechtlichen oder moralischen) Regel lediglich als eine ,Prima-Facie-Verpflichtung: Als ein notwendiger, aber zu prüfender Ausgangspunkt.“ (Ebd., S. 42)

Menke schafft hier eine Verknüpfung von Ungleichheitsdiskurs und Vorurteil: Vorurteile sind demnach problematisierte Personenauffassungen bzw., im Anschluss an Berger, problematisierte Ungleichheitssemantiken. Die Vorurteilskritik markiert damit gewissermaßen den Bereich des Ungleichheitsdiskurses, in dem über die Unterscheidung zwischen legitimer Ungleichheit und antiegalitärer Diskriminierung gestritten wird. Genauer gesagt: er markiert einen Aspekt dieses Bereiches, denn nicht alle Positionen im Streit um die Auslegung der Gleichheitsnorm sind notwendig Vorurteile oder bestimmen solche als Problem. ${ }^{7}$ Welchen Inhalt ei-

7 Wenn bspw. die deutsche Belegschaft des Versandhändlers Amazon für Tariflöhne und eine Einstufung nach den üblichen Standards des Versandhandels streitet und damit die von ihrem Arbeitgeber (und zumindest Teilen der Belegschaft) bislang als normal akzeptierten Lohn- und Beschäftigungsverhältnisse problematisiert, so wird sie dies höchstwahrscheinlich nicht unter Verweis auf ,Vorurteile“ des Amazon-Managements tun. 
ne vorurteilskritische Problematisierung von Personenauffassungen hat, bleibt mit dieser Bestimmung also zunächst offen. Die von Neckel und Sutterlüty gebrauchte Unterscheidung von kategorialen und graduellen Klassifikationen wurde als ein näherungsweises Kriterium vorgeschlagen, um vorurteilige von nicht-vorurteiligen Ungleichheitssemantiken zu unterscheiden: Als Vorurteil würden dann insbesondere solche Formen des antiegalitären Vollzuges der Gleichheitsnorm kritisiert, die mit zugeschriebenen Gruppenmerkmalen wie Ethnizität, Geschlecht, sexueller Orientierung oder Alter verfestigte Differenzkonstruktionen verbinden. Auch hiermit ist freilich kein inhaltliches Kriterium gegeben, denn auch kategoriale Gruppenzuschreibungen sind nicht notwendigerweise Gegenstand von Vorurteilskritik. Als zusätzliche systematische Bestimmung wurde zum Ende des vorigen Abschnittes die These herangezogen, dass das ,Kategoriale“ an kategorialen Klassifikationen keine formal-semantische Eigenschaft der Grenzziehung bezeichnet, sondern das Ausblenden von deren eigener Kontingenz. Nach dieser Auffassung beginnen Klassifikationen also an dem Punkt kategorial zu werden, an dem sie eine Naturalisierung von Ungleichheit im Rahmen egalitärer Normvorstellungen betreiben, d.h. ihre eigenen Grenzziehungen außerhalb des Bereiches der Rechtfertigung zu stellen versuchen.

Nun bleibt auch diese Bestimmung, die den Abbruch von Reflexivität im vorurteiligen Sprechen zu dessen wichtigstem Merkmal macht, eine formal-abstrakte Bestimmung, die für sich genommen kein hinreichendes Kriterium für einen Vorurteilsbegriff bietet. Wenn Naturalisierung als Ausblenden der Kontingenz getroffener Unterscheidungen gefasst wird, so fallen unter diesen Gegenstandsbereich eine Vielzahl alltäglicher Praktiken, die keinesfalls alle sinnvoll als Vorurteil bezeichnet werden können. Im Anschluss an Niklas Luhmanns kommunikationstheoretischen Gesellschaftsbegriff könnte man sogar einwenden, dass in modernen, funktional differenzierten Gesellschaften überhaupt jede Handlungsfähigkeit auf dem Ausblenden der Kontingenz von zugrunde gelegten Unterscheidungen beruht (Luhmann 1980, S. 33 f.), bzw. auf einem Abbruch der Paradoxien, in die die zum Handeln nötige Selbstreflexivität führt (vgl. Luhmann 1987a, S. 602 ff.). Wenn also jedes soziale Handeln durch eine Semantik stabilisiert werden muss, die Selbstreflexion an einer bestimmten Stelle abbricht, um einen Handlungssinn überhaupt verfügbar zu machen, wie kann dann die Naturalisierung von Ungleichheitssemantiken ein Kriterium zur Bestimmung von Vorurteilen sein? Ausgehend von dieser Annahme, scheint das Problem des vorurteiligen Sprechens sich nicht anhand der Unterscheidung selbstreferentiell geschlossen/empirisch offen bzw. Abbruch/Fortführung der Reflexion bestimmen zu lassen. Der Charakter vorurteiligen Sprechens ist vielmehr in der spezifischen Form der Selbstreferenzunterbrechung zu suchen.

Luhmann selbst unterscheidet zwischen „,natürlichen“ und ,artifiziellen“ Einschränkungen von Selbstreferenz“ (Luhmann 1987b, s. 171) und markiert dabei die 
artifiziellen Semantiken als diejenigen, die eine Reflexion auf Kontingenz zulassen, die natürlichen hingegen als solche, die Kontingenz weitestgehend abblenden:

„Als natürlich kann man diejenigen Selbstreferenzunterbrechungen bezeichnen, die einem System als notwendige Bedingungen der Möglichkeit seiner Operation erscheinen. Als artifiziell werden dagegen solche Beschränkungen gesehen, die als kontingent, als auch anders möglich wahrgenommen werden. Natürliche Selbstreferenzunterbrechungen verhindern also den Durchblick auf die Paradoxie und die Tautologie selbstreferentieller Identität. Sie invisibilisieren das Problem. Artifizielle lassen diese Durchblick zu, postulieren aber, daß irgendetwas geschehen muss, um die Paradoxie zu entparadoxieren.“ (Ebd., S. 171)

Der naturalisierende Aspekt von vorurteiligen Ungleichheitssemantiken bestünde demnach nicht nur in einem Abbruch von Selbstreferentialität, sondern zusätzlich in der Invisibilisierung dieses Abbruches. Ein ,artifizieller' Umgang mit Differenzkonstruktionen (sozialer Ungleichheit) hingegen müsste zwar auch im Moment der Unterscheidung Setzungen vornehmen, stellt aber zugleich, in negativer Selbstbezüglichkeit, diese Setzungen unter Kontingenzverdacht. ${ }^{8}$

Mit dieser Unterscheidung ist freilich noch immer kein striktes Kriterium für die Abgrenzung von Vorurteil und Nicht-Vorurteil gegeben. Es wird aber klarer ersichtlich, dass sich das Problem verschiebt: Weg von der Frage nach definierbaren Kriterien und hin zu einem selbstreflexiven Gebrauch nicht-trennscharfer Unterscheidungen. Denn die Unterscheidung von natürlichen und artifiziellen Reflexionsabbrüchen, und die Verortung von Vorurteilen auf der natürlichen Seite, sagt auch etwas über das Selbstverständnis der Vorurteilskritik aus: Wenn, wie oben behauptet, jede Beobachtungsoperation letztendlich durch dieselbe nicht-Begründbarkeit und folglich durch mehr oder weniger transparente „Selbstreferenzunterbrechungen“ gekennzeichnet ist, dann auch die Kritik naturalisierender Selbstreferenzabbrüche. In dieser Formulierung stecken zwei zentrale methodologische Annahmen über den Charakter der Vorurteilskritik, die in Kapitel 3 bereits aufgegriffen wurden: (1) die Teilnehmerperspektive jeder Vorurteilskritik, die sich nicht außerhalb derjenigen Diskurse stellen kann, die sie als Vorurteilige kritisiert; und (2) der dadurch bedingte normative Charakter sozialwissenschaftlicher Theorie, die immer auch einen Standpunkt beziehen, d.h. selbst Reflexion abbrechen und eine Unterscheidung treffen muss, um überhaupt Aussagen über ihren Gegenstand machen zu können. Die Frage, inwieweit solche Kritik dann überhaupt noch den An-

8 Interessanterweise bezeichnet Luhmann das moderne Gleichheitspostulat als „Semantik mit eher gekünstelten, zunächst überraschend implausiblen Prämissen“ (Luhmann 1980, S. 32; Herv. F. K.), was als Hinweis auf die Reflexivität des egalitären Normvollzuges hinsichtlich der in ihm getroffenen „Personenauffassungen“ (Menke) verstanden werden kann. 
spruch erheben kann, sich als „wissenschaftliche“ von anderen politischen Diskursbeiträgen zu unterscheiden, ist eng verknüpft mit der Unterscheidung von natürlichen und artifiziellen Semantiken: Kritik muss ihre Selbstreflexion (durch die sie sich ja u.a. vom Vorurteil unterscheidet) an irgendeinem Punkt unterbrechen, um überhaupt operieren zu können, aber sie muss zugleich die Kontingenz dieser Unterscheidung erkennbar machen, um kritisch operieren zu können.

Das paradoxe Resultat der bis hierher angestrengten ungleichheitstheoretischen bzw. herrschaftskritischen Erweiterung der Vorurteilskritik ist also, dass es kein abschließendes Kriterium zur Definition von Vorurteilen bzw. zur Begründung eines vorurteilsfreien Standpunktes der Vorurteilskritik geben kann: Vorurteilskritik befindet sich im Kampf um die Auslegung der Gleichheitsnorm gewissermaßen auf Augenhöhe mit den Kritisierten, und muss sich doch von ihrem Gegenüber unterscheiden. Die Unterscheidung vom Vorurteil erreicht sie einerseits dadurch, dass sie dessen Unterscheidungen nach der „Unsichtbarkeit ihres Ausgangspunktes“ befragt und somit unter Kontingenzverdacht stellt (Luhmann 1987b, S. 164); andererseits muss sie, um diese Frage stellen zu können, sich nach ihren eigenen Ausgangspunkten befragen, die sie in ihrem Handeln beständig zu verdecken droht. Somit ist eine Kritik anti-egalitärer Praxen nur dann kritisch, wenn sie zugleich eine Kritik der egalitären Norm ist, von der sie selbst ausgeht. Diese „Paradoxie der Kritik“ (Bonacker 2000, S. 30), die prekäre Spannung zwischen einem Handeln potentiell verunmöglichenden Kontingenzverdacht und politischer Teilnahme, ist kennzeichnend für die Form der „,erschließenden Kritik“ (Bonacker 2008), nach deren Modell im Folgenden die Vorurteilsforschung beschrieben wird.

\subsection{VORURTEIL ALS IDEOLOGIE, VORURTEILSFORSCHUNG ALS ,ERSCHLIESSENDE KRITIK“}

Wenn Vorurteile, wie in den vorigen Abschnitten vorgeschlagen, als im Kontext egalitärer Normen problematisierte Differenzkonstruktionen gefasst werden, so stellt sich im Anschluss daran die Frage nach der normativen Grundlage einer solchen herrschaftskritischen Perspektive. Angesichts der prinzipiellen Kontingenz der symbolischen Ordnung sozialer Ungleichheit bzw. der Ungleichheitssemantiken, durch die sie sich reproduziert, stellt sich jene Frage nach der Begründung einer Unterscheidung von ,richtigen“ und ,falschen“ Differenzkonstruktionen mit besonderer Dringlichkeit. Eine soziologische Vorurteilskritik, so die hier zu entwickelnde Position, kann diesem Problem nicht dadurch begegnen, dass sie nach einer letzten Begründung bestimmter Ungleichheitssemantiken in Abgrenzung zu anderen sucht. Das besondere kritische Potential eines sozialwissenschaftlichen Vorurteilsbegriffs besteht nicht darin, irgendeine anthropologische Essenz der Gleichheit ausfindig zu 
machen, auf deren Grundlage sie sich im Streit um die Gleichberücksichtigung dann um so vehementer durchsetzen könnte. Wenn sie aber ihrem Gegenstand keine letztgültig ,bessere' Ungleichheitssemantik gegenüberstellen kann, worauf stützt sich dann eine solche Vorurteilkritik „unter nachessentialistischen Bedingungen“ (Bonacker 2000, S. 14) bzw. wie kann sie es vermeiden, lediglich eine Gleichheitsauffassung unter vielen zu sein?

Thorsten Bonacker hat vorgeschlagen, dieses Normativitätsproblem kritischer Gesellschaftstheorie so zu lösen, dass der normative Anspruch der Kritik ,an der Unvollständigkeit und Kontingenz der Normgeltung und -begründung“ ansetzt (ebd.). Eine Vorurteilskritik, die sich auf keine gültigen Standards der Gerechtigkeit gründet, muss sich demnach auf die „normative Kraft der Kontingenz“ (ebd., S. 15) berufen. Sofern sich eine solche Kritik dabei auf egalitäre Normen bezieht, bedeutet dies: Wenn die moderne Gleichheitsidee, wie im Anschluss an Menke gezeigt wurde, durch eine immanente Spannung zwischen individuellen Bedürfnissen und universeller Gleichbehandlung gekennzeichnet ist, ihre Realisierung also nur als ein Prozess des Streits um Gleichberücksichtigung begriffen werden kann, dann ist das Problem der Vorurteilskritik nicht, dass es problematisierte Personenauffassungen gibt, also um diese gestritten wird - dies gehört zum politischen Tagesgeschäft demokratischer Gesellschaften. Das Problem des Vorurteils beginnt vielmehr erst damit, dass der Streit um Personenauffassungen bzw. deren Kontingenz systematisch abgebrochen wird. In den vorausgegangenen Abschnitten wurde diese Tendenz des Abbruchs eines egalitären Normvollzuges als Naturalisierung von Differenzkonstruktionen bzw. im Anschluss an Luhmann als „Selbstreferenzunterbrechung“ beschrieben: d.h. als eine Rechtfertigung, die versucht den Bereich der Rechtfertigungsbedürftigkeit zu verlassen, indem sie die tautologische oder paradoxe Grundlage ihrer Position verschleiert. Für die Kritik solcher Sprechweisen stellt sich das doppelte Problem, dass die Bestimmung ihres Gegenstandes als Ideologie zugleich eine Reflexion auf die Kontingenz des eigenen normativen Standpunktes bedeutet. Sie muss einerseits am vorurteiligen Sprechen zeigen, dass darin anti-egalitäre Positionen egalitär gerechtfertigt werden, und damit zugleich ihren eigenen Ausgangspunkt kritisch hinterfragen, indem sie zeigt, dass die egalitäre Norm keinen prinzipiellen Einwand gegen solche anti-egalitären Vollzüge bietet. Diese beiden Hinsichten eines kritischen Vorurteilsbegriffs werden im Folgenden unter den Titeln der Ideologie und der erschließenden Kritik verhandelt.

\subsubsection{Ideologie und Rechtfertigung}

In modernen, funktional differenzierten Gesellschaften haben die Semantiken, durch die sich eine Gesellschaft selbst beobachtet und reproduziert, keine traditionale, sondern maßgeblich eine tautologische oder paradoxale Form: „Die Gesell- 
schaft ist, was sie ist; oder: die Gesellschaft ist, was sie nicht ist." (Luhmann 1987b, 163) D.h., dass diese Semantiken, wenn sie auf ihre Gültigkeit befragt werden, nur auf sich selbst verweisen können und ihre Eigenlogik durch keine Letztgegebenheit jenseits der Vielfalt möglicher anderer Semantiken begründen können (Luhmann 1980, S. 33 f.). Damit, so Luhmanns zentrale Annahme, geraten die Normen und Semantiken moderner Gesellschaften sämtlich unter Kontingenzverdacht (vgl. ebd. sowie Luhmann 1987b, S. 168). Mit dem Begriff der Ideologie, so Luhmann, wird seit den Arbeiten von Karl Marx und Friedrich Engels eine spezifische Form der Bearbeitung dieses Rechtfertigungsdrucks bezeichnet, der das Problem der Tautologie bzw. Paradoxie der eigenen Begründung aufgreift und zugleich verdeckt:

„Seitdem markiert dieser Begriff eine eigentümliche, beobachtungsresistente, der Kritik trotzende Reflexivität. Er postuliert eine Art Rückhalt, der verhindert, daß die Ideologie sich bei Aufklärung ihrer Funktion auflöst.“ (Luhmann 1987b, S. 164)

Entscheidend ist an dieser Adaption des Begriffes, dass Ideologie hier, in Abgrenzung zur Vorstellung einer ungebrochenen ,semantischen Steuerung der gesellschaftlichen Reproduktion durch Ideen“ oder einem „rein pejorativen und polemischen Gebrauch“ des Terminus (ebd.), eine bestimmte Form der Reflexivität bezeichnet: Ideologische Konstruktionen unterscheiden sich von nicht-ideologischen gerade nicht durch einen gänzlich abweichenden normativen oder semantischen Hintergrund, sie sind weder weltfremder Wahnsinn noch bewusst-strategisches Manipulationsinstrument; sondern sie sind eine spezifische Form, mit dem Kontingenzproblem bzw. daraus resultierenden Rechtfertigungsdrücken moderner Semantiken umzugehen. Ideologie bedeutet nicht die Abwesenheit, sondern eine bestimmte Art von Reflexion. Ideologiekritik richtet sich demzufolge nicht gegen ein rundheraus moralisch oder propositional falsches Denken, sondern gegen eine falsche Reflexionsform ambivalenter Normen. Worin diese ,Falschheit‘ besteht, soll im Folgenden dargelegt werden.

Die besondere Funktion ideologischer Sprechweisen liegt Luhmann zufolge in der gleichzeitigen Bearbeitung und Verschleierung ihres jeweiligen Ausgangsproblems, der Paradoxie oder Tautologie eines zugrundeliegenden Normgefüges, d.h. ihrer Selbstwidersprüchlichkeit oder Unbegründbarkeit:

„Der Rückhalt jeder Ideologie liegt zunächst in der Inkommunikabilität ihres Bezugsproblems, in der Verschlüsselung ihrer Inspiration, in der Unsichtbarkeit ihres Ausgangspunktes. An die Stelle einer auf Tautologie oder Paradoxie zurücktreibenden Identitätsreflexion trifft [sic] die Reflexion auf den Gegensatz der Ideologien [...].“ (Ebd.)

Die ideologische Bearbeitung von Kontingenzproblemen besteht also in einer doppelten „,Invisibilisierung “ - sowohl der Operation selbst als auch ihres Problems“ 
(ebd., S. 163): Sie lässt nicht nur ein Begründungsproblem oder einen Widerspruch verschwinden, sondern auch das Verschwindenlassen selbst. Die besondere Reflexionsform vorurteiliger Differenzkonstruktionen, so wird im Folgenden angenommen, besteht dementsprechend darin, dass sie die in modernen funktional differenzierten Gesellschaften brüchig gewordenen universalisierenden Kategorien von Ethnie, Nationalität, Geschlecht, etc. reproduzieren, dabei aber deren Brüche zugleich ideologisch aufgreifen und unsichtbar machen (indem sie etwa ethnozentrisch-kategoriale Differenzkonstruktionen mittels egalitärer Semantik begründen).

Bezogen auf den Diskriminierungsbegriff kann man sagen: Gerade in der impliziten, invisibilisierenden Reflexion der Kontingenz von Ungleichheitssemantiken liegt das ideologische Moment ihrer Reproduktion; und erst durch dieses Moment wird es möglich, überhaupt von Diskriminierung sprechen. Nur in einer Gesellschaft, die sich schon auf das Ideal der Gleichheit verpflichtet hat, kann diskriminiert werden. Das heißt nicht, dass es innerhalb solcher Gesellschaften keine Differenzkonstruktionen mehr gibt, in denen kategoriale Klassifizierungen gebraucht werden, als seien sie nie unter Kontingenzverdacht geraten. Ideologisch ist aber erst derjenige Gebrauch, der mit dem Kontingenzverdacht rhetorisch umgeht.

Adorno hat diese innere Spannung ideologischer Konstruktionen unter Bedingungen moderner Gleichheitspostulate wie folgt zusammengefasst:

„Als objektiv notwendiges und zugleich falsches Bewußtsein, als Verschränkung des Wahren und Unwahren, die sich von der vollen Wahrheit ebenso scheidet wie von der bloßen Lüge, gehört Ideologie, wenn nicht bloß der modernen, so jedenfalls einer entfalteten städtischen Marktwirtschaft an. Denn Ideologie ist Rechtfertigung. Sie erheischt ebenso die Erfahrung eines bereits problematischen gesellschaftlichen Zustandes, den es zu verteidigen gilt, wie andererseits die Idee der Gerechtigkeit selbst, ohne die eine solche apologetische Notwendigkeit nicht bestünde, und die ihr Modell am Tausch von Vergleichbarem hat.“ (Adorno 2003a, S. 465)

Ideologisch ist das Vorurteil also gerade deshalb, weil es sich nicht rundheraus gegen den Gleichheitsgrundsatz wendet und auch seine Bezugnahme auf diesen nicht allein als taktisch-instrumentell gewertet werden kann. Vielmehr klingt im ideologischen vorurteiligen Sprechen sowohl die diskriminierende Praxis als auch die egalitäre Norm an, es reproduziert sowohl den ,,problematischen gesellschaftlichen Zustand[es]“ der Diskriminierung als auch die egalitäre „Idee der Gerechtigkeit“, gegen die dieser Zustand verstößt. Erst wenn sich die Möglichkeit eines Anderen gesellschaftlich anzeigt - und d.h. nicht nur für die KritikerInnen in irgendeiner Art von Hellsicht, sondern auch in den Wahrnehmungsmustern und Sprechweisen der kritisierten Akteurinnen und Akteure selbst - kann man von denjenigen Mustern, mit denen am Bestehenden festgehalten wird, als Ideologie sprechen. Erst unter den 
Kontingenzbedingungen moderner Gesellschaften sind also ideologische Phänomene überhaupt möglich:

„Wo bloße unmittelbare Machtverhältnisse herrschen, gibt es eigentlich keine Ideologien. [...] Eine rationale Theorie des monarchischen Systems, die dessen eigene Irrationalität begründen soll, müßte überall dort, wo das monarchische Prinzip noch substantiell ist, wie Majestätsbeleidigung klingen.“ (Adorno 2003a, S. 465)

Man kann sagen, dass Vorurteilsäußerungen ihre besondere Tragik darin haben, dass sie zwar die egalitäre Norm als paradoxe Bedingung der Diskriminierung reflektieren - es werden heute etwa in vielen Kontexten nicht mehr ,Ausländer' angefeindet, ohne die jeweilige Position zugleich irgendwie als egalitär auszuweisen. Aber sie vollziehen diese Reflexion auf solche Weise, dass der immanente Widerspruch der Gleichheitsidee gewissermaßen falsch aufgehoben und damit auch der Widerspruch innerhalb der diskriminierenden Praxis entschärft wird. Tragisch ist dieser Vorgang, weil in ihm nicht Reflexion durch Blindheit, Ignoranz o.ä. abgebrochen wird, sondern durch Reflexion selbst. Diese Tragik ist aber keineswegs als unabwendbare Notwendigkeit aufzufassen. Vielmehr kann die daraus folgende Konsequenz einer Nichtidentität der egalitären Reflexion - dass diese auch in antiegalitärer Weise erfolgen kann - zugleich als theoretischer Ansatzpunkt und Bedingung der Vorurteilskritik dienen. Denn die Kritik muss, will sie mehr als bloßer Protest sein, eine Spur des eigenen normativen Ausgangspunktes in der kritisierten Praxis voraussetzen (vgl. Bonacker 2000, S. 35).

\subsubsection{Vorurteilskritik als „,normative Theorie ohne Normativität“}

Zwar nimmt auch eine sozialwissenschaftliche Kritik des Vorurteils ihren Ausgang bei gegenwärtigen Problematisierungen von Personenauffassungen und muss dies tun, sofern sie ihren Gegenstand überhaupt treffen will - ein methodologisches Selbstverständnis, das in Kapitel 3.3 unter bedeutungstheoretischen Gesichtspunkten bereits expliziert wurde. Mit ebenso großer Notwendigkeit muss sie sich aber in der Art ihres Anknüpfens an diese Problematisierungen von anderen Diskursbeiträgen unterscheiden, um ihr kritisches Potential entfalten zu können. Bliebe sie in paternalistisch-aufklärerischer Haltung bei der bloßen Behauptung einer überlegenen Normativität stehen, so wäre nicht einsichtig, inwiefern sie sich von einem beliebigen anderen moralischen Standpunkt unterschiede (Bonacker 2000, S. 33; vgl. auch Honneth 2007c, S. 58). Wie oben bereits angerissen, vollzieht sie diesen Schritt „von Zeitdiagnose zu Gesellschaftskritik“ (Bonacker 2000, ebd.), indem sie auf spezifische Weise die Kontingenz ihrer eigenen Unterscheidungen reflektiert, um so eine neue Perspektive auf die Kontingenz der kritisierten Unterscheidungen zu 
erschließen. Kritik braucht somit immer zwei Ansatzpunkte: Die geltende normative Ordnung ihres Gegenstandsbereiches (in dem sie selbst vorkommt), innerhalb der bestimmte Differenzkonstruktionen als problematisch angesprochen werden können; und die Kontingenz dieser Normativität, die die Geltung des eingenommenen Standpunktes unterläuft und damit das eigene kritische Potential bedingt. Insofern ist Kritik gleichzeitig Teil des Bestehenden, nimmt ihren Ausgangspunkt im Protest gegen diskriminierende Differenzkonstruktionen, und unterläuft diese Unterscheidung, indem sie darauf reflektiert, dass die egalitäre Norm sich selbst nicht gleich ist, d.h. keinen ,reinen' Ausgangspunkt zur Vorurteilskritik bietet, sondern im Vorurteil selbst schon vorkommt. In dieser „notwendige[n] und unmögliche[n] Gleichzeitigkeit von Innen und Außen“ besteht die „Paradoxie der Kritik“ (Bonacker 2000, S. 30): Dass sie zugleich normativ urteilend zu gesellschaftlichen Tatbeständen Stellung bezieht, ohne dabei aber ihre Position aus einer bereits bestehenden Normativität ableiten zu können. Denn unter „,nicht- oder nachessentialistischen Bedingungen" (ebd., S. 11) muss sich kritische Theorie stets dessen bewusst bleiben, dass ,in der Kritik nicht-legitimer Institutionalität [...] auf etwas noch nicht legitimes zurückgegriffen werden [muss], dass seinerseits mit Kritik konfrontiert werden kann“ (ebd., S. 13).

Übersetzt in die hier entwickelte Vorurteilskritik bedeutet dies erstens, dass die Praxis der Kritik eine Norm mit den kritisierten Sprechweisen teilen muss (Gleichheitsideal), dass sie zweitens diese Norm aber als interpretationsbedürftig bzw. ambivalent ausweist und drittens zeigt, wie diese Interpretationsbedürftigkeit in den kritisierten Sprechweisen invisibilisiert wird (in naturalisierenden Differenzkonstruktionen). D.h. Ausgangspunkt der Kritik ist eine geltende Norm, man sagt: Es wird Ungleichheit reproduziert, die ungerecht ist. Die Operation der Kritik ist selbst aber kein ungebrochener, deduktiver Normvollzug inklusive fertigem Gegenbild zum kritisierten Vorurteil (etwa einem Bild davon, wie perfekte, gerechte Gleichheit aussähe), sondern eine Zurückweisung der Vereindeutlichung der Norm, die das kritisierte Gegenüber vornimmt. Das Problem ist Ungleichheit, aber nicht im Unterschied zu perfekter Gleichheit, sondern im Unterschied zu einer Ungleichheit, die nicht mehr problematisiert werden kann.

Eine solche „normative Theorie ohne Normativität“ muss im Anschluss an Thorsten Bonacker insbesondere zwei Probleme berücksichtigen: Sie muss (1) „eine zureichende gesellschaftstheoretische Begründung" für die prinzipielle Unvollständigkeit von Normen bzw. deren Kontingenz geben (ebd., S. 14), um die beanspruchte „normative Kraft der Kontingenz“, also das, was an ihrer normativen Grundlage über geltende Normen hinausreicht, zu rechtfertigen. Und sie muss (2) zeigen, dass bzw. inwiefern in der kritisierten Praxis wirklich schon die Norm reflektiert wird, die sie selbst zum Ausgangspunkt hat. Kann sie dies nicht, bleibt der Einsatz der Kontingenz als normativer Rückhalt ,zweiter Ordnung ' selbst essentialistisch bzw. gerät zum naturalistischen Fehlschluss, der aus der deskriptiven Fest- 
stellung der möglichen Veränderbarkeit eines Phänomens die präskriptive Forderung von dessen Veränderung ableitet. Mit Theodor W. Adornos kritischer Theorie lässt sich Bonacker zufolge eine normative Theorie formulieren, die beiden Kriterien gerecht wird.

Die Begründung der Kontingenz geltender Normen nimmt ihren Ausgangspunkt in einem erkenntniskritischen Argument. Bonacker verortet das ,,antiessentialistische Motiv“ kritischer Theorie ,in einer Dialektik von Geltung und Genese, die jeden in kognitiven oder evaluativen Kontexten erhobenen Geltungsanspruch unterläuft und die dadurch zugleich einem essentialistischen Standpunkt seine Aporien aufzeigt“" (ebd., S. 132). ${ }^{9}$ Einerseits widersprechen sich Geltung und Genese: Geltung beansprucht die Unbedingtheit des Geltenden, Genese hingegen dessen Relativität. Mit Adorno lässt sich aber zeigen, dass beide Aspekte zugleich auch aufeinander verweisen: Das Beanspruchen von Geltung impliziert die Genese (Relativität) des Geltenden, weil es sonst gar keine Geltung beanspruchen müsste - es gälte immer schon. Das relativierende Moment der Genese hingegen macht nur gegenüber einem Gegenstand Sinn, bzgl. dessen schon Geltung beansprucht wird. Wenn er nicht als geltend behauptet würde, könnte er gar nicht auf seine Genese hin befragt werden:

„Alles was Geltung beansprucht muß mit anderen Worten auf seine Einheit immer schon verzichten und ist immanent unhintergehbar different, weil Geltung und Genese aufeinander verweisen müssen.“ (Ebd., S. 150)

Diese Dialektik lässt sich zunächst anhand von Erkenntnisakten nachvollziehen, d.h. im Nachweis einer immanenten Selbstwidersprüchlichkeit jedes begrifflichen Bezugs auf die Welt. Die Bedingungen der Möglichkeit von Erkenntnis fasst Adorno als Aporie:

„Für die Erkenntniskritik liegt diese Bedingung weder im erkennenden Subjekt noch in der objektiven Welt, sondern in der konstitutiven Nichtidentität von Begriff und Sache oder von (erkennendem) Begriff und (erkannter) Welt. Erkenntnis ist nur dann Erkenntnis, wenn sie nicht schon vorher mit der Welt in Einklang gebracht, das heißt identifiziert wird, denn in einem solchen Fall würde die Notwendigkeit von Erkenntnis hinfällig. Wenn wir mit Begriffen immer schon erkennen würden - wie der Realismus und Der Nominalismus Adorno zufolge

9 ,Genese ' kann dabei nicht nur eine diachrone Bedeutung annehmen, d.h. die historische Entwicklung eines Gegenstandes bezeichnen, sondern auch eine synchrone, mit der „die innere Struktur, das heißt die Konstitution von etwas“ bezeichnet wird (Bonacker 2000, S. 16). Dabei wird zur „Konstitution“ sozialer Phänomene, den praxistheoretischen Annahmen dieser Arbeit entsprechend (vgl. Kap. 3), auch deren Einbindung in einen jeweiligen sozialen Kontext gezählt. 
unterstellen -, dann bräuchten wir nicht mehr zu erkennen. Der Begriff der Erkenntnis verlöre seinen Sinn, der erst dadurch entsteht, daß Begriff und Sache nicht zusammenfallen." (Bonacker 2000, S. 159)

Der gelingende Erkenntnisakt hat demnach paradoxerweise zur Voraussetzung, dass das darin Begriffene nicht vollständig im Begriff aufgeht. Hiermit ist eine grundlegende Spannung im begrifflichen Sprechen beschrieben: Wie jede faktische Feststellung von etwas schon eine begriffliche Bestimmung dessen voraussetzt, so macht keine begriffliche Konstruktion Sinn „ohne allen Bezug auf Faktizität“ (Adorno zit. n. Bonacker 2000, S. 160). Erkenntnis wird in erkenntniskritischer Perspektive also gerade dadurch möglich, dass sie auf ihre eigene Unmöglichkeit, d.h. die Unauflösbarkeit der besagten Spannung, reflektiert.

„Die Differenz zwischen Begriff und Sache bildet in der erkenntniskritisch angelegten Methodologie der kritischen Theorie mit anderen Worten die Bedingung der Möglichkeit, um überhaupt von Erkenntnis sprechen zu können. Gleichzeitig ist sie aber auch die Bedingung der Unmöglichkeit vollständiger Erkenntnis, bei der die Differenz von Begriff und Sache zur Deckung käme.“ (Ebd., S. 160)

Genau diese Spannung im Begriff der Erkenntnis lässt sich mit Bonacker als Spannung von Geltung und Genese fassen: „In dem für Erkenntnis notwendigen Begriffsbezug äußert sich ihr Geltungsaspekt und im ebenso unhintergehbaren Sachbezug ihr genetischer Aspekt.“ (Ebd.)

Da aber der „Sachbezug“ des Sprechens nicht realistisch, d.h. nicht als Korrespondenz von sprachlichen Zeichen und außersprachlicher Welt, gedacht werden kann (vgl. Kap. 3.2), muss das besagte genetische Moment, das den Geltungsaspekt jeder Proposition unterläuft, in anderer Form konzipiert werden. In der kritischen Theorie Adornos, so Bonacker, ist dieses Moment als Praxisaspekt des Sprechens bestimmt, d.h. als dessen Einbindung in jeweilige Handlungskontexte, die aber nicht als etwas schlechthin außersprachliches gedacht werden, sondern als praktisches Moment sprachlicher Bedeutung. Dies gilt auch für sozialwissenschaftliche Gegenstände, die niemals im Sinne einer ,reinen Subjekt-Objekt-Beziehung“ konzipiert werden können (ebd., S. 166), sondern immer als durch gesellschaftliche Praxis Vermittelte: „Tatsachen aber gehören der Praxis an, sie bezeichnen überall den Kontakt des einzelnen Subjekts mit der Natur als gesellschaftlichem Objekt [...]“ (Adorno zit. n. ebd.; Herv. F. K.). An dieser Stelle konvergiert die erkenntniskritische Position Bonackers mit der Praxistheorie der Bedeutung, die in Kapitel 3 im Zusammenhang des Performativitätsbegriffes verhandelt wurde: 
„Der Bedeutungsgehalt von Begriffen kann also nicht unter Absehung ihrer gesellschaftlichen Verwendungsweisen bestimmt werden, so daß sich der Sachbezug von Begriffen nicht ohne den Praxis- beziehungsweise Erfahrungsbezug denken lässt.“ (Ebd.)

Demzufolge ist jeder Erkenntnisakt, und damit jeder Akt der Kritik, auch ein sprachpraktischer Akt, der seinen Sinngehalt maßgeblich durch die Einbettung in einen jeweiligen sozialen Kontext erlangt. ${ }^{10}$ Die Dialektik von Genese und Geltung, die bei Adorno die Unhintergehbarkeit der Kontingenz begründet, ist nach Bonacker also ,als notwendige Kontextualität jeder Geltung“ zu verstehen (Bonacker 2000, S. 151):

„Danach sieht sich jeder Geltungsanspruch immer schon in einen ihn begrenzenden Kontext gestellt, der das genetische Moment im Erheben von Geltungsansprüchen zum Tragen bringt. Das Bemühen um kontextunabhängige Erkenntnis oder kontextunabhängige moralische Normen ist infolgedessen zum Scheitern verurteilt.“ (Ebd.)

Auch in dieser Hinsicht konvergiert Adornos Kontingenzbegründung mit derjenigen, die in Kapitel 3.3 im Anschluss an Winch und Wittgenstein gegeben wurde: Es gibt keine Regel, die ihren eigenen Gebrauch regeln kann - ,wir werden immer zu einem Punkt gelangen, an dem wir über die Anwendung der Formel Rechenschaft abgeben müssen“ (Winch 1966, S. 41).

Hinsichtlich der Frage einer normativen Begründung der Vorurteilskritik ist aber vor allem von Interesse, inwieweit sich das erkenntniskritische Argument auf den Bereich normativer Geltungsansprüche übertragen lässt, inwieweit also „Genese und Geltung auch in Bezug auf moralische Normen konstitutiv aufeinander bezogen sind“ (Bonacker 2000, S. 210). Bonacker geht diesbezüglich davon aus, dass Adornos „Metakritik der Erkenntnistheorie“ mit einer „Metakritik der Moralphilo-

10 Wenngleich übrigens Adornos Wittgenstein-Rezeption immer sporadisch blieb und vor allem von antipositivistischer Skepsis gegenüber den frühen Thesen des Tractatus geprägt war, finden sich vereinzelt auch explizite Hinweise auf die Parallelität seiner Überlegungen mit denen einer pragmatischen Bedeutungstheorie. So hält er etwa in seiner Einleitung zum Positivismusstreit fest: „Wittgenstein musste dem Rechnung tragen, daß sie [die Sprache, F. K.] von allem faktisch Seienden sich abhebt, weil es nur durch sie gegeben wird, und dennoch denkbar ist nur als Moment der Welt, von der seiner Reflexion gemäß anders als durch Sprache hindurch nichts gewußt werden kann. Damit hat er die Schwelle eines dialektischen Bewußtseins von den sogenannten Konstitutionsproblemen erreicht und das Recht des Szientismus ad absurdum geführt, dialektisches Denken abzuschneiden.“ (Adorno 2003b, 301 f.; vgl. zur Konvergenz von Adornos Kritischer Theorie und Wittgensteins Sprachkritik auch Wiggershaus 2000; Wiggershaus 1975; Demmerling 1994; Wellmer 2007; Richter 2010) 
sophie“ die argumentative Grundstruktur teilt, „daß sie schon Gedeutetes kritisch im Hinblick auf uneingestandene Aporien deutet, um auf diesem Weg zu Aussagen über den Gegenstand, also über moralische Normen, zu gelangen“ (Ebd., S. 202).

\begin{abstract}
„Würden moralische Normen vollständig begründbar sein, bräuchten sie eigentlich gar nicht begründet zu werden. Weil aber der Geltungsanspruch, um ein solcher zu sein, die Norm als nicht vollständig begründbar voraussetzt, steckt im Anspruch auf Begründung beziehungsweise auf begründete Geltung schon die Antinomie moralischer Normen. [...] Mit anderen Worten: Normen, die Geltung beanspruchen und kognitiv begründbar sein sollen, können gar nicht vollständig begründbar sein, weil sie ansonsten gewissermaßen selbstevident wären und keinen Anspruch auf Geltungsbegründung erheben müssten.“ (Ebd.)
\end{abstract}

Mit dieser Übertragung des erkenntniskritischen Arguments auf die Kritik moralischer Normen wird das erste der obengenannten Kriterien einer „,normativen Kritik ohne Normativität" erfüllt. Es wird die prinzipielle Kontingenz nicht nur von deskriptiven, sondern auch evaluativen Urteilen begründet. Das Theoriemodell einer normativen Theorie ohne Normativität kann hierbei freilich nicht stehenbleiben, denn Erkenntniskritik macht zwar plausibel, dass jeder Anspruch auf Normgeltung hinsichtlich seiner Genese zu befragen ist bzw. durch diese in Frage gestellt wird; sie kann aber nicht begründen, warum spezifische Normvollzüge zum Gegenstand der Kritik werden sollten, und andere nicht. Erkenntniskritik kann

„nicht erklären, worin die Ungerechtigkeit besteht, sondern nur, warum Deutungen notwendig kontingent sind und warum eine kritische Theorie sich deshalb als Deutung zweiter Ordnung, als Denken in Modellen verstehen muß. Ungerechtigkeit kann als solche erst benannt werden, wenn eine darauf abzielende Theorie evaluativ zur Welt Stellung nimmt und dazu muß sie sich auf Normen beziehen, die Werturteile begründen und legitim erscheinen lassen." (Ebd., S. 203; Herv. F. K.)

Um einen Ansatzpunkt für die normative Zurückweisung bestimmter Sprachpraxen zu gewinnen, muss die Kritik also „evaluativ zur Welt Stellung“ nehmen und dabei auf geltende Normen, im Falle der Vorurteilskritik: auf geltende Auffassungen der Gleichheitsidee, Bezug nehmen. Es wäre ein Missverständnis anzunehmen, dass eine Selbstwidersprüchlichkeit im kritisierten Sprechen bzw. dessen Ausblenden der eigenen Kontingenz schon einen zureichenden Grund der Kritik böten. Weder aus dem Satz vom ausgeschlossenen Dritten noch aus der Kontingenz aller performativen und deskriptiven Urteile lässt sich eine prinzipielle Normativität ableiten. Bspw. wäre es absurd und reduktionistisch, einer rassistischen Rhetorik allein logische Inkonsistenz vorzuhalten. Zudem wird der logische Reduktionismus einer solchen Position von der anderen Seite her ersichtlich, wenn man sich vergegenwär- 
tigt, dass auch ein offener, selbstwiderspruchsfreier Rassismus in den Gegenstandsbereich der Vorurteilskritik fiele. ${ }^{11}$

Die Einsicht in die prinzipielle Kontingenz aller Normvollzüge bzw. -begründungen bildet zunächst das Korrektiv, mit dem sich die Kritik dagegen absichert, selbst autoritär zu werden. Wie kann sie darüber hinaus aber auch dazu gebraucht werden, den autoritären Charakter des kritisierten Sprechens auszuweisen? An dieser Stelle, kommt die zweite der eingangs genannten Anforderungen an eine ,normative Theorie ohne Normativität" zum Tragen, nämlich das Selbstverständnis als Teilnehmerin ihres Gegenstandes:

,jede normative Kritik einer institutionellen Ordnung oder bestimmter sozialer Praktiken [...] setzt immer schon eine gewisse Affirmation derjenigen moralischen Kultur voraus, die in der betreffenden Gesellschaft vorherrscht; denn ohne eine solche Identifikation mit dem jeweils vorfindlichen Werthorizont wäre der Kritiker gar nicht in der Lage, etwas als einen sozialen Mißstand zu identifizieren, was auch von den restlichen Mitgliedern der Gesellschaft potentiell als Unrecht wahrgenommen werden kann. Eine Form der Gesellschaftskritik hingegen, die den lokal eingespielten Werthorizont einzuklammern oder zu transzendieren versuch, indem sie sich auf externe, universalistische Moralprinzipien beruft, nimmt zwangsläufig eine zu distanzierte Perspektive ein, um von ihren Adressaten noch verstanden werden zu können.“ (Honneth 2007c, S. 57 f.)

Diese Anforderung beinhaltet nun aber die eingangs besprochene Paradoxie kritischer Erkenntnis: Kritik kann einerseits ihren Gegenstand normativ nur dann treffen - und d.h. bezogen auf die Vorurteilsforschung: überhaupt nur treffen - wenn sie

11 Wie in der Einleitung dieser Arbeit sowie im vorigen Abschnitt zum Ideologiebegriff bereits nahegelegt, gilt dies unter der Einschränkung, dass der Gegenstand der Vorurteilskritik im engeren Sinne tatsächlich erst mit selbstrechtfertigenden, performativ widersprüchlichen Vorurteilsausdrücken beginnt; und zwar in dem Sinne, dass zur Zurückweisung explizit und widerspruchslos anti-egalitärer (Sprech-)Handlungen gar keine Kritik nötig ist: Ihr Normverstoß ist offensichtlich und ihre Argumentationsstruktur im oben beschriebenen Sinne nicht ideologisch. Natürlich waren auch die Anschläge vom 11. September 2001 antiamerikanische Taten, aber um sie als solche zu kennzeichnen, bedarf es keiner Kritik. Sie verstoßen eindeutig gegen etablierte demokratische Normen und geltendes Recht. Die Antiamerikanismuskritik setzt gewissermaßen erst dort ein, wo bspw. die Terrorakte vor dem Hintergrund demokratischer Normen gerechtfertigt oder begründet werden: ,Die Amerikaner haben es nicht anders verdient', ,sie haben die Taten mit ihren eigenen Menschen- und Völkerrechtsverletzungen provoziert', etc. Anders formuliert: Wo Kritik keine Spur der von ihr selbst beanspruchten Normen (Gerechtigkeit, Gleichheit) im Kritisierten voraussetzen kann, verfehlt sie ihren Gegenstand bzw. hat diesem paradoxerweise nichts entgegenzusetzen. 
geltende Normen aufgreift, die sie gegen den Gegenstand richtet, sich selbst also als Teil derselben Sprachpraxis begreift, der auch dieser angehört. Sie kann andererseits ihn aber nur kritisch treffen, wenn sie die grundlegende Annahme einer prinzipiellen Unvollständigkeit normativer Gründe auch auf sich selbst anwendet, und sich dadurch von anderen Positionen in ihrem Gegenstandsbereich unterscheidet. Vor dem Hintergrund der erkenntniskritischen Argumentation ließe sich vereinfachend zusammenfassen, dass der Anspruch begrifflicher Geltung die notwendige Äußerlichkeit der Kritik zum Kritisierten erzeugt, während die praktische Teilnahme ihren genetischen Bezug zum „Innen“ des Gegenstandes herstellt. Das Problem besteht nun darin, dass jener genetische Bezug zugleich die begriffliche Distanz zum Gegenstand unterläuft, und jede Kritik somit potentiell Gefahr läuft, in unkritische Normativität abzugleiten. Mit Habermas stellt sich die Frage, „was es heißt, als Argumentationsteilnehmer einen unparteiischen Standpunkt einzunehmen“ (Habermas 1995, $60 \mathrm{f}$.).

Die vorliegende Arbeit geht von der Annahme aus, dass dieses Spannungsverhältnis zwischen genetischer Teilnahme und unparteiischer Geltung nicht zu einer der beiden Seiten bzw. in einem übergreifenden Dritten restlos aufgelöst werden kann. Vielmehr bleibt die beschriebene Paradoxie zugleich Bedingung und Bedrohung kritischer Erkenntnis. Die stets vorläufige ,Lösung' für dieses Problem, besteht in einer methodologischen Reflexion jener Paradoxie. Eine Möglichkeit hierzu wird im folgenden Abschnitt mit dem Begriff der „erschließenden Kritik“ (Bonacker 2008) umrissen. Dieses Kritikmodell beruht auf einer rekonstruktionslogischen Position, die auf eine Erschließung systematisch verdeckter Aspekte gesellschaftlicher Praxen zielt.

\subsubsection{Rekonstruktion und Rhetorik: „erschließende Kritik“}

Eine kritische Sozialwissenschaft kann weder als „externe (oder starke und kontexttranszendierende)“, noch als ,interne (oder schwache und kontextualistische) Form der Kritik“ (Celikates 2009, S. 160 f.) aufgefasst werden. Beide Modelle führen in komplementäre epistemologische und normative Probleme. Die externe Variante droht den sinnverstehenden Bezug zu ihrem Gegenstand zu verlieren und zu einer autoritären Vormundschaft zu werden; die interne Variante hingegen kann mangels der nötigen Distanz zum Gegenstand ihren begrifflichen Geltungsanspruch nicht einlösen und gerät allzu leicht zu einer affirmativen Reproduktion der untersuchten Normen und Wissensbestände. Beide Varianten sind damit im engeren Sinne des Begriffes unkritisch.

Auf welcher Grundlage kann aber eine Kritik stehen, die den Grundsatz eines ,,methodologischen Egalitarismus" (Celikates 2009, S. 102) beibehält, d.h. sich kein prinzipielles epistemologisches oder normatives Privileg gegenüber den beobachte- 
ten Subjekten zuspricht, und dennoch mit ihrer Theoriebildung über deren Praxen hinausweisen möchte? Die Antwort, die die kritische Theorie hierauf in verschiedenen Variationen gegeben hat, ist ein rekonstruktionslogisches Vorgehen (vgl. Honneth 2007c, S. 59). Hier wird die Paradoxie der Kritik, vereinfacht gesagt, dadurch gelöst, dass man dem Gegenstand selbst eine immanente normative und kognitive Ambivalenz zuschreibt, eine Nichtidentität der vollzogenen Praxis, die von den Agierenden selbst in unterschiedlichem Maße, aber niemals gänzlich, reflektiert werden kann. Die Aufgabe kritischer Theorie ist dann, in einer jeweils spezifischen Hinsicht offenzulegen, was Agierende ,noch tun', indem sie etwas Bestimmtes tun. Das Problem gleichzeitiger Teilnahme und Distanz wird also dahingehend aufgehoben, dass man an den kritisierten Praxen teilnimmt, indem man ihnen ihre blinden Flecken bzw. „strukturellen Reflexivitätsdefizite“ (Celikates 2009, S. 166) aufzeigt, und mit einer solchen ,erschließenden Kritik“"12 (Bonacker 2008; Honneth 2000) zugleich über sie hinausweist. Da dieses rekonstruktive Modell bzw. die darin formulierte Nichtidentitäts-Annahme auch auf die kritische Praxis selbst anzuwenden ist, hat es Konsequenzen für das methodologische Selbstverständnis kritischer Theorie und die Geltungsansprüche der von ihr formulierten Hypothesen. Sie muss erstens davon ausgehen, dass auch ihr eigenes Handeln blinde Flecken aufweist und prinzipiell Deutung ist, d.h. ihre Ergebnisse niemals an einem äußeren Kriterium restlos eingelöst werden können. Und sie muss sich zweitens, in Ermangelung zwingender Belege und externer Bewertungsmaßstäbe, auf ihren rhetorischen Charakter besinnen, d.h. darauf, dass sich das Gelingen ihrer Deutungen letztendlich daran zeigt, dass sie andere von deren Geltung überzeugt. Beide Aspekte eines rekonstruktionslogischen Kritikmodells - praxistheoretische Gegenstandsbestimmung und rhetorisches Selbstverständnis - werden im Folgenden umrissen und auf das Vorgehen einer soziologischen Vorurteilskritik angewendet.

12 Der Terminus wurde ursprünglich von Axel Honneth eingeführt, um die Aktualität von Adornos und Horkheimers Dialektik der Aufklärung gegen Lesarten zu verteidigen, die diese als performativ selbstwidersprüchliche, radikal pessimistische Geschichtsphilosophie betrachten. Erschließende Kritik bezeichnet demnach eine bestimmte rhetorische Form der Gesellschaftstheorie, die das Ziel verfolgt, nicht „,sozialtheoretisch eine andere Interpretation der Gattungsgeschichte vorzuschlagen, sondern eine veränderte Wahrnehmung von Beständen unserer scheinbar vertrauten Lebenswelt zu provozieren, durch die wir auf deren pathologischen Charakter aufmerksam werden“ (Honneth 2000, S. 84). Durch rhetorische Mittel wie Metaphern, Chiasmen und Übertreibungen wird versucht, die praktisch fraglose Geltung etablierter Wahrnehmungsmuster und Wertüberzeugungen in ethischer Hinsicht zu problematisieren (vgl. ebd.). Dabei formuliert erschließende Kritik nicht unmittelbar Gerechtigkeitsurteile, sondern sie zielt auf „soziale Pathologien“ (ebd., S. 80), d.h. sie befragt die in Gerechtigkeitsurteilen angelegten moralischen Maßstäbe selbst. 
In Kapitel 3.2 wurde auf der Grundlage von Wittgensteins Praxistheorie der Bedeutung für eine „systematische Ambiguität“ sprachlicher Ausdrücke argumentiert. D.h. dass Sprechakte prinzipiell ihre praktische Bedeutung erst im Rahmen eines über sie hinausweisenden lebensweltlichen Praxiszusammenhangs gewinnen. Weder Sprecher noch Hörer können sich im Prozess der Kommunikation auf eine ,gesicherte Übertragung ' von Information verlassen, die nach expliziten Regeln codiert und decodiert werden könnte: „Die Deutungen allein bestimmen die Bedeutung nicht.“ (Wittgenstein 2006, S. 344) Etwas meinen, so könnte man auch sagen, ist keine subjektive, sondern eine interaktive Tätigkeit, die zudem fließend in die alltäglichen Praxen eines lebensweltlichen Zusammenhangs übergeht (vgl. Wellmer 2004, S. 60 ff.). Die (intendierte und nicht-intendierte) praktische Bedeutung eines jeden Sprechhandelns entsteht erst durch dessen Einbettung in einen lebensweltlichen Kontext, der vom sprechenden Subjekt nicht völlig kontrolliert werden kann, weil er konstitutiv für dessen Sprechen ist, und den es doch mit seinem Handeln mit reproduziert. Soziale Praxen können hinsichtlich dieses ,Bedeutungsüberschusses“ in kritischer Absicht befragt werden. im Rahmen einer Vorurteilskritik kann etwa das Sprechen über Amerika hinsichtlich der diskriminierenden Differenzkonstruktionen befragt werden, die in diesem mitkommuniziert werden.

Dieses zunächst bedeutungstheoretisch gefasste Phänomen der Nichtidentität zielgerichteten Handelns wird im Rahmen kritischer Theorie zum Ansatzpunkt einer „immanenten Kritik“ (Honneth 2007c, S. 68), die eine „betreffende Lebensform oder das betreffende Subjekt anhand von Maßstäben beurteilt, die diese selbst aufgestellt hat bzw. die in ihr selbst impliziert sind“ (Jaeggi 2005a, S. 59). Dabei ist entscheidend, dass die systematische Ambiguität des Sinngehalts von (Sprech-) Handlungen nicht nur zu einem pluralistischen Nebeneinander verschiedener Bedeutungsfacetten führen kann, sondern auch zu selbstwidersprüchlichen Konstruktionen innerhalb einer Praxis. An solchen performativen Widersprüchen setzt eine immanente Kritik an, indem sie diese als Phänomene der „Verdinglichung“ (Honneth 2005; Demmerling 1994, S. 118 ff.) bzw. „Entfremdung“ behandelt: „Angesprochen ist damit die Eigendynamik von Verhältnissen, die gegenüber den in ihnen Handelnden zur ,fremden Macht" geworden sind.“"(Jaeggi 2005b, S. 124; vgl. auch Adorno 1973b, S. 358)

Damit ist zugleich eine wichtige Einschränkung des Gegenstandsbereichs kritischer Theorie bezeichnet, denn mit dem oben umrissenen praxistheoretischen Hinweis auf die „notwendige Kontextualität“ (Bonacker 2000, S. 151) jeden sinnvollen Handelns ist nicht an sich schon das Problem benannt, gegen das sie sich richtet. Wie im Rahmen der Erläuterung des Ideologiebegriffs (Kap. 4.4) bereits gezeigt wurde, ist die Tatsache, dass Handlungsfähigkeit auf einer Ausblendung der Kontingenz von zugrunde gelegten Unterscheidungen beruht, kein veränderungsbedürftiger Missstand, sondern konstitutive Notwendigkeit von Handeln überhaupt. Unbeobachtete Ambiguität und Kontextualität von Handeln wird erst in dem Moment 
zum Problemgegenstand der Kritik, in dem potentiell beobachtbare Aspekte einer Praxis von der Reflexion ausgeschlossen und als natürliche nochmals festgeschrieben werden: „Die gesellschaftliche Praxis, auf die die Deutung sich richtet, ist verstellt, genauer: verstellt sich durch Konstruktionen, die das prozessuale Geschehen der Praxis objektivierend stillstellen - ihren ,Text" auf ,Begriffe“ oder ,Systeme“ reduzieren.“ (Menke 1997, S. 56) Kritik zielt somit immer auf ein Sichtbarmachen von performativen Selbstwidersprüchen, in denen ein Praxisvollzug sich systematisch gegen die eigene Kontingenz abschirmt.

Dieser Hinweis ist wichtig, da sonst leicht der Eindruck entstehen kann, Ziel kritischer Theorie sei ein ,restlos aufgeklärter ' Zustand, in dem vollständig selbstidentische Subjekte vollkommene Kontrolle über das eigene Handeln erlangen. Christoph Menke hat am Beispiel des Entfremdungsbegriffs bei Horkheimer aufgezeigt, inwiefern Texte zumindest der frühen Frankfurter Schule zu diesem Missverständnis selbst beitragen. Mit dem Begriff der Entfremdung wählt Horkheimer demzufolge ,ein Interpretament, mit dem ein ganzes Feld zugleich binärer wie hierarchischer Oppositionen verbunden ist“" (ebd., S. 50). Die mit dem Entfremdungsbegriff einhergehenden hierarchischen Oppositionen widersprechen aber dem zuvor von Horkheimer selbst umrissenen praxistheoretischen Konzept, denn sie zeichnen den „Entwurf eines Modells unentfremdeten Handelns als differenzlos beisichbleibende Übersetzung“ (ebd.). Demnach würden im nicht entfremdeten Zustand die Notwendigkeiten menschlicher Existenz restlos in vollkommen kontrollierte Produktion übersetzbar sein. Ein solches Idealbild ist aber Ausdruck einer „Idee ungetrübter Transparenz“ (ebd.), die mit dem oben explizierten erkenntnis- und moralkritischen Selbstverständnis kritischer Theorie nicht vereinbar ist:

„Im überhellen Licht des Entfremdungsbegriffes erscheint damit alle unbeherrschbare Notwendigkeit als scheinhaft, alle nicht selbstgesetzte Objektivität als falsch. Die Kritik der Entfremdung ist unkritisch: Sie kann nicht zwischen scheinhafter und wirklicher Notwendigkeit, zwischen Objektivismus und Objektivität unterscheiden.“ (Ebd.)

Fernerhin sind solche und ähnliche Gebräuche des Entfremdungsbegriffs „unkritisch“, insofern sie davon ausgehen, ,dass sich das (für das menschliche Leben) objektiv Gute auszeichnen lässt“, und sie somit einer „objektivistisch-perfektionistischen Ethik“ entsprechen, die auf einen moralischen „Paternalismus“ hinausläuft (Jaeggi 2005a, S. 47). Die nichtidentischen Momente gesellschaftlicher Praxis, so lässt sich gegen solche Entfremdungskonzepte einwenden, sind „,nicht nur etwas Verhinderndes, sondern Ermöglichendes“ (Menke 1997, S. 53). Sie bilden auch einen Widerspruch zum Ideal absoluter Kontrolle und naturwüchsiger Identität, gegen das sich kritische Theorie ja gerade richtet. Gäbe es diese Brüche innerhalb gesellschaftlicher Praxen nicht, und wären „Reflexivität und Kritik“ nicht auch ,imma- 
nente und konstitutive Dimensionen der Alltagspraxis“"(Celikates 2009, S. 164), so wäre Kritik überhaupt unmöglich.

Die Rekonstruktionen kritischer Theorie befassen sich also nicht mit vollkommen ,paranoiden 'Subjekten oder , objektiv' falschen Normen, sondern mit „'Pathologien ' zweiter Ordnung" (Celikates 2009, S. 169), d.h. mit solche Praxen, in denen ein selbstreflexives Potential zwar anklingt, aber zugleich durch eine „Naturalisierung gesellschaftlicher Verhältnisse" verdeckt wird.

„Der unhinterfragte Schein der Legitimität oder der Natürlichkeit bestimmter sozialer Praktiken und Institutionen - den man natürlich auch als Ideologie bezeichnen kann - lässt sich deshalb auf einer zweiten Ebene verorten, weil durch ihn die Reflexion und Kritik von Meinungen, Dispositionen, Präferenzen, Handlungsweisen und sozialen Kontexten auf der ersten Ebene verhindert oder erschwert wird.“ (Ebd.)

So lassen sich Vorurteile als Sprachpraxen bestimmen, die eine Reflexion und Kritik der eigenen, diskriminierenden Differenzkonstruktionen durch einen „unhinterfragte[n] Schein der Legitimität“ oder „Natürlichkeit“ erschweren. Damit eine solche rekonstruktive Kritik „Zweiter Ordnung“ gelingt, ist entscheidend, dass die Problematik der jeweiligen Differenzkonstruktionen nicht extern an die kritisierten Sprechweisen angelegt wird, sondern in ihnen selbst auftaucht:

„Rekonstruktive Kritik trägt die normativen Maßstäbe der Kritik nicht von außen an die Adressaten heran, sondern versucht sie aus den (von Letzteren nicht unbedingt vollständig artikulierten und explizit gewussten) normativen Strukturen der für einen bestimmten sozialen Zusammenhang konstitutiven Praktiken zu entwickeln - genauer: aus den mit diesen Praktiken verbundenen Normen, Werten, Selbstverständnissen, Erwartungen und Intuitionen. Die Rekonstruktion stellt demnach den Versuch dar, einen impliziten normativen Gehalt explizit zu machen.“ (Ebd., 187)

Kritische Theorie begegnet der Spannung zwischen Teilnahme und Äußerlichkeit der Kritik also damit, dass sie zunächst im Gegenstand selbst eine Spannung zwischen Eigenem und Fremdem sowie die Möglichkeit der Reflexion dieser Spannung annimmt; ihre Kritik setzt dann dort an, wo die Möglichkeit solcher Reflexion systematisch abgebrochen wird. Mit diesem rekonstruktiven Selbstverständnis gehen zwei zentrale methodologische Aspekte einher, die beide in Horkheimers Formulierung anklingen, kritische Theorie sei „Selbstinterpretation des gegenwärtigen Menschen" (Horkheimer 2005, S. 225): Erstens muss ihre Rekonstruktion impliziter normativer Gehalte Interpretation bzw. Deutung bleiben, d.h. sie kann sich an keinem externen Kriterium ihrer Geltung versichern. Und zweitens muss sie, um normative Gehalte deutend erschließen zu können, an den gedeuteten Praxen teilneh- 
men. ${ }^{13}$ Kritik im oben ausgeführten Verständnis ist wesentlich Deutung und als solche ,immer nur vorläufig, weil ihr das Kriterium für die Beurteilung ihres Gelingens konstitutiv fehlt“ (Bonacker 2000, S. 184). Es fehlt ihr konstitutiv, weil ihre Teilnahme an demjenigen, was sie kritisiert, zugleich ihren Bezug darauf ermöglicht bzw. glaubwürdig macht und einen rein objektiven Standpunkt außerhalb des Kritisierten verhindert. Anders gesagt: weil es keine Gewissheit jenseits konkurrierender Deutungen gibt, d.h. die „Differenz zwischen Deutung und Gedeutetem“ eine „Differenz in der Deutung“ ist (ebd.). Kritik als „Deutung zweiter Ordnung“ (ebd., S. 201) ist mit ihrem Gegenstand (Deutungen erster Ordnung) aufgehoben in gesellschaftlicher Praxis als Deutungspraxis insgesamt. Weil sie als Teilnehmerin am Kritisierten kein externes Kriterium für die Wahrheit ihrer Deutung haben kann, gelangt sie nie zu einem zweifelsfreien Befund über das Kritisierte:

„Ein solches selbstreflexives Verständnis erschließender Kritik kann die eigenen Möglichkeitsbedingungen nur sehen, ohne sie rückgängig zu machen oder auszuhebeln und deshalb alles sehen zu können. Verstehen, so ließe sich diese erkenntniskritische Position zusammenfassen, ist überhaupt nur um den Preis des nicht ganz Verstehens möglich, weil jede Deutung als Deutung auf Totalität verzichten muss.“ (Bonacker 2008, S. 71)

Das Ziel einer deutend verfahrenden Kritik ist nicht die Übereinstimmung von Deutung und Gedeutetem, da sie sich sonst als Deutung gewissermaßen selbst überflüssig machte. Was eine solche ,,materialistische Erkenntnis“ (Adorno 1973a, S. 336) ${ }^{14}$

13 Horkheimers Formulierung, die kurzerhand die Teilnehmerposition zur vollen Identität von Beobachter und Beobachteten vereinfacht (,Selbstinterpretation“), ist freilich als rhetorische Übertreibung zu verstehen. Hinter dieser droht aber eine wichtige Frage zu verschwinden, die von späteren Theoretikern, etwa Habermas und Luhmann, präziser gestellt wurde. Der sozialwissenschaftliche Beobachter nimmt mit seiner deutenden Praxis einen ähnlichen Status ein, wie der „,sozialwissenschaftliche Laie“, aber: „Wie weit reicht die strukturelle Ähnlichkeit zwischen den Interpretationsleistungen des einen und des anderen?" (Habermas 1995, S. 167) Welchen Unterschied macht es, dass soziologische Beobachter zunächst im Handlungssystem der Wissenschaft ihre Zwecke verfolgen und am untersuchten Handlungskontext nur in der Rolle des ,virtuellen Teilnehmers“ (ebd., 168) beteiligt sind? Ein ähnliches Argument hinsichtlich der normativen Einbindung der Sozialwissenschaften findet sich in: Luhmann 1990, S. 35.

14 Es sei an dieser Stelle zumindest kursorisch darauf hingewiesen, dass sich die referierten Konzepte Adornos auf das Vorgehen einer ,deutenden Philosophie“ (Adorno 1973a, S. 336; Herv. F. K.) beziehen, die zwar ihr Material den verschiedenen Einzelwissenschaften - ,vorwiegend der Soziologie“ (ebd., S. 340) - entnimmt, nicht aber selbst Einzelwissenschaft ist. Was hier nun also als Modell für den einzelwissenschaftlichen, nämlich soziologischen, Umgang mit empirischem Material aufgegriffen wird, wurde von Adorno ur- 
stattdessen liefern kann, ist vielmehr, dass sie ihren Gegenstand neu erschließt, ohne dabei den Rahmen geltender Normen und geteilten Wissens so weit zu verlassen, dass ihre Ergebnisse unverständlich würden. Durch diese ,performative[n] Einstellung eines Interaktionsteilnehmers“ (Habermas 1995, S. 167) bleibt erschließende Kritik immer ein Stück Rhetorik:

„Weil sich kritische Theorie eben nicht auf kontexttranszendierende Maßstäbe berufen kann, bleibt ihr nichts anderes übrig, als darauf zu hoffen, dass ihre Neubeschreibung der sozialen Welt andere überzeugt.“ (Bonacker 2008, S. 65)

Dies bedeutet freilich nicht, dass eine erschließende Kritik in ihren Interpretationen völlig willkürlich verfahren kann. Deutung bleibt an Kriterien wie begriffliche Klarheit, intersubjektive Nachvollziehbarkeit, Widerspruchsfreiheit (bzgl. einfacher Kontradiktionen) und Ergebnisoffenheit gebunden. Diese Bindung ist dadurch gegeben, dass jede Deutung einen Geltungsanspruch erhebt, also um begriffliche Abstraktion bemüht ist (vgl. Bonacker 2008, S. 73). Dieses Bemühen um begriffliche Geltung befindet sich aber in einem Spannungsverhältnis mit der genetischen Teilnahme am Gegenstand. In diesem Spannungsverhältnis beruft sich deutende Kritik auf eine ,exakte Phantasie [...], die die Elemente der Frage umgruppiert, ohne über den Umfang der Elemente hinauszugehen, und deren Exaktheit kontrollierbar wird

sprünglich als höherstufige, philosophische Modellbildung durch Konstellation einzelwissenschaftlicher Befunde konzipiert. Ohne die Problematik einer Übertragung der philosophischen Konzeption auf einzelwissenschaftliche Methodologie hier im Detail diskutieren zu können, möchte ich doch zumindest auf einen Ansatz zu deren Lösung bzw. Entschärfung hinweisen. Adorno hat nicht zufällig die Soziologie als erste Materiallieferantin einer deutenden Philosophie ausgezeichnet, sondern sein Soziologieverständnis ist insgesamt so angelegt, dass die Grenzen zwischen Philosophie und Soziologie, zwischen ,Interpretin“ und ,Materiallieferantin“ nicht scharf gezogen sind. Das Sachgebiet der Soziologie, so erörtert er 1968 in seiner Einleitung in die Soziologie, stellt „,eine ,schlechte Unendlichkeit““ dar: „Es gibt nichts unter der Sonne, aber wirklich nichts, was nicht dadurch, daß es vermittelt ist durch menschliche Intelligenz und menschliches Denken, eben auch zugleich gesellschaftlich vermittelt wäre.“ (Adorno 1993, S. 32) Dieser Befund, der letztendlich auch ein Verweis auf den konstitutiv selbstreflexiven Charakter der Soziologie ist, lässt es zumindest naheliegend erscheinen, das Modell einer „deutenden Philosophie“ sozialwissenschaftlich zu adaptieren. Zieht man zudem Adornos Allegorie der Soziologie als „Fassadenkletterer[in]“ in Betracht, die aus dem maroden Gebäude der traditionellen Philosophie rettet, was beim Zusammenbruch des alten Hauses verloren zu gehen droht (Adorno 1973b, S. 340), so wird deutlich, dass sich in der Perspektive kritischer Theorie nicht nur die Soziologie der Philosophie anähnelt, sondern auch Philosophie als materialistische Deutung der Soziologie näher rückt. 
am Verschwinden der Frage“ (Adorno 1973a, S. 342). Das Verschwinden der Frage, d.h. des Problemgegenstands der Kritik, ist dabei ebenfalls nicht als zwingender Grund für die Geltung einer Deutung zu verstehen; es meint nicht, dass die Ausgangsfrage nicht mehr gestellt werden könnte, sondern vielmehr, dass sie sich verschiebt oder verändert, das Ausgangsproblem in einem anderen Licht erscheint. In diesem Licht der deutenden Kritik wird bestenfalls eine alternative Bearbeitung des Gegenstandes denkbar, die über die bisherigen Theorieansätze sowie über die kritisierten Praxen selbst hinausweist:

„Ihren Wahrheitsanspruch können sie [die Deutungen, F. K.] nur dadurch aufrechterhalten, dass sie noch vom überzogenen Geltungsanspruch des von ihr [sic] nochmals Gedeuteten zehren, indem sie jenem die eigene Unentscheidbarkeit immanent aufweisen und das heißt auf die Möglichkeit der Veränderung hin öffnen. Die erschließende Kritik kann zwar ihren blinden Fleck nicht beseitigen, so dass sie Wirklichkeit nicht besser oder totaler erfassen kann, als andere Deutungen. Sie kann aber jenen vorgängigen Deutungen zumindest deren konstitutiven blinden Fleck nachweisen und trägt aufgrund ihrer Selbstverstrickung in den von ihnen erschlossenen Gegenstand immer schon zur Veränderung bei [...].“ (Bonacker 2008, S. 75) ${ }^{15}$

15 Problematisch an dieser Theorieperspektive, in der soziologische Kritik letztendlich als eine ,transformative[r] soziale[r] Praxis“ (Wehling 2014, S. 27) verstanden wird, bleibt die Frage, wie bzw. woran der angestrebte transformative Effekt der Kritik auf gesellschaftliche Praxis festgestellt werden kann. Wenn man davon ausgeht, dass sich die Geltung sozialwissenschaftlicher Deutungen nicht unabhängig davon begründen lässt, dass sie andere überzeugt, so stellt sich die Frage, wer überzeugt werden muss, woran sich der überzeugende Effekt festmacht und mit welchen methodischen Mitteln dieser beobachtet werden kann. Unabhängig davon, dass es auf diese Frage prinzipiell keine umfassende Antwort in Form klar einzulösender Kriterien geben kann - denn wenn die Kritik schon wüsste, worauf sie hinauswill, wäre sie überflüssig - macht es Sinn, nach einem besseren „Sensorium“ dafür zu fragen, ,wie Kritik zwischen Idee und Handeln vermittelt, wie also die vom Theoretiker ausgewiesene Position in Praxis übergeht“ (Vobruba 2013, S. 158). Anregungen hierzu könnte eine Verknüpfung von soziologischer Kritik mit Methoden einer „kommunikativen Validierung“ (Steinke 2012, S. 320; vgl. auch Kvale 1995, S. 30 ff.), bieten, mit denen sozialwissenschaftliche Deutungen an die Beforschten rückgemeldet und hinsichtlich ihrer Nachvollziehbarkeit diskutiert werden. Gerade im Bereich der Vorurteilsforschung ist aber von einem naiven Einsatz solcher Methoden abzusehen, da hier oftmals „Bedeutungen jenseits einer subjektiv-intentionalen Ebene rekonstruiert“ werden (Steinke 2012, S. 329) und aufgrund der starken normativen Implikationen der Vorurteilskritik Konflikte mit den Teilnehmenden zu erwarten sind. Wenn aus diesem Konfliktpotential aber nicht der Schluss gezogen werden soll, dass die Kommunikation mit den Beforschten an dieser Stelle prinzipiell abbrechen muss, so wären alternative 
Für eine rekonstruktiv verfahrende Vorurteilskritik folgen aus dieser Konzeption drei wesentliche methodologische Anforderungen. Als ,immanente Kritik“ (Honneth 2007 c, S. 68) muss sie zum einen ausweisen, auf welche normativen Grundlagen sie sich selbst bezieht, und zum anderen zeigen, inwiefern dieselben normativen Grundlagen in den kritisierten Sprechweisen schon angelegt sind und nicht von außen an sie herangetragen werden. Ersteres glaube ich für die hier entwickelte Antiamerikanismuskritik zumindest näherungsweise mit dem vorliegenden Kapitel zu leisten; letzteres wird im Zuge der Darstellung der qualitativen Ergebnisse zu belegen sein. Darüber hinaus muss eine erschließende Vorurteilskritik sich der ungeklärten Geltungsreichweite ihrer Deutungen bewusst bleiben, die aus ihrem deutenden Vorgehen resultiert. Dies hat nicht zuletzt Auswirkungen auf den Umgang mit empirischen Forschungsmethoden und Ergebnissen - etwa hinsichtlich des Verhältnisses von qualitativ-hermeneutischen und quantitativ-statistischen Zugängen - wie ich in Kapitel 5 weiter ausführen werde.

In den Abschnitten dieses Kapitels wurden drei zentrale Aspekte einer erschließenden Vorurteilskritik erörtert: Die spezifisch ideologische Struktur ihres Gegenstandes, d.h. des vorurteiligen Sprechens; die damit korrespondierende ideologiekritische Struktur der Vorurteilsforschung; und schließlich die aus dieser ideologiekritischen Argumentationsstruktur resultierende Methodologie der Deutung.

Der Gegenstand der Vorurteilskritik zeichnet sich demnach durch eine spezifische Form der Rechtfertigung aus. In vorurteiligen Sprechweisen wird nicht nur eine dem Gleichheitsideal widersprechende Differenzkonstruktion reproduziert, sondern deren Widerspruch zur egalitären Norm wird zugleich verdeckt. Rassistische Vorurteile bspw. behaupten nicht nur eine essentielle Differenz zwischen ethnisch klassifizierten Gruppen, sondern werden zugleich auf eine Weise geäußert, die diesen Widerspruch entweder gar nicht erst thematisch werden lässt oder ihn explizit zurückweist. In vorurteiliger Rede kommen also Ungleichheitssemantiken zum Ausdruck, die sich im Rahmen egalitärer Normen selbst stabilisieren. Das bedeutet auch, dass sie das Gleichheitsideal, das sie selbst verletzen, gleichzeitig in ideologischer Weise reproduzieren.

Indem Vorurteilskritik ihren Gegenstand auf diese Weise bestimmt, nimmt sie eine spezifische rhetorische Form an. Da sie an ihrem Gegenstand kritisch die Nichtidentität egalitärer Normen aufzeigen will - dass antiegalitäre Klassifikationsmuster mit Gleichheitsidealen vereinbar sind - kann sie sich selbst nicht auf Gleichheit als ungebrochene normative Grundlage stützen. Stattdessen findet sie ihre Grundlage in der Kontingenz der egalitären Norm. Diese wendet sie kritisch ge-

Formen einer diskursiven Rückbindung kritischer Interpretationen an die Beforschten zu erwägen. Überlegungen dazu existieren in der Vorurteilsforschung meines Wissens bislang nicht. 
gen ein ideologisches Sprechen, das diese Kontingenz invisibilisiert. Um diese normative Position ohne Bezug auf eine starke Normativität einnehmen zu können, muss sie (1) nachweisen, dass die zugrunde gelegte Norm tatsächlich prinzipiell unabgeschlossen ist bzw. einen immanenten Widerspruch aufweist; und sie muss (2) am Gegenstand zeigen, dass dieser normative Selbstwiderspruch darin tatsächlich auftritt, und zugleich systematisch ausgeblendet wird. Ersteres konnte unter Rückgriff auf ein erkenntniskritisches Argument Adornos und die Egalitarismuskritik Menkes gezeigt werden (vgl. Kap. 4.4). Letzteres ist eine empirische Frage, die mit der Ergebnisdarstellung in Kapitel 7 eingehend behandelt wird.

Ebenjenes Aufzeigen moralischer Widersprüche oder Ambivalenzen am Gegenstand der Kritik geht mit einer rekonstruktiven Methodologie einher, die mit dem Begriff der erschließenden Kritik erläutert wurde. Ihrem methodologischen Selbstverständnis nach begreift sich erschließende Kritik in zweierlei Hinsicht als Rhetorik: Zum einen betrachtet sie sich als aktive Teilnehmerin des von ihr bearbeiteten Gegenstandsbereiches. D.h. weder kann sie sich selbst prinzipiell von Vorurteilen freisprechen, noch die kritisierten Handelnden als pathologisch abweichende Subjekte klassifizieren. Sie zielt vielmehr darauf ab, Kritik als dialogischen Deutungsprozess zu vollziehen, in dessen Verlauf (zumindest potentiell) sowohl die Begriffe der Forschenden als auch diejenigen der Beforschten neu erschlossen werden. Aus dieser Auffassung von Kritik als Deutungspraxis folgt aber, dass die Ergebnisse der Vorurteilskritik niemals als gesicherte Wahrheit gelten können, sondern letztendlich nur auf der Überzeugungskraft ihrer Rhetorik fußen. Dies folgt einerseits aus ihrer eigenen Verstrickung in den Gegenstand, die sie zwar reflektieren, aber niemals gänzlich lösen kann, ohne zugleich den Bezug zum Kritisierten zu verlieren. Andererseits können für die notwendige Unvollständigkeit der Deutung wiederum erkenntniskritische Gründe aufgeführt werden: Demnach kann die Güte einer Deutung nicht anhand der Übereinstimmung mit dem Gedeuteten bemessen werden, da sie in diesem Moment aufhören würde, Deutung zu sein.

Vor dem sozialtheoretischen und methodologischen Hintergrund dieses Begriffes einer erschließenden Vorurteilskritik können im Folgenden nun weitere Schritte in Richtung einer empirischen Anwendung dieses Konzeptes unternommen werden. Hierbei wird nationale Identität als ein zentraler Referenzpunkt vorurteiliger Differenzkonstruktionen ausgemacht, an den ethnozentrische, rassistische und antisemitische Rhetoriken funktional angebunden sind. Dieser rhetorische Komplex von nationaler Identifikation und vorurteiligem Sprechen bildet die Grundlage der empirischen Analyse antiamerikanischer Sprachgebräuche, die in Kapitel 7 dokumentiert ist. Mit den Konzepten des Nationalismus, Ethnozentrismus und sekundären Antisemitismus werden im Folgenden also weitere Bausteine in das heuristische Fundament der Interviewanalysen eingefügt. 


\subsection{VORURTEIL UND NATIONALE IDENTITÄT: EthNOZENTRISMUS, Antisemitismus, ANTIAMERIKANISMUS}

In den Abschnitten 4.2 und 4.3 wurden anhand der Arbeiten von Weiß, Sutterlüty und Neckel solche Beispiele für vorurteilige Ungleichheitssemantiken angeführt, deren Funktion in der unmittelbaren Benachteiligung oder Exklusion bestimmter Outgroups besteht. Neben solchen rassistischen bzw. fremdenfeindlichen ${ }^{16}$ Rhetoriken lassen sich aber auch Formen vorurteiligen Sprechens ausmachen, deren Funktion nicht unmittelbar in der Schädigung oder dem Ausschluss einer konstruierten Fremdgruppe besteht, sondern in der Naturalisierung und Rechtfertigung kategorialer Wir-Gruppenkonstruktionen. ${ }^{17}$ Bei solchen Formen richtet sich die vorurteilige

16 Die Liste unmittelbar schädigender Rhetoriken ließe sich natürlich über die genannten Beispiele hinaus fortsetzen: Homophobie, Sexismus, Antisemitismus, Antiziganismus, etc.

17 Dies bedeutet nicht, dass ich Wir- und Fremd-Gruppenkonstruktionen als Aspekte vorurteiligen Sprechens streng trennen möchte. Vielmehr teile ich die Annahme der Komplementarität von Selbst- und Fremdbild, die Klaus Holz in seiner Antisemitismusanalyse formuliert hat: „Auch die antisemitische Semantik kann nur angemessen rekonstruiert werden, wenn das komplementäre Selbstbild angemessen berücksichtigt wird. In dieser Semantik ist die Abgrenzung vom Judenbild konstitutiv für die Konstruktion einer WirGruppe. Das eine gibt es nur mit dem anderen.“ (Holz 2001, S. 17, vgl. auch S. 37) Vorurteiliges Sprechen ist also in gewisser Weise immer für Identitätskonstruktion funktional, und dennoch lassen sich Formen davon hinsichtlich der Wahrscheinlichkeit oder Intensität, mit der sie sich auf die Verfolgung oder Diskriminierung jeweiliger Gruppen auswirken, unterscheiden. Genau an dieser Stelle setzen jene Kritiken des Antiamerikanismusbegriffes an, die in Kapitel 2.1 angesprochen wurden: Sie halten den Begriff für relativistisch, da es sich bei Antiamerikanismus lediglich um ein „falsches Meinen“, beim Antisemitismus aber um eine manifeste Verfolgungspraxis handele, und der Vergleich beider Phänomene daher ,ungewollt die im Antisemitismus steckende Gewalt gegen Juden [...] zu einer bloß falschen Denkweise“" verharmlose (Claussen 2010). Gegenüber dieser Kritik ist einzuwenden, dass (1) es durchaus auch manifeste Gewalt gegen Amerikanerinnen und Amerikaner gibt, etwa in Form von antiamerikanischem Terrorismus, diese Unterscheidung also nicht mit der behaupteten Eindeutigkeit funktioniert; und dass (2) auch vermittelte Zusammenhänge mit Diskriminierung und Verfolgung von Gruppen eine Vorurteilskritik begründen können, wie im weiteren Verlauf dieses Abschnitts dargelegt wird. Anders formuliert: Es kann auch dann sinnvoll von Vorurteil gesprochen werden, wenn ein mittelbarer Zusammenhang zwischen antiamerikanischem Sprachge- 
Funktion sozusagen in erster Linie ,nach innen', indem sie der Konturierung, Stabilisierung und Aufwertung der Eigengruppe dient. Eine zentrale Wir-Gruppenkonstruktion, auf die solche ,nach innen' gerichtete vorurteilige Rhetorik wirkt, ist die nationale Identität. Da Nationalismen, zumindest in ihrer naturalisierenden, kategorial-verfestigten Form, wiederum mit der Benachteiligung und Exklusion bestimmter Fremdgruppen zusammenhängen, gewinnen in einer performativen Perspektive auch solche Rhetoriken vorurteiligen Charakter. Der vorurteilige Effekt entsteht dann mittelbar, indem durch den Gebrauch bestimmter In- und Outgroup Stereotype eine Identitätskonstruktion reproduziert und stabilisiert wird, die systematisch mit Diskriminierung und Exklusion zusammenhängt. Für den Vorurteilsbegriff bedeutet dies vor allem, dass die effektiv benachteiligte oder verfolgte Gruppe, deren Diskriminierung die Grundlage dafür gibt, überhaupt von vorurteiliger Rede zu sprechen, nicht unbedingt auch diejenige sein muss, gegen die sich eine jeweilige vorurteilige Rhetorik explizit richtet. Übertragen auf Antiamerikanismus: Ein stereotypes Sprechen über Amerika muss keine Diskriminierung oder Verfolgung von Amerikanerinnen und Amerikanern zur Folge haben, um als Antiamerikanismus kritisiert werden zu können. Wenn gezeigt werden kann, dass es eine rechtfertigende oder stabilisierende Funktion z.B. für ethnozentrische, fremdenfeindliche Konstruktionen hat (die wiederum zur konkreten Diskriminierung oder Verfolgung anderer Gruppen beitragen), so kann auch dies zum Ansatz einer Antiamerikanismuskritik werden.

Es liegt auf der Hand, dass solche mittelbar diskriminierenden Differenzkonstruktionen für die Kritik des Antiamerikanismus besondere Relevanz besitzen: In Kapitel 2 wurde die häufig bemerkte Besonderheit des Antiamerikanismus beschrieben, dass dieser vergleichsweise selten mit einer unmittelbaren Diskriminierung amerikanischer StaatsbürgerInnen einhergeht und sich in den meisten Fällen nicht gegen eine Minderheit richtet. Tatsächlich wird man angesichts vieler Gebräuche von Amerikastereotypen festhalten müssen, dass diese zwar als negative kategoriale Klassifikationen gebraucht werden, jedoch nicht zu einer Schädigung von Mitgliedern der klassifizierten Outgroup führen - oder doch zumindest nicht in einer Weise, die vergleichbar wäre z.B. mit der manifesten Diskriminierung und Verfolgung von Menschen mit Migrationshintergrund oder ohne deutsche Staatsbürgerschaft, wie sie durch fremdenfeindliche und rassistische Vorurteile in Deutschland bedingt wird. Wenn jemand rhetorisch die Oberflächlichkeit und den Egoismus ,der Amerikaner" gegen die Tiefsinnigkeit und Solidarität ,der Deutschen" ausspielt, so mag dies gegenüber der als amerikanisch angesprochenen

brauch und Diskriminierung, Verfolgung oder Exklusion bestimmter Gruppen besteht (die nicht unbedingt , amerikanisch` sein müssen; vgl. auch Kap. 2.4 und 3.4). 
Gruppe abwertend, vielleicht sogar feindselig sein. Es wird aber auf diese Gruppe kaum eine unmittelbar benachteiligende oder verletzende Wirkung haben. ${ }^{18}$

Wie können dann aber Äußerungen von Antiamerikanismus im Sinne eines performativen Vorurteilsbegriffes als Vorurteile gefasst werden, wenn dieser den vorurteiligen Gehalt von Ausdrücken doch gerade an deren rhetorischer Funktion im Rahmen von Ungleichheit und Diskriminierung festmacht? Wie sieht die oben angesprochene mittelbare vorurteilige Wirkung aus? Dem hier vorgeschlagenen Verständnis zufolge, können diese grob in zwei Formen aufgeteilt werden: Zum einen kann von antiamerikanischen Vorurteilen dann gesprochen werden, wenn bestimmte Amerikastereotype unmittelbar dazu genutzt werden, eine nationale Wir-Gruppe aufzuwerten oder das nationalistische Weltbild, in dem diese verortet ist, zu stabilisieren. Dies geschieht im Falle antiamerikanischer Rhetorik in der Regel auf der Grundlage einer kulturellen Semantik, die die Heterogenität, Unkultiviertheit, moralische oder politische Schlechtigkeit ,der Amerikaner' gegen die Tugenden der Eigengruppe stellt. Diese Stabilisierungsfunktion antiamerikanischer Rhetorik kann auch dann im Kontext von Ungleichheit und Diskriminierung problematisiert werden, wenn sich mit den antiamerikanischen Ausdrücken keine unmittelbare Schädigung der als amerikanisch markierten Gruppe verbindet. Die Überlegung hierbei ist, dass der Nationalismus, als dessen stützendes Element der Antiamerikanismus wirkt, systematisch mit der Reproduktion diskriminierender und exkludierender Praxen gegenüber ,Ausländern', ,Migranten“ und anderen Fremdgruppen zusammenhängt (vgl. Giesen 1993, S. 94 ff.; Richter 1996, S. 123 ff.; Scherr 2008, S. 2010 f.; Schlüter und Christ 2012). Dass er dies tut, lässt sich auch anhand der Interviewbeispiele insbesondere in Kapitel 7.3 und 7.4 nachvollziehen, in denen antiamerikanische Sprechweisen im rhetorischen Zusammenhang mit fremdenfeindlichen, rassistischen und antisemitischen Konstruktionen auftreten.

In den folgenden beiden Abschnitten werden als Vorbereitung der Ergebnisdarstellung in Kapitel 7 die verschiedenen Stabilisierungs- und Konturierungsfunktionen antiamerikanischen Sprechens theoretisch untermauert bzw. eingeordnet. Dies geschieht wesentlich im Rückgriff auf Arbeiten von Armin Nassehi zu nationalistischen Gebräuchen kultureller Semantiken im Multikulturalismus sowie mit Bezug auf Klaus Holz' Analyse der antisemitischen Semantik als Struktursicherung der nationalen Weltanschauung durch die Konstruktion einer „Figur des Dritten“ (Holz 2002). Die ideologische Form antiamerikanischen Sprechens, in der Amerikastereotype zur Rechtfertigung bzw. Entparadoxierung widersprüchlicher Normorientierungen gebraucht werden, wird ebenfalls im Rückgriff auf Klaus Holz’ Antisemi-

18 Damit soll keinesfalls unterschlagen werden, dass es solche unmittelbaren Effekte von Antiamerikanismus auf Amerikanerinnen und Amerikaner auch gibt: von den Anfeindungen amerikanischer Touristen und Einwanderer in Europa (vgl. Jaecker 2014, S. 11 ff.) bis hin zu den antiamerikanischen Terroranschlägen des 11. September 2001. 
tismusanalyse erörtert, insbesondere bzgl. der Bearbeitung einer „Paradoxie der Normalisierung“ (Holz 2007) im deutschen Antisemitismus nach 1945.

\subsubsection{Ethnozentrismus und ,Kultur': Konturierende und stabilisierende Funktionen nationaler Identität}

Armin Nassehi hat im Anschluss an die Soziologie Niklas Luhmanns gezeigt, wie das „,stahlharte Gehäuse der Zugehörigkeit“ (Nassehi 1997a) ethno-nationaler Identifikation auch dort wirksam sein kann, wo sich eine Unterscheidung von Ethnien mittels einer kulturellen Semantik etabliert hat und deren Zusammenleben nach einem multikulturalistischen Integrationsmodell funktioniert (vgl. auch Neubert et al. 2013). Im Multikulturalismus wird die Pluralität der ethno-nationalen Weltordnung gewissermaßen innerhalb einer Nation abgebildet, er ,,verschiebt die Differenz zwischen Nationen in das Innere politischer Gemeinwesen und affirmiert sie dort als Kulturvielfalt" (ebd., S. 192). Weil die jeweilige Nation dabei aber immer als bestimmte (z.B. deutsche) Nation mit klaren Grenzen ansprechbar bleibt und diese Grenzziehung zudem an ethnisch-kulturelle Bestimmungen gekoppelt ist, die sagen, was bzw. wer als ,deutsch' gilt, reproduziert gerade auch der Multikulturalismus zumindest in einigen populären Varianten (vgl. Nassehi 1997a, S. 180 ff.; Neubert et al. 2013, S. 16 ff.) - eine ethno-nationale Ordnung. Das multikulturalistische Programm hat daher, so Nassehi, nicht die ihm häufig zugeschriebene vermittelnde Wirkung, die zu einer Aufweichung der Grenzziehungen und einer Versöhnung zwischen ,den Völkern' führen soll; weil diese ,Völker' in ihr immer schon als identische vorausgesetzt werden, wirkt sie vielmehr stabilisierend für etablierte Systeme strikter ethnischer Gruppenunterscheidungen. Die Offenheit, die der Kulturbegriff suggeriert, erscheint in dieser Perspektive als ideologische Stütze genau derjenigen Weltsicht, deren interethnisches Konfliktpotential der Multikulturalismus aufheben bzw. abmildern soll. Auch wenn die völkisch-rassische durch eine kulturelle Semantik ersetzt wird, konstruiert doch ein multikulturalistischer Nationalismus häufig dieselbe „Herder'sche Weltsicht“ (Wimmer 2008, S. 60), wie seine offen ethnozentrischen ${ }^{19}$ Varianten: Die Menschheit erscheint demnach als gegliedert

19 Unter Ethnozentrismus werden im Folgenden Differenzkonstruktionen bezeichnet, in denen ,ethnisch ' markierte Gruppen einander nach rigiden Unterscheidungskriterien gegenübergestellt werden (Rieker 1997, S. 14 ff.). Eigen-, Fremd- und Feindgruppenkonstruktionen sind hierbei stets aufeinander bezogen und bedingen sich wechselseitig, wobei „die Orientierung an den Maßstäben der eigenen Gruppe [...] die Beziehungen zu dieser und zu anderen Gruppen“ maßgeblich prägt (ebd.). Der Begriff Ethnozentrismus beinhaltet demnach zwei Dimensionen: ,Zentriert“ ist in ethnozentrischen Sinnkonstruktionen einerseits die Unterteilung der Menschheit oder ggf. auch kleinerer lokaler Zusammenhänge in ,ethnische 'Gruppen selbst. Andererseits steht innerhalb dieser auf ,Ethnizität ‘ 
in Ethnien bzw. Nationen, die jeweils als naturwüchsige Volksgemeinschaften mit eigenem Territorium und spezifischen kulturellen und charakterlichen Eigenschaften vorgestellt werden (vgl. ebd., S. 59). Die Einkleidung einer solchen ethnonationalen Weltsicht in die Terminologie des Multikulturalismus wird Nassehi zufolge dadurch ermöglicht, dass der Gebrauch des Kulturbegriffes im Rahmen nationaler Identitätsbildungsprozesse hinter den spezifischen reflexiven Gehalt zurückfällt, den etwa die Systemtheorie Luhmanns diesem Konzept zuschreibt:

„Fast alle Beiträge, zumindest so weit sie sich an der Unterscheidung Pro oder Contra [Multikulturalismus, F. K.] beteiligen, tun so, als handle es sich bei jenen Kulturen, deren Summe die multikulturelle Gesellschaft ausmacht, um gewissermaßen beobachtungsfrei existierende Sachverhalte. Zumindest bis in diesen Diskurs ist die der Kultursemantik eingeschriebene Reflexivität, das Bewußtsein von der historischen Kontingenz kultureller Phänomene offenbar nicht vorgedrungen.“ (Nassehi 1997a, S. 190)

De facto werden kulturelle Semantiken ihrem Selbstverständnis nach also gerade nicht gemäß dem soziologisch beschriebenen Prinzip der paradoxen „Kontingenzbewältigung durch Betonung von Kontingenz" gebraucht, sondern dienen vielmehr der Identitätssicherung indem sie sich „ein besonderes normatives Gewicht, eine erhabene Erscheinung" verleihen und gegen Kontingenzbewusstsein abschotten (ebd., S. 188). ,Kultur' in diesem Sinne, wird synonym mit Traditionalität und regrediert somit vom modernen Prinzip der „Nicht-Zugehörigkeit“ zum „Prinzip der vorgeordneten Zugehörigkeit zu (relativ) geschlossenen sozialen Aggregaten“ (ebd., S. 195). Durch diese Ungleichzeitigkeit erzielt die kulturelle Semantik ähnliche Effekte, wie sie von Ferdinand Sutterlüty anhand der ,paradoxalen Folgen ethnischer Gleichheit“ beschrieben wurden (Sutterlüty 2011): Die Idee einer prinzipiellen Gleichheit ethnisch unterschiedener Gruppen, die eine ähnliche immanent paradoxe Struktur aufweist, wie der Kulturbegriff im Sinne Nassehis bzw. Luh-

zentrierten Weltsicht wiederum die ,ethnische“ Eigengruppe im Zentrum des Interesses bzw. liefert relevante Orientierungsmuster. Wie im weiteren Verlauf dieses Abschnittes anhand der Arbeiten von Nassehi, Sutterlütty, Neckel und Holz argumentiert wird, beginnt also Ethnozentrismus nicht erst in dem Moment, in dem die eigene Ethnie relativ zu anderen aufgewertet bzw. als höherwertig markiert wird, sondern schon dann, wenn ethnische Gruppenkonstruktionen eine zentrale argumentative und sinnstiftende Funktion im Sprechen einer Person übernehmen. Da mit dem Ethnozentrismusbegriff nicht klar eingegrenzt ist, wer bzw. wie jeweils als ,ethnische' Gruppe konstruiert wird, ist der Begriff zunächst relativ unspezifisch (vgl. ebd., S. 15). Im Kontext der vorliegenden empirischen Arbeit bezieht sich der Ethnizitätsbegriff vornehmlich auf völkisch-nationale Identitätskonstruktionen. Die Übergänge zwischen Ethnozentrismus, Fremdenfeindlichkeit und Rassismus sind daher hier in vielen Fällen als fließend anzusehen. 
manns $^{20}$, wird eingeholt von einem ,ethnischen ,Verwandtschaftsglauben[s]““ (ebd., S. 111), dessen rigide Differenzkonstruktionen sie zu ethnozentrischer Ideologie gerinnen lässt. Egalitäre Formeln werden zur Legitimationsinstanz ethnonationalistischer Herrschaft. Wie ich insbesondere in Kapitel 7.2 und 7.4 anhand des Interviewmaterials zeigen werde, weisen antiamerikanische Rhetoriken aufgrund ihrer kulturellen Semantik eine besondere Affinität zu dieser Form nationalistischer Identitäts- bzw. Herrschaftssicherung auf: So tauchen die USA in antiamerikanischen Konstruktionen häufig nicht einfach als minderwertige oder feindliche Nation auf, sondern als Ort, an dem die als selbstverständlich angenommene Verkopplung von Nation und Ethnie nicht funktioniert. Wenn ,Kulturen' im nationalistischen Sprachgebrauch die Rolle von ,Rassen “ oder ,Völkern “ übernommen haben, so wird mit der Zuschreibung einer , amerikanischen Kulturlosigkeit' die Möglichkeit thematisiert, dass die Menschheit nicht ethno-national geordnet sein könnte. Mit dieser Formulierung greife ich einen zentralen Topos der Antisemitismusanalyse Klaus Holz' auf, den ich in meiner Analyse antiamerikanischer Rhetorik adaptiere (vgl. u. sowie Holz 2010, S. 296).

Klaus Holz hat in seiner Analyse des modernen Antisemitismus als zentrales Ergebnis eine bestimmte Form der Struktursicherung nationaler Identität durch die antisemitische Semantik ausgemacht. Diese funktioniert demnach nicht (nur) nach der ,klassischen ' Vorurteils-Funktion einer relativen Aufwertung der Eigengruppe (vgl. Heitmeyer 2002b), d.h. ,die Juden“ werden darin nicht als eine fremde oder feindliche Nation der eigenen gegenübergestellt, sondern als eine selbstwidersprüchliche „Figur des Dritten“ (Holz 2010, S. 296), als Außen zur nationalen Ordnung überhaupt konstruiert. Wenn die jeweils übrigen Nationen das Außen einer nationalen Wir-Gruppe bilden, so bilden ,die Juden“ als Figur des Dritten das Außen zu dieser Unterscheidung zwischen nationaler Wir- und Fremdgruppe. In dieser Figur des Dritten werden nicht nur die kontingenten und wandelbaren Aspekte der eigenen essentialistisch vorgestellten Nation ausgelagert, sondern die der ethnonationalen Ordnung, d.h. des Bildes einer in ursprünglich-natürliche Völker mit angestammten Lebensraum eingeteilten Welt, insgesamt: „In der Figur des Dritten, im nationalen Antisemitismus, wird zugleich thematisiert und abgewehrt, dass , unsere Identität und die Ordnung der Welt nicht national sein könnten.“ (Holz 2010, S. 296) ,Die Juden“ erscheinen in antisemitischen Konstruktionen als Nichtidentische, als das Tertium non Datur der Zwei-Seiten-Form Nation. Sie sind konstruiert als die paradoxe Identität eines Volkes das zugleich nicht Volk, einer Nation die nicht Na-

20 Wo die moderne Gleichheitsidee allgemeine Gleichheit um der individuellen Besonderheit Willen fordert, versucht der moderne Kulturbegriff, die Identität gesellschaftlicher Lebensformen unter Verweis auf deren Kontingenz und Wandelbarkeit zu begründen (vgl. auch Kap. 4.4 oben). 
tion ist und verkörpern somit die Negation der nationalen Ordnung (vgl. Holz 2001, S. 543).

In Kapitel 7.2 werde ich argumentieren, dass Konstruktionen einer amerikanischen Outgroup eine ähnliche Funktion in der Stabilisierung nationaler WirGruppenidentitäten einnehmen können. So erscheinen in der ethno-nationalen Rhetorik von Herrn F die USA als eine widersprüchliche Figur: Sie bilden zugleich eine starke nationale Einheit und bestehen doch ,nur aus Einwanderern“. Während Herr F keine befriedigende Lösung für diesen Widerspruch findet und ihn daher offen lässt, scheint bzgl. der deutschen Eigengruppe trotz der auch dort beobachteten Heterogenität ein vergleichbares Problem gar nicht erst zu entstehen. Hier sorgt eine multikulturalistisch-essentialistische Semantik dafür, dass sich trotz aller ethnischen Heterogenität stets eingewanderte von ,eigentlichen“ Deutschen unterscheiden lassen. Das kulturelle Wesen der deutschen Wir-Gruppe bleibt über Assimilationsprozesse hinweg als quasi-natürliches erhalten. Hinter Herrn Fs vermeintlich liberalem Verständnis nationaler Identität verbirgt sich somit ein völkisch-essentialistisches Kriterium dafür, was eine Nation konstituiert bzw. wer deutsch ist. ,Amerika ', so mein Argument, dient hier als Außen zu genau jener nationalen Ordnungsvorstellung: Es steht für den möglichen Kollaps der Unterscheidung von ,Migranten “ und ,Autochthonen', auf deren Grundlage auch ein multikulturalistisch variierter Nationalismus funktioniert.

Es sei an dieser Stelle noch einmal darauf hingewiesen, dass die Adaption der Holz'schen Figur des Dritten keine Gleichsetzung antisemitischer und antiamerikanischer Struktursicherungsfunktionen bedeutet: So besteht zwischen diesen zum einen der Unterschied, dass die Konstruktion der , amerikanischen Nichtidentität‘ weniger als Bedrohung für die Nationale Ordnung fungiert, denn als Bedrohung für eine Ordnung, in der ethnische und nationale Zugehörigkeit untrennbar verbunden sind. Denn die Existenz der USA als ökonomisch und politisch mächtige Nation stellt ja nicht die nationale Ordnung der Welt in Frage - wohl aber die Ordnung der Welt in ethnisch-essentialistisch verfasste Nationen. Zum anderen ist festzuhalten, dass aus der antiamerikanischen Konstruktion historisch keine vergleichbare eliminatorische Konsequenz gezogen wurde, wie sie die Konstruktion ,des Juden ‘ als Figur des Dritten gehabt hat und wieder zu haben droht: Das ,Amerika' vieler antiamerikanischer Konstruktionen muss, im Gegensatz zu ,den Juden“ im nationalen Antisemitismus, nicht ausgelöscht werden, um die nationale Ordnung zu erhalten. ${ }^{21}$

21 Als wie bedrohlich dieses, amerikanische Andere" in jeweiligen antiamerikanischen Konstruktionen wahrgenommen wird bzw. welche Konsequenzen aus dieser Störung der ethno-nationalen Ordnung gezogen werden, variiert von Fall zu Fall. So kann z.B. ein islamistischer Antiamerikanismus durchaus eliminatorische ,Lösungsperspektiven“ entwickeln, der zufolge der „große Satan“ Amerika vernichtet werden muss, um die gottgewollte Ordnung der Welt wieder herzustellen - hierin konvergiert solcher Antiamerika- 


\subsubsection{Antisemitismus, Kommunikationslatenz und die „Paradoxie der Normalisierung“}

Einen Spezialfall der antisemitischen Struktursicherung nationaler Identität beschreibt Holz für den deutschen Antisemitismus nach 1945. Dieser funktioniert hinsichtlich eines unvermeidlichen Bezugs auf die nationalsozialistische Judenvernichtung und der damit einhergehenden Sanktionierung antisemitischer Kommunikation unter besonderen Bedingungen, die im Anschluss an Klaus Holz als „Paradoxie der Normalisierung“ bestimmte werden können: Nach 1945 ist in Deutschland „die nationalsozialistische Judenvernichtung zu einem konstitutiven Bezugspunkt für das nationale Selbstverständnis“ geworden (Holz 2007, S. 51), so dass jede positive Identifikation mit Deutschland auf die nationalsozialistische Judenverfolgung rekurrieren muss, will sie nicht als revisionistisch, rechtsradikal oder gar antisemitisch gelten. Dieser Rekurs aber stellt zugleich eine Grenze der Normalisierung deutscher Nationalidentität dar, denn die Erinnerung des Holocaust verunmöglicht eine positive, kontinuierliche nationale Wir-Gruppe. Somit ist die Bedingung einer positiven deutschen Nationalidentität nach 1945 zugleich deren Negation. Ein „,demokratischer Antisemitismus“ (Holz 2005, S. 54) zielt daher nicht nur darauf, die Identität der deutschen Wir-Gruppe bzw. deren weltanschaulich-nationale Einbettung antisemitisch zu stabilisieren, sondern er muss zugleich vermeiden, als antisemitisch wahrgenommen zu werden. Denn gerade der Holocaust steht ja jener bruchlosen Identifikation mit der deutschen Nation im Wege, die der Antisemitismus erzeugen will, so dass die Judenvernichtung zum Gegenstand der antisemitischen Sicherung von Nationalidentität werden muss (vgl. ebd., S. 58 ff.). ${ }^{22}$ Die prominentesten Strategien hierzu sind die Verharmlosung oder Leugnung des Holocaust, sowie eine damit einhergehende Täter-Opfer Umkehr, in deren Ergebnis ,die Deutschen“ als Opfer einer falschen Anklage bzgl. ihrer NS-Verbrechen und ,die Juden“ als Täter ebendieser Anklage erscheinen. In sekundär antisemitischen Konstruktionen tritt daher die Judenvernichtung in erster Linie als Problem nationaler Identifikation auf:

nismus mit einem klassischen Vernichtungsantisemitismus. Auch antiamerikanische Konstruktionen der neuen Rechten in Deutschland können sich diesem Programm anschließen, z.B. wenn der NPD-Abgeordnete Jürgen W. Gansel in strategischer Abwägung „Zwischen Islamismus und Amerikanismus“ (Gansel zit. n. Höttemann et al. 2010, S. 280) für eine temporäre Solidarität mit Islamisten im „Verteidigungskampf gegen die Aggressoren der ,Mc World““ (ebd., S. 281) optiert.

22 Dies gilt natürlich nicht für solche Antisemitismen, die explizit gegen jede demokratische Ordnung und für die antisemitische Politik des Nationalsozialismus Position beziehen. Im Fokus von Holz Analyse steht aber ein „demokratischer Antisemitismus“ (Holz 2005, S. 54), also solchen Formen antisemitischer Ausdrücke, die sich zugleich als mit egalitären Normen vereinbar zu rechtfertigen suchen. 
„Die Erinnerung der nationalsozialistischen Judenvernichtung verhindert eine selbstverständliche, positive Identifikation mit der Nation. [...] Auschwitz bedroht ,unsere Identität“." (Ebd., S. 49) Deshalb spricht der Antisemitismus nach 1945 „,nicht davon, warum und wie es zur Tat und Täterschaft kam, sondern von den Belastungen, die der Täter seitdem zu erdulden hat" (ebd., S. 55). Zugleich stellt man klar, dass man die Taten des Nationalsozialismus rundheraus verurteilt, jedoch „fährt dann mit einem ,aber“ fort“ (ebd., S. 56) und schließt eine Verurteilung der jüdischen Ankläger an. Diese Verurteilung rückt, den Effekt der Täter-Opfer Umkehr verstärkend, ,die Juden“ häufig in die Nähe nationalsozialistischer Praktiken der Verfolgung und Propaganda. Ebenfalls ist $\mathrm{zu}$ beobachten, dass in solchen schuldumkehrenden Konstruktionen ,den Juden “ unlautere Motive wie Profitgier, Rachsucht u. ä. unterstellt werden, wodurch nicht selten klassisch antisemitische Stereotype reproduziert werden. Mit der Inszenierung der Deutschen als Opfer und der Konstruktion eines externen, unrechtmäßigen Anklägers wird der Widerspruch zwischen einer Anerkennung des Holocaust und einer , guten ' deutschen Identität verdeckt: „Die Paradoxie wird verborgen, indem die Schuld indirekt geleugnet und der fortgesetzte Schuldvorwurf den Juden zur Last gelegt wird.“ (Ebd., S. 52)

Die „Paradoxie der Normalisierung“ deutscher Nationalidentität nach 1945 betrifft allerdings nicht nur antisemitische Konstruktionen der , Vergangenheitsbewältigung', d.h. sie kann nicht nur im Rahmen einer antisemitischen Semantik bearbeitet werden. Jede Kommunikation einer bruchlosen Identifikation mit Deutschland nach 1945 muss tendenziell ,leugnen, verdrehen, aufrechnen, normalisieren, bewältigen“, um den Holocaust thematisieren zu können, ohne dass diese Thematisierung in Widerspruch zur positiven Wir-Gruppenkonstruktion gerät (ebd., S. 51). Die Rhetoriken der Normalisierung verbleiben dabei häufig , an der Schwelle‘ zum sekundären Antisemitismus, indem sie die besagte Täter-Opfer Umkehr nur teilweise vollziehen: Wenn ,die Deutschen“ nach 1945 zwar als Opfer einer unrechtmäßigen Anklage dargestellt werden, die Bezeichnung ,der Juden“ als Kläger aber ausbleibt, so wird ein ähnlicher Effekt erzielt, ohne dass im engeren Sinne von einer antisemitischen Rhetorik die Rede sein könnte. Wie in Kapitel 7.3 ausführlich dargestellt wird, können antiamerikanische Sprechweisen an dieser Stelle als funktionales Äquivalent zu antisemitischen Auflösungen der „Paradoxie der Normalisierung“ dienen. So wird z.B. die Rolle eines unrechtmäßigen Anklägers der Deutschen von Herrn B mit ,den Amerikanern` besetzt. Der Verweis auf den Genozid an amerikanischen Ureinwohnern verhilft ihm indessen dazu, die Judenvernichtung implizit zu thematisieren und zu relativieren, ohne Juden oder den Holocaust jemals explizit benennen zu müssen. Mit dieser Substituierung der ,rachsüchtigen Juden` durch die , amerikanische Weltpolizei` erfüllt Herr B also eine doppelte Normalisierungsfunktion hinsichtlich der deutschen Nationalidentität: Er kann die Deutschen als eine Nation unter vielen mit Genozid-Vergangenheit normalisieren, und sich zugleich als guter Demokrat rechtfertigen. Dies gelingt ihm, indem er die Spezifik des Holo- 
caust durch Referenz auf den, amerikanischen Genozid' verdeckt, der ihm zugleich als Kontrastfolie zur moralischen Selbstaufwertung dient.

Jenes Verdeckt-Halten des antisemitisch bzw. antiamerikanisch bearbeiteten Problems, d.h. hier: des Holocaust, wird in der Antisemitismusforschung unter dem Begriff der „Kommunikationslatenz“ (Bergmann und Erb 1986, S. 226) verhandelt. Da dieses Konzept in der Ergebnisdarstellung des qualitativen Materials insbesondere in den Kapiteln 7.3 und 7.4 eine zentrale Rolle spielt, soll das dabei angenommene Verständnis des Latenzbegriffes hier kurz umrissen werden. Es wird sich dabei zeigen, dass dessen Verwendung weitgehend deckungsgleich mit dem in Abschnitt 4.5.1 dargelegten Ideologiebegriff ist: Sowohl das Konzept einer ideologischen Funktion vorurteiligen Sprechens als auch ein kommunikationstheoretisch verstandener Latenzbegriff zielen auf eine spezielle, tragische Art der Reflexivität $\mathrm{ab}$, in der eine Problematik zugleich thematisiert und invisibilisiert wird. Latenz, in diesem Verständnis, bezeichnet eine bestimmte Art der indirekten, gewissermaßen metaphorischen Kommunikation: Etwas anzusprechen, ohne es auszusprechen.

Diese Verwendung des Latenzbegriffes weicht ab vom weithin üblichen Verständnis dieses Terminus, das treffender vielleicht als „Umwegkommunikation“ bezeichnet werden kann (vgl. Heyder et al. 2005, S. 158). Hier wird Latenz weniger als eine Eigenschaft der antisemitischen Kommunikation, als vielmehr eine des Antisemitismus als psychischer Disposition bestimmt, d.h. die Grundannahme ist: der Antisemitismus bleibt als Einstellung stets derselbe, wird aber ggf. nicht auf explizitem Weg geäußert. Die einstellungspsychologische Logik hinter diesem Verständnis von Kommunikationslatenz äußert sich auch in den empirischen Forschungsdesigns, die zu dessen Testung genutzt werden: Hier werden häufig sowohl klassische, manifeste antisemitische Äußerungen als auch implizite, ,demokratische‘ Ausdrücke bzw. der empfundene Latenzdruck mit getrennten Instrumenten erhoben, um dann anhand der Korrelation beider Konstrukte einen Beleg für den impliziten antisemitischen Gehalt der latenten Ausdrücke zu geben (Heyder et al. 2005; Bergmann und Erb 1991, S. 279 ff.). Mit der hier eingenommen sprechaktbzw. praxistheoretischen Perspektive auf Vorurteile ist dieses Verständnis von Kommunikationslatenz nur teilweise vereinbar, denn die rhetorisch-ideologische Bearbeitung der Ambivalenz des Antisemitismus nach 1945 (bzw. des vorurteiligen Sprechens unter egalitärem Vorzeichen überhaupt) wird darin zugunsten einer mehr oder weniger bewussten, taktischen Abwägung zwischen antisemitischer Einstellung und Konformitätsbedürfnis vernachlässigt. Insbesondere die oben genannten Forschungsdesigns erscheinen aus der Perspektive eines performativen Vorurteilsbegriffes problematisch, da die Grundannahme des Latenzbegriffes ja ist, dass antisemitische, rassistische oder antiamerikanische Sprechweisen gerade nicht in , klassischer' Form explizit geäußert werden, d.h. auch nicht parallel gemessen werden können. Damit soll nicht bestritten werden, dass es das Phänomen der Umwegkommunikation gibt, d.h. dass sich Personen finden lassen, die in bestimmten Situa- 
tionen sich explizit antisemitisch äußern, in anderen aber einem Konformitätsdruck folgend auf latent-antisemitische Codes ausweichen - und solche Formen antisemitischen Sprechens ließen sich dementsprechend auch mit den genannten Paralleltest-Designs erfassen. Problematisch erscheint dieses Verständnis von Kommunikationslatenz aber, insofern es (1) den theoretischen Fokus auf die antisemitische Einstellung des Individuums legt. Die konzeptuellen Probleme eines solchen psychologischen Reduktionismus sind in Kapitel 2.4 bereits dargelegt worden. Ein Verständnis des Latenzbegriffes im Sinne einer Umwegkommunikation tendiert außerdem (2) dazu, die rhetorischen Mittel und Wege aus dem Blick zu verlieren, die ein indirektes oder metaphorisches vorurteiliges Sprechen möglich machen, und auf deren ideologisch-rechtfertigende Funktionsweise die Vorurteilskritik bislang nur ungenügende Aufmerksamkeit verwendet hat.

Werner Bergmann und Rainer Erb haben in ihrem einflussreichen Artikel über Kommunikationslatenz, Moral und öffentliche Meinung bereits 1986 mit Nachdruck auf die Wichtigkeit einer präzisen Unterscheidung von Kommunikationslatenz und Bewusstseinslatenz hingewiesen (Bergmann und Erb 1986, S. 225; Bergmann und Erb 1991, S. 275 ff.). Zu häufig, so Bergmann und Erb, werde Latenz insgesamt mit einer psychologisch verstandenen Bewusstseinslatenz gleichgesetzt, d.h. mit einer Verdrängung von Antisemitismus aus dem individuellen Bewusstsein; als seien die Deutschen nach 1945 ,so antisemitisch wie zuvor' geblieben, hätten dies nur nicht mehr offen geäußert. Die Autoren plädieren stattdessen dafür, antisemitische Kommunikationslatenz auch als gesellschaftliches Phänomen zu verstehen: Einer solchen soziologischen Perspektive geht es um die Bedingungen der „Ermöglichung und Steuerung von Kommunikation“ (ebd.), also die überindividuell geltenden Regeln der Sagbarkeit und Nicht-Sagbarkeit antisemitischer Kommunikationsinhalte, die z.B. steuern, ob und in welcher Weise von ,den Juden ' gesprochen werden darf. Diese sind zunächst unabhängig davon zu betrachten, ob individuelle Sprecher von ihrer psychischen Disposition her als Antisemiten zu klassifizieren sind, oder nicht. „Latenzschutz“ ist demnach eine Funktion sozialer Systeme, hier insbesondere der neugegründeten demokratischen Institutionen der BRD (ebd., S. 228). Nicht zuletzt aufgrund von „externen Integrationsanforderungen“, nämlich der Außendarstellung des Nachfolgestaats als demokratisch und antifaschistisch, von der die „Aufnahme der Bundesrepublik ins westliche Lager“ abhing (ebd., S. 227), mussten antisemitische Kommunikationen systematisch blockiert werden. Dies bedeutet aber mitnichten, dass diese einfach verschwinden, sondern es ,werden Strukturen ausgebildet, die regeln, was in welchen Situationen gesagt bzw. verschwiegen, gesehen bzw. übersehen werden muß“ (ebd., S. 226). Im weiteren Verlauf ihrer Analyse geht es den Autoren dann insbesondere um die Wirkungen, die solche Kommunikationslatenz auf das antisemitische Potential der deutschen Gesellschaft hat: Einerseits schütze es, insbesondere in den unmittelbaren Nachkriegsjahren, tatsächlich die noch nicht selbsttragenden demokratischen Institutionen. 
Andererseits verhindere es durch die Unterdrückung einer offen antisemitischen Kommunikation auch die Kommunikation über Antisemitismus, und damit eine Veränderung antisemitischer Einstellungen.

Ein Problem des Latenzbegriffes von Bergmann und Erb liegt nun darin, dass er zwar eine theoretische Entkopplung von Bewusstseinslatenz und Kommunikationslatenz leistet, d.h. die Frage nach der Entwicklung des Antisemitismus in Deutschland nach 1945 ist nun nicht mehr allein eine Frage nach der individuellen Psyche von Antisemiten. Zugleich aber bleiben Bergmann und Erb bei der Bestimmung von Antisemitismus der von ihnen selbst kritisierten psychologisierenden Auffassung verhaftet. Ihre soziologische Frage nach der gesellschaftlichen Funktionalität der Latenz wird gleichsam auf die fortbestehende Kernannahme aufgesetzt, dass Antisemitismus ein Merkmal von individuellen Personen ist, das je nach gesellschaftlichen Rahmenbedingungen mehr oder weniger geäußert werden kann: Wenn der Antisemitismus nicht in der Kommunikation ist, dann ist er in den Köpfen. Wie oben bereits angemerkt, muss diese Annahme vor dem Hintergrund des in Kapiteln 2 und 3 explizierten praxistheoretischen Verständnisses vorurteiligen Sprechens ungenau erscheinen. Es stellt sich die Frage, wie man jenseits von kommuniziertem Antisemitismus, diesen überhaupt bestimmen kann? Björn Milbradt hat in seiner Dissertation zum Stereotypiebegriff eine ähnliche Kritik des Kommunikationslatenzbegriffs bei Bergmann und Erb formuliert:

„Kommunikationslatenz bezeichnet somit ein Schweigen - unter ihren Auswirkungen bleibt der Antisemitismus unter bestimmten Bedingungen im Befragten verschlossen, er ist vorhanden, aber eben nicht sprachlich, und das Bemühen der empirischen Forschung von Bergmann und Erb ist es gewissermaßen, zu ergründen, ob ein empfundener Latenzdruck eine Versprachlichung verhindert. Diese Wechselwirkung bleibt aber eine der Sprache äußerliche, bezieht sich also auf die Bedingungen, unter denen Antisemitismus geäußert oder verschwiegen wird, und nicht auf etwaige Veränderungen im Sprechen." (Milbradt 2013, S. 38 f.)

Diesem Begriff von Latenz als Schweigen oder Abwesenheit gegenüber soll hier ein Verständnis stark gemacht werden, demzufolge Latenz eine gleichzeitige Anwesenheit und Abwesenheit antisemitischen Gehalts in Kommunikation bedeutet. Eine solche, gewissermaßen radikalisierte, kommunikationstheoretische Perspektive zielt darauf, Latenz als ein Merkmal vorurteiliger Kommunikation zu bestimmen, das an bestimmten Sprechweisen aufgezeigt werden kann, ohne eine dahinterliegende ,explizite" Einstellung anzunehmen. Kommunikationslatenz fände sich demnach in Rhetoriken, in denen beides nachgewiesen werden kann: Die antisemitische Funktion und deren Invisibilisierung. Wie man in Abwandlung des oben explizierten Ideologiebegriffs formulieren könnte: Das kommunikationslatente Vorurteil reflektiert implizit auf die paradoxe Bedingung seiner selbst - dass man nicht vorurteilig sprechen darf - und deckt diese damit gleichzeitig zu, um die Funktion 
vorurteiligen Sprechens dennoch realisieren zu können. Schuldabwehr- bzw. sekundärer Antisemitismus ist demnach eine ideologische Form des Vorurteils, das als Teil seiner Performanz zugleich auf seinen Widerspruch reflektiert (sei es eine externe Sanktionierung oder eine Ambivalenz des Sprechers selbst), aber in solch verdeckter Weise, dass die vorurteilige Performanz nicht behindert wird. Latente Vorurteilsausdrücke brechen ein Kommunikationsverbot, und vermeiden zugleich systematisch die damit verbundenen Sanktionen. Kommunikationslatenz ist als diese ideologische Funktion der Invisibilisierung eines behandelten Problems nicht auf den Bereich des sekundären Antisemitismus bzw. die Bearbeitung der „Paradoxie der Normalisierung“ deutscher Nationalidentität beschränkt. Die oben bereits beispielhaft angeführte ideologische Abwehr von Rassismusvorwürfen mittels bestimmter Amerikastereotype, wie sie sich bei Herrn A und E findet, kann ebenfalls als Latenzfunktion antiamerikanischen Sprechens bezeichnet werden: Die rassistischen Implikationen der eigenen ethnozentrischen Identitätskonstruktion werden anhand ,der USA ' thematisiert und verurteilt, und die eigene Position präventiv vor Rassismusvorwürfen geschützt, ohne die Möglichkeit solcher Vorwürfe gegen die eigene Position je explizit thematisieren zu müssen (vgl. Kap. 7.4).

Der kritisch geführte Nachweis solcher Latenzfunktionen wird hier, entsprechend des in Abschnitt 4.5.3 dargelegten Kritikverständnisses und entgegen den oben kritisierten Paralleltest-Designs, als Deutung verstanden, also als ein gerechtfertigtes Lesen-als, das gerade an solchen Stellen Relevanz gewinnt, an denen keine externe Validierungsinstanz in Form irgendeines expliziten, eindeutigen Vorurteilsausdruckes oder einer nachweisbaren psychischen Disposition vorliegt. Denn der Problemgegenstand, dem der Latenzbegriff sich widmet, besteht ja gerade darin, dass es Antisemitismus gibt, aber „,keine Antisemiten mehr“ (Horkheimer und Adorno 2004, S. 209). Wenn vorurteilige Praxis letztendlich weder als psychische Disposition, noch als lexikalisch-semantisch definierbarer Sinngehalt theoretisch überzeugend bestimmt werden kann, sondern erst anhand der kontextuellen, performativen Wirkung von Sprechweisen (vgl. Kap. 2.4), dann muss der Latenzbegriff eine Änderung in diesen vorurteiligen Sprechweisen selbst beschreiben - nicht nur im Ausdruck eines psychisch identifizierten, als bewusstseinslatent unverändert vorausgesetzten Vorurteils.

\subsection{ZWISCHENFAZIT: EIN PERFORMATIVER ANTIAMERIKANISMUSBEGRIFF III}

Ausgangspunkt des performativen Antiamerikanismuskonzeptes war die These, dass die Kriterien einstellungstheoretischer Antiamerikanismusdefinitionen in zweifacher Hinsicht ungenau sind: Einerseits bedeutet die Bestimmung antiamerikani- 
scher Vorurteile als feindselige, irrationale und weltanschaulich geschlossene Einstellung eine übermäßige Engführung des Konzeptes. Die Flexibilität und Fragmentiertheit antiamerikanischer Vorurteilsausdrücke kann durch eine solche Begriffsbildung nicht systematisch erfasst werden. Andererseits lassen konventionelle Vorurteilskonzepte überzeugende sozialtheoretische Gründe für eine Antiamerikanismuskritik vermissen. Jenseits des Verweises auf drastische Beispiele antiamerikanischer Gewalt, wie etwa den Terroranschlägen des 11. September 2001, scheinen einstellungstheoretische Konzepte wenig überzeugende Antworten auf die Frage zu geben, was an antiamerikanischen Sprechhandlungen in spezifisch vorurteilskritischer Hinsicht problematisch ist. Die Kriterien der propositionalen Falschheit, Stereotypie und Aversivität solcher Ausdrücke geben keine theoretisch zureichenden Gründe dafür, warum diese als antiamerikanisches Vorurteil problematisiert werden sollte, und bleiben in diesem Sinne reduktionistisch.

Als alternative Theorieperspektive wurde vorgeschlagen, den Antiamerikanismusbegriff auf den performativen Sinn antiamerikanischer Sprechhandlungen hin auszurichten. Gefragt wird in dieser Perspektive nicht, was eine antiamerikanisch sprechende Person sagt, welche semantischen und formalen Merkmale ihre Aussage aufweist und ob diese mit ,der Realität "Amerikas korrespondiert. Gefragt wird danach, was jene Person tut, indem sie über ,Amerika' spricht, d.h. welche praktische Bedeutung ihrem Sprechen als sozialem Handeln zukommt.

Die praxis- bzw. sprechakttheoretischen Prämissen dieser Forschungsperspektive wurden in Kapitel 3 erörtert, wobei die Flexibilität, Sozialität und Normativität sprachlichen Handelns in den Fokus rückten. In der Diskussion der letzteren beiden Aspekte wurde deutlich, dass mit der Frage nach dem performativen Sinn antiamerikanischen Sprechens zugleich auch die Performativität des Sprechens über Antiamerikanismus in den Blick gerät. So impliziert die Frage, was Personen tun, wenn sie antiamerikanisch sprechen, reziprok die Frage, was Forschende tun, wenn sie ein Sprechen als antiamerikanisch kritisieren.

In Vorbereitung der empirischen Ergebnispräsentation späterer Kapitel, wurden im vorliegenden zunächst die sozialtheoretischen Grundlagen des Antiamerikanismusbegriffes reflektiert - d.h. der soziologische Funktionskontext des Sprechens über Antiamerikanismus. Den Rahmen hierzu bildet eine Soziologie der Ungleichheit und Diskriminierung, deren wissenssoziologisch-hermeneutische Blickrichtung sich mit dem methodologischen Selbstverständnis einer erschließenden Kritik verbindet. Antiamerikanische Vorurteile werden in dieser Perspektive als Ungleichheitssemantiken bestimmt, die rhetorisch zur Reproduktion und Stabilisierung diskriminierender gesellschaftlicher Verhältnisse beitragen. Mittels des Ideologiebegriffes konnte die spezifische Form vorurteiligen Sprechens weiter eingegrenzt werden: Ausgehend von der Annahme, dass ein alltäglicher „Kampf um Klassifizierungen" zwischen konkurrierenden Gleichheitsauffassungen die Normalität egalitärer Gesellschaften darstellt, kann der Ansatzpunkt der Vorurteilskritik nicht die Tat- 
sache konfligierender Differenzkonstruktionen an sich sein. Stattdessen rücken als Vorurteile solche kategorialen Klassifikationsmuster in den Fokus, die geltende egalitäre Normen verletzen, und diese Verletzung zugleich rhetorisch verdecken. In dieser Gleichzeitigkeit einer antiegalitären Identitätskonstruktion und der Invisibilisierung von deren antiegalitärem Gehalt besteht die spezifische ideologische Form vorurteiligen Sprechens.

Diese Bestimmung des Vorurteils als verfehlte Reflexion der egalitären Norm verlangt nach einem spezifischen Verständnis der normativen Grundlage und Methodologie der Vorurteilskritik. Wenn Vorurteile, insbesondere in ihrer alltagssprachlichen, flexiblen und fragmentierten Form, kein absolutes Außen zur Gleichheitsnorm darstellen, so kann diese Norm der Vorurteilskritik nicht als feste Grundlage dienen. Verfestigte Auffassungen der egalitären Norm, in denen der Normvollzug mit antiegalitären Positionen zusammenstimmt, sind ja gerade, wogegen sie sich richtet. Kein hehres Ideal der Gerechtigkeit, sondern die Kontingenz und prinzipielle Wandelbarkeit historisch gewordener Ungleichheitssemantiken bilden daher die paradoxe normative Grundlage der Vorurteilskritik. Sie versucht zu zeigen, wie auch gleichheitsorientierte Rhetoriken einen antiegalitären performativen Sinn bekommen können, und dass die egalitäre Norm somit einen antiegalitären Vollzug nicht prinzipiell ausschließt. Ihre Kritik an der symbolischen Gewalt des Vorurteils ist zugleich eine Kritik der egalitären Norm, die sie selbst zur Grundlagen hat.

Um diese Kontingenz der modernen Gleichheitsidee als normative Grundlage „ohne Normativität“ wirksam werden zu lassen, verfolgt Kritik eine besondere Methode: Sie zeigt an ihrem Gegenstand einen normativen Selbstwiderspruch und eine rhetorische Abwehr oder Invisibilisierung dieses Selbstwiderspruches auf. Mit anderen Worten: Um kritisch zu sein, muss sie den ideologisch-rechtfertigenden Charakter der kritisierten Rhetorik nachweisen. Ihr Vorgehen dabei muss deutendrekonstruktiv angelegt sein, und ihre Ergebnisse behalten letztendlich rhetorischen Charakter. Dies gilt aus zwei Gründen: Da zwischen vorurteiliger Normverletzung und Normkonformität, und damit auch zwischen Vorurteilsforschung und ihrem Gegenstand, keine strenge Äußerlichkeit besteht, hat die Kritik von Vorurteilen prinzipiell eine Als-Struktur. Sie zeigt nicht einfach mit dem Finger auf eindeutige Normverstöße, sondern sie versucht als Vorurteil erkennbar zu machen, was vielen als völlig normaler, unbedenklicher Common Sense gilt - und in diesem Sinne auch Common Sense ist. Da sie sich somit als Teilnehmerin in einem Streit um die Auslegung gesellschaftlicher Normalität versteht, kann sie ihre Deutungen niemals als schlechthin gültige postulieren. Sie arbeitet vielmehr daran, dass die von ihr erschlossene Sicht andere überzeugen möge und damit einen verändernden Einfluss auf gesellschaftliche Diskurse hat. In diesem Selbstverständnis als Teilnehmerin an politischen Diskursen einer Lebensform liegt der letztendlich rhetorische Charakter der Kritik. Der entscheidende Unterschied zu den affirmierenden Sprechweisen ih- 
res Gegenstandsbereichs liegt darin, dass sich Kritik, indem sie die Sprechweisen anderer umdeutet, stets auch gegen sich selbst wendet.

In Abschnitt 4.6 wurde das Konzept einer erschließenden Antiamerikanismuskritik bzw. der performative Antiamerikanismusbegriff mit zusätzlichen Konzepten aus Forschung zu nationaler Identität, Ethnozentrismus und Antisemitismus ergänzt. Diese Ergänzung geschieht im Hinblick auf die in Kapitel 7 erfolgende Ergebnisdarstellung und konkretisiert den theoretischen Blick, mit dem antiamerikanisches Sprechen dort rekonstruiert wird. Während die Struktur vorurteiligen Sprechens bislang auf der vergleichsweise abstrakten Ebene egalitärer Normen und deren Vollzügen behandelt wurde, kommen mit ethnozentrischen, nationalistischen und (sekundär) antisemitischen Identitätskonstruktionen nun konkrete Formen des Vorurteils in den Blick. Diese bilden die Vergleichsfolie, mithilfe derer Antiamerikanismus im untersuchten Material erschlossen wird. Zugleich bietet diese vergleichende Perspektive aber auch den Ausgangspunkt für die Analyse des rhetorischen Zusammenspiels von Antiamerikanismus und anderen Vorurteilsformen.

Als zentral Funktionsweise vorurteiligen Sprechens wurde hier zunächst die Konturierung und Stabilisierung nationaler Identität herausgearbeitet. Im Anschluss an Arbeiten Armin Nassehis wurde argumentiert, dass der Kulturbegriff zu einem Medium des Ausdrucks ethnozentrischer und nationalistischer Positionen werden kann. In ethnopluralistischen und multikulturalistischen Konstruktionen können solche rigiden Formen nationaler Identifikation zudem mit Gleichheitsidealen in Einklang gebracht werden, wie Sighard Neckel und Ferdinand Sutterlütty zeigen. ,Kulturen“ und deren ,respektvolles' Verhältnis zueinander werden in solchem Sprechen zum Teil einer ethno-nationalen Ordnung mit traditional begründeten hierarchischen Verhältnissen zwischen ,Ethnien“.

Im Anschluss an Klaus Holz' Arbeiten zum nationalen Antisemitismus wurden zwei weitere rhetorische Funktionsmuster vorurteiligen Sprechens im Rahmen nationaler Identität herausgearbeitet. So können ,die USA‘, ähnlich wie ,die Juden“ im Antisemitismus, in antiamerikanischen Sprechweisen als ein stabilisierendes Außen zur ethno-nationalen Weltordnung fungieren. Als Figur des Dritten dienen sie der Thematisierung und gleichzeitigen Verdrängung der Möglichkeit, dass die angenommene ethno-nationale Ordnung der Welt tatsächlich kontingent und nicht essentiell gegeben sein könnte. Eine ähnliche rhetorische Gleichzeitigkeit von Bearbeitung und Ausblendung findet sich in Formen sekundär bzw. latent antisemitischer Kommunikation. Hier wird der Holocaust bzw. das nationalsozialistische Erbe Deutschlands normalisiert bzw. relativiert, d.h. als Problem nationaler Identifikation aus dem Weg geräumt, und diese Normalisierung gleichzeitig latent gehalten. Wie in Kapitel 7 gezeigt wird, können antiamerikanische Sprechweisen vergleichbare latente Normalisierungsfunktionen hinsichtlich Holocaust und NSVergangenheit annehmen. 
Anhand dieser Beschreibungen vorurteiliger Rhetorik wird auch ersichtlich, wie der ,mittelbare‘ vorurteilige Effekt solcher Sprechweisen bestimmt werden kann, die unmittelbar weder sprachliche, noch andere Gewalt gegen Amerikanerinnen und Amerikaner ausüben. Der vorurteilige Gehalt rassistischer, antisemitischer oder antiamerikanischer Rhetorik kann auch darin bestehen, dass sie nationalistischen und ethnozentrischen Identitätskonstruktionen zuarbeiten, diese stabilisieren, konturieren oder legitimieren. Die Verknüpfung von vorurteiligem Sprechen und Diskriminierung geschieht dann vermittelt über diese Differenzkonstruktionen, die ihrerseits mit hoher Wahrscheinlichkeit mit Diskriminierung und Verfolgung zusammenhängen. 


\section{Empirische Methode und Methodologie}

Die theoretische Grundlage der vorliegenden Arbeit, die in den Kapiteln 2 bis 4 entwickelt wurde, baut auf einer Kombination hermeneutischer bzw. praxistheoretischer Soziologie und kritischer Theorie auf. Erstere wurde vor allem dazu gebraucht, eine praxistheoretische Alternative zu den Engführungen einstellungstheoretischer Antiamerikanismusbegriffe zu formulieren, in der der Gebrauchsaspekt antiamerikanischen Sprechens, d.h. dessen rhetorische Funktionen und flexible Realisierungen, eine stärkere Berücksichtigung finden. Im Anschluss an aktuelle Überlegungen zur methodolgischen Grundlage einer soziologischen Gesellschaftskritik konnte zudem die Form der damit vollzogenen Vorurteilskritik nach dem Modell einer erschließenden bzw. immanenten Kritik konstruiert werden.

In den folgenden Abschnitten wird es nun darum gehen, diese theoretischen Überlegungen mit den Methoden empirischer Sozialforschung zu verknüpfen, die in der vorliegenden Studie angewendet werden. Dabei wird die Konvergenz eines performativen Antiamerikanismusbegriffes bzw. einer erschließenden Vorurteilskritik mit der Methodologie empirisch begründeter Theoriebildung (Kelle 1997) aufgezeigt. Den Ausgangspunkt bilden hierbei einige Überlegungen zum Verhältnis von Theorie und Empirie in sozialwissenschaftlicher Forschung: Unter Rückgriff auf die methodologischen Überlegungen Peter Winchs zum Begriff der Familienähnlichkeit (vgl. Kap. 3.3) wird argumentiert, dass sich theoretische und empirische Soziologie nicht als getrennte sozialwissenschaftliche Bereiche, sondern als reziprok verknüpfte Aspekte ein und derselben Erkenntnispraxis betrachten lassen. Unter dem Titel einer ,theoretischen Empirie“ (Kalthoff 2008) wird die besondere Nähe qualitativ-interpretativer Forschungsmethoden zu einer solchen methodologischen Auffassung sowie zum deutenden Vorgehen einer erschließenden Kritik dargelegt.

Unter Bezug auf Udo Kelles Konzeption einer ,empirisch begründeten Theoriebildung“ (Kelle 1997) kann die vorgeschlagene Verbindung von qualitativer Empirie und Vorurteilskritik genauer ausgeführt werden. Hierbei kommen insbesondere die Konzepte des empirischen Gehalts bzw. der theoretischen Sensibilität sowie der hypothetischen Schlussfolgerung in Betracht. Anhand konkreter Bei- 
spiele wird der Gebrauch empirisch gehaltloser heuristischer Konzepte sowie qualitativer Induktionen in der vorliegenden Arbeit erörtert.

Diese Verknüpfung von Vorurteilsbegriff und theoretischer Empirie geht zunächst mit einer Kritik standardisierter Verfahren der Vorurteilsempirie einher, die um der Genauigkeit ihrer ,Messungen“ Willen den Äußerungskontext antiamerikanischer Sprechhandlungen vernachlässigen müssen. Gleichzeitig basiert aber die vorliegende Studie auf einem methodenintegrativen Design: Surveydaten bzw. die darin vorfindlichen Korrelationen von Antiamerikanismus und anderen Vorurteilskonstrukten bilden den Ausgangspunkt der empirischen Analysen. Sie dienen einerseits als Medium des Feldzuganges und der systematischen Fallauswahl für die qualitativen Analysen und stellen andererseits die statistischen Explananda, zu denen jene Erklärungshypothesen generieren. In der Diskussion des Verhältnisses quantitativer und qualitativer Methoden wird daraufhin gezeigt, inwiefern diese Methodenkombination keinen Widerspruch darstellt. Ausgehend von der These, dass sich Mixed Methods Designs nicht allein nach technischen Gesichtspunkten beurteilen lassen, sondern selbst ein interpretatives Moment beinhalten, kann das Vorgehen als kritischer Anschluss an standardisierte Formen der Vorurteilsempirie methodologisch begründet werden. Das Kapitel schließt mit einer Überblicksdarstellung zu Fallauswahl und Erhebungsverfahren der vorliegenden Studie sowie mit einer ausführlichen Dokumentation des sequenzanalytischen Vorgehens der qualitativen Materialauswertung.

\subsection{DAS WECHSELVERHÄLTNIS VON THEORIE UND EMPIRIE UND DIE BEDEUTUNG QUALITATIVER Methoden}

In Kapitel 3.3 wurde das Modell der Familienähnlichkeit als begriffliche Grundlage für einen performativen Antiamerikanismusbegriff vorgeschlagen. Als ein Hauptmerkmal dieses Begriffsmodells wurde das darin angelegte reziproke Verhältnis von Theorie und empirischer Forschung beschrieben. So setzt jede empirische Deutung eines Sprechhandelns als antiamerikanisch bereits einen Antiamerikanismusbegriff voraus, um Ähnlichkeiten und Überschneidungen mit anderen antiamerikanischen Ausdrücken nachvollziehen zu können. Diese begriffliche Voraussetzung der Empirie ist selbst aber durch vorherige empirische Beobachtungen von Antiamerikanismus, d.h. eine bereits vollzogene Begriffsanwendung bedingt. Nicht nur ist jegliche empirische Beobachtung, aus der Theorie entspringen oder an der Theorie geprüft werden soll, immer schon „,mit Theorie imprägniert“ (Winch 1966, S. 158) bzw. ein „'theory-laden“ undertaking“ (Hanson 1972, S. 19). Sondern auch jede begriffliche Abstraktion macht nur Sinn, wenn sie ,gesättigt mit der Kraft von 
Erfahrung“ ist (Adorno 2003e, S. 556), durch ihren Gebrauch in der Beobachtung empirischer Phänomene.

An diesem paradoxen Wechselverhältnis wird einerseits erkennbar, dass eine strikte Trennung in theoretische und empirische Soziologie - trotz ihrer Etabliertheit als quasi-disziplinärer Differenzkonstruktion (vgl. Kalthoff 2008, S. 8 f.) - nur unter Ausklammerung zentraler erkenntnistheoretischer Probleme möglich ist (Winch 1966, S. 55 ff.). Berücksichtigt man hingegen diese erkenntniskritischen Grundlagen der Soziologie, so impliziert dies eine prinzipielle Unabgeschlossenheit soziologischer Theoriebildung: Wenn diese nicht ohne empirische Anwendung Sinn macht, da ihre allgemeinen Begriffe notwendig systematisch ambig sind (vgl. Kap. 3.3), dann eignet jeder Theorie notwendig ein zeitdiagnostisches Moment, das in ihrer Anwendung je und je expliziert werden muss (vgl. auch Kelle 2008a, S. 58 ff. sowie S. 98). Empirische Sozialforschung, so könnte man vor dem Hintergrund dieser Überlegungen formulieren, ist derjenige Teil der Theoriebildung, der auf die Unabgeschlossenheit der soziologischer Theorie verweist: Empirie ist Theorie sofern sie unabgeschlossen ist.

Theorie und Empirie erscheinen aus dieser Blickrichtung als unterschiedliche Momente einer übergreifenden Erkenntnispraxis, die durch eine prinzipielle Spannung zwischen empirischen und theoretischen Gegenstandsbezügen gekennzeichnet ist und mit der Unterscheidung von empirischen Daten und theoretischem Vorwissen nur ungenau modelliert wird. Vor diesem Hintergrund muss eine deduktivistisch-selbstreferentielle Theoriebildung ebenso problematisch erscheinen, wie jedwede induktivistische Empiriekonzeption, denn beide Ansätze laufen auf eine strikte Trennung theoretischer und empirischer Forschungspraxis hinaus. Erstere geht davon aus, Theorie bilden zu können, bevor diese mit Erfahrung konfrontiert wird; letztere behauptet, Erfahrungen machen zu können, ohne theoretische Begriffe vorauszusetzen.

Innerhalb des Bereichs sozialwissenschaftlicher Empirie tritt diese problematische Tendenz insbesondere in Gestalt eines im weitesten Sinne abbildtheoretischen Selbstverständnisses empirischer Forschung auf. Herbert Kalthoff kritisiert ein solches Verständnis soziologischer Forschung dahingehend, ,daß soziologische Theorie nicht als Repräsentationsidiom verstanden werden kann, so als würde sie Gesellschaft oder gesellschaftliche Umstände auf realistische Weise abbilden“ (ebd., S. 15). Theorien sind demnach „keine wörtlichen Übersetzungen gesellschaftlicher Wirklichkeit, sondern Vorschläge, diese mit der theoretischen Begrifflichkeit zu sehen und zu begreifen“ (ebd.). Vor dem Hintergrund einer Praxistheorie der Bedeutung kann man dies auch so fassen, dass Theorien deshalb keine ,wörtlichen Übersetzungen“ des Beobachteten seien können, weil sie selbst - zumindest gebrochen schon die Sprache des Gegenstandsbereiches sprechen. Sozialwissenschaftliche Theoriebildung, ,deals with a universe which is already constituted within frames of meaning by social actors themselves, and reinterprets these within its own theoreti- 
cal schemes“ (Giddens 1993, S. 170). Im Sinne dieser „,double hermeneutic“ (ebd.) ist die Reziprozität von soziologischer Theorie und Empirie eng verbunden mit der Reziprozität von Soziologie und Gesellschaft überhaupt.

Unter dem Vorbehalt einer genaueren Klärung des Verhältnisses qualitativer und quantitativer Forschungsmethoden in den folgenden zwei Abschnitten möchte ich mich zunächst Kalthoffs Einschätzung anschließen, dass sich hinsichtlich der Sensibilität für besagte immanente Spannung der Theoriebildung ein Unterschied zwischen interpretativer qualitativer Sozialforschung und standardisierter quantitativer Empirie ausmachen lässt. Wenngleich erstere keineswegs pauschal als ,immun' gegen induktivistische Verkürzungen betrachtet werden kann (vgl. Kelle und Kluge 2008, S. 18 ff.), so ist sie doch einer Reflexion auf die obengenannten erkenntniskritischen und normativen Aporien besonders zugeneigt. So werden zentrale theoretische Bezugspunkte der sprechakttheoretischen Grundlagen dieser Arbeit, wie Reflexivität, Kontextorientierung und eine Orientierung am Alltagsgeschehen als typische Leitgedanken qualitativer Empirie genannt (vgl. Flick et al. 2012, S. 24; Hopf 1993, S. 14 ff.; Kelle 1997, S. 44 ff.). In standardisiert-quantifizierenden Methoden und dem mit diesen meist einhergehenden hypothetiko-deduktiven Modell sozialwissenschaftlicher Theoriebildung zeigt sich hingegen ein stärker dichotomisierender Umgang mit dem Verhältnis von Theorie und Empirie (vgl. Kelle und Kluge 2008, S. 16).

Auf die Tendenz standardisierter Empirie zur systematischen Ausklammerung des Wechselverhältnisses von Theorie und Empirie wird im folgenden Abschnitt 5.3 genauer eingegangen. Hier sei zunächst die besondere Nähe qualitativer Sozialforschung zu den oben explizierten erkenntniskritischen Grundlagen sozialwissenschaftlicher Methodologie herausgestellt: In aller Kürze kann man diese Sensibilität für die Verwobenheit von Theorie und Empirie als eine kritische Selbstreflexivität fassen, mit der die qualitative Forschungsmethode systematisch die Unterscheidung zwischen beiden Bereichen im empirischen Forschungsprozess unterläuft. Wo im Rahmen einer hypothetiko-deduktiven Forschungslogik die Genese neuer Hypothesen als ,unbegründete und unbegründbare Antizipationen“ (Karl Popper zit. n. Kelle 1997, S. 137) aufgefasst und von der empirischen Geltungsprüfung strikt getrennt wird, integrieren die methodologischen Grundlagen qualitativer Forschung Genese und Geltung in die Arbeit am empirischen Material. Entscheidend ist dabei, dass die Unterscheidung theoretischen und empirischen Wissens im Prozess der empirischen Forschung reflektiert wird, d.h. in einem Umgang mit empirischem Material, der weder dem theoretischen Vorwissen, noch der empirischen Evidenz ein Primat zuspricht. Stattdessen bleibt qualitative Empirie in Prozess der Bildung von Codes, Kategorien und schließlich Begriffen beständig um ein produktives Wechselverhältnis beider Seiten bemüht. Qualitativ-interpretative Forschung wendet Begriffe an und unterläuft diese zugleich durch die Konfrontation mit empirischem Material. Sie sammelt empirische Erfahrungswerte und ist sich zugleich des interpretativen 
Gehalts dieser Tätigkeit bewusst: dass sie die Gegenstände der Erfahrung theoretisch betrachtet und insofern auch mit hervorbringt.

Herbert Kalthoff und KollegInnen haben diese paradoxe Reflexivität qualitativer Methoden im Anschluss an Georg Simmel mit dem Titel „theoretische Empirie“ bezeichnet (Kalthoff 2008, S. 9). Ein Kernmoment dieses methodologischen Selbstverständnisses ist die Reflexion auf die theoretische ,Gemachtheit" der eigenen empirischen Daten, bzw. auf die Annäherung von Datum und Lesart in der eigenen Forschungstätigkeit. Zwar messen auch qualitative Methoden der Empirie einen hohen Stellenwert bei, im Sinne einer prinzipiellen Skepsis gegenüber der Vertrautheit und Verfügbarkeit gesellschaftlicher Gegenstände (vgl. ebd., S. 16): Es muss prinzipiell davon ausgegangen werden, dass Forschungsgegenstände den Forschenden fremd und die Geltungsreichweite soziologischen Wissens begrenzt ist. Dem stellt sich aber ein Bewusstsein darüber entgegen, dass der ,,starke Stellenwert des Empirischen durch eine Neigung auszubalancieren ist, die die Relation von Daten und Generierungsprozeß reflexiv mitführt. Denn was sich dem Forscher als ,Datum' darbietet, ist etwas durch den Forschungsprozeß ,Gemachtes': Faktum und Fiktion werden einander deutlich angenähert." (Ebd., S. 18)

Ein zweites Kernmoment theoretischer Empirie ist die Ausrichtung der empirischen Forschung, nicht auf die möglichst präzise und detailreiche Beschreibung eines Gegenstandes oder auf die Prüfung bereits existierender theoretischer Sätze, sondern auf die Fort- und Neuentwicklung theoretischer Perspektiven. Dieses Selbstverständnis der qualitativen Forschungspraxis schließt an die zuvor gemachte Feststellung an, dass die „Rekonstruktion des sozialen Geschehens die Konstruktion des wissenschaftlichen Objekts reflexiv mitführt" (ebd., S. 20):

„Weder sind also ihre Forschungsinstrumente theorieneutral, denn sie arbeiten immer schon mit bestimmten Annahmen über das Soziale, noch übt sie sich in theoretischer Zurückhaltung. Ihr geht es vielmehr darum, soziologische Theorien für die eigene Forschung in dem Sinne zu aktivieren, daß durch sie hindurch das empirische Material ,zum Sprechen' gebracht und auf diesem Wege Theorie entfaltet werden kann, indem diese ihr Potential bei der empirischen Analyse zeigt." (Ebd., S. 20 f.)

Es lassen sich in der Methodologie qualitativer Sozialforschung also zwei Grundmerkmale finden, die der im vorigen Kapitel 4.5 beschriebenen Theorieperspektive einer erschließenden Kritik nahe stehen: Eine Reflexivität hinsichtlich des reziproken Spannungsverhältnisses von Genese und Geltung gewonnener Theorieaussagen sowie eine daraus abgeleitete rhetorisch-erschließende Funktion sozialwissenschaftlicher Erkenntnis, die ihre Deutungen als „"second order' concepts“ (Giddens 1984, S. 284) und sich selbst immer auch als Teilnehmerin des beobachteten gesellschaftlichen Phänomens begreift. Eine ,empirisch begründete Theoriebildung“ (Kelle 1997) mittels qualitativer Methoden ist weder allein mit der prüfenden Anwendung 
,externen" Theoriewissens befasst, noch kann sie sich als quasi theoriefreie ,interne" Anschauung von Tatbeständen verstehen, durch die neue Erkenntnisse unmittelbar aus den Daten „emergieren“ (ebd., S. 25). Sie muss stattdessen eine Zwischenposition einnehmen, in der sowohl ein theoretisch informierter Blick das Material auf bestimmte Weise erschließt und dadurch zugleich die investierten Theorieannahmen auf neue Weise, zum Sprechen gebracht werden'. Insofern hierbei auch die alltagstheoretischen (Selbst-)Deutungen der Akteure im Untersuchungsfeld miteinbezogen und zu den Theorieannahmen der Forschenden ins Verhältnis gesetzt werden, können „Methoden der qualitativen Sozialforschung [...] zu einem Werkzeug der ,Ideologiekritik des Alltags“ werden“ (Kelle und Kluge 2008, S. 35).

\subsection{VORURTEILSKRITIK ALS „EMPIRISCH BEGRÜNDETE THEORIEBILDUNG“}

Nachdem im vorigen Abschnitt die Reziprozität empirischer und theoretischer Aspekte wissenschaftlicher Erkenntnisoperationen grundlegend umrissen wurde, soll nun im Anschluss an Udo Kelles Konzeption einer „empirisch begründeten Theoriebildung“ (Kelle 1997) der methodologische Rahmen für den theoriegenerativen Aspekt empirischer Forschung abgesteckt werden. Dabei wird zu zeigen sein, inwiefern sich das Modell einer sozialwissenschaftlichen Vorurteilskritik, wie sie im vorigen Kapitel entwickelt wurde, als empirisch begründete Theoriebildung verstehen lässt. Die im vorigen Abschnitt explizierte Spannung zwischen Theorie und Empirie taucht im Rahmen theoriegenerativer Forschung als ,Widerspruch zwischen dem Postulat der Theoriegeleitetheit empirischer Forschung einerseits und der Notwendigkeit empirisch begründeter Theoriebildung andererseits“ (Kelle 2008b, S. 329) auf. D.h. qualitativ-sinndeutend Forschende müssen einerseits neues Wissen generieren, das sich von bestehendem Theoriewissen zumindest teilweise unterscheidet, und sie müssen dabei zugleich anerkennen, dass sie nichts werden ,sehen' können, was nicht durch ex ante bestehende Theoriebestände schon mit strukturiert wird. Wenn es unverzichtbar ist, Theorieannahmen in den empirischen generativen Forschungsprozess einzubeziehen, weil jede auch noch so unvoreingenommene Beobachtungsoperation ein theorieimprägniertes ,seeing as“ impliziert (Hanson 1972, S. 19), so hängt das Gelingen empirisch begründeter Theoriebildung $\mathrm{ab}$ von einer prekären Balance zwischen theoretischer Überformung des Gegenstands und induktivistischem Selbstmissverständnis (vgl. Kelle und Kluge 2008, S. 18 ff.).

Udo Kelle hat zur methodologischen Reflexion und methodischen Handhabe dieses Balanceakts eine systematische Unterscheidung verschiedener Typen und Verwendungsweisen theoretischen Vorwissens in der Empirie vorgeschlagen. Im 
Anschluss an eine Formulierung Barney Glasers und Anselm Strauss ‘ beschreibt er diese Reflexivität als ,theoretische Sensibilität“ der Forschenden. Die theoretischen Konzepte, die eine solche Sensibilität ermöglichen, können im Anschluss an Herbert Blumer als ,sensitizing concepts“ bezeichnet werden (Kelle und Kluge 2008, S. 28):

„ForscherInnen sehen die Realität ihres empirischen Feldes stets durch die ,Linsen` bereits vorhandener Konzepte und theoretischer Kategorien, sie benötigen eine bestimmte theoretische Perspektive, um ,relevante Daten` zu ,sehen'. Die Verfügbarkeit und flexible Verwendung dieser theoretischen Perspektiven führt zu der von GLASER und STRAUSS beschriebenen ,theoretischen Sensibilität", der Fähigkeit, über empirisch gegebenes Material in theoretischen Begriffen zu reflektieren.“(Ebd.)

Um eine Methodisierung dieser Reflexivität zu ermöglichen, greift Kelle auf die Konzepte des ,empirischen Gehalts“ (Kelle und Kluge 2008, S. 35) sowie der „Abduktion“ bzw. ,qualitativen Induktion“ (Kelle 1997, S. 145 ff.) zurück. Das Gelingen empirisch begründeter Theoriebildung lässt sich demnach dadurch befördern, dass (1) die dabei gebrauchten ,sensibilisierenden Konzepte“ (Kelle und Kluge 2008, S. 30) weitgehend empirisch gehaltlos sind und (2) die Forschenden ihre empirische Praxis nach dem Modell eines abduktiven Schließens reflektieren. Beide Konzepte werden im Folgenden kurz umrissen und auf das empirische Vorgehen der vorliegenden Arbeit angewandt.

Das Kriterium des empirischen Gehalts, das auf die wissenschaftstheoretischen Arbeiten Karl Poppers zurückgeht, bezeichnet den Grad, indem sich eine formulierte Hypothese der Falsifikation durch empirische Befunde aussetzt: ,Je mehr mögliche Beobachtungsaussagen formuliert werden können, die zu einer Theorie in Widerspruch stehen, desto höheren empirischen Gehalt hat diese Theorie." (Kelle und Kluge 2008, S. 35) Wenngleich es für den Übergang von empirisch gehaltvollen zu gehaltlosen Theorien in den Sozialwissenschaften kein exaktes Kriterium geben kann, so lassen sich ihre Theoreme häufig doch zumindest tendenziell einer der beiden Seiten zuordnen. Als Beispiel für ein empirisch relativ gehaltloses Theorem nennt Kelle die Annahmen der soziologischen Rollentheorie (Kelle 2005, S. 15 f.). Die Theorieannahme, dass soziale Handlungen durch Rollenerwartungen geprägt sind, lässt sich auf nahezu jede beobachtbare Interaktion anwenden, dementsprechend aber auch an keiner Beobachtung empirisch falsifizieren. Eine Hypothese der folgenden Form hingegen, kann nach vergleichsweise klaren Kriterien an empirischen Befunden scheitern:

„Bei einer Befragung von 2000 zufällig gezogenen jungen Erwachsenen bejaht derselbe Anteil von Personen mit formal niedrigem wie mit formal hohem allgemeinbildendem Schulab- 
schluss Einstellungsfragen, die eine fremdenfeindliche Einstellung zum Ausdruck bringen." (Kelle und Kluge 2008, S. 36)

Die Formulierung von Hypothesen mit einem größtmöglichen empirischen Gehalt ist typisch für das Vorgehen einer hypothetiko-deduktiven, hypothesentestenden Forschung. In hypothesengenerierender Empirie dagegen, kann gerade eine empirische Gehaltlosigkeit der gebrauchten Begriffe von Vorteil sein. Die Tatsache, dass diese keine unmittelbaren empirischen Vorhersagen bzw. Tests zulassen, qualifiziert sie in besonderer Weise dazu, im Rahmen qualitativer Empirie als „Heuristiken“ zu dienen. Sie stellen dann ,dem Forscher oder der Forscherin jene ,Linsen“ oder theoretischen Perspektiven zur Verfügung, durch die er oder sie soziologisch relevante Phänomene überhaupt erst wahrnehmen und beschreiben kann“" und sind „gleichzeitig hinreichend ,offen“, so dass die Gefahr verringert wird, dass die Relevanzsetzungen der Befragten durch die vorgängigen Forscherhypothesen überblendet werden“ (ebd., S. 37).

Der in den vorausgegangenen Kapiteln 2 bis 4 entwickelte performative Antiamerikanismusbegriff kann als ein solches empirisch gehaltloses Theorem aufgefasst werden. Die Bestimmung von Antiamerikanismus als Sprechhandeln bzw. die damit verknüpfte Annahme verschiedener rhetorischer Funktionen von Amerikastereotypen in verschiedenen Funktionskontexten lässt sich zunächst auf jedes Sprechen über Amerika anwenden und beinhaltet an sich keinerlei empirische Aussagen über dessen Gehalt und Form. Hierzu müssen erst die besagten Amerikastereotype, Funktionskontexte und rhetorischen Funktionen empirisch spezifiziert werden. Die genannten Komponenten eines performativen Antiamerikanismusbegriffes können hierbei ,,als theoretische Matrix oder als theoretisches Raster verwendet werden, welches dann anhand empirischer Beobachtungen zunehmend ,aufgefüllt" wird." (Kelle und Kluge 2008, S. 37)

Das theoretische Raster, das den interpretativen Umgang mit dem Material anleitet, kann im Verlauf der Analyse selbst modifiziert und ausgebaut werden. So kommen in der vorliegenden Studie weitere Analyseheuristiken zum Einsatz, bspw. der in Kapitel 4 mit dem Begriff der „Ungleichheitssemantik“ beschriebene rhetorische Zusammenhang von Vorurteil und Diskriminierung oder das aus der Antisemitismustheorie adaptierte Konzept der „Kommunikationslatenz“ (für eine Überblicksdarstellung der gebrauchten heuristischen Konzepte vgl. Kap. 5.6). Auf diesem Weg wird die allgemeine Analyseheuristik des performativen Antiamerikanismusbegriffes im Dialog mit dem empirischen Material nach und nach mit zunehmend empirisch gehaltvollen Theoriefragmenten angereichert. Die so am empirischen Material gewonnenen Verknüpfungen der gehaltlosen Heuristik mit beobachtbaren sozialen Tatbeständen können als „Brückenhypothesen“ verstanden werden (Kelle 1997, S. 104 ff.) die eine empirisch gehaltvolle Bestimmung von Antiamerikanismus zulassen. Die empirische Gehaltlosigkeit der Analyseheuristiken 
dient der Erschließung neuer Antiamerikanismustheorie, weil sie der Mittelbarkeit der Verbindung von theoretischem Erkennen und empirischer Evidenz Rechnung trägt, die im vorigen Abschnitt beschrieben wurde: Weder ist das, was ich im Material finde, an diesem ohne theoretische Vermittlung ablesbar, noch kann ich Theorie weiterentwickeln ohne empirische Impulse aufzugreifen, die über bestehendes Wissen hinausweisen.

Es ist an dieser Stelle auf eine besondere Problematik des zeitlichen Ablaufs theoriegenerativer Forschung hinzuweisen: Die im Verlauf der vorliegenden Kapitel als Analyseheuristiken und somit als Ausgangsbedingung der empirischen Analysen genannten Konzepte, der Begriff der Ungleichheitssemantik, die rhetorische Funktion des Vorurteils etc., sind in gewisser Weise zugleich Ergebnis des empirischen Forschungsprozesses. Die genannten heuristischen Begriffe wurden zumindest teilweise nicht vor der empirischen Erhebung und Analyse, sondern im Laufe der Empirie expliziert. In übertragenem Sinne könnte man diese eigenartige Gleichzeitigkeit, mit der Analyseheuristiken zugleich Bedingung und Ergebnis von Erkenntnisprozessen sein können, mit dem psychoanalytischen Begriff der ,Nachträglichkeit“ fassen (vgl. Dahl 2010) ${ }^{1}$ : Man bezieht sich auf etwas Vorhergegangenes (bspw. ein traumatisches Erlebnis) aus der Perspektive eines durchlaufenen Erfahrungsprozesses, der durch jenes Vorhergegangene selbst angestoßen wurde, zugleich aber den Rückblick darauf strukturiert. D.h. übertragen auf das methodische Vorgehen: Es muss einen Begriff gegeben haben (z.B. den des performativen Sprechens), damit empirisches Material als unter diesen Begriff fallend interpretiert werden konnte, aber zugleich hängt das Erscheinen des Begriffes von ebendieser Interpretation $\mathrm{ab}$. In der methodologischen Konzeption von Udo Kelle und Susann Kluge wird diesem Umstand durch den Hinweis Rechnung getragen, dass theoretische Heuristiken häufig erst im Prozess der Analyse aus dem impliziten Vorwissen der Forschenden entstehen:

„Das (implizite) soziologische Theoriewissen dient in einem solchen Fall als ,Linse“ oder ,Brille', durch die der Forscher oder die Forscherin die empirische Realität wahrnimmt. Bestimmte Phänomene können dann beispielsweise als ,Rollenkonflikte', ,Stigmatisierungsprozesse` oder ,funktionale Differenzierung (um nur einige soziologische Begriffe nahezu willkürlich herauszugreifen), gesehen` werden, auch wenn nicht zu Beginn der Untersuchung die explizite Erwartung formuliert wurde, Stigmatisierung, Rollenkonflikte oder funktionale Differenzierung im Untersuchungsfeld zu beobachten. Das Ausmaß, in dem ForscherInnen solche impliziten Konzepte kognitiv zur Verfügung stehen, macht ihre theoretische Sensibilität

1 Meiner Adaption psychoanalytischer Konzepte beruht auf einem Verständnis der Psychoanalyse als einer kritischen Hermeneutik bzw. Praxistheorie, die handlungstheoretische sowie normative Dilemmata und Paradoxien zum Gegenstand hat (vgl. Habermas 1973, S. 277; Davidson 1982; Rorty 1995; Billig 1997). 
aus, ihre Fähigkeit, empirische Sachverhalte in einer theoretischen Sprache zu beschreiben. In manchen Fällen kann dieses theoretische Vorwissen vor der Datenerhebung ausführlich expliziert werden, häufig ist eine solche Explikation aber schwierig." (Kelle und Kluge 2008, S. 32)

In gewissem Sinne ergibt sich also die begriffliche Grundlage qualitativhypothesengenerierender Forschung, die notwendige Voraussetzung jeder Empirie, erst im Verlauf der empirischen Forschung.

Diesem paradoxen Spannungsverhältnis der Analyseheuristik trägt auch das zweite Konzept Rechnung, dass Kelle zur Methodisierung des „Entdeckungszusammenhangs“" (Kelle 1997, S. 133) empirisch begründeter Theoriebildung heranzieht: Die erstmals von Charles S. Peirce beschriebene Schlussform der Abduktion bzw. der qualitativen Induktion. Wenn der Prozess der Entdeckung neuer Hypothesen einerseits auf bestehendes Theoriewissen zurückgreift, andererseits aber ein kreatives Moment beinhaltet, so bewegt er sich logisch gesprochen in einem Bereich zwischen deduktiven und induktiven Schlussformen. Mit der hypothetischen Schlussfolgerung hat Peirce in einer Umstellung dieser klassischen Syllogismen (vgl. Kelle 1997, S. 151) eine dritte Schlussform formuliert, die er unter Differenzierung zweier Varianten als Abduktion bzw. qualitative Induktion bezeichnet. ${ }^{2}$ Zum besseren Verständnis dieser Konzepte seien die Formen der Induktion und Deduktion hier noch einmal in Erinnerung gerufen (vgl. Kelle 2008a, S. 89): Die Deduktion nimmt, in der Terminologie der klassischen Syllogistik gesprochen, ihren Ausgangspunkt bei einer Kombination von allgemeiner Regel (Prämissa maior) und beobachtetem Fall (Prämissa minor) und schließt dabei wahrheitskonservierend aber nicht gehaltserweiternd auf ein Resultat (Konklusion). ${ }^{3}$ Die Induktion hingegen beobachtet (wiederholt) das gemeinsame Auftreten von Resultat und Fall, und schließt dabei gehaltserweiternd aber nicht wahrheitskonservierend auf eine allgemeine Regel. ${ }^{4}$ Die qualitative Induktion beschreitet nun einen dritten Weg, indem

2 Die hier gebrauchten Begriffe sind das Ergebnis einer längeren terminologischen Entwicklung in Peirce's Schriften, deren Verlauf für die hiesigen Zwecke aber vernachlässigt werden kann (vgl. dazu Kelle 1997, S. 152 ff.; Kelle 2008a, S. 89).

3 Beispielsweise weiß ich, dass mein Nachbar die Spiele des örtlichen Fußballvereines stets besucht (Regel), beobachte weiterhin, dass am heutigen Tag ein solches Spiel stattfindet (Fall), und schließe somit sicher darauf (gegeben die Gültigkeit der allgemeinen Regel), dass der Nachbar demnächst aufbrechen wird, um das Spiel zu sehen, oder dies schon getan hat (Resultat).

4 Beispielsweise beobachte ich wiederholt, dass mein Nachbar bei Spielen des örtlichen Fußballvereins (Fall) an diesen Ereignissen teilnimmt (Resultat), und schließe somit darauf, dass er dies in Befolgung einer allgemeinen Regel tut, wobei ich allerdings auch irren kann (die Möglichkeit, dass er sich eines Tages entgegen der von mir induzierten Re- 
sie die Beobachtung eines zunächst sich grundlos darstellenden Resultates zum Ausgangspunkt nimmt und dieses um eine bereits bekannte Regel ergänzt, um das Beobachtete als Fall dieser Regel begreifen zu können. ${ }^{5}$ Die Abduktion stellt lediglich eine radikalisierte Variante dieser „Schlussfolgerung auf die beste Erklärung“ (ebd.) dar, in der ein beobachtetes Resultat nicht unter Hinzunahme einer bekannten Regel erklärt, sondern die erklärende Regel zugleich variiert oder neu gebildet wird. Hier wird also gleichzeitig, und daher besonders riskant, auf Regel und Fall geschlossen.

Seine methodologische Relevanz im Rahmen der qualitativen Sozialforschung erhält das Konzept der Abduktion vor allem als Impulsgeber methodologischer Reflexivität. So reflektiert der Abduktionsbegriff zunächst einmal dasselbe Spannungsverhältnis von Theorie und Empirie, zu dessen Veranschaulichung bereits der Begriff des empirischen Gehalts herangezogen wurde: Es zeigt (1), dass ich auch und gerade dann, wenn ich neue Hypothesen am Material generiere, auf theoretisches Vorwissen Bezug nehmen muss, sowie (2), dass die Geltungsreichweite der generierten Hypothesen durch die Deutung selbst nicht sicher ermessen werden kann. Insbesondere letzterer Punkt ist zu betonen, da sich mit dem Konzept der Abduktion häufig die irrtümliche Hoffnung verbindet, dieses könne an sich schon die Validität empirischer Forschungsergebnisse sichern (vgl. Reichertz 2013, S. 38 ff.). Peirces Konzept der hypothetischen Schlussfolgerung beschreibt aber „nicht eine Methode der Forschung, sondern nur eine Form der Schlussfolgerung“ (Kelle 2008a, S. 128), und kann somit nicht als methodische Verfahrensregel dienen. Die Regelanwendung bzw. Regelneubildung, die in hypothetischen Schlussfolgerungen geschieht, findet weder in der logischen Form des Schlusses oder dem präsupponierten allgemeinen Gesetz Halt (wie etwa bei der Deduktion), noch kann sie sich statistisch bzw. probabilistisch auf die Häufung der beobachteten Resultate stützen (wie bei der quantitativen Induktion). Ihren Nutzen entfalten die Konzepte der Abduktion und qualitativen Induktion vielmehr bei der theoretischen Verortung neugenerierter Hypothesen im Rahmen bestehenden Theoriewissens, sowie als Quelle einer angemessenen Skepsis hinsichtlich der Geltung empirisch begründeter Theoreme.

gel verhalten wird, ist durch keine vorhergegangene Beobachtung vollends auszuschlieBen).

5 Beispielsweise beobachte ich, dass mein Nachbar sich auf den Weg zum örtlichen Fußballplatz macht (Resultat), weiß um die allgemeine Regel, dass er dies bei Spielen ,seines' Vereins stets zu tun pflegt (Regel), und schließe nun darauf, dass ein solches Spiel heute stattfindet (Fall), wobei ich allerdings irren kann (es gibt prinzipiell unendlich viele Alternativerklärungen dafür, dass er sich zum Fußballplatz begibt, z.B. könnte er selbst dort trainieren, als Platzwart arbeiten, etc.). 
Auf das empirische Vorgehen der hier entwickelten Vorurteilskritik lässt sich der Abduktionsbegriff wie folgt anwenden: Die Kritik nimmt, wie in Kapitel 4.5 beschrieben, ihren Ausgangspunkt an einem erklärungsbedürftigen bzw. problematisierten Gegenstand. Im Fall antiamerikanischer Vorurteile geschieht diese Problematisierung einerseits von sozialwissenschaftlich-theoretischer Seite her, als „Definitionsproblem“ des Antiamerikanismusbegriffes (vgl. Kap. 2.2); andererseits greift die Vorurteilsforschung mit ihrer Gegenstandsbestimmung immer auch gesellschaftliche Diskurse auf, in denen das anvisierte Phänomen als normatives Problem angesprochen wird (vgl. Kap. 3.3 und 4.5). Aus diesen beiden Quellen (alltags-) theoretischen Vorwissens speist sich die ,theoretische Sensibilität“, mit der die Forschungsfrage am empirischen Material behandelt wird. Theoreme der Vorurteils-, Diskriminierungs- und Nationalismusforschung sowie alltagstheoretische Wissensbestände hinsichtlich politischer Rhetorik und Gesprächsverhalten werden als Analyseheuristiken herangezogen, und in der Auseinandersetzung mit dem empirischen Material so arrangiert, dass dieses auf neue Weise als Antiamerikanismus beschreibbar wird, was auch eine Neufassung des Antiamerikanismusbegriffes impliziert. Hierbei kann insbesondere das Konzept der qualitativen Induktion zur Veranschaulichung der geleisteten theoretisch-empirischen Arbeit dienen. So lassen sich alle Ergebnisse der vorliegenden Arbeit als Adaptionen von Theoriefragmenten aus verwandten Arbeitsbereichen beschreiben: Die These einer antiamerikanischen Normalisierung des Holocaust greift Forschungsergebnisse zum sekundären Antisemitismus auf (Holz 2007; Bergmann und Erb 1986), um verwandte rhetorische Mechanismen im antiamerikanischen Sprechen nachzuweisen. Die These einer antiamerikanischen Abwehr von Rassismusvorwürfen bzw. Rechtfertigung ethnozentrischer Identitätskonstruktionen kombiniert Theoreme eines rhetorischen bzw. symbolischen Rassismuskonzeptes (Martin 2013; Weiß 2001) und einer wissenssoziologischen Ethnozentrismuskritik (Nassehi 1997a; Rieker 1997), um überraschende Resultate im Interviewmaterial als Fall antiamerikanische Rhetorik verstehbar zu machen. Und auch die gesellschaftstheoretische Rahmung des performativen Antiamerikanismusbegriffes insgesamt kombiniert ungleichheits- und diskriminierungstheoretische (Berger 1989; Neckel und Sutterlüty 2005; Menke 2004) mit ideologiekritischen (Adorno 2003a; Billig 1991), sprechakttheoretischen (Winch 1966; Wellmer 2004; Butler 2006) sowie vorurteilstheoretischen Konzepten (Wetherell und Potter 1992; Dixon et al. 2012) - und liefert auf diese Weise ein neues Modell zur soziologischen Fundierung des Antiamerikanismusbegriffes, das auf Probleme der normativen Verortung sowie des theoretischen Reduktionismus reagiert.

Bei allen diesen theoriegenerativen Schritten muss zugleich aber klar sein, dass die Geltungsreichweite der darin formulierten Hypothesen empirisch ungeklärt bleibt. Zwar baut das entwickelte Konzept genetisch auf einer breiten Basis empirischer Indizien auf. Die Generalisierbarkeit der qualitativ-induktiv entwickelten Interpretationen hinsichtlich größerer Populationen kann aber auf der Grundlage die- 
ser Plausibilität allein nicht zuverlässig geschätzt werden (vgl. Kelle 2008a, S. 144 ff.).

Zusammenfassend kann eine enge Verwandtschaft zwischen den Methodologien abduktiv-theoriegenerativer Empirie und erschließender Kritik festgehalten werden. Dies gilt hinsichtlich dreier Aspekte: Es lässt sich erstens das Bewusstsein der unsicheren Geltungsreichweite neu generierter Hypothesen, das die Reflexion auf die hypothetische Schlussfolgerung methodologisch erzeugt, mit dem Bewusstsein der Unabgeschlossenheit und des letztlich rhetorischen Charakters der erschließenden Kritik vergleichen. Auch für letztere ist ein Bewusstsein darüber charakteristisch, dass ihre Deutungen ,immer nur vorläufig“ sein können, ,weil ihr das Kriterium für die Beurteilung ihres Gelingens konstitutiv fehlt“ (Bonacker 2000, S. 184).

Zweitens weisen beide methodologischen Standpunkte eine besondere Sensibilität für die erkenntniskritische Balance zwischen theoretischer Überformung und induktivistischem Selbstmissverständnis auf: Als ein zentrales Kriterium einer erschließenden Kritik wurde in Kapitel 4.5 die Teilnahme am kritisierten Gegenstand bezeichnet. Um seinen Gegenstand treffen zu können, muss die Kritik sich als MitReproduzentin des beobachteten Phänomens verstehen bzw., umgekehrt formuliert, müssen im beobachteten Gegenstand zumindest Spuren der normativen Ausgangsposition der Kritik (etwa der egalitären Norm) aufzuweisen sein. Analog hierzu lässt sich der Anspruch einer ,theoretischen Sensibilität“ verstehen, den Relevanzsetzungen und Sinndeutungen in der beobachteten Praxis das gleiche Gewicht beizumessen, wie den theoretischen Begriffen, die an es herangetragen werden. Wie die Methodologie einer ,immanenten Kritik“ (Honneth 2007c, S. 68; vgl. auch Kap. 4.5.2) kann auch die qualitativ-interpretative Sozialforschung weder eine externe, noch ein rein interne Position gegenüber ihrem Gegenstand einnehmen. In der Praxis erschließender Kritik sowie in der empirisch begründeten Theoriebildung ist das Ziel vielmehr ein theoretisch produktiver Dialog von alltagstheoretischer und wissenschaftlicher Sprache.

Damit hängt schließlich eine dritte Übereinstimmung zwischen beiden methodologischen Konzeptionen zusammen: Es wurde im vorigen Kapitel expliziert, dass sozialwissenschaftliche Kritik sich gerade dadurch auszeichnet, dass sie in der Anwendung ihrer Konzepte nicht nur die beobachteten Handlungen neu interpretiert, sondern dabei zugleich ihre eigenen Begriffe modifiziert und verändert. Auf einen sehr ähnlichen Zweck zielt auch die empirisch begründete Theoriebildung mit der Verwendung abduktiver Schlussformen ab: „Abduktionen erfordern eine Revision bisheriger Annahmen, Elemente bislang für sicher gehaltener Wissensbestände werden aufgegeben, modifiziert, voneinander getrennt und neu kombiniert.“ (Kelle 1997, S. 156) Erschließende Kritik wie abduktiv-empirische Theoriebildung verlangen nach einer „exakte[n] Phantasie“ (Adorno 1973a, S. 342), d.h. nach einer 
„Verklammerung von kreativen und methodisch kontrollierten Vorgängen“ im theoretisch-empirischen Erkenntnisprozess (Kelle 1997, S. 180).

\subsection{DIE INTEGRATION QUALITATIVER UND QUANTITATIVER METHODEN IN DER EMPIRISCH BEGRÜNDETEN THEORIEBILDUNG}

In den vorherigen beiden Abschnitten wurde das Verhältnis einer erschließenden Vorurteilskritik zur Methodologie empirisch begründeter Theoriebildung erörtert. Hierbei lag der Fokus auf qualitativ-interpretativen Verfahren und deren besonderer Nähe zu einem praxistheoretisch-performativen Theorieansatz. Die vorliegende Arbeit basiert aber, trotz eines klaren Fokus auf qualitativer Empirie, auf einem methodenintegrativen Forschungsdesign: Den Ausgangspunkt der empirischen Analysen bildet eine Survey-Studie, in der ein likert-skaliertes Instrument zur Erhebung antiamerikanischer Vorurteile eingesetzt wurde. Im folgenden Abschnitt sollen daher nun Aufbau und Funktion des Mixed Methods Designs der vorliegenden Studie vorgestellt und methodologisch eingeordnet werden. Hierbei wird sich zeigen, dass sozialwissenschaftliche Empirie grundlegend durch eine Spannung zwischen interpretativen und generalisierenden Erkenntnisoperationen gekennzeichnet ist, die auch durch methodenintegrative Forschungsdesigns nicht aufgelöst werden kann. Vielmehr muss die Kombination qualitativ-interpretativer und quantitativgeneralisierender Designkomponenten selbst wiederum als gelingend interpretiert werden. Diese im Anschluss an Udo Kelles Abduktionskonzept sowie die in Kapitel 4.5 explizierten erkenntniskritischen Überlegungen entwickelte Lesart kann anschließend in Zusammenhang mit der praxistheoretischen und ideologiekritischen Anlage dieser Arbeit gebracht werden.

In aller Kürze kann der Aufbau der vorliegenden Studie als sequentielles quantitativ-qualitatives Mixed Methods Design bezeichnet werden (vgl. Kelle 2008a, S. 286). Die statistischen Ergebnisse einer Surveyuntersuchung bilden darin Explananda, zu deren Erklärung in einer anschließenden qualitativen Studie Hypothesen generiert werden. Die standardisierte Empirie ermöglicht zugleich den Feldzugang für die qualitative Datenerhebung, d.h. die Teilnehmenden der Interviewstudie bilden ein Subsample des Survey, wodurch eine engere Verknüpfung beider Designkomponenten erzielt wird. Von der Warte des qualitativen Untersuchungsteils aus betrachtet, dienen die Surveydaten also einerseits ,,der Identifikation von (ggfs. schwer interpretierbaren) statistischen Zusammenhangen, die als Explananda die Suche nach sozialwissenschaftlichen Erklärungen anregen sollen“ (Kelle 2008a, S. 286). Zugleich ermöglichen die im Survey erhobenen Antiamerikanismus-Skalen aber auch die „Identifikation von Kriterien für die Fallauswahl für den qualitativen 
Anteil der Studie“ (ebd.). ${ }^{6}$ Einer Klärung der Geltungsreichweite der qualitativinterpretativ generierten Hypothesen kann dieses Design nicht leisten. Wie im vorherigen Abschnitt bereits angerissen, haben die qualitativen Ergebnisse hier grundlegend hypothetisch schlussfolgernden Charakter und bleiben somit hinsichtlich ihrer begrifflichen Geltung „mehr oder weniger riskante Vermutungen“ (ebd., S. 145).

An dieser Stelle soll einem Einwand vorgegriffen werden, der gegenüber dem beschriebenen Forschungsdesign mit einiger Berechtigung formuliert werden könnte. Er betrifft eine gewisse Reibung zwischen der sprechakttheoretisch-rhetorischen Theoriegrundlage der vorliegenden Arbeit und dem gleichzeitigen Anschluss an standardisierte Verfahren der Vorurteilsempirie. Tatsächlich legen Fragestellung und Theorieanlage der Arbeit erhebliche Zweifel an der Validität standardisierter ,Messungen“ von Antiamerikanismus nahe. Vor dem Hintergrund einer Praxistheorie der Bedeutung muss das Vorgehen standardisierter Empirie als weitgehende Ausblendung genau jenes Gebrauchsaspekts erscheinen, der die Rede von einem vorurteiligen Gehalt jeweiliger Sprechweisen überhaupt erst begründet. ${ }^{7}$ Wenn, wie

6 In der Terminologie von John W. Creswell und Vicki L. Plano Clark würde man von einem ,explanatory sequential design“ sprechen (Creswell und Plano Clark 2011, S. 67 ff.), in dem die Analysen des qualitativen Strangs die statistischen Befunde erklären. Diese Bezeichnung kann zu Missverständnissen führen, da in ihr eine ebenso strikte wie ungenaue Unterscheidung von erklärenden und verstehenden (bzw. ,explorativen') Verfahren gebraucht wird (die umgekehrte Reihung von qualitativen und quantitativen Verfahren heißt bei Creswell und Plano Clark „,exploratory sequential design“, vgl. ebd.). Geht man von einer grundlegenden Reziprozität bzw. Konvergenz erklärender und sinnverstehender Erkenntnisprozesse aus (vgl. Kelle 2008a, S. 111 ff. sowie S. 267), könnte man das „explanatory sequential design“ genauso gut als „,interpretive sequential design“ oder eben „exploratory sequential design“ bezeichnen.

7 Vom Gebrauchsaspekt des wissenschaftlichen Sprechens, also des Sprechens über Antiamerikanismus her betrachtet, könnte man die messtheoretische Perspektive auch als den Versuch einer doppelten Formalisierung sprachlicher Bedeutung fassen: Nicht nur wird der Antiamerikanismusbegriff definitorisch festgelegt, sondern auch die empirische Anwendung dieses Begriffes soll durch (operationale) Definitionen eindeutig geregelt sein. Spätestens an dieser Stelle, der Formalisierung des Gebrauchsaspektes, droht die empirische Soziologie das reflexive Bewusstsein über den Deutungsaspekt ihrer eigenen Beobachtungssprache zu verlieren - und damit auch den Blick für wesentliche Aspekte ihres Gegenstandes. Aaron V. Cicourel hat in seiner Kritik sozialwissenschaftlicher Messverfahren ein ähnliches Argument formuliert: „Die genaue Messung sozialer Handlungen (die impliziert, daß begriffliche Strukturen zahlenmäßige Eigenschaften erzeugen, die existierenden oder konstruierbaren Messungssystemen entsprechen) erfordert den Gebrauch sprachlicher oder nicht-sprachlicher Bedeutungen, die nicht als gegeben ange- 
in Kapitel 2 und 3 argumentiert wurde, der situative Gebrauch sprachlicher Ausdrücke deren Bedeutung bzw. perlokutionäre und illokutionäre „Kraft“ (Butler 2006, S. 11) bedingt, dann kann die standardisierte Abfrage von Surveyitems Vorurteile im engeren Sinne nicht beobachten. Denn deren messtheoretische Annahmen gehen ja gerade von einer möglichst situationsunabhängigen Zuordnung von Messwerten zu ebenso situationsunabhängig vorhandenen Realitäten aus. Dieses abbildtheoretische Verständnis sprachlicher Bedeutung schließt ex ante den performativen Aspekt des Handlungssinns aus, an dem ein gesellschaftstheoretisch wohlbegründeter Begriff des Vorurteils gerade ansetzt. Das bedeutet nicht, dass Vorurteilsskalen nicht gute Proxyvariablen für vorurteiliges Sprechhandeln sein können; es heißt aber, dass die vermeintliche ,Messung' von Vorurteilen tatsächlich einen interpretativen Akt darstellt, der in empirischen Studien bzw. in deren begrifflich-methodologischer Reflexion häufig wenig Beachtung findet.

Im Lichte dieser Kritik wird allerdings die Funktion der hier erhobenen Antiamerikanismusskalen als Ausgangspunkt für das qualitative Sampling fragwürdig. Das interpretative Verfahren soll die engen Grenzen der standardisierten Vorurteilsempirie überwinden, und muss doch zu einem gewissen Grad die Validität der vorausgegangenen ,Messung' von Antiamerikanismus voraussetzen, um dies überhaupt tun zu können. Salopp formuliert: Wenn man ohnehin nicht überzeugt ist, dass die erhobenen Skalen Antiamerikanismus messen, wieso sollte man anhand dieser Skalen geeignete Interviewteilnehmende zur Rekonstruktion antiamerikanischer Sprechweisen auswählen können?

Mit dieser Frage ist zunächst ein Reibungspunkt im vorgestellten Forschungsdesign treffend bezeichnet. Ich möchte im Folgenden aber anhand einiger Überlegungen zum Verhältnis qualitativer und quantitativer Verfahren in Mixed Methods Designs zeigen, inwieweit diese Reibung das theoretisch-empirische Vorgehen der vorliegenden Arbeit nicht in Frage stellt. In gewisser Weise, so lässt sich argumentieren, stellt eine bloß mittelbare, nicht-reibungslose Passung verschiedener Methodenstränge in integrativen Designs vielmehr eine Notwendigkeit dar, die sich zudem sinnvoll mit den Prämissen einer erschließenden Vorurteilskritik in Einklang bringen lässt.

Traditionell werden quantitative und qualitative Verfahren in den Sozialwissenschaften gemäß einem Methodendualismus aufgeteilt, wobei sich die AnhängerInnen beider Seiten häufig als separaten Schulen zugehörig empfinden (vgl. Kelle 2008a, S. 25 ff.; Giddens 1984, S. 329 ff.). Quantitative Verfahren werden dabei mit der kausaladäquaten Erklärung sozialer Phänomene assoziiert, d.h. mit der Identifikation fallübergreifend gültiger Handlungsbedingungen. Qualitative Verfah-

nommen werden können, sondern als Studienobjekte betrachtet werden müssen. Mit anderen Worten, die Messung setzt ein enges Netz gemeinsamer Bedeutungen voraus, d.h. eine Theorie von Kultur.“ (Cicourel 1974, S. 28). 
ren hingegen verbindet man üblicherweise mit einem sinnadäquaten Verstehen fallspezifischer Handlungsbegründungen. Qualitative Empirie dient demnach v.a. dazu, lokale Wissensbestände und Rationalisierungen individueller Akteure zu beschreiben, während quantitative Empirie mit der Beobachtung kontexttranszendierender bzw. überindividueller Merkmale befasst ist.

Dieser Methodendualismus lässt sich jedoch aus verschiedenen methodologischen Blickrichtungen als inadäquate Beschreibung sozialwissenschaftlicher Erkenntnispraxen kritisieren. So zeigt etwa Udo Kelle anhand des Konzeptes der hypothetischen Schlussfolgerung die Konvergenz der Schlussformen in qualitativer und quantitativer Empirie auf. Die für den traditionellen Methodendualismus grundlegende Unterscheidung zwischen erklärenden und verstehenden Erkenntnisoperationen beruht demnach ,auf einem philosophiegeschichtlich überholten Verständnis dieser Begriffe“" (Kelle 2008a, S. 267):

„Verstehen und Erklären greifen auf dieselbe Form der Schlussfolgerung zurück, den von Peirce beschriebenen ,hypothetischen Schluss' bzw. den "Schluss auf die beste Erklärung', welcher letztendlich auch in den von Hempel und Oppenheim herangezogenen naturwissenschaftlichen Beispielen verwendet wird.“ (Ebd.)

Im Umgang mit unbekannten, überraschenden Phänomenen konvergieren erklärende und verstehende Handlungsbeschreibungen, insofern beide unter Rückgriff auf bestehendes Regelwissen das beobachtete Phänomen als Fall ebenjener bekannten Regeln verstehbar bzw. erklärbar machen. Eine ähnliche Argumentation ließe sich auch auf der Grundlage von Max Webers Konzeption eines erklärenden Verstehens entwickeln (vgl. Weber 1988, S. 550), demzufolge in sozialwissenschaftlichen Handlungserklärungen kausalanalytische und sinndeutende Aspekte wechselseitig aufeinander bezogen sind.

Zudem lassen sich, so argumentiert auch Kelle (Kelle 2008a, S. 78 f.), mithilfe von Anthony Giddens’ Konzept der ,duality of structure“ (vgl. Giddens 1984, S. 16 ff.) gute sozialtheoretische Gründe für die Konvergenz qualitativer und quantitativer Verfahren angeben: Soziale Phänomene sind demnach immer gleichzeitig durch überindividuelle Strukturen bedingt und durch individuelle Interpretationen begründet. Akteure greifen in ihrem alltäglichen Handeln auf Regeln und Ressourcen zurück, die unabhängig von ihren individuellen Entscheidungen und Wissensbeständen existieren, gebrauchen und adaptieren diese aber in einem je situativen Handlungskontext gemäß ihrer subjektiven Absichten und Situationseinschätzungen. Eine dualistische Trennung quantitativer und qualitativer Forschungslogiken ist also auch deshalb problematisch, weil sozialwissenschaftliche Theoriebildung qua der Struktur ihres Gegenstandes prinzipiell mit beiden Anforderungen zugleich konfrontiert ist: eine plausible Interpretation des lokalen Handlungssinnes in einem jeweils beobachteten Fall zu leisten und den Nachweis zu erbringen, dass solche 
bzw. ähnliche Handlungsmuster auch über den Kreis der beobachteten Fälle hinaus sozial relevant sind. Jede Sozialwissenschaftliche Theoriebildung muss interpretieren und generalisieren (vgl. Reichertz 2014, S. 74). Allerdings lassen sich die beiden Seiten dieser doppelten Anforderung nicht einfach zur Deckung bringen, sondern bilden eine erkenntnistheoretische Aporie analog zu der in Kapitel 4.5.2 diskutierten Dialektik von Geltung und Genese: Eine Handlungsinterpretation, die sich bruchlos auf sämtliche relevanten Anwendungskontexte generalisieren ließe, wäre keine Interpretation mehr, sondern die deduktive Anwendung einer axiomatischen Regel. Hierin zeigt sich wiederum die Konvergenz erschließender Kritik und interpretativer Sozialforschung: Verstehen ist in beiden Fällen ,nur um den Preis des nicht ganz Verstehens möglich“ (Bonacker 2008, S. 71).

In dieser Perspektive erweisen sich quantitative und qualitative Methoden also als unterschiedliche Umgangsweisen mit demselben erkenntnistheoretischen Spannungsverhältnis. Der Unterschied besteht dabei in einer jeweils verschiedenen Schwerpunktsetzung auf kontextsensitive Interpretation bzw. kontextübergreifende Generalisierbarkeit. Diese Auffassung quantitativer und qualitativer Verfahren als verschiedene Bearbeitungsweisen desselben Problems hat Konsequenzen für das Verständnis methodenintegrativer Designs. Zu Anfang dieses Abschnitts wurde die Frage aufgeworfen, ob der hermeneutisch-interpretative Schwerpunkt der vorliegenden Analysen im Widerspruch zum gleichzeitigen Einsatz quantitativer Methoden stehe. Diese Frage kann vor dem Hintergrund des oben explizierten Verständnisses von Methodenintegration folgendermaßen beantwortet werden: Wenn qualitative und quantitative Methoden verschiedene Bearbeitungsweisen derselben „erkenntnistheoretischen Aporie" (Kelle 1997, S. 180) sind, gibt es letztendlich keine technisch saubere Arbeitsteilung zwischen qualitativ-interpretativen und quantitativ-generalisierenden Verfahren, weil beide die beschriebene Spannung von Interpretation und Generalisierung (bzw. Genese und Geltung) jeweils schon in sich tragen. Sie können deshalb in Mixed Methods Designs nicht zusammengesetzt werden wie Puzzleteile. Methodenintegrative Designs stellen vielmehr selbst ein Verhältnis von Verhältnissen dar (vgl. Abbildung 3). Inwiefern eine Kombination verschiedener Methodenstränge als passend oder produktiv aufgefasst werden kann, ist eine Frage, die nicht nach technischen Regeln in Absehung von Material, Gegenstand und theoretischem Rahmen beantwortet werden kann. Die Entscheidung über die Produktivität eines methodenintegrativen Designs ist letztendlich selbst Deutung, zu der allerdings das Konzept der hypothetischen Schlussfolgerung eine gute heuristische Orientierung bietet. 
Abbildung 3: Methodenintegration als Verhältnis von Verhältnissen (von Interpretation und Generalisierung)

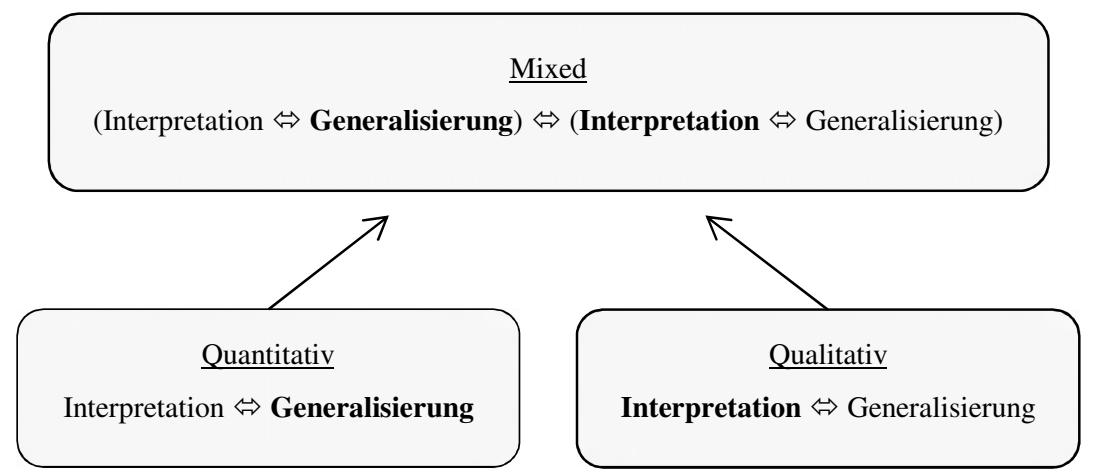

Udo Kelle kommt in seiner Kritik konkurrierender Gebräuche der Triangulationsmetapher in der Mixed Methods Literatur zu einem ähnlichen Schluss. Demnach kann die Kombination empirischer Forschungsmethoden weder nach einem messtheoretischen Modell wechselseitiger Validierung, noch nach dem Muster eines relativistischen Perspektivenpluralismus gedacht werden:

„Die [...] aus der Diskussion um das Triangulationskonzept stammende Frage, ob qualitative und quantitative Methoden eher zur wechselseitigen Validierung oder zu einer gegenseitigen Ergänzung von Forschungsergebnissen dienen sollten, erweist sich also als empirie- und forschungsfern. Diese beiden Möglichkeiten bilden keinen Gegensatz bei der Methodenkombination: qualitative und quantitative Ergebnisse erscheinen vielmehr oft in einem anderen Licht, wenn sie mit Resultaten kontrastiert werden, die mit Hilfe der jeweils anderen Methodentradition gewonnen wurden. [...] Schlussfolgerungen, die aus Ergebnissen monomethodischer Forschung anfangs gezogen wurden, erweisen sich beim Einbezug zusätzlicher Methoden als fehlerhaft und die Methodenkombination führt dann zu einem umfassenderen und damit gleichzeitig valideren Bild des Gegenstandsbereiches.“ (Kelle 2008a, S. 261)

Qualitative und quantitative Befunde müssen als zueinanderpassend gedeutet werden; läge aber in den jeweils konstellierten methodischen Zugängen nicht zugleich schon etwas Korrespondierendes vor, so bliebe völlig uneinsichtig, wieso bzw. in Bezug worauf sich diese pluralistisch ergänzen sollten. ${ }^{8}$

8 Ähnlich argumentiert Thorsten Bonacker in seiner Kritik universalistischer und relativistischer Auffassungen soziologischer Theorievergleiche: „Bei beiden findet sich aus erkenntniskritischer Sicht der gleiche Fehler: Beide gehen von der Identität des Objektes aus, das erkannt werden soll.“ (Bonacker 2001, S. 497) 
Im Hinblick auf die Methodologie der vorliegenden Arbeit bedeutet dies, dass die oben formulierte Kritik standardisierter Vorurteilsempirie keine strikte Unterscheidung zwischen ,richtigen" und ,falschen“ Methoden trifft. In Kapitel 4.5 wurde als zentrales Merkmal eines nicht-essentialistischen Kritikbegriffes ja gerade herausgestellt, dass Kritik keine entweder-oder Entscheidung bedeutet. Kritik nimmt ihren Ausgangspunkt vielmehr an einer bestehenden Begrifflichkeit, die sie anwendet und im Zuge dieser Anwendung zugleich unterläuft, d.h. gezielt nach den Grenzen begrifflicher Klassifikation befragt.

In diesem Sinne nimmt die vorliegende Arbeit nicht nur theoretisch, sondern auch empirisch-methodisch ihren Ausgangspunkt bei etablierten Vorurteilskonzepten (prejudice as attitude) bzw. bei einer der am weitesten verbreiteten Formen der Vorurteilsempirie (Likert-skalierte Fragebogeninstrumente), knüpft an diese aber kritisch an. D.h. sie greift grundlegende Annahmen auf, verweist aber zugleich auf Grenzen und Probleme des Ansatzes. In diesem Sinne geht diese Arbeit davon aus, dass einstellungstheoretische Antiamerikanismuskonzepte wichtige Aspekte des Gegenstandes treffen und sich diese zumindest teilweise in der internen Konsistenz (Faktorstruktur) und Konstruktvalidität (Korrelationen mit anderen Vorurteilsformen) standardisierter Instrumente spiegeln. Daher kann sie diese als Quelle statistischer Explananda und als Medium für Fallauswahl und Feldzugang nutzen. Zugleich ist aber die Annahme forschungsleitend, dass die mittels standardisierter Instrumente festgestellten Merkmalsverteilungen und Zusammenhänge einen erheblichen Anteil unbeobachteter Heterogenität (vgl. Holman 2004 sowie Kelle 2008a, S. 233 ff.) beinhalten. Der heuristische Hintergrund des performativen Antiamerikanismusbegriffs legt nahe, dass sich hinter den für die Survey-Population insgesamt statistisch ausgewiesenen Zusammenhängen (v.a. zwischen Antiamerikanismus und anderen Vorurteilsformen) tatsächlich eine Vielzahl unterschiedlicher Teilpopulationen verbirgt, in denen die Zustimmung zu den Antiamerikanismus-Skalen jeweils unterschiedliche Bedeutung haben und auf unterschiedliche Weise mit anderen (Vorurteils-)Konstrukten zusammenhängen kann. In den qualitativ-empirischen Analysen soll daher sichtbar gemacht werden, was durch die korrelative Logik der standardisierten Empirie zwar nahegelegt, zugleich aber auch verdeckt wird: das rhetorische Zusammenspiel der verschiedenen Vorurteilsformen sowie die flexible vorurteilige Performanz antiamerikanischen Sprechens.

In diesem Sinne zielt der qualitative Strang der vorliegenden Untersuchung darauf, über die Engführungen seines standardisiert-empirischen Ausgangspunktes hinauszugelangen. Da die Arbeit ihren Schwerpunkt auf dieses Moment der deutenden „Übertreibung“ (Bonacker 2008, S. 66) legt, d.h. auf die qualitativhypothesengenerierende Empirie, muss sie die Geltungsreichweite der neuformulierten Theoreme allerdings weitgehend unbeobachtet lassen. 


\subsection{Fallauswahl und Feldzugang}

Der Feldzugang für die Hauptuntersuchung wurde über ein CATI-Survey (Computer Assisted Telephone Interviewing) ermöglicht. Gezogen wurde hierzu eine Zufallsstichprobe nach dem Gabler-Häder-Verfahren (vgl. Gabler und Häder 1997) im Umfang von $\mathrm{N}=808$ Teilnehmenden. Die Auswahlgesamtheit setzte sich aus den in deutschen Telefonhaushalten lebenden Personen ab 18 Jahren zusammen. Der Erhebungszeitraum der Daten erstreckte sich von August bis September 2011. ${ }^{9}$ Teil des Surveyfragebogens war neben den Konstrukten des Syndroms Gruppenbezogener Menschenfeindlichkeit auch eine Antiamerikanismus-Skala, die über sechs Likert-skalierte Items eine Erfassung antiamerikanischer Stereotype ermöglicht (zu Item-Wortlauten, Dimensionalität und Reliabilität der Skala vgl. Kap. 6). Zusätzlich wurden die Bereitschaft der Teilnehmenden zu einer wiederholten Befragung sowie ggf. deren Kontaktdaten für ein weiteres Interview erhoben. Von der Gesamtstichprobe waren $81 \%(n=656)$ der Befragten bereit zu einem weiteren Interview, wovon nahezu alle $(n=655)$ ihre Kontaktdaten tatsächlich zur Verfügung stellten.

Aus dem Pool wiederbefragungsbereiter Teilnehmender wiesen 14,31\% ( $\mathrm{n}=$ 73) ${ }^{10}$ eine überdurchschnittlich hohe Zustimmung zu den Antiamerikanismus-Items auf, d.h. diese Personen lagen mehr als eine Standardabweichung über dem Skalenmittel $\left(x_{i}>3,34\right)$. Diese Gruppe bildet die Auswahlgesamtheit für das qualitative Sample. Ausgehend von der Annahme, dass die Teilnehmenden mit den höchsten Skalenwerten die stärkste Neigung zu antiamerikanischer Rhetorik aufweisen, wurden diese Fälle als erste kontaktiert. Die Interviews wurden per Telefon geführt und fanden im Zeitraum zwischen dem 18. Oktober und 21. November 2011 statt. $^{11}$ Die erste Welle von Interviewkontakten bzw. Kontaktversuchen umfasste eine Liste von $n=13$ Teilnehmenden mit einem Skalenwert $x_{i} \geq 4,5$. Nachdem aus der ersten Interviewwelle 10 Interviews realisiert werden konnten (die übrigen Personen waren

9 Die Erhebung der Daten wurde durch das DFG-Graduiertenkolleg „Gruppenbezogene Menschenfeindlichkeit: Ursachen, Phänomenologie und Konsequenzen“ ermöglicht, das in den Jahren 2004 bis 2012 an den Universitäten Marburg und Bielefeld aktiv war. Geplant und koordiniert wurde der Survey von einer Gruppe von insgesamt 10 promovierenden Mitgliedern des Kollegs.

10 Angegeben sind hier gültige Prozente, d.h. der Prozentanteil an der Stichprobe nach Abzug der Kontaktdaten-Verweigerer und sonstiger fehlender Werte. Grundlage dieser Fallauswahl war die Gesamtskala, d.h. der Mittelwert über alle 6 Antiamerikanismus-Items. Bei der Berechnung des Mittelwertindex wurde ein listenweiser Fallausschluss zugrunde gelegt, was bedeutet, dass nur die Fälle berücksichtigt wurden, die auf keinem der sechs Items fehlende Werte aufweisen.

11 Zusätzliche Informationen zu Gestaltung und Ablauf der Interviews finden sich im folgenden Abschnitt 5.4.2. 
nicht erreichbar oder zu keinem Gespräch bereit), wurden noch 5 weitere Interviews mit Teilnehmenden mit einem geringeren Skalenwert $\left(3,5 \leq \mathrm{x}_{\mathrm{i}} \leq 4,5\right)$ geführt. Von diesen $n=15$ Interviewteilnehmenden war eine Person nicht bereit, das Gespräch aufzeichnen zu lassen, weshalb dieser Fall mangels Dokumentation in den Analysen nicht berücksichtigt werden konnte. Insgesamt wurden aus der Hauptstudie also $\mathrm{n}=14$ Interviewtranskripte analysiert, von denen letztendlich $\mathrm{n}=6$ in die Ergebnisdarstellung dieser Arbeit einflossen.

Um die oben beschriebene Fallauswahl methodisch zu begründen, müssen insbesondere zwei Fragen beantwortet werden: Warum wurde die Erhebung neuer Teilenehmender nach 15 realisierten Interviews gestoppt? Und warum tauchen von den 15 erhobenen Interviews der Hauptstudie nur 6 in der Ergebnisdarstellung auf? Im Folgenden werde ich beide Fragen kurz erläutern und mich dabei auf methodische Überlegungen von Barney Glaser und Anselm Strauss beziehen, die unter dem Begriff „Theoretisches Sampling“ (Glaser und Strauss 2010, S. 61) populär geworden sind.

Die Frage nach dem Abbruch des Sampling-Prozesses lässt sich mit der von Glaser und Strauss beschriebenen ,theoretische[n] Sättigung“ begründen (ebd., S. 76). Die Erhebung neuer Fälle wurde an dem Punkt abgebrochen, an dem die beobachteten Amerikabilder und Argumentationsmuster sich zu wiederholen begannen und somit ein reichhaltiger Materialkorpus vorlag, der eine empirische Antwort auf die behandelten Forschungsfragen erwarten ließ. ${ }^{12}$ Die Eignung des Materials wurde in diesem Abschnitt der Untersuchung insbesondere an der Frequenz und argumentativen Einbindung von Amerikastereotypen in den jeweiligen Interviewtexten festgemacht: Anregendes Analysematerial wurde insbesondere in solchen Fällen gesehen, in denen häufig über Amerika gesprochen und die dabei gezeichneten Amerikabilder nicht lediglich , aufgezählt‘ oder beiläufig genannt, sondern in Argumentationen eingebettet wurden.

Dass nach der Erhebung von fünfzehn Interviews (plus $n=20$ aus den Voruntersuchungen) ein reichhaltiger Materialkorpus vorlag, bedeutet jedoch nicht, dass sämtliches erhobene Material ein dichtes Gewebe aus Argumentationen und Ame-

12 Hierbei ist zu berücksichtigen, dass im Vorfeld der Hauptuntersuchung bereits drei Pilotstudien mit insgesamt $\mathrm{n}=20$ realisierten Interviews unternommen wurden, die ebenfalls in die Beurteilung des Erhebungsprozesses der Hauptuntersuchung eingingen. Fallauswahl und Ablauf der Vorstudien werden weiter unten in diesem Abschnitt genauer beschrieben (vgl. auch Tabelle 2). Es ist an dieser Stelle aber auch zu betonen, dass die hier beschriebene Fallauswahl nicht dem Vorgehen des theoretischen Sampling im engeren Sinne entspricht, da „die Kriterien dafür, was überhaupt erhoben werden soll“ vor allem aus theoretischen Überlegungen im Vorfeld der empirischen Analysen und nicht ,aus der entstehenden Theorie selbst abgeleitet" wurden (Glaser und Strauss 2010, S. 64), d.h. nicht aus den Ergebnissen eines bereits fortgeschrittenen Auswertungsprozesses. 
rikastereotypen enthielt. Vielmehr finden sich unter den insgesamt fünfunddreißig Interviewtexten auch zahlreiche Beispiele für ,flaches' oder inhaltlich irrelevantes Material. Solche Interviews, in denen kaum über Amerika gesprochen wurde oder das Interviewgespräch nie die Form eines distanzierten und einsilbigen FrageAntwort-Spiels verließ, wurden noch vor einer eingehenderen Codierung und Interpretation aus der Analyse ausgeschlossen bzw. teilweise gar nicht erst transkribiert. Aus diesem Umstand erklärt sich, dass von den insgesamt fünfunddreißig erhobenen Interviews lediglich zweiundzwanzig codiert und hinsichtlich ihrer rhetorischen Funktionen analysiert wurden (vgl. Tabelle 2).

Von diesen zweiundzwanzig codierten Fällen wurden schließlich neun für die Ergebnisdarstellung ausgewählt. Der Grund hierfür ist, dass in den übrigen dreizehn Fällen anhand der gebrauchten Analyseheuristiken keine antiamerikanische Rhetorik festgestellt werden konnte. Zwar wurden hier Überschneidungen im Bereich der gebrauchten Amerikabilder beobachtet, jedoch keine Argumentationen gefunden, die auf eine (antiamerikanische) diskriminierende Performanz im Rahmen nationaler, ethnischer oder sonstiger Differenzkonstruktionen schließen lassen. ${ }^{13}$ Die in der Begriffsbildung bzw. Ergebnisdarstellung nicht inkludierten Fälle enthielten also weder zusätzliche relevante Informationen bzgl. der bearbeiteten Fragestellung, noch fanden sich darin amerikabezogene Sprechweisen, die in Widerspruch zu den vorgelegten Ergebnissen stehen.

Wie oben bereits angemerkt, wurden Im Vorfeld der Hauptuntersuchung zusätzliche Interviews im Rahmen dreier Pilotuntersuchungen geführt, von denen insgesamt drei Fälle aufgrund ihrer theoretischen Relevanz ebenfalls in die qualitative Ergebnisdarstellung aufgenommen wurden. Eine Übersicht der insgesamt erhobenen Daten sowie der daraus analysierten und anschließend in die Ergebnisdarstellung aufgenommenen Fälle lässt sich Tabelle 2 entnehmen.

Für die erste dieser Pilotstudien wurden Teilnehmende per Aushang an der Uni Marburg rekrutiert. Der Aushang richtete sich dabei allgemein an Menschen, die „sich für das Verhältnis zwischen Europa und den USA“ interessieren. Insgesamt 6 Interviews wurden auf dieser Grundlage im Mai 2010 realisiert. Von den Interviews dieser Pilotstudie fand eines (Herr F) Eingang in die abschließende Ergebnispräsentation.

13 Zwei solcher Fälle (Frau J und Herr G), in denen zwar eine große Ähnlichkeit der Amerikastereotype, aber kein antiamerikanischer Sprachgebrauch gefunden wurde, tauchen dennoch als kursorische Beispiele in der Ergebnisdarstellung auf. Sie bieten auch eine gute Veranschaulichung der These, dass sich der antiamerikanische Gehalt von Ausdrücken nicht allein anhand der darin gebrauchten Amerikabilder festmachen lässt (vgl. auch Kap. 2.4). 
Tabelle 2: Übersicht Sampling und Fallzahlen

\begin{tabular}{|l|l|l|l|l|}
\hline Untersuchung & Auswahlgesamtheit & $\begin{array}{l}\text { Realisiertes } \\
\text { Sample }\end{array}$ & $\begin{array}{l}\text { Analy- } \\
\text { siert }\end{array}$ & $\begin{array}{l}\text { Ergebnisdarstel- } \\
\text { lung }\end{array}$ \\
\hline $\begin{array}{l}\text { Haupt- } \\
\text { untersuchung } \\
\text { (CATI-Survey } \\
\text { 2011) }\end{array}$ & $\begin{array}{l}\mathrm{n}=73 \text { Teilnehmende mit } \\
\text { Kontakdaten und einem } \\
\text { Antiamerikanismus-Score } \\
>3,34 \text { (M + SD) }\end{array}$ & $\mathrm{n}=15$ & $\mathrm{n}=14$ & $\begin{array}{l}\mathrm{n}=6 \\
\text { (Herr A, } \\
\text { Herr B, Herr C, } \\
\text { Herr D, Herr I, } \\
\text { Frau K) }\end{array}$ \\
\hline $\begin{array}{l}\text { Pilot 3 (CATI- } \\
\text { Survey 2010) }\end{array}$ & $\begin{array}{l}\mathrm{n}=22 \text { Teilnehmende mit } \\
\text { Kontaktdaten, Ursachen- } \\
\text { zuschreibung auf, Ameri- } \\
\text { kaner' und Nationalismus- } \\
\text { Kriterien }\end{array}$ & $\mathrm{n}=12$ & $\mathrm{n}=5$ & $\begin{array}{l}\mathrm{n}=2 \\
\text { (Herr E, Frau H) }\end{array}$ \\
\hline $\begin{array}{l}\text { Pilot 2 (Flakhel- } \\
\text { fer-Generation) }\end{array}$ & $\begin{array}{l}\text { Stadtteilethnographie } \\
\text { Kraft/Seidelsohn }\end{array}$ & $\mathrm{n}=2$ & $\mathrm{n}=1$ & - \\
\hline $\begin{array}{l}\text { Pilot 1 (Studie- } \\
\text { rende Marburg) }\end{array}$ & $\begin{array}{l}\text { Selbstselektierend via } \\
\text { Aushang }\end{array}$ & $\mathrm{n}=6$ & $\mathrm{n}=2$ & $\begin{array}{l}\mathrm{n}=1 \\
\text { (Herr F) }\end{array}$ \\
\hline Gesamt & - & 35 & 22 & 9 \\
\hline
\end{tabular}

Mit dem Ziel, den Anteil von Teilnehmenden mit gehobenem Alter zu erhöhen, wurden für die zweite Pilotstudie im Januar 2011 gezielt Angehörige der sog. „Flakhelfergeneration“ angesprochen (vgl. Bude 1987). ${ }^{14}$ Der Feldzugang kam durch die freundliche Unterstützung von Manuela Freiheit und Kristina Seidelsohn zustande, die zu diesem Zeitpunkt ethnographische Feldforschungen in einem Berliner Stadtteil durchführten. Nach der Durchführung zweier Interviews wurde dieser Feldzugang jedoch abgebrochen und stattdessen der Schwerpunkt auf die methodenintegrativen Möglichkeiten eines Feldzuganges per Surveydaten gelegt. Antiamerikanische Rhetoriken konnten in den beiden Fällen der zweiten Pilotstudie nicht festgestellt werden, so dass diese nicht in die Ergebnisdarstellung aufgenommen wurden.

Für die dritte Pilotstudie wurde in Vorbereitung der oben beschriebenen Hauptuntersuchung ebenfalls die Daten eines CATI-Surveys herangezogen: Aus einer 2010 erhobenen deutschlandweiten Zufallsstichprobe von $n=843$ Fällen waren $51,7 \%(\mathrm{n}=436)$ bereit zu einer wiederholten Befragung. ${ }^{15} \mathrm{Da}$ es sich um eine Se-

14 Hinter diese Vorgehen stand die Annahme eines Kohorteneffektes: Von den Interviews mit Angehörigen der besagten Altersgruppe erhoffte ich mir insbesondere Aufschluss über die Wahrnehmung ,der Amerikaner' durch Menschen, die den zweiten Weltkrieg sowie die unmittelbare Nachkriegszeit unter amerikanischer Besatzung persönlich miterlebt hatten.

15 Wie bei dem Survey der Hauptuntersuchung handelte es sich auch bei dieser Erhebung um ein Projekt des DFG Graduiertenkollegs „Gruppenbezogene Menschenfeindlichkeit“. 
kundärnutzung der Daten handelte, enthielt der Datensatz keine spezifischen Instrumente zur Erhebung von Antiamerikanismus. Stattdessen wurden als näherungsweises Auswahlkriterium ein Item zur Ursachenattribution bzgl. der damaligen Wirtschafts- und Finanzkrise ausgewählt (vgl. Becker et al. 2010): „Die Ursache der Wirtschafts- und Finanzkrise liegt bei den Amerikanern.“ Dieses Item, welches für sich genommen freilich kaum als ein valider Antiamerikanismus-Indikator gelten kann, wurde dann auch im Leitfaden der qualitativen Interviews als Gesprächseinstieg genutzt. Unter den wiederbefragungsbereiten Teilnehmenden stimmten 66,1\% ( $\mathrm{n}=257)$ einer Attribution der Krisenursache auf ,die Amerikaner $\mathrm{zu}^{16}$

Da sich aus vorläufigen Ergebnissen der vorigen Pilotstudien ein theoretischheuristischer Fokus auf die Konstruktion nationaler Identität als zentrales Moment antiamerikanischen Sprechens ergeben hatte, wurden das Sample zusätzlich anhand von drei Fragen zu nationaler Identität und Nationalismus eingeschränkt. Ziel dieses Samplings war die Maximierung der Varianz des Merkmals Nationalismus, das in Ermangelung eines Antiamerikanismus-Indikators zur Fallauswahl herangezogen wurde. Es wurden anhand der drei Nationalismus-Items drei Auswahlbedingungen konstruiert: Eine Gruppe von $\mathrm{n}=9$ Teilnehmenden, die einem Item zu Nationalismus (,Staatstreue ist die erste und wichtigste Voraussetzung, um ein guter Bürger zu sein.") und einem Item zu nationaler Identität (,Für mein Selbstbild ist es wesentlich, Deutsche(r) zu sein.“) ,,voll und ganz“ zustimmen. Eine Gruppe von n = 7 Teilnehmenden, die einer revisionistisch-schuldabwehrenden Identitätskonstruktion „voll und ganz“ zustimmten (,Das Schuldbewusstsein über den Nationalsozialismus ist uns von den Siegermächten doch nur eingeimpft worden."). Und schließlich eine Gruppe von $\mathrm{n}=6$ Teilnehmenden, die allen drei Nationalismus-Items ,,eher nicht“ oder ,überhaupt nicht“ zustimmten. Insgesamt ergab sich also ein Sample von $n=22$ potentiellen Interviewteilnehmenden. Aus diesem Pool konnten $n=12$ Interviews realisiert werden, von denen schließlich $n=5$ für eine eingehendere Auswertung ausgewählt und transkribiert wurden. Wenngleich diese Pilotstudie in erster Linie einer vorläufigen Felderkundung sowie der Erprobung der Telefoninterviewmethode galt, wurden zwei Fälle aus dieser Erhebung in die abschließende Ergebnisdarstellung übernommen, da sie sich für die Rekonstruktion antiamerikanischer Sprechweisen als aufschlussreich erwiesen (Frau H, Herr E).

16 Antworthäufigkeiten der Kategorien „Stimme eher zu“ und „Stimme voll und ganz zu“ auf einer vierwertigen Likert-Skala. 


\subsection{ERHEBUng DES QUALitativen Materials}

Das qualitative Material der Hauptstudie wurde in telefonisch geführten Leitfadeninterviews erhoben. Entgegen anfänglicher Bedenken schienen die Unverbindlichkeit und Distanz der Telefonverbindung sowie das für die Teilnehmenden oftmals unerwartete und plötzliche Zustandekommen der Interviews (nur ein Bruchteil der Gespräche wurde mit vorheriger Terminabsprache geführt) keine hemmende Wirkung auf den Gesprächsverlauf zu haben. Ein Großteil der Gespräche verlief außerordentlich offen und kommunikativ, obwohl die Teilnehmenden sozusagen von einem fremden Sozialforscher mit unbekannter Agenda in ihrem Wohnzimmer überrascht worden waren. ${ }^{17}$ Die Gesprächsdauer, die mit ca. 30 Minuten eingeplant und mit „ca. 10-30 Minuten“ auch den Teilnehmenden angekündigt wurde, erstreckte sich im Durchschnitt auf 43,2 Minuten. Die Interviewlänge rangierte zwischen 11 und 68 Minuten.

Der Interviewablauf wurde in Anlehnung an kognitive Pretestverfahren (vgl. Willis 2005; Faulbaum et al. 2009) gestaltet, wobei die Items der Antiamerikanismus-Skala als „,erzählungsgenerierende Fragen“ (Helfferich 2011, S. 102) dienten. Die Studie wurde den Teilnehmenden als eine Nachfolgeuntersuchung zu jenem Survey präsentiert, an dem sie vor ein bis zwei Monaten partizipiert hatten. Sie wurden gebeten, ihre dort gemachten Antworten genauer zu erläutern bzw. zu kommentieren. Der Leitfaden bestand im Wesentlichen aus fünf der erhobenen Antiamerikanismus-Items ${ }^{18}$ sowie einigen zusätzlichen Gesprächsanreizen und Nachfragen. Zum Einstieg des Interviews wurden den Teilnehmenden ihre Antworten aus dem vorhergegangenen Survey vorgelegt. Sie wurden z.B. auf ihre Zustimmung zur Aussage „Die US-Amerikaner sind mir eher unsympathisch“ angesprochen und gebeten, diese Antwort näher zu erläutern. Falls durch diesen Ansatz allein noch kein Gesprächseinstieg gefunden werden konnte, schlossen sich zusätzliche Fragen an, wie etwa: „Können Sie mir beschreiben, wie sie in der letzten Befragung zu ihrer Antwort gekommen sind?““, „Können Sie mir sagen, was sich für sie persönlich mit dieser Abneigung verbindet?“, „Fällt Ihnen ein Beispiel dafür ein, was Ihnen an

17 Inwiefern Telefoninterviews durch das für die Teilnehmenden natürliche Interviewsetting und die größere Distanz der Kommunikationssituation gerade bei der Erhebung sensibler Themen sogar Vorteile gegenüber Face-to-Face-Interviews aufweisen können, ist in der Methodenliteratur umstritten (vgl. Schulz und Rudat 2012; Opdenakker und Raymond 2006; Irvine et al. 2013).

18 Lediglich das sechste Item mit dem Wortlaut „Ich kann es gut verstehen, wenn manchen Leuten die US-Amerikaner unangenehm sind.“ wurde zugunsten der Übersichtlichkeit des Leitfadens sowie aufgrund der begrenzten Interviewzeit ausgelassen, da es sich ohnehin inhaltlich in großer Nähe zum Item „Mir sind die US-Amerikaner eher unsympathisch." bewegt. 
den Amerikanern unangenehm ist?“, „Können Sie ein persönliches Erlebnis schildern, mit dem ihre Abneigung zusammenhängt?“, etc. (Auszüge aus dem Interviewleitfaden). Dieses Vorgehen wiederholte sich im Verlauf des Interviews dann mit den verschiedenen Antiamerikanismus-Items, wobei deren Reihenfolge bis auf das erste Item flexibel an den Gesprächsfluss angepasst wurde. Es wurde besonderes Gewicht darauf gelegt, an die Assoziationen der Teilnehmenden anzuknüpfen. Durch ,aktives Zuhören“, durch Paraphrasen und präsuppositionsarme Nachfragen (ebd., S. 90 ff., 104 ff.) wurde versucht, auf deren Themenvorschläge einzugehen und ihren persönlichen Relevanzsetzungen Raum zu geben. Diese Orientierung am offenen Dialog ${ }^{19}$ (vgl. ebd., S. 114 ff.) mit den Teilnehmenden wurde grundsätzlich einem gleichmäßigen oder vollständigen Gebrauch des Leitfadens vorgezogen. Dennoch konnten in den meisten Fällen alle Survey-Items im Interview zumindest angesprochen werden. Im Gegenteil zur stärker testend-abfragenden Ausrichtung der meisten kognitiven Pretestverfahren war die Interviewführung also insgesamt stark ,narrativ fundiert“ (Nohl 2012, S. 14), d.h. die Haltung des Interviewers entsprach eher derjenigen in ,narrativen“ oder ,problemzentrierten Interviews“ (vgl. ebd.; Hopf 2012; Witzel 2000).

Da die Interviews der Pilot-Erhebungen nicht nach dem Muster kognitiver Pretests an eine vorhergegangene Surveystudie anschließen konnten bzw. in Pilotstudie 3 sich in dem vorhergegangenen Survey keine Antiamerikanismus-Skala befand, wurden hier andere Leitfäden eingesetzt. Im Falle der ersten Pilotstudie mit Marburger Studierenden (Rekrutierung per Aushang „Interesse am Verhältnis zwischen den USA und Europa“, $n=6$ ) wurde als anfänglicher Erzählstimulus nach dem persönlichen Interesse an der Interviewteilnahme gefragt (,,Bitte schildern Sie mir doch Ihr Verhältnis zu Amerika!“). Im Anschluss daran wurden die Interviewpartner, sofern sich kein anderweitiger Gesprächsverlauf ergab, um eine Einschätzung zu politischen Themen wie der Nobelpreisverleihung an Barack Obama oder der Finanz-

19 Im Gegensatz zur häufig z.B. in narrativen Interviews vertretenen „Abstinenzregel“ (vgl. Helfferich 2011, S. 87), wurde die Erhebungsmethode trotz ihrer prinzipiellen Offenheit als dialogische Form begriffen, so dass bei Verständnisschwierigkeiten Nachfragen gestellt und u.U. auch auf Unklarheiten beharrt werden konnte. Auf diesem Weg entwickelte sich stellenweise ein argumentativer Gesprächsstil, wenn etwa als selbstevident präsentierte Fakten oder Allgemeinplätze (,Im Irak- und Afghanistankrieg geht es nur um Öl‘) mit Gegenfragen des Interviewers konfrontiert wurden (,Aber ist der Sturz des Talibanoder Baath-Regimes nicht auch eine positive Konsequenz?'). Auf diese Weise sollte im Material die Analyse von Rechtfertigungs- und Erklärungsmustern befördert werden. Gleichwohl wurde eine antagonistisch verhärtete Gesprächshaltung vom Interviewer bewusst vermieden, um die Gespräche ggf. nicht zu einer bloßen Gegenüberstellung von Meinungen gerinnen zu lassen, die aller Voraussicht nach wenig ergiebiges Material für spätere Analysen abgegeben hätte. 
und Wirtschaftskrise gebeten. Die Haltung des Interviewers entsprach hierbei hinsichtlich ihrer „narrativen Fundierung“ weitestgehend der beschriebenen Interviewpraxis der Hauptstudie.

Die Interviewgespräche der zweiten Pilot-Erhebung wurden als Folgeerhebung zum vorausgegangenen Survey gerahmt. Als anfänglicher Erzählstimulus diente das Thema der Wirtschafts- und Finanzkrise, da dieses einerseits Bestandteil des vorigen Surveys war und andererseits einen Bezug zu den USA nahelegte, der in dieser Studie nicht unmittelbar durch den Interviewer vorgegeben wurde. ${ }^{20} \mathrm{Im}$ Verlauf des Interviews wurden die Teilnehmenden, sofern das Gespräch im Zusammenhang der Krisen-Thematik nicht von selbst auf die USA kam, mit ihrer Einschätzung aus dem Survey konfrontiert, dass die Ursache der Finanz- und Wirtschaftskrise „bei den Amerikanern" liege (vgl. Kap. 5.4.1). Da sich die Forschungsperspektive im Zuge der ersten Pilot-Erhebung mit Marburger Studierenden bereits in Richtung eines Zusammenhangs von nationaler Identität und Antiamerikanismus entwickelt hatte, wurde als zusätzlicher Erzählstimulus das Motiv der „Deutschenfeindlichkeit" angesprochen (vgl. Posor und Meyer 2009, Shoomann 2010). Dieser zur Zeit der Erhebung häufig in rechtspopulistischer Weise gebrauchte Terminus sollte das Gesprächsthema auf nationale Identität lenken, um ggf. deren Verknüpfung mit antiamerikanischer Rhetorik beobachten zu können.

Alle Interviews wurden mit einem Audiorekorder aufgezeichnet und für die Auswertung vollständig transkribiert. Die Transkription erfolgte wörtlich, d.h. nicht phonemisch exakt, sondern leicht geglättet. Die Orthographie wurde an normale Schriftsprache angepasst und mit entsprechender Interpunktion versehen. Die Transkriptionsregeln wurden aus den Darstellungen von Udo Kuckartz und Uwe Flick adaptiert (Flick 2007, S. 379 ff.; Kuckartz 2007, S. 43 ff.).

\subsection{Auswertung des qualitativen Materials}

Das methodische Vorgehen der Interviewanalysen orientierte sich an den theoriegenerativen Analyseverfahren des „offenen Codierens“ (Kelle und Kluge 2008, S. 61 ff.) bzw. einer ,induktive[n] Kategorienbildung“ (Mayring 2010, S. 67 ff.) sowie an der Methodik einer sequenzanalytischen, sozialwissenschaftlichen Hermeneutik (Soeffner 2004). Ausgangspunkt dieses an Barney Glasers und Anselm Strauss

20 Hiermit verband sich das Vorhaben, nicht nur das Wie antiamerikanischer Sprechweisen zu beobachten, sondern auch ob und ggf. wann im Gespräch ,die Amerikaner' von Seiten der Teilnehmenden selbst eingebracht würden (vgl. Baethge et al. 2010, S. 368 f.). Dieser Aspekt der Fragestellung wurde jedoch in der Hauptuntersuchung zugunsten eines methodenintegrativen Vorgehens sowie eines stärkeren Fokus auf das Wie antiamerikanischer Rede zurückgestellt. 
Grounded-Theory-Methodologie angelehnten Analyseverfahrens bildete die Suche nach Amerikabildern, wobei zunächst noch nicht zwischen antiamerikanischen und nicht-antiamerikanischen Sprechweisen geschieden wurde. Es wurden im Interviewmaterial also zunächst alle Bezüge auf ,Amerika ' bzw. ,AmerikanerInnen“ gesammelt, unabhängig davon, mit welchen Bewertungen, Argumentations- oder Erklärungsmustern diese verknüpft waren. Die theoriegenerative Ausrichtung der vorliegenden Arbeit insgesamt sowie deren spezifische Fragestellung legten ein solches Vorgehen in zweierlei Hinsicht nahe: Zum einen macht eine empirisch begründeten Neuentwicklung von Theoriewissen, wie in Abschnitt 5.2 beschrieben, grundsätzlich die Verwendung nicht von präzisen Definitionen und Operationalisierungen, sondern von ,sensitizing concepts“ nötig, die eine hinreichende empirische Offenheit bzw. Interpretabilität aufweisen um ,in Auseinandersetzung mit der untersuchten Lebensform“ (Kelle und Kluge 2008, S. 29 f.) erst ihren spezifischen Sinngehalt zu entwickeln. Da zum anderen die behandelte Fragestellung besonderes Gewicht auf die Flexibilität antiamerikanischen Sprechens sowie dessen fließende Übergänge zu nicht-vorurteiligen Sprechweisen legt, d.h. auf die Frage nach der Unterscheidung von Antiamerikanismus und, legitimer Amerikakritik', kann der heuristische Ausgangspunkt der Empirie nicht ein bereits definierter Grenzverlauf sein, sondern muss am Sprechen über Amerika überhaupt seinen Anfang nehmen. In den Termini der in Kapitel 2.4 explizierten Analyseheuristik formuliert: Um zu jenen bestimmten Amerikabildern zu gelangen, die antiamerikanisch gebraucht werden, mussten zunächst alle im Material vorfindlichen Amerikabilder betrachtet und auf ihren jeweiligen Gebrauch hin befragt werden. Die „Richtung der Analyse“ (Mayring 2010, S. 56) blieb dabei stets auf Sprechakte als zentrale Auswertungseinheit fokussiert, d.h. die Rekonstruktionsarbeit zielt nicht auf eine Klassifikation antiamerikanischer Individuen, Einstellungen oder ähnlicher personenbezogener Einheiten. Die Grundeinheit der Analyse bilden vielmehr antiamerikanische Sprechhandlungen, die innerhalb eines Interviews in verschiedener Form und Anzahl beobachtet werden können. Wenn also in einem Fall eine bestimmte antiamerikanische Rhetorik beschrieben wird, so bedeutet dies nicht, dass der Fall insgesamt antiamerikanisch ,ist'; es bedeutet vielmehr, dass der Interviewteilnehmende an einer Stelle des Interviews antiamerikanisch gehandelt hat. Es können also auch Passagen im Interview auftreten, die für die bearbeitete Fragestellung kaum relevant sind. Weiterhin bedeutet das Auffinden einer antiamerikanischen Rhetorik nicht, dass diese die einzige antiamerikanische Rhetorik in jenem Fall sein muss es können zusätzlich andere darin vorkommen. Da Sprechhandlungen nur innerhalb des Gesamttextes des jeweiligen Interviews Sinn ergeben, behält die Analyse dennoch eine gewisse Einzelfallorientierung bei. Diese dient aber nicht der Entwicklung personenbezogener Klassifikationsmuster, sondern der Kontextsensitivität der Analyse, die nicht vorschnell vom jeweiligen Gebrauchskontext der Amerikabilder abstrahieren kann, will sie ihren performativen Blick auf das Material beibehalten. 
Abbildung 4 veranschaulicht das Ablaufmodell der qualitativen Analyse, das in drei Auswertungsphasen unterteilt werden kann: Die fallspezifische Sequenzierung der Texte und Codierung von amerikabezogenen Segmenten (1), die fallspezifische Interpretation des Gebrauchskontextes der jeweils gefundenen Amerikabilder (2), und schließlich die fallvergleichende Kategorisierung der gebrauchten Amerikabilder und ihrer antiamerikanischer Gebräuche (3).

\section{Abbildung 4: Ablaufmodell der qualitativen Analyse}

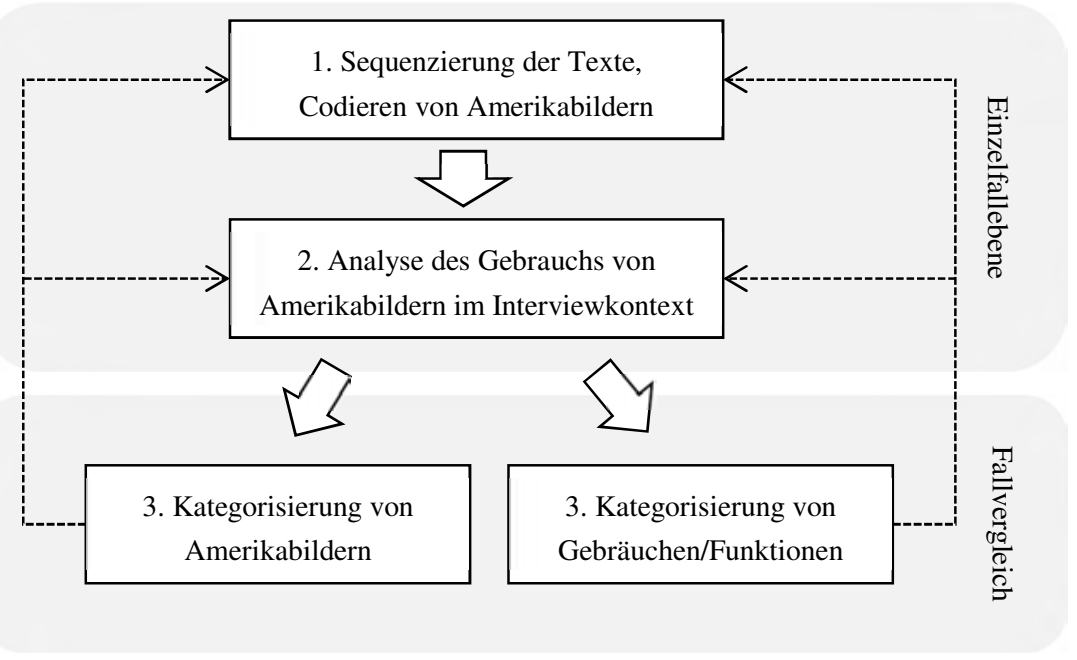

Im ersten Analyseschritt wurden die Interviewtranskripte in inhaltliche Sinnabschnitte unterteilt, deren Länge von einzelnen Sätzen bis hin zu mehreren Absätzen variieren konnte. Zwar stand auch in diesem Arbeitsschritt schon die Suche nach amerikabezogenen Sprechweisen im Vordergrund; es wurden aber auch jene Textabschnitte codiert, die keinen unmittelbaren Amerikabezug beinhalten, da für die angestrebte kontextualisierende Deutung auch der diskursive Rahmen relevant ist, in dem ein jeweiliger Amerikabezug bedeutsam wird. Die Einteilung und Bezeichnung der Sequenzen hatte dabei maßgeblich deskriptiven Charakter. Sofern also Amerikabilder auftauchten, bildeten diese den thematischen Fokus der Sequenzierung, darüber hinaus wurde versucht, den inhaltlichen Ablauf der Äußerungen der Interviewteilnehmenden zunächst möglichst allgemein paraphrasierend nachzuvollziehen. Auf diese Weise konnte ein genereller Überblick über Inhalt und Ablauf des jeweiligen Gesprächsprotokolls geschaffen werden. Ergebnis dieses ersten Codiervorganges war eine jeweils einzelfallspezifische Sequenzierung der Transkripte, die je nach Textumfang bzw. Interviewdauer zwischen 5 und 29 Einzelsequenzen um- 
fasste. Abbildung 5 veranschaulicht diese Sequenzierung am Beispiel von Herrn I (vgl. Kap. 7.5).

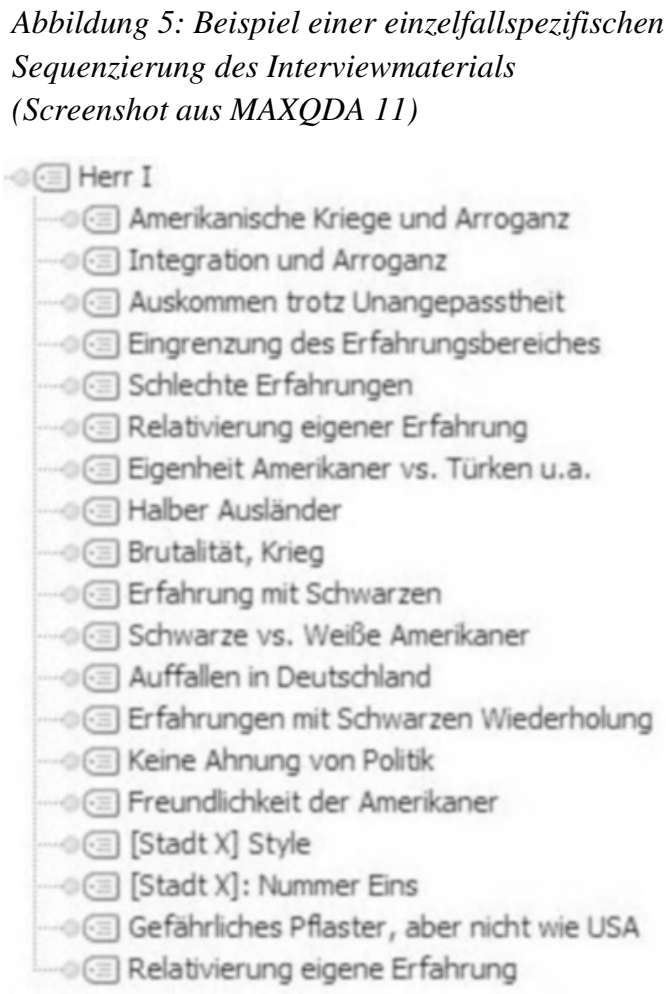

In einem zweiten Analyseschritt konnte anhand der sequenzierten Texte, noch auf Einzelfallebene verbleibend, eine erste Interpretation der Gebrauchsweisen der jeweiligen Amerikabilder generiert werden. In den Termini der in Kapitel 2.4 beschriebenen Analyseheuristik gesprochen: Nachdem für jeden Fall die jeweils gebrauchten Amerikabilder gesammelt waren, wurde nach deren spezifischem Gebrauch im weiteren Kontext des Interviewtranskriptes gefragt, um sich auf dieser Grundlage dem performativen Gehalt antiamerikanischen Sprechens zu nähern. ${ }^{21}$

21 Mir ist durchaus bewusst, dass die hier getroffene Unterscheidung von lexikalischer und performativer Bedeutung, der zufolge man ,zuerst“ Amerikabilder sammeln können soll, um diese ,daraufhin“ in ihrem Gebrauchskontext zu untersuchen, im Licht der in Kap. 3 explizierten pragmatischen Bedeutungstheorie als bestenfalls grobschlächtig, wenn nicht inkonsistent erscheint. Ich möchte an dieser Stelle aber daran erinnern, dass der Begriff des lexikalischen Sinngehaltes nicht im Sinne einer Subsumtion unter Wörterbuchdefini- 
Hierzu wurden zu den einzelnen Fällen, teilweise in Tabellenform, teilweise in Form von Fließtexten, Deutungsskizzen angefertigt, in denen zu jeder relevanten Sequenz eine inhaltliche Paraphrase erstellt, zentrale Zitate entnommen sowie der Bezug zur Forschungsfrage expliziert wurde.

Ausgangspunkt der Interpretationsarbeit am empirischen Material waren insbesondere drei Forschungsheuristiken, die zunächst relativ eng an die eingangs dargestellte Forschungsfrage anknüpfen (vgl. Kap. 1.2):

1. Identitätskonstruktionen und Gruppenstereotype: Welche Wir-, Fremd- und ggf. Feindbildkonstruktionen treten in der Rede über Amerika bzw. in deren $\mathrm{Zu}$ sammenhang auf?

2. Rhetorische Funktion: Welche rhetorischen Funktionen lassen sich (ggf. neben weltanschaulichen) am Sprechen über Amerika feststellen und inwiefern sind diese als Vorurteilige einzustufen?

3. Weltanschauliche Geschlossenheit und Erklärungsfunktion: Inwieweit zeigen die analysierten Sprechweisen einen Schematismus bzw. eine weltanschauliche Geschlossenheit? Funktionieren sie als umfassende ,Welterklärung'?

Im Zuge des zweiten Interpretationsschrittes wurden zunächst für jeden Einzelfall empirisch begründete Kriterien dafür entwickelt, warum in einer jeweiligen Sequenz bzw. einem zusammenhängenden Komplex mehrerer Sequenzen von antiamerikanischem Sprechen die Rede sein konnte. Dies geschah ausgehend von den heuristischen Orientierungspunkten des performativen Antiamerikanismusbegriffes sowie den in Kapitel 2 und 4 explizierten Theoriefragmenten:

- Die Annahme einer funktionalen Verknüpfung von Vorurteil und Diskriminierung bzw. das Konzept der Ungleichheitssemantiken und -pragmatiken.

- Die Annahme einer besonderen Relevanz nationaler Identitätskonstruktionen in diesem Zusammenhang.

- Die damit zusammenhängenden Konzepte rassistischer, fremdenfeindlicher und antisemitischer Rhetorik, die durch die statistischen Ergebnisse der Surveystudie angezeigt wurden.

- Die Annahme einer ideologischen Reflexivität bzw. eines Rechtfertigungszusammenhangs im vorurteiligen Sprechen.

tionen verstanden werden muss. Es kann damit - und so wird der Begriff hier gebraucht auch zunächst eine typisch-allgemeine Bedeutung von Wörtern und Sätzen festgehalten werden (vgl. Kap. 2.3.1), die nicht als grundlegend kontext- und praxisunabhängig aufgefasst wird, aber deren ,lexikalische` Typisierung zunächst relativ kontextunspezifisch und unscharf verbleibt. Es ist diese Unschärfe, die in den anschließenden Deutungen des Gebrauchs von Amerikabildern nach aufgehoben werden soll. 
Es wurde also jeder Fall daraufhin befragt, ob und v.a. wie die darin auftretenden Amerikabilder als rhetorisches Mittel zur Konstruktion nationaler Identitätskonstruktionen mit (potentiell) diskriminierender Wirkung gebraucht werden. Bei dieser Rekonstruktion von Ungleichheitssemantiken wurde insbesondere auf das Auftreten rassistischer, fremdenfeindlicher und antisemitischer Rhetorik im Zusammenhang der gebrauchten Amerikabilder geachtet, deren statistischer Zusammenhang mit Antiamerikanismus durch die vorausgegangenen Survey-Untersuchung nahegelegt wurde (vgl. auch Kap. 6.5). In diesem Zuge konnte das Zusammenspiel der verschiedenen vorurteiligen Rhetoriken im Rahmen nationaler Identitätskonstruktionen auch auf Formen von Kommunikationslatenz bzw. ideologische Rechtfertigungsmuster hin untersucht werden.

Ergebnis der interpretativen Anwendung dieser Theoriefragmente ist eine $\mathrm{Zu}$ sammenstellung der jeweiligen antiamerikanischen Sprachgebräuche innerhalb jedes Einzelfalls. Wie in den Einzelfalldarstellungen in Kapitel 7 anschaulich wird, traten dabei häufig verschiedene Antiamerikanismen in vernetzter oder durchmischter Form auf. Dies wird nicht zuletzt daran erkennbar, dass in der Ergebnisdarstellung einige Fälle in mehreren Teilkapiteln auftauchen, d.h. dieselben Teilnehmenden Beispiele für unterschiedliche antiamerikanische Sprechweisen liefern.

In einem dritten Analyseschritt wurden schließlich auf fallvergleichender Ebene die im Material gefundenen Amerika-Semantiken sowie deren antiamerikanische Gebräuche gesammelt und kategorisiert. Hierzu wurden einerseits in einem höherstufigen Codierschema die Amerika-Bezüge aus den fallspezifischen Analysen unter Kategorien zusammengefasst (vgl. Kap. 7.1.2). In diesem Arbeitsschritt wurde von den jeweiligen fallspezifischen Gebrauchskontexten zunächst weitgehend abgesehen und lediglich ein Überblick hinsichtlich des lexikalisch-semantischen Gehalts der beobachteten Amerikabilder geschaffen, wobei die Leitfrage war: Wie werden , die Amerikaner' bzw. , die USA‘ in einer jeweiligen Sequenz explizit dargestellt?

Schließlich konnten die verschiedenen antiamerikanischen Sprachgebräuche den folgenden drei Funktionskontexten zugeordnet werden:

- $\quad$ Nationale Identität (Kap. 7.2)

- Antisemitismus und Normalisierung des Nationalsozialismus (Kap. 7.3)

- Rassismus und Ethnozentrismus (Kap. 7.4)

Diese drei Kategorien, die auch die Ergebnispräsentation in Kapitel 7 gliedern, fassen den funktionalen Aspekt der rekonstruierten Familie antiamerikanischer Sprechakte zusammen. Vor dem Hintergrund der praxistheoretischen Theorieannahmen eines performativen Antiamerikanismusbegriffes (vgl. Kap. 2 und 3) kommt diesem Analyseschritt die größte Bedeutung zu. Denn dem peformativen Theorieansatz zufolge begründet erst die Bestimmung einer rhetorischen Funktion 
im Kontext von Ungleichheit und Diskriminierung überhaupt die Kritik der jeweiligen Sprechakte als antiamerikanisch.

Da die ideologiekritische Ausrichtung der vorliegenden Arbeit mit einer Konzentration auf die Grauzonen der Antiamerikanismuskritik bzw. die fließenden Übergänge von antiamerikanischem Vorurteil zu ,vorurteilsfreiem‘ Sprechen einhergeht, werden in Kapitel 7.5 zusätzlich solche amerikabezogenen Sprachgebräuche beschrieben, die keinem der drei Funktionskontexte klar zugeordnet werden konnten. Anhand dieser Beispiele, die also nicht oder doch nur , unscharf‘ als antiamerikanisch gelten können, werden die Ränder des entwickelten Antiamerikanismuskonzeptes beleuchtet.

\subsection{ZWISCHENFAZIT}

In diesem Kapitel wurden die methodologischen Ausgangspunkte und methodischen Verfahrensweisen der vorliegenden empirischen Studie dargestellt. Besonderes Augenmerk lag dabei auf der Verknüpfung empirisch methodologischer Überlegungen mit den im vorigen Kapitel explizierten erkenntniskritischen und sozialtheoretischen Grundlagen kritischer Theorie. Eine zentrale Gemeinsamkeit von erschließender Kritik und qualitativ-interpretativer Sozialforschung liegt in deren deutendem Vorgehen und dem damit einhergehenden methodologischen Schwerpunkt auf Kontext- und Gebrauchssensitivität.

Im Anschluss an das in Kapitel 3.3 entwickelte, auf Familienähnlichkeit beruhende Begriffsmodell bildete das Verhältnis theoretischer und empirischer Forschung einen Kernaspekt der methodologischen Überlegungen. Theorie und Empirie lassen sich nur unzureichend als getrennte Departments sozialwissenschaftlicher Forschung beschreiben, da zwischen beiden ein reziprokes Verhältnis besteht: Theoretische Begriffe sind prinzipiell durch eine systematische Ambiguität gekennzeichnet, die nur durch deren Anwendung am empirischen Material aufgehoben werden kann, und somit jenseits eines solchen Gebrauchs praktisch bedeutungslos. Empirische Beobachtungen hingegen stellen auch in ihrer vermeintlich unmittelbarsten Form immer schon ein theoriegeladenes Unterfangen dar. Der Terminus ,theoretische Empirie“ wurde im Anschluss an Herbert Kalthoff als methodologischer Titel für dieses Wechselverhältnis gewählt. Hiermit geht zugleich die Annahme einher, dass qualitativ-interpretative Forschungsmethoden eine besondere Affinität zu der skizzierten methodologischen Position aufweisen. Durch ihre genuin hypothesengenerierende Ausrichtung sind sie in besonderer Weise dazu geeignet, das Spannungsverhältnis zwischen Theorie und Empirie in der empirischen Analyse zu reflektieren. Im Gegensatz zu standardisierten Verfahren, die ihre Anwendung von Begriffen im Vorhinein definitorisch festlegen, zielen qualitative Methoden auf 
eine Modifikation und Adaption ihrer Begriffe im Dialog mit dem empirischen Material. Dieses systematische Unterlaufen der eigenen Begriffe rückt sie in große Nähe zur Methodologie erschließender Kritik. Beide ziehen ihr besonderes Potential aus einer reflexiven Bewegung, in der die Deutung des Gegenstandes zugleich immer auch eine Deutung der eigenen Forschungspraxis ist und die letztendlich auf die praktisch-rhetorische Veränderung des untersuchten gesellschaftlichen Phänomens zielt.

Ausgehend von diesem theoretisch-empirischen Spannungsverhältnis kann man sagen, dass das Gelingen eines solchen interpretativen, hypothesengenerierenden Forschungsprozesses, methodologisch gesprochen, maßgeblich von einer prekären Balance zwischen theoretischer Überformung des Gegenstandes und induktivistischem Selbstmissverständnis abhängt: Ein Dialog mit dem empirischen Material kommt nur dann zustande, wenn in der Erschließung neuer Deutungen weder eine deduktivistisch-subsumtive Erklärung des Materials, noch die Illusion einer theorielosen Emergenz neuen Wissens aus dem Material die Oberhand gewinnt. Diesem Balanceakt wurde im Anschluss an Kelles Arbeiten zu empirisch begründeter Theoriebildung ein methodologischer Rahmen gegeben, wobei insbesondere die Konzepte des empirischen Gehalts und der Abduktion eine tragende Rolle spielen. Beide dienen als Impulsgeber methodologischer Reflexivität. So lassen sich die in qualitativer Empirie gebrauchten Theoriefragmente hinsichtlich ihres empirischen Gehalts auf ihre Eignung als Forschungsheuristiken befragen: Mit steigendem empirischem Gehalt steigt hierbei auch die Gefahr eine theoretischen Überformung des Materials. Anhand der formallogischen Schlussform der Abduktion bzw. qualitativen Induktion lässt sich hingegen die Notwendigkeit des Theoriebezuges in der hypothesengenerierenden Empirie und zugleich die Unmöglichkeit einer restlosen Absicherung der Generalisierbarkeit der aufgestellten Hypothesen zeigen. Beide Konzepte lassen sich als forschungsmethodische Ergänzung einer erschließenden Kritik begreifen, die sich des vorläufigen und letztendlich rhetorischen Charakters ihrer Deutungen bewusst ist und dennoch mit dem Anspruch einer präzisen theoretischen Rahmung ihres Vorgehens auftreten muss.

Doch auch eine gelingende ,exakt-phantasievolle' Deutung geht mit spezifischen Schwächen bzw. blinden Flecken einher: Je mehr sie auf die jeweils kontextspezifische Angemessenheit und methodologische Reflexivität ihrer Deutungen fokussiert, desto weniger kann sie zugleich die Verallgemeinerbarkeit ihrer neugewonnenen Theoreme im Blick behalten. Quantitative Verfahren weisen eine hierzu komplementäre Schwäche auf: Sie sind in erster Linie konzentriert auf die Prüfung fallübergreifend generalisierbarer Hypothesen, so dass sie die interpretativen Aspekte ihrer Beobachtungen, und das heißt insbesondere, deren performative und kontextsensitive Momente, aus dem Blick verlieren. Eine wechselseitige Ergänzung beider Methodentraditionen kann dabei helfen, die Schwächen beider Methodentraditionen auszugleichen. Dies gilt umso mehr, da qualitative und quantitative Me- 
thodenstränge letztendlich auf derselben abduktiven Schlussform beruhen. Die Komplementarität interpretativer und generalisierender Methoden sollte dabei aber nicht nach dem Bild sich ineinanderfügender Puzzleteile gedacht werden. Die Kombination qualitativer und quantitativer Methoden, so wurde gezeigt, stellt vielmehr selbst einen interpretativen Akt dar, dessen Gelingen an keinem externen Kriterium jenseits spezifischer Forschungsfragen und -gegenstände festgemacht werden kann.

Vor diesem methodologischen Hintergrund erschließt sich das methodische Vorgehen der Studie. In einem sequentiellen methodenintegrativen Design werden hier Surveydaten mit weitestgehend teilstandardisierten qualitativen Interviews kombiniert. Die Surveydaten liefern dabei einerseits Explananda in Form statistischer Zusammenhänge zwischen den erhobenen Vorurteilsmaßen, zu denen in den qualitativen Interviews Erklärungshypothesen generiert werden. Andererseits bieten die im Survey erhobenen Antiamerikanismusskalen zugleich eine Möglichkeit zur Auswahl relevanter Fälle für die qualitativ-empirischen Analysen. Die performativen Aspekte antiamerikanischen Sprechens, die in den Surveyinstrumenten systematisch unterbelichtet werden, können somit im qualitativen Strang der Untersuchung exemplarisch rekonstruiert werden. Eine Geltungsprüfung der somit gewonnenen neuen Hypothesen erfolgt in diesem Design allerdings nicht, so dass die Reichweite der in Kapitel 7 dargestellten Ergebnisse jenseits der Plausibilität der fallspezifischen Deutungen vorerst fraglich bleiben muss. 


\section{Statistische Ergebnisse: Antiamerikanismus in den Surveydaten}

Im vorigen Kapitel wurde als eine zentrale Stärke standardisiert-empirischer bzw. statistischer Methoden herausgestellt, dass sie die Schätzung von Merkmalsverteilungen und Zusammenhängen anhand großer Stichproben erlauben. Diese Vorzüge bzgl. der Beobachtung überindividueller sozialer Phänomene sowie der Generalisierbarkeit von Ergebnissen kommen in der vorliegenden Studie auf zweifache Weise zum Tragen. Zum einen kann anhand der analysierten Surveydaten die Verbreitung potentiell antiamerikanischer Stereotype in der deutschen Bevölkerung geschätzt und damit zugleich die Relevanz des Antiamerikanismuskonzeptes im Rahmen einer vergleichenden Vorurteilsforschung beurteilt werden. Zum anderen liefern die Korrelationen zwischen Antiamerikanismus und verschiedenen anderen Vorurteilsformen aus dem Syndrom gruppenbezogener Menschenfeindlichkeit (GMF) Indizien für die Funktion antiamerikanischer Sprechweisen als Ungleichheitssemantiken.

Die Antiamerikanismus-Skalen und deren Zusammenhänge mit den GMFElementen dienen zugleich der Identifikation von Explananda für den qualitativen Strang der vorliegenden Untersuchung. Es ist davon auszugehen, dass die standardisierten Beobachtungsinstrumente mit einem erheblichen Anteil unbeobachteter Heterogenität einhergehen (vgl. Kap. 5.3). Hinter den allgemeinen Antworttendenzen, die sich in den statistischen Analysen zeigen, kann sich eine Vielzahl verschiedener Rhetoriken verbergen. Um diese rhetorischen Praxen sichtbar zu machen, muss die statistisch-populationsorientierte Beschreibung antiamerikanischer Tendenzen durch die kontext- und gebrauchssensitive Perspektive der qualitativen Interviewanalysen ergänzt werden.

Im Folgenden werden nun zunächst die gebrauchten AntiamerikanismusIndikatoren und die daraus konstruierten Skalen vorgestellt. Anschließend kann die Verbreitung antiamerikanischer Vorurteile in der deutschen Bevölkerung anhand grundlegender soziodemographischer Analysen geschätzt werden. Schließlich wird gezeigt, dass deutliche Korrelationen von Antiamerikanismus und GMF existieren. 
Dabei zeigen Rassismus, Fremdenfeindlichkeit, Antisemitismus und antizionistischer Antisemitismus die stärksten Zusammenhänge mit der AntiamerikanismusSkala.

\subsection{Beschreibung Der ANTIAMERIKANISMUS-INDIKATOREN}

Für die Erhebung antiamerikanischer Stereotype bzw. der Tendenz zu antiamerikanischen Sprechweisen wurden insgesamt sechs Indikatoren verwendet. Es wurde erwartet, dass alle sechs Items gemeinsam eine konsistente Dimension bilden und dabei zugleich eine differenzierte Operationalisierung des Konstruktes zulassen: Das Instrument umfasst zu diesem Zweck Stereotype über die amerikanische Kultur und Gesellschaft (Oberflächlichkeit und Egoismus), sowie das Bild eines schädlichen Einflusses amerikanischer Machtpolitik und das Bedrohungsszenario eines amerikanischen Imperialismus. Kombiniert wurden diese sozio-kulturellen und global-politischen Komponenten mit einer zusätzlichen affektiven Dimension, in der der Grad der Abneigung gegenüber, den Amerikanern` erfasst wird.

Dazu wurde zunächst auf zwei bewährte Items zurückgegriffen, die eine stereotype Beschreibung amerikanischer Kultur und Gesellschaft beinhalten (Knappertsbusch und Kelle 2010, S. 150 f.):

„Die Menschen in den USA sind überaus eigennützig und egoistisch.“

„Die US-Amerikanische Kultur ist oberflächlich.“

Diese beiden Items lassen sich als Ausdrücke einer kulturkonservativen Abwertung der USA begreifen. Das erste Item nimmt Bezug auf das gängige AmerikaStereotyp, demzufolge die amerikanische Gesellschaft durch einen Mangel an Solidarität und gemeinschaftlichen Werten gekennzeichnet ist. Im Zusammenleben ,der Amerikaner' dominieren gemäß diesem Bild individuelle Nutzenkalküle und marktwirtschaftliche Kriterien. Es wird davon ausgegangen, dass diese Stereotype in antiamerikanischen Sprachgebräuchen zur Konturierung eines glorifizierten (nationalen) Wir-Gruppenbildes genutzt wird, das als homogen und solidarisch gilt. Das zweite Item ist als Ausdruck der Idee eines Mangels ,der Amerikaner' an traditionellen kulturellen Werten konzipiert. In antiamerikanischen Ausdrücken kann es dazu gebraucht werden, die Eigengruppe als ursprüngliche und , authentische ' Gemeinschaft darzustellen.

Zwei weitere Items wurden ausgewählt, um auch die Dimension eines antiamerikanischen Bedrohungsszenarios in die Erhebung aufzunehmen (vgl. ebd., S. 
$146 \mathrm{f}$.), in dem die USA nicht nur als abgelegener Ort kulturellen und gesellschaftlichen Verfalls erscheinen, sondern als Gefahr für die Werte und Lebenschancen der Eigengruppe. Zu diesem Zweck wurden zwei Items aus den Studien zur Mitte in der Krise von Oliver Decker und KollegInnen adaptiert (Decker et al. 2010, S. 125 f.):

„Die US-Amerikaner sind daran schuld, dass wir so viele Weltkonflikte haben.“

„Der US-amerikanische Imperialismus ist die eigentliche Gefahr für den Weltfrieden.“”

Neben einer nationalisierenden Ursachenzuschreibung globalpolitischer Phänomene auf ,die Amerikaner' sollte mit diesen Items vor allem der Aspekt der Opferinszenierung erhoben werden. Beide Items enthalten dementsprechend neben Stereotypen amerikanischer ,Kriegstreiberei ' und eines imperialistischen Machtstrebens in unterschiedlich ausgeprägter Form die Identifikation mit einer von den USA bedrohten oder benachteiligten Gruppe: „wir“ leiden unter ,den Amerikanern“. Zusätzlich wurden zwei weitere Items in die Erhebung aufgenommen, die nicht auf konkrete Stereotypeninhalte abzielen, sondern eine generelle Abneigungen gegen , die USA“ erfassen und ebenfalls von Oliver Decker und KollegInnen übernommen wurden (vgl. ebd.):

„Mir sind die US-Amerikaner eher unsympathisch.“

„Ich kann es gut verstehen, wenn manchen Leuten die US-Amerikaner unangenehm sind.“

Das erste Item beschreibt auf direkte Weise die affektive Haltung der Befragten gegenüber den USA. Auch wenn Antiamerikanismus keineswegs mit einer unmittelbaren Abwertung oder Abneigung gegen Amerikanerinnen und Amerikaner einhergehen muss (vgl. Kap. 2.3.2), so kann doch ein generalisierter negativer Affekt gegenüber den USA als ein wichtiges Moment antiamerikanischer Vorurteile betrachtet werden. Das zweite Item kann als eine entschärfte Variante dieser affektiven Dimension betrachtet werden: Bzgl. dieses Indikators wird davon ausgegangen, dass ein Verständnis für die Abneigung anderer gegen „die US-Amerikaner“ als

1 Beim zweiten Item wurde die Originalformulierung „Der amerikanische Imperialismus..." abgeändert zu „Der US-amerikanische Imperialismus...“ um einerseits Inkonsistenzen unter den Item-Wortlauten zu vermeiden und andererseits eine eindeutige Referenz auf die USA zu erzeugen. Weiterhin ist festzuhalten, dass das besagte Item ursprünglich nicht von Decker und Brähler selbst stammt, sondern aus einem Instrument von Richard Stöss zur Messung von ,antikapitalistische[n] und globalisierungskritische[n] Einstellung[en]“ (ebd.). 
vermittelter Ausdruck der eigenen negativen Empfindungen funktioniert (vgl. Decker et al. 2010, S. 124 f.).

Die Zustimmung bzw. Ablehnung zu den jeweiligen Aussagen wurde über eine fünfwertige Skala erhoben (,stimme überhaupt nicht $\mathrm{zu}^{\prime}=1$, „stimme eher nicht $\mathrm{zu}^{\prime \prime}=2$, „stimme teils zu teils nicht $\mathrm{zu}^{\prime \prime}=3$, ,stimme eher $\mathrm{zu}^{\prime \prime}=4$, ,stimme voll und ganz zu“ = 5). Die Skala wurde einem Online-Pretest unterzogen, dessen Stichprobe im Schneeball-Verfahren zusammengesetzt wurde. ${ }^{2}$ In einer explorativen Faktorenanalyse wurde eine eindimensionale Struktur der Skala bestätigt ${ }^{3}$ und das Instrument wies eine befriedigende Reliabilität auf (Cronbachs $\alpha=, 825$ ), so dass alle sechs Items als eine Skala in die Hauptuntersuchung aufgenommen wurden.

Tabelle 3 zeigt die relativen Häufigkeiten und Kennwerte der Einzelitems in der Hauptuntersuchung. Insgesamt erweisen sich sämtliche Items als eher schwierig ${ }^{4}$, wie es bei Skalen zur Erhebung von Vorurteilen üblich ist, d.h. die Verteilungen sind allesamt rechtsschief mit einem deutlichen Übergewicht ablehnender Antworten bzw. der Mittelkategorie. Am stärksten ausgeprägt ist diese Tendenz bei den Items 5, 4 und 2. Nur 7 Prozent der Befragten drücken eine persönliche Abneigung gegen ,die US-Amerikaner“ aus (Antwortkategorien 4 und 5 zusammengefasst). Ebenso scheinen die Schlagworte eines amerikanischen Imperialismus und Egoismus ein eher zurückhaltendes Antwortverhalten hervorzurufen: mit 17,4 resp. 15,8 Prozent liegen auch diese beiden Items deutlich unter den 22 bis 27,1 Prozent Zustimmung der übrigen Indikatoren.

2 Teilnehmende wurden in Seminaren der Fachbereiche Gesellschaftswissenschaften und Philosophie sowie sowie über Emailverteiler angesprochen und zudem gebeten, den Link zum Online-Fragebogen an Freunde und Bekannte weiterzuleiten. Die Stichprobe ( $\mathrm{n}=$ 124) setzt sich überwiegend aus Studierenden zusammen (84\%), der Altersdurchschnitt liegt bei 25,25 Jahren und die Befragten waren überwiegend weiblich (63\%).

3 In einer Hauptachsenanalyse in SPSS wurde nach dem sogenannten Kaiser-Kriterium (Faktoreigenwerte $\geq 1$ ) ein Faktor extrahiert (Eigenwert $=2,66$; Varianzaufklärung $=$ 44,38\%). Die Ladungen der einzelnen Items liegen im Bereich ,57 $\leq \mathrm{a}_{\mathrm{ij}} \leq, 76$. Wie in Abschnitt 6.2 erläutert, wurde die Skala in der Hauptuntersuchung allerdings in zwei Subdimensionen unterteilt. Zum Zeitpunkt des Pretests fand sich für die Überlegenheit dieser Lösung jedoch noch keine Evidenz.

4 Der Begriff der Itemschwierigkeit bezeichnet die Zentraltendenz der Antworten zu einem Item, d.h. wie ,leicht' oder ,schwer' es den Befragten im Durchschnitt fiel, einem item zuzustimmen: Je näher sich der Mittelwert am zustimmenden Pol der Skala befindet, desto ,leichter' ist das Item (relativ zu anderen). Der Begriff stammt ursprünglich aus der psychometrischen Leistungsmessung, wo er den Schwierigkeitsgrad verschiedener Testaufgaben beschrieb, und wird im Zusammenhang der Vorurteilsforschung im übertragenen Sinne gebraucht (vgl. Bühner 2006, S. 79 und 83). 
Tabelle 3: Relative Häufigkeiten (gültige \%) der Antiamerikanismus-Indikatoren, Hauptuntersuchung $(n=808)$

\begin{tabular}{|c|c|c|c|c|c|c|}
\hline Item & 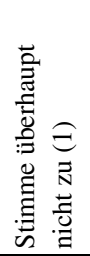 & 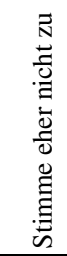 & 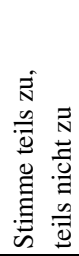 & 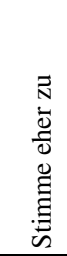 & 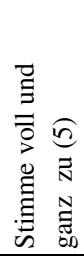 & $\begin{array}{l}\mathrm{n} \text { fehlend, } \\
\text { Mittelwert, } \\
\text { Standardab- } \\
\text { weichung }\end{array}$ \\
\hline $\begin{array}{l}\text { 1. „Die US-amerikanische } \\
\text { Kultur ist oberflächlich.“ }\end{array}$ & 18,9 & 20,3 & 31,4 & 18,3 & 11 & $\begin{array}{l}\mathrm{n} \text { fehlend }=83 \\
\mathrm{M}=2,82 \\
\mathrm{SD}=1,25\end{array}$ \\
\hline $\begin{array}{l}\text { 2. „Die Menschen in den } \\
\text { USA sind überaus eigennüt- } \\
\text { zig und egoistisch.“ }\end{array}$ & 26,6 & 27,3 & 30,3 & 11,2 & 4,6 & $\begin{array}{l}\mathrm{n} \text { fehlend }=105 \\
\mathrm{M}=2,40 \\
\mathrm{SD}=1,13\end{array}$ \\
\hline $\begin{array}{l}\text { 3. „Die US-Amerikaner sind } \\
\text { daran schuld, dass wir so } \\
\text { viele Weltkonflikte haben“ }\end{array}$ & 20,2 & 21,8 & 37 & 12,1 & 9 & $\begin{array}{l}\mathrm{n} \text { fehlend }=45 \\
\mathrm{M}=2,68 \\
\mathrm{SD}=1,19\end{array}$ \\
\hline $\begin{array}{l}\text { 4. „Der US-amerikanische } \\
\text { Imperialismus ist die eigent- } \\
\text { liche Gefahr für den Welt- } \\
\text { frieden.“ }\end{array}$ & 30,7 & 25,7 & 26,2 & 10,6 & 6,8 & $\begin{array}{l}\mathrm{n} \text { fehlend }=74 \\
\mathrm{M}=2,37 \\
\mathrm{SD}=1,21\end{array}$ \\
\hline $\begin{array}{l}\text { 5. „Mir sind die US- } \\
\text { Amerikaner eher unsympa- } \\
\text { thisch.“ }\end{array}$ & 51,6 & 25,5 & 15,8 & 3,5 & 3,5 & $\begin{array}{l}\mathrm{n} \text { fehlend }=47 \\
\mathrm{M}=1,82 \\
\mathrm{SD}=1,05\end{array}$ \\
\hline $\begin{array}{l}\text { 6. „Ich kann es gut verstehen, } \\
\text { wenn manchen Leuten die } \\
\text { US-Amerikaner unangenehm } \\
\text { sind.“ }\end{array}$ & 25,9 & 21,1 & 25,9 & 18,4 & 8,7 & $\begin{array}{l}\mathrm{n} \text { fehlend }=51 \\
\mathrm{M}=2,63 \\
\mathrm{SD}=1,28\end{array}$ \\
\hline
\end{tabular}

Dass die Items aber trotz dieser Verteilungsunterschiede als Indikatoren eines gemeinsamen Antiamerikanismus-Konstruktes gewertet werden können, legen die Korrelationen in Tabelle 4 nahe. Zwar lassen sich hinter dieser Korrelationsmatrix durchaus verschiedene Antwortmuster bzw. Subdimensionen der Skala vermuten, aber zugleich ist deren übergreifender Zusammenhang evident: Im folgenden Abschnitt wird die Dimensionalität des Instrumentes mithilfe von explorativen und konfirmatorischen Faktorenanalysen herausgearbeitet. Dabei zeigt sich, dass, im Gegensatz zur ursprünglichen Annahme einer eindimensionalen Struktur, die Skala am besten durch zwei distinkte aber hoch korrelierte Subdimensionen beschrieben wird. 
Tabelle 4: Korrelationen zwischen Einzelindikatoren (Pearsons Produkt-MomentKorrelation, alle Werte signifikant bei $\alpha=0,01$ )

\begin{tabular}{|c|c|c|c|c|c|c|}
\hline Item & 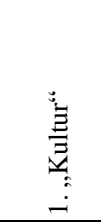 & 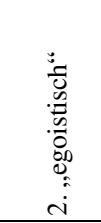 & 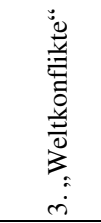 & 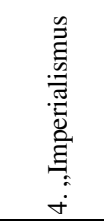 & 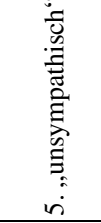 & 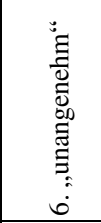 \\
\hline $\begin{array}{l}\text { 1. „Die US-amerikanische } \\
\text { Kultur ist oberflächlich.“ }\end{array}$ & $\begin{array}{l}1 \\
\mathrm{n}=763\end{array}$ & $\begin{array}{l}461 \\
n=684\end{array}$ & $\begin{array}{l}, 588 \\
\mathrm{n}=716\end{array}$ & $\begin{array}{l}, 354 \\
\mathrm{n}=733\end{array}$ & $\begin{array}{l}, 374 \\
\mathrm{n}=695\end{array}$ & $\begin{array}{l}, 349 \\
n=726\end{array}$ \\
\hline $\begin{array}{l}\text { 2. „Die Menschen in den USA } \\
\text { sind überaus eigennützig und } \\
\text { egoistisch.“ }\end{array}$ & $\begin{array}{l}, 461 \\
\mathrm{n}=684\end{array}$ & $\begin{array}{l}1 \\
n=703\end{array}$ & $\begin{array}{l}, 523 \\
\mathrm{n}=672\end{array}$ & $\begin{array}{l}, 472 \\
n=686\end{array}$ & $\begin{array}{l}, 470 \\
\mathrm{n}=665\end{array}$ & $\begin{array}{l}, 470 \\
\mathrm{n}=685\end{array}$ \\
\hline $\begin{array}{l}\text { 3. „Die US-Amerikaner sind } \\
\text { daran schuld, dass wir so viele } \\
\text { Weltkonflikte haben“ }\end{array}$ & $\begin{array}{l}, 588 \\
\mathrm{n}=716\end{array}$ & $\begin{array}{l}, 523 \\
\mathrm{n}=672\end{array}$ & $\begin{array}{l}1 \\
n=734\end{array}$ & $\begin{array}{l}, 462 \\
\mathrm{n}=710\end{array}$ & $\begin{array}{l}, 396 \\
\mathrm{n}=681\end{array}$ & $\begin{array}{l}, 443 \\
\mathrm{n}=707\end{array}$ \\
\hline $\begin{array}{l}\text { 4. „Der US-amerikanische } \\
\text { Imperialismus ist die eigentli- } \\
\text { che Gefahr für den Weltfrie- } \\
\text { den.“ }\end{array}$ & $\begin{array}{l}, 354 \\
\mathrm{n}=733\end{array}$ & $\begin{array}{l}, 472 \\
\mathrm{n}=686\end{array}$ & $\begin{array}{l}, 462 \\
n=710\end{array}$ & $\begin{array}{l}1 \\
n=761\end{array}$ & $\begin{array}{l}, 450 \\
\mathrm{n}=706\end{array}$ & $\begin{array}{l}, 511 \\
\mathrm{n}=736\end{array}$ \\
\hline $\begin{array}{l}\text { 5. „Mir sind die US- } \\
\text { Amerikaner eher unsympa- } \\
\text { thisch.“ }\end{array}$ & $\begin{array}{l}, 374 \\
\mathrm{n}=695\end{array}$ & $\begin{array}{l}, 470 \\
\mathrm{n}=665\end{array}$ & $\begin{array}{l}, 396 \\
\mathrm{n}=681\end{array}$ & $\begin{array}{l}, 450 \\
\mathrm{n}=706\end{array}$ & $\begin{array}{l}1 \\
\mathrm{n}=725\end{array}$ & $\begin{array}{l}, 509 \\
n=708\end{array}$ \\
\hline $\begin{array}{l}\text { 6. „Ich kann es gut verstehen, } \\
\text { wenn manchen Leuten die } \\
\text { US-Amerikaner unangenehm } \\
\text { sind.“ }\end{array}$ & $\begin{array}{l}, 349 \\
\mathrm{n}=726\end{array}$ & $\begin{array}{l}, 470 \\
\mathrm{n}=685\end{array}$ & $\begin{array}{l}, 443 \\
\mathrm{n}=707\end{array}$ & $\begin{array}{l}, 511 \\
\mathrm{n}=736\end{array}$ & $\begin{array}{l}, 509 \\
\mathrm{n}=708\end{array}$ & $\begin{array}{l}1 \\
n=757\end{array}$ \\
\hline
\end{tabular}

\subsection{Dimensionalität UND VeRTEILUNG DER ANTIAMERIKANISMUS-SKALA}

Entgegen der ursprünglichen und im Pretest zunächst bestätigten Annahme einer eindimensionalen Struktur der Antiamerikanismus-Items legte eine explorative Faktorenanalyse (EFA) für die Daten der Hauptuntersuchung eine zweifaktorielle Lösung nahe (vgl. Tabelle 5). 
Tabelle 5: EFA Antiamerikanismus Hauptuntersuchung $(n=796)^{5}$

\begin{tabular}{|c|c|c|}
\hline & Faktor 1 & Faktor 2 \\
\hline $\begin{array}{l}\text { „Die US-Amerikaner sind daran schuld, dass wir so vie- } \\
\text { le Weltkonflikte haben“ }\end{array}$ & 0,744 & $-0,007$ \\
\hline $\begin{array}{l}\text { „Der US-amerikanische Imperialismus ist die eigentli- } \\
\text { che Gefahr für den Weltfrieden.“ }\end{array}$ & 0,689 & 0,138 \\
\hline $\begin{array}{l}\text { „Ich kann es gut verstehen, wenn manchen Leuten die } \\
\text { US-Amerikaner unangenehm sind.“ }\end{array}$ & $-0,085$ & 0,800 \\
\hline „Die US-amerikanische Kultur ist oberflächlich.“ & 0,006 & 0,679 \\
\hline „Mir sind die US-Amerikaner eher unsympathisch.“ & 0,055 & 0,650 \\
\hline $\begin{array}{l}\text { „Die Menschen in den USA sind überaus eigennützig } \\
\text { und egoistisch.“ }\end{array}$ & 0,301 & 0,451 \\
\hline
\end{tabular}

Die Ergebnisse der explorativen Faktorenanalyse zeigen, dass eine zweifaktorielle Lösung statistisch die beste Passung mit den empirischen Daten aufweist. Die beiden sich ergebenden Faktoren sind weiterhin auch inhaltlich sinnvoll zu deuten: So werden die beiden Items zu „Weltkonflikte[n]“ und „Imperialismus“ durch eine gemeinsame Dimension erklärt, die als antiimperialistischer Antiamerikanismus bezeichnet werden kann. Beide Items verweisen auf eine Bedrohung des weltweiten Friedens durch, die Amerikaner' bzw. die USA und legen dabei eine einseitige Identifikation mit einer Wir-Gruppe nahe, die den kriegerischen USA als Opfer bzw. Leidtragende gegenübergestellt wird. Die zweite Dimension lässt sich anhand der restlichen vier Indikatoren als kulturkonservative Abwertung der USA bezeichnen. Hierin finden sich sowohl die beiden Indikatoren für eine affektive Abneigung gegen ,die Amerikaner، sowie die Stereotype einer amerikanischen ,Kulturlosigkeit" und einer egoistischen, unsolidarischen US-Gesellschaft. Das letzte Item zu Eigennutz und Egoismus weist zwar eine substantielle Nebenladung auf, kann aber aufgrund der deutlich höheren Ladung sowie der besseren inhaltlichen Passung dem zweiten Faktor zugerechnet werden. Die hohe Korrelation zwischen den Faktoren ( $\mathrm{r}$ $=, 681$ ) zeigt zudem in der EFA schon an, dass die beiden Dimensionen trotz spezifischer Varianzanteile als Ausdrücke eines gemeinsamen Faktors gedeutet werden können. Diese Interpretation wird durch die Ergebnisse einer konfirmatorischen Prüfung dieser Faktorstruktur (vgl. Tabelle 6) zusätzlich erhärtet, in der die Faktorkorrelation mit $r=, 773$ geschätzt wird. In der konfirmatorischen Faktorenanalyse

5 Schätzverfahren: Maximum Likelihood Robust; Rotation: Geomin (Oblique); Faktorkorrelation $\mathrm{r}=, 681 ; \mathrm{Chi}^{2}=7,832 ; \mathrm{df}=4 ; \mathrm{p}=, 0979 ; \mathrm{CFI}=, 996$; RMSEA = ,037; $\operatorname{SRMR}=, 010$ 
$(\mathrm{CFA})^{6}$ lässt sich zudem auch das in der EFA mit einer Nebenladung auftretende ,Egoismus'-Item eindeutig Faktor 2 zuordnen.

Tabelle 6: CFA Antiamerikanismus Hauptuntersuchung $(n=796)^{7}$

\begin{tabular}{|c|c|c|}
\hline & Faktor 1 & Faktor 2 \\
\hline $\begin{array}{l}\text { „Der US-amerikanische Imperialismus ist die eigentli- } \\
\text { che Gefahr für den Weltfrieden.“ }\end{array}$ & 0,830 & \\
\hline $\begin{array}{l}\text { „Die US-Amerikaner sind daran schuld, dass wir so vie- } \\
\text { le Weltkonflikte haben.“ }\end{array}$ & 0,696 & \\
\hline $\begin{array}{l}\text { „Die Menschen in den USA sind überaus eigennützig } \\
\text { und egoistisch.“ }\end{array}$ & & 0,704 \\
\hline $\begin{array}{l}\text { „Ich kann es gut verstehen, wenn manchen Leuten die } \\
\text { US-Amerikaner unangenehm sind.“ }\end{array}$ & & 0,701 \\
\hline „Mir sind die US-Amerikaner eher unsympathisch.“ & & 0,689 \\
\hline „Die US-amerikanische Kultur ist oberflächlich.“ & & 0,675 \\
\hline
\end{tabular}

Aufgrund der Ergebnisse der Faktorenanalyse wurden zwei Skalen gebildet: Die aus den Items zu „Imperialismus“ und „Weltkonflikten“ berechnete Skala wird im Folgenden als ,antiimperialistischer“ Antiamerikanismus bezeichnet; die aus den restlichen vier Items konstruierte Skala als „kulturkonservativer“ Antiamerikanismus. Die Kennwerte der Skalen sind in Tabelle 7 angegeben. ${ }^{8}$ Die Reliabilitätskennwerte (Cronbachs $\alpha$ ) zeigen eine befriedigende bis gute Konsistenz der Skalen an. Ein Skalenwert der mehr als eine Standardabweichung über dem Mittelwert liegt, kann als statistisches Kriterium für eine besonders starke Tendenz zur Reproduktion antiamerikanischer Stereotype dienen: Fälle mit solchen Werten weichen überdurchschnittlich stark vom Gruppenmittel ab.

6 Zu den Vorteilen von CFA gegenüber EFA vgl. Brown 2006, S. 49 ff.

7 Schätzverfahren: Maximum Likelihood Robust; Faktorkorrelation $r=$,773; $\mathrm{Chi}^{2}=24,812 ; \mathrm{df}=8 ; \mathrm{p}=, 001 ; \mathrm{CFI}=, 984 ;$ RMSEA $=, 051 ;$ SRMR $=, 025$

8 Die hier berichteten Werte beruhen auf Composite-Scores, d.h. sie entsprechen dem Mittelwert über alle eingehenden Items und sind nicht latent berechnet. Der Wertebereich der Skalen ist identisch mit dem der Einzelitems (Werte zwischen 1 und 5). Die aus zwei Items bestehende, antiimperialistische' Skala erhielt gültige Werte nur bei Fällen, die für beide eingehenden Items gültige Werte aufwiesen, um zu verhindern dass Werte in die Skala eingehen, die nur auf Einzelitems beruhen. Bei der „kulturkonservativen“ Skala musste ein Fall mindestens bei 3 Indikatoren gültige Werte aufweisen, um einen gültigen Skalenwert zu erhalten. 
Tabelle 7: Kennwerte der Antiamerikanismus-Skalen (Composite Scores), Anteil der Teilnehmenden mit hohen Skalenwerten

\begin{tabular}{|l|c|c|c|c|c|}
\hline & $\mathrm{m}$ & $\mathrm{sd}$ & Cronbachs $\alpha$ & $\mathrm{n}$ & $\mathrm{N}_{\mathrm{xi}>\mathrm{m}+1 \text { SD }}$ (gültige \%) \\
\hline antiimperialistisch & 2,524 & 1,078 &, 741 & 716 & $67(9,4)$ \\
\hline kulturkonservativ & 2,410 & 0,928 &, 782 & 739 & $113(15,3)$ \\
\hline
\end{tabular}

Anhand dieses Kriteriums kann zunächst festgehalten werden, dass ca. 9 Prozent (,antiimperialistisch`) bzw. 15 Prozent (,kulturkonservativ') der deutschen Bevölkerung eine gesteigerte Tendenz zu antiamerikanischer Rhetorik zeigen. ${ }^{9}$ Obwohl die antiimperialistische Dimension einen leicht höheren Mittelwert aufweist, ist über die gesamte Stichprobe betrachtet die Zustimmung zu Items, die die USA als ,kulturlose“ und von ,Egoismus‘ geprägte Gesellschaft beschreiben, weiter verbreitet, als die Anfeindung eines kriegerischen und weltpolitisch bedrohlichen Amerika. An der ebenfalls etwas höheren Standardabweichung der antiimperialistischen Dimension lässt sich ablesen, dass hier extreme Werte kleinerer Teilgruppen den Mittelwert stärker beeinflussen, wogegen der kulturkonservative Antiamerikanismus auf einem niedrigeren Niveau aber mit größerer Konstanz und Einheitlichkeit im Antwortverhalten auftritt.

Im Vergleich zu anderen Vorurteilsskalen liegen die Mittelwerte der Antiamerikanismus-Skalen im gehobenen Bereich. So ist die mittlere Zustimmung höher als bei den ebenfalls im Survey der Hauptstudie erhobenen Skalen zu Rassismus ( $m=$ $1,59)$, Sexismus $(m=1,58)$, Antisemitismus $(m=1,49)$ und Homophobie $(m=$ 1,74). Auf vergleichbarem Niveau mit den Antiamerikanismus-Skalen befinden sich dagegen Islamfeindschaft $(\mathrm{m}=2,07)$ und Fremdenfeindlichkeit $(\mathrm{m}=2,07)$ sowie antizionistischer Antisemitismus $(\mathrm{m}=2,43)$, Etabliertenvorrechte $(\mathrm{m}=2,62)$ und die Abwertung von Langzeitarbeitslosen $(\mathrm{m}=3,05){ }^{10}$

9 Das Ausmaß von Antiamerikanismus in Stichprobe und Population lässt sich auf diese Weise freilich nur ungenau bestimmen, da es sich bei der verwendeten Skala nicht um ein standardisierten Test mit klaren Cut-Off-Punkten handelt. Vielmehr ist das gebrauchte Kriterium ein rein statistisches und sagt über die praktisch-inhaltliche Bedeutung eines Skalenwertes z.B. oberhalb von $x_{i}=3,6$ (bei , antiimperialistischem' Antiamerikanismus) noch nichts aus. Es besagt lediglich, dass die Teilnehmenden in diesem Bereich überdurchschnittlich hoch von der zentralen Antworttendenz abweichen. Die Annahme einer damit einhergehenden gesteigerten Tendenz zu antiamerikanischem Sprechen fußt also immer auf interpretativen Annahmen über die Bedeutung dieses Antwortverhaltens und stellt keine ,Messung ' von Antiamerikanismus im strikten Sinne dar (vgl. Kap. 5.3).

10 Die Item-Formulierungen der übrigen Konstrukte finden sich in Abschnitt 6.4 Es sei an dieser Stelle betont, dass aus dem obigen Vergleich mit anderen Vorurteils-Skalen keine 


\subsection{Die Verbreitung von Antiamerikanismus in DER BEVÖLKERUNG DEUTSCHLANDS}

Einen genaueren Einblick in die Verteilung antiamerikanischer Tendenzen vermitteln Gruppenvergleiche anhand von wichtigen soziodemographischer Variablen. Um einen allgemeinen Überblick zu geben, werden im Folgenden die Mittelwerte der zwei Antiamerikanismus-Dimensionen nach Altersgruppen, Geschlecht, Bildungsgrad sowie zwischen West- und Ostdeutschland (ehemalige DDR) verglichen. Als zusätzliche Vergleichsgröße wird anschließend die politische Orientierung der Befragten untersucht, da sich anhand der Unterscheidung von ,linkem “ und ,rechtem“ Antiamerikanismus sowie deren Verhältnis zur politischen ,Mitte interessante Abweichungen von der Verteilungsmustern anderer Vorurteilsformen zeigen lassen.

Tabelle 8: Ergebnisse einer multivariaten Varianzanalyse für beide Antiamerikanismus-Skalen

\begin{tabular}{|c|c|c|c|c|c|}
\hline & Pillai-Spur & F & df Hypothese & df Fehler & Sig. \\
\hline Ost/West &, 010 & 3,194 & 2 & 633 &, 042 \\
\hline Bildung &, 021 & 3,410 & 4 & 1268 &, 009 \\
\hline Geschlecht &, 013 & 4,189 & 2 & 633 &, 016 \\
\hline Alter &, 010 & 1,618 & 4 & 1268 &, 167 \\
\hline
\end{tabular}

Um die Bedeutsamkeit der insgesamt eher geringen Mittelwertdifferenzen besser einschätzen zu können, wurden der Einfluss aller vier soziodemographischen Variablen in einer multivariaten Varianzanalyse (MANOVA) auf Signifikanz geprüft. ${ }^{11}$

Aussagen über die Verbreitung einzelner Vorurteilstypen im Vergleich mit anderen getroffen werden können: Aussagen im Sinne von „Antiamerikanismus ist in Deutschland weiter verbreitet als Rassismus" sind aufgrund der mangelnden Vergleichbarkeit der Item-Formulierungen nicht möglich. Es muss davon ausgegangen werden, dass die Erhebungsinstrumente unterschiedliche Skalierungen bzw. Itemschwierigkeiten aufweisen und nicht ohne weiteres in einen gemeinsamen Maßstab übersetzt werden können.

11 Das Verfahren der MANOVA erlaubt den Einbezug mehrerer abhängiger Variablen, in diesem Fall die beiden Antiamerikanismus-Skalen, deren Mittelwertdifferenzen für verschiedene Gruppen simultan getestet werden. Dies bietet gegenüber mehreren aufeinanderfolgenden univariaten Analysen den Vorteil, dass einerseits die Kovarianz der beiden unabhängigen Variablen im Gruppenvergleichen mitberücksichtigt wird, was im Fall der Antiamerikanismus-Skalen aufgrund der Annahme eines starken gemeinsamen Faktors angemessen ist. Andererseits vermeidet der simultane Gruppenvergleich eine Inflation des Alpha-Fehlers, die durch multiple unabhängige Tests entstehen kann. 
Es zeigt sich, dass sich die Befragten nach Geschlecht, Bildungsgrad und Bundesland (Ost/West) signifikant in ihren Gruppenmittelwerten unterscheiden (vgl. Tabelle 8). Der Unterschied zwischen verschiedenen Altersgruppen hinsichtlich der beiden Antiamerikanismus-Skalen ist jedoch nicht signifikant.

Im Folgenden werden die Mittelwertdifferenzen hinsichtlich der einzelnen Faktoren zusätzlich deskriptiv im Detail berichtet. Betrachtet man die Mittelwertdifferenzen zwischen Ost- und Westdeutschen zeigt sich eine leicht gegenläufige Antworttendenz zwischen den Regionen (vgl. Abbildung 6). Zwar liegt der Mittelwert der antiimperialistischen Dimension in Ost- und Westdeutschland oberhalb desjenigen der kulturkonservativen Dimension. Im Gebiet der ehemaligen DDR rangiert aber die mittlere Zustimmung zur kulturkonservativen Dimension unterhalb und diejenige zur antiimperialistischen oberhalb der westdeutschen.

Abbildung 6: Mittelwerte der Antiamerikanismus-Skalen gruppiert nach Ost- und Westdeutschland

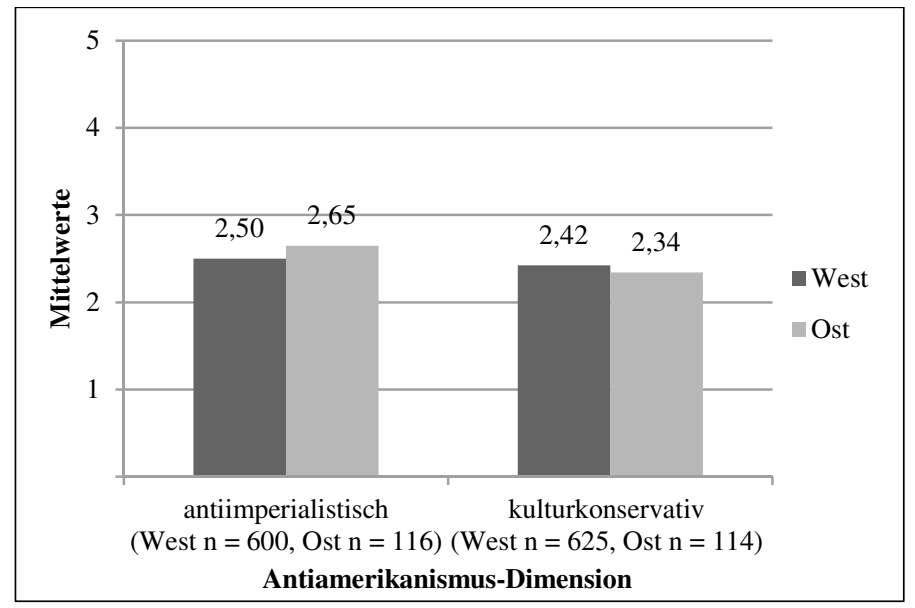

Befragte in Ostdeutschland stimmen auf der antiimperialistischen Dimension stärker zu als Westdeutsche und neigen auch zu geringeren Werten auf der kulturkonservativen Dimension. Diese Diskrepanz zwischen den beiden AntiamerikanismusDimensionen kann als Echo des antiimperialistischen und anti-westlichen Selbstverständnisses der DDR gedeutet werden, in dem die USA als Hort der „Dollarkönige“ erschienen (Haury 2004). ${ }^{12}$ Andererseits ist aber unklar, warum nicht auch die

12 Der Befund ist jedenfalls nicht durch eine überproportionalen Anteil sich als politisch ,links ' einstufender Befragter in Ostdeutschland zu erklären: Die Verteilung der politischen Orientierung ist in beiden Regionen nahezu gleich (vgl. auch die Ausführungen zu politischer Orientierung und Antiamerikanismus unten). 
kulturkonservative Dimension in Ostdeutschland höhere Werte erzielen sollte, da in der SED-Propaganda gerade auch völkisch-nationale und traditionalistische Momente eine große Rolle spielten (vgl. ebd., S. 71 ff.).

In der Vorurteilsforschung ist der Bildungsgrad der Befragten vielfach als einer der stärksten Prädiktoren vorurteiliger Tendenzen repliziert worden (vgl. Davidov et al. 2011; Decker et al. 2010, S. 82; Heyder 2003). Mit zunehmendem Bildungsniveau nimmt die Zustimmung zu vorurteiligen Aussagen demnach ab. Auch hinsichtlich der Antiamerikanismus-Skalen lässt sich diese Tendenz beobachten, wobei insbesondere die Befragten mit einem hohen Bildungsniveau sich im Mittel ihrer Zustimmung von den übrigen Bildungsgruppen unterscheiden (vgl. Abbildung 7). ${ }^{13}$ Dieser Effekt ist für die antiimperialistische Dimension klarer ausgeprägt, als für die kulturkonservative: Während der Mittelwert hier vom niedrigsten zum höchsten Bildungsniveau stetig abnimmt, liegt für die kulturkonservative Dimension der Wert der mittleren oberhalb der übrigen Bildungsgruppen. Insgesamt zeigt sich dennoch ein negativer Zusammenhang von Bildungsniveau und antiamerikanischer Tendenz, was als Untermauerung der These gelten kann, dass es sich bei antiamerikanischen Vorurteilen heute nicht mehr um ein Elitenphänomen, sondern um ein massenhaft verbreitetes Vorurteil handelt (vgl. Markovits 2004, S. 15 ff.). ${ }^{14}$ Dass sich diese Verteilungstendenz bei der kulturkonservativen Dimension nur eingeschränkt findet, lässt vermuten, dass die Zurückweisung amerikanischer ,Kulturlosigkeit' und ,mangelnder Solidarität‘ eine für Gruppen mit geringerem sozialem Status wenig attraktive Rhetorik darstellt, wenn auch die oberen Schichten dieser Dimension nicht (mehr) herausragend zustimmen. Die geringere Zustimmung in

13 Das Bildungsniveau wird hier über den höchsten allgemeinbildenden Schulabschluss operationalisiert. Die Ausprägungen dieser Variable wurden wie folgt in drei Kategorien zusammengefasst:

,niedrig' = 'keinen Abschluss', 'Abschluss polytechnische Oberschule der DDR 8./9. Klasse', 'Hauptschulabschluss/Volksschulabschluss';

,mittel' = 'Abschluss polytechnische Oberschule der DDR 10. Klasse', 'Realschulabschluss/mittlere Reife';

,hoch“ = 'Fachhochschulreife/Abschluss Fachoberschule', 'allgemeine/fachgebundene Hochschulreife/Abitur'.

14 Bildung wird hier als Proxi-Variable für sozialen Status interpretiert. Für diese Interpretation spricht, dass ein Schichtindikator, der aus Berufsprestige (Treimann-Index), NettoÄquivalenzeinkommen und Bildung berechnet wurde, weitestgehend denselben Einfluss auf Antiamerikanismus hat, so dass davon ausgegangen werden kann, dass Bildung die bestimmende Einflussgröße im Schichtindex ist. Um Probleme mit Autokorrelationseffekten von Bildung und Schichtindex zu vermeiden sowie um die Anzahl von Faktoren in der MANOVA möglichst gering zu halten, wurde allein der Bildungsgrad als Faktor in die Analyse aufgenommen. 
niedrigeren Statuspositionen ließe sich in diesem Sinne als Überbleibsel eines ehemals elitären Charakters des Antiamerikanismus deuten, demzufolge die USA für die abhängigen und besitzlosen Klassen historisch eher ein Glücksversprechen bedeuteten, für die mächtigen und besitzenden hingegen die Bedrohung eines Verfalls traditioneller Ordnungen und Privilegien (vgl. Markovits 2007, S. 44 ff.).

Abbildung 7: Mittelwerte der Antiamerikanismus-Skalen gruppiert nach Bildungsniveau

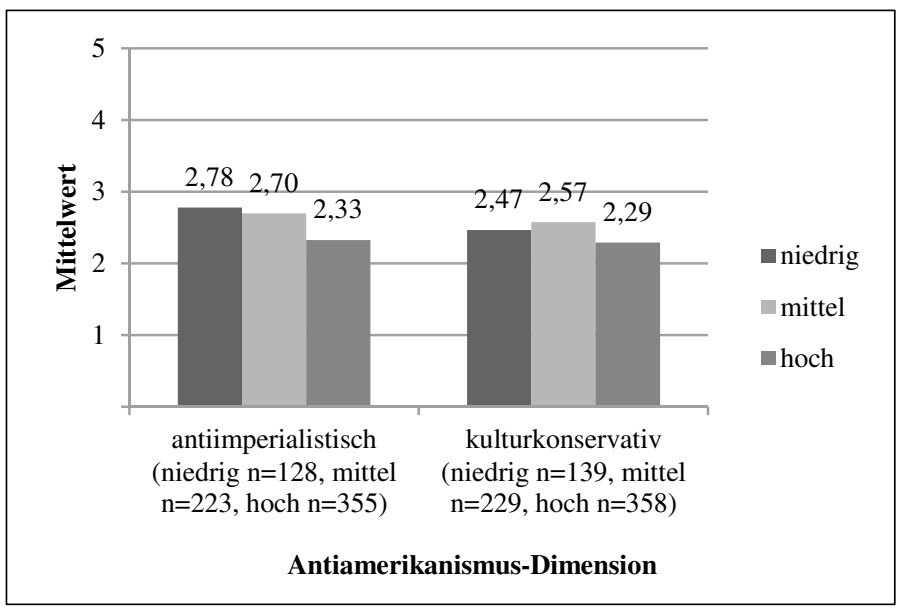

Zwischen Männern und Frauen lässt sich ebenfalls eine signifikante Mittelwertdifferenz feststellen, die auf beiden Dimensionen mit rund 0,3 Skalenpunkten gleich stark ausfällt (vgl. Abbildung 8). Wenngleich diese geschlechtsspezifische Antworttendenz auch in anderen Vorurteilsstudien gefunden wird (vgl. Decker et al. 2010, S. 83; Küpper und Zick 2011, S. 192 ff.), so ist sie bzgl. des Antiamerikanismus im Vergleich zu den übrigen soziodemographischen Faktoren hier besonders deutlich ausgeprägt.

Anhand der Balkendiagramme in Abbildung 9 lässt sich ein negativer Einfluss des Alters auf die Zustimmung zu den Items beider Antiamerikanismus-Skalen erkennen. Für die antiimperialistische Dimension gilt dies nur eingeschränkt, da hier zwar die älteste Gruppe im Mittel niedriger liegt als die jüngste, insgesamt aber die Befragten mittleren Alters den geringsten Wert aufweisen. Die Bedeutsamkeit dieser Tendenz ist insgesamt sehr vorsichtig zu beurteilen, zumal es sich um sehr geringe Differenzen handelt die im Gegensatz zu den übrigen soziodemographischen Variablen nicht statistisch signifikant sind (vgl. Tabelle 8). ${ }^{15}$ Dennoch stellt dies im

15 Betrachtet man die Mittelwerte der Altersklassen auf der antiimperialistischen Antiamerikanismus-Dimension, so liegt die Vermutung nahe, dass zwischen den Variablen ein 
Vergleich zu anderen Vorurteilsformen einen überraschenden Befund dar, da für die meisten Vorurteilskonstrukte (etwa Rassismus, Antisemitismus, Sexismus, Homophobie) gewöhnlich ein leichter bis moderater positiver Effekt von Alter auf die Zustimmungstendenz gefunden wird (vgl. Davidov et al. 2011; Decker et al. 2010, S. 84; Zick et al. 2012, S. 73 ff.).

\section{Abbildung 8: Mittelwerte der Antiamerikanismus-Skalen gruppiert nach Geschlecht}

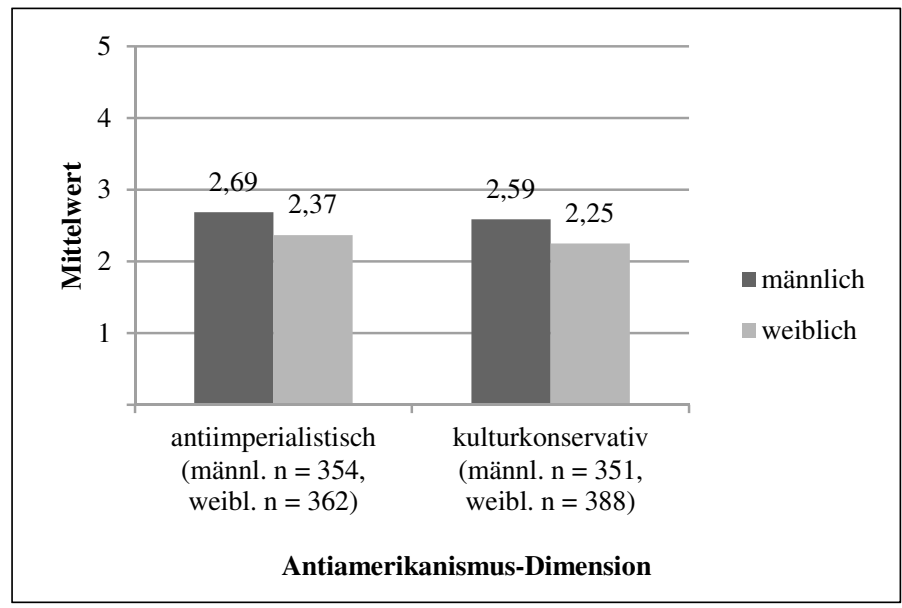

Auch in den vorliegenden Surveydaten sind die Antiamerikanismus-Skalen gemeinsam mit der Skala zur Abwertung von Langzeitarbeitslosen die einzigen Konstrukte, bei denen die ältesten Befragten nicht auch die höchste mittlere Zustimmung auf der Vorurteilsskala aufweisen. Wenngleich dieser Befund aufgrund des nicht signifikanten Effekts unter Vorbehalt zu interpretieren ist, so deutet er doch in eine klare Richtung, der zufolge jüngere Befragten den älteren Generationen, zu denen ja auch Angehörige der 68er-Linken sowie der sogenannten „Flakhelfer-Generation“ gehören, hinsichtlich ihrer antiamerikanischen Tendenzen in nichts nachstehen. Das Verteilungsmuster spricht jedenfalls für die Annahme einer großen Aktualität an-

quadratischer Zusammenhang besteht und die fehlende Signifikanz in der MANOVA durch eine Fehlspezifikation als lineares Modell zu erklären ist. Allerdings lassen sich auch in separaten Tests (einfaktorielle Varianzanalyse mit Post-Hoc-Test nach Bonferroni) zwischen den untersuchten Altersklassen keinerlei signifikante Mittelwertdifferenzen für antiimperialistischen Antiamerikanismus feststellen, so dass nicht davon auszugehen ist, dass in der MANOVA ein vorhandener Effekt durch falsche Verteilungsannahmen verdeckt wird. 
tiamerikanischer Vorurteile, die keineswegs allein zum rhetorischen Repertoire von Alt-Linken oder Alt-Nazis gehören.

\section{Abbildung 9: Mittelwerte der Antiamerikanismus-Skalen gruppiert nach Alter}

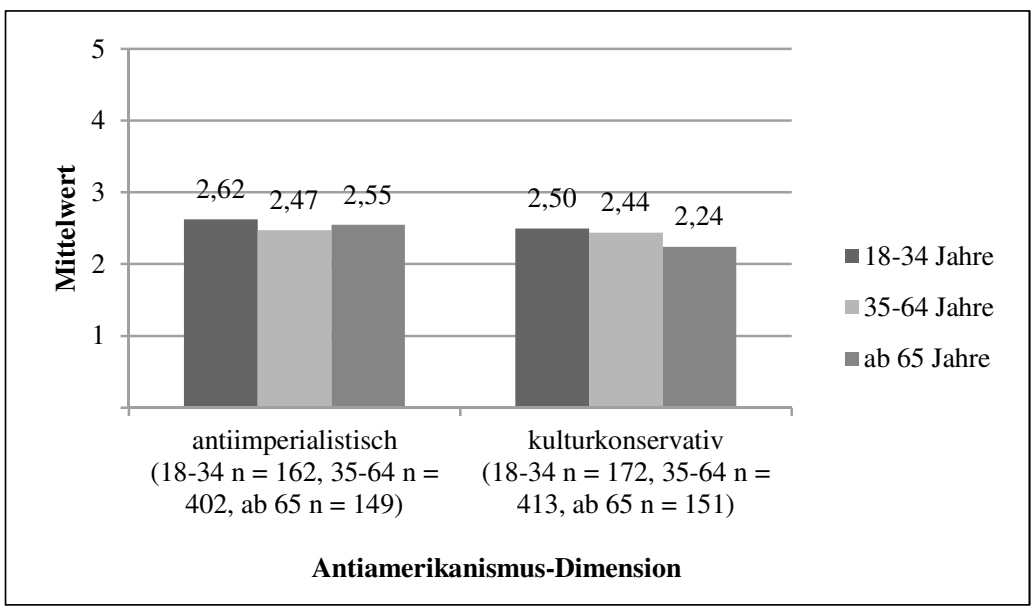

Ein besonders interessanter Einflussfaktor bzgl. der Ausprägung antiamerikanischer Vorurteile ist die politische Orientierung. In der Antiamerikanismusliteratur findet sich hierzu die These, dass Antiamerikanismus als eine politische Lager übergreifenden „Lingua Franca“ fungiert (Markovits 2007, S. 11; vgl. auch Diner 2003, S. 50). Trotz der Überschneidungen zwischen linkem und rechtem Antiamerikanismus, so bemerkt Andrei Markovits, lassen sich aber argumentative Varianten unterscheiden. So konstruieren zwar beide Positionen typischerweise politischökonomische und kulturelle Bedrohungsszenarien. Während aber der linke politisch-ökonomische Antiamerikanismus in den USA vor allem den ,leading capitalist state“ sieht, der ,stands at the summit of everything that is reactionary worldwide“, fürchtet die rechte Variante in erster Linie um die ,authenticity of other peoples, their institutions, and their autonomy“ (Markovits 2007, S. 29). In ähnlicher Weise ist die kulturelle Komponente des Antiamerikanismus bei Rechten stärker an Ideen der Bewahrung ,ethnischer“ Werte und Traditionen orientiert, während die Linke in amerikanischer Kultur vor allem ein Instrument der kapitalistischen Ausbeutung sieht (ebd., S. 30). Wenngleich also linke und rechte Varianten antiamerikanischer Bilder existieren, so kommen sie sich doch in den grundlegenden Dimensionen (Kulturkritik, Antiimperialismus) nahe.

Vergleicht man antiamerikanische Tendenzen nach linker und rechter politischer Orientierung in den vorliegenden Surveydaten, so wird Markovits Argument bekräftigt. An der grafischen Darstellung der Mittelwerte in Abbildung 10 und Ta- 
belle 9 lassen sich drei zentralen Befunde herausstellen: Antiamerikanismus unterscheidet sich erstens nur geringfügig zwischen den politischen Lagern, insbesondere zwischen der Mittelkategorie und den Bereichen ,eher links“ und ,eher rechts“ gibt es keine nennenswerten Unterschiede. ${ }^{16}$ Zugleich kann man aber festhalten, dass die Tendenz zu Antiamerikanismus hier tendenziell U-förmig verteilt ist, d.h. die linken und rechten Extreme heben sich jeweils in dieselbe Richtung von der Mitte ab. Drittens ist diese U-förmige Verteilung allerdings für die antiimperialistische und die kulturkonservative Dimension nicht gleichmäßig ausgeprägt, sondern erstere hat im linken Extrem ihren höchsten Mittelwert, letztere im rechten (vgl. Tabelle 9).

Abbildung 10: Mittelwerte der Antiamerikanismus-Skalen gruppiert nach politischer Orientierung

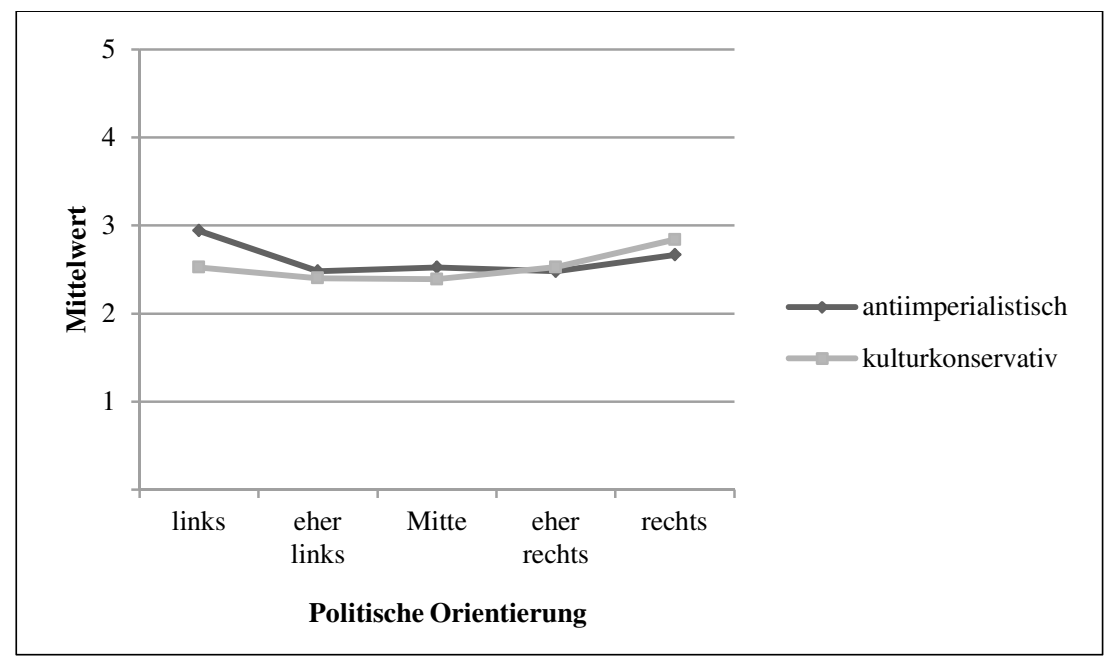

16 Dies bedeutet nicht, dass die Selbsteinschätzungsskala generell invalide ist und zu wenig Varianz produziert bzw. tatsächliche links-rechts Unterschiede nicht abbilden kann: Im Gegensatz zum Antiamerikanismus lassen sich bei anderen Vorurteilsformen durchaus Unterschiede auch zwischen den drei mittleren Kategorien finden. So liegen bspw. bei den Skalen zu Islam- und Fremdenfeindlichkeit sowie Antisemitismus und Rassismus bereits die Befragten in der ,eher links` Kategorie deutlich unter dem Wert der Mittelkategorie, so dass sich ein nahezu kontinuierlicher Anstieg der mittleren Zustimmung von ,links' nach ,rechts' ergibt. 
Tabelle 9: Mittelwerte der Antiamerikanismus-Skalen gruppiert nach politischer Orientierung

\begin{tabular}{|c|c|c|c|c|c|}
\hline & links & eher links & Mitte & eher rechts & rechts \\
\hline \multirow{2}{*}{ antiimperialistisch } & 2,94 & 2,48 & 2,53 & 2,48 & 2,67 \\
& $\mathrm{n}=34$ & $\mathrm{n}=202$ & $\mathrm{n}=368$ & $\mathrm{n}=70$ & $\mathrm{n}=15$ \\
\hline \multirow{2}{*}{ kulturkonservativ } & 2,52 & 2,40 & 2,39 & 2,53 & 2,84 \\
& $\mathrm{n}=36$ & $\mathrm{n}=201$ & $\mathrm{n}=378$ & $\mathrm{n}=68$ & $\mathrm{n}=18$ \\
\hline
\end{tabular}

Sich als links identifizierende Befragte stimmen vor allem auf der antiimperialistischen Dimension stärker zu, wogegen Befragte mit rechter Selbsteinschätzung sich vor allem auf der kulturkonservativen Dimension abheben. Insgesamt sind antiamerikanische Vorurteile aber auch in der politischen Mitte stark vertreten, so dass sich nur die Extrempole der politischen Orientierung nennenswert von der verbreiterten Mittelkategorie unterscheiden. Es muss an dieser Stelle aber betont werden, dass es sich bei dieser Interpretation der Daten nicht um statistisch gesicherte Befunde handelt, da allein schon die sehr geringen Fallzahlen an den Extremen der politischen Orientierung keine verlässliche Schätzung zulassen. ${ }^{17}$

Die Befunde bzgl. der soziodemographischen und politischen Verortung antiamerikanischer Vorurteile lassen sich insgesamt wie folgt zusammenfassen: der leicht negative (allerdings nicht signifikante) Effekt von Alter auf antiamerikanische Tendenzen deutet darauf hin, dass Antiamerikanismus in beiden gemessenen Dimensionen heute auch bei jüngeren Altersgruppen Anklang findet und keineswegs einen weltanschaulichen Anachronismus darstellt. Darüber hinaus verweist der negative Effekt des Bildungsgrades darauf, dass es sich bei Antiamerikanismus nicht um ein Eliten-Vorurteil handelt, sondern er - ähnlich den meisten Vorurteilsformen - eine breite Basis in der weniger gebildeten Mehrheit aufweist, und mit zunehmendem Bildungsgrad tendenziell zurückgeht. Im Gebiet der ehemaligen DDR liegt die Zustimmung zur antiimperialistischen Dimension oberhalb derjenigen in Westdeutschland, was als weltanschauliches Erbe der SED-Propaganda gedeutet werden kann. Frauen neigen insgesamt deutlich weniger zur Reproduktion antiamerikanischer Stereotype, als männliche Befragte.

Im Gegensatz zu anderen Vorurteilsformen, so das vielleicht interessanteste Ergebnis, nimmt die Tendenz zu antiamerikanischen Sprechweisen zu beiden Seiten des politischen Spektrums zu. Diese Tendenz beschränkt sich allerdings nur auf die Extrempole der rechts-links-Skala während die moderat links und rechts Orientier-

17 Eine auf drei Ausprägungen rekodierte politische Orientierung, in der die Kategorien ,eher links" und ,eher rechts " mit der Mittelkategorie zusammengefasst wurden, erzielt als Faktor einer MANOVA mit beiden Antiamerikanismus-Skalen lediglich marginal signifikante Werte ( $\mathrm{p}=, 074 ;$ Pillai-Spur $=, 013 ; \mathrm{F}=2,137$; $\mathrm{df}$ Hypothese $=4$; df Fehler $=1298$ ). 
ten sich hinsichtlich ihres Antiamerikanismus zu einer breiten Mitte zusammenfügen. Dies spricht im Übrigen auch gegen eine Interpretation dieses Befundes nach dem Muster einer Extremismustheorie, die ungeachtet der jeweils spezifischen Semantiken und Praxen linke und rechte Positionen als gleichwertige Abweichungen von einer demokratischen ,Mitte“ auffasst (vgl. Butterwegge 2011). Vielmehr sprechen die statistischen Ergebnisse dafür, die Konvergenzen und Unterschiede in Ausformungen rechter und linker Antiamerikanismen vor dem Hintergrund zu betrachten, dass Antiamerikanismus überhaupt eine vorurteilige Rhetorik mit auffällig breiter Resonanz in der gesamten Bevölkerung Deutschlands darstellt.

An den linken und rechten Extremen der politischen Selbsteinschätzung deutet sich dann eine Tendenz zur unterschiedlichen inhaltlich-rhetorischen Ausformung ,linker' und ,rechter' Antiamerikanismen an: während politisch links identifizierte Befragte eher zu antiimperialistischer Semantik tendieren, greifen rechts identifizierte eher kulturkonservative Motive auf. Auch dieser Befund ist jedoch zweifelhaft. Er widerspricht der weithin dokumentierten Beobachtung, dass auch und gerade in rechtsradikalen Bewegungen antiimperialistisch-emanzipatorische Rhetorik eine lange Tradition hat, die zunehmend reaktualisiert wird, etwa bei rechtsradikalen Jugendbewegungen wie den sogenannten, autonomen Nationalisten“ (vgl. Schedler und Häusler 2011). Diese Annahme wird zusätzlich gestützt durch die im folgenden Kapitel berichteten Korrelationen mit rassistischen, fremdenfeindlichen und antisemitischen Äußerungen, die für antiimperialistischen Antiamerikanismus deutlich höher ausfallen, als für die kulturkonservative Dimension.

Zieht man in Betracht, dass eine Zustimmung auf den genannten VorurteilsSkalen für politisch links identifizierte Befragte durchwegs niedriger ausfällt, als für die Kategorien ,rechts‘ und ,Mitte ${ }^{18}$, so lässt der gesteigerte antiimperialistische Antiamerikanismus unter ,Linken“ auf verschiedene Subpopulationen schließen: Zwar neigen auch links-identifizierte Befragte verstärkt zur Reproduktion antiimperialistischer Amerikastereotype, aber antiimperialistischer Antiamerikanismus geht insgesamt mit einer Tendenz zu Stereotypien einher (Antisemitismus, Rassismus, Fremdenfeindlichkeit), die von Linken eher abgelehnt werden. Die hier erhobene Skala zu antiimperialistischem Antiamerikanismus kann also sowohl rechts- als auch links-politisch konnotiert sein. Bei all dem ist zu berücksichtigen, dass die berichteten Antworttendenzen in den Extremgruppen auf extrem geringen Fallzahlen beruhen. Die gegenläufigen Befunde geben aber dennoch einen Hinweis auf die

18 Die Mittelwertdifferenzen sind signifikant auf einem Niveau von $\mathrm{p}=, 05$ (einfaktorielle Varianzanalyse mit Post-Hoc-Test nach Bonferroni), mit Ausnahme der Differenz von ,Rassimus‘ zwischen ,links‘ und ,Mitte‘. Die Mittelwerte verteilen sich wie folgt:

Fremdenfeindlichkeit: ,links ${ }^{`}=1,50 ;$, Mitte $^{`}=2,03 ;$, rechts ${ }^{`}=3,05$

Rassismus: ,links' $=1,34 ;$, Mitte $^{`}=1,57 ;$, rechts $^{\circ}=2,26$

Antisemitismus: ,links' $=1,13 ;$, Mitte $^{`}=1,48 ;$, rechts ${ }^{`}=2,16$ 
Flexibilität des Gebrauches bestimmter Amerikastereotype: Offenbar kann derselbe antiimperialistische Amerikabezug im rassistischen oder antisemitischen Sprechen politisch rechter Gruppen, in der ,bürgerlichen Mitte', aber auch in linken Diskursen auftreten, die sich typischerweise gegen Rassismus und Antisemitismus positionieren.

\subsection{KorRELATIONEN VON ANTIAMERIKANISMUS UND GRUPPENBEZogener MenSCHENFEINDLICHKEIT}

Um die Bedeutung der erhobenen Antiamerikanismus-Dimensionen im Zusammenhang der etablierten Vorurteilsforschung einzuschätzen, bietet deren Beziehung $\mathrm{zu}$ anderen Vorurteilskonstrukten wichtige Anhaltspunkte. Im Folgenden werden hierzu die Korrelationen zwischen Antiamerikanismus und neun weiteren Vorurteilsmaßen diskutiert, die im Rahmen der Forschung zu ,gruppenbezogener Menschenfeindlichkeit“ (GMF) entwickelt und angewendet wurden (Heitmeyer 2002a; Zick et al. 2012). Die Itemwortlaute, Kennwerte und Verteilungen dieser Konstrukte sind in Tabelle 10 aufgeführt. Bei der Auswahl der korrelierten Maße stand die Idee im Vordergrund, zunächst explorativ einen Überblick über die Verortung antiamerikanischer Rhetorik im Zusammenhang eines Syndroms gruppenbezogener Menschenfeindlichkeit zu geben. Es wurden daher ex ante keine Hypothesen über den Zusammenhang von Antiamerikanismus mit spezifischen Vorurteilsformen formuliert. Vielmehr steht die allgemeine Annahme im Vordergrund, dass Antiamerikanismus im weiteren Rahmen vorurteiligen Sprechens eine Bedeutung hat, die in der Forschung bislang kaum systematisch bearbeitet wurde (vgl. Kap. 1 und 2).

Wie in Kapitel 5.3 beschrieben wurde, zielt das Forschungsdesign der vorliegenden Arbeit darauf ab, quantitativ aufgezeigte Zusammenhänge zwischen Antiamerikanismus und Elementen von GMF mittels qualitativ-hermeneutischer Methoden zu explizieren, d.h. Hypothesen darüber zu entwickeln, welche rhetorischen Funktionen für die gefundenen Korrelationen zwischen verschiedenen Vorurteilsformen verantwortlich sein können. Die statistischen Ergebnisse werden somit zu Explananda der qualitativ-empirisch begründeten Theoriebildung. Zentraler Ausgangspunkt sind hierbei die korrelativen Beziehungen zwischen Antiamerikanismus und anderen Vorurteilsformen. 
Tabelle 10: Relative Häufigkeiten (gültige \%) der Items zu Gruppenbezogener Menschenfeindlichkeit $(n=808)$

\begin{tabular}{|c|c|c|c|c|c|c|c|}
\hline Item & & 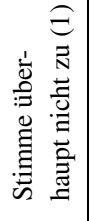 & 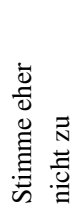 & 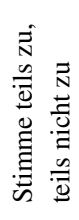 & 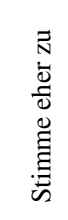 & 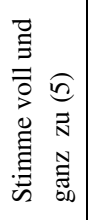 & $\begin{array}{l}\mathrm{n} \text { fehlend, } \\
\text { Mittelwert, } \\
\text { Standardab- } \\
\text { weichung }\end{array}$ \\
\hline 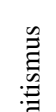 & $\begin{array}{l}\text { „Juden haben in Deutschland } \\
\text { zuviel Einfluss.“ }\end{array}$ & 68,3 & 16,1 & 9,6 & 2,9 & 3,1 & $\begin{array}{l}\mathrm{n} \text { fehlend }=57 \\
\mathrm{M}=1,56 \\
\mathrm{SD}=, 99\end{array}$ \\
\hline 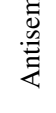 & $\begin{array}{l}\text { „Durch ihr Verhalten sind die } \\
\text { Juden an ihren Verfolgungen } \\
\text { mitschuldig.“ }\end{array}$ & 75,8 & 11,4 & 8,3 & 2,3 & 2,2 & $\begin{array}{l}\mathrm{n} \text { fehlend }=37 \\
\mathrm{M}=1,44 \\
\mathrm{SD}=, 90\end{array}$ \\
\hline$\stackrel{\mathscr{z}}{\vec{z}}$ & $\begin{array}{l}\text { „Israel führt einen Vernich- } \\
\text { tungskrieg gegen die Palästi- } \\
\text { nenser.“ }\end{array}$ & 20,8 & 20,6 & 35,9 & 12,0 & 10,7 & $\begin{array}{l}\mathrm{n} \text { fehlend }=125 \\
\mathrm{M}=2,71 \\
\mathrm{SD}=1,23\end{array}$ \\
\hline : & $\begin{array}{l}\text { „Bei der Politik die Israel } \\
\text { macht, kann ich gut verste- } \\
\text { hen, dass man etwas gegen } \\
\text { Juden hat.“ }\end{array}$ & 42,6 & 21,9 & 22,8 & 8,3 & 4,4 & $\begin{array}{l}\mathrm{n} \text { fehlend }=99 \\
\mathrm{M}=2,10 \\
\mathrm{SD}=1,17\end{array}$ \\
\hline$\frac{\omega}{\vec{z}}$ & $\begin{array}{l}\text { "Aussiedler sollten besser ge- } \\
\text { stellt werden als Ausländer, } \\
\text { da sie deutscher Abstammung } \\
\text { sind.“ } \\
\end{array}$ & 57,8 & 19,6 & 14,2 & 4,3 & 4,1 & $\begin{array}{l}\mathrm{n} \text { fehlend }=18 \\
\mathrm{M}=1,77 \\
\mathrm{SD}=1,10\end{array}$ \\
\hline$\approx \tilde{\sharp}$ & $\begin{array}{l}\text { „Die Weißen sind zu Recht } \\
\text { führend in der Welt.“ }\end{array}$ & 76,2 & 12,2 & 7,5 & 2,0 & 2,0 & $\begin{array}{l}\mathrm{n} \text { fehlend }=13 \\
\mathrm{M}=1,41 \\
\mathrm{SD}=, 87\end{array}$ \\
\hline 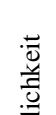 & $\begin{array}{l}\text { „Es leben zu viele Ausländer } \\
\text { in Deutschland.“ }\end{array}$ & 37,6 & 20,3 & 23,8 & 7,8 & 10,4 & $\begin{array}{l}\mathrm{n} \text { fehlend }=11 \\
\mathrm{M}=2,33 \\
\mathrm{SD}=1,33\end{array}$ \\
\hline 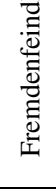 & $\begin{array}{l}\text { „Wenn Arbeitsplätze knapp } \\
\text { werden, sollte man die in } \\
\text { Deutschland lebenden Aus- } \\
\text { länder wieder in ihre Heimat } \\
\text { zurückschicken.“ }\end{array}$ & 55,7 & 21,0 & 15,4 & 3,6 & 4,2 & $\begin{array}{l}\mathrm{n} \text { fehlend }=5 \\
\mathrm{M}=1,80 \\
\mathrm{SD}=1,09\end{array}$ \\
\hline 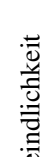 & $\begin{array}{l}\text { „Durch die vielen Muslime } \\
\text { hier fühle ich mich manchmal } \\
\text { wie ein Fremder im eigenen } \\
\text { Land.“ } \\
\end{array}$ & 37,7 & 20,8 & 22,2 & 9,6 & 9,7 & $\begin{array}{l}\mathrm{n} \text { fehlend }=18 \\
\mathrm{M}=2,33 \\
\mathrm{SD}=1,33\end{array}$ \\
\hline$\frac{\stackrel{0}{E}}{\frac{\pi}{a}}$ & $\begin{array}{l}\text { „Muslimen sollte die Zuwan- } \\
\text { derung nach Deutschland un- } \\
\text { tersagt werden.“ }\end{array}$ & 53,2 & 21,8 & 18,7 & 3,3 & 3,0 & $\begin{array}{l}\mathrm{n} \text { fehlend }=15 \\
\mathrm{M}=1,81 \\
\mathrm{SD}=1,04\end{array}$ \\
\hline
\end{tabular}




\begin{tabular}{|c|c|c|c|c|c|c|c|}
\hline \multirow{2}{*}{ 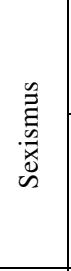 } & $\begin{array}{l}\text { „Frauen sollten sich wieder } \\
\text { mehr auf die Rolle der Ehe- } \\
\text { frau und Mutter besinnen.“ }\end{array}$ & 63,5 & 14,5 & 12,7 & 5,3 & 4,0 & $\begin{array}{l}\mathrm{n} \text { fehlend }=2 \\
\mathrm{M}=1,72 \\
\mathrm{SD}=1,12\end{array}$ \\
\hline & $\begin{array}{l}\text { "Für eine Frau sollte es wich- } \\
\text { tiger sein, ihrem Mann bei } \\
\text { seiner Karriere zu helfen, als } \\
\text { selbst Karriere zu machen.“ } \\
\end{array}$ & 73,8 & 13,0 & 9,2 & 1,7 & 2,2 & $\begin{array}{l}\mathrm{n} \text { fehlend }=7 \\
\mathrm{M}=1,46 \\
\mathrm{SD}=, 90\end{array}$ \\
\hline \multirow{2}{*}{$\begin{array}{l}\frac{0}{0} \\
0 \\
\frac{0}{2} \\
\frac{0}{0} \\
0 \\
0\end{array}$} & $\begin{array}{l}\text { „Es ist ekelhaft, wenn Homo- } \\
\text { sexuelle sich in der Öffent- } \\
\text { lichkeit küssen.“ }\end{array}$ & 61,2 & 13,0 & 10,6 & 5,6 & 9,6 & $\begin{array}{l}\mathrm{n} \text { fehlend }=7 \\
\mathrm{M}=1,90 \\
\mathrm{SD}=1,34\end{array}$ \\
\hline & $\begin{array}{l}\text { „Homosexualität ist unmora- } \\
\text { lisch.“ }\end{array}$ & 71,4 & 12,6 & 7,2 & 3,4 & 5,5 & $\begin{array}{l}\mathrm{n} \text { fehlend }=4 \\
\mathrm{M}=1,59 \\
\mathrm{SD}=1,12\end{array}$ \\
\hline \multirow{2}{*}{ 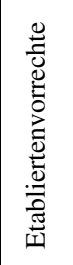 } & $\begin{array}{l}\text { „Wer irgendwo neu ist, sollte } \\
\text { sich erst mal mit weniger zu- } \\
\text { frieden geben.“ }\end{array}$ & 14,9 & 17,5 & 26,8 & 20,3 & 20,6 & $\begin{array}{l}\mathrm{n} \text { fehlend }=8 \\
\mathrm{M}=3,14 \\
\mathrm{SD}=1,33\end{array}$ \\
\hline & $\begin{array}{l}\text { „Wer schon immer hier lebt, } \\
\text { sollte mehr Rechte haben, als } \\
\text { die, die später zugezogen } \\
\text { sind.“ } \\
\end{array}$ & 47,3 & 19,1 & 17,2 & 8,6 & 7,7 & $\begin{array}{l}\mathrm{n} \text { fehlend }=7 \\
\mathrm{M}=2,10 \\
\mathrm{SD}=1,30\end{array}$ \\
\hline \multirow{2}{*}{ 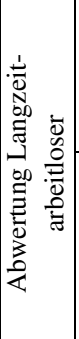 } & $\begin{array}{l}\text { „Die meisten Langzeitarbeits- } \\
\text { losen sind nicht wirklich da- } \\
\text { ran interessiert, einen Job zu } \\
\text { finden.“ }\end{array}$ & 19,6 & 18,6 & 35,1 & 12,4 & 14,3 & $\begin{array}{l}\mathrm{n} \text { fehlend }=18 \\
\mathrm{M}=2,83 \\
\mathrm{SD}=1,28\end{array}$ \\
\hline & $\begin{array}{l}\text { „Ich finde es empörend, wenn } \\
\text { sich die Langzeitarbeitslosen } \\
\text { auf Kosten der Gesellschaft } \\
\text { ein bequemes Leben ma- } \\
\text { chen.“ }\end{array}$ & 14,9 & 15,2 & 26,3 & 15,1 & 28,5 & $\begin{array}{l}\mathrm{n} \text { fehlend }=11 \\
\mathrm{M}=3,27 \\
\mathrm{SD}=1,40\end{array}$ \\
\hline
\end{tabular}

Tabelle 11 zeigt die Ergebnisse einer simultanen CFA der AntiamerikanismusSkalen und der Elemente Gruppenbezogener Menschenfeindlichkeit. Zwischen Antiamerikanismus und GMF bestehen diesen Ergebnissen zufolge deutliche, signifikante Zusammenhänge. Die Korrelationen liegen im Bereich von ,222 $\leq \mathrm{r} \leq, 546$ und bewegen sich, verglichen mit den Korrelationen unter den übrigen GMFElementen, auf einem mittleren bis niedrigen Niveau. ${ }^{19}$ Herausragend hohe Zu-

19 Beim Vergleich der Zusammenhangsgrößen ist allerdings zu berücksichtigen, dass vier der gemessenen Konstrukte sich in extremer inhaltlicher Näher zueinander befinden: Rassismus, Fremdenfeindlichkeit, Islamfeindlichkeit und Etabliertenvorrechte bilden ein nahezu perfekt korreliertes Cluster $(, 726 \leq r \geq 962)$, so dass angenommen werden kann, dass diese eher als verschiedene Aspekte derselben Fremdgruppenkonstruktion aufgefasst werden können, denn als separate Differenzkonstruktionen. Dies wird untermauert durch empirische Belege für die assoziative Nähe von ,Moslems` und ,Ausländern“ (insbesondere ,Türken`) in der Wahrnehmung der deutschen Bevölkerung, sowie die gleichzeitige 
sammenhänge mit Antiamerikanismus weisen die Konstrukte Antisemitismus, antizionistischer Antisemitismus, Rassismus und Fremdenfeindlichkeit auf.

Tabelle 11: Korrelationen zwischen Antiamerikanismus und GMF in simultaner $C F A^{20}$

\begin{tabular}{|c|c|c|c|c|c|c|c|c|c|c|}
\hline & 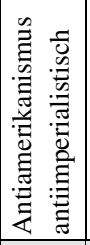 & 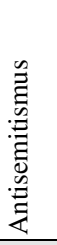 & 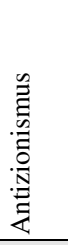 & 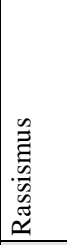 & 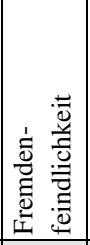 & 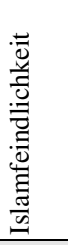 & 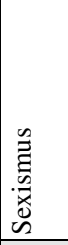 & 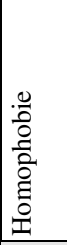 & 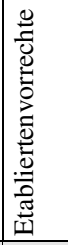 & 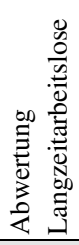 \\
\hline $\begin{array}{l}\text { Antiamerikanismus } \\
\text {,kulturkonservativ }\end{array}$ &, 774 & ,294 &, 488 &, 364 &, 247 &, 243 &, 279 &, 222 &, 303 &, 277 \\
\hline $\begin{array}{l}\text { Antiamerikanismus } \\
\text {, antiimperialistisch }\end{array}$ & - & 452 & ,486 &, 546 &, 434 &, 371 &, 333 &, 291 & 409 &, 352 \\
\hline Antisemitismus & & - & 628 & ,722 &, 652 &, 544 & ,483 &, 517 &, 537 & 428 \\
\hline Antizionismus & & & - &, 483 &, 454 & 411 & 467 &, 430 &, 515 &, 429 \\
\hline Rassismus & & & & - &, 818 &, 726 &, 718 &, 517 &, 768 &, 526 \\
\hline $\begin{array}{l}\text { Fremdenfeindlich- } \\
\text { keit }\end{array}$ & & & & & - & ,967 &, 544 &, 520 &, 826 & 619 \\
\hline Islamfeindlichkeit & & & & & & - & ,459 &, 454 &, 809 & ,644 \\
\hline Sexismus & & & & & & & - &, 572 &, 454 &, 399 \\
\hline Homophobie & & & & & & & & - &, 455 &, 323 \\
\hline Etabliertenvorrechte & & & & & & & & & - & 685 \\
\hline
\end{tabular}

Auffällig ist dabei weiterhin, dass nahezu alle genannten Konstrukte mit der antiimperialistischen Antiamerikanismus-Dimension deutlich höher korrelieren, als mit der kulturkritischen. Einzig beim antizionistischen Antisemitismus fallen die Zusammenhänge mit den beiden Antiamerikanismus-Skalen gleichermaßen hoch aus. Es scheint also, trotz pazifistischer Schlagworte, gerade der antiimperialistische Antiamerikanismus einen besonders ausgeprägten vorurteiligen Gehalt zu besitzen.

Konstruktion dieser Fremdgruppe als Bedrohung eigener sozioökonomischer Positionen (vgl. Fuchs et al. 1993).

$20 \mathrm{n}=808 ; \mathrm{Chi}^{2}=344.22 ; \mathrm{df}=197 ; \mathrm{p}<, 0001 ; \mathrm{CFI}=, 973 ;$ RMSEA $=0,030$; SRMR $=, 030$ 
Stärker als die konservative Anfeindung eines vermeintlich kulturlosen und übermäßig individualistischen Amerika ist der Bezug auf „Weltfrieden“ und ein globales „Wir“ mit vorurteiligen Sprachgebräuchen verknüpft. Dies könnte ex post einerseits durch die etwas ,aggressiveren“ Itemformulierungen der antiimperialistischen Dimension begründet werden. Andererseits liegt die Interpretation nahe, die beobachteten Zusammenhänge als vermittelt durch eine völkisch-nationalistische bzw. ethnopluralistische Weltsicht zu begreifen, in der das im Survey-Item bezeichnete „Wir" eine Gemeinschaft ethnisch identifizierter Nationen darstellt. Die Klage über eine Störung des „Weltfriedens“ durch Amerika könnte somit das Beharren auf einem ungestörten Fortwesen dieser nationalen Weltordnung bedeuten, die, wie in Kapitel 4.6 bereits expliziert, nur zu gut mit Rassismus, Fremdenfeindlichkeit, Antisemitismus und anderen diskriminierende Ungleichheitssemantiken vereinbar ist.

\subsection{ZUSAMMENFASSUNG DER STATISTISCHEN ERGEBNISSE}

Die Bereitschaft zur Reproduktion antiamerikanischer Stereotype lässt sich mit den erhobenen Instrumenten in zwei Dimensionen erfassen. Dabei können antiimperialistische und kulturkonservative Amerikastereotype inhaltlich sinnvoll und faktoranalytisch trennscharf unterschieden werden. Die beiden Dimensionen weisen eine hohe Korrelation $(r=773)$ sowie ähnliche Mittelwerte auf $(\mathrm{m}=2,52 ; \mathrm{m}=2,41)$. Inhaltlich erfasst die antiimperialistische Dimension ein antiamerikanisches Bedrohungsszenario auf globalpolitischer Ebene, das mit einer kollektiven Opferinszenierung einhergeht: Wir gegen , die Amerikaner‘. Die kulturkonservative Dimension erfasst abwertende Zuschreibungen bzgl. eines vermeintlichen Mangels an Solidarität und gemeinschaftlichen Werten sowie kultureller Tradition und Authentizität in der amerikanischen Gesellschaft.

Aufgrund der vorliegenden Daten kann von einer weitreichenden Verbreitung potentiell antiamerikanischer Stereotype in der deutschen Bevölkerung ausgegangen werden: Ca. 9 Prozent (,antiimperialistisch') bzw. 15 Prozent (,kulturkonservativ ${ }^{\star}$ ) der Befragten weisen gesteigerte Zustimmungswerte auf (mehr als eine Standardabweichung über dem Skalenmittel).

Dass das in den Surveydaten dokumentierte Verhalten tatsächlich auf eine weithin vorhandene Neigung zu antiamerikanischem Sprechen schließen lässt (nicht bloß auf die Verbreitung bestimmter Amerikabilder), wird durch die korrelativen Beziehungen zu anderen Vorurteilsmaßen bekräftigt: die Korrelationen mit Elementen des Syndroms gruppenbezogener Menschenfeindlichkeit liegen insgesamt im mittleren Bereich (,222 $\leq \mathrm{r} \leq, 546)$, was nahelegt, dass Antiamerikanismus im weiteren Rahmen vorurteiliger Rede eine erhebliche Rolle spielt. Besonders auffällig sind hierbei die Korrelationen mit Rassismus, Antisemitismus, antizionistischem 
Antisemitismus und Fremdenfeindlichkeit. Während die Assoziation mit antisemitischen bzw. antizionistischen Sprechweisen aufgrund bestehender Theoriebildung nachvollziehbar erscheint (Markovits 2005; Diner 2003; Holz 2005) und vorherige empirische Befunde repliziert (Beyer und Liebe 2010; Knappertsbusch und Kelle 2010), sind insbesondere die Verknüpfungen mit rassistischen und fremdenfeindlichen Rhetoriken erklärungsbedürftig. Es nehmen daher diese rhetorischen Funktionen eine besondere Rolle als Ausgangspunkt für die qualitative Phase des Forschungsprojektes ein. Wie die Ergebnisdarstellung in Kapitel 7 zeigt, konnten in den Interviewanalysen tatsächlich vor allem hinsichtlich des Zusammenspiels antiamerikanischer, rassistischer, fremdenfeindlicher und nationalistischer Rhetoriken Deutungsansätze entwickelt werden.

Soziodemographische und regionale Unterschiede in der Zustimmung zu den abgefragten Antiamerikanismus-Skalen zeigen sich zwischen west- und ostdeutschen Befragten, zwischen unterschiedlichen formalen Bildungsniveaus sowie der politischen Selbstverortung der Teilnehmenden. So neigen Befragte aus den Gebieten der ehemaligen DDR eher zur Zustimmung auf der antiimperialistischen Antiamerikanismus-Dimension, während westdeutsche Länder eine gegenläufige Tendenz zeigen. Dies kann als Nachhall antiamerikanischer SED-Parteidoktrin gelesen werden. Dennoch ist diese ex post Hypothese aufgrund der minimalen (wenngleich signifikanten) Mittelwertunterschiede nur unter Vorbehalt zu formulieren. Hinsichtlich des Bildungsniveaus zeigt sich der vielfach replizierte negative Effekt formaler Bildungsabschlüsse auf vorurteiliges Antwortverhalten, wobei dieser Effekt für die kulturkonservative Dimension leicht abgemildert vorliegt: Gruppen mit hohem und mit niedrigem Bildungsniveau fallen hier gegenüber der mittleren Gruppe leicht ab. Dies kann als Bekräftigung der Lingua-Franca-These gelesen werden, die eine über sozioökonomische, politische und kulturelle Grenzen hinweg gleichermaßen starke Verbreitung von Antiamerikanismus annimmt.

Zusätzliche bekräftigende Hinweise für diese These liefert die Analyse der Mittelwertdifferenzen zwischen verschiedenen politischen Orientierungen. Hierbei ist zunächst festzuhalten, dass sich auf einer fünfwertigen Skala der politischen Selbsteinschätzung mit den Extrempolen „rechts“ und ,links“ gesteigerte Zustimmungstendenzen nur für die jeweiligen Extrempole feststellen lassen, während zwischen den mittleren drei Kategorien keine nennenswerten Unterschiede bestehen. Bzgl. der erhobenen antiamerikanischen Tendenzen besteht kein signifikanter Unterschied zwischen den politischen Lagern. Hinsichtlich der linken und rechten Extremgruppen ist dennoch bemerkenswert, dass links-identifizierte Befragte eine stärkere Tendenz zu antiimperialistischen Bildern aufweisen, rechts-identifizierte hingegen stärker zur kulturkonservativen Dimension neigen. Dieser Befund mag auf den ersten Blick einleuchten, aufgrund alltagstheoretischer Annahmen über den politisch ,linken“ Charakter antiimperialistischer Positionen, wird aber konterkariert durch eine besonders hohe Korrelation von antiimperialistischem Antiamerikanis- 
mus mit Rassismus, Fremdenfeindlichkeit und Antisemitismus, denen von politisch , links‘ identifizierten signifikant weniger zugestimmt wird. Diese Ergebnisse sind aufgrund der fehlenden statistischen Bedeutsamkeit bzw. geringer Fallzahlen in den Extremgruppen wenig aussagekräftig (rechts $n=19$; links $n=39$ ). Sie können aber als Hinweis auf die Flexibilität des Gebrauchs von Amerikaklischees gelten, die offenbar sowohl im Kontext eines linken Antiimperialismus als auch im Kontext eines rechten oder politisch , mittigen“ Ethnozentrismus auftreten.

Insgesamt kann aufgrund der Surveydaten angenommen werden, dass antiamerikanische Sprechweisen heute in der deutschen Bevölkerung über politische und Klassengrenzen hinweg weitläufig reproduziert werden. ${ }^{21}$ Einen wichtigen Hinweis auf den vorurteiligen Gehalt der abgefragten Amerikastereotype, d.h. deren Funktionalität im Rahmen von Ungleichheitssemantiken, geben dabei die Korrelationen mit anderen Vorurteilsformen. Hierbei stechen insbesondere die Zusammenhänge mit rassistischen, fremdenfeindlichen und antisemitischen Motiven ins Auge, die als statistische Explananda in den qualitativen Strang der vorliegenden Untersuchung eingehen.

21 Ein fehlender negativer Effekt des Alters der Befragten auf die Zustimmung zu den Antiamerikanismus-Skalen lässt auf eine große historische Kontinuität der abgefragten Amerikastereotype schließen. Über den Wandel, den die praktische Bedeutung dieser Bilder erfahren haben mag, kann auf dieser Grundlage freilich wenig ausgesagt werden (vgl. Baethge et al. 2010, S. 366 f.). 



\section{Ergebnisdarstellung der qualitativen Empirie}

\subsection{EINLEITUNG}

Die statistischen Analysen des vorherigen Kapitels legen nahe, dass gut ein Zehntel der deutschen Bevölkerung eine gesteigerte Tendenz $\mathrm{zu}$ antiamerikanischen Sprechweisen zeigt. Die interne Konsistenz des gebrauchten Instrumentes sowie dessen Korrelationen mit anderen Vorurteilsformen deuten darauf hin, dass sich hinter den statistischen Beobachtungen ein überindividuell geteilter Pool antiamerikanischer Rhetoriken verbirgt. Der lexikalisch-semantische Gehalt der SurveyItems lässt aber nur eine sehr grobe Einschätzung darüber zu, wie diese antiamerikanische Rhetorik wirklich aussieht. Welche (unterschiedlichen) argumentativen Funktionen werden mit Amerikastereotypen erfüllt und in welche Gebrauchskontexte sind diese eingebettet? Verbergen sich hinter der Konsistenz der Surveyantworten tatsächlich auch konsistente antiamerikanische Weltanschauungen? Und wie lassen sich die Zusammenhänge zwischen Antiamerikanismus und anderen Vorurteilsformen verstehen? Wie funktioniert die Einbindung des Antiamerikanismus in ein „Syndrom gruppenbezogener Menschenfeindlichkeit“ (Zick et al. 2012)?

In den folgenden Teilkapiteln werden Rekonstruktionen antiamerikanischer Sprechweisen aus $n=9$ Interviews präsentiert (davon $n=6$ aus dem Surveysample der Hauptstudie). Auf der Datengrundlage dieser 9 Fälle konnte eine Familie antiamerikanischer Sprechakte rekonstruiert werden, deren performative Wirkungen sich nach drei Funktionskontexten gliedern lassen: Nationale Identität, Erinnerungspolitik und Antisemitismus sowie Ethnozentrismus und Rassismus. Die Gliederung der folgenden Ergebnisdarstellung entspricht dieser Einteilung von Funktionskontexten, wenngleich zwischen allen dreien empirisch keine scharfen Grenzen zu ziehen sind. Vielmehr gruppieren sich alle hier versammelten Antiamerikanismen um Konstruktionen nationaler bzw. ethno-nationaler Identität, in deren Rahmen sie verschiedene Funktionen der Konturierung, Aufwertung und Stabilisierung erfüllen. Die Korrelationen zwischen Antiamerikanismus, Rassismus, Ethnozentrismus und Antisemitismus werden vor allem in den Kapiteln $7.3 \mathrm{zu}$ Erinnerungspolitik und $7.4 \mathrm{zu}$ Eth- 
nozentrismus als Explananda aufgegriffen, wobei die Grundannahme ist, dass sich die verschiedenen Vorurteilsformen rhetorisch-funktional ergänzen.

Im Teilkapitel 7.5 wird schließlich noch einmal dezidiert auf die Frage der Konsistenz und weltanschaulichen Geschlossenheit antiamerikanischer Vorurteile eingegangen. Hierbei werden zwei Interviewbeispiele herangezogen, die in unterschiedlicher Hinsicht als Grenzfälle einer rhetorischen Antiamerikanismusbestimmung gelten können. So lässt sich an ihnen einerseits die Möglichkeit der Fragmentierung und Ambivalenz antiamerikanischer Vorurteilsausdrücke nachvollziehen. Andererseits verweist einer der beiden Fälle auf die unscharfen Ränder einer rhetorisch-funktionalen Antiamerikanismusbestimmung, da der Gebrauch von Amerikastereotypen hier trotz großer funktionaler und semantischer Überschneidungen mit anderen Fällen nicht im Zusammenhang diskriminierender Identitätskonstruktionen zu stehen scheint.

Um die Lesbarkeit und Nachvollziehbarkeit der Detailanalysen zu erhöhen, werden im Folgenden zunächst noch einmal drei zentrale Kategorien der Ergebnispräsentation zusammengefasst: Amerikabilder, Funktionskontexte und rhetorische Funktionen. Darauf folgt eine Überblicksdarstellung der im Material gefundenen Amerikastereotype bzw. der fallübergreifend gebildeten Kategorien, mit denen diese gesammelt wurden. Wie in Kapitel 5.6 dargestellt wurde, bilden diese Amerikabezüge im Interviewmaterial die Ausgangsbasis der Analyse.

\subsubsection{Zentrale Begriffe der Ergebnisdarstellung}

Amerikabilder, -Stereotype und -Semantiken: Diese Begriffe werden synonym zur Bezeichnung der semantischen Motive gebraucht, die in antiamerikanischen Sprechakten rhetorische Funktionen erfüllen können (vgl. Kap. 2.4). Hierunter fallen zunächst alle Zuschreibungen auf ,die USA'bzw. ,die Amerikaner', die im Interviewmaterial beobachtet wurden. In der Auswertung wurden für jedes Interview separat die Amerikabezüge fallspezifisch codiert und anschließend zu fallvergleichenden Kategorien zusammengefasst (vgl. Kap. 5.6 zum methodischen Vorgehen der qualitativen Analysen). Wenn in den Auswertungen bspw. auf Stereotype der ,Gewalttätigkeit‘, der ,amerikanischen Weltpolizei“ oder der ,Heterogenität“ der USA referiert wird, so meint dies immer Sequenzen, die in eine der fallvergleichenden Kategorien für Amerikabilder eingeordnet wurden.

Funktionskontexte: Als Funktionskontexte werden die rhetorischen Zusammenhänge bezeichnet, in denen amerikabezogene Sprechweisen als funktional und somit als vorurteilig bzw. antiamerikanisch gedeutet werden. Es werden dabei drei Themenkomplexe unterschieden: Nationalismus und nationale Identität, Schuldabwehr und Antisemitismus sowie Ethnozentrismus und Rassismus. Die Gliederung der folgenden drei Kapitel folgt dieser Einteilung von Funktionskontexten. Die 
Themenkomplexe leiten sich aus der in Kapitel 4 entwickelten Theoriegrundlage $\mathrm{ab}$, gemäß der Vorurteile als Differenzkonstruktionen im funktionalen Zusammenhang mit sozialer Ungleichheit und Diskriminierung begriffen werden.

Rhetorische Funktionen: Innerhalb eines gegebenen Funktionskontextes können antiamerikanische Sprechweisen verschiedene rhetorische Funktionen erfüllen, wie etwa die Konturierung oder Stabilisierung einer Wir-Gruppenkonstruktion oder die Bearbeitung normativer Dilemmata. Innerhalb dieser Funktionen können teilweise wiederum wichtige Unterscheidungen getroffen werden, wie bspw. zwischen manifesten und latenten Formen der Schuldabwehr- bzw. Normalisierungsrhetorik (vgl. Kap. 7.3). Die verschiedenen argumentativen Gebrauchsweisen werden als rhetorische Funktionen antiamerikanischen Sprechens bezeichnet.

\subsection{2 Überblicksdarstellung der Amerikabilder im Interviewmaterial}

Den Ausgangspunkt der qualitativ-empirischen Analysen bildete eine Sammlung aller Zuschreibungen auf ,Amerikaner' oder ,die USA“ im untersuchten Material. Diese zunächst fallspezifisch codierten und anschließen fallübergreifend kategorisierten Amerika-Semantiken werden in Tabellen 12 und 13 zusammengefasst. Die Materialgrundlage bilden hierbei nicht die gesamten $n=22$ analysierten Fälle, sondern nur die in diesem Kapitel dargestellten Detailanalysen $(n=9)$. Das bedeutet, dass alle aufgeführten Amerikabilder in Sprachgebräuchen auftreten, die im Zuge der Detailanalysen als antiamerikanisch eingeordnet wurden (mit Ausnahme der Fälle von Herrn I und Frau H, die als fragmentierte bzw. nicht eindeutig klassifizierbare Rhetoriken interpretiert wurden, vgl. Kap. 7.5).

Allein an der Vielzahl der fallübergreifenden Kategorien wird erkennbar, dass bei der Kategorienbildung größeres Gewicht auf die Heterogenität der beobachteten Amerikastereotype gelegt wurde, als auf die synthetisierende Zusammenfassung der Codings in wenigen Kategorien. Gleichwohl haben nahezu alle Kategorien eine fallvergleichend-zusammenfassende Funktion, insofern sie Codings aus mindestens zwei Interviewtranskripten umfassen (mit Ausnahme der Kategorien USA und Israel, Atombombe und 9/11 Inside Job).

Durch die thematische Breite der getroffenen Zuschreibungen wird zunächst der in der Antiamerikanismusforschung häufig wiederholte Befund bekräftigt, dass im Antiamerikanismus ein inhaltlich weit gefächertes Set an Stereotypen gebraucht wird, welches auf verschiedenste gesellschaftliche Aspekte der USA Bezug nimmt (vgl. Jaecker 2014; S. 16 ff.; Markovits 2007, S. 81 ff.). So ließen sich die hier gebildeten Stereotypen-Kategorien z.B. gemäß der gängigen Unterscheidung politischer, ökonomischer und kultureller Gesellschaftsbereiche einteilen (vgl. Beyer 2014, S. 22 und 200; Jaecker 2014, S. 5 f.). Schon unter den ersten zehn am häu- 
figsten beobachteten Stereotypen (vgl. Tabelle 13) sind alle drei Kategorien vertreten: Das Bild einer , amerikanischen Weltpolizei` sowie einer überheblichen Einmischung in Angelegenheiten anderer Nationen prägt die politischen Zuschreibungen auf ,die Amerikaner'; das ökonomische Amerikabild scheint von Vorstellungen eines falschen oder ausbeuterischen Wirtschafts- und Finanzsystems dominiert zu sein; Kultur und Gesellschaft der USA werden als oberflächlich und bindungslos dargestellt. Es findet sich also auch in den hier analysierten Daten der häufig beschriebene Facettenreichtum von Amerikabildern im Antiamerikanismus - zumindest auf fallvergleichender Ebene.

Tabelle 12: Auflistung aller antiamerikanisch gebrauchten Amerikabilder mit Interviewbeispielen, geordnet in absteigender Reihenfolge nach Häufigkeit der codierten Fälle.

\begin{tabular}{|l|l|}
\hline $\begin{array}{l}\text { Kategorie } \\
\text { Amerikabild }\end{array}$ & Interviewbeispiel \\
\hline $\begin{array}{l}\text { Einmischung und } \\
\text { Weltpolizei }\end{array}$ & $\begin{array}{l}\text { Ja, also weil sie überall äh::: meinen, in jedem Land präsent sein zu müs- } \\
\text { sen, und praktisch die halbe Welt mit Krieg überziehen, ja? (Frau K) }\end{array}$ \\
\hline $\begin{array}{l}\text { Arroganz und } \\
\text { Überheblichkeit }\end{array}$ & $\begin{array}{l}{[\ldots] \text { mittlerweile sind andere (.) Staaten (.) auf der Welt kräftiger, stärker }} \\
\text { geworden, und der Ami hat, ist immer noch der Meinung, auf seine Rech- } \\
\text { te pochen zu können, und - ja, wie gesagt, immer noch der Mittelpunkt } \\
\text { der Welt zu sein. (Herr A) }\end{array}$ \\
\hline $\begin{array}{l}\text { Amerikanische } \\
\text { Kultur, }\end{array}$ & $\begin{array}{l}\text { Die haben gar keine. (lacht) Also die Kultur, wenn man, man das versteht } \\
\text { als Denker und Dichter, was hier Deutschland in den letzten 200, 300 Jah- } \\
\text { Kulturlosigkeit oder noch viel länger [...], das hat es in den USA nicht so gegeben. } \\
\text { Weil die USA ist ein Mischmasch von Kulturen! (Herr A) }\end{array}$ \\
\hline Amerikanisierung & $\begin{array}{l}\text { Und das ist ja auch alles von Amerika gekommen, was wir in Deutsch- } \\
\text { land haben, ist ja... Wenn wir überlegen, die letzten Jahre, wie wir Millio- } \\
\text { näre dazu genommen haben. Ja. Genau so viele Millionäre hinzugekom- } \\
\text { men, wie, wie, wie, wie Arme dazugekommen sind. (Herr C) }\end{array}$ \\
\hline Heterogenität USA & $\begin{array}{l}\text { Den Amerikaner als Solches gibt`s ja gar nicht. Das ist so ein Schmelztie- } \\
\text { gel an Kulturen. Ja. Da kommen irgendwelche Latinos, da kommen Asia- } \\
\text { ten. Dann mal der Uramerikaner, wobei der Uramerikaner eigentlich der } \\
\text { Indianer ist, und die Jungs, die sich Uramerikaner schimpfen, die kom- } \\
\text { men auch aus Europa. (Herr F) }\end{array}$ \\
\hline
\end{tabular}




\begin{tabular}{|c|c|}
\hline $\begin{array}{l}\text { Oberflächlichkeit, Be- } \\
\text { ziehungsunfähigkeit }\end{array}$ & $\begin{array}{l}\text { [...] man merkt es dann schon, dass das alles mehr so oberflächlich ist. } \\
\text { Man unterhält sich, man geht aus was trinken, aber mehr ist da nicht. } \\
\text { Wenn einer wegzieht nur fünf M-, fünf Meilen weg, dann sieht der An- } \\
\text { dere den nie mehr wieder. (Herr E) }\end{array}$ \\
\hline Rassismus in den USA & $\begin{array}{l}{[\ldots] \text { diese Ungerechtigkeit irgendwie dann, naja, also auch Schwarzen }} \\
\text { gegenüber. Also die werden da ja als erste schuldig angesehen, und so } \\
\text { weiter, ne. So was hört man ja immer wieder, ne? (Frau K) }\end{array}$ \\
\hline $\begin{array}{l}\text { Unrecht amerikani- } \\
\text { sche Ureinwohner }\end{array}$ & $\begin{array}{l}\text { [...] wie ich das in Erinnerung habe, waren`s da die Indianer, die doch } \\
\text { des Land gehabt haben und dann sind alle, }[\ldots] \text { rüber gewandert sind } \\
\text { nach Amerika. [...] von allen Ländern sind die damals doch mit den } \\
\text { Schiffen rüber nach Amerika, weil sie meinten, da gibt`s Geld. [...] } \\
\text { Und haben durch des ja auch die Indianer verdrängt, aus ihrem Land } \\
\text { raus. (Frau H) }\end{array}$ \\
\hline $\begin{array}{l}\text { Falsches Wirts } \\
\text { system }\end{array}$ & $\begin{array}{l}\text { Auch die ganzen Heuschrecken, Hedgefonds, das, das, das sind halt } \\
\text { amerikanische Konstrukte. Ja, ähm, der Kapitalismus, so wie ihn den, } \\
\text { so wie ihn die Amerikaner betreiben, der ist halt, ja, der ist halt einfach } \\
\text { krass. Also die nehmen keine Rücksicht. (Herr F) }\end{array}$ \\
\hline $\begin{array}{l}\text { Bildung, Dummheit, } \\
\text { Naivität }\end{array}$ & $\begin{array}{l}{[\ldots] \text { in Amerika werden die Leute eher dumm gehalten [...], der durch- }} \\
\text { schnittliche Amerikaner kann nicht wirtschaftlich denken oder handeln, } \\
\text { das geht nicht, das hat der noch nie gelernt, hat er auch noch nie was } \\
\text { von gehört und wenn man mit ihm über so was spricht, der guckt einen } \\
\text { dann ganz verwundert an (Herr E) }\end{array}$ \\
\hline Soziale Ungle & $\begin{array}{l}\text { Die Geldpolitik ist die zweite Frage [...]. Wenn es jetzt auch geht um } \\
\text { die Vermögenssteuer, der Reichensteuer, äh, und das Geld ist ja in } \\
\text { Amerika noch mal ganz anders, weil ja die Schere zwischen arm und } \\
\text { reich noch viel größer ist. (Herr C) }\end{array}$ \\
\hline $\begin{array}{l}\text { Manipulation öffentli- } \\
\text { cher Diskurse }\end{array}$ & $\begin{array}{l}\text { Und dass die Amerikaner jetzt einzig und allein unser, äh, Schulbil- } \\
\text { dungssystem, äh, praktisch so vorschreiben von klein auf an, was wir } \\
\text { wissen dürfen, was wir nicht wissen dürfen. Dass heute noch Akten } \\
\text { über einen Weltkrieg geheim gehalten werden, der praktisch schon ein } \\
\text { halbes Jahrhundert zurückliegt [...]. (Herr B) }\end{array}$ \\
\hline Amerikanisches Recht & $\begin{array}{l}\text { [...] allein was die Rechtssicherheit der Bevölkerung gegenüber dem } \\
\text { Staat angeht, ist das in Deutschland... Na, anders rum, ist das in den } \\
\text { USA dermaßen eklatant schlechter. Ja. Das kann man sich gar nicht } \\
\text { vorstellen. (Herr F) }\end{array}$ \\
\hline
\end{tabular}




\begin{tabular}{|c|c|}
\hline $\begin{array}{l}\text { Unehrlichkeit, } \\
\text { Unzuverlässigkeit, } \\
\text { Untreue }\end{array}$ & $\begin{array}{l}\text { Unzuverlässig, ne, und Freundschaft, immer gut, ja, Freundschaft ist } \\
\text { immer gut, aber wenn du sie brauchst, sind sie nicht da, ne. Deswegen. } \\
\text { Darum will ich mit den Amerikanern eigentlich weniger zu tun haben, } \\
\text { ne, ne. (Herr D) }\end{array}$ \\
\hline Anglizismen & $\begin{array}{l}\text { Aber das wir im Sprachgebrauch... Wer nicht äh irgendwie im, im Satz } \\
\text { ein amerikanischen Sa- Wort drin hat, äh, äh, äh, das ist ja nicht mehr } \\
\text { in! (Herr C) }\end{array}$ \\
\hline $\begin{array}{l}\text { Wirtschaftliche } \\
\text { Inkompetenz, } \\
\text { sinnloser Konsum }\end{array}$ & $\begin{array}{l}{[\ldots] \text { die haben alle mehrere Kreditkarten und die waren alle maxed out, }} \\
\text { also die waren bis auf den Anschlag am Limit, und im Moment ist es } \\
\text { so, [...] da kriegt kaum, so gut wie kein Mensch mehr einen Kredit } \\
\text { durch, weil sie alle hochgradig verschuldet sind [...]. (Herr E) }\end{array}$ \\
\hline $\begin{array}{l}\text { Illoyale Deutsche, } \\
\text { Auswanderung }\end{array}$ & $\begin{array}{l}\text { Und der Gottschalk verdient damit [i.e. Gummibärchen, F.K.] richtig } \\
\text { Geld, der braucht nicht mal mehr „Wetten, dass...“ machen. Sein } \\
\text { Schloss hat er nun gezahlt, ja, ist ja wieder nach Deutschland zurückge- } \\
\text { kommen. Und, äh, damit bin ich auch nicht einverstanden, ja. (Herr C) }\end{array}$ \\
\hline USA und Israel & $\begin{array}{l}\text { Die Amerikaner wird, werden, wird von den, von Israel äh, praktisch } \\
\text { zum großen Teil dirigiert. [...] die haben ja also eine ganze, eine riesen } \\
\text { Abteilung in Amerika, ne? In der Politik, ne? (Frau K) }\end{array}$ \\
\hline $\begin{array}{l}\text { Aggressivität, } \\
\text { Gewalt }\end{array}$ & $\begin{array}{l}\text { Ja ach ey, die Amerikaner sind halt einfach so, ich mein, da kann man } \\
\text { mit sechszehn Alter, einfach eine Shotgun haben und direkt drauf ge- } \\
\text { hen, ja? Also, was soll ich dazu sagen? (Herr I) }\end{array}$ \\
\hline Anstiftung Kriege & $\begin{array}{l}\text { Aber das ist auch äh, in, in Amerika so. Die müssen also die äh Kriege } \\
\text { anzetteln, damit die Waffenindustrie, äh, äh, gut läuft. Ne? (Frau K) }\end{array}$ \\
\hline $\begin{array}{l}\text { Mangelnde Sittlich- } \\
\text { keit }\end{array}$ & $\begin{array}{l}\text { Wie die Wohnung ausgeschaut hat. (.) Aus einer Wohnung haben sie } \\
\text { mal zehn Kubik Müll... Und das war ein Ami, ein Ami mit drei Kin- } \\
\text { dern. Also... Und nur, die haben nur auf Säcken geschlafen, die Kinder. } \\
\text { Auf Müll. (Herr D) }\end{array}$ \\
\hline Atombombe & $\begin{array}{l}\text { Wenn der Hitler nicht gewesen wäre, hätte es das [i.e. den Holocaust, } \\
\text { F.K.] überhaupt nicht gegeben. Ne. Aber da müssen wir, müssen wir } \\
\text { wieder einmal anfangen, ne, was, was, was die Amerikaner mit den Ja- } \\
\text { panern gemacht haben! Mit ihrer Hiroshima-Bombe! (Herr D) }\end{array}$ \\
\hline 9/11 Inside Job & $\begin{array}{l}\text { Amerika hat eine riesen, ähm, Militärapparat, Amerika hat ein riesen, } \\
\text { äh, Geheimdienstnetz, ähm, und die waren [...] trotzdem nicht in der } \\
\text { Lagen, äh ähm, ähm, ähm, ähm, vielleicht auch vier riesige Passagier- } \\
\text { flugzeuge [...] aufzuhalten? Also weiß ich nicht, was ich davon halten } \\
\text { soll. (Herr B) }\end{array}$ \\
\hline
\end{tabular}


Auf eine systematische Zusammenfassung der vorhandenen Kategorien auf lexikalisch-semantischer Grundlage wird an dieser Stelle bewusst verzichtet. Der Grund dafür ist, dass eine solche Kategorisierung zwar zunächst einen besseren Überblick über die gesammelten Stereotype bieten mag, über deren praktische Bedeutung im beobachteten Sprachgebrauch aber kaum etwas aussagt. ${ }^{1}$ Genau auf diese praktische Bedeutung kommt es aber einem performativen Antiamerikanismusbegriff an. Die lexikalische Bedeutung von Amerikastereotypen lässt demzufolge keinerlei direkte Rückschlüsse auf den antiamerikanischen Sinngehalt vorurteiliger Äußerungen zu. Verbleibt die Analyse auf dieser lexikalisch-semantischen Ebene, droht sie den Sinngehalt antiamerikanischen Sprechens ggf. sogar eher zu verschleiern, als genauer zu erschließen. Zwar ist es ein interessanter Befund, dass in antiamerikanischem Sprechen generell auf Stereotype aus einem breit gefächerten Themenspektrum zurückgegriffen wird. Die weitaus wichtigere Frage ist aber, welche Stereotype $\mathrm{zu}$ welchen rhetorischen Zwecken gebraucht werden, und ob dieser Stereotypengebrauch tatsächlich mit der Konsistenz und thematischen Breite erfolgt, die eine fallübergreifende Stereotypensammlung zunächst suggeriert.

Tabelle 13: Häufigkeiten der antiamerikanisch gebrauchten Amerikabilder,in absteigender Reihenfolge nach Häufigkeit der codierten Fälle

\begin{tabular}{|c|c|c|c|c|c|c|c|c|c|c|c|}
\hline \multirow{2}{*}{$\begin{array}{l}\text { Kategorie } \\
\text { Amerikabild }\end{array}$} & \multirow{2}{*}{$\begin{array}{l}\mathrm{n} \\
\text { Fälle }\end{array}$} & \multirow{2}{*}{$\begin{array}{l}\mathrm{n} \\
\text { Codings }\end{array}$} & \multicolumn{9}{|c|}{ n Codings fallweise } \\
\hline & & & I & $\mathrm{D}$ & K & A & B & $\mathrm{C}$ & E & $\mathrm{H}$ & $\mathrm{F}$ \\
\hline $\begin{array}{l}\text { Arroganz und } \\
\text { Überheblichkeit }\end{array}$ & 7 & 10 & 1 & - & - & 2 & 1 & 1 & 1 & 2 & 2 \\
\hline $\begin{array}{l}\text { Einmischung und } \\
\text { Weltpolizei }\end{array}$ & 6 & 13 & - & 2 & 4 & 1 & 3 & 1 & - & - & 2 \\
\hline Amerikanisierung & 5 & 13 & - & - & - & 2 & 4 & 3 & - & 1 & 3 \\
\hline Heterogenität USA & 5 & 10 & - & - & - & 2 & - & 2 & 1 & 2 & 3 \\
\hline $\begin{array}{l}\text { Amerikanische Kultur, } \\
\text { Kulturlosigkeit }\end{array}$ & 5 & 8 & - & 1 & - & 2 & - & 2 & 1 & - & 2 \\
\hline $\begin{array}{l}\text { Oberflächlichkeit, } \\
\text { Beziehungsunfähigkeit }\end{array}$ & 5 & 7 & 1 & 3 & 1 & - & - & - & 1 & - & 1 \\
\hline Rassismus in den USA & 5 & 7 & - & 1 & 1 & 2 & - & 2 & 1 & - & - \\
\hline
\end{tabular}

1 Vgl. dazu Kapitel 2.3.1, insbesondere Klaus Holz’ Kritik ,subsumtionslogischer Interpretation“ (Holz 2001, S. 121 f.). 


\begin{tabular}{|c|c|c|c|c|c|c|c|c|c|c|c|}
\hline Kategorie & & & & odir & $\mathrm{s}$ fa & we & & & & & \\
\hline Amerikabild & Fälle & Codings & I & D & K & A & B & $\mathrm{C}$ & $\mathrm{E}$ & $\mathrm{H}$ & $\mathrm{F}$ \\
\hline $\begin{array}{l}\text { Falsches } \\
\text { Wirtschaftssystem }\end{array}$ & 4 & 11 & - & - & 1 & - & 2 & 2 & - & - & 6 \\
\hline $\begin{array}{l}\text { Bildung, Dummheit, } \\
\text { Naivität }\end{array}$ & 4 & 7 & 3 & - & - & - & 1 & - & 1 & - & 2 \\
\hline Soziale Ungleichheit & 4 & 7 & - & - & 1 & - & 1 & 3 & - & - & 2 \\
\hline Amerikanisches Recht & 4 & 5 & - & - & 2 & - & - & 1 & - & 1 & 1 \\
\hline $\begin{array}{l}\text { Unrecht amerikanische } \\
\text { Ureinwohner }\end{array}$ & 4 & 5 & - & - & - & - & 1 & 1 & - & 2 & 1 \\
\hline $\begin{array}{l}\text { Unehrlichkeit, Unzuverläs- } \\
\text { sigkeit, Untreue }\end{array}$ & 3 & 6 & - & 4 & - & - & - & - & 1 & - & 1 \\
\hline $\begin{array}{l}\text { Manipulation öffentlicher } \\
\text { Diskurse }\end{array}$ & 3 & 5 & - & - & - & - & 3 & 1 & - & 1 & - \\
\hline Anglizismen & 3 & 4 & - & - & - & - & 2 & 1 & - & - & 1 \\
\hline $\begin{array}{l}\text { Wirtschaftliche Inkompe- } \\
\text { tenz, sinnloser Konsum }\end{array}$ & 3 & 4 & - & - & - & - & - & - & 2 & 1 & 1 \\
\hline $\begin{array}{l}\text { Illoyale Deutsche, Auswan- } \\
\text { derung }\end{array}$ & 3 & 3 & - & 1 & - & - & - & 1 & - & 1 & - \\
\hline Aggressivität, Gewalt & 2 & 5 & 1 & 4 & - & - & - & - & - & - & - \\
\hline Anstiftung Kriege & 2 & 4 & - & - & 3 & - & - & - & 1 & - & - \\
\hline Mangelnde Sittlichkeit & 2 & 2 & - & 1 & - & - & - & - & - & 1 & - \\
\hline USA und Israel & 1 & 9 & - & - & 9 & - & - & - & - & - & - \\
\hline Atombombe & 1 & 1 & - & 1 & - & - & - & - & - & - & - \\
\hline 9/11 Inside Job & 1 & 1 & - & - & - & - & 1 & - & - & - & - \\
\hline
\end{tabular}

Die Detailanalysen der folgenden Kapitel 7.2 bis 7.5 werden zeigen, dass stereotype Darstellungen ,der USA' bzw. ,der Amerikaner' selten en bloc als weltanschauliches Schema auftreten, sondern vielmehr einzelne Amerikabilder zu bestimmten rhetorischen Zwecken gebraucht werden. Zwar bleibt dabei eine gewisse Flexibilität oder „Austauschbarkeit“ (Baethge et al. 2010, S. 377; vgl. auch Kap. 2.3.3) der 
gebrauchten Bilder bestehen, so dass keine eindeutige Systematik von Funktionen und korrespondierenden Semantiken rekonstruiert werden kann. Als undifferenzierter ,Amerikahass' oder weltanschauliches Schema, in dem alle nur erdenklichen Aspekte amerikanischer Ökonomie, Kultur und Politik zusammenfließen, kann Antiamerikanismus jedoch ebenso wenig begriffen werden. 


\subsection{ANTIAMERIKANISMUS IN FUNKTIONSKONTEXTEN NATIONALER IDENTITÄT}

In diesem Teil werden anhand zweier Interviewanalysen (Herr C und Herr F) Funktionen antiamerikanischer Rhetorik im Rahmen nationaler Identifikation aufgezeigt. Hierbei lassen sich grob zwei Modi von Identitätsfunktionen unterscheiden. Zum einen findet sich sowohl bei Herrn $\mathrm{C}$ als auch bei Herrn $\mathrm{F}$ eine Konturierung und relative Aufwertung der Eigengruppe mittels amerikabezogener Vergleiche. ,Amerika' wird als negative Vergleichsfolie herangezogen, an deren Mängeln die Qualitäten und Tugenden der Wir-Gruppe erkennbar werden. Zum anderen finden sich neben diesen explizit konturierenden bzw. externalisierenden Funktionen antiamerikanischer Rhetorik solche mit struktursichernder und kommunikationslatenter Wirkung: Amerikabilder werden in diesen Fällen nicht nur gebraucht, um eine fraglos bestehende Wir-Gruppenkonstruktion mit positiven Attributen zu versehen bzw. von negativen Attributen zu befreien; vielmehr werden widersprüchliche Aspekte der Wir-Gruppenkonstruktion mittels amerikabezogener Sprechweisen aufgegriffen und bearbeitet, ohne diese dabei explizit benennen zu müssen.

Am Beispiel von Herrn F lässt sich zeigen, wie die Kontingenz ethno-nationaler Identität, d.h. die Hybridität und historische ,Gemachtheit' der essentialistischen Wir-Gruppenkonstruktion, durch antiamerikanische Rhetorik latent bearbeitet werden. In Analogie zu jener nationalen Struktursicherungsoperation, die Klaus Holz für den Antisemitismus rekonstruiert hat, kann dieser Antiamerikanismus als die Konstruktion einer „Figur des Dritten“ der nationalen Ordnung betrachtet werden (Holz 2010, S. 296; vgl. Kap. 4.6.1), die eine „Negation der nationalen Form aus der Perspektive der Innenseite der nationalen Form“ ermöglicht (ebd., S. 302).

Im Interview mit Herrn $\mathrm{C}$ hingegen wird ein spezifischer Bruch in der nationalen Eigengruppe antiamerikanisch bearbeitet: die Teilung in Ost- und Westdeutschland und ihre politisch-ökonomischen Nachwirkungen nach der Wiedervereinigung 1989. Trotz seiner ausgeprägten ,gesamtdeutschen' Nationalidentität thematisiert Herr C nachdrücklich einen innerdeutschen Konflikt zwischen Ost und West, wobei er emphatisch für seine ostdeutsche Wir-Gruppe Partei ergreift. Diese Spannung, dass Herr $\mathrm{C}$ eine einheitliche deutsche Nationalidentität anstrebt, zugleich aber nicht umhin kann, deren inneren Bruch, d.h. insbesondere die ,Arroganz ' der Westdeutschen zu beklagen, wird von ihm antiamerikanisch aufgelöst: Einerseits einigt er die deutsche Nation insgesamt gegen ,Amerika' und die ,Amerikanisierung'. Andererseits unterscheidet er innerhalb dieser Konstruktion ,amerikanisierte“ Westdeutsche von , authentischen' Ostdeutschen, und erhält somit trotz der nationalen Einigung die Ost-West-Unterscheidung aufrecht. 


\subsubsection{Falldarstellung Herr C: Wiedervereinigung gegen Amerika und der schädliche Einfluss der, Amerikanisierung“}

Wie bereits in der Einleitung beschrieben, erfüllt die antiamerikanische Rhetorik von Herrn C eine doppelte Funktion: Einerseits wird die kulturelle Homogenität, wirtschaftliche Rationalität und politische Solidarität der deutschen Eigengruppe gegen , amerikanische' Wirtschafts- und Konsumpraxen sowie die kulturelle Heterogenität Amerikas abgegrenzt. Andererseits wird anhand jenes Erklärungsmusters der ,Amerikanisierung' auch ein von Herrn $\mathrm{C}$ beklagter Bruch zwischen West- und Ostdeutschland nach der Wiedervereinigung bearbeitet. Die Gegenüberstellung von deutscher Wir-Gruppe und amerikanischer Fremdgruppe dient damit gleichzeitig der Homogenisierung und Aufwertung der nationalen Identitätskonstruktion insgesamt und der Markierung einer Differenz innerhalb dieser Konstruktion. Herrn Cs Antiamerikanismus verknüpft sozusagen zwei widersprüchliche Leitunterscheidungen: , authentische Ostdeutsche vs. amerikanisierte Westdeutsche " und ,Deutschland vs. Amerika'. In einem ersten Schritt wird nun jene homogenisierende, antiamerikanisch externalisierende Rhetorik nationaler Einigkeit und Ursprünglichkeit rekonstruiert. In einem zweiten Schritt kann anschließend gezeigt werden, wie antiamerikanische Sprechweisen gleichzeitig dazu dienen, eine Differenz zwischen Ostund Westdeutschland zu markieren und aufrechtzuerhalten, ohne den dadurch thematisierten Bruch nationaler Identität zu weit in den Vordergrund treten zu lassen.

\subsubsection{Der schädliche Einfluss der ,Amerikanisierung‘}

Das Interview beginnt mit der Bitte, Herr C möge seine Zustimmung zu dem Survey-Item ,Ich kann es gut verstehen, wenn manchen Leuten die US-Amerikaner unangenehm sind“ näher erläutern. Daraufhin formuliert er eine umfangreiche Liste negativer Attribute. Neben seiner Zurückweisung der amerikanischen „Cowboymentalität“, der zufolge sich die Amerikaner als ,die größten [...] und die Weltpolizei" fühlen, seiner Ablehnung des Irak- und Afghanistankrieges sowie seiner Empörung darüber, „was die mit den Schwarzen gemacht“ haben, spielen vor allem Ökonomie und Finanzwirtschaft in dieser Anfangssequenz eine wichtige Rolle. ${ }^{1}$ Herr $C$ verurteilt die soziale Ungleichheit und Armut in den USA:

Herr C: Die Geldpolitik ist die zweite Frage [...]. Wenn es jetzt auch geht um die Vermögenssteuer, der Reichensteuer, äh, und das Geld ist ja in Amerika noch mal ganz anders, weil ja die Schere zwischen arm und reich noch viel größer ist. Und das hängt natürlich mit ihrer Meinung von Freiheit zusammen, dass sie eben die Freiheit haben, Milliard-, Milliardär zu

1 Nicht zusätzlich gekennzeichnete Zitate in doppelten Anführungszeichen geben direkt den Wortlaut eines jeweiligen Interviewtranskripts wieder. 
werden aber auch, unter der Brücke zu schlafen. [...] Und natürlich Amerika, was jetzt hier diese Demonstrationen bringen, dass ein Prozent der Menschen glaube ich 48 oder sogar 46 [sic] Prozent des Vermögens haben. Das ist ja nicht normal.

An diesem frühen Ausschnitt des Interviews wird bereits die Dichte erkennbar, mit der verschiedene Amerikabilder in Herrn Cs Rhetorik auftreten: In sprunghafter Assoziation ruft er eine Vielzahl von Themen auf, zwischen denen plötzlich hin und her gewechselt wird, so dass es einige Konzentration erfordert, seinem Argument überhaupt zu folgen. In diesem Amerikabild werden zwar immer wieder einzelne Gruppen herausgegriffen, die in besonderem Maße verantwortlich, schuldig oder unschuldig bzw. Opfer sind - so verweist der Teilnehmer etwa auf die Aktionen der Occupy-Wall-Street Bewegung. In der Gesamttendenz zielt Herr Cs Rhetorik aber immer wieder auf eine Verurteilung, der Amerikaner' insgesamt.

Dieses Muster wird auch in der folgenden Sequenz erkennbar, in der von illegitimen Bankgeschäften ,im luftleeren Raum“ und Finanzgeschäften mit „Scheinnummern" die Rede ist, die in keinem nachvollziehbaren Verhältnis zur Realwirtschaft stünden. Auch hier wird mit der Finanzwirtschaft eine relativ spezifische Teilgruppe ,der Amerikaner“ als schädlich und schuldig herausgegriffen. Dieser werden „ganz normale Menschen“ und „seriöse Banken“ gegenübergestellt, denen man „keinen Vorwurf machen“ könne. Diese Unterscheidung, die an die aus der Antisemitismusforschung bekannten Gegensatzpaare von ,Gemeinschaft vs. Gesellschaft' bzw. ,raffendem vs. schaffendem Kapital' erinnert (vgl. Holz 2001, S. 544 f.; Schatz und Woeldike 2001, S. 87 ff.; Postone 2005, S. 183 ff.), geht also zunächst nicht unmittelbar mit einer starken nationalen Grenzziehung einher: Explizit verweist Herr C z.B. darauf, dass es auch ,,in Amerika [...] Bankenmitarbeiter“ gebe, die „ganz normale Menschen“ seien.

In den nächsten beiden Elementen seiner Assoziationskette findet sich allerdings die generalisierende Negativattribution aus den vorigen Sequenzen wieder. Hier zählt er zunächst Missstände im amerikanischen Gesundheitssystem sowie den öffentlichen Widerstand gegen dessen Reform als weitere Beispiele für die extreme Ungleichheit bzw. Ungerechtigkeit in der Gesellschaft der USA auf. Auf die paraphrasierende Nachfrage des Interviewers, ob Herr $\mathrm{C}$ also insgesamt eine Dominanz oder Herrschaft der wohlhabenden Bevölkerung in den USA beschreibe, verweist er nun auf den vermeintlich amerikanischen Ursprung vergleichbarer Phänomene in Deutschland:

Herr C: Ja. Und das ist ja auch alles von Amerika gekommen, was wir in Deutschland haben, ist ja... Wenn wir überlegen, die letzten Jahre, wie wir Millionäre dazu genommen haben. Ja. Genau so viele Millionäre hinzugekommen, wie, wie, wie, wie Arme dazugekommen sind. (lacht) Und das denkt man ja, dass die Schere hier auch immer weiter auseinandergeht, zwischen arm und reich. 
Die Formulierung, dass dies ,alles von Amerika gekommen“ sei, „,was wir in Deutschland haben“, kann als rhetorische Übertreibung verstanden werden. Dennoch wird darin die grundlegende Stoßrichtung von Herrn Cs antiamerikanischem Argument erkennbar: Nicht alles in Amerika ist schlecht (es gibt auch dort ,normale Menschen"), aber alles Schlechte (in Deutschland) kommt aus Amerika. In der darauffolgenden Sequenz breitet Herr C das Motiv eines schädlichen amerikanischen Einflusses auf Deutschland anhand der Beispiele Sprachgebrauch und (Ess-)Kultur weiter aus:

Herr C: Äh, wir sind als Deutschland, äh, äh sehr, äh, USA äh, äh, äh, sagen wir mal, es ist doch sehr viel aus der USA rüber gekommen. Ich bin hier im Osten, und wird immer gesagt, wir hier im Osten sind russifiziert! Also wir sind doch bei Weitem nicht so viel russifiziert, wie im Westen amerikanisiert! Ich bin der Meinung, ein Deutscher kann die deutsche Sprache sprechen. Wenn ich mit einem Amerikaner spreche, ist klar, entweder man spricht deutsch oder, oder Englisch. Das ist klar. Aber das wir im Sprachgebrauch... Wer nicht äh irgendwie im, im Satz ein amerikanischen Sa- Wort drin hat, äh, äh, äh, das ist ja nicht mehr in! Ja, und so werden wir als Gesellschaft genauso... McDonalds hat nicht in Amerika seinen Gewinn gemacht, sondern in, in Europa! Ja, die haben sehr gute Zahlen, und äh, aber den meisten Gewinn haben sie in Europa gemacht! Ja, diese, diese, diese Ketten, ja und so wird unsere Ernährung immer schlimmer! Und das kommt eigentlich alles... Ich war auch in Amerika, schon öfters, ja, und äh, äh wenn ich, wenn ich sehe, wie die da essen und machen, und... niveaulos, ja, bei Landwirten, ich äh, die einen relativ großen Hof haben, und, und relativ gut eingerichtet sind, die essen aus einem Plastikbesteck und Plastiklöffel und danach wird eben alles in den, in den Sack geschmissen.

Herr C erweitert hier seine antiamerikanische Konstruktion um Bilder eines Sprachund Kulturverfalls in Deutschland: Die deutsche Sprache verfalle durch den zunehmenden Gebrauch ,amerikanisch[er] “2 Worte; ebenso sind ,wir als Gesellschaft" durch amerikanischen Einfluss beeinträchtigt. Besonders empörend sei an

2 Ironischerweise drückt Herr $\mathrm{C}$ seine Ablehnung von Anglizismen aus, indem er einen Anglizismus gebraucht (man sei ohne Anglizismen ,nicht mehr in“). Inwieweit dies als bewusst eingesetztes rhetorisches Mittel oder als impliziter Ausdruck einer Ambivalenz in Herrn Cs Amerikabild zu deuten ist, kann anhand des Materials nicht eindeutig entschieden werden. Bemerkenswert ist aber die Tatsache, dass Anglizismen hier als ,amerikanische[s] Wort[e]" kategorisiert werden. Eine solche Ursprungzuschreibung muss angesichts der weltweiten Verbreitung der englischen Sprache als äußerst projektiv erscheinen und kann als eine weitere Variante einer nationalistischen Verfallserzählung betrachtet werden, in der , die Amerikanisierung ' als treibende Kraft der Desintegration fungiert (vgl. Jaecker 2014, S. 221 ff.; Markovits 2007, S. 90 ff.). Ähnliche Motive finden sich in den Interviews mit Herrn B und Herrn F. 
diesem ,schädlichen Einfluss', dass ,amerikanische“ Konzerne auch noch davon profitieren, dass sie „unsere Ernährung“ verderben. Dass es sich tatsächlich um einen ,Kulturverfall“ amerikanischen Ursprungs handelt, sucht Herr C anhand seiner eigenen Erfahrungen in den USA zu bekräftigen: Dort habe er jene „niveaulos[en]“ Essgewohnheiten und die ,Wegwerfkultur' gesehen, die er nun in Deutschland wiederzuentdecken meint. In einem späteren Teil des Interviews wird Herr C vom Interviewer noch einmal auf ,amerikanische Kultur' angesprochen. Er erkundigt sich bei Herrn C, wo ihm diese begegne bzw. was er damit assoziiere. Er führt daraufhin seine Beschreibung des schädlichen Einflusses Amerikas auf die Esskultur in Deutschland weiter aus:

Herr C: Mir, mir speziell nicht. Ich versuche, äh, äh, sagen wir mal... Äh, die Menschen werden ja auch durch die Reklame und, äh, werden die ja gezielt, ähm, äh beeinflusst, ja, und, und McDonalds und äh, und, und, und, und... Es wird ja für Sachen Reklame gemacht, und desto schlechter das Produkt teilweise ist, desto mehr Reklame wird gemacht, und desto mehr wird es gekauft. Ja, und wenn ich diese Zuckertiere sehe, ja, die Zuckerbärchen, ja, für die jeden Tag Reklame... Da verdient irgendjemand unwahrscheinlich viel Geld dafür. Das ist viel zu süß und davon brauchen die Kinder nicht so viel essen, ja. Aber das kennen sie alle, ja. Und der Gottschalk verdient damit richtig Geld, der braucht nicht mal mehr „Wetten, dass...“ machen. Sein Schloss hat er nun gezahlt, ja, ist ja wieder nach Deutschland zurückgekommen. Und, äh, damit bin ich auch nicht einverstanden, ja. Und ein Jauch, dass der im Jahr seine acht oder neun Millionen verdient, äh:::, bin ich einfach... Und, und, und, uns erhöhen sie die, und uns erhöhen sie die Gebühren, die Fernsehgebühren für ARD und ZDF. So aber das soll ja damit nicht sagen, äh... Die Menschen werden ja einfach gesteuert durch die Reklame. Und wenn McDonalds eine gute Reklame macht, und denn, sein Gelumpe, und das hören die Kinder, und dann da wollen sie eben hin, wenn sie McDonalds sehen. Oder auch andere Produkte, Milchschnitte zum Beispiel, ja, die so ungesund ist, aber da wird so viel... Auch wenn unsere Boxer mit ihrer Milchschnitte, ja, und so. Also das... Und das ist ja, das kommt ja eigentlich von Amerika.

Neben der zuvor bereits geführten Klage über das „Gelumpe“ von „McDonalds“ wird in dieser Sequenz vor allem das Motiv eines irrationalen Konsums betont: demzufolge werden „Die Menschen [...] gesteuert durch die Reklame“, was dazu führe, dass ,schlecht[e]“ Produkte trotz ihrer Mängel hohen Absatz fänden. Diese vermeintliche Überformung der ,wahren“ Qualität von Produkten durch Werbung dient als Erklärung dafür, dass ,wertlose‘ und sogar ,schädliche“ (,viel zu süß“, „Gelumpe“, „,ungesund“) Produkte in Deutschland großen Absatz finden. Das Prinzip dieser manipulativen Täuschung, durch die der, eigentliche' Gebrauchswert der Waren hinter einem ,fingierten' verschwindet, verortet er als etwas wesentlich Amerikanisches: „das kommt ja eigentlich von Amerika“. 
Dabei richtet sich seine antiamerikanische Konsumkritik nicht allein gegen amerikanisches „Gelumpe“ - mit Gummibärchen und Milchschnitte werden auch Produkte als Beispiele aufgeführt, die nicht aus den USA stammen. Vielmehr erscheint der grundlegende Mechanismus der Verblendung, den er für den irrationalen Konsum verantwortlich macht, als ein amerikanischer. Dass mit ,wertlosen“ Produkten „unwahrscheinlich viel Geld“ verdient wird, scheint ihm das Ergebnis einer bewussten und zielgerichteten Täuschung, durch die im Interesse einzelner Profitierender die breite Bevölkerung irregeleitet wird. Dass dabei ausgerechnet „unsere Boxer“ und „,der Gottschalk“33 Geld verdienen, bedeutet für Herrn C ein zusätzliches Ärgernis. Es kommt einem Verrat an der Eigengruppe gleich, dass sich diese Deutschen dem ,amerikanischen ' Prinzip des Massenkonsums andienen. Dies klingt insbesondere bezüglich der Person von Thomas Gottschalk an, mit dessen Rückkehr nach Deutschland (nach einigen Jahren Aufenthalt in Kalifornien) Herr C „,nicht einverstanden" ist. ${ }^{4}$ Seine besondere Empörung über diese Verhaltensweisen stützt zusätzlich die Deutung, dass das Sprechen über amerikanische Kultur und ,Amerikanisierung' hier eine reinigende und stabilisierende Funktion für nationale Identität erfüllt. So sind Wir-Gruppenmitglieder, die in Herrn Cs Konstruktion dem ,amerikanischen“ Prinzip von Konsum und Kulturverfall entsprechen, entweder ,gesteuert durch die Reklame“, oder aber korrumpierte Abtrünnige, die effektiv schon nicht mehr zur Wir-Gruppe gezählt werden.

Soziale Ungleichheit und Armut, eine ungerechte Steuerpolitik, der vermeintliche Verfall deutscher Sprache und Esskultur, das Auseinandertreten von Tauschund Gebrauchswert konsumierter Waren - all diese Phänomene haben in Herrn Cs Konstruktion mit der deutschen Wir-Gruppe wesentlich nichts zu tun. Sie können allesamt den USA und deren Einfluss auf Deutschland und Europa zugeschrieben werden. Damit ist nicht nur eine Erklärung für diese beunruhigenden Phänomene gefunden, sondern die Eigengruppe ihrem ,Wesen“ nach von all diesen Übeln gereinigt. Sie erscheint als Opfer fremder Mächte in einer maßgeblich nationalistisch strukturierten Welt. Die Widersprüche und Verwerfungen einer kapitalistischen Marktwirtschaft sowie einer globalisierten, wandelbaren Welt spielen sich diesem Weltbild zufolge maßgeblich zwischen Nationen, nicht innerhalb der nationalen Eigengruppe oder jenseits nationaler Unterscheidungen $\mathrm{ab}$. Sie lassen Herrn $\mathrm{C}$ nicht an der Homogenität, Solidarität und Stabilität der deutschen Nation als Identitäts-

3 Gemeint sind höchstwahrscheinlich die erfolgreichen Schwergewichtsboxer Vitali und Wladimir Klitschko, die für ,Milchschnitte" warben, sowie der Entertainer Thomas Gottschalk und dessen Werbung für ,Haribo Goldbären`.

4 Eine ähnliche Ablehnung von in die USA emigrierten Berühmtheiten findet sich bei Herrn D, der Boris Becker und Michael Schumacher gerne die deutsche Staatsbürgerschaft entziehen würde, weil diese seiner Ansicht nach aus Gründen der Steuerersparnis nach Amerika ausgewandert sind. 
konstrukt zweifeln, sondern führen in dieser Erzählung gerade zu einer Bestärkung der nationalistischen Weltsicht: Deutschland muss gegen den vermeintlichen , amerikanischen' Eingriff verteidigt werden - paradoxerweise umso mehr, je offener die Inkonsistenzen der nationalen Identitätskonstruktion zu Tage treten.

\subsubsection{Wiedervereinigung gegen Amerika - eine antiamerikanische Aufhebung der Teilung Deutschlands}

In den bisher erläuterten Beispielen antiamerikanischer Rhetorik wurden Verwerfungen innerhalb der nationalen Eigengruppe externalisiert so dass die Wir-Gruppe als Ganze stabilisiert bzw. von Widersprüchen frei gehalten werden konnte. Sofern ,Deutsche“ an jenen , amerikanischen“ Verfallserscheinungen mitwirken, wurden sie entweder als ,gesteuert durch die Reklame“ oder als Abtrünnige dargestellt. Im Gegensatz dazu wird im Folgenden ein Widerspruch in der Wir-Gruppenkonstruktion explizit thematisiert: Der Bruch zwischen Ost- und Westdeutschen nach der Wiedervereinigung. Diese Spaltung stellt Herrn Cs rhetorische Bemühungen um eine bruchlose Einigung der nationalen Wir-Gruppe vor eine neue Herausforderung: Die Konstruktion einer widerspruchslosen nationalen Identität wird durchkreuzt von dem Bestreben, seine Identifikation mit der ostdeutschen Subgruppe sowie deren Höherwertigkeit und Opferstatus zu markieren. Anhand der folgenden Interviewsequenzen wird gezeigt, inwiefern eine antiamerikanische Rhetorik dazu gebraucht werden kann, diese Ambivalenz in der nationalen Identifikation aufzuheben.

Diese antiamerikanische Aufhebung der Ost-West-Spaltung kann gegenüber der zuvor besprochenen Externalisierungsfunktionen als höherstufige, reflexive Entparadoxierung begriffen werden: Während in der oben beschriebenen Externalisierung sozioökonomische und kulturelle Widersprüche der Wir-Gruppe nahezu restlos ausgeblendet wurden, bleibt der Unterschied zwischen west- und ostdeutschen Subgruppen in der folgenden antiamerikanischen Identitätskonstruktion erhalten: Er erscheint zugleich als Widerspruch zwischen Deutschland und Amerika sowie zwischen ost- und westdeutscher Subgruppe. Die antiamerikanische Polemik erlaubt es, ein Ressentiment gegenüber Westdeutschland auszudrücken ohne dabei die Vorstellung eines geeinten, identischen Deutschland allzu sehr in Frage stellen zu müssen. Ein und dieselbe Rhetorik dient gleichzeitig der Identifikation mit der gesamtdeutschen Wir-Gruppe und der ostdeutschen Teilgruppe. In dieser gleichzeitigen Bearbeitung und Verdeckung eines Ost-West-Konfliktes steckt der ideologische Gehalt dieser antiamerikanischen Rhetorik (vgl. Kap. 4.5.1). In Adaption des in Kapitel 4.6.2 umrissenen Konzeptes der Kommunikationslatenz kann diese ideologische Rhetorik auch als latente Bearbeitung eines deutschen Ost-West-Konfliktes begriffen werden.

Ausschlaggebend für diese Latenzfunktion ist ein unterschiedlicher Gebrauch des Amerikanisierungs-Motivs hinsichtlich der zwei deutschen Subgruppen. Im 
Anschluss an die oben beschriebene Darstellung Herrn Cs, der zufolge soziale Spaltungen in Deutschland amerikanischen Ursprungs seien, bittet der Interviewer ihn um eine eingehendere Erläuterung jenes Einflusses:

Herr C: Äh, wir sind als Deutschland, äh, äh sehr, äh, USA äh, äh, äh, sagen wir mal, es ist doch sehr viel aus der USA rüber gekommen. Ich bin hier im Osten, und wird immer gesagt, wir hier im Osten sind russifiziert! Also wir sind doch bei Weitem nicht so viel russifiziert, wie im Westen amerikanisiert!

An dieser Stelle lässt sich zeigen, wie die Gegenüberstellung Amerika vs. deutsche Wir-Gruppe in doppelter Weise gebraucht wird: Zunächst wird der amerikanische Einfluss betont, unter dem „wir [...] als Deutschland“ insgesamt stehen. Im Anschluss daran wird jedoch die Ost-West-Unterscheidung eingeführt und betont, dass „wir hier im Osten“ weitaus weniger amerikanisiert seien. Damit wird das Attribut der ,Amerikanisiertheit' als grundlegend westdeutsches eingegrenzt. Zwar wird parallel eine ,Russifizierung' Ostdeutschlands eingestanden, jedoch zugleich betont, dass es sich um ein weitaus geringeres Maß an fremdem Einfluss handele. Die WirGruppe der Ostdeutschen ist demnach nur mittelbar amerikanisiert, d.h. nur insofern sie mit Westdeutschland in Berührung gekommen ist, insbesondere nach 1989. Im Gegensatz zu den bisher beschriebenen antiamerikanischen Konflikt- oder Bedrohungsszenarien, wird in dieser Konstruktion vergleichsweise offen thematisiert, dass der beschriebene Konflikt mit den USA zugleich ein innerdeutscher Konflikt ist. Die Begegnung mit Westdeutschland ist eine Begegnung mit Amerika; die Gegnerschaft gegen Amerika ist eine Gegnerschaft gegen Westdeutschland.

Wie anhand der folgenden Interviewsequenzen gezeigt wird, liegt es nahe, die antiamerikanische Rhetorik von Herrn $\mathrm{C}$ zu weiten Teilen als Ausdruck eines Unbehagens an der deutschen Wiedervereinigung zu lesen. Mit der Chiffre ,Amerika wird demnach alles belegt, was nach 1989 als negativ empfunden wurde. Da Herr C aber zugleich eine starke ,gesamtdeutsche“ Identifikation anstrebt und der Konflikt zwischen Ostdeutschland und Westdeutschland eine massive Störung dieses Ideals darstellt, kann er nicht bei einer einseitigen Anfeindung der westdeutschen Fremdgruppe stehenbleiben. Vielmehr muss die Spaltung der Eigengruppe latent gehalten werden, so dass es nicht zum vollständigen Bruch kommt. Die antiamerikanische Rhetorik dient Herrn $\mathrm{C}$ als Mittel zu diesem ideologischen Balanceakt.

Für die These, dass in der Feindschaft gegen Amerika eine Feindschaft gegen Westdeutschland latent kommuniziert wird, spricht auch die Tatsache, dass die einzigen positiven Eigenschaften, die Herr C Amerika zuschreibt, in Bezug auf Westdeutschland vor der Wiedervereinigung auftreten. Im Anschluss an die oben zitierte Passage zur Amerikanisierung der Konsumkultur fügt Herr C im Hinblick auf die Nachkriegszeit an: 
Herr C: Ja, äh und ich will nun nicht sagen, dass Amerika nur für Deutschland schlechtes hatte. Die hat ja Deutschland nach dem Zweiten Weltkrieg äh, äh sehr viel geholfen, ja, und durch die Besatzung in Deutschland ist ja auch hier das Geld reingekommen, ja, dadurch, dass sie die vierziger oder fünfziger Jahre hier waren, ja. Im Osten war es anders: wir haben sie bezahlt, und die haben wenigstens noch ein bisschen Geld gebracht. Aber die Diskussion brauchen wir nicht mehr führen, dass ist vorbei.

Dieser Darstellung zufolge hat die westdeutsche Bevölkerung vom Einfluss Amerikas zumindest in wirtschaftlicher Hinsicht durchaus profitiert. Dem wird eine gegenteilige Situation in den sowjetisch besetzten Gebieten gegenübergestellt (,wir haben sie bezahlt“). ${ }^{5}$ Ähnlich wie die korrumpierten Deutschen, „Gottschalk“ und „unsere Boxer“ aus den vorigen Sequenzen, haben die Westdeutschen aus der Amerikanisierung zunächst Gewinn gezogen, der dann aber mit den von Herrn $\mathrm{C}$ beklagten Verfallserscheinungen von Deutschland insgesamt bezahlt wurde. ,Die Wessis ' fungieren in dieser Argumentation also nicht nur als Einfallstor für die Amerikanisierung Deutschlands, sondern haben zudem noch davon profitiert, während Ostdeutschland zusätzlich zum Opfer sowjetischer Ausbeutung wurde.

Dass der darin sich ausdrückende Konflikt zwischen Ost- und Westdeutschen keineswegs „Vorbei“ ist, wie Herr C behauptet, zeigt sich im weiteren Verlauf dieser Sequenz, in der die vermeintlich beendete „Diskussion“ sich fortschreibt. Unmittelbar im Anschluss an die Feststellung, dass man ,diese Diskussion nicht mehr führen“ brauche, berichtet Herr $\mathrm{C}$ die folgende Episode:

Herr C: Denn ich habe, ich habe jetzt noch gehört von welche, Gäste aus Wuppertal waren das, da hat eine Frau gesagt: ,Ihr in der Zone könnt doch zufrieden sein, dass wir euch übernommen haben.“ Ja... (amüsiert, zynisch) Da hatte ich aber, da hatte ich aber einen guten Tag! Da habe ich zu der jungen Frau gesagt, die war siebzig, sage ich: „Junge Frau, es ist eigentlich egal, in welcher Zone man wohnt. Ob in der britischen Besatzungszone, in der englischen, französischen oder engl- oder amerikanischen." Das haben alles die Russen gemacht, so, das sind so, so die, die Meinungen und die Diskussionen. Aber, aber ich meine, von der Kultur ist ja eine Menge, was jetzt McDonalds ist und dergleichen. Und auch diese Finanzkultur, die kommt ja irgendwie auch mehr aus Amerika wie aus Deutschland, ja. Unsere Banken sind ja immer noch nicht groß genug, am liebsten drei große Banken und...

5 Dasselbe Motiv taucht in einer späteren Sequenz noch einmal auf, nachdem der Interviewer Herrn $\mathrm{C}$ gebeten hat, weitere Beispiele für einen positiven amerikanischen Einfluss auf Deutschland zu nennen: „Naja, auch was das Geld angeht und, und äh, und durch den Marshallplan ist ja auch, ist ja auch, da kann man ja auch Amerika als positiv sehen, ja dass sie die Bundesrepublik unterstützt haben. Das meine ich, ja. Und wir in Ostdeutschland haben unser Geld, ja, dass was wir verdient haben, haben wir nach Russland gebracht. Nach der Sowjetunion, das war ja genau das Gegenteil.“ 
Die Wuppertalerin aus seiner Erzählung veranschaulicht das Konfliktpotential, das Begegnungen mit Westdeutschen für Herrn $\mathrm{C}$ immer wieder entfalten und das ein Vergessen der empfundenen Ungerechtigkeit unmöglich macht: sie verkörpert das Bild der verblendeten Westdeutschen, die von der amerikanischen Besatzung profitiert ohne die ,schädlichen“ Auswirkungen der ,Amerikanisierung' zu bemerken, und die zu allem Überfluss sich gegenüber den Ostdeutschen als gnädige Wohltäterin inszeniert.

Bezeichnend ist in diesem Zusammenhang die Reaktion von Herrn C: Er konfrontiert die Wuppertalerin nicht direkt mit dem Vorwurf der Überheblichkeit oder Selbstüberschätzung, sondern er verweist stattdessen auf die Gleichheit aller Deutschen als Opfer der Besatzung, wendet sich also nur mittelbar gegen die Westdeutsche und primär gegen die (ehemalige und offenbar noch immer als präsent empfundene) Besatzungsmacht. Der Konflikt Ostdeutschland vs. Westdeutschland (Herr C vs. die Wuppertalerin) wird bearbeitet als Konflikt Deutschlands mit den Besatzungsmächten.

Bezeichnend ist auch, dass die damit verbundene Negativbewertung , der Amerikaner' über die erzählte Streit-Episode hinaus als dominantes rhetorisches Muster wirksam bleibt. Während Herr C vor der Episode über die Wuppertalerin positiv vom amerikanischen Einfluss (bzgl. der BRD) sprechen konnte und sich negativ auf den russischen Einfluss in der DDR bezog, sind anschließend seine Bewertungsmaßstäbe wieder vertauscht: Er relativiert jetzt sogar den Einfluss der russischen Besatzung (,Das haben alles die Russen gemacht, [...] das sind so [...] die Meinungen“) und betont stattdessen den schädlichen Einfluss ,,aus Amerika“ durch „McDonalds“ und „Finanzkultur“. Die Ablehnung dieser vermeintlich amerikanischen Übel scheint also funktional verknüpft mit der Zurückweisung wahrgenommener westdeutscher Arroganz. Die Bearbeitung der innerdeutschen Spaltung bestimmt die Bewertung Amerikas (bzw. der Sowjets). Oder anders ausgedrückt: Das Sprechen über Amerika stellt die rhetorischen Mittel bereit, den deutschen OstWest-Konflikt latent zu bearbeiten.

\subsubsection{Zusammenfassung Herr C}

Am Gespräch mit Herrn C konnte gezeigt werden, wie Antiamerikanismus einerseits eine externalisierende Funktion bei der Aufwertung der nationalen Eigengruppe erfüllt: ökonomische und sozialpolitische Probleme, wie Armut, Finanzkrisen und soziale Ungleichheit werden als ,amerikanische" Phänomene aus der Eigengruppe ausgelagert. D.h. die relative Aufwertung der nationalen Eigengruppe wird nicht allein durch Gegenüberstellung mit einer negativen Vergleichsfolie erzeugt, sondern ,Amerika‘ wird als Einflussgröße oder Wirkmechanismus ,hinter den wahrgenommenen Verfallserscheinung ausgemacht. Herr $\mathrm{C}$ impliziert nicht nur: ,Im Vergleich zu den USA werden die überlegenen Qualitäten der Deutschen er- 
kennbar', sondern ,Alles, was in meiner Wir-Gruppe problematisch erscheint, ist amerikanisch".

Andererseits konnte als zweite Funktion antiamerikanischer Rhetorik eine latente Bearbeitung des innerdeutschen Ost-West-Konfliktes gezeigt werden: Ausgangspunkt ist hierbei Herrn Cs widersprüchliches Bestreben nach Einigung der nationalen Eigengruppe und zugleich Betonung einer fortwirkenden inneren Spaltung nach 1989. Der Topos der ,Amerikanisierung ' wird hierbei zu einer Chiffre, mit der antiwestdeutsche Animositäten und Kränkungen latent verhandelt werden können, ohne dass das Ideal einer gesamtdeutschen Identifikation darüber zerbricht. Sich gegen ,Amerikanisierung' aufzulehnen bedeutet zugleich, die Westdeutschen für die wahrgenommenen Ungerechtigkeiten im Wiedervereinigungsprozess anzugreifen und Ostdeutschland gegenüber dem ,amerikanisierten“ Westen aufzuwerten. Diese antiamerikanische Bearbeitung der deutschen Spaltung erfüllt somit eine ideologische Funktion: Der innerdeutsche Konflikt zwischen Ost und West kann thematisiert werden, ohne dass die nationalistische Identifikation mit ,Deutschland“ insgesamt dadurch gebrochen würde. Herrn Cs Rhetorik erinnert im doppelten Sinne an das antiamerikanisch Programm, das der SED Funktionär Albert Norden 1952 formulierte: „Sich gegen Wallstreet und Washington orientieren, das heißt sich auf Deutschland orientieren." (zit. n. Haury 2004, S. 82) Und zwar, im Fall von Herrn $\mathrm{C}$, auf Deutschland als zugleich geteilte und einige Nation. Dieses gleichzeitige Thematisieren und Zudecken einer Ambivalenz bzw. eines Widerspruches in der nationalen Identifikation macht den ideologischen Charakter des antiamerikanischen Sprechens aus.

Wie ich in Kapitel 7.4 zeige, wird nicht nur Herrn Cs Nationalismus antiamerikanisch gestützt, sondern auch die ethnozentrischen Argumentationsmuster, die mit diesem einhergehen. So werden durch rhetorischen Verweis auf , amerikanischen Rassismus ' die rassistischen Implikationen des eigenen Migrations- und Integrationsdiskurses entschärft (vgl. Kap. 7.4.2.2). Angesichts der Dichte der beobachteten Amerikastereotype, sowie der Vielfältigkeit ihres antiamerikanischen Gebrauchs (relative Aufwertung der Wir-Gruppe, Externalisierung, latente Regelung des OstWest-Konfliktes, Rechtfertigung von Ethnozentrismus) kann von einer vergleichsweise starken weltanschaulichen Geschlossenheit dieses Antiamerikanismus gesprochen werden. ${ }^{6}$

6 Für die Zuordnung dieses Merkmals gibt es freilich kein striktes Kriterium (vgl. auch die Diskussion in Kap. 7.6.5). 


\subsubsection{Falldarstellung Herr F: Multikulturalismus und eine antiamerikanische Figur des Dritten}

Ähnlich wie Herr C erfüllt auch Herr F mit antiamerikanischer Rhetorik nationale Identitätsfunktionen. Hierbei wird immer wieder das Streben nach einer bruchlosen Identifikation mit der nationalen Wir-Gruppe erkennbar: „Die Deutschen sind alle Deutsche“, wie Herr F an einer zentralen Interviewstelle feststellt. $\mathrm{Zu}$ diesem Zweck werden einerseits Strategien der relativen Aufwertung der Eigengruppe durch kontrastierende Amerikastereotype angewandt: im Vergleich zu Amerika wird, so Herr F, die große Rechtssicherheit, Solidarität und Rationalität ,der Deutschen' erkennbar. Mit dieser Relativierung und Herabminderung des Image der USA ist bei Herrn F eine erinnerungspolitische Rhetorik verknüpft: nach 1945 habe sich aufgrund der Nazi-Vergangenheit eine Art deutscher Selbsthass entwickelt, der die Deutschen übermäßig empfänglich für amerikanische Einflüsse mache. Zwar betont Herr F wiederholt, dass dies keine allzu negativen Folgen gezeitigt habe und er die ,deutsche Identität‘ dadurch nicht ernstlich gefährdet sehe. Er nimmt aber dieses Thema zum Anlass, sein Verständnis nationaler Identität auszubreiten, das wesentlich auf einer essentialistischen Idee von Ethnizität beruht.

Einen unmittelbar chauvinistischen Eindruck vermeidend, wird die deutsche Wir-Gruppe in ein multikulturalistisches Verständnis nationaler Identität eingefasst. In einer Nation können demnach Gruppen verschiedener ethnischer Herkunft nebeneinander leben, wobei jeweils eine ethnische Gruppe (in Deutschland: ,die Deutschen') die kulturelle Hegemonie behält. Dieses Multikulturalismusverständnis ist der innernationale Spiegel einer nationalistischen Weltsicht, die die Welt nach dem Muster „Ein Volk, ein Staat, eine Nation“ (Holz 2001, S. 162) in Gruppen einteilt. Herrn Fs vermeintlich liberale multikulturelle Orientierung bildet tatsächlich ein „stahlharte[s] Gehäuse der Zugehörigkeit“ (Nassehi 1997a), in dem die Pluralität multikultureller Gesellschaften auf dem Zwang ethnischer Identifikation gründet.

Die USA kommen in Herrn Fs Rhetorik als das Andere dieser Ordnung ins Spiel. ,Amerika' repräsentiert das nichtidentische Moment ethno-nationaler Klassifikation, das in seinen Wir- und Fremd-Gruppenkonstruktionen systematisch ausgeschlossen wird. Die USA sind die Nation, die nur aus Immigrierten besteht und dennoch nicht aufhört, Nation zu sein. Damit verkörpern sie den Widerspruch, dass die vermeintlich ursprünglichen und festgefügten ethno-nationalen Identitäten von Hybridität und Heterogenität durchzogen und letztendlich historisch kontingent sind. An ,Amerika', so kann in Adaption der Holz'schen Antisemitismusanalyse formuliert werden, ,wird zugleich thematisiert und abgewehrt, dass , unsere ' Identität und die Ordnung der Welt nicht national sein könnten“ (Holz 2010, S. 296; vgl. auch Kap. 4.6.1). In dieser Latenzfunktion antiamerikanischen Sprechens liegt, ähn- 
lich der antiamerikanischen Behandlung des Ost-West-Konfliktes durch Herrn C, der ideologische Gehalt von Herrn Fs Antiamerikanismus.

\subsubsection{1 „Es läuft schon anders, als in Europa“ - Relative Aufwertung der Eigengruppe}

Zum Einstieg des Interviews wird Herr F gebeten, zu beschreiben, warum er sich auf den Aushang zur Studie hin gemeldet habe und in welcher besonderen Beziehung zu den USA er sich sehe. Er erläutert daraufhin, dass er generell ein großes Interesse an ,politischen Zusammenhängen“ habe, eine intensive Zeitungslektüre pflege und zeitgeschichtliche Entwicklungen verfolge; ,persönlich“ habe er aber weder eine „familiäre Bindung“ noch eine „Urlaubsbindung zu den USA“. Nachdem er sich auf diese Weise als interessierter, aber nicht persönlich involvierter Beobachter vorgestellt hat, leitet er über zu einem vergleichenden Blick auf die USA und Deutschland bzw. Europa. Hierbei werden zwei Themenstränge aufgegriffen, die auch im weiteren Verlauf des Interviews eine maßgebliche Rolle spielen: Soziale Probleme in den USA sowie das Image der USA im Nachkriegsdeutschland.

Herr F: Ähm, und dementsprechend kriegt man auch viel mit. Ich mein, es läuft halt schon anders, als in Europa, und ich sag auch immer wieder im Freundeskreis, wenn über Deutschland oder die schlimmen Verhältnisse in Deutschland gemeckert wird, wir leben hier in den vereinigten arabischen Emiraten der westlichen Welt. Also, das ist einfach so. Uns geht`s hier dermaßen gut. Man muss halt nur, wie gesagt, bei den USA über den Tellerrand gucken. Mit dem Krankenversicherungsstreit und den ganzen Problemen, die die da teilweise haben, also das ist längst nicht so das gelobte Land, wie es vielleicht mal in den 50er Jahren, zumindest aus der Sicht der Deutschen, waren als sie damals halt irgendwie ,Befreier' rüber gekommen sind, was auch irgendwo verständlich war.

Auffällig ist hier zunächst, wie die Beschreibung von Verhältnissen in den USA zur Aufwertung der deutschen Wir-Gruppe gebraucht wird, was Herr F auch explizit reflektiert: „uns geht's hier dermaßen gut. Man muss halt nur [...] bei den USA über den Tellerand gucken“. Amerika ist die Vergleichsfolie, anhand welcher die guten Zustände in Deutschland sich zeigen. ${ }^{7}$

Der zweite wichtige Aspekt, der in dieser Einstiegssequenz bereits anklingt, ist das Image der USA in Deutschland nach 1945. In den 50er Jahren seien die USA

7 Das bedeutet natülich nicht unbedingt, dass die USA die bevorzugte oder gar die einzig relevante Vergleichsgröße für solche Relativierungen sind. Es bieten sich diverse nationale Vergleiche an, um ähnliche Effekte zu erzielen. In einer späteren Sequenz wird Herr F tatsächlich auf Vergleiche mit Frankreich und Italien zurückgreifen, um ,deutsche Tugenden" herauszustreichen. 
den Deutschen als „das gelobte Land“ erschienen, was heute allerdings nicht mehr gelte und rückblickend vor allem aus dem Weltkriegs-Zusammenhang verständlich werde. An dem lapidaren Ton mit dem Herr F beschreibt, dass die USA nach 1945 ,,irgendwie Befreier“ gewesen seien und diese Perspektive der damaligen deutschen Bevölkerung auch ,irgendwo verständlich“ sei, deuten sich bereits Ambivalenzen hinsichtlich dieser erinnerungspolitischen Erzählung an. In einer späteren Sequenz wird sich zeigen, dass die NS-Vergangenheit und deren Erinnerung Herrn F in erster Linie als Hindernis nationaler Identifikation erscheinen, als ein „Päckchen“, das Deutschland $\mathrm{zu}$ tragen habe, dessen Bedeutung aber nicht überbewertet werden sollte.

Entlang dieser beiden Themenbereiche entwickelt sich das erste Drittel des Interviewgespräches, dessen wichtigste Inhalte im Folgenden zusammenfassend dargestellt werden. Herr F fährt zunächst damit fort, die ,ganzen Probleme[n]“ näher zu erläutern, die ihm an den USA negativ auffallen. Mangelnde Rechtssicherheit, die Abwesenheit von gesellschaftlichem Zusammenhalt und Sicherheitsdenken sowie eine irrationale „Kreditmentalität“" sind die drei Themenschwerpunkte, die Herr F spontan assoziiert und ausführlich darlegt:

Herr F: Na, ähm, ich studiere selber Jura, und allein was die Rechtssicherheit der Bevölkerung gegenüber dem Staat angeht, ist das in Deutschland... Na, anders rum, ist das in den USA dermaßen eklatant schlechter. Ja. Das kann man sich gar nicht vorstellen. Man hat halt mit den USA immer so ein gewisses Bild im Kopf irgendwie. Ja: „Howdy, howdy, howdy“, ja, und ,wir gehen alle zusammen nach vorne“, ja, und „du hattest deine Chance“, ja. Wenn du deine Chance nicht genutzt hast, dann war's das aber auch! Du hast in Deutschland, allein vom Rechtssystem, einen viel größeren Auffang.

Am Beispiel der rechtlichen Absicherung zeichnet Herr F ein Bild der USA, in dem hinter der vermeintlich solidarischen Fassade der Chancengleichheit (,wir gehen alle zusammen nach vorne“) der sprichwörtliche Abgrund lauert (,wenn du deine Chance nicht genutzt hast, dann war's das aber auch"). In Deutschland herrsche hingegen ,ein viel größerer Auffang“, was er am Beispiel des Arbeitsrechts weiter ausführt:

Herr F: [...] es ist unvorstellbar für uns, dass man einfach, selbst der, der simpelste Hilfsarbeiter von heute auf morgen einfach rausgeschmissen werden kann. Ja. Ähm, und, äh, je höher die, die, die, ähm (.) ja, Einstellungsvoraussetzungen sind, oder je höher deine Jobposition ist in Deutschland, oder generell eigentlich in Westeuropa, ja, Desto mehr Arbeitsrechtsschutz hast du eigentlich gegenüber der Firma. Ja. Das ist auch gut. In den USA dagegen, äh, selbst der krasseste Firmenboss, äh, wenn die noch krasseren Firmenbosse, mal ganz platt gesagt, zu dem morgens hingehen: ,Ja, Jim, kannst Deine Sachen packen!“”, dann kann er auch seine Sachen packen. 
Was in Deutschland schon auf den niedrigsten Rängen der Statushierarchie ,unvorstellbar“ sei, stellt in den USA selbst für die „krasseste[n] Firmenboss[e]“ alltägliche Realität dar: Jederzeit kann das soziale Band der Zusammenarbeit aufgekündigt, die gesellschaftliche Anteilnahme abgeschnitten werden. Dieser gravierende Mangel an Absicherung und Halt in der amerikanischen Gesellschaft zeigt sich Herrn F zufolge nicht nur in den Arbeitsverhältnissen, sondern auch im Konsumverhalten und in der Ökonomie insgesamt:

Herr F: Oder, ähm, was auch ganz eklatant ist, ich hab vor meinem Stu-, Jurastudium hab ich ne Ausbildung zum Versicherungskaufmann gemacht. Hab deswegen auch so ne gewisse Bank- oder Versicherungstechnische Sicht von vielen Dingen. Und in Amerika ist es halt, nicht überall, man kann so was ja nie verallgemeinern, aber ist es so, dass die Leute kaufen und dann zahlen. Und in Deutschland ist es zum Glück noch so. Auch nicht mehr, wird auch aufgeweichter, aber die Leute kaufen erst dann, wenn sie das Geld dann wirklich dafür haben. Und diese ,erst kaufen und dann zahlen', Diese Kreditmentalität führt auch wieder zu nem Aspekt, wie er sich jetzt ganz krass vor einem Jahr ausgeweitet hat, ja, dass diese Kreditblasen pla-, platzen. Und das ist zum Beispiel einfach, dieses Sicherheitsdenken ist, glaube ich, bei den Amerikanern gar nicht so ausgeprägt.

Es handelt sich bei der beschriebenen Haltlosigkeit in der amerikanischen Gesellschaft also nicht nur um eine Form der fehlenden Solidarität, so dass sozial schwächere Personen unter der Indifferenz der Mächtigen leiden, sondern es mangelt ,den Amerikanern“ insgesamt an „Sicherheitsdenken“. Die ökonomische Irrationalität der amerikanischen „Kreditmentalität“ wird von Herrn F dabei auch als Erklärung für die Finanzkrise 2008 herangezogen, was die Bedrohlichkeit dieser Eigenschaft (auch für andere Staaten) unterstreicht. Im Anschluss daran kehrt er zur Frage der inneramerikanischen Solidarität zurück und fügt die zuvor gemachten Ausführungen zu einer Allegorie zusammen:

Herr F: Also die, die haben erstens, bis jetzt so auf außenpolitische Interessen bezogen... Aber halt innenpolitisch haben die Amerikaner kein besonderes, so Solidaritätsgefühl, wie es wahr-, wie es in Deutschland irgendwie doch irgendwo noch mehr vorherrscht. Ja. Dass man irgendwie... Ja, für die ist es echt so, ganz, ja, platt gesagt, die ziehen sich auf ihre Ranch zurück, ja, laden ihre Knarre durch, und wer dann da bei denen auf's Grundstück kommt, ja, der muss halt sehen, was passiert.

Neben dem wiederum betonten Vergleich zu Deutschland, fällt an dieser Sequenz vor allem die Dichte des gewählten Bildes auf: Die „Ranch“ symbolisiert die Weite und Vereinzelung spärlich besiedelten Landes, mit der sich ,Amerika' gegen die vermeintliche Solidarität und Nähe bei ,uns Deutschen“ absetzt. Die durchgeladene 
„Knarre“ drückt die Aggressivität und Rücksichtslosigkeit aus, die sich für Herrn F mit dem amerikanischen Individualismus verbindet. Die Bedrohlichkeit dieser Vereinzelung wird im letzten Satz der obigen Sequenz deutlich: wer die Grundstücksgrenzen überschreite, müsse „halt sehen, was passiert“. Bei Androhung des Todes ist es untersagt, die Grenzen des amerikanischen Individualismus zu überschreiten. In diesem Bild scheinen Solidarität und Zusammenhalt der Gesellschaft nicht nur unterentwickelt oder abwesend, sondern sie verkehren sich geradezu in ihr Gegenteil: Die amerikanische Gesellschaft erscheint als potentiell lebensbedrohliche Gefährdung.

\subsubsection{Amerikanisierung und „diese Ressentiments [...] gegen Deutschland“"}

Seine zuvor maßgeblich negative Darstellung der USA relativiert Herr F, indem er auf die Errungenschaften und weltweiten Erfolge amerikanischer (Kultur-)Industrie und Computertechnik verweist und betont, dass er sich mit manch positivem Aspekt der USA durchaus identifiziere: „Das ist auch cool. Immerhin trag ich selbst irgendwie so leichte Baggy-Jeans, ja, und, und irgendwelche Sneaker. Das kommt nun mal aus der Ecke. Aber man muss das halt immer sehr (.) von zwei Seiten aus betrachten." Diese Ambivalenz bzw. teilweise Identifikation mit ,amerikanischer Kultur' nimmt der Interviewer zum Anlass, Herrn F auf den Terminus der „Amerikanisierung" anzusprechen. An dieser Stelle zeigt sich, dass der Topos amerikanischer Einflussnahme - ähnlich wie in Herrn Bs Rhetorik (vgl. Kap. 7.3) - eng verknüpft ist mit erinnerungspolitischen Themen. Herr F lässt die Errungenschaften amerikanischer (Kultur-)Industrie, mit denen er sich kurz zuvor noch positiv identifiziert hatte, nun zunächst beiseite. An deren Stelle tritt ein negativeres Bild der ,Amerikanisierung' im Nachkriegsdeutschland:

Herr F: Ja. Dahingehend zur Amerikanisierung denke ich mal. Wertet jeder irgendwo anders, aber es lässt sich vielleicht schon dahingehend festhalten, dass, dass, ähm... Ne Zeit lang, mittlerweile ist es nicht mehr ganz so krass, aber alles was Deutsch war, war erstmal per se schlimm, ja, ,wehret den braunen Anfängen“ und so weiter und so fort ich mein (lacht) wir haben da schon irgendwie so unser Päckchen mit uns herumzutragen. Gar keine Frage, aber es wurde doch teilweise von bestimmten Bildungs- und, und ideologischen Schichten (.) Wurde das sehr, sehr stark gefördert, diese Ressentiments einfach gegen Deutschland. Und, äh, Infolge dessen ist, glaube ich, viel was, was früher so einfach selbstverständlich war, ja, ein Deutscher Ausdruck wird durch einen englischen ersetzt, ja, ist ganz wichtig, dass grade in der Businesssprache - ich fang selber schon so an, nicht ,in der Geschäftssprache“ sondern ,in der Businesssprache“...

Interviewer: (lacht) 
Herr F: ...dass halt amerikanische Aus-, oder englische Ausdrücke eingesetzt werden. Aber die kommen halt nicht aus England, sondern in der Regel dann auch aus Amerika, was auch wieder damit zusammen liegt, dass die halt jahrzehntelang federführend in Sachen, ja, globale Geschäftsbeziehungen und so was waren, ganz klar.

Was kurz zuvor noch als völlig unproblematisch und sogar identitätsstiftend beschrieben wurde, der amerikanische Einfluss auf die deutsche Gesellschaft, erscheint hier nun als fremd und potentiell identitätsbedrohend. Möglich wird der Verlust von „,viel [...] was früher so einfach selbstverständlich war“ durch eine Schwächung des nationalen Selbstbewusstseins. Die „Ressentiments [...] gegen Deutschland“, die diesen Identitätsverlust bedingen, wurden in Herrn Fs Augen durch eine übermäßige Thematisierung von NS-Vergangenheit bzw. -Kontinuitäten bedingt:

Herr F: Ähm, aber es ist doch so, dass wahrscheinlich aufg-, so in den letzten 20 Jahren aufgrund dieser starken Ressentiments gegenüber dem (ironisch) dumpfen, traurigen, kleinbürgerlichen, spießigen Deutschen irgendwo dann doch ne vielleicht etwas zu hohe Amerikanisierungswelle Infolge dessen irgendwie so über Deutschland hineingeschwappt ist. Mittlerweile hat man sich damit absolut arrangiert. Also es würde keiner irgendwie sagen: „Ja, was ist denn jetzt los?“ Aber, ich glaub, wenn man das noch mit vor dreißig Jahren ver-, äh, vergleicht, gibt`s doch irgendwo, gibt`s nen deutlichen Unterschied. Ob das jetzt schlimm oder nicht schlimm ist. Wie gesagt, jeder hat sich damit arrangiert, und ich bin jetzt keiner, der jetzt groß Anglizismen oder so was in seiner Sprache verwendet, bis auf das kleine Beispiel da eben.

Zwar relativiert Herr F im Anschluss an seine Schilderung der Schwächung deutscher Identität sein Urteil (,Ob das jetzt schlimm oder nicht schlimm ist [...] jeder hat sich damit arrangiert") und geht zudem nicht so weit, den beschriebenen Identitätsverlust als Eingriff einer äußeren Macht zu schildern - im Gegensatz bspw. zu Herrn B, der ,amerikanische Medienmanipulation“ als Ursache für das ,falsche“ schuldbeladene Selbstbild der Deutschen ausmacht. ${ }^{8}$ Dennoch zeichnet sich an dieser Stelle des Interviews deutlich ab, dass mit ,amerikanischem Einfluss‘ auch negative Assoziationen verknüpft sind: Dieser wird nun als ,etwas zu hohe Amerikanisierungswelle“ beschrieben, die althergebrachte Praxen und Konventionen wegzuschwemmen und mit einem Verlust nationaler Identität einherzugehen droht.

8 Wie sich in einer späteren Sequenz zeigt, meint Herr F mit den „bestimmten Bildungsund [...] ideologischen Schichten“, die jene „Ressentiments [...] gegen Deutschland“ fördern, die deutsche Linke, insbesondere die 68er und die RAF: „Das ist eher so ein innenpolitisches oder innersoziales Problem [...]. Das hat nichts mit Amerika zu tun.“ 
Ähnlich wie bei Herrn B wird die Rede von „Amerikanisierung“ zum Anlass genommen, den Nationalsozialismus und die Identifikation mit Deutschland nach $1945 \mathrm{zu}$ thematisieren; und ähnlich wie bei Herrn B folgt diese Thematisierung dem Muster einer Entlastung der nationalen Wir-Gruppe via einer teilweisen TäterOpfer Umkehr (vgl. Kap. 7.3.1 und 4.6.2). Deutsche Nationalidentität ist demnach heute nicht etwa aufgrund der im Nationalsozialismus verübten Verbrechen problematisch, sondern weil bestimmte Gruppen „Ressentiments [...] gegen Deutschland" schüren. Mit dieser Figur eines ,Feindes im Innern“ folgt Herr F zwar einem klassischen Muster des sekundären Antisemitismus. Seine Bearbeitung der „Paradoxie der Normalisierung“ (Holz 2007) deutscher Nationalidentität nach 1945 kann allerdings weder als antisemitisch noch antiamerikanisch im engeren Sinne gelten, da die Rolle der ,Inneren Feinde“ weder mit ,den Juden“ noch mit ,Amerika ‘ besetzt wird. Dennoch ist die Verknüpfung der Topoi ,Amerikanisierung' und ,Erinnerungspolitik' aus der Perspektive einer Antiamerikanismuskritik bedeutsam: Amerikanischer Einfluss wird hier, trotz der Ambivalenzen in Herrn Fs persönlichem Bezug zu den USA, als Ausdruck einer Störung bzw. eines Bruches nationaler Identität konstruiert. Zwar hat man ,sich damit arrangiert“, aber die ,Amerikanisierung ' ist im Grunde doch ein Problem, das durch eine Beschädigung des Selbstbewusstseins ,der Deutschen` entstand. Herrn Fs positive Identifikation mit Teilen , amerikanischer Kultur ${ }^{9}$ mag dazu beitragen, dass er keine antiamerikanische Variante dieser Schuldumkehr-Rhetorik reproduziert.

Insgesamt deuten die vorigen Sequenzen darauf hin, dass sein Amerikabild mit einer nationalistischen Weltsicht zusammenhängt, deren Identitätsbrüche und Ambivalenzen durch vorurteilige Rhetorik bearbeitet bzw. ausgeblendet werden. Diese rigide nationale Identifikation, die durch die Offenheit und Weltgewandtheit von Herrn Fs Sprechen immer wieder durchscheint, wird im Folgenden Abschnitt anhand einiger Beispiele zum Gebrauch von Nationalstereotypen näher dargestellt.

\subsubsection{3 „Jede Nation hat irgendwie so ganz bestimmte Kerneigenschaften"}

Neben der oben dargestellten Konturierung und Aufwertung nationaler Identität erfüllt ,Amerika' in der Rede Herrn Fs noch eine weitere, in gewissem Sinne grundlegendere Funktion für dessen nationale Ordnungsvorstellungen. In den folgenden Interviewsequenzen dienen Amerikabilder weniger als negative Vergleichsfolie für bestimmte Attribute der nationalen Eigengruppe, sondern die USA werden als Au-

$9 \mathrm{Zu}$ Beginn des Interviews betont Herr F, nachdem er seine prinzipiell „unvoreingenommen[e]“ Sicht und sein „ganz objektives Verhältnis zu den USA“ hervorgehoben hat, dass er sich durchaus ,,begeistern“ könne für ,,ihre alten Autos [...] Und das Essen, das ist schon ganz lecker manchmal“". 
Benseite der ethno-nationalen Unterscheidung insgesamt eingesetzt: Amerika ist nicht nur eine Nation unter vielen, die sich hinsichtlich ihrer typischen Eigenschaften mit den übrigen vergleichen lässt, sondern sie untergräbt das Prinzip der ethnonationalen Identifikation überhaupt. Das Grundprinzip dieser Identifikation, nach der die Welt sich in nationale Gruppen mit klar umgrenzten Identitäten einteilen lässt, formuliert Herr F wie folgt:

Herr F: Ich glaub jedes... Jeder, jede Bevölkerung oder jeder Staat oder jede Nation hat irgendwie so ganz bestimmte Kerneigenschaften, ja, die sie von anderen im gewissen Maße, also raus heben, oder so was. Ich glaub bei den Amerikanern ist das echt zum Teil diese Musik und, und, und so dieser Way of Life, der von vielen anderen gerne, ja, antizipiert, genutzt, äh, oder aufgesogen wird und, pf. Ja. Ob das jetzt wirklich als Amerikanisierung im Negativen zu sehen ist, möchte ich nicht sagen. Eher nö, eher weniger.

Jede nationale Gruppe lässt sich demzufolge durch ,ganz bestimmte Kerneigenschaften“ identifizieren. In dieser Bestimmbarkeit von „Kerneigenschaften“ gleichen sich alle Nationen, mögen sich ihre jeweiligen Eigenschaften auch unterscheiden. Es macht hier zunächst den Anschein, als seien auch die USA in diesem Sinne als nationale Einheit identifizierbar: Amerikanische „Musik“ und „dieser Way of life“" stellen deren herausstechende Merkmale dar, die von Herrn F explizit nicht als „Amerikanisierung im Negativen“, d.h. nicht als etwas Minderwertiges oder Bedrohliches angesehen werden. Anhand der folgenden Stelle, in der Herr F die amerikanischen „Kerneigenschaften“ näher beschreibt, wird allerdings ersichtlich, dass zugleich ein grundlegender Unterschied zwischen deutscher und amerikanischer Nationalidentität konstruiert wird:

Herr F: Ich glaub, das ist in den USA, man sagt halt von den Amerikanern, die haben halt ein krasses Organisationsgeschick, -talent, ja, die können so Massen begeistern und dann, äh, alle uns nach. Aber, ähm, das ist halt... Oder ja, so einen Way of Life propagieren irgendwie. Das ist halt das, was die Amerikaner ganz grundsätzlich, äh, nicht auf den Einzelnen bezogen, aber auf die Masse, ganz grundsätzlich ausmacht, ähm. Können Trends setzen, ähm, aber eher so, so, so, im, im Lifestyle-Bereich. Schon wieder so ein (lacht) Anglizismus. Halt eher so im Lifestyle-Bereich, ähm, während das in Deutschland, ja, so sehr auf grundlegende Werte bezogen ist.

„Trends“ im „Lifestylebereich“ werden hier den ,grundlegende[n] Werte[n]“ der Deutschen gegenübergestellt, wodurch auf Seiten der amerikanischen Eigenschaften Konnotationen von Oberflächlichkeit und Substanzlosigkeit aufgerufen werden. 
Stärker als in den vorigen Vergleichen mit europäischen Ländern ${ }^{10}$ wird hier der essentielle und ursprüngliche Charakter , der Deutschen' herausgekehrt, indem dieser einem instrumentell-flexiblen „Organisationsgeschick“ (,Massen begeistern“, ,,alle uns nach") , der Amerikaner" gegenübergestellt wird. Im Folgenden wird argumentiert, dass dies nicht als eine Gegenüberstellung von besseren und schlechteren Eigenschaften zu verstehen ist, sondern als eine von Eigenschaften und Eigenschaftslosigkeit. Dass die vermeintliche Eigenschaftslosigkeit der USA hier dennoch anhand von nationalen Eigenschaften ,der Amerikaner' beschrieben wird, macht den spezifischen Gehalt der antiamerikanischen Figur des Dritten aus: An ,Amerika ' erscheint das Andere der nationalen Ordnung in Gestalt einer Nation.

In der anschließenden Sequenz wird der Kontrast zwischen Deutschland und Amerika als einer zwischen ethnischer Homogenität und ethnischer Heterogenität erweitert. Damit nimmt die Konstruktion Amerikas als Außenseite der ethnonationalistischen Ordnung konkrete Züge an:

Herr F: Ja. Man muss halt dazu auch einfach sagen, ich mein Deutschland das ist irgendwo ne homogene Masse. Ja. Die Deutschen sind alle Deutsche. Ja. Selbst die Ausländer, die hier bei uns in Deutschland leben, sofern sie sich gut integriert haben, solange sie irgendwie, was weiß ich, dritte Gastarbeitergeneration da irgendwie, die sind teilweise ,deutscher“, in Anführungsstrichen, als jeder normale Deutsche. Ja. In Amerika is... In Amerika... Den Amerikaner als Solches gibt's ja gar nicht. Das ist so ein Schmelztiegel an Kulturen. Ja. Da kommen irgendwelche Latinos, da kommen Asiaten. Dann mal der Uramerikaner, wobei der Uramerikaner eigentlich der Indianer ist, und die Jungs, die sich Uramerikaner schimpfen, die kommen auch aus Europa. Ja. Das ist so ein Potpourri an, an, an Mentalitäten und Kulturen, deswegen kann man das eigentlich gar nicht so vergleichen wie in Deutschland.

Die bruchlose Identität, als die Herr F die deutsche Wir-Gruppe konstruiert, zeigt sich komprimiert in dem Satz: „Die Deutschen sind alle Deutsche“. Die tautologische Formel dient als rhetorischer Ausdruck dafür, dass Herr F diachrone oder synchrone Hybridität bzw. Wandelbarkeit in seiner Wir-Gruppenkonstruktion ausklammert. Auf den ersten Blick mag die darauffolgende Ergänzung, in Deutschland seien ,selbst die Ausländer“ deutsch, ja sogar ,teilweise deutscher [...] als jeder normale Deutsche“, dieser Interpretation wiedersprechen. Auf den zweiten Blick zeigt sich aber gerade an dieser Stelle das essentialistische Fundament der nationalen Identifikation: Dass „,die Ausländer“ auch dann, wenn ,sie sich gut integriert

10 Auf die Bitte hin, die deutschen „Kerneigenschaften“ zu beschreiben, wählt Herr F dann zunächst auch nicht die USA, sondern europäische Länder, insbesondere „Frankreich, Spanien, Italien“, als Vergleichsgrößen, deren mangelnder Arbeitsmoral, unzureichendem ökologischen Bewusstsein er „Fleiß, Disziplin und [...] Qualitätsanspruch“ der Deutschen gegenüberstellt. 
haben“ nur „,in Anführungsstrichen“ deutscher als „,normale Deutsche“ sind, markiert eine unüberbrückbare ethnische Grenze. Deutsch-Sein wird implizit in zwei Dimensionen aufgeteilt, die kulturelle, auf der , die Ausländer' manchen ,normalen Deutschen “ übertreffen können, und die völkisch-essentialistische, an der Menschen allein durch Abstammung Anteil haben. Herrn Fs scheinbar liberale, multikulturalistische Konstruktion gründet in diesem Sinne auf rigiden ethnischen Grenzziehungen bzw. der Annahme einer unveräußerlichen ethnischen Zugehörigkeit, einem ethnischen Verwandtschaftsglauben (Sutterlüty 2008).

Dieser ethno-nationalistischen Konstruktion wird nun Amerika als „Schmelztiegel an Kulturen“ gegenübergestellt. Um die ethnische ,Bodenlosigkeit" der USA aufzuzeigen, zählt Herr F verschiedene Gruppen auf, „Latinos“ und „Asiaten“, um schließlich auch den „Uramerikaner“ anzuführen. Dieser „Uramerikaner“ ist aber nicht in derselben Weise identifizierbar, wie andere Ethnien. „Eigentlich“, so merkt Herr F an, wären „die Indianer“ an die Stelle der „Uramerikaner“ zu setzen. Aber auch diese ethnische Ursprungserzählung bietet keine befriedigende Lösung für die amerikanische ,Uneigentlichkeit“. Amerika als Nation von „Indianern“ zu betrachten, erscheint abwegig. Zugleich können aber auch diejenigen, die sich selbst „Uramerikaner schimpfen“, nicht als ,echte“ Amerikaner gelten, da sie ,auch aus Europa“ stammen. Der obenstehende Interviewausschnitt endet mit der Feststellung, dass man daher beide Nationen ,gar nicht so vergleichen“ könne.

Im Rahmen der hier vorgeschlagenen Interpretation einer antiamerikanischen Figur des Dritten ist diese Unvergleichbarkeit in doppelter Weise zu verstehen: Nicht nur sind Deutschland und die USA in dem umgangssprachlichmetaphorischen Sinne nicht vergleichbar, dass zwischen ihnen ein extremer Unterschied hinsichtlich der Bevölkerungsstruktur besteht; vielmehr sind die verschiedenen ethnischen Gruppen innerhalb der jeweiligen Nation nicht auf dieselbe Weise miteinander vergleichbar, und gerade darin besteht der Unterschied zwischen Deutschland und den USA. Mangels des ethnischen Maßstabs eines „Uramerikaners“ lassen sich „Latinos“, „Asiaten“ und andere Ethnien als Amerikanerinnen und Amerikaner nicht so zueinander ins Verhältnis setzen, wie „Ausländer“ und „,normale Deutsche“ in Deutschland.

In dieser Konstruktion deutscher Nationalität macht sich die Gleichheit der Bürger als Deutsche an einer essentiellen ethnischen Differenz fest: Man wird deutsch indem man sich der Referenzgruppe der ,ethnisch Deutschen“ annähert, was aber zugleich bedeutet, dass man nur qua Geburt „normale[r] Deutsche[r]“ werden kann. In den USA gibt es keine identifizierbare ethnische Referenzgruppe, die als Grundlage der nationalen Identität fungieren kann, weshalb alle ethnischen Gruppen in den USA zwar als Amerikaner gleich sind, es für dieses amerikanischSein aber ,eigentlich“ gar keinen Vergleichsmaßstab gibt. Das amerikanisch-Sein, so könnte man auch sagen, hat hier keinen ,ethnischen Kern'. 
Dies führt im Rahmen des ethnonationalen Weltbildes von Herrn F in ein Dilemma: Die verschiedenen Bevölkerungsteile der USA gehören nicht ,eigentlich“ ihren ethnischen Gruppen an, weil sie AmerikanerInnen sind; sie sind aber auch nicht ,eigentlich“ AmerikanerInnen, da die USA nur aus verschiedenen Einwanderergruppen bestehen und es somit kein ethnisches Kriterium für die nationale Zugehörigkeit gibt. Zugleich scheint aber die Anerkennung der USA als nationale Einheit unvermeidlich. Man kann das Dilemma nicht einfach lösen, indem man die amerikanischen Bürger als „Europäer“, „Latinos“ und „Asiaten“ betrachtet, die sich außerhalb ihres , angestammten“ Territoriums befinden. Denn in der nationalen Ordnung muss dieses ,Außerhalb“ selbst wieder national bestimmt werden. Genau dies, so kann in Adaption von Klaus Holz Analyse des nationalen Antisemitismus gesagt werden, ist die Leistung der antiamerikanischen Figur des Dritten: Sie ermöglicht es, ein Außen der nationalen Ordnung zu thematisieren, ohne die Geltung der nationalen Ordnung einzuschränken. Amerika als Drittes der Kulturnationen ist „die Negation der nationalen Form aus der Perspektive der Innenseite der nationalen Form“ (Holz 2010, S. 302). Und dies auf eine bestimmte Weise, nämlich indem die Verknüpfung von Ethnizität und Nationalität in Frage gestellt wird: An Amerika erscheint die Möglichkeit, dass Nationen nicht ethnisch begründet bzw. Ethnizität nicht national verfasst sein könnte. In einem weiteren Sinne bedeutet dies die Kontingenz ethnischer Identität insgesamt: Dass ,die Deutschen“ nur als eine historisch kontingente und wandelbare Beobachtungskategorie existieren bzw. Deutsch-Sein sich nicht durch „grundlegende[n] Werte[n]“ und bruchlos-tautologische Identität absichern lässt - all das scheint an Amerika auf und wird im selben Moment wieder entschärft. Die Kontingenz der eigenen ethno-nationalen Identifikation wird an Amerika sozusagen ,im abgesicherten Modus“ beobachtet. Darin liegt der ideologische Gehalt dieser antiamerikanischen Rhetorik: Die Brüchigkeit der eigenen Identitätskonstruktion auf solche Weise latent zu thematisieren, dass deren nationalistische Kernprämisse zugleich bestärkt wird.

Diese ideologische Funktion, die latente Thematisierung von Hybridität bei gleichzeitiger Stabilisierung ethno-nationaler Homogenität, wird in der folgenden Sequenz noch einmal deutlich. In einem späteren Teil des Gespräches bittet der Interviewer Herrn F um zusätzliche Erläuterungen dazu, warum der Einfluss ,amerikanischer Kultur' so groß bzw. weit verbreitet sei:

Herr F: Ja, ich denke, das liegt einfach daran... Ich hab ja eingangs schon erwähnt, dass der... Den Amerikaner als Solches, oder Amerika als Solches ist halt keine in sich homogene Struktur oder homogene Gesellschaft, das sind halt hunderte von Kulturen, die von außen hineinschwappen und von dort aus nur kanalisiert irgendwo weitergegeben werden.

Interviewer: Okay. 
Herr F: Also ich mein, ähm, hier Hip-Hop zum Beispiel. Ich mein, dass es halt grundschwarze Musik gibt... Als Solches, sollte es eigentlich gar keinen schwarzen Am-, Amerikaner geben. Ja. Die sind halt alle als Sklaven damals eingeschleppt worden bzw. wandern jetzt möglicherweise nach Amerika aus, aus irgendwelchen, äh, anderen Regionen in der Welt, äh... Weil sie da halt sich ein besseres Leben erhoffen. Und das nur mal als eines, als ein Beispiel.

Amerika wird von Herrn F als bloßes Medium beschrieben, das „nur kanalisiert“ was ,von außen“ hineinkommt. In dieser Perspektive erscheint die amerikanische Heterogenität als Abweichung vom ,Normalzustand" ethnischer Identifikation: Hybridität als Identitätsmerkmal wird von Herrn F systematisch ausgeschlossen bzw. nur aus sicherer Distanz, aus dem Innenraum ethnischer Identität heraus, zur Beobachtung zugelassen.

Dass diese ideologische Thematisierung von Hybridität mit einem umso schärferen ethnozentrischen Essentialismus zusammenhängt, zeigt der Bezug auf AfroAmerikaner und Hip Hop in der obigen Sequenz: Es sollte ,eigentlich gar keinen schwarzen [...] Amerikaner geben“, Afro-Amerikanerinnen und -Amerikaner erscheinen Herrn F als, verschleppte Afrikaner“. Dies veranschaulicht, dass die Identitätskonstruktion, die hier antiamerikanisch gesichert wird, zugleich mit ethnozentrischen bzw. rassistischen Zuschreibungen auf andere Gruppen einhergeht. So gilt Herrn F „Hip Hop“ zugleich als ,grund-schwarze Musik“ und als genuin amerikanisch. Genau diese Hybridität darf in seiner Weltsicht aber ,eigentlich“ gar nicht bzw. nur als amerikanische Ausnahme vorkommen: Im Grunde bleiben , die Afrikaner“ immer ,Afrikaner“, so wie ,die Deutschen [...] alle Deutsche“ sind. Hinter diesem Begriff nationaler Kulturen verbirgt sich also eine völkisch-essentialistische Konstruktion - „,Kulturnation“ ist Blutsgemeinschaft soft“ (Welsch 2010, S. 10; vgl. auch Kap. 7.4.1.2).

In der anschließenden Sequenz zählt Herr F zusätzliche Beispiele ,amerikanischer Kultur' auf, wobei sich das oben rekonstruierte Muster reproduziert: Sobald etwas als ,typisch amerikanisch“ dargestellt wird, wird auch auf dessen ethnischkulturelle Uneigentlichkeit hingewiesen.

Herr F: Oder, ähm, was, was gibt`s noch? Was bei uns so als typisch Amerikanisch wahrgenommen wird? Ja, Tex-Mex, so diese, diese, ja, Burritos und so was, ne. Denken alle immer: „Jo, geil, amerikanisches Essen.“ Ja, Pustekuchen. Ist eigentlich lateinamerikanisch, aber der gesamte Südwesten von Amerika ist halt voll von irgendwelchen Chicos. Ja. Und, und die importieren natürlich auch ihr Essen. Ja. Das ist ja bei uns in Deutschland in Teilen vergleichbar. Äh, wenn wir irgendwie Schawarma oder Döner essen. Na gut, Döner ist noch ne deutsche Erfindung, zumindest so, wie wir ihn essen, aber das ist ja auch eigentlich grundsätzlich irgendwas Arabisch- bzw. Türkisches. Und so ist es auch in Amerika. [...] Weil was zum Beispiel ja auch faszi-... Oder wenn man sich das mal genau überlegt, ähm, es gibt, 
glaube ich, nichts, was so vom Uramerikaner herkommt. Also ich... Man hat halt auch immer so ein, das stereotype Bild von irgendeinem Farmer irgendwo mittleren Westen vor sich, ja. Also von diesen Leuten gibt es halt im Grunde genommen nichts, ja, was, was als kulturelle Bereicherung irgendwie nach Europa schwappt. Das sind in der Regel von musikalisch, sind's halt meistens irgendwelche Schwatte oder Latinos oder Latinas, hier Beyonce, oder, wie heißt die andere, Jennifer Lopez, oder so was. Das ist ja... Wie gesagt, die haben andere Wurzeln. Vom Kulinarischen sind's auch, nicht ausschließlich, aber teilweise, ähm, kommt das im Grunde auch aus anderen Regionen, ja, und so halt. Das ist... Ich denk eher, das ist so ne Kanalisierung der gesamten Kulturen, und die wird dann halt in die Welt rausgeschickt.

Zwar ist die ethnische Heterogenität Amerikas mit dem deutschen Multikulturalismus ,,in Teilen vergleichbar“, insofern Immigrierende in beiden Ländern ihre Essgewohnheiten ,importieren“. Der anschließende Hinweis auf die kulturelle Bedeutungslosigkeit des „Uramerikaners“ markiert aber den oben bereits rekonstruierten Unterschied zwischen deutscher Nation und amerikanischer Anti-Nation: In Deutschland ergänzen sich die ,importierten“ Essgewohnheiten mit denjenigen der ,Autochthonen“. Selbst „Döner“ ist ,noch ne deutsche Erfindung“. In Amerika hingegen existiert eine ,reine“ Heterogenität, da dort ,nichts [...] vom Uramerikaner herkommt“. Die „Burritos“ bleiben ,lateinamerikanisch“. In diesem Antiamerikanismus erscheinen die USA als bloße „Kanalisierung der gesamten Kulturen“, während jene Nationalkulturen als „beobachtungsfrei existierende Sachverhalte“ (Nassehi 1997a, S. 190) aufgefasst werden: Amerika wird als paradoxe Identität, als reine Vermittlung konstruiert, um die prinzipielle Vermitteltheit und Kontingenz der übrigen ,kulturellen Identitäten` unsichtbar werden zu lassen.

\subsubsection{Zusammenfassung Herr F}

Zwei rhetorische Funktionen antiamerikanischen Sprechens wurden im Gespräch mit Herrn F ausgemacht. Einerseits konnte eine umfassende Konturierung und Aufwertung der nationalen Wir-Gruppe mittels einer , amerikanischen' Vergleichsfolie rekonstruiert werden. Gegen die vermeintliche Prekarität ,amerikanischer Verhältnisse“ erscheint die Gesellschaft Deutschlands als besonders wohlhabend und sozial abgesichert: „die vereinigten arabischen Emirate der westlichen Welt“. Gegen den aggressiven Egoismus ,der Amerikaner' erscheinen ,die Deutschen ‘ als solidarische Gemeinschaft. Gegen die Flüchtigkeit und Oberflächlichkeit des ,amerikanischen Lifestyle“ erscheint das Leben in Deutschland als ,auf grundlegende Werte bezogen“. Über , amerikanische Probleme“ sprechen bedeutet bei Herrn F immer auch, über ,deutsche' Sicherheit, Rationalität, Traditionalität und Gemeinschaft zu sprechen. An ,Amerika' zeigt sich, wer, wir' sind.

Eingebettet ist diese Identitätskonstruktion in eine ethno-nationalistische Weltsicht: Herrn Fs weltoffener Multikulturalismus basiert auf rigiden ethnischen 
Grenzziehungen, mittels derer die Welt in eine Menge von ,Völkern“ mit spezifischen „Kerneigenschaften“ und quasi-natürlichen, nationalen Territorien eingeteilt wird. Bilder einer ,Kulturlosigkeit" und ,bodenlosen Heterogenität“ Amerikas dienen der Struktursicherung dieser „Herder'sche[n] Weltsicht“ (Wimmer 2008, S. 60 ), indem die USA als eine Figur des Dritten konstruiert werden, die nicht nur als Negation des ,deutschen Nationalcharakters" sondern als Anderes der ethnonationalen Ordnung überhaupt fungieren. Die USA sind demnach die einzige Nation, die nur aus Einwanderern besteht. Qua dieses Mangels an einer ethnisch identifizierbaren Referenzgesellschaft können sie gemäß der Herder'schen Weltsicht nicht ,eigentlich“ eine Nation sein: Es gibt keinen „Uramerikaner“. Zugleich aber scheint es Herrn F unumgänglich, ,Amerika‘ als Nation anzusprechen. In diesem widersprüchlichen Amerikabild erscheint somit auf ideologisch verdeckte Weise, was ein essentialistischer ethno-Nationalismus systematisch ausschließen muss: die uneigentliche Nation. An ,Amerika' wird latent thematisiert, dass alle ethnischnationale Identität entgegen ihrem eigenen Homogenitätsanspruch hybrid, entgegen ihrem Ursprünglichkeitsanspruch historisch geworden und kontingent ist.

Dabei zielt diese antiamerikanische Struktursicherungsfunktion hauptsächlich auf den Zusammenhang zwischen ethnischer und nationaler Identität: An ,den Amerikanern' entzieht sich etwas der ethnischen Zuordnung, insofern diese nach Amerika eingewandert und somit ihrer ,ursprünglichen' ethnischen Gruppe entfremdet sind. Zugleich aber ist das Konstrukt einer amerikanischen Nation notwendig, um die angesprochenen Gruppen überhaupt national klassifizieren zu können. Ebenso wenig, wie die jeweiligen Personengruppen einfach ,Mexikaner', ,Europäer' etc. sind, sind die USA einfach ,Niemandsland‘. Da es aber gemäß Herrn Fs Amerikabild keine ,Ur-Amerikaner' gibt, die den USA die ethno-nationale Weihe geben könnten, springt seine Konstruktion ,der Amerikaner' beständig hin und her zwischen deren Bestimmung als Vielzahl ethnischer Gruppen, die aufgrund ihres Amerikanisch-Seins nicht, eigentlich“ ihrer jeweiligen Ethnie zugehören, und der Gesamtheit amerikanischer Bürgerinnen und Bürger, die aufgrund ihrer jeweils verschiedenen Ethnizität nicht ,eigentlich amerikanisch“ sind. Als Drittes der ethnonationalen Weltordnung stellen somit, die USA ‘ eine ideologische Verarbeitungsform der Kontingenz des ethnopluralistischen Nationalismus von Herrn F dar.

Darüber hinaus finden sich im Sprechen von Herrn F durchaus ethnozentrische und schuldabwehrende Motive, wie sie in den Kapiteln 7.3 und 7.4 anhand anderer Fälle detailliert behandelt werden. Jedoch weichen die antiamerikanischen Sprachgebräuche Herrn Fs in beiden Bereichen entscheidend von den Funktionen ab, die bspw. bei Herrn A oder Herrn B beobachtet werden können: Im Gegensatz zu Herrn A liegt bei Herrn F die Funktion antiamerikanischen Sprechens nicht in der Rechtfertigung oder ,Entschärfung ' des eigenen Rassismus. Und auch die erinnerungspolitische Problematik des Umganges mit der NS-Vergangenheit wird nicht, wie etwa bei Herrn B, antiamerikanisch bearbeitet: Die Widersprüchlichkeit positiv deutsch- 
nationaler Identifikation nach 1945 wird hier nicht durch amerikanischen Einfluss o.ä. erklärt, sondern die „Ressentiments [...] gegen Deutschland“ werden als innerdeutsches Problem dargestellt (befördert durch ,Linke“ und ,68er'), dessen Folge eine übermäßige Amerikanisierung ist. Der Antiamerikanismus von Herrn F bewegt sich damit zwar in einem sehr ähnlichen weltanschaulichen Kontext, wie die Beispiele in Kapitel 7.3 und 7.4, kann aber dennoch aufgrund seiner rhetorischfunktionalen Eigenschaften sinnvoll von diesen unterschieden werden: Die zentrale Funktion antiamerikanischer Rede bei Herrn F besteht in der rhetorischen Absicherung einer bruchlosen ethno-nationalistischen Ordnung mittels einer latenten Bearbeitung der nichtidentischen Aspekte dieser Ordnungsvorstellung.

\subsubsection{Zwischenfazit: Antiamerikanismus im Funktionskontext nationaler Identität}

Ausgangspunkt des hier entwickelten performativen Antiamerikanismusbegriffes ist die Annahme, dass die Bestimmung von Vorurteilen notwendig verknüpft ist mit der Kritik einer Praxis von Ungleichheit und Diskriminierung (vgl. Kap. 2.4, 3.4 und 4). D.h. dass der vorurteilige Gehalt einer Sprechweise sich weder an lexikalisch-semantischen noch an psychischen Merkmalen festmachen, sondern letztendlich nur unter Bezug auf dessen Wirkung in Diskriminierungs- und Verfolgungspraxen aufzeigen lässt. In Kapitel 4.6.1 wurde erläutert, dass dies nicht bedeutet, dass jedes vorurteilige Sprechen notwendig unmittelbar zur Benachteiligung oder Schädigung der bezeichneten Personen(-gruppen) führen muss. Vielmehr kann der vorurteilige Gehalt antiamerikanischer Sprechweisen auch mittelbar darin bestehen, dass sie der Konturierung, Aufwertung und Struktursicherung von Identitätskonstruktionen und weltanschaulichen Ordnungsmustern dienen, die wiederum systematisch mit Diskriminierung und Verfolgung zusammenhängen.

Anhand der Fälle von Herrn C und Herrn F konnte nun gezeigt werden, wie Antiamerikanismus als Ausdruck und funktionaler Bestandteil rigider nationaler Identitätskonstruktionen fungieren kann. Hierbei wurden zwei Hauptfunktionen herausgearbeitet: Einerseits werden Amerikastereotype dazu genutzt, durch Vergleiche von nationaler Eigengruppe und ,amerikanischer' Fremdgruppe, eine klare Konturierung und positive Bewertung der Wir-Gruppeneigenschaften zu erzeugen. Über ,Amerika' sprechen heißt bei Herrn C und Herrn F, über die Werte, Tugenden und die Ursprünglichkeit der Eigengruppe zu sprechen. Andererseits konnten in beiden Fällen rhetorische Funktionen mit kommunikationslatenter Wirkung herausgearbeitet werden: Von beiden Teilnehmern werden Amerikabilder dazu gebraucht, Widersprüche und Kontingenzen in ihren nationalen Identitätskonstruktionen zu bearbeiten, ohne diese explizit ansprechen zu müssen. Bei Herrn $\mathrm{C}$ bezieht sich diese Latenzfunktion auf die Teilung Ost- und Westdeutschlands. Sich gegen ,Amerikani- 
sierung' zu positionieren bedeutet hier, ein einiges Deutschland zu konturieren und aufzuwerten, und zugleich einen internen Konflikt mit ,den Wessis‘ auszutragen.

Eine ähnliche Latenzfunktion erfüllt die antiamerikanische Rhetorik im Sprechen von Herrn F. Hier werden die USA als eine Figur des Dritten konstruiert, als selbstwidersprüchliche, uneigentliche Nation, die als Außen der ethno-nationalen „Herder'schen“ Weltsicht fungiert. ,Amerika“ wird hierbei einerseits als Nation vorgestellt, und deren Bürgerinnen und Bürger als ,Amerikaner'. Andererseits wird aber daran festgehalten, dass der nationale Charakter ,Amerikas' sich an keiner ethnisch identifizierbaren Gruppe von „Uramerikanern“ festmachen lässt und die USA deshalb aus ethno-nationalistischer Perspektive überhaupt keine Nation sein können. Diese Spannung wird im Sprechen von Herrn F nicht zu einer Seite hin aufgelöst. Die USA symbolisieren somit die Möglichkeit, dass ethnische und nationale Identität nicht quasi-natürlich gegeben und für alle Zukunft gesichert sein könnten. Sie unterminieren den Begriff der Nation, mit dem sie zugleich aber angesprochen werden müssen. Oder, in Anlehnung an Klaus Holz (vgl. Kap. 7.2.2.3): Sie erlauben die Negation der ethno-nationalen Ordnung, unter fortlaufender Geltung der ethno-nationalen Ordnung.

In beiden Fällen konnten zudem Ähnlichkeiten mit antisemitischen und rassistischen bzw. ethnozentrischer Konstruktionen aufgezeigt werden. So findet sich bei Herrn $\mathrm{C}$ ein Antagonismus von solidarischer, produktiver Gemeinschaft und egoistischer, parasitärer Gesellschaft, der sich in großer Nähe zu den Konstruktionsprinzipien des modernen Antisemitismus bewegt. Ebenfalls in rhetorischer Verwandtschaft zu antisemitischen Konstruktionen befindet sich das schuldumkehrende Argumentationsmuster von Herrn F, dem zufolge ,linke' Gruppen innerhalb Deutschlands nach 1945 systematisch einen Schuldkomplex erzeugt hätten, der das ,deutsche Selbstbewusstsein ' geschwächt und empfänglich für ,Amerikanisierung ' gemacht habe. Derartige Schuldabwehrkonstruktionen werden im folgenden Kapitel 7.3 genauer analysiert.

Die nationalistische Weltsicht Herrn Fs, so konnte gezeigt werden, geht zudem nahtlos über in ethnozentrische Diskriminierung, die dort aufscheint, wo rigide Ausschluss- bzw. Inklusionskriterien formuliert werden. Bspw. wenn Herr F beschreibt, dass es ,eigentlich gar keinen schwarzen am-, Amerikaner geben“ sollte, da diese schließlich ,eigentlich“ aus anderen Ländern stammten, oder dass „Ausländer“ in Deutschland, die „sich gut integriert haben“, u.U. „deutscher, in Anführungsstrichen, als jeder normale Deutsche“ wären - was eine unüberwindliche ethnische Grenze zwischen ,normalen Deutschen“ und ,integrierten Ausländern“ markiert.

Die Zusammenhänge zwischen nationalistischen, ethnozentrischen, antisemitischen und antiamerikanischen Konstruktionen scheinen bislang also v.a. durch den gemeinsamen Bezug auf einen essentialistischen Ethnonationalismus begründet. Hierbei wird auch deutlich, dass zwischen den verschiedenen beschriebenen Vorur- 
teilsformen gewissermaßen fließende Übergänge bestehen. Dennoch können insbesondere die beiden rekonstruierten Latenzfunktionen als besondere (wenngleich nicht exklusive) rhetorische Wirkweisen des Antiamerikanismus angesehen werden. Ähnlich wie beim Antisemitismus scheint antiamerikanische Rhetorik dazu geeignet, bestimmte Widersprüche nationaler Identitätskonstruktionen latent zu thematisieren und dadurch ideologisch zu entschärfen. 


\subsection{ANTIAMERIKANISMUS IM FUNKTIONSKONTEXT VON ERINNERUNGSPOLITIK, SCHULDABWEHR UND ANTISEMITISMUS}

Antiamerikanische Rhetorik erfüllt, so konnte im vorigen Kapitel gezeigt werden, Funktionen der Konturierung und Stabilisierung nationaler Identität. Amerika dient dabei nicht nur als negative Vergleichsfolie zur unmittelbaren ethnozentrischen Aufwertung der Eigengruppe, sondern kann darüber hinaus auch der Struktursicherung eines ethno-nationalistischen Weltbildes dienen: ,Amerika' bildet in solchen Konstruktionen das Außen zu einer nationalen Ordnung, in der ethnische Identität und nationale Zugehörigkeit eine quasi-natürliche Einheit bilden. Im vorliegenden Kapitel wird es um eine andere Form der Konstruktion und Sicherung nationaler Identität gehen, die sich insbesondere auf die Herstellung einer positiven deutschen Nationalidentität nach 1945, d.h. angesichts der nationalsozialistischen Vergangenheit, bezieht. Wie in Kapitel 4.6.2 dargestellt wurde, befindet sich jeglicher Versuch einer positiven Identifikation mit Deutschland nach 1945 in einem spezifischen Dilemma: Die nationalsozialistische Vergangenheit Deutschlands verunmöglicht jeden positiven Bezug auf deutsche Nationalidentität, der nicht zugleich auch diesen Bruch in Betracht zieht. Im Anschluss an Klaus Holz' Arbeiten zum demokratischen Antisemitismus wurde diese „Paradoxie der Normalisierung“ (Holz 2007) zu einem Kernmoment antisemitischer Ausdrücke nach 1945 erklärt: Dieser muss demnach - wie im Grunde jede bruchlos positive Nationalidentifikation - die deutsche Judenvernichtung ,leugnen, verdrehen, aufrechnen, normalisieren, bewältigen“ (ebd., S. 51), um die negativen Implikationen einer positiven Identifikation mit Deutschland zu vermeiden. Aus nationalistischer Perspektive wird nach 1945 der Holocaust zu einem zentralen ,Identitätsproblem', das auch antisemitisch bearbeitet werden kann. Das wichtigste rhetorische Muster hierbei ist die Täter-Opfer Umkehr, in der , die Deutschen “ nicht mehr als Täter des Holocaust, sondern als Opfer einer unrechtmäßigen Verurteilung von außen erscheinen. Sofern als Ankläger in diesem Szenario ,die Juden " auftreten, handelt es sich um eine antisemitische Bearbeitung der „Paradoxie der Normalisierung“: Das ,nationale Identitätsproblem“ des Vernichtungsantisemitismus wird antisemitisch gelöst. Hierbei kommen nicht selten auch klassisch-antisemitische Stereotype etwa einer ,jüdischen Rachsucht* oder ,Habgier' zum Einsatz.

In den folgenden Abschnitten werde ich anhand meines Interviewmaterials eine antiamerikanische Variante dieser Vergangenheitsbewältigung aufzeigen, in der ,die Amerikaner' anstelle ,der Juden` die Rolle der unrechtmäßigen Ankläger und 
Manipulateure einnehmen. ${ }^{1}$ Neben dem Stereotyp einer , amerikanischen Medienmanipulation'bzw. einer , amerikanischen Weltpolizei' kommen in den unten aufgeführten Rhetoriken Bilder eines ,amerikanischen Rassismus‘ sowie des Genozids an amerikanischen Ureinwohnern zum Einsatz. Diese erlauben es Herrn B und Herrn D, im Vergleich mit Amerika die nationalsozialistische Judenvernichtung zu normalisieren, und durch die Ablehnung , amerikanischer Verbrechen " zugleich die eigene moralische bzw. demokratische Integrität zu demonstrieren. In Herrn Bs Fall ist die ideologische Funktion besonders deutlich ausgeprägt, da der Holocaust von ihm über das gesamte Interviewgespräch latent gehalten wird: Normalisierende Vergleiche mit einem , amerikanischen Genozid“ ermöglichen es ihm, die deutsche Judenvernichtung rhetorisch zu bearbeiten ohne sie jemals explizit ansprechen zu müssen. Im Fall von Herrn D hingegen wird eine Erinnerung an nationalsozialistische Verbrechen zunächst vollkommen ausgeblendet, also gerade nicht im oben explizierten Sinne latent gehalten. Demensprechend werden Amerikastereotype erst dann erinnerungspolitisch gebraucht, als das Thema der Judenvernichtung vom Interviewer explizit angesprochen wird. Hier dient der Vergleich mit den amerikanischen Atomangriffen auf Hiroshima dann als explizite Vergleichsfolie, mit der die Bedeutung der nationalsozialistischen Vergangenheit relativiert wird.

Wenngleich die Sprechweisen von Herrn B und D nicht als antisemitisch einzustufen sind, kann an ihnen beispielhaft die Verwandtschaft antisemitischer und antiamerikanischer Rhetorik aufgezeigt werden. Dies gilt in zweierlei Hinsicht: Zum einen existiert eine funktionale Parallele zwischen diesem und einem demokratischen Antisemitismus. Beide Vorurteilsformen bearbeiten dasselbe Problem einer „Paradoxie der Normalisierung“ deutscher Nationalidentität und greifen hierzu auf Strategien der Täter-Opfer Umkehr, der Kommunikationslatenz und des relativierenden Vergleichs zurück. Zum anderen gebraucht Herr B in seiner antiamerikanischen Schuldabwehr Amerikabilder, die als semantische Anleihen aus dem Repertoire des modernen Antisemitismus gelten können, insbesondere dasjenige einer ,amerikanischen Medienkontrolle'.

Am Beispiel von Frau K wird abschließend eine klassisch antisemitische Konstruktion aufgezeigt, in der , die Juden“ als ,Drahtzieher' einer amerikanischen Politik dargestellt werden, die aus Profitinteressen ,die halbe Welt mit Krieg überziehen“. In diesem nur notdürftig durch antizionistische „Camouflage“ (Holz 2005, S. 82 ff.; Holz 2001, S. 440 ff.) geschützten Antisemitismus erfüllt antiamerikanisches

1 Mit einer leicht schiefen Analogie sprechen Andrei Markovits und Lars Rensmann diesbzgl. von einem „secondary anti-americanism“ (Markovits und Rensmann 2007, S. 176) - schief ist diese deshalb, weil der Antisemitismus nach 1945 seinen ,sekundären“ Status aus einer antisemitischen Abwehr antisemitischer Taten zieht, ein sekundärer Antiamerikanismus sich aber, zumindest in den vorliegenden Beispielen, nicht auf die Abwehr antiamerikanischer Taten bezieht. 
Sprechen keine Latenz- oder Rechtfertigungsfunktion, sondern ist Bestandteil der antisemitischen Rhetorik.

\subsubsection{Falldarstellung Herr B: Antiamerikanische Schuldabwehr und latente Normalisierung des Holocaust}

Am Beispiel von Herrn B wird im Folgenden eine antiamerikanische Form der Normalisierungsrhetorik rekonstruiert, die starke Ähnlichkeit mit sekundärantisemitischen Argumentationsmustern aufweist. Antiamerikanische Sprechweisen übernehmen hierin die Funktion einer Entlastung der Täter des Nationalsozialismus, die so mit den nachgeborenen Generationen zu einer positiven nationalen WirGruppe versöhnt werden. Dies funktioniert wesentlich durch eine Rhetorik der Täter-Opfer Umkehr, in der ,wir Deutsche“ als Opfer eines durch ,die Amerikaner" inszenierten Schulddiskurses erscheinen. Um diese schuldabwehrende Homogenisierung der Wir-Gruppe realisieren zu können, müssen die Taten der NSGenerationen, insbesondere der Holocaust, normalisiert werden. Dies geschieht bei Herrn B wiederum durch antiamerikanischen Sprechakte, in denen das Motiv eines , amerikanischen Völkermords ‘ dazu gebraucht wird, die Vernichtung der europäischen Jüdinnen und Juden (1) latent zu thematisieren und (2) zu einem Genozid unter vielen zu relativieren, ohne den deutschen Vernichtungsantisemitismus jemals explizit benennen zu müssen. So verhilft Herrn Bs Antiamerikanismus ihm dazu, sich von den NS-Täter-Generationen zu distanzieren - um nicht als „,rechtsradikal“ zu gelten - und zugleich über den Bruch der Judenvernichtung hinweg eine homogene deutsche Wir-Gruppenidentität zu konstruieren.

\subsubsection{Amerikanische „Weltpolizei“ und deutsche Opferrolle}

Das Interview beginnt mit der Bitte, Herr B möge seine Zustimmung zu dem Survey-Item „Ich kann es gut verstehen, wenn manchen Leuten die US-Amerikaner unangenehm sind" erläutern. Er zeichnet daraufhin das Bild einer amerikanischen „Weltpolizei“, die die Politik anderer Staaten kontrolliert und beeinflusst:

Herr B: Die US-Amerikaner, äh, spiegeln ja so was wie die Weltpolizei wieder. Also die mischen sich praktisch, äh, überall ein, äh, in die politischen, wirtschaftlichen, äh, meist auch dann mit militärischer Gewalt, äh, oder sonstigen Mitteln, halt andere Regierungen, andere Staatengemeinschaften praktisch [...] auf diesen amerikanischen Kurs, äh, dieses amerikanische Weltbild drauf hin einzulenken, und das finde ich halt, ähm ja, finde ich halt persönlich nicht ganz so demokratisch, wie man im Allgemeinen Demokratie verstehen würde. 
Nach dem Gehalt jenes ,amerikanische[n] Weltbild[s]“ befragt, erläutert Herr B, dass die USA in der Welt gewöhnlich als „Land der unbegrenzten Möglichkeiten“ angesehen würden, dass dies aber gar nicht der Realität der USA entspreche, die „praktisch mit genau denselben Mitteln wie hier in Europa“ arbeiteten; so sei dort etwa die „Kriminalitätsrate“ genauso hoch und „Korruption“ genauso verbreitet. Das „amerikanische Weltbild“ meint in diesem Zusammenhang also nicht das Weltbild der US-Bürger, sondern das Bild, das in der Welt über Amerika vorherrscht. Dieses Bild wird Herrn Bs Ansicht zufolge anderen Nationen durch die USA „mit militärischer Gewalt oder sonstigen Mitteln“ aufgezwungen. Damit widerspreche Amerika „demokratisch[en]“ Werten, wie sie „im Allgemeinen“ verstanden würden und als deren Verfechter sich Herr B hier präsentiert.

In dieser ersten Sequenz klingt damit bereits ein zentrales Motiv an, das im weiteren Interviewverlauf das antiamerikanische Sprechen Herrn Bs prägt: Die USA als gewalttätige „Weltpolizei“ und Manipulateure der öffentlichen Meinung, die durch ihre Eingriffe die demokratische Verfassung ,anderer [...] Staatengemeinschaften" stört. Anhand der folgenden Interviewabschnitte werde ich zeigen, dass diese Amerikabilder hier primär zur schuldabwehrenden Normalisierung der deutschen Wir-Gruppe gebraucht werden. Dass Herrn Bs moralische Empörung als ,guter Demokrat " eng mit einer nationalistischen Wir-Gruppenkonstruktion zusammenhängt, zeichnet sich bereits im darauffolgenden Themenwechsel ab: Befragt nach einer genaueren Ausführung seiner Assoziationen zu „Weltpolizei“ und deren Einmischung in internationale Angelegenheiten, greift Herr B nicht etwa die häufig gebrauchten Beispiele der US-geführten Interventionen in Irak oder Afghanistan auf, sondern das Thema Nationalsozialismus und Erinnerungspolitik:

Herr B: Ja, also ich möchte jetzt irgendwie keinesfalls als, ich möchte jetzt irgendwie keinesfalls als rechtsradikal oder so was gelten, aber (...) wenn ich mir da mal in Bezug auf, auf die Geschichte, äh, dann um an den Zweiten Weltkrieg, äh, zurück (unverständlich)... Klar, es ist durchaus sehr, sehr furchtbar, was in Deutschland passiert ist, und, ähm äh, das sollte so in der Form auch nirgendwo in keinem Staat auf dieser Welt wieder passieren, das ist ganz klar, nur, dass die Amerikaner jetzt einzig und allein praktisch das ganze Bildungssystem in Europa darauf hinaus ausgelegt haben, das praktisch an einem Weltkrieg - äh und da beginnt für mich der Knackpunkt, wo man halt immer so ein bisschen hellhörig werden sollte - an einem Weltkrieg kann sich nicht ein einziges Land alleine beteiligen. Also ich denke, es sind alle, sowohl England, Frankreich, Italien, Russland - und ich weiß nicht, welche Länder da großartig noch mitgemischt haben- äh, waren durchaus daran beteiligt. Und dass die Amerikaner jetzt einzig und allein unser, äh, Schulbildungssystem, äh, praktisch so vorschreiben von klein auf an, was wir wissen dürfen, was wir nicht wissen dürfen. Dass heute noch Akten über einen Weltkrieg geheim gehalten werden, der praktisch schon ein halbes Jahrhundert zurückliegt, ähm, warum dann nicht öffentlich und vernünftig darüber diskutiert wird. 
Mit dem Bild einer sich gewaltsam einmischenden „Weltpolizei“ verbindet sich für Herrn B in erster Linie das Szenario einer unrechtmäßigen Verurteilung Deutschlands im Hinblick auf den zweiten Weltkrieg, die ,die Amerikaner“ durch systematische Beeinflussung des deutschen Bildungssystems „,vorschreiben“. ${ }^{2}$ Dabei folgt Herr B der für vorurteilige Rhetorik typischen „Ja, aber“-Argumentation oder „Prolepsis“ (Billig 2012, S. 146; vgl. auch Markovits 2007, S. 28 f.; Holz 2007, S. 56), in der mögliche moralische Einwände gegen die eigene Position präventiv abgewehrt werden. Er möchte nicht als „,rechtsradikal“ gelten und distanziert sich dementsprechend von Nazi-Deutschland, indem er betont, was ,in Deutschland passiert ist“ sei „sehr, sehr furchtbar“. ${ }^{3}$ Zugleich aber relativiert er jene Distanzierung, indem er sich wiederum von einer umfassenden Verurteilung Deutschlands distanziert, die seiner Ansicht nach durch amerikanische Propaganda systematisch befördert wird. Damit bearbeitet er, so die im Folgenden entwickelte Hypothese, einen Selbstwiderspruch in seiner nationalen Wir-Gruppenkonstruktion, die von Klaus Holz treffend beschriebene „Paradoxie der Normalisierung“ (vgl. Kap. 4.6.3): Um eine positive Identifikation mit der deutschen Nation zu erzeugen, muss Herr B Wege finden, die deutsche Wir-Gruppe zu normalisieren, d.h. den Holocaust zu verdecken bzw. zu verharmlosen, um den Bruch zwischen den Täter-Generationen des Nationalsozialismus und den Folgegenerationen zu überbrücken. Gemäß gel-

2 Ein sehr ähnliches Motiv taucht im Gespräch mit Herrn G auf, der betont, er habe sein relevantes Wissen über Amerika nicht „,in der Schule gelernt“, dort sei „man eher verarscht worden, was also solche Informationen anging“. Auch hier verbindet sich die Idee einer gezielten Fehlinformation im Bildungssystem mit dem Bild der USA als unrechtmäßigem „Weltsheriff“; jedoch werden, anders als bei Herrn B, in diesem Kontext ,die Amerikaner' nicht als Urheber der Informationskontrolle ausgemacht. In anderen Zusammenhängen ist das Motiv einer explizit , amerikanischen' Medienkontrolle aber präsent, so spricht Herr G etwa davon, dass die USA ihrer „Kriegsführung im Nahen Osten“ eine „Kontrolle der Medien eingeführt“ hätten, um eine „positive Kriegsberichterstattung“ zu erzeugen. Das Motiv einer ,amerikanischen Medienkontrolle‘ steht außerdem in großer Nähe zu verschwörungstheoretischen Konstruktionen, was daran erkennbar wird, dass Herr G und Herr B beide eine amerikanische Inszenierung der Anschläge vom 11. September 2001 für wahrscheinlich halten.

3 Worauf sich Herr B mit jenem ,was in Deutschland passiert ist“ bezieht, bleibt an dieser Stelle undeutlich, auch wenn die Formulierung einen Bezug auf die Judenverfolgung zumindest nahelegt - denn ,in Deutschland“ ist schließlich nicht ,der Weltkrieg“ passiert, auf den sich Herr B im weiteren Verlauf der Sequenz bezieht. Dennoch wäre ein Bezug auf ,Diktatur', ,Staatsterror' o.ä. denkbar. Im Lichte des weiteren Interviewverlaufs erscheint diese Stelle bereits als Ausdruck jener Kommunikationslatenz, mit der die nationalsozialistische Judenvernichtung in Herrn Bs Rhetorik implizit thematisiert, jedoch niemals explizit angesprochen wird. 
tender erinnerungspolitischer Normen muss er dazu aber gerade das aufgreifen und bearbeiten, was den Bruch überhaupt erst erzeugt. Dazu benötigt er eine Rhetorik, in der der Holocaust zugleich anklingt und verdrängt wird, mit anderen Worten: in der Nationalsozialismus und Judenvernichtung latent kommuniziert werden. Damit befindet sich Herr B in jenem von Klaus Holz beschriebenen performativen Widerspruch: „Einerseits durfte Ausschwitz nicht vergessen werden, weil nur Erinnerung und Schuldakzeptanz den Bruch mit dem Nationalsozialismus und die Demokratisierung Deutschlands belegen konnten. Andererseits wurde damit gerade das, was der Normalisierung widerspricht und unbewältigt bleiben wird, eben Auschwitz, zum entscheidenden Thema der ,Normalisierung Deutschlands “ und der ,Bewältigung der Vergangenheit“" (Holz 2005, S. 59). Dieses latent-Halten von Nationalsozialismus und Judenvernichtung funktioniert im vorliegenden Fall wesentlich antiamerikanisch. ,Die Amerikaner‘ übernehmen hier die Rolle der Täter in einer Täter-Opfer Umkehr, die die deutschen Täter des NS zu Opfern heutiger Unterdrückung erklärt (vgl. Holz 2007, S. 40). ${ }^{4}$ Wichtig ist an dieser Stelle, dass in dieser Täter-Opfer Umkehr die NS-Täter-Generationen mit den Nachgeborenen vereinigt werden, zu denen Herr B sich selbst zählt. Zwar distanziert er sich zunächst von der Täter-Generation insofern er deren Taten als ,schrecklich“ verurteilt und in einer späteren Sequenz betont, dass seine Generation ,nichts mehr [...] am Hut“" habe mit dem, was seine Vorfahren „ganz, ganz dummerweise“ taten (vgl. Kap. 7.3.1.2). Doch seine Anklage falscher , amerikanischer Anschuldigungen“ widerspricht dieser oberflächlichen Distanzierung: Die Darstellung von ,uns Deutschen“ als Opfern , amerikanischer Täter' macht nur dann Sinn, wenn die Darstellung des nationalsozialistischen Deutschlands in den Geschichtsbüchern, die ,die Amerikaner" vermeintlich manipulieren, tatsächlich ungerecht ist, d.h. die Taten der NSGenerationen falsch darstellt. Herrn Bs Anklage einer , amerikanischen Medienmanipulation“ verteidigt also nicht nur die Nachgeborenen gegen den Vorwurf, Nazis zu sein, sondern sie zielt implizit auch auf eine Normalisierung und Rehabilitierung der Täter-Generationen. Sie erzeugt eine Kontinuität der deutschen Wir-Gruppe, die die Täter des Nationalsozialismus mit einschließt und gleichzeitig eine offene Identifikation mit diesen vermeidet.

Neben dem Verweis auf eine ,amerikanische‘ Manipulation des Bildungssystems funktioniert die Normalisierung der deutschen Wir-Gruppe bis hierher maßgeblich über den Vergleich der NS-Taten mit denen anderer Nationen. Insgesamt tendiert Herr B zu einer Verallgemeinerung der NS-Verbrechen zum Ausdruck eines anthropologischen Grundübels. Diese Einordnung der Judenvernichtung als Teil eines noch größeren allgemeinen Verhängnis, wenngleich nicht prinzipiell falsch (vgl. Adorno 2003c, S. 675), hat im Nachkriegsdeutschland insbesondere seit

4 Im Gegensatz zu antisemitischen Konstruktionen bleibt diese Täter-Opfer Umkehr unvollständig, da in ihr die jüdischen Opfer des NS nicht als die heutigen Täter auftreten. 
den 68ern als ,projektive Entlastung“ gewirkt (Diner 2003, S. 136 ff., hier S. 138): Der vermeintlich kritische Hinweis auf die Allgegenwärtigkeit der Bedingungen für ,Holocaust-ähnliche' Taten befreit die nationale Identifikation von einer Auseinandersetzung mit der historischen Spezifizität der deutschen Verbrechen. Herr Bs moralischer Standpunkt, dass die Taten der Deutschen „,nirgendwo, in keinem Staat auf dieser Welt wieder passieren" sollten, kann als Ausdruck einer solchen projektiven Entlastung gelesen werden. ${ }^{5}$ Dieser Schritt der Verallgemeinerung der Judenvernichtung erlaubt es dem Sprecher die ,heiklen' Spezifika des deutschen Massenmordes als Nebenaspekt eines allgemeineren Problems zu behandeln. Dieser entlastende Effekt zeigt sich auch in der Weise, wie Herr B im unmittelbaren Anschluss die Frage nach der Kriegsschuld Deutschlands aufgreift ohne dass der Themenwechsel von dem, ,was in Deutschland passiert ist“, zum „Weltkrieg“ insgesamt weitere Beachtung findet. Auch an anderen Stellen findet sich die Universalisierung bzw. Relativierung deutscher Taten als eine dominante Strategie: Absurd wirkt etwa das Argument, Deutschland könne allein deshalb schon keine besondere Schuld am Krieg tragen, weil sich ,an einem Weltkrieg [...] nicht ein einziges Land alleine beteiligen“ könne. Hier werden Fragen der spezifischen Verantwortlichkeit verschiedener kriegsbeteiligter Nationen mit Fragen der Semantik des Wortes „Weltkrieg" verwechselt (i.e. dass dessen lexikalische Bedeutung eine Mehrzahl streitender Parteien logisch impliziert). Im Sinne der sprichwörtlichen Weisheit, dass zu einem Streit immer mehrere gehören, wird die Frage nach der spezifischen Schuld der Deutschen beiseite geschoben.

Bedingung für all diese relativierenden bzw. normalisierenden Sprechweisen ist das systematische latent-Halten des Holocaust. Wie im folgenden Abschnitt gezeigt wird, greift Herr B zur Realisierung dieser Bedingung auf ein weiteres Amerikastereotyp zurück: Der Genozid an amerikanischen Ureinwohnern erfüllt in seiner antiamerikanischen Schuldabwehr die doppelte Funktion, implizit auf die Vernichtung

5 Eine ähnliche Formulierung findet sich im Interview mit Frau J, die ebenfalls eine Schuldabwehr-Argumentation vorbringt, allerdings ohne dabei antiamerikanische noch antisemitische Motive zu gebrauchen: „Da kann man denen jungen Menschen das nicht noch anlasten und sagen: ,Ja, Ihr wart ja Nazis, Ihr habt ja... ' Is schlimm genuch, was der Deutsche gemacht hat. Äh, da beißt die Maus den Faden nicht ab und so was so soll um Gottes Willen auch nie wieder passieren. In keinem Land, ob das nun Deutschland oder Norwegen oder nehmen Sie England oder auch Frankreich nehmen, das wäre das Letzte. Aber, äh, es kann nicht uns ewig nach-, anhängen." In solchen Argumentationen wird an der nationalsozialistischen Judenvernichtung vor allem hervorgehoben, dass sie nichts Spezifisches über die Geschichte Deutschlands sagt. Alle anderen Aspekte verschwinden in der Allgemeinheit einer schon als anthropologische Tatsache akzeptierten ,Grausamkeit des Menschen`. 
der europäischen Jüdinnen und Juden zu verweisen und zugleich in Abgrenzung gegen Amerika die eigene demokratische Position zu markieren.

\subsubsection{Genozid an „,indianische[n] Ureinwohner[n]“}

Während Herr B in der bisher rekonstruierten Täter-Opfer Umkehr hauptsächlich mit den NS-Täter-Generationen beschäftigt war, d.h. mit deren Rehabilitierung als Teil einer kontinuierlichen deutschen Wir-Gruppe, blieben die Opfer des Holocaust nahezu vollkommen unbenannt. Um die Latenzfunktion seiner Normalisierung der deutschen Nation zu realisieren, muss er aber auch die Opfer-Seite berücksichtigen, da seine Rhetorik sonst Gefahr liefe, als Leugnung oder Verharmlosung des Holocaust zu gelten. Um eine solche Berücksichtigung zu ermöglichen, die zugleich die Latenz der Judenvernichtung aufrechterhält, bedient sich Herr B des Stereotyps eines , amerikanischen Genozids‘. Dieses taucht im unmittelbaren Anschluss an die oben zitierte Sequenz auf, als der Interviewteilnehmer noch einmal genauer auf die vermeintliche Vergleichbarkeit verschiedener, Weltkriegsverbrechen“ eingeht:

Herr B: Dass sowohl von Seiten der Alliierten als auch der, äh, Gegenparteien, ähm, Fehler unterlaufen sind, und auch Sachen unterlaufen sind, die nicht gerade den Genfer Konventionen entsprechen, äh, ist klar. Aber dann darf Amerika auch nicht hingehen, und Deutschland alleine bis heute dafür verurteilen, für das, was Amerikaner im Vorfeld, äh, vor den Weltkriegen schon getan hat, nämlich ganze Völker auszulöschen - wenn ich da mal zurückdenke an die Ureinwohner. Da sind 500 indianische, äh, Ureinwohner, Völker, ganze Stammesgruppen sind vernichtet worden. Klar, es mögen jetzt nicht alles Amerikaner gewesen sein, die meisten, die nach Amerika gekommen sind, waren ja eben Neuübersiedler, in die neue Welt aus Europa, Holländer, Russen, Chinesen, weiß der Geier was, aber ich denke, da sollte auch ein Stückchen weit von amerikanischer Seite her doch noch einiges an Aufklärung betrieben werden, damit, äh, - sage ich mal - dieses Gleichgewicht von, von Gerechtigkeit, äh, irgendwo doch noch, ähm, ja, ins heutige Europa mit einfließt. Also das ist meine persönliche, politische Ansicht dazu.

Herrn Bs Zurückweisung einer vermeintlich ungerechten, manipulativen Ächtung der Deutschen durch die USA wird hier zunächst hinsichtlich Verstößen gegen die „Genfer Konventionen“ weitergeführt: Da nicht nur die Kriegsschuld, sondern auch die Kriegsverbrechen der Deutschen prinzipiell mit denen anderer Kriegsparteien vergleichbar seien, rechtfertigen diese keine spezifische Verurteilung Deutschlands. Bis hierher ist der Holocaust nahezu vollkommen ausgeblendet geblieben. Im darauffolgenden Argument wird dieser dann aber implizit aufgegriffen: Wenn „Amerikaner[n]" selbst einen Völkermord an amerikanischen Ureinwohnern begangen haben, so Herr B, dann haben die USA kein Recht, den Deutschen vorzuwerfen „Völker [...] vernichtet“ zu haben. Die Quintessenz dieser Konstruktion lautet: Am 
Holocaust, so „schrecklich“ er war, ist nichts Besonderes, weswegen er den Deutschen nicht zum Vorwurf gemacht werden kann. Die deutsche Schuld ist dieselbe wie die der USA (und anderer Kriegsparteien) und damit als Problem deutscher Identität effektiv annulliert. Der Verweis auf amerikanische „Ureinwohner“ erfüllt dabei zugleich eine relativierende und eine Latenzfunktion: Er ermöglicht es Herrn $\mathrm{B}$, die Judenvernichtung zu einem Genozid unter vielen zu normalisieren, ohne sie jemals explizit benennen zu müssen. Denn wie bereits zu Anfang der hier behandelten Sequenz deutlich wurde, ist Herrn B durchaus bewusst, dass er jene mörderische deutsche Geschichte nicht einfach rundheraus negieren oder ignorieren kann, sofern er nicht „als rechtsradikal gelten“ will. Die ideologische Funktion dieses antiamerikanischen Sprechens liegt also darin, den deutschen Vernichtungs-Antisemitismus nicht völlig zu verdrängen, sondern sein beständiges sich-Aufdrängen so zu managen, dass es nicht in Widerspruch mit einer positiven nationalen Identifikation gerät (vgl. Holz 2007, S. 49).

Die Konsequenz, die Herr B aus der Empörung über jenen , amerikanischen Genozid“ zieht, macht zusätzlich deutlich, dass seine vermeintlich humanistischdemokratische Selbstdarstellung auf eine Entlastung der deutschen Wir-Gruppe zielt. Er wünscht sich, dass ,,von amerikanischer Seite her doch noch einiges an Aufklärung betrieben“" werde, jedoch nicht etwa um der Anerkennung von native Americans willen, sondern damit ein „Gleichgewicht von [...] Gerechtigkeit [...] ins heutige Europa mit einfließt“" (Herv. F.K.). Offenkundig zielt Herrn Bs Argument nicht darauf, die Schrecken deutscher oder amerikanischer Verbrechen zu vergegenwärtigen und möglicherweise in Zukunft verhindern zu können o.ä., sondern auf die Entledigung Deutschlands von seiner mörderischen Geschichte: In seiner Klage über Genozid und Kriegsgräuel geht es letztendlich um „Gerechtigkeit für Deutschland“, ganz im Sinne der antisemitischen Rhetorik, die Martin Hohmann in seiner Rede anlässlich des Tags der deutschen Einheit 2003 vorbrachte (Holz 2007, S. 54; vgl. auch Bergmann 2007, S. 28). Dass es Herrn B bei dieser Gerechtigkeit für Deutschland nicht allein um die Abwehr eines Schuldvorwurfes gegen die Nachgeborenen, sondern auch um eine Rehabilitation der Täter-Generationen geht, wird anhand der nachfolgenden Sequenz noch einmal deutlich erkennbar. Auf die paraphrasierende Nachfrage des Interviewers, ob Herrn B sich also durch die Zuschreibung einer alleinigen deutschen Verantwortung für den zweiten Weltkrieg gestört fühle, reagiert dieser mit einer gespaltenen Argumentation:

Interviewer: Das heißt, es stört Sie auch, dass sozusagen in dieser Darstellung Deutschland allein verantwortlich gemacht wird für den zweiten Weltkrieg und die Gräuel, die das mit sich gebracht hat, oder verstehe ich Sie falsch?

Herr B: Nein, da haben sie mich ganz richtig verstanden, ähm, weil ... Sehen wir das mal so, also meine Generation zumindest, wir haben mit dem, was vor so und so viel Jahren in 
Deutschland, beziehungsweise hier in Europa überhaupt passiert ist, haben wir gar nichts mehr mit am Hut. Es ist (unverständlich)... Wir sind in der Nachkriegszeit aufgewachsen, beziehungsweise die Generation davor, und wir können einfach nicht ungeschehen machen, was Vorfahren von uns, äh, ja ganz, ganz dummerweise muss ich sagen, äh, begangen haben. Ein Krieg überhaupt an sich ist nicht schön, egal wo er stattfindet, ob es hier ist, Syrien, Irak, Iran. Wenn ich da an die Golfkriege zurückdenke (.) Ja, und ich meine, über den Irakkrieg, der ja viel, viel weniger Zeit zurückliegt, als das, was im zweiten Weltkrieg passiert ist, äh, und der Irakkrieg hat ja praktisch schon den halben Balkan, den halben nahöstlichen Raum da, äh, mit sich reingezogen und darüber verliert heutzutage eigentlich kein Mensch mehr irgendein Wort. Es wird eigentlich nur noch in den Geschichtsbüchern darüber gehandelt, der Zweite Weltkrieg, der Zweite Weltkrieg, der Zweite Weltkrieg. Aber warum der Zweite Weltkrieg entstanden ist, dass damit eigentlich der erste Weltkrieg, und die ganzen Wirtschaftsrestriktionen, äh ähm, die vorher stattgefunden haben, wie zum Beispiel hier das amerikanische Alkoholverbot und, und, und... Dass das alles damit zusammenhängt, ähm, das kann ja keiner mehr nachlesen. Also, ich denke, das ist eine etwas fälschlichere öffentliche Meinung, was Amerika da versucht, in Europa darzustellen, dass, ähm, ja der Zweite Weltkrieg eben aufgrund nur von, von Faschismus, von Hass und Gewalt von einigen wenigen Diktatoren, die es hier gegeben hat, äh ähm, so zu belassen. Also ich denke, das sollte einfach mal, ja, überdacht werden.

Herrn Bs erste Reaktion ist die Markierung eines Bruches zwischen seiner Generation und der der Täter, mit der ,wir gar nichts mehr [...] am Hut“ haben. Unmittelbar im Anschluss beginnt er aber, diese Grenzziehung aufzuheben, indem er wiederum zu einer Relativierung der Taten der deutschen Weltkriegs-Generationen ansetzt, die er in die Kontinuität einer positiven Nationalidentität zu integrieren versucht. Diese Reparatur verläuft nach demselben antiamerikanischen Muster wie zuvor: Zunächst werden die deutschen Taten verurteilt, zugleich aber relativiert (,was hier in Deutschland beziehungsweise hier in Europa überhaupt passiert ist“; ,Ein Krieg überhaupt an sich ist nicht schön, egal wo er stattfindet"), wobei die Verallgemeinerung auf das, was ,hier in Europa“ passiert ist und den „Krieg an sich“ der Latenz der spezifisch deutschen Verbrechen dienen. Im Anschluss daran werden Beispiele vermeintlich vergleichbarer amerikanischer Taten herangezogen (Vergleich mit „Golfkriege[n]“, Verweis auf ,amerikanische Ursachen“ des zweiten Weltkrieges) und schließlich eine vermeintliche Manipulation der öffentlichen Meinung durch die USA ausgemacht (,das ist eine etwas fälschlichere öffentliche Meinung, was Amerika da versucht, in Europa darzustellen“) in deren Licht ,wir Deutsche" als Opfer falscher Anschuldigungen erscheinen. Diese Sequenz veranschaulicht also noch einmal sehr eindrücklich, dass Herr B mit einer ,Befreiung ‘ seiner eigenen Generation von vermeintlichen Schuldvorwürfen nicht zufrieden ist: Es geht um „Gerechtigkeit für Deutschland“ als kontinuierlicher, positiver WirGruppe. 


\subsubsection{Zusammenfassung Herr B}

In den vorigen beiden Abschnitten wurde gezeigt, wie Antiamerikanismus als Ausdruck eines revisionistischen Nationalismus funktionieren kann und dabei vergleichbare ideologische Funktionen erfüllt, wie der von Klaus Holz beschriebene „demokratische[r] Antisemitismus“ (Holz 2005, S. 54): Die antiamerikanische Rhetorik dient der Auflösung der „Paradoxie der Normalisierung“ - sie bearbeitet das Problem, dass die Normalität der deutschen Nation nur herzustellen ist durch ein Erinnern dessen, was ihre Normalität verunmöglicht. Die rhetorischen Mittel hierzu sind eine antiamerikanische Schuldabwehr mittels des Stereotyps einer amerikanischen „Weltpolizei“, sowie ein latent-Halten des Holocaust durch Vergleiche mit einem ,amerikanischen Genozid‘. So werden einerseits ,die Deutschen' zu Opfern einer amerikanischen Schuld-Kampagne erklärt, in der durch gezielte Manipulation die ,wahre Geschichte' des zweiten Weltkrieges verschleiert werde. In dieser (unvollständigen) Täter-Opfer Umkehr werden zudem implizit die NS-Täter-Generationen rehabilitiert und mit den Nachgeborenen zu einer kontinuierlichen nationalen Wir-Gruppe vereinigt. Da aber eine solche, demokratische' Schuldabwehrkonstruktion, will sie nicht „als rechtsradikal“ erscheinen, die Opfer der nationalsozialistischen Judenvernichtung nicht vollkommen ausblenden kann, muss der Holocaust latent thematisiert werden. Hierzu greift Herr B auf das Stereotyp eines , amerikanischen Genozids ‘ zurück: Im Zerrspiegel dieser Vergleichsgröße kann der Holocaust implizit erscheinen, ohne explizit angesprochen zu werden, während der angestellte Vergleich diesen zugleich zu einem Völkermord unter vielen normalisiert. Qua dieser Kommunikationslatenz vollbringt Herrn Bs antiamerikanische Schuldabwehr das ,Kunststück', mit demokratischen Werten für eine restlose Normalisierung der deutschen Nation - und das heißt: für eine Rehabilitierung der NS-TäterGenerationen - zu argumentieren.

Wenngleich diese Schuldabwehrkonstruktion nicht als antisemitisch bezeichnet werden kann, tritt in ihr doch die Verwandtschaft von Antisemitismus und Antiamerikanismus deutlich hervor. Diese erstreckt sich über die beschriebenen funktionalen Parallelen hinaus auch auf die Stereotype, mit denen ,die Amerikaner' dargestellt werden: So kann die Benennung der USA als Manipulateur der öffentlichen Meinung, die „Rancune gegen die re-education“ (Adorno 2003d, S. 559), als direkte Anleihe aus dem semantischen Inventar des modernen Antisemitismus gelten. Das Bild, demzufolge sich hinter dem Wechselspiel von öffentlicher Meinung und modernen Medien ein verdeckter Nutznießer verbirgt, der „den Geist der Gemeinschaft, $[\ldots]$ das gesunde Volksempfinden, das nationale Selbstbewusstsein und den Stolz nationaler Zugehörigkeit" sabotiere, ist ein Klassiker antisemitischer Stereotypie (Holz 2007, S. 43). Zudem ist die Verortung dieser verschwörerischen Macht bei ,den Amerikanern' überaus anschlussfähig für antisemitische Konstruktionen, 
die in den USA zugleich ein Instrument ,jüdischer Herrschaftsbestrebungen ‘ und das vorderste Beispiel für deren, zersetzende Wirkung' sehen.

Aus Sicht der Vorurteilskritik liegt die Ironie dieses Rechtfertigungsmusters darin, dass es sich durch seinen Gebrauch antiamerikanischer Rhetorik genau derjenigen NS-Weltanschauung annähert, von der es sich zu distanzieren vorgibt. Dies ist sein ideologischer Gehalt: Herrn Bs Antiamerikanismus ist Ausdruck einer nationalen Identifikation, die gerade in dem Moment, in dem sie versucht das Erbe des NS abzustreifen, dieses Erbe bereits antritt. Anders gesagt: Die „Paradoxie der Normalisierung“ wird durch die Latenzfunktion nur scheinbar gelöst; das ideologische Ausblenden des Nationalsozialismus ist ein performatives Erinnern - d.h. ein Reinszenieren - des Nationalsozialismus.

\subsubsection{Zusätzliche Interviewbeispiele}

Anhand zwei weiterer Interviewbeispiele sollen nun einerseits die oben aufgestellten Thesen zur funktionalen Analogie von Antiamerikanismus und Antisemitismus zusätzlich plausibilisiert, andererseits aber auch auf den Gebrauch antiamerikanischer Motive in ,klassisch“ antisemitischer Rhetorik hingewiesen werden. Hierzu wird zunächst das Beispiel von Herrn D herangezogen, der ebenfalls Amerikastereotype verwendet, um die Bedeutsamkeit des Holocaust zu relativieren und diesen als Identitätsbedrohung der nationalen Wir-Gruppe auszuräumen. Im Unterschied zu Herrn B findet sich aber in seiner Rhetorik keine Kommunikationslatenz des Holocaust, sondern dieser wird explizit gegen , amerikanische Verbrechen' aufgerechnet.

Während die Rhetorik Herrn Ds ebenso wie diejenige Herrn Bs nicht als antisemitisch im engeren Sinne gelten kann, lässt sich am Beispiel von Frau K das Fortleben antiamerikanischer Motive in ,klassisch“ antisemitischen Konstruktionen veranschaulichen. In diesem Fall fungieren Stereotype einer zerstörerischen Weltmacht ,Amerika‘, die zum Zwecke des eigenen wirtschaftlichen Nutzens kriegerische Auseinandersetzungen provoziert, als Teil einer antisemitischen Erklärung für weltweite Konflikte und Krisen. Dabei erscheinen die USA als Instrument und Komplize einer ,machthungrigen“ und ,streitlustigen“ Gruppe von „Israelis“, die als eigentliche Initiatoren des krisenhaften Zustands der Welt fungieren. Im Gegensatz zu Herrn D und B erfüllt Antiamerikanismus hier also keine rechtfertigende oder latenzsichernde Funktion, sondern tritt als Element eines welterklärenden Antisemitismus auf. Dabei wird das antisemitische Judenbild nur notdürftig durch antizionistische Camouflage verdeckt. 


\subsubsection{Herr D: Explizite antiamerikanische Holocaustrelativierung}

Die am Beispiel von Herrn B entwickelten Thesen über Schuldabwehr und Antiamerikanismus können zusätzlich plausibilisiert werden, indem eine ähnliche Funktion antiamerikanischen Sprechens bei Herrn D rekonstruiert wird. Auch hier dient ein Vergleich mit den USA dazu, den Holocaust zunächst auszublenden und anschließend zu normalisieren. Somit wird die eigene nationale Identifikation von den Widersprüchen abgeschirmt, die mit dessen Erinnerung einhergehen. Im Gegensatz zu Herrn Bs Rede liegt in diesem Fall allerdings eine wesentlich weniger subtile Form der Verdrängung bzw. Relativierung vor: Der Verweis auf , amerikanische Fremdenfeindlichkeit ' und ,amerikanischen Rassismus', der zunächst der präventiven Abwehr des Vorwurfs der Fremdenfeindlichkeit dient, scheint eine Verknüpfung von deutscher Nation und Holocaust zunächst vollkommen zu blockieren. Es kann dementsprechend im vorliegenden Fall nicht von Kommunikationslatenz gesprochen werden, da das Thema nicht implizit thematisiert und bearbeitet wird, wie bei Herrn B. Trotz mehrfacher Hinweise des Interviewers gewinnt die nationalsozialistische Judenvernichtung so lange keine Salienz für Herrn D, bis sie vom Interviewer explizit angesprochen wird. Ab diesem Moment geht Herr D dann zu einer ebenso expliziten Normalisierung der nationalsozialistischen Vergangenheit über. Hierzu dienen ihm Bilder des amerikanischen Atomangriffes auf Hiroshima, die er als normalisierende Vergleichsgröße heranzieht. Im Gegensatz zu Herrn B gelingt es Herrn D also nicht, den Holocaust latent zu thematisieren. ${ }^{6}$ Stattdessen wird der Holocaust so lang wie möglich vollständig ausgeblendet, im Moment seines Auftretens aber Auschwitz direkt mit Hiroshima aufgewogen.

Die folgenden Interviewsequenzen entspinnen sich im Anschluss an Herrn Ds Nachfrage, was mit den Interviewaufzeichnungen im Rahmen der weiteren Forschung geschehen werde. Der Hinweis des Interviewers, dass dieses Material für eine Studie zu Amerikabildern in Deutschland ausgewertet würde, die sich auch mit

6 Es kann vermutet werden, dass statt einer entwickelten Kommunikationslatenz bei Herrn D tatsächlich eine Bewusstseinslatenz vorliegt, so dass ihm die Holocaust-Assoziation im besprochenen Kontext kognitiv überhaupt nicht verfügbar wird (vgl. Kap. 4.6.2). Eine solche Bewusstseinslatenz könnte dann auch der Grund dafür sein, dass keine effektiven Muster der kommunikativen Latenzsicherung gebraucht bzw. überhaupt erlernt werden konnten. Inwieweit diese Thesen zutreffen, lässt sich am vorliegenden Material natürlich nicht entscheiden, ist für dessen rhetorisch-performative Analyse aber auch von nachrangiger Bedeutung. Dies gilt übrigens auch für die Kommunikationslatenz bei Herrn B: $\mathrm{Ob}$ dieser bei seiner Rede über amerikanische „Ureinwohner“ insgeheim an die Vernichtung der europäischen Jüdinnen und Juden gedacht hat, ist anhand des Interviewmaterials nicht zu zeigen, jedoch für die hier gestellt Frage des „Wie“ und „Wozu“ antiamerikanischer Sprechweisen von geringem Interesse. 
„kritischen bis hin zu feindseligen Haltungen Amerika gegenüber“ befasse, stößt bei Herrn D auf Widerspruch: er beginnt auf verschiedenen Wegen den Vorwurf einer ,Feindseligkeit gegen Amerika' zu antizipieren bzw. abzuwehren. Dass Herr D diesen Vorwurf gegen sich selbst erwartet, scheint in Anbetracht seiner zuvor geäuBerten Stereotypen Abwertung von ,Amerikanern', ,Russen ${ }^{6}$ und , Türken ${ }^{67}$ durchaus plausibel. Seine Strategie hierzu ist die Relativierung bzw. Externalisierung des Problems der ,Menschenfeindlichkeit‘ im Vergleich mit ,Amerika‘. Er verweist zunächst auf Feindseligkeiten gegenüber MigrantInnen an der mexikanischamerikanischen Grenze, ,was jetzt Amerika bloß alles macht, mit den Ausländern“, und äußert sehr nachdrücklich seine Wut über diese Zustände: ,da sind sie [die USA, F.K.] schon feindselig gegen Ausländer, ne? [...] Da möchte ich, also wenn ich das sehe, ne, möchte ich dem Ami ins Gesicht spucken.“ Als der Interviewer das Thema auf Immigration und Fremdenfeindlichkeit in Deutschland wendet, reagiert Herr D überraschenderweise weitaus weniger empathisch gegenüber der Situation von Migrantinnen und Migranten und beklagt deren übermäßige staatliche Versorgung in Deutschland, die er als „Frechheit“ empfindet. Als der Interviewer daraufhin nach fremdenfeindlichen Tendenzen in Deutschland fragt, streitet er deren Existenz vehement $\mathrm{ab}$ und betont den Unterschied zwischen Deutschland und den USA in dieser Hinsicht:

Interviewer: Aber es gibt ja auch immer wieder Debatten darüber, dass es in Deutschland eine Ausländerfeindlichkeit gäbe.

Herr D: Pf, wo denn? Wo denn? Die, die Deutschen reden doch bloß drüber! Die Deutschen machen doch bloß Luft! Ist doch so! Die Deutschen machen nur Luft! Sagen tun sie viel, aber was machen sie, denen geht es doch zu gut, das habe ich schon oft genug gesagt. Wenn die, wenn die Ausländer, äh, im Monat zweihundert Euro kriegen, juckt es den Deutschen auch nicht. Hauptsache, dem geht es noch gut! Ist ja wurscht, ob der jetzt, jetzt äh, von sei- äh, von seinem Lohn noch zehn Prozent mehr bezahlen muss, dass juckt den doch auch nicht! Ne. Da bin, da ist der Unterschied gegen die Ami und die Deutschen, also, hundert Prozent. Ne! Wie die mit den Ausländern umgehen, und die Deutschen die Au-, mit, mit den anderen Ausländern umgehen. Das ist ja, dann eine hundertprozentige Ding, ne. Wie die umgehen, ne.

Auffällig ist an dieser Sequenz zum einen die völlige Ignoranz gegenüber Fremdenfeindlichkeit und Rassismus in Deutschland: Die Phrase „Die Deutschen machen doch bloß Luft" signalisiert, dass Herr D die Thematisierung von Ausländerfeindlichkeit in Deutschland für , leeres Gerede ' hält. Zum anderen lässt sich an der Wut,

7 ,Die Amerikaner` werden von Herrn D, ähnlich wie ,Russen“ und ,Türken`, pauschal als gewalttätige, unzuverlässige Alkoholiker dargestellt. Eine ausführlichere Beschreibung dieser Gruppenkonstruktionen findet sich in Kapitel 7.4.2.3. 
mit der Herr D über eine vermeintliche Überversorgung von „Ausländern“ in Deutschland und die Benachteiligung, der Deutschen“ spricht, ablesen, dass sich seine Solidarität hier von den Migranten auf ,die Deutschen' verschoben, und damit ins Gegenteil verkehrt hat: es scheint, als ob Herr D es begrüßen würde, wenn in Deutschland im Umgang mit „Ausländern“ einmal ,härter durchgegriffen“ würde, gerade so, wie er es bzgl. der USA zuvor verurteilt hatte. Während Einwandernde in den USA als Opfer dargestellt und ,die Amerikaner' für deren Misshandlung verurteilt werden, erscheinen in Deutschland die ,Normalbürger' als Opfer einer ungerechten Bevorzugung von ,Ausländern' (vgl. Kap. 7.4).

In den folgenden Abschnitten wird zudem deutlich, dass Herrn Ds Ignoranz gegenüber menschenfeindlicher Gewalt in Deutschland weit über aktuelle Formen von Fremdenfeindlichkeit oder Rassismus hinausweist. Im Verlauf der folgenden Sequenzen ist eine bemerkenswerte Verdrängung der nationalsozialistischen Vergangenheit zu beobachten:

Interviewer: Das heißt, die Fälle, wo es beispielsweise Anschläge auf Asylbewerberheime gibt, das [sind so Extremfälle...]

Herr D: [Ja:::, das sind], das sind doch kleine Pappenstiele, guck doch einmal, guck doch einmal, guck doch einmal bei den Amerikanern an, was da abgeht! Was sie mit ihren Negern gemacht haben. Gelyncht! Äh, ganze, äh, äh ganze Familien ausgelöscht! Was hat denn der Deutsche gemacht! Was gibt es denn da viel!

Auf das Nachhaken des Interviewers reagiert Herr D mit einem Verweis auf extremere Formen von , amerikanischem Rassismus‘. Um die Gewalt gegen Asylbewerber in Deutschland als „Pappenstiele“ abzutun, muss er eine stärkere Vergleichsgröße heranziehen, um nicht selbst als fremdenfeindlich zu erscheinen. Die zitierten Formulierungen Herrn Ds, insbesondere die Frage, was „denn der Deutsche gemacht habe" und die Feststellung, in den USA seien ,ganze Familien ausgelöscht" worden, provozieren dabei die Assoziation von Holocaust und NS-Terror. Für Herrn D selbst scheint diese Assoziation allerdings fern zu liegen:

Interviewer: Na ja, gut, vor 60 Jahren hat es in Deutschland ja doch noch mal so was Ähnliches in ganz anderem Ausmaß gegeben, nicht, also das...

Herr D: Mh. Aber nicht so traurig, wie, wie, wie die Amerikaner, was die gemacht haben, mit den Negern.

Interviewer: Würden Sie nicht sagen? 
Herr D: Sklaven, Sklaven, lauter so Zeug haben die gemacht, die Amerikaner. Lauter Sklaven gehalten und so Zeug. Was, was wollen wir, wir Deutschen drüber reden, wir haben, wir haben, wir haben, wir haben andere Leute rüber gelassen, unseren Dreck wegzumachen, jetzt haben wir sie hier.

Dass Herr D die Referenz des Interviewers auf die nationalsozialistische Judenvernichtung nicht versteht, und stattdessen weiter deutsche ,Gastarbeiter' mit amerikanischen Sklaven vergleicht, ist auch dann noch bemerkenswert, wenn man die Ungenauigkeit im historischen Verweis des Interviewers in Betracht zieht. ${ }^{8}$ Diese Ignoranz erweist sich in der folgenden Interviewstelle als umso hartnäckiger, denn auch ein direkter Hinweis auf die Zeit des ,zweiten Weltkrieg[s]“ scheint die Assoziation des Holocaust nicht näher zu rücken:

Interviewer: Ja. Aber ich meinte jetzt beispielsweise im Zweiten Weltkrieg, also...

Herr D: Ja. Haben wir ja gebraucht, wir haben ja Leute gebraucht! Dass sie den Dreck aufräumen. Das ist, die sind ja auch hier! (.) Die haben ja ihre Familie alle hier. Wir haben ja, wir haben ja genug Geld bezahlt! Ne. Was macht denn der, was hat denn der Amerikaner für die Neger gemacht, was er, was er den Negern angetan hat. Was hat er denn gemacht! Nichts.

Auch mit dem Thema zweiter Weltkrieg assoziiert Herr D ,Gastarbeiter", die, wie er wiederum betont, in Deutschland gut behandelt worden seien. Erst als der Interviewer der amerikanischen Sklaverei explizit die Judenverfolgung in Deutschland gegenüberstellt ${ }^{9}$, springt auch Herr D auf das Thema an:

Interviewer: Wobei man eben fairer weise sagen müsste, dass es zu der Zeit, zu der es in den USA noch Sklaverei gab, es in Deutschland auch die Judenverfolgung beispielsweise gegeben hat, nicht?

8 Die Zeitangabe des Interviewers ,,vor 60 Jahren“ verweist rein rechnerisch zum Erhebungszeitpunkt des Interviews auf das Jahr 1951 und könnte daher irreführend wirken: gemeint war die Zeit des Nationalsozialismus. Es ist hier aber zu berücksichtigen, dass es im Gespräch mit Herrn D weniger um die präzise Beschreibung historischer Zeiträume zu gehen scheint, sondern vielmehr um eine Aufrechnung deutscher und amerikanischer Vergangenheit insgesamt - schließlich war 1951 auch die Sklaverei in den USA bereits abgeschafft.

9 Ein Vergleich, das sei hier noch einmal betont, der insgesamt nicht unproblematisch ist und vom Interviewer zudem historisch inkorrekt gebraucht wird. 
Herr D: Ja. Die hat es gegeben, ja. Und nur, weil wir einen kleinen Hitler gehabt haben. Sonst hätte es die nicht gegeben. Wenn der Hitler nicht gewesen wäre, hätte es das überhaupt nicht gegeben. Ne. Aber da müssen wir, müssen wir wieder einmal anfangen, ne, was, was, was die Amerikaner mit den Japanern gemacht haben! Mit ihrer Hiroshima-Bombe! Ja, pf, (?)! Ja. Da sollen sie froh sein, dass der, dass der, der Hitler da drüben an Russland erfroren ist! Dass er da nicht durchgekommen ist! Was, wie tät denn die Welt jetzt ausschauen. He!

Nachdem nun der Holocaust die längste Zeit verdrängt wurde - mit einem Ausdruck Werner Bergmanns könnte man dies als „Thematisierungsverweigerung“ (Bergmann 2007, S. 30) bezeichnen - greift Herr D auf direkte Relativierungen zurück, um die eigene nationale Identität weiterhin von menschenfeindlichen Aspekten frei zu halten. Herrn Ds Normalisierung des Holocaust basiert dabei auf demselben rhetorischen Muster, mit dem er zuvor deutsche Fremdenfeindlichkeit zu „Pappenstiele[n]“ erklärt hat. Lediglich der Maßstab des relativierenden AmerikaVergleichs wird mit dem Verweis auf die „Hiroshima-Bombe“ abermals vergrößert. Es tritt allerdings ein weiteres Rechtfertigungsmuster hinzu, das der antiamerikanischen Rhetorik sozusagen als Hilfskonstruktionen zur Seite gestellt wird: Mit dem Verweis auf „einen kleinen Hitler“ ${ }^{\text {10 }}$ wird die Verantwortung für die Taten der NSGenerationen auf einen begrenzten Täterkreis eingeschränkt, und somit die deutsche Wir-Gruppe rückblickend rehabilitiert. Diese „Abspaltung der Verantwortung“ ist auch im Schuldabwehr-Antisemitismus ein weit verbreitetes Rechtfertigungsmuster (vgl. Bergmann 2007, S. 17 f.).

Antiamerikanismus hat im vorliegenden Fall also keine Latenzsichernde Wirkung, sondern die normalisierende Funktion wird durch eine offene Relativierung erzeugt. Insofern das Thema der Schuldzuschreibungen gegen Deutschland hier nicht, oder nur sehr marginal, auftaucht, können diese Rechtfertigungsmuster auch nicht als Schuldabwehr-Antiamerikanismus bezeichnet werden. Sie bearbeiten aber im Grunde ein sehr ähnliches Problem: Den Widerspruch zwischen einer positiven deutschen Nationalidentität und dem Bedürfnis einer Distanzierung von Rassismus, Fremdenfeindlichkeit und Nationalsozialistischer Vergangenheit. Während Herr B diese Spannung von sich aus aufgreift und latent bearbeitet, funktioniert die antiamerikanische Abwehr des Vorwurfes der „Feindseligkeit“ bei Herrn D maßgeblich über explizite Relativierung: Anschläge auf Asylbewerberheime sind „Pappenstiele“ im Vergleich zur Fremdenfeindlichkeit in den USA, der Holocaust ist vor dem Hintergrund von Hiroshima kaum bemerkenswert. Zusätzlich scheint der relativie-

10 Die gleiche Formulierung findet sich bei Frau J: ,,[... es wird immer nur auf dem Deutschen rumgehackt und eigentlich unser kleiner Hitler is schon, schon, äh, eigentlich Vergangenheit.“ In ihrem Fall wird als relativierende Vergleichsfolie allerdings „Napoleon“ herangezogen, der ,genau die gleichen Kriege geführt“ habe, wie Hitler, dessen Nachfahren dies aber im Gegensatz zu den Deutschen nicht vorgehalten werde. 
rende Vergleich mit ,amerikanischen Taten“ eine Art „Thematisierungsverweigerung“ zu befördern: Die extrem naheliegende Verknüpfung von fremdenfeindlicher Gewalt in Deutschland mit den Verbrechen des Nationalsozialismus scheint für Herrn D durch sein Amerikabild geradezu blockiert zu sein. Unabhängig davon, ob dies bewusst oder unbewusst geschieht, ist die Fixierung des Gespräches auf amerikanische „Ausländerfeindlichkeit“, „Sklaverei“ und „Lynchmorde“ ausreichend dominant, um die nationalsozialistische Vergangenheit nicht thematisch werden zu lassen.

\subsubsection{Frau K: Antiamerikanismus und ,klassischer Antisemitismus}

Zum Zweck der Kontrastierung soll hier abschließend auf das Beispiel einer antiamerikanischen Rede eingegangen werden, die sich mit antisemitischen Sprechweisen verbindet, ohne dabei - im Gegensatz zu Herr B und D - eine Latenz- oder Rechtfertigungsfunktion zu übernehmen. Insgesamt ist der Latenzschutz des antisemitischen Sprechens bei Frau K so gering ausgeprägt, dass von einem nahezu expliziten Antisemitismus gesprochen werden kann. Lediglich eine oberflächliche antizionistische „Camouflage“ (Holz 2001, S. 440 ff.; Holz 2005, S. 82 ff.), nach der ,die Juden“ stets als „Israelis“ angesprochen werden, grenzt ihre Rhetorik von einem expliziten Antisemitismus ab. Antiamerikanische Sprechweisen spielen als ideologische Latenzsicherung keine Rolle, werden aber im Rahmen der antisemitischen Verschwörungstheorie Frau Ks relevant: ,Amerika' tritt hier als zerstörerische Macht auf, deren untergründiges Wirken zu Kriegen und Konflikten weltweit führt, um aus diesen Profit schlagen zu können. Zum Schluss des Interviews stellt sich zudem heraus, dass Frau K , die Juden“ als treibende Kraft hinter dieser , amerikanischen' Politik identifiziert. Im Folgenden werden die Eckpunkte dieses antizionistisch-antiamerikanischen Antisemitismus skizziert.

Zu Beginn des Interviews erläutert Frau K, dass ihr die Amerikaner deswegen unsympathisch seien, weil sie ohne nachvollziehbare Gründe ,praktisch die halbe Welt mit Krieg überziehen“. Die amerikanisch angeleiteten Interventionen in Irak und Afghanistan, sowie der Konflikt um das iranische Atomprogramm erscheinen ihr als durch die USA und Israel ,provoziert":

Frau K: Die, die äh machen, die, die machen irgendwas, damit es einen Brandherd gibt auf der Welt. Und damit was neues, äh sich entzündet. Ja?

Interviewer: Verstehe ich Sie richtig, dass sind auch amerikanische...

Frau K: Da sind auch Israelis dabei! Ja? Also der M- äh Mossad? Ja, Mossad. Ne, diese Leute. 
Interviewer: Der israelische [Geheimdienst]...

Frau K: [Und, und die]... Ja genau, und die Amerikaner haben ja auch solche, diese privaten Sicherheitsleute... [Ja, ja, also]...

Hierbei werden die USA als Profiteure kriegerischer Auseinandersetzungen dargestellt, die durch das bewusste Anzetteln von Konflikten ihre Militärindustrie in Gang halten: „Die müssen also die äh Kriege anzetteln, damit die Waffenindustrie, äh, äh, gut läuft. Ne?“ Im Nahost Konflikt zwischen Israel und den Palästinensern sind es hingegen vor allem die Israelis, die einer friedlichen Lösung im Wege stehen, weil sie so „furchtbar dickköpfig“ sind und „,sich auch nichts sagen“ lassen. Dabei sei es prinzipiell möglich, dass „Palästinenser und Israelis, äh::, also halt friedlich miteinander leben würden [...] aber die, die Israelis die, die wollen einfach nicht".

Und auch hinter dem schädlichen Einfluss der US-Politik stehen in Frau Ks Konstruktion letztendlich ,die Israelis“. Nachdem der Interviewer sie zum Ende des Interviews auf ihre politische Orientierung anspricht, betont diese, dass sie ,wie man sagt, rechts“ sei, jedoch nicht als ,,ausländerfeindlich“ gelten wolle. Im Anschluss daran bekräftigt sie aber ihre ,kritische“ Haltung gegenüber den USA mit dem Hinweis auf ,die Regierung, oder, oder wer eben da im Hintergrund das Sagen hat“. Sie berichtet von diversen ,unbequem[en]“ Büchern, die sie gelesen und die ihr Einblick in die dubiosen Vorgänge der US-Politik gegeben hätten. Auf die Frage, wer denn ihrer Meinung nach in den USA ,im Hintergrund das Sagen“ habe, erläutert sie:

Frau K: Pf::: (.) tja, da dürfen, dürfen Sie mal raten, wer da dahinter steckt.

Interviewer: Ja, Sie meinen, dass die...

Frau K: Die Amerikaner wird, werden, wird von den, von Israel äh, praktisch zum großen Teil dirigiert.

Interviewer: Also von Lobbyisten dann...

Frau K: Von... Ja, jaja, jaja, die haben ja also eine ganze, eine riesen Abteilung in Amerika, ne? In der Politik, ne?

Auf die Nachfrage des Interviewers, wie diese Macht ,der Israelis` zu erklären sei, wo diese doch in den USA eine sehr kleine Minderheit seien, erklärt Frau K: „Mh, pf, ja also die, die streiten halt auch gerne, also... Also das ist das, was sie am besten können.“ Dieselben „Israelis“ stellen weiterhin in Frau Ks Konstruktion Wieder- 
gutmachungsforderungen an Deutschland, die ihrer Ansicht nach unangemessen sind und auf ,mysteriös[e]“ Weise häufig nicht die rechtmäßigen Adressaten erreichen.

Frau K: [...] Juristen, wo sie da so Massen, äh, äh, na, Gelder von Deutschland gefördert haben, gefordert haben, um, um irgendwelche Leute da auszuzahlen, und früher... Und die haben das dann also irgendwie doch nicht gekriegt, so irgendwie. Ist also irgendwie mysteriös.

Interviewer: Das habe ich nicht ganz verstanden. Gelder...

Frau K: Ja also so, so, ja äh, Ausgleichs-[Gelder irgendwie].

Interviewer: [Nach dem Zweiten Weltkrieg]?

Frau K: Ja, ja, ja. Also, aber mehrmals, ne? Auch wenn wir schon bezahlt hatten, dann kamen sie, dann kamen sie, dasselbe wieder von vorne, ne?

Interviewer: Die Amerikaner jetzt, oder...

Frau K: Nee, also die Israelis in, in Amerika, ne? Die haben sich dann äh, so einen, so einen speziellen Anwalt genommen, und dann machen sie solche, äh, äh, äh, solche Sammelklagen, ne, ne?

Interviewer: Was Ihnen jetzt dubios, oder irgendwie unrechtmäßig erscheint?

Frau K: Ja, beziehungsweise, irgendwie haben die glaube ich, äh, die Betroffenen die Gelder auch gar nicht so bekommen, irgendwie, wie, wie das jetzt sein soll, oder so irgendwas, ne?

Spätestens an dieser Stelle ist klar erkennbar, dass die Bezeichnung „Israelis“ in Frau Ks Rede als antizionistische Camouflage eines antisemitischen Judenbildes fungiert: Es ist nicht davon auszugehen, dass mit den „Israelis [...] in Amerika“, die besagte Kompensationsforderungen stellen, tatsächlich allein israelische Staatsbürgerinnen und Staatsbürger gemeint sind, die in den USA leben. Diese Annahme ist auch vor dem Hintergrund plausibel, dass in der obigen Sequenz implizit der Holocaust thematisiert wird - das einzige Auftreten von Latenzkommunikation in diesem Interview -, in dem bekanntlich nicht „Israelis“ sondern Jüdinnen und Juden verfolgt wurden. Die Behauptung, geleistete Kompensationszahlungen seien nicht an die „Betroffenen“ weitergeleitet worden, impliziert zudem, dass es Betroffene und also auch die Verbrechen gegeben hat, für die nun kompensiert werden soll. Damit klingt der Holocaust in Frau Ks Rede zumindest implizit an, jedoch, gemäß 
den Regeln eines sekundären Antisemitismus, in erster Linie als Problem der deutschen Wir-Gruppe und unter Verwendung antisemitischer Stereotype. So müssen die Deutschen in dieser Konstruktion ,immer wieder" Zahlungen leisten, auch „wenn wir schon bezahlt hatten“, die Schuld also bereits abgegolten war, und werden somit erneut zum Opfer ,jüdischer Gier` und ,Betrügerei` stilisiert. Ein weiteres antisemitisches Motiv liegt darin, dass , die Juden' als in sich gespaltene, selbstzerstörerische Einheit konstruiert werden (vgl. Holz 2001, S. 243 ff.). „Die Israelis“ treten einerseits als geschlossene Gruppe auf, die durch ihre ,übertriebenen “ Kompensationsforderungen die deutsche Wir-Gruppe ausbeuten; zugleich betrügen sie sich aber untereinander, so dass ihr ,parasitärer' Charakter gewissermaßen auch nach Innen wirkt. Trotz dieser inneren Spaltung bleiben , die Juden ' aber gemäß der antisemitischen „Regel der Identität“ (ebd., S. 158 f.) als paradoxe Einheit bestehen, der sämtliche negativen Attribute kollektiv zugeschrieben werden.

Hinsichtlich der Latenzfunktion ihrer antisemitischen und antiamerikanischen Konstruktionen stellt Frau K einen Grenzfall dar: Zwar ist sie sich der Sanktionierungen hinsichtlich antisemitischer (und generell vorurteiliger) Rede durchaus bewusst, was an ihrem Gebrauch der antizionistischen Camouflage („Israelis“ statt ,Juden“), an der nahezu vollkommenen Ausblendung des Holocaust sowie an ihrer Selbstrechtfertigung als ,rechts und doch wieder nicht rechts“ erkennbar wird. Zugleich ist aber der Latenzschutz in ihrer antisemitischen Kommunikation nur äuBerst unvollständig ausgeprägt. So finden sich kaum latente Thematisierungen des Holocaust, d.h. dieser wird nur in der Rede von , unangemessenen " Wiedergutmachungsforderungen implizit angesprochen, ansonsten aber vollkommen ausgeblendet. An keiner Stelle versucht Frau K - im Gegensatz zu Herrn B - ihre eigene demokratische oder humanistische Ablehnung der nationalsozialistischen Judenvernichtung auszudrücken. Darüber hinaus ist auch die antizionistische Camouflage, nach der ,Juden“ stets nur als „Israelis“ angesprochen werden, nur ein notdürftiger Schleier für den Gebrauch klassischer antisemitischer Stereotype (,jüdische Streitlust', ,Starrsinn “, ,Gier' und ,Betrug', ,Drahtzieher' in den USA), die zur Erklärung weltweiter Konflikte dienen. Insbesondere macht Frau K, im Unterschied zu den vorigen Beispielen in diesem Kapitel, keinen rechtfertigenden oder latenzerzeugenden Gebrauch von antiamerikanischen Stereotypen. Diese sind vielmehr in klassischer Form in ihre antisemitischen Erklärungsmuster integriert: Die USA fungieren demnach als Instrument, der Juden', mithilfe dessen sie ihren ,zerstörerischen Einfluss` auf die Welt ausüben. Als latenzerzeugendes rhetorisches Mittel dient lediglich die antizionistische Camouflage, so dass von einer Latenz des Holocaust kaum gesprochen werden kann. Latenz bedeutet hier über weite Strecken also tatsächlich „ein Schweigen“ (Milbradt 2013, S. 38; vgl. Kap. 4.6.2): Der Holocaust wird weitestgehend ausgeblendet, nicht aber implizit thematisiert, so dass von einer latenten Bearbeitung der „Paradoxie der Normalisierung“ nicht die Rede sein kann. 
Insgesamt ist anhand der Rede von Frau K nicht viel Neues zur Funktion von Antiamerikanismus im Rahmen von Erinnerungspolitik und Antisemitismus zu erkennen. Es treten aber die bereits bekannten Zusammenhänge von antiamerikanischer und antisemitischer Rhetorik in ihrer Funktionsweise noch einmal besonders deutlich hervor: Amerika wird als störende und zerstörerische Macht dargestellt, als nationale Verkörperung eines amoralischen kapitalistischen Profitstrebens, das mit verschwörerischen Methoden seine Ziele verfolgt. ${ }^{11}$ Als steuernde Kraft hinter diesen zerstörerischen Vorgängen werden, die Juden` ausgemacht, die mit ihrer ,Streitlust', ,Gier' und ,Hinterlistigkeit' gewissermaßen als , un-menschliche', personale Verkörperung des amoralischen Wirkens ,der Amerikaner' auftreten.

\subsubsection{Zwischenfazit: Antiamerikanismus im Funktionskontext von Erinnerungspolitik, Schuldabwehr und Antisemitismus}

Mit der oben rekonstruierten antiamerikanischen Sprechweisen konnte ein differenzierter Einblick in das rhetorische Zusammenspiel antisemitischer und antiamerikanischer Vorurteile gegeben werden. Hierbei wurde vor allem die funktionale Affinität von Antiamerikanismus und demokratischem Antisemitismus herausgearbeitet, die in einer (latenten oder expliziten) Normalisierung des deutschen Vernichtungsantisemitismus besteht. Darüber hinaus wurde die Ergänzung von Amerika- und Judenbildern in einem weltanschaulichen Antisemitismus beschrieben, der in erster Linie welterklärende Funktionen erfüllt. Anhand der drei analysierten Fälle lassen sich also drei Formen dieses Zusammenspiels unterscheiden. Im Fall von Herrn B ist die funktionale Analogie von Antiamerikanismus und demokratischem bzw. sekundärem Antisemitismus besonders ausgeprägt: Nicht nur bearbeitet der antiamerikanische Gebrauch der Bilder einer ,amerikanischen Weltpolizei` sowie eines ,amerikanischen Genozids“ dieselbe Paradoxie deutscher Nationalidentität nach 1945, sondern er stimmt auch in den rhetorischen Formen überein. D.h. es wird mit den Mitteln der Täter-Opfer Umkehr, der Kommunikationslatenz und des relativierenden Vergleichs gearbeitet, die auch im sekundären Antisemitismus zu finden sind.

Die antiamerikanische Rhetorik Herrn Ds stellt eine weniger komplexe Variante dieser ideologischen Funktion dar: Zwar wird auch hier das Problem einer „Paradoxie der Normalisierung“ deutscher Nationalidentität behandelt; jedoch greift Herr D dabei weder auf das Mittel der Täter-Opfer Umkehr, noch auf eine latente Kommu-

11 In diesem antiamerikanischen Sprechen sind übrigens auch kontrastierende Funktionen zu finden, wie sie anhand der Fälle von Herrn F und C in Kapitel 7.2 bereits beschrieben wurden: So ist von der ,Oberflächlichkeit der Amerikaner' und der extremen sozialen Ungleichheit in den USA die Rede, die als negative Kontrastfolie zur Qualifizierung der deutschen Eigengruppe gebraucht werden. 
nikation der NS-Vergangenheit zurück. Diese wird vielmehr mit auffälliger Nachhaltigkeit vollkommen ausgeblendet, bis eine direkte Konfrontation mit dem Thema dies unmöglich macht. Ab diesem Punkt bedient sich Herr D der expliziten Relativierung bzw. Externalisierung der Genozid-Problematik durch direkten Vergleich mit vermeintlich ebenso gravierenden amerikanischen Taten. Auch hier dient antiamerikanisches Sprechen also der Normalisierung eines deutschen Nationalismus, jedoch gelingt es Herrn D nicht im selben Maße wie Herrn B, die darin beschlossene normative Paradoxie ideologisch aufzuheben: Ohne die Mittel der Kommunikationslatenz und Täter-Opfer Umkehr ist er gezwungen, dem erinnerungspolitischen Common Sense einer besonderen historischen Schuld und Verantwortung Deutschlands offen zu widersprechen. Dementsprechend abrupt endet an dieser Stelle dann auch das Interviewgespräch durch einen radikalen Themenwechsel des Teilnehmers.

Am Beispiel von Frau K wurde eine Funktion antiamerikanischen Sprechens als integraler Teil einer antisemitischen Argumentation aufgezeigt. Bilder einer zerstörerischen ,Weltmacht USA“ sowie eines ,kriegslüsternen Israel' greifen ineinander bei der Konstruktion bzw. Erklärung eines Weltweiten Bedrohungsszenarios, in dem durch verborgene ,Drahtzieher' um des Profites willen Kriege angezettelt werden. Antisemitisch ist diese welterklärende Rhetorik, weil ebenjene ,Drahtzieher“ als „Israelis“ identifiziert werden, womit gemäß Frau Ks antizionistischer Camouflage ,Juden“ gemeint sind. Antiamerikanische Sprechweisen erfüllen hier also keine Latenz- oder Normalisierungsfunktion, sondern ergänzen sich mit antizionistischantisemitischen Klischees zu einer welterklärenden Rhetorik.

Die Zusammenschau aller drei präsentierten Antiamerikanismen gibt Einblick in das rhetorische Zusammenspiel antiamerikanischer und antisemitischer Rhetoriken. Vor dem Hintergrund der obigen Falldarstellungen wird eine mögliche Erklärung der statistisch beobachteten Korrelationen zwischen Antisemitismus und Antiamerikanismus ersichtlich: Beide Vorurteilsformen wären demnach deshalb assoziiert, weil sie eine ideologische Bearbeitung desselben Identitätsproblems des deutschen Nationalismus nach 1945 ermöglichen und dabei auf ähnliche rhetorische Muster zurückgreifen. Die von Klaus Holz beschriebene „Paradoxie der Normalisierung" kann auch antiamerikanisch bearbeitet werden, mithilfe der rhetorischen Mittel der Täter-Opfer Umkehr, der Kommunikationslatenz sowie der vergleichenden Relativierung. Am Beispiel von Herrn B lässt sich das Zusammenspiel aller drei Rhetoriken beobachten, während die Rede von Herrn D eine rhetorisch weniger komplexe, dadurch aber auch ideologisch weniger effektive Variante veranschaulicht, in der lediglich die explizite Relativierung des Holocaust erzielt wird. Anhand der antizionistisch-antisemitischen Konstruktion von Frau K lässt sich darüber hinaus eine weitere Erklärungshypothese entwickeln, der zufolge Antiamerikanismus als ergänzendes Moment einer antisemitischen Welterklärung auftreten kann. ,Isra- 
el' und ,Amerika' fungieren dann als unterschiedene Erscheinungsformen desselben zerstörerischen ,jüdischen Einflusses` auf das Weltgeschehen. 


\subsection{ANTIAMERIKANISMUS IM FUNKTIONSKONTEXT VON ETHNOZENTRISMUS UND RASSISMUS}

Im vorigen Teilkapitel wurde eine ideologisch-rechtfertigende Funktion antiamerikanischer Rede rekonstruiert. Diese zeichnet sich dadurch aus, dass ,Amerika' in ihr nicht nur der Konturierung und Evaluation einer nationalen Wir-Gruppe dient, sondern zugleich bestimmte problematische Aspekte dieser Wir-Gruppenkonstruktion aufgegriffen und bearbeitet werden. Am Beispiel von Herrn B konnte gezeigt werden, wie Amerikastereotype dazu gebraucht werden können, eine kontinuierliche deutsche Wir-Gruppe zu konstruieren, in der das ,demokratische Deutschland" mit den Täter-Generationen des NS versöhnt und zugleich die nationalsozialistische Judenvernichtung verdeckt und verharmlost wird.

Im vorliegenden Abschnitt soll nun eine ähnliche ideologische Doppelfunktion antiamerikanischer Rhetorik aufgezeigt werden, die sich im Kontext von Ethnozentrismus und Rassismus rekonstruieren lässt. Am Beispiel von Herrn A wird gezeigt, wie Bilder amerikanischer ,Kultur-' und ,Wurzellosigkeit' dazu gebraucht werden können, eine ethnozentrisch-essentialistische Nationalidentität zu konstruieren, während zugleich Bilder eines ,amerikanischen Rassismus' dazu verhelfen, die rassistischen Aspekte dieser Wir-Gruppenkonstruktion zu externalisieren bzw. zu relativieren. Ähnlich wie in den in Kapitel 7.2 geschilderten Fällen werden antiamerikanische Sprechweisen also dazu gebraucht, die Tugenden der Eigengruppe zu demonstrieren und in einer essentialistischen Ursprungserzählung abzustützen. Diese antiamerikanisch aktualisierte Wir-Gruppenkonstruktion geht aufgrund ihres ethnozentrisch-essentialistischen Charakters mit fremdenfeindlichen und rassistischen Rhetoriken einher und gerät somit in Widerspruch $\mathrm{zu}$ demokratisch-egalitären Normen. Dieser Widerspruch wird von den Interviewteilnehmenden selbst reflektiert, d.h. Menschenfeindlichkeit und Rassismus werden als Problemgegenstände aufgegriffen. Bezeichnend ist nun, dass dies in allen hier präsentierten Fällen unter Verweis auf den Rassismus ,der Amerikaner' geschieht, der, so soll gezeigt werden, als negative Vergleichsfolie zur Relativierung bzw. Externalisierung des Rassismusproblems dient. Rassismus ist nach dieser Logik immer das, was in Amerika passiert, während die (eigene) systematische Exklusion oder Abwertung von ,Türken', ,Russen', ,Amerikanern', etc. in Deutschland legitimer Ausdruck nationaler Identität ist.

Diese Rhetorik kommt teilweise explizit und vergleichsweise offen zum Einsatz; so thematisieren Herr E und Herr D jeweils explizit die Gefahr, aufgrund der von ihnen vertretenen Positionen als „Nazi“ oder „,feindselig“ angesehen zu werden, und weisen diesen Vorwurf präventiv zurück. Um ihr Argument zu bekräftigen, rekurrieren sie auf den ,wirklichen“ Rassismus , der Amerikaner'. Von Herrn A hingegen wird die Rassismusproblematik, d.h. der rassistische oder fremdenfeindli- 
che Aspekt der eigenen Wir-Gruppenkonstruktion, latent bearbeitet. Es findet sich kein Rekurs auf die Möglichkeit einer politisch-moralischen Sanktionierung seiner Position, stattdessen aber eine nachdrückliche Verurteilung rassistischer Vorgänge in den USA. Diese antirassistische Positionierung wird im Folgenden als implizite Rechtfertigung der eigenen (rassistischen) Position gedeutet: Indem Herr A dieselbe Form rassistischer Diskriminierung im deutschen Kontext befürwortet, in den USA aber vehement ablehnt, bearbeitet er das Dilemma einer gleichzeitig egalitärdemokratischen und ethnozentrischen politischen Orientierung. Der Gebrauch antiamerikanischer Stereotype erlaubt ihm, ähnlich der Rhetorik von Herrn B, das Problem rassistischer Diskriminierung aufzugreifen und zu relativieren, ohne es (in Bezug auf seine Eigengruppe) jemals explizit ansprechen zu müssen.

Diese Latenzfunktion antiamerikanischer Rede wird im Folgenden zunächst ausführlich am Beispiel von Herrn A erläutert. Kurzdarstellungen von Interviewauszügen der Teilnehmer E, C und D dienen anschließend dazu, die eingangs entwickelte Deutung zu untermauern, indem Ähnlichkeiten und Differenzen zwischen den verschiedenen Fällen aufgezeigt werden.

\subsubsection{Falldarstellung Herr A: Antiamerikanismus als rassistischer ,Antirassismus“}

Anhand des Falles von Herrn A lässt sich exemplarisch ein antiamerikanisches Sprechen zeigen, das zur Legitimation ethnischer Diskriminierung unter den Bedingungen demokratisch-egalitärer Normen dient. Im Folgenden wird zunächst dargestellt, wie Herr A an den USA insbesondere einen dort virulenten Rassismus ablehnt und insofern in seiner Positionierung gegen Amerika eine egalitäre Haltung stark macht: Die rassistische Opposition gegen Obama wird von ihm als unverständlich und ungerecht dargestellt. Im Gespräch über das rassistische Potential der deutschen Bevölkerung zeigt sich allerdings, dass Herr A für die Eigengruppe andere normative Standards anlegt: Dass deutschen Staatsangehörigen mit (insbesondere türkischem) Migrationshintergrund bestimmte politische Ämter (Bundeskanzler, Außenminister) prinzipiell vorenthalten bleiben sollen, gilt ihm im Rahmen der deutschen Wir-Gruppe nicht als rassistisch, sondern als eine Art gesunden Nationalbewusstseins. Diese widersprüchliche normative Konstellation - dass in gewissem Sinne dasselbe Phänomen ethnozentrischer Exklusion in den USA als Rassismus verurteilt, in Deutschland aber legitimiert wird - wird durch den Gebrauch bestimmter Amerikabilder (und korrespondierender Wir-Gruppenbilder) ermöglicht. Das Sprechen über , amerikanischen Rassismus“ wird hier also zum Ausdruck einer rassistischen Praxis. Das Dilemma einer ethnozentrischen und zugleich egalitären Orientierung wird antiamerikanisch gelöst, indem die Rassismus-Problematik in 
Bezug auf die Wir-Gruppenkonstruktion latent gehalten wird, während sich die Anerkennung der egalitären Norm im Protest gegen amerikanischen Rassismus äußert.

\subsubsection{Rassismus in den USA und Deutschland}

Zum Einstieg des Interviews bittet der Interviewer Herrn A um eine Erläuterung seiner Zustimmung zum Survey-Item „Mir sind die US-Amerikaner eher unsympathisch“. Herr A zählt eine Reihe ungeliebter Eigenschaften ,der Amerikaner" auf, unter denen sich neben deren vermeintlicher Arroganz und Überheblichkeit auch rassistische Anfeindungen gegenüber US-Präsident Barack Obama finden.

Herr A: [...] mit dem jetzigen Präsidenten, mit dem Obama, da hat nun wirklich, sag ich mal, ich persönlich, irgendwie die Hoffnung gehabt, okay, jetzt wird sich etwas ändern, wobei ich so ein bisschen auch meine Zweifel hatte, ob sich das ändern wird, weil der Weiße hat halt immer noch die Herrschaft in den USA, und das zeigt sich wohl jetzt immer stärker. Die fahren wirklich einen Staat an die Wand, nur um eine Regierung fertig zu machen, einen schwarzen Präsidenten fertig zu machen, und - okay, und dann die Herrschaft wieder übernehmen zu können.

In einer späteren Sequenz fragt der Interviewer Herrn A noch einmal nach dessen Einschätzung, dass Obama ,ein Problem wegen seiner Hautfarbe haben könnte“, und dieser Antwortet:

Herr A: Haben könnte? Er hat ein Problem wegen seiner Hautfarbe. Ich meine, diese, diese Gegenpartei, die jetzt gerade (.) - jetzt fällt mir der Namen nicht von der Truppe ein - (.) da gibt es doch so eine...

Interviewer: Die Tea Party Bewegung.

Herr A: Tea, Tea Party, genau die hier! Und die proklamieren ja das wirklich in der Öffentlichkeit, den Mann total zu diffamieren und bloßzustellen. Und die gesamte Regierung (.) bloßzustellen, also, Mobbing, oder vielleicht ist es noch schlimmer, was die da drüben treiben. Das wird ja sehr offensichtlich dargestellt! Auch die Meinungen, die dort öffentlich dargestellt werden, das ist ja schon manchmal verrückt. Also, da muss man sich als Deutscher schon an den Kopf langen, wie man so was öffentlich und mit einer hundertprozentigen Sicherheit darstellt. Bloß um diesen, um diese Regierung zu stürzen. Und alles wieder zurückzubringen, nur den Schwarzen nicht an die Macht zu lassen. (...) Ja.

Als Beispiel für eine rassistisch motivierte Opposition gegen Obama werden hier zunächst Tea-Party-Aktivisten genannt. Diese ,diffamieren ‘ und ,mobben` den Prä- 
sidenten, um „,den Schwarzen nicht an die Macht zu lassen“. Zugleich wird die Eigengruppe in scharfen Kontrast zu diesem Verhalten gesetzt: ,als Deutscher“ ist eine solche Anfeindung völlig unverständlich und scheint bei Herrn A nur Ablehnung und Verwunderung zu erzeugen. Herrn As Konstruktion einer amerikanischen Machtelite, die aus rassistischen Motiven die Präsidentschaft Obamas sabotiert, wird im Anschluss an diese Stelle im Zusammenhang mit einem wirtschaftlichen Abschwung in den USA weiter ausgeführt:

Herr A: $[\ldots]$ Aber die haben ganze Städte blankgemacht. Die haben Werke dichtgemacht. Die haben nichts mehr investiert! Wenn (.) ich (.) was tun will für mein, für mein Land oder für meine, für meinen Konzern, dann versuche ich doch, in den USA (.) hier wirtschaftlich was aufzubauen. Die haben da gar kein Interesse! Mir scheint, die fahren das mit Absicht runter, um die Regierung (.) in den Ruin zu treiben! [...] Und das ist ja eine richtige Strategie, wie man das langsam beobachtet. Du hörst wirklich nicht, das die da drüben wirklich (.) aggressiv was tun! Ich meine, gut, hier in Deutschland, in Europ-, in Deutschland ist es se:hr (.) wir sind sehr aggressiv auf dem Weltmarkt. [...] Der Ami tut das gar nicht, der macht da nichts! Das ist irgendwie scheint mir (.) schlafen die da drüben, ich habe keine Ahnung!

Herr A deutet hier in verschwörungstheoretischer Manier an, dass die gegenwärtigen wirtschaftlichen Probleme in den USA ebenfalls durch den Rassismus , der Amerikaner“ bzw. der „Lobby“ (ebd., S. 122) in Industrie und Wirtschaft erklärt werden könnte, die es vorziehe, ihre eigenen Unternehmen zu ruinieren, anstatt einen schwarzen Präsidenten im Amt zu belassen. Diese Passage verdeutlicht zusätzlich, dass Rassismus im Amerikabild von Herrn A ein großer Stellenwert zukommt. Bis hierher könnte man diese Position als anti-rassistische Haltung mit verschwörungstheoretischen Zügen werten. Der weitere Interviewverlauf legt aber eine andere Lesart dieses Interesses an , amerikanischem Rassismus' nahe. Diese beginnt sich abzuzeichnen, als der Interviewer das Gespräch auf die Möglichkeit einer vergleichbaren Rassismus-Problematik in Deutschland lenkt. Auf die Frage, ob hier eine ähnliche Anfeindung eines Politikers denkbar wäre, antwortet Herr A:

Herr A: Inwieweit? Durch Rassismus, oder was? [...] Das glaube ich nicht, das glaube ich nicht. In Deutschland... (.) Es gab auch so: (.) Lobbys, es gab eine Herrschaftsschicht, nur die bröckelt ziemlich stark. Und (.) das sieht man auch an der Parteiengesellschaft. [...] Aber diese, dieses Lobby, dieses, dieses Lobbydenken früher, mit Regierung und so, das ist alles nicht mehr da. Man weiß wirklich nicht, wer morgen regiert!

Die Existenz rassistischer Tendenzen in Deutschland wird vom Teilnehmer zunächst also rundheraus abgestritten. Unmittelbar darauf wechselt er das Thema und spricht nun von Orientierungslosigkeit und Unsicherheit in der deutschen Parteipolitik. Um den Vergleich zwischen den USA und Deutschland zu betonen, fragt der 
Interviewer an dieser Stelle nach, ob sich Herr A die Wahl eines türkischstämmigen Bundeskanzlers in Deutschland vorstellen könne. In Herrn As Reaktion auf diese Frage wird die normative Ambivalenz seiner Wir-Gruppenkonstruktion erkennbar:

Herr A: Oje. (...) Oje, oh, das kann ich mir (lacht) nicht vorstellen, dass es das tut. Da::s glaube ich nicht. Also::., also ich denke mal, der Deutsche, der Deutsche::... (..) Ich sage mal, im Geheimen ist er ein Deutscher. (...) Das, was da (.) akzeptiert wird ode:r, wie sagt man, geduldet wird, (.) das sind die (.) Türken, Italiener, Griechen. Das wird geduldet, sage ich mal. Aber wirklich lieben tut die keiner. Ich meine, Italiener vielleicht, Spanier auch, weil die nicht dieses (.) Machtstreben haben. Der Türke ist da schon, hat da schon ein Machtstreben. Ja. Wenn der türkische Staatspräsident da sich aufspielt, ihr dürft in Deutschland alles machen, aber eure Religion dürft ihr nie vergessen. Also (.) sicher (.), man hat schon, man hat schon ein bisschen im Hintergrund ob die Türken... Also, die haben zwar damals in Wien die Schlacht verloren, abe:r vielleicht unterwandern die das. Davor hat der Deutsche, denke ich, Angst. Vor dem Islam, vor den Türken (.) und das, das (.) merkt man manchmal, wenn das alles unterwandert wird. Ja, man verweicht etwas, man weicht gewisse Dinge auf, und merkt aber nicht, dass man andere Dinge zulässt, ja. Und (.) davor haben viele Angst. Und das, was der Sarrazin da in seinem Buch dargestellt hat, das zeigt die Angst, das zeigt die Angst.

Was an den USA als Rassismus kritisiert wurde, der Ausschluss von politischen Ämtern aufgrund ethnischer Kriterien, wird für die deutsche Eigengruppe hier emphatisch befürwortet. Diese Befürwortung wird zwar über weite Strecken so vermittelt, als gebe Herr A lediglich die ,Meinung des Volkes‘ wieder, kann aber aufgrund der insgesamt sehr nachdrücklichen Ablehnung sowie des völligen Fehlens jeglicher Problematisierung der beschriebenen Positionen als Haltung des Sprechers selbst gelesen werden. " „Türken, Italiener, Griechen“ werden in Deutschland zwar geduldet, als Teil der nationalen Wir-Gruppe nach Herrn As Verständnis aber nicht angenommen. Auffällig ist hierbei einerseits die Abwertung und Ablehnung von „Türken“, die als Bedrohung der deutschen Wir-Gruppe gekennzeichnet werden: Bilder eines türkischen „Machtstreben[s]“, einer religiösen ,Unterwanderung“ Deutschlands werden aufgerufen um ein insgesamt islam- und ausländerfeindliches Szenario zu zeichnen. Dieses wird unter Verweis auf die Mehrheit ,des Volkes“ bzw. den Erfolg von Sarrazins Buch als legitime Angst beschrieben. Andererseits werden hier schon Grenzen der Sagbarkeit thematisiert, die in einem späteren Abschnitt dieser Analyse größere Bedeutung gewinnen: „Der Deutsche“ ist nur „,im Geheimen [...] ein Deutscher“. Dies ist als Ergänzung der zuvor festgestellten Unmöglichkeit eines türkischstämmigen Bundeskanzlers zu lesen. Die ethnozentrische

1 Diese Lesart wird auch durch spätere Sequenzen gestützt, in denen sich Herr A gegen „Verfremdung“ und für ethnische Identität und Homogenität ausspricht (vgl. Kap. 7.4.1.2). 
Exklusion, wenngleich i.d.R. nicht öffentlich geäußert, ist Teil der nationalen Identität: „Im Geheimen“ ist der Deutsche ein Deutscher, und was geheim bleiben muss, ist eben die Ablehnung der, Ausländer'.

Insgesamt findet sich also bei Herrn A die widersprüchliche Konstruktion, dass der gleiche Sachverhalt, der in den USA als Rassismus problematisiert wird, in der deutschen Eigengruppe als legitimer Ausdruck nationaler Identität gilt. Dies bekräftigt Herr A im Anschluss an die oben zitierte Sequenz, indem er mit Cem Özdemir ${ }^{2}$ ein Beispiel für jene Deutschen mit Migrationshintergrund gibt, denen bestimmte politische Ämter seiner Ansicht nach verwehrt sind (bzw. sein sollten):

Herr A: Nein, glaube ich nicht, glaube ich nicht. Also wenn schon... In Deutschland glaube ich das gar nicht. Also das kann das hin und her sein, wie auch immer. Also, von mir aus kann der Özdemir, was weiß ich, kann der Entwicklungsminister sein oder irgendwas, aber der wird nie Außenminister sein. Kann ich mir nicht vorstellen. Und Bundeskanzler sowieso nie.

Bezeichnend an dieser Position ist, dass Herrn A der Selbstwiderspruch, den ich oben aufgezeigt habe, selbst nicht bewusst zu sein scheint bzw. genauer: dass die gleichzeitige Inanspruchnahme egalitärer Normen und ethnozentrischer Exklusivität für ihn offenbar keinen Widerspruch darstellt. Dies wird nicht zuletzt an der relativen Offenheit deutlich, mit der die fremden- bzw. islamfeindliche Diskriminierung türkischstämmiger Deutscher vertreten wird, obwohl zuvor mit Empörung über amerikanischen Rassismus in einem vergleichbaren gesellschaftlichen Bereich gesprochen wurde. Ich werde im folgenden argumentieren, dass die Kontrastierung von ,amerikanischem Rassismus “ und ,deutschem Nationalbewusstsein “ als rhetorische Rechtfertigung jener widersprüchlichen normativen Konstellation funktioniert: Die Ablehnung von amerikanischem Rassismus ermöglicht es Herrn A, ethnische Diskriminierung (in Deutschland) zu legitimieren, und sich zugleich auf egalitäre Normen (hinsichtlich der USA) zu beziehen. Das vermeintlich kritische Zurückweisen von Rassismus in den USA wird somit zum Moment einer rassistischen Praxis.

Man könnte dies auch so formulieren, dass sich mit der anti-rassistischen Haltung des Teilnehmers ein ethnopluralistisch eingehegter Vollzug der Gleichheitsidee verbindet, in dem ethnische Gruppen nur insofern gleichberechtigt sind, als jeder Gruppe ein nationaler Ort zugewiesen wird, an dem sie gewisse naturgegebene Vorrechte genießt. Nach dem Vorbild eines „Herder“schen“ Modells ethnischer Grenzziehung (Wimmer 2008, S. 60) verbindet sich der formale Gleichheitsgrundsatz mit einem ethnischen Verwandtschaftsglauben (Sutterlüty 2008); so können

2 Gemeint ist der Bundesvorsitzende der Partei Bündnis 90/Die Grünen, der 1994 als erster Abgeordneter mit türkischem Migrationshintergrund in den deutschen Bundestag gewählt wurde (vgl. Özdemir). 
,ethnisch Deutsche“ gegenüber ,ethnisch Fremden“ privilegiert werden, ohne dass dadurch der Gleichheitsgrundsatz verletzt würde. Die ethno-nationalistische Personenauffassung bildet die „Maske der Gleichheit, unter der die einzelnen in das Blickfeld der egalitären Einstellung treten“ (Menke 2004, S. 41). Diese Variante der egalitären Einstellung beinhaltet also zugleich ein anti-egalitäres Moment: Sie rechtfertigt diskriminierende hierarchische Ungleichheitsbeziehungen. Das Amerikabild von Herrn A erfüllt genau diese ideologische Funktion: Rassismus als Problem der eigenen Position auszuschließen, ohne ein Rassismusproblem ganz leugnen zu müssen.

\subsubsection{2 „Kultur“ und Ethno-Nationalismus}

Die oben entwickelte Deutung eines funktionalen Zusammenhangs von Amerikabild, Wir-Bild und rassistischer Praxis lässt sich zusätzlich anhand von Interviewstellen untermauern, in denen das Thema ,amerikanischer Kultur" verhandelt wird. In Abgrenzung zu den USA und deren „Mischmasch von Kulturen“ konturiert Herr A hier das Bild einer kulturellen Homogenität und Traditionalität der deutschen Eigengruppe. Der Begriff der Kultur, so werde ich im Folgenden argumentieren, kann im Sprachgebrauch von Herrn A als ein Ausdruck seines Ethnozentrismus gelesen werden: Mit ,Kultur' ist demnach die jeweilige ,Substanz' einer ethnischen Gemeinschaft bezeichnet. ,Kultur' ist die Chiffre, mit der das „stahlharte Gehäuse der Zugehörigkeit“ ethno-nationaler Identität (Nassehi 1997a) reproduziert wird.

Im Anschluss an das Thema amerikanischer Einflüsse auf Deutschland spricht der Interviewer Herrn A auf das Thema amerikanischer Kultur an und fragt ihn, wo ihm diese im Alltag begegne. Herr A reagiert, indem er die vermeintliche Substanzlosigkeit amerikanischer Kultur der ,gewachsene[n] Kultur“ Deutschlands gegenüberstellt:

Herr A: Die haben gar keine. (lacht) Also die Kultur, wenn man, man das versteht als Denker und Dichter, was hier Deutschland in den letzten 200, 300 Jahren, oder noch viel länger - das hat ja schon noch viel viel früher angefangen - aber was so wirklich stark war, war die Klassik, Goethe, Schiller (.), das hat es in den USA nicht so gegeben. Weil die USA ist ein Mischmasch von Kulturen! Eine eigene... Ich denke, das war mehr wirtschaftlich, was da drüben aufgebaut wurde, und dann schwappte das hier rüber als Idee:::, und das wurde vermarktet, und so ging es zum nächsten Teil über. Eine wirkliche Kultur hat USA (.) gar nicht.

Einer einheitlichen Traditionslinie deutscher Kultur stellt der Interviewteilnehmer die Heterogenität amerikanischer Un-Kultur gegenüber. Was von ihm als amerikanische Kultur dennoch angesprochen wird, ist Herrn A zufolge eher durch ,wirtschaftlich[e]“ Prozesse entstanden. Einem traditionsreichen Amerika-Stereotyp folgend, trennt Herr A wirtschaftliche von kulturellen Entwicklungen und identifiziert 
dabei die USA mit ersterem, die Eigengruppe hingegen mit der Ursprünglichkeit und Homogenität von ,Kultur‘ (vgl. Diner 2003, S. 46; Jaecker 2014, S 130 ff.). Dieser Kulturbegriff, so werde ich zeigen, steht in Herrn As Gebrauch tatsächlich aber für die Natur des deutschen ,Volkes', wie es vielfach für moderne Formen von Rassismus beschrieben wurde (vgl. Nassehi 1997a, S. 182 ff.; Martin 2010, S. 65 ff.). Die kulturelle Traditionsgemeinschaft funktioniert, ähnlich wie in Kapitel 7.2.2 am Beispiel von Herrn F beschrieben, als essentialistische Volksgemeinschaft. Dieses Verständnis von Kultur als quasi-natürlicher Substanz ethnischer Abstammungsgemeinschaften wird in der Metaphorik der folgenden Sequenz erkennbar:

Herr A: Warum. (...) Also, sage mal, hier in Deutschland, in Europa, das ist eine gewachsene Kultur, von den Germanen angefangen, und das hat es in den USA gar nicht gegeben. Es gab die Inder, äh, die Indianer, und dann kam der Mischmasch mit Spanien und England und Iren und was weiß ich. Deutsche waren auch dabei, und das hat ja erst so ab, was weiß ich, wann die rüber sind. 1800 (.) sind die rüber, und haben eigentlich nur leben wollen, ihr Land bewirtschaften wollen, und mehr gab es da nicht. (.) Wahrscheinlich ist das dieser, dieser krasse Unterschied, ja. (.) Und bei uns ist das mehr eine gewachsene Sache. (.) Das kann man in den USA in dem Maße gar nicht aufbauen, denke ich. (.) Ja, der Chinese hat zum Beispiel auch eine Kultur. (.) Die ganzen Mings, und wie die alle heißen, ja. Auch der Inder hat eine Kultur. Eine gewachsene Kultur. Und das ist in den USA gar nicht.

Die USA und ihr „Mischmasch von Kulturen“ dienen hier als Kontrastfolie nicht nur zur Konstruktion und Bewertung der eigenen nationalen Identität, sondern, wie der Verweis auf „den Chinesen“ und dessen ebenfalls „gewachsene Kultur“ nahelegt, auch der Reproduktion einer ethnopluralistischen Weltsicht, die die Welt in nationale ,Lebensräume' für kulturell und ethnisch homogene Völker aufteilt. Die USA bilden das Außen zu dieser nationalen Ordnung. Eine Nation ,ohne Kultur heißt hier: eine Nation , ohne Volk‘. Im vorigen Abschnitt wurde gezeigt, wie die USA von Herrn A als Beispiel für Rassismus verurteilt werden, während dieser zugleich rassistische Positionen in Bezug auf ,Ausländer' in Deutschland vertritt. ,Amerika‘ dient dabei der ideologischen Entschärfung des Rassismusproblems, das von Herrn A zugleich reproduziert wird. Anhand der hier präsentierten Stellen wird nun eine zusätzliche Funktion der gebrauchten Amerikastereotype erkennbar: ,Amerika' dient nicht nur der rhetorischen Kontrolle des Rassismusproblems, sondern wird von Herrn A zugleich zur Konstruktion jener ethno-nationalistischen Wir-Gruppe genutzt, deren Rassismusproblem dann bearbeitet werden muss. Die antiamerikanische Rhetorik hat hier also eine zweifache Wirkung: Sie hilft sowohl bei der ethnozentrischen Konturierung der Eigengruppe, als auch bei der ideologischen Invisibilisierung der rassistischen Komponenten dieser Identitätskonstruktion. 
Auf der Grundlage der oben beschriebenen Unterscheidung von amerikanischer Un-Kultur und deutscher Ethno-Kultur lässt sich zusätzlich eine These darüber aufstellen, wieso gerade ,Amerika' sich als Projektionsfläche für diese Doppelfunktion anbietet: Weil es Herrn A zufolge in den USA zwar verschiedene Ethnien gibt, aber keiner davon ein traditionelles Privileg als ,amerikanisches Volk‘ zuzusprechen ist, darf sich dort auch keine partikulare Gruppe eine Dominanzposition gegenüber einer anderen anmaßen. Wo es keine quasi-natürliche Verbindung von Nation und Ethnie gibt, kann ethnische Ungleichheit nicht legitimiert werden und bedeutet deshalb Rassismus. In Deutschland hingegen, wo die ,ethnisch Deutschen“ ein naturwüchsiges Privileg qua ,kultureller` Tradition genießen, stellt die Diskriminierung von ,Ausländern “ und anderen Outgroups eine völlig legitime Form der Hierarchiebildung dar. Man kann sagen: Die Unterscheidung von homogener Kulturnation vs. amerikanischem „Mischmasch“ funktioniert nicht nur als evaluatives Kriterium auf der Dimension besser vs. schlechter, sondern die Struktur der Unterscheidung Kultur vs. Un-Kultur ermöglicht zugleich eine ideologische Verschiebung der Rassismusproblematik, die demzufolge erst in dem Moment beginnt, wo sich verschiedene Ethnien außerhalb ihrer ,natürlichen Lebensräume“ begegnen. Die rassistischen Implikationen der Konstruktion eben dieser Lebensräume selbst, wie sie Herr A vornimmt, werden dadurch effektiv ausgeblendet.

Die ethno-nationalistische Orientierung von Herrn A kann zudem an der folgenden Sequenz verdeutlicht werden, die im Anschluss an die oben zitierte Darstellung eines türkischen Bedrohungsszenarios folgt. Auf die Frage hin, ob Herr A die Angst ,des Deutschen“ vor ,türkischer Unterwanderung' für berechtigt halte, antwortet dieser:

Herr A: Ja, ich denke das, ich denke das. Also, hier vielleicht weniger, weil die:: (...), die Leute hier bei uns, in [Stadt 1], Raum [Stadt 1], die Schwaben, die Schwaben, es gibt ja doch viele Schwaben, ja (.), das ist ja ein eigener Kulturstamm. Und die haben eine eigene Mentalität, eine andere, eigene Denkweise, als z.B. ein Rheinländer. [...] Was zum Beispiel auch extrem ist, ist Ostfriesland, zum Beispiel. Die haben das (.) ziemlich extrem mal gemacht, das haben mir... Ich habe geschäftlich viel in Ostfriesland zu tun gehabt, und da haben mir Leute dort drüben erzählt, als damals die Polen rüberkamen ins Ruhrgebiet, nach dem zweiten Weltkrieg, oder vorher schon, aus Polen rüberkamen (.) - die sind ja alle ins Ruhrgebiet, weil es dort Arbeit gab - und dann gab es auch viele, die wollten nach Ostfriesland. Denen haben sie, denen haben sie Geld in die Hand gedrückt und haben gesagt: Da, geh woanders hin. Die haben die nicht rein gelassen, ja (.), und das war ein Volk für sich! Die haben das nicht geduldet. Und die haben auch nicht diese Verfremdung haben wollen. Und ich denke, das ist hier bei uns ähnlich. Es gibt Landstriche, die akzeptieren das alles, für die ist das alles nicht so wichtig. Es gibt aber andere Landstriche, die::: (.) wollen ihre Kultur behalten (.) und pflegen sie auch. Das ist in Bayern so, das ist bei uns hier so. 
Zwar wird in diesem Zitat die nationale Unterscheidung ,Deutsche“ vs. ,Türken“ etc. durch eine Differenzierung von innerdeutschen Ethnien ergänzt: Anstelle ,des Deutschen“stehen nun ,Ostfriesen“, ,Schwaben“, ,Bayern“. Aber das Prinzip ethnischer Homogenität und Territorialität, die gegen ,Verfremdung“ verteidigt werden muss, bleibt erhalten, wie sich am zentralen Beispiel „Ostfriesland“ vs. „,die Polen“ ablesen lässt. Herr As Begeisterung für ,deutsche Kulturstämme“ lässt sich also als innerdeutsche Spiegelung seines Ethno-Nationalismus lesen. Auch diese Aufspaltung der deutschen Wir-Gruppe in ethnische Subgruppen funktioniert dabei als rhetorische Abmilderung der fremdenfeindlich-nationalistischen Konstruktion. Darauf deutet vor allem hin, dass der Ausgangspunkt der obigen Sequenz nicht die Frage nach lokalpatriotischen Abgrenzungen, sondern nach der ,Unterwanderung Deutschlands durch, die Türken“ war: Wenn Herr A von Ostfriesen und Schwaben als „,Volk für sich“" schwärmt, das keine ,,Verfremdung“ duldet, so schwärmt er implizit von einem , deutschen Volk', das sich gegen ,Unterwanderung ' auflehnt, vermeidet dabei aber den allzu undemokratischen Klang ebendieser Formulierungen. ${ }^{3}$

\subsubsection{Zusammenfassung Herr A}

In den vorigen zwei Abschnitten wurde gezeigt, wie Antiamerikanismus die ideologische Funktion übernehmen kann, eine gleichzeitige Orientierung an ethnischer Gleichheit und ethnozentrischer Diskriminierung zu ermöglichen. Es wurde argumentiert, dass ,Amerika‘ bzw. dessen kulturelle Heterogenität im Sprechen von Herrn A einerseits dazu dient, die Traditionalität und essentielle Homogenität der nationalen Wir-Gruppe zu konstruieren und aufzuwerten. Paradoxerweise präsentiert sich Herr A andererseits aber in Abgrenzung gegen ,Amerika' auch als Verfechter gerade jener Gleichheitsgrundsätze, die durch diese Wir-Gruppenkonstruktion verletzt werden. ,Amerika' dient als Kontrastfolie zur Konstruktion einer ethnozentrisch-essentialistischen nationalen Wir-Gruppe sowie zur ideologischen Invisibilisierung des daraus entstehenden normativen Widerspruchs zum egalitären Prinzip.

Aufgrund des vorliegenden Materials kann davon ausgegangen werden, dass es sich dabei nicht um einen bewusst-taktischen Akt der Selbstdarstellung handelt. Damit soll nicht bestritten werden, dass im Sprechen von Herrn A ein gewisses ,praktisches Bewusstsein' (Giddens 1984, S. 41 ff.) der Widersprüchlichkeit seiner normativen Orientierung existiert. Denn auch die Alternativerklärung einer völligen ,Verblendung‘ des Teilnehmers scheint mir dem Phänomen unangemessen. Vielmehr ist zunächst auf rhetorisch-praktischer Ebene festzuhalten, dass in Herrn As

3 Dies wird auch daran erkennbar, dass „Schwaben“, „Ostfriesen“ und „Bayern“ sich hier nicht gegeneinander verteidigen müssen, sondern gegen „Türken“ und „Polen“: Die leitende Unterscheidung verläuft nach wie vor entlang nationaler Grenzen. 
Rede beides auftritt: Der Widerspruch zwischen egalitär-antirassistischen und antiegalitär-ethnozentrischen Positionen und dessen Invisibilisierung. Herr A nimmt den Widerspruch also auf eine praktische Weise durchaus wahr, folgt dabei aber einem ideologischen Muster, durch das die entstehenden Widersprüche im Moment ihrer Reflexion zugleich entschärft, d.h. nicht als Widersprüche reflektiert werden.

Die These, dass antiamerikanisches Sprechen die ideologischen Bedingungen für ein egalitäres anti-egalitäres Sprechen bereitstellt, die Ablehnung von ,amerikanischem Rassismus ' hier also Ausdruck von Rassismus ist, beansprucht nicht eine Kausalerklärung dieser widersprüchlichen Konstellation zu geben. Dass Herr A widersprechende normative Haltungen vertritt, wird nicht durch sein Amerikabild verursacht, d.h. es wäre z.B. nicht sinnvoll zu behaupten, er sei Rassist (bzgl. der deutschen Wir-Gruppe) weil er sich gegen amerikanischen Rassismus richtet, oder vice versa. Was meine Deutung vielmehr erschließen will, ist, dass Herr A rassistisch handelt, indem er antiamerikanisch handelt, und wie aus dieser Verknüpfung von antiamerikanischer und ethnozentrischer Sprechweise ein ideologischer Mehrwert entsteht, nämlich das rhetorische Latent-Halten des eigenen Rassismus. Wie in Kapitel 3 und 4 beschrieben wurde, zielt meine Studie nicht primär auf die Entdeckung kausaler Ursachen für antiamerikanisches Sprechen, sondern möchte aufzeigen, inwiefern der Gebrauch bestimmter Amerikabilder in bestimmten weltanschaulichen Kontexten als antiamerikanisches Vorurteil kritisiert werden kann. Auf diese mehrfach gestufte Fragestellung gibt die oben explizierte Deutung folgende Antworten:

(1) Es wurde gezeigt, wie antiamerikanisches Sprechen mit ethnozentrischen, fremdenfeindlichen und rassistischen Identitäts- bzw. Vorurteilskonstruktionen rhetorisch verknüpft werden kann: in einer Kombination von Kontrastierungs- und Rechtfertigungsfunktion bei der Konstruktion ethnozentrischer Nationalidentität. Antiamerikanische Rhetorik scheint im Zusammenhang solcher Ethnozentrismen deshalb besonders gut zu funktionieren, weil beide Konstrukte eine besondere Affinität zu einer kulturellen Semantik aufweisen: Wenn „Kultur“ den argumentativen Platz einnimmt, den einst der Rassebegriff belegte, dann werden die ,kulturlosen“ USA zu dem Ort, an dem die quasi-natürliche Ordnung der Völker aufgehoben ist. Paradoxerweise wird dadurch in einem „Herder' schen“ Ethnozentrismus ,Amerika“ zu dem Ort, an dem Rassismus als Problem erst möglich wird, gerade weil hier die natürliche ethno-nationale Ordnung aufgehoben ist: Amerika versinnbildlicht innerhalb einer rassistischen Weltsicht die Möglichkeit, dass die hierarchische Ordnung der ,Völker' nicht naturgegeben sein könnte. ,Rassismus‘ wird damit im antiamerikanischen Sprechen ironischerweise zum Titel für das ,Rassenproblem` der Rassisten, das gerade nicht darin besteht, dass Menschen aufgrund ethnischer Zuschreibungen diskriminiert werden, sondern dass die ethno-nationale Ordnung der Welt aus den Fugen zu geraten scheint. 
(2) Dabei wurde zugleich veranschaulicht, wie der vorurteilige Sinngehalt einer bestimmten amerikabezogenen Sprechweise - hier insbesondere die Bilder eines amerikanischen Rassismus und amerikanischer Kultur - als performative Bedeutung rekonstruiert werden kann: Erst der Gebrauch besagter Amerikabilder im Kontext von Ethnozentrismus und Fremdenfeindlichkeit macht sie zum Moment antiamerikanischer Rhetorik. Damit wird der antiamerikanische Gehalt der analysierten Aussagen unabhängig davon bestimmbar, ob diese unmittelbar feindselig gegen ,Amerikaner sind, sowie unabhängig vom propositionalen Gehalt der getroffenen Aussagen (vgl. Kap. 2.3).

\subsubsection{Zusätzliche Interviewbeispiele: Ähnliche antiamerikanische Sprachgebräuche im Kontext von Rassismus und Ethnozentrismus}

Um die Funktionsweise der im vorigen Abschnitt beschriebenen antiamerikanischen Rhetorik zusätzlich zu verdeutlichen, wird im Folgenden auf vergleichbare Sprechweisen in der Rede drei weiterer Fälle verwiesen. Herr E, Herr C und Herr D greifen in ähnlicher Weise das Bild eines ,amerikanischen Rassismus“ auf, um damit eine egalitäre, anti-rassistische Haltung vor dem Hintergrund eigener rassistischer bzw. fremdenfeindlicher Positionen zu markieren. Aus Gründen der Übersichtlichkeit und Lesbarkeit der vorliegenden Arbeit können diese Fälle nur kursorisch dargestellt werden. Daher werden die Fälle von Herrn C und D ohne ausführliche Zitate aus dem Interviewmaterial zusammengefasst.

\subsubsection{Herr E}

In der Rede von Herrn E lässt sich eine fremdenfeindliche Rhetorik beobachten, in der „Ausländer“ pauschalisierend zu einer Bedrohung der deutschen Wir-Gruppe erklärt werden. Hierbei greift der Interviewteilnehmer in ähnlicher Weise wie Herr A auf Bilder eines amerikanischen Rassismus zurück, um seine eigenen Positionen präventiv gegen Rassismusvorwürfe abzuschirmen. Im Unterschied zu Herrn A geschieht dies aber explizit, d.h. es wird vom Interviewteilnehmer direkt angesprochen, dass eine pauschalisierend negative, seinem eigenen Verständnis nach ,kritische“, Darstellung von „Ausländern“ Gefahr läuft, als fremdenfeindlich angesehen zu werden. In der antiamerikanischen Rhetorik von Herrn E fehlt hier also jene Latenzfunktion, mit der das Problem eines möglichen fremdenfeindlichen oder rassistischen Gehalts der eigenen Position zugleich verdeckt wird.

Das Interviewmaterial wurde im Rahmen der in Kapitel 5.4 beschriebenen dritten Pilotstudie erhoben. Der Interviewleitfaden sah hier u.a. Fragen zur sogenannten „Deutschenfeindlichkeit“, also einer gegen deutsche Personen gerichteten Men- 
schenfeindlichkeit, vor. Letztere bildet auch den Einstieg zu den im Folgenden dargestellten Interviewsequenzen. Auf die Frage des Interviewers, ob Herr E mit dem Begriff „Deutschenfeindlichkeit“ etwas anfangen könne, antwortet dieser:

Herr E: [...] Das gibt`s schon immer, nur w-, wird das immer totgeschwiegen. Das wird nicht, äh, wie soll ich sagen, das wird halt nicht publik gemacht. Wurde schon vor zwanzig, dreißig Jahren wurden in, was weiß ich, in Discotheken oder Clubs wurden vielleicht, was weiß ich, deutschlandweit bestimmt im Monat zwanzig, dreißig Leute ab (...), von irgendwelchen Ausländern abgestochen oder irgendwie, irgendwas in der Art ist vorgefallen, aber das wurde immer mehr oder weniger totgeschwiegen, nur wenn ein Deutscher was anstellt und dann wird das richtig publik gemacht, also das ist auch verrückt.

In Herrn Es Einschätzung, dass monatlich in Deutschland „zwanzig, dreißig Leute [...] von irgendwelchen Ausländern abgestochen“" würden, deutet sich bereits ein stereotypes und abwertendes Bild jener Gruppe an, die er als „Ausländer“ bezeichnet. Die Bedrohung, die er mit dem Begriff der „Deutschenfeindlichkeit“ assoziiert, wird seiner Ansicht nach allerdings ,totgeschwiegen“. Auf die Nachfrage, worin diese Schweigen, d.h. die von ihm beschriebene voreingenommene Berichterstattung begründet sei, erläutert er:

Herr E: Weil viele Leute die Wahrheit nicht hören wollen (lacht) oder wie auch immer, (lacht) was weiß ich, die vertragen die Wahrheit nicht oder sie wollen einfach nur sch-, wegen zweiten Weltkrieg, sie wollen halt einfach schlecht reden. Is klar, es gibt auch viele Deutsche die gewalttätig sind und so, aber eben die Mehrheit is ganz klar bei den Ausländern, des (...), die Hemmschwelle zu kriminellen Handlungen die is ne e-, die ist einfach deutlich tiefer angesiedelt, das sieht man ja, wenn man (...), schon in den Gefängnissen sitzen ja unheimlich viele Ausländer, wenn man das ins Verhältnis setzt zur (...) angeblichen Ausländeranteil in Deutschland ist das natürlich verheerend, is es ein unheimlich hoher Anteil. Nur natürlich sind natürlich die mei-, viele auch eingebürgerte, die haben ein deutschen Pass, die sprechen zwar kaum Deutsch, aber die haben einen deutschen Personalausweis. Das sind aber für mich auch immer noch Ausländer, in Anführungszeichen (lacht).

In diesem Zitat wird einerseits die stereotype und abwertende Darstellung von „Ausländern“ zusätzlich verstärkt, denen hier pauschal eine geringere „Hemmschwelle zu kriminellen Handlungen“ und Gewalt zugeschrieben wird. Zudem beschreibt er sein Kriterium für die Zugehörigkeit zu jener Gruppe genauer: „Ausländer“ ist demzufolge nicht allein, wer keine deutsche Staatsangehörigkeit hat. Diese Bemerkung legt zumindest nahe, dass Herr E ein ethnisches Zugehörigkeitskriterium verwendet, wobei damit noch keine rassistisch-kategoriale Unterscheidung von ,ethnisch Deutschen“ und „Ausländern“ verbunden sein muss (der Verweis auf die mangelnde Sprachkompetenz ließe auch ein graduelles Integrationskriterium zu). In 
jedem Fall wird aber die Distanz zwischen einer deutschen Wir-Gruppe und „Ausländern“ betont. Zugleich wird hier die Tabuisierung seiner eigenen Position in der Öffentlichkeit thematisiert. Der Verweis auf den ,zweiten Weltkrieg“ stellt dieses vermeintliche Tabu in den Kontext einer falschen oder vorschnellen Verurteilung der von ihm geäußerten Ansichten als rassistisch und fremdenfeindlich: Die Leute, die einen Vergleich mit Nazi-Deutschland anstreben, ,vertragen die Wahrheit nicht“ oder ,wollen einfach halt schlecht reden“. Damit macht Herr E implizit klar, dass er sich von diesem Vorwurf distanziert und seine eigene Position nicht als rassistisch oder fremdenfeindlich verstanden wissen will: Nur weil er ,kritisch “ über „Ausländer“ spricht, ist er noch lang kein „Nazi“. Auf die Nachfrage, ob er eigene Erfahrungen mit der besprochenen „Deutschenfeindlichkeit“ gemacht habe, erörtert Herr E:

Herr E: Ja, lange, als Kind war das schon so, jetzt natürlich nicht mehr, um Gottes Willen, aber man merkt natürlich schon, dass die, äh, also mal auch vom, vom Arbeiten her, dass wenn man mit Ausländern zu tun hat, dass dann oft, äh, wie soll ich sagen, die (...), man wird mehr provoziert und sie benehmen sich anders. Respektloser und, äh, akzeptieren nichts und, äh, wollen immer diskutieren und, und, praktisch um, um ihr Ziel durchzusetzen. Also ist schon ein anderes, ein anderes Verhalten, sagen wir mal so. Da gibt`s, wenn man mal sagt „Nein“, das akzeptieren die nicht, und wenn ich zu nem deutschen Kunden sag, okay, ne, d-, mehr geht nicht, das ist der Mindestpreis, dann wird das akzeptiert und fertig, aber bei, bei nem, speziell jetzt bei nem Türken, der will noch stundenlang drüber diskutieren.

An dieser Stelle wird der Katalog der abwertenden Zuschreibungen auf „Ausländer“, hier insbesondere auf „Türken“, um die Attribute ,respektlos“ und ,provozierend" erweitert. Zugleich betont Herr E aber, dass diese Haltung in der Öffentlichkeit zu Unrecht als vorurteilig abgestempelt werde und macht somit deutlich, dass er, ähnlich der oben rekonstruierten Position von Herrn A, einen demokratischegalitären Standpunkt für sich beansprucht. Dies macht er in der folgenden Sequenz noch einmal deutlich, in der er einerseits seine Angst beschreibt, als „Nazi“ abgestempelt zu werden, zugleich aber das Bedrohungsszenario der „Deutschenfeindlichkeit“" in Bezug auf ,deutsche Schulkinder' zuspitzt:

Herr E: Ja das is, wenn einer irgendwie was gegen einen Ausländer sagt, dann wird das (...), dann wird das (...), äh, spricht man dann gleich von ,der Nazi“ oder wie auch immer. Ob das ein (...), ob es einer ist oder nicht. Man hat Angst irgendwas zu sagen, weil`s einem gleich praktisch rumgedreht wird und man muss sich auch teilweise, wenn man in Schulen, wenn da auch deutsche und ausländische Kinder sind, müssen sich die Kinder oft ganz anders, äh, ausländischen Kindern gegenüber benehmen, wenn sie da auf ihr, auf ihr Recht pochen würden, da würden sie zusammengesch-, zusammengeschlagen werden, die müssen da viel vorsichtiger sein, und das wird eigentlich alles mehr oder weniger totgeschwiegen. 
Ob man als Erwachsener „,was gegen einen Ausländer sagt“ oder „deutsche [...] Kinder“ auf dem Schulhof ,,ausländischen Kindern gegenüber [...] auf ihr Recht pochen“, in Herrn Es Konstruktion müssen ,Deutsche“ immer damit rechnen zum Opfer öffentlicher Stigmatisierung oder gewalttätiger „Ausländer“ zu werden. Ähnlich wie bei Herrn A findet sich also auch hier ein Widerspruch zwischen der stereotypen, ethnozentrischen Darstellung und dem Anspruch, dies sei weder diskriminierend noch abwertend. Im Gegensatz zu Herrn A wird dieser Widerspruch von Herrn E allerdings offen thematisiert. Vor dem Hintergrund dieser selbstwidersprüchlichen Position kann der folgende Kommentar über Rassismus in den USA als relativierende Entlastung der eigenen Position verstanden werden. Auf die Frage des Interviewers, ob er während seiner Aufenthalte in den USA ähnliche unangenehme Kommunikationsformen mit Amerikanerinnen und Amerikanern erlebt habe, wie er sie oben „Ausländern“ zuschreibt, antwortet Herr E:

Herr E: Ja in, in Amerika ist eins ganz anders im Vergleich zu Deutschland. In Deutschland redet man immer von Rassismus und so, den es aber eigentlich gar nicht gibt, aber in Amerika gibt`s den tatsächlich, da tun meistens die Schwarzen und da is (...), die sind untereinander, die Weißen sind untereinander, die Vietnamesen oder Asiaten leben für sich, während der Arbeit okay, kommen sie vielleicht zusammen, aber ansonsten tun sie sich strikt trennen. Also da is (...), hab ich, oder gibt`s ganze Straßenblöcke wo nur Asiaten leben und wo sie (...), wird wirklich mehr abgeschirmt. Da hab ich das eher erlebt. Aber bei uns wird das so hoch gespielt, aber es gibt`s im Grunde genommen nicht. Nicht so in dem Umfang.

Bezeichnenderweise bezieht sich Herrn Es Reaktion nicht auf ,provozierende` oder ,respektlose` Kommunikation, auf die die Frage des Interviewers abzielte, sondern Herr E nutzt den Vergleich Deutschlands mit den USA, um zu betonen, dass es in Deutschland „eigentlich“ keinen Rassismus gebe, obwohl davon so häufig gesprochen werde. Die Frage des Interviewers, ob es sich bei den Menschen in den USA auch um solch , unangenehme“ „Ausländer“ handele, wie bei den zuvor von Herrn E beschriebenen, wird hier zu der Frage, ob es in den USA Ausländerfeindlichkeit bzw. Rassismus gebe. In ähnlicher Weise, wie zuvor bei Herrn A, wird hier also , amerikanischer Rassismus' thematisiert, um die eigene Position präventiv (der Interviewer hat keinerlei Kritik geäußert) gegen Rassismus-Vorwürfe zu verteidigen, diese sozusagen aus dem Bereich der Eigengruppe auszuklammern: Wenn Herr E sagt, in Deutschland gebe es keine Rassismus, so sagt er auch: Ich bin kein Rassist. Zusätzlich versucht Herr E die Bedeutung des Rassismus-Begriffes zu seinen Gunsten zu verschieben, indem er als Beispiel von Rassismus in den USA vornehmlich die Segregation ethnischer Gruppen heranzieht. Dadurch, dass er, anstatt einen Vergleich rassistischer Äußerungen in den USA und Deutschland anzustreben, von ethnischer Segregation in den USA spricht, entfernt er den Referenzbereich des Rassismusbegriffes zusätzlich von seiner eigenen Position. Auch hier dient also ei- 
ne vermeintlich ,kritische ' Rede über amerikanischen Rassismus der Rechtfertigung der eigenen fremdenfeindlichen bzw. rassistischen Position.

Bezeichnend für die Funktion antiamerikanischer Vorurteile in diesem Interview ist weiterhin, dass die Wir-Gruppenkonstruktion Herrn Es nicht nur gegen „Ausländer“ in Deutschland abgegrenzt und aufgewertet wird, sondern auch gegen , die Amerikaner‘. Amerikastereotype werden hier nicht nur genutzt, um die fremdenfeindlichen Aspekte der Wir-Gruppenkonstruktion zu relativieren bzw. externalisieren, sondern auch unmittelbar zur Konturierung und Aufwertung dieser Konstruktion selbst. Als Hauptdimensionen dieser antiamerikanischen Konturierung der Eigengruppe lassen sich die Themen ökonomische Rationalität bzw. Sparsamkeit sowie Solidarität und kulturelle Integration ausmachen. So spricht Herr E zu Anfang des Interviews im Zusammenhang mit der Finanzkrise von der extremen Verschuldung vieler amerikanischer Haushalte und stellt diese der Sparsamkeit ,der Deutschen' gegenüber:

Herr E: Ja, ich (...) ich hab in Amerika mal gelebt und da war`s so, dass wirklich jeder, also nahezu jeder, also ganz, ganz wenige Ausnahmen, die haben alle mehrere Kreditkarten und die waren alle maxed out, also die waren bis auf den Anschlag am Limit, und im Moment ist es so, dass so gut wie kein Amerikaner ein Haus kaufen kann oder irgendwas, weil die jetzt (...), mittlerweile haben die ne Bankenaufsichtsbehörde und, ähm, da kriegt kaum... so gut wie kein Mensch mehr ein Kredit durch, weil sie alle hochgradig verschuldet sind, weil der Amerikaner immer mehr ausgegeben hat, wie er eingenommen hat. Und das hat na-, macht natürlich viel aus. Das ist bei uns nicht so, wir sparen ja, wir Deutschen sind ja Weltmeister im Sparen.

Dass „der Amerikaner“ ökonomisch derart inkompetent handelt, begründet er damit, dass „,in Amerika [...] die Leute eher dumm gehalten“ würden: „der durchschnittliche Amerikaner kann nicht wirtschaftlich denken oder handeln, das geht nicht, das hat der noch nie gelernt, hat er auch noch nie was von gehört und wenn man mit ihm über so was spricht, der guckt einen dann ganz verwundert an.“

Zum Ende des Interviews wird Herr E gebeten, seine Zustimmung oder Ablehnung bzgl. einiger amerikabezogener Surveyitems zu beschreiben. Auf das Item „Die Menschen in den USA sind überaus eigennützig und egoistisch“ reagiert Herr E zustimmend und erläutert seine Haltung mit einigen kurzen Episoden aus seiner Zeit in den USA. Grundsätzlich sei man ,,sehr selbstsüchtig drüben, man denkt nur an sich“. Auch familiärer oder freundschaftlicher Zusammenhalt sei in den USA kaum zu finden:

Herr E: Wie soll ich`s erklären. Wenn da einer, äh, (lacht), Probleme hat oder Geld hat oder Geldn-, in Geldnot ist, da hilft keiner dem Anderen, außer jetzt vielleicht in der Familie und selbst da nicht so und des is (...), oder viele Kinder werden mit 18 aus dem Haus geschmis- 
sen, weil die werden nur als Ballast angesehen, es ist schon ne andere Art zu Leben. Des is mehr so wie, wie die (...) wie zur Cowboyzeit (lacht).

Das scherzhaft gebrauchte Bild der „Cowboyzeit“ kann als allegorischer Kristallisationspunkt verstanden werden, in dem die gebrauchten Stereotype einer bindungslos-individualistischen, unverantwortlichen bzw. nicht-nachhaltigen amerikanischen Lebensweise gebündelt werden. Herr E führt dieses Bild anhand einiger persönlicher Erfahrungen weiter aus, in denen er von der „Oberflächlichkeit“ seiner Bekanntschaften in den USA berichtet:

Herr E: [...] man merkt es dann schon, dass das alles mehr so oberflächlich ist. Man unterhält sich, man geht aus was trinken, aber mehr ist da nicht. Wenn einer wegzieht nur fünf M-, fünf Meilen weg, dann sieht der Andere den nie mehr wieder. Es ist diese Bindung, wie es in Deutschland, oder so, üblich ist, die gibt`s dort sehr, sehr (...), so gut wie gar nicht praktisch. Das ist alles mehr oberflächlich. Ist alles Smalltalk praktisch.

Auffällig ist an dieser Sequenz wiederum, dass Herr E auch hier einen direkten Vergleich mit „Deutschland“ anstrengt: Das geschilderte Amerikabild ist eng verknüpft mit einer Konstruktion der Eigengruppe, wobei stets deren positive Aspekte betont werden. Die Darstellung, der Deutschen“ als familienorientierte, solidarische „Weltmeister im Sparen“ wird im Folgenden mit der kulturellen Heterogenität der USA in Zusammenhang gebracht. Seine Zustimmung zu dem Surveyitem „Die USamerikanische Kultur ist oberflächlich“" umschreibt Herr E wie folgt:

Herr E: [...] Kultur in der s-, haben sie ja nicht, weil das sind ja alles, von allen möglichen Ländern das zusammengeschmolzen. Ein Mischmasch aus allem, aber es ist sehr oberflächlich alles. [...] wenn sie irgendwas machen, dann wird das einfach nur so (...), we-, da würde der Amerikaner sagen „half-assed“ so schnell, schnell und so halbherzig, lieblos gemacht. Die Arbeitsweise und so, wenn sie irgendwas machen, des is alles etwas, so lustlos [...].

Die vermeintliche Lieblosigkeit, Halbherzigkeit und Lustlosigkeit ,der Amerikaner ist hier also, ähnlich wie in der Rede von Herrn A und Herrn F in den vorigen Abschnitten, eng assoziiert mit Vorstellungen kultureller Homogenität und Traditionalität. Amerika ist das Gegenbild zur Konturierung der wichtigsten Eigenschaften der nationalen Wir-Gruppe, und diese Eigenschaften sind wiederum bedingt durch die kulturelle Ursprünglichkeit dieser Gruppe. Neben Sparsamkeit, Familie und Freundschaft zählen auch Moral und Ehrlichkeit zu diesen Werten, wie Herr E mit Verweis auf die USA deutlich macht: „ein Mann ein Wort, das gibt's da drüben [...] so gut wie gar nicht, das ist alles mehr so oberflächlich.“

Wie anhand dieser kurzen Überblicksdarstellung der von Herrn E verwendeten Amerikabilder erkennbar wird, dienen diese, ähnlich wie bei Herrn A, nicht nur der 
präventiven Abwehr von Rassismusvorwürfen gegen die eigene ethnozentrische Identitätskonstruktion, sondern sie funktionieren auch als wichtiges Moment dieser Identitätskonstruktion selbst. Was die Essenz der ,ethnisch Deutschen“ ausmacht, zeigt sich maßgeblich im Kontrast zu den ,kulturlosen USA‘.

\subsubsection{Herr C}

Ähnlich wie Herr A kommt Herr C von selbst auf das Thema ,amerikanischer Rassismus ‘ zu sprechen. Es ist eines in einer lange Liste negativer Attribute, die er auf die Frage hin aufzählt, was ihm an den USA unsympathisch sei. Herr C berichtet dabei von berufsbedingten Aufenthalten in den USA, in deren Zuge er Rassismus insbesondere in den amerikanischen Südstaaten („Alabama“) kennengelernt habe. Er schildert Rassismus als wesentliches Merkmal der USA, als ,ihre Philosophie“, die in verschiedenen gesellschaftlichen Bereichen, Arbeitsmarkt, Recht, Justiz, wirksam sei. Ähnlich wie bei Herrn A verliert sich diese anti-rassistische Position allerdings vollkommen, wenn das Gespräch auf die deutsche Wir-Gruppe kommt: In Deutschland, so argumentiert Herr C, gebe es kein Rassismus-Problem, hier steht vielmehr ein Integrationsproblem im Zentrum der Aufmerksamkeit. Insbesondere die ,Türken“ in Deutschland seien nach 50 Jahren Aufenthalt noch immer unangepasst, sprächen zu wenig Deutsch, nutzten den Sozialstaat aus und unterwanderten die ,europäische Kultur' Deutschlands. Die mangelnde gesellschaftliche Integration verschiedener ethnischer Gruppen ist dieser Konstruktion zufolge in den USA ausschließlich verursacht durch den Rassismus der weißen Mehrheit; in Deutschland hingegen ist, einem Bringschuld-Verständnis von Integration folgend, die ,türkische‘ Minderheit für das Problem verantwortlich, unter dem die , deutsche‘ Mehrheit leiden muss.

Dabei deutet sich, wie in den oben beschriebenen Fällen Herr A und Herr E, auch bei Herrn $\mathrm{C}$ an, dass hinter dem vermeintlich graduellen IntegrationsKriterium eine kategoriale rassistische Unterscheidung zwischen ,ethnisch Deutschen' und ,Ausländern' steht: So beschwert er sich darüber, dass als Beispiel für gelungene Integration immer nur diejenigen ,,Türken“ sich zu Wort meldeten, die tatsächlich so gut integriert sind, dass sie als ,Türken“ (zumindest hinsichtlich ihrer Sprachkompetenz) kaum noch zu erkennen seien. Denn gegen diese ,zehn Prozent, oder fünfzehn“ habe niemand etwas, ,die machen ihre Arbeit und die werden akzeptiert“, im Gegensatz zu jenen ,dreißig, fünfunddreißig Prozent“ die den Sozialstaat ausnutzten. Diese Logik impliziert, dass ein „Türke“ nur dann ,gut integriert“ ist, wenn sein Migrationshintergrund eigentlich nicht mehr $\mathrm{zu}$ erkennen, er als „Türke“ also effektiv verschwunden ist. Und selbst dann ist das höchste, worauf er hoffen kann, von den ,echten“ Deutschen ,akzeptiert“ zu werden. Das bedeutet, dass Integration hier als einseitige Assimilation konzipiert ist, die immer unter dem Vorbehalt einer grundlegenden ethnischen Differenz steht. Diese gilt es so weitge- 
hend wie möglich unsichtbar zu machen, um ,Akzeptanz' bzgl. des letztendlich unüberwindlichen Unterschieds zu erzielen.

Wie kann es dann aber sein, dass sich Herr C zugleich so emphatisch gegen Rassismus in den USA ausspricht? Man kann den Interviewtext, ähnlich wie bei Herr A und Herr E, so lesen, dass der Grund in seinem ethnopluralistisch durchbrochenen Rassismus- bzw. Diskriminierungsverständnis zu suchen ist. Rassismus meint demnach für Herrn $\mathrm{C}$ nicht jegliche Diskriminierung von Menschengruppen aufgrund ethnischer Zuschreibung; Vielmehr schließt die anti-rassistische Position von Herrn $\mathrm{C}$ nicht aus, dass es je nach nationaler Verortung durchaus hierarchische Beziehungen zwischen ethnischen Gruppen geben kann, z.B. Privilegien von ,ethnisch Deutschen“ gegenüber „Türken“ in Deutschland. Dies wird auch an seinem Verständnis von „Kultur“ erkennbar, das er von der ,Kultur-“ und ,Geschichtslosigkeit“ der USA abgrenzt. Die Kultur ist in diesem Verständnis der Ausdruck der traditionellen Lebensweise einer ethnischen Gemeinschaft und die USA sind der Ort, an dem es keine solche ethnische Referenzgruppe gibt. Daher ist die mangelnde Integration von Afroamerikanerinnen und Afroamerikanern in den USA bloße Diskriminierung, die Integration von „Türken“ in Deutschland, wo es seiner Ansicht nach eine ethnische Referenz-Gesellschaft gibt, ein bloßes Problem der Integrationsunwilligen „Türken“ selbst. Wie bei Herrn A und E schon gezeigt, wird auch hier ein gegen Amerika gerichteter Anti-Rassismus zum Moment des Ausdrucks einer ethnozentrischen Position. Die Konzentration auf amerikanischen Rassismus führt dazu, dass Herr C andere Formen von Rassismus und Diskriminierung (z.B. die der eigenen Wir-Gruppenkonstruktion) ausblendet. Diese Ausblendung erscheint im Rahmen von Herrn Cs Rhetorik umso funktionaler, zieht man in Betracht, dass er sich der Möglichkeit politisch-moralischer Sanktionierung seiner Position durchaus bewusst zu sein scheint. So beschreibt er im Anschluss an seine Ausführungen zum deutschen ,Integrationsproblem“ den öffentlichen Sanktionsdruck, der Menschen mit „kritische[n] Meinung[en]“ zu diesem Thema zum Schweigen bringe:

Herr C: Ja, man muss mit so viel Fingerspitzengefühl, man kann es andeuten, aber man muss, siehe Sarrazin oder siehe... Wer, wer bisschen, äh, bisschen hart durchgreift in seiner Argumentation, der wird doch, der wird doch dann sofort äh, äh als Rechter abge-, abgestempelt. Ich sitze im [lokalpolitisches Gremium] neben drei Rechten. Ich bin von [Partei] bei uns im [lokalpolitisches Gremium], und ich sitze neben drei, ja. Aber, was die manchmal sagen, ist ja gar nicht ganz verkehrt! Sie werden halt, viel in ihrer Argumentation...Ja, und, und, und wenn einer von der CDU ein bisschen weit rechts ist, naja, äh, äh und, und ein bisschen kritisch ist, naja dann wird der auch schon als Rechter abgestempelt.

Aus dieser Passage wird erkenntlich, wie sensibel Herr C für die von ihm beschriebene Gefahr ist, ,abgestempelt“ zu werden. Dabei lässt Herrn Cs Parteinahme für 
NPD-Abgeordnete bzw. sein Plädoyer für einen unvoreingenommenen Dialog mit diesen es zweifelhaft erscheinen, dass sich hinter seiner Ablehnung rassistischer Vorgänge in den USA ein universelles anti-rassistisches Motiv verbirgt. Besser lässt sich dieses Plädoyer als Ausdruck einer politischen Position verstehen, die egalitäre Normen mit ethnozentrischer Diskriminierung in Einklang bringt.

\subsubsection{Herr D}

Auf eine ähnliche Argumentationsfigur sei hier zusätzlich am Beispiel von Herrn D hingewiesen. Der Teilnehmer macht im Laufe des Interviews wiederholt regen Gebrauch von Nationalstereotypen, d.h. es finden sich explizit abwertende Zuschreibungen auf „Russen“, „Türken“ und „Amerikaner“ in teilweise recht drastischer Form. „Die Amerikaner“ seien seiner eigenen Erfahrung nach „unzuverlässig“, „aggressiv“, „behandeln ihre Frauen schlecht“ sind „ungewissenhaft“ im Umgang mit ihren Kindern und „oberflächlich“. Seine Bekanntschaften mit in Deutschland stationierten amerikanischen Soldaten habe er deshalb ,alle abgebrochen“. Auch „die Türken“ und „die Russen“ seien ,,aggressiv“ und „brutal“, „,saufen [...] nur Schnaps“, sind untreu oder gewalttätig gegenüber ihren Frauen. Herrn Ds Bild ,der Amerikaner" reiht sich hier also in ein breites Feld ethnozentrischer Identitätskonstruktionen ein, dessen Konstrastierungsfunktion hinsichtlich der deutschen Eigengruppe zudem noch biologistisch-rassistisch begründet wird. Auf die Frage, wie er sich die beschriebenen Negativattribute, der Amerikaner' erkläre, verweist Herr D auf genetische Eigenschaften der jeweiligen Gruppen:

Interviewer: Und haben Sie eine Idee, woher das kommen kann, also ihrer Erfahrung nach, woher kommt diese, diese Verrohung oder so, mit dem Saufen und dem...

Herr D: Das ist... Die Gene, die Gene. Denen kann ja niemand in den Kopf gucken, wie die sind. $\mathrm{Ne}$ ?

Interviewer: Also Gene jetzt als was spezifisch Amerikanisches, also [amerikanische Gene, sozusagen]?

Herr D: [Genau, genau], jaja, So was denke ich jetzt mal. (.) Ja guck doch den Deutschen an, guck den Amerikaner an. Der Deutsche trinkt sein Bier, die Amerikaner saufen ihren Wodka, nicht Wodka, ihren, ihren Jim Beam. Die saufen ja hauptsächlich nur Schnaps. Da siehst du es doch schon. Was der Deutsche ist, was der Russe ist, der Russe säuft Wodka! Ne, jeder hat sein Getränk! Ne?

Hier werden also Motive und Argumentationsmuster eines klassischen, biologistischen Rassismus angewandt und auf die antiamerikanische Fremdbildkonstruktion 
ausgeweitet. Dennoch verwehrt sich der Teilnehmer vehement dagegen, als „feindselig" angesehen zu werden. Als negative Kontrastfolie dient ihm hierbei die Fremdenfeindlichkeit ,der Amerikaner', von der er sich vehement abzugrenzen sucht. Diese Rhetorik vermengt sich zum Ende des Interviews mit einer Holocaustrelativierenden Argumentation: Unter Verweis auf die Geschichte der Sklaverei in den USA und die nuklearen Angriffe auf Hiroshima werden die nationalsozialistischen Verbrechen normalisiert. Diese Rhetorik wurde in Kapitel 7.3 detailliert dargestellt. Hier sei aber in aller Kürze der abwehrende Gebrauch geschildert, den Herr D vom Stereotyp amerikanischer Fremdenfeindlichkeit macht.

Im Zuge der Ausleitung des Interviewgespräches erkundigt sich Herr D danach, was mit dem gesammelten Material nun geschehen werde. Als der Interviewer erläutert, dass die Daten im Zusammenhang einer Forschungsarbeit zu Amerikabildern in Deutschland und auch „kritischen bis hin zu feindseligen Haltungen Amerika gegenüber" ausgewertet würden, erhebt Herr D Einspruch: Wenn man Feindseligkeiten gegenüber den USA untersuche, dann müsse man der Ausgewogenheit halber auch berücksichtigen, wie feindselig , die Amerikaner ' gegenüber „Ausländern“ seien. Daraufhin empört sich Herr D nachdrücklich über die Weise, wie Einwanderer aus Mexiko in den USA behandelt würden: Er möchte „,dem Ami ins Gesicht spucken", wenn er sieht, wie in den USA Einwanderer behandelt würden und findet, „die Amerikaner müssten auch mal richtig so behandelt werden [d.h. wie die Einwanderer in den USA, F.K.], hier in Deutschland“. Als der Interviewer Herrn D dann auf Debatten über Fremdenfeindlichkeit in Deutschland anspricht, wendet sich dessen Wut allerdings in die entgegengesetzte Richtung: „Italiener“, „Griechen“, „die, wo bei uns alle rüberkommen“ werden seiner Ansicht nach in Deutschland viel zu gut behandelt. Am Beispiel von „Deutschrussen“ (gemeint sind Spätaussiedler) macht er fest, dass diese in Deutschland staatliche Unterstützung im Übermaß bekämen, was er als „Frechheit“" empfindet. In Deutschland würden „Ausländer“ also gut behandelt, befindet er, eigentlich zu gut, so dass er sich selbst wiederum ungerecht behandelt fühlt. Das Nachhaken des Interviewers, dass es aber doch in Deutschland auch Gewalt z.B. gegen Asylbewerber gebe, wischt Herr D als „Pappenstiele" beiseite, die im Vergleich zur Fremdenfeindlichkeit der USA völlig unbedeutend seien.

Auffällig ist an dieser Argumentation, dass Herrn Ds vermeintliche Empathie für die Lage von mexikanischen Einwanderern in den USA in Bezug auf die deutsche Eigengruppe ins Gegenteil umzuschlagen scheint: Er argumentiert nicht, dass in Deutschland glücklicherweise ein anderer Umgang mit „Ausländern“ vorherrsche, der leider auch von ausländerfeindlichen Momenten durchbrochen sei, o.ä., wie es seine Empörung über die Lage von Migrantinnen und Migranten in den USA nahelegen würde. Stattdessen geht es ihm am Beispiel Deutschlands nun um eine übermäßige Bevorzugung dieser Fremdgruppe, und er begibt sich selbst samt seiner deutschen Wir-Gruppe in die Opferrolle. Dieser Umschwung deutet darauf hin, dass 
es Herrn D weder am Beispiel der USA, noch am Beispiel Deutschlands wesentlich um die Situation von Migrantinnen und Migranten geht. Vielmehr geht es in beiden Fällen darum, die eigene Opferinszenierung bzw. die damit korrespondierende xenophobe Haltung aufrechtzuerhalten, und zugleich den Eindruck von Feindseligkeit und Vorurteil abzuwenden.

Das muss nicht heißen, dass sich Herr D nicht möglicherweise tatsächlich mit mexikanischen Einwandernden in den USA identifiziert bzw. mit diesen empathisch ist. Dass aber seine Empathie mit MigrantInnen an der deutschen Grenze plötzlich endet, verleiht seiner Empörung über amerikanisches Unrecht einen instrumentellen Charakter. Dieser lässt sich besser verstehen, wenn man jene externalisierende, abwehrende Funktion antiamerikanischen Sprechens in Betracht zieht, die anhand der drei vorigen Beispiele bereits beschrieben wurde: Rassismus ist demnach immer das, was , in Amerika' passiert, und die Rede kommt immer dann auf dieses Thema, wenn implizit oder explizit eine Rassismusproblematik bzgl. der Interviewteilnehmer selbst bzw. deren Wir-Gruppe auftritt. In der hier besprochenen Schluss-Sequenz ist dies besonders augenscheinlich, denn Herrn Ds antiamerikanische Parteinahme für mexikanische Einwanderer nimmt ihren Ausgang in der Bemerkung des Interviewers, es gehe in der Studie u.a. um ,feindselige Haltungen Amerika gegenüber", was für den Teilnehmer implizieren muss, dass er als amerikafeindlich gelten könnte. Erst als diese Möglichkeit in Betracht kommt, beginnt er, sich über amerikanische Fremdenfeindlichkeit zu echauffieren. Auch in diesem Fall scheint die Beschäftigung mit amerikanischem Rassismus im Rahmen eigener ethnozentrischer Abwertungsmuster funktional zu sein.

\subsubsection{Zwischenfazit: Antiamerikanismus im Kontext von Ethnozentrismus und Rassismus}

Antiamerikanische Rhetoriken können, so wurde anhand der vier oben präsentierten Interviewpassagen gezeigt, als Moment ethnozentrisch-essentialistischer bzw. rassistischer Identitätskonstruktion auftreten. Hierbei lassen sich die zwei in Kapitel 4.6 theoretisch umrissenen Grundformen vorurteiliger Rhetorik unterscheiden: ,Amerika‘ wird zunächst zur Konturierung bzw. Aufwertung und Stabilisierung der nationalen Wir-Gruppe gebraucht, ähnlich wie es in Abschnitt 7.2 anhand der Interviews mit Herrn F und Herrn C gezeigt wurde. Die USA erscheinen dann als negative Vergleichsfolie, anhand deren vermeintlicher Kultur- und Geschichtslosigkeit sowie den damit assoziierten moralischen Mängeln die Überlegenheit, Solidarität und Homogenität der Eigengruppe demonstriert wird. Diese Konturierung und „relative Aufwertung“ der Eigengruppe kann teilweise die Form eines antiamerikanischen Rassismus im Sinne einer rassistischen Anfeindung von Amerikanerinnen und Amerikanern annehmen, wie etwa am Beispiel von Herrn D gezeigt wurde. 
Dies gilt unabhängig davon, dass , die Amerikaner“ nicht als ethnische Gruppe im biologistischen Sinne einer ,Rasse ' dargestellt werden, insbesondere wenn man in Betracht zieht, dass auch moderne Rassismen gegenüber anderen Gruppen längst nicht mehr hauptsächlich biologistische, sondern maßgeblich kulturelle Semantiken gebrauchen. Auch dass , die Amerikaner“ insbesondere für ihre ethnische Heterogenität und Kulturlosigkeit angefeindet werden, ändert daran nichts: Wenngleich ,die Amerikaner' nicht im selben Sinne als Ethnie angesprochen werden, wie z.B. , Türken ' oder ,Russen“, so werden sie doch gerade aus derselben Position einer ethnisch-essentialistischen Wir-Gruppe bzw. eines „Herder“schen“ Weltbildes angesprochen. Fasst man besagte Semantik nationaler Kulturen als Ausdruck eines ethnozentrischen Nationalismus, in dem ,Nationalkulturen' effektiv die Rolle von ,Blutsgemeinschaften“ übernommen haben, so wird die zweite zentrale Funktion antiamerikanischer Rhetorik im Kontext von Rassismus und Ethnozentrismus erkennbar: Nicht nur können ,die USA' aufgrund ihrer zugeschriebenen kulturellen und ethnischen Heterogenität im vorurteiligen Sprechen eine besondere Stützfunktion als Außen der ethno-nationalistischen Weltordnung einnehmen, wie in Abschnitt 7.2 geschildert; aufgrund ihrer vermeintlich nicht-ethnischen und nichtkulturellen Qualität eigenen sie sich besonders als Ausdruck ethnozentrischer Orientierungen im Rahmen egalitärer Ordnungen. Dies gilt nicht nur in dem Sinne, dass der Gebrauch amerikabezogener Nationalstereotype als besonders legitim bzw. unproblematisch wahrgenommen wird, da , die Amerikaner'schließlich ,keine Rasse" seien und Antiamerikanismus somit ,kein Rassismus'. Anhand des in diesem Abschnitt präsentierten Interviewmaterials wurde gezeigt, dass paradoxerweise die USA gerade im Zusammenhang ethnozentrisch-nationalistischer Rhetoriken als Negativbeispiel für Rassismus angeführt werden: Das ,wurzellose Amerika dient somit nicht nur der Konturierung und Stabilisierung einer ethnozentrisch verfassten Wir-Gruppe, sondern das ,rassistische Amerika' dient zugleich der Externalisierung des Rassismus, der mit dieser Identitätskonstruktion einhergeht. Hierin liegt die ideologische Funktion des Antiamerikanismus im Zusammenhang von Rassismus und Ethnozentrismus: Er dient zugleich der kontrastierenden Konstruktion und der egalitär-demokratischen Rechtfertigung einer ethnozentrisch-nationalistischen WirGruppe. Dies kann entweder explizit geschehen (Herr E, Herr D), indem die Möglichkeit antirassistischer Kritik an den eigenen Positionen benannt und diese dann im Verweis auf Amerika zurückgewiesen wird. Oder es können sowohl der mögliche Rassismusvorwurf als auch dessen Relativierung implizit bleiben: Durch die Zurückweisung eines , amerikanischen Rassismus ‘ wird dann eine egalitäre Normorientierung implizit ausgedrückt, die durch die eigene Haltung gegenüber ,Ausländern', ,Türken“ etc. zugleich verletzt wird. Diese ideologisch-rechtfertigende Doppelfunktion ist sicherlich nicht als Alleinstellungsmerkmal antiamerikanischer Rhetorik zu fassen - es wären ähnliche Konstruktionen auch in Bezug auf andere OutGroups, etwa ,die Franzosen“ oder andere ehemalige Kolonialmächte denkbar. 
Amerikastereotype scheinen aber aufgrund ihrer spezifischen Verknüpfung mit der kulturellen Semantik des Ethno-Nationalismus eine besondere Wahlverwandtschaft zu solchen rassistischen, Anti-rassismen“ zu haben: Wenn die USA als der Ort konzipiert werden, an dem die quasi-natürliche nationale Ordnung aufgehoben ist, dann ist dies der Ort, an dem eine Ungerechtigkeit, zwischen den Völkern' als menschengemachte, nicht naturwüchsige überhaupt erst möglich wird. An ,Amerika“ thematisiert und verdrängt der Ethnonationalismus zugleich, dass eine hierarchische Ungleichheit ethnischer Gruppen ein ethisches Problem ist. 


\subsection{DiE UNSCHARFEN RÄNDER DES ANTIAMERIKANISMUSBEGRIFFES - AMBIVALENZEN, FRAGMENTIERUNG UND VERSCHOBENE FUNKTIONSKONTEXTE}

In den Kapiteln 7.2 bis 7.4 wurden antiamerikanische Rhetoriken rekonstruiert, die Funktionen im Zusammenhang mit nationaler Identität, Ethnozentrismus und Rassismus, Schuldabwehr und Antisemitismus erfüllen. Anhand diverser Interviewbeispiele konnte gezeigt werden, wie Antiamerikanismus als rhetorisches Mittel der Konturierung und relativen Aufwertung sowie der Struktursicherung kategorial verfestigter Identitätskonstruktionen dient. Hierbei standen nationalistische und ethnozentrische Identitätskonstruktionen im Vordergrund, über deren engen Zusammenhang mit Praxen der Diskriminierung, Exklusion und Verfolgung zugleich eine gesellschaftstheoretisch-normative Begründung der Antiamerikanismuskritik formuliert werden konnte.

Schon bei der Darstellung dieser Fälle wurde allerdings auch nahegelegt, dass Antiamerikanismus im alltäglichen Sprachgebrauch überwiegend nicht als geschlossene Weltanschauung auftritt. Zudem muss festgehalten werden, dass die Kontinuität, mit der in den analysierten Texten über Amerika gesprochen wird, nicht zuletzt auch durch die zwar flexible aber dennoch zielgerichtete Interviewführung bedingt ist. Nur in wenigen Fällen entstand der Eindruck, das angesprochene Interviewthema erzeuge ein so intensives Interesse, dass sich die Befragten allein von sich aus über den gesamten Gesprächszeitraum damit befassen. Von einem kognitiven „Schematismus“ (Beyer 2014, S. 21; vgl. Kap. 2.2 und 2.3) oder gar einer „obsession“ (Berman 2008, S. 40; vgl. Kap. 2.3.1) der Teilnehmenden mit ,Amerika‘ kann hier jedenfalls nicht die Rede sein.

Dies mag bis zu einem gewissen Grad wiederum der Künstlichkeit der Gesprächssituation im Interview geschuldet sein. Es ist anzunehmen, dass gegenüber einem vollkommen fremden Sozialforscher am Telefon nicht unmittelbar derselbe Redefluss entsteht, wie er im vertrauten Umfeld, in wirklich alltäglicher Kommunikation stattfinden mag. Es ist also durchaus denkbar, dass einige Teilnehmende in anderen sozialen Situationen eine intensivere Beschäftigung mit dem Thema und einen extensiveren Gebrauch antiamerikanischer Rhetorik zeigen. Diesseits solcher Vermutungen, die am Material selbst nicht zu belegen sind, muss aber von einem kontextspezifischen und fragmentierten Gebrauch antiamerikanischer Vorurteile ausgegangen werden. Dass diese indessen auch ohne die Theorieannahme einer psychischen Disposition oder eines geschlossenen weltanschaulichen Denksystems als antiamerikanische ausgewiesen bzw. kritisiert werden können, wurde in den rhetorischen Analysen der vorausgehenden Kapitel ausführlich dargelegt. 
In diesem Kapitel sollen nun die Fragmentierung und Ambivalenzen des Antiamerikanismus im alltäglichen Sprechen zusätzlich illustriert werden, und zwar bis zu dem Punkt, an dem nicht mehr eindeutig von antiamerikanischer Rhetorik gesprochen werden kann. Gemäß des in Kapitel 3 vorgeschlagenen gebrauchssensiblen Begriffsmodells, das sowohl den Gebrauchsaspekt des untersuchten Sprechens, als auch den eigenen Sprachgebrauch reflektiert, werden somit die Grenzgebiete der Antiamerikanismuskritik skizziert. Ein nach dem Modell der Familienähnlichkeit entwickelter Antiamerikanismusbegriff muss auf die Unschärfe der eigenen Grenzen verweisen, sollen die Ergebnisse der empirischen Rekonstruktionen nicht schlussendlich doch auf definitorische Formeln reduziert werden.

Diese Unschärfe wird an den folgenden empirischen Beispielen in drei Dimensionen rekonstruiert: der Fragmentierung, der Ambivalenz und der Verschiebung der Funktionskontexte antiamerikanischen Sprechens. Am Beispiel von Frau $\mathrm{H}$ wird die Fragmentierung von Antiamerikanismus aufgezeigt. Die Teilnehmerin gebraucht in einem Teil des Interviews eine ethnozentrisch-essentialistische Rhetorik, die ihre nationale Wir-Gruppe gegen , die Amerikaner' abgrenzt, während sich in den übrigen Gesprächsabschnitten keinerlei Anzeichen für einen solchen Nationalismus finden. Weiterhin lässt sich sowohl bei Frau $\mathrm{H}$ als auch bei Herrn I eine groBe Ambivalenz hinsichtlich der gebrauchten antiamerikanischen Argumentationsmuster feststellen. Deutlich expliziter als die bisher dargestellten Fälle reflektieren beide auf den (potentiell) vorurteiligen Charakter ihrer Rede und sind bemüht, den Eindruck zu vermeiden, sie seien antiamerikanisch bzw. rassistisch eingestellt. Im Interview mit Herrn I zeigt sich zudem, was als Verschiebung des Funktionskontextes begriffen werden kann: Antiamerikanische Rhetorik erfüllt hier konturierende und stabilisierende Funktionen nicht im Kontext ethno-nationaler Identifikation, sondern im Zusammenhang einer lokalpatriotischen Stadtteilidentität. Inwiefern Herrn Is Stadtteilidentität als diskriminierende Differenzkonstruktion gelten kann, bleibt dabei aber - zumal im Vergleich zu antisemitischen oder rassistischen (Sprach-)Praxen - zumindest fragwürdig. Damit wird auch der antiamerikanische Gehalt der in diesem Zusammenhang gebrauchten Amerikastereotype unklar.

Die in diesem Kapitel vorgestellten Fälle weisen also einerseits semantische und rhetorische Ähnlichkeiten mit den Sprechweisen auf, die in den vorausgegangenen Kapiteln als antiamerikanische rekonstruiert wurden: Sie greifen auf Stereotype arroganter und überheblicher, wurzel- und geschichtsloser Amerikaner zurück und gebrauchen diese zur rhetorischen Konturierung und Aufwertung ihrer WirGruppenkonstruktionen. Zugleich aber schränken die Ambivalenz und Fragmentiertheit bzw. der funktionale Kontext dieser Sprechweisen den Sinn ein, in dem hier von antiamerikanischem Vorurteil gesprochen werden kann. 


\subsubsection{Falldarstellung Frau H}

Im Fall von Frau $\mathrm{H}$ ist der Amerikabezug zu Beginn des Interviews maßgeblich durch eine ausgeprägte Unsicherheit bzgl. der eigenen Urteilsfähigkeit gekennzeichnet. Zwar verortet sie die Ursachen der anfänglich thematisierten Finanzkrise bei , den Amerikanern' und verweist auf deren wirtschaftliche Inkompetenz, Arroganz und Überheblichkeit sowie deren Einmischung in fremde Angelegenheiten. Gegenüber diesem negativen Bild ,protziger Amerikaner' identifiziert sie sich als ,Kleine', d.h. als bescheidene, vergleichsweise ohnmächtige Normalbürgerin. Diese Konturierung der ,kleinen' Eigengruppe gegen die ,großen Amerikaner' bestimmt die Fremd- und Wir-Gruppenkonstruktionen über weite Strecken des Interviews.

Bezeichnend ist hierbei die Ambivalenz und Unsicherheit, mit der Frau H selbst diesen vergleichsweise vorsichtigen Gebrauch von Amerikastereotypen vollzieht. Unter Verweis darauf, dass sie als ,Kleine“ im Grunde nicht fähig sei, derartige Urteile zu fällen, werden ihre Ansätze antiamerikanischen Sprachgebrauchs immer wieder relativiert: Sie kümmert sich „nicht so wie andere um die Politik“, grenzt sich von besser informierten „Experten“ ab und stellt generell die Frage, wer ,überhaupt Ahnung" von der besprochenen Thematik habe. Explizit unterstreicht sie diese Ambivalenz bzgl. des gezeichneten Amerikabildes nach der Hälfte des Interviewgespräches, indem sie dem Interviewer versichert, nicht „,gegen Amerika“ zu sein.

Überraschenderweise schwingt diese Haltung in der zweiten Interviewhälfte um. Hier greift Frau H diverse Stereotype auf, mittels derer sie ihr Missfallen gegenüber ,den Amerikanern“ ausdrückt: So spricht sie von ihrem ausdrücklichen Desinteresse an einer Reise in die USA sowie vom negativen , amerikanischen Einfluss` auf das deutsche Krankenversicherungssystem. Dieser plötzliche Umschwung kulminiert darin, dass Frau $\mathrm{H}$ die ethnische Homogenität und Ursprünglichkeit ihrer jetzt nationalistisch konstruierten Wir-Gruppe gegen die Heterogenität der „zusammengewürfelte[n]“ USA ausspielt. ,Die Amerikaner" sollen demnach nicht „groß tun“, wenn sie nicht einmal die „ur-ur-Urwurzeln“ ihres ,Volkes“ nachweisen können. Diese antiamerikanisch-ethnozentrische Wir-Gruppenkonstruktion steht in starkem Kontrast zur vorsichtigen, ambivalenten Positionierung in den vorausgegangenen Interviewsequenzen. Dieser Kontrast wird zum Ende des Interviewgesprächs auch Frau $\mathrm{H}$ selbst bewusst, als sie sich erneut auf ihre vorherige Identitätskonstruktion als ,Kleine' zurückzieht und gleichzeitig noch deutlicher als zuvor ihre Ambivalenz und Selbstzweifel explizit macht. Sie betont, sich „nicht um Kopf um Kragen reden“ zu wollen und räumt ein, es sei ,vielleicht [...] verkehrt [...], so zu denken“. Im Kontrast der beiden Interviewteile sticht die Fragmentierung antiamerikanischen Sprechens deutlich hervor. 


\subsubsection{1 ,Die Kleinen` gegen ,die Großen`}

Die erste Referenz auf die USA in diesem Interview findet sich in Frau Hs Erläuterung der Ursachen der Finanzkrise, die das Einstiegsthema des vorliegenden Interviews darstellen.

Interviewer: Okay, verstehe, ja. Ähm, wir haben jetzt gesprochen über die Auswirkung, die die Krise hat, ähm, und ich würde Sie jetzt gerne noch mal danach fragen, was Sie meinen, was denn die Ursachen für die Krise liegen, also wer hat diese Krise verursacht, was würden Sie sagen?

Frau H: Oh, das muss ich ganz ehrlich sagen, da bin ich... Steh ich da jetzt nicht so in der Materie, dass ich sagen kann ,ah“ oder beschäftige mich nicht ganz so viel, aber eins, denk ich mal, sind... Hängt es auch wirklich von den Banken.

Interviewer: Ja, klar.

Frau H: Also durch des, dass da eben die Banken mit dem Geld und, ähm, viellei-, also für mich ist Bank der große, wo ich sag, die haben da irgendetwas gemacht, ähm, was auch immer, wie sie die Leute beraten haben, was sie... Wie auch immer, des doch da in der... Dass es da in der Wirtschaftskrise, und ich weiß auch nicht, ob der Euro... Inwiewei- es ist ja mal ja von Amerika rübergekommen des ganze ja und, äh, mein Auszubaden haben wir es alle mit, aber ich weiß nicht, also Bank ist für mich des erstmal, das A und $\mathrm{O}[\ldots]$.

Neben den Banken, die „das A und O“ der Krisenverursachung darstellen, treten die USA hier als Ort der Krisenursache auf: „es ist ja mal von Amerika rübergekommen“. Bemerkenswert ist an dieser Stelle, dass Frau H ihre Erklärungsansätze wenig selbstsicher und mit großer Vorsicht präsentiert: Sie stehe „da jetzt nicht so in der Materie“. Als der Interviewer daraufhin nachhakt, indem er Frau H auf ihre Angaben aus dem vorausgegangenen Survey anspricht, erläutert sie ihre These über einen amerikanischen Krisenursprung ausführlicher:

Interviewer: Ja. Sie haben ja in der letzten Befragung auch der Aussage zugestimmt, die Amerikaner hätten die Krise verursacht, das haben Sie jetzt auch grade schon mal angesprochen. Ähm, können Sie diese Einschätzung noch ein bisschen genauer erläutern oder ausführen?

Frau H: Ähm, ja, es ist ja so, dass von Amerika vieles rüberkommt, äh eher, mmm, ja, hört sich zwar jetzt „Der Große Bruder“ auch wie immer, da vieles vorgegeben wird, wo man..., wo sich die Länder doch auch nach richten und, ähm, ja, auch derje-, oder das Land auch meint, es ist reich an vielen Sachen und und und, na-, Naturschätzen und so weiter, des da, äh, 
deswegen des da, von da aus irgendwas falsch, äh, bewirkt oder berechnet worden ist, gewirtschaft worden, gewirtschaftet worden ist, des man vielleicht meinte, aha, wir haben so viel, diese Plus, die man ja auch hat, die Jahre, die „fetten Jahre“, würde ich sie so nennen, und dass man`s nicht gedacht hat, aha, was kommt, mhm, da kommt auch mal wieder andere Zeiten, dass man vielleicht wie ein Kleiner sagt, da mal was auf die Seite geschafft hat für Zeiten, die nicht so gut ist, dass man ne Reserve hat und dass man aus dem Vollen geschöpft hat ohne nachzudenken oder nicht nachdenken wollte. Äh, ich mein, da sind natürlich viele andere Experten, die da drüber studiert haben, dass da irgendwo, ja, mal ein bissel geschludert worden ist, möchte ich meinen.

Frau Hs Erklärungsansatz beinhaltet zwei Argumentationsstränge, die jeweils als Aktualisierung traditioneller Amerikastereotype aufgefasst werden können: Einerseits beschreibt sie einen generellen Einfluss der USA, durch den ,vieles vorgegeben wird [...] wo sich die Länder doch auch nach richten“ und durch den schließlich auch die Krise „,von Amerika rübergekommen“ sei. Amerika erscheint hier als fragwürdiger Orientierungspunkt für andere Nationen, wobei der Gebrauch des Wortes ,vorgeben“ eher ein Autoritäts- bzw. Dominanzverhältnis impliziert, als eine bloße Vorbildfunktion. ${ }^{1}$ Andererseits wird im Anschluss daran argumentiert, dass in den USA ,falsch [...] gewirtschaftet" worden sei: Aufgrund einer Überschätzung des eigenen Reichtums habe man es versäumt, eine Reserve für schlechtere Zeiten anzulegen, und stattdessen ,,aus dem Vollen geschöpft [...] ohne nachzudenken“. Hierin spiegelt sich das Stereotyp der ökonomisch irrationalen, zu nachhaltigem Wirtschaften unfähigen Amerikaner (vgl. ähnliche Bilder bei Herrn E, Kap. 7.4.2.1).

Die Formulierung, in Amerika habe man nicht „,wie ein Kleiner“ etwas ,auf die Seite geschafft“", erscheint in diesem Zusammenhang zunächst nebensächlich. Im weiteren Interviewverlauf wird Frau $\mathrm{H}$ die Identifikation als ,Kleine‘, d.h. als bescheidene, sparsame und ohnmächtige ,Normalbürgerin“ aber wiederholt ins Zentrum ihrer Selbstdarstellung rücken. Konturiert wird dieses Selbstbild stets gegen die Größe und Überheblichkeit, der Amerikaner‘. Bezeichnend ist an der obigen Sequenz außerdem, dass Frau $\mathrm{H}$ die Erweiterung ihres Erklärungsansatzes sogleich wieder relativiert, indem sie darauf verweist, dass es ,natürlich viele andere Experten“ gebe, „die darüber studiert haben“, zu denen sie sich selbst aber nicht zählt. Frau H nähert sich hier also tendenziell antiamerikanischen Rhetoriken an, indem sie zur Erklärung des undurchsichtigen Finanzkrisengeschehens auf Stereotype amerikanischer Irrationalität und Großspurigkeit zurückgreift und sich als deren Opfer identifiziert. Sie durchbricht aber zugleich die Orientierungs- und Ordnungsfunktion ihrer Rhetorik, indem sie ihr eigenes Wissen und ihre diesbzgl. Urteilskraft in Frage stellt.

1 Ähnliche Bilder finden sich bei Herrn A sowie bei Herrn B (vgl. Kap. 7.3.1) 
Diese Gegenüberstellung von ,kleinen Normalbürgern` und ,übergroßen Amerikanern' wird in der untenstehenden Sequenz weiter ausgeführt, in der vor allem das „Protzen“ und die Überheblichkeit der Amerikaner betont werden:

Frau H: Wie ich schon gesagt hab, wenn man so, ähm, ich kenn's nur aus Erzählungen oder von Bekannten, die verf-, wo sie`s... Also die nach Amerika ausgewandert sind, die Geschwister, dass die dann irgendwo hierher kommen und dann auch so protzen. Das Protzen, wissen Sie. Was früher der Wessi im Osten getan hat, das wird der Ami hier. Ich kann mich noch an ein Beispiel erinnern, da war... Die Geschwister sind ausgewandert, alle nach Amerika, und was weiß ich, die Kinder sind alle da geboren und die eine Schwester sollte hier des Haus verkaufen. [...] Ähm, und die sich des so alles so ,ach, und dann verkaufst du des“ oder so, die wollten des nicht vermietet haben, die wollten, dass das Haus verkauft wird von den Eltern und dann..., und da weiß ich nur, dass..., die stellen sich das alles so leicht vor, ne und, ähm, ja, das sind so, nur solche Beispiele, die man mir dann so erzählt hat, wo man sich so sein Bild dann daraus macht.

Die Arroganz ,der Amerikaner“ (,Was früher der Wessi im Osten getan hat, das wird der Ami hier.") wird hier am Beispiel eines Familienkonfliktes erläutert: Nach dem Tod der Eltern schlagen die in die USA ausgewanderten Geschwister einen Verkauf des Elternhauses vor, ohne sich ein Bild von den Problemen diese Vorganges zu machen (,die stellen sich das alles so leicht vor"). In einer späteren Sequenz des Interviews wird, den Amerikanern' insgesamt eine ähnliche Arroganz zugeschrieben, als Frau H die , amerikanischen' Kriege als Krisenursachen beschreibt. Hierbei stört sie besonders, ,dass der Bush sich überall eingemischt hat" und für dessen fehlgeleitete Interventionen ,,viel Geld [...] rausgeschmissen worden ist“. Vom Interviewer erneut gebeten, ihr Urteil zur amerikanischen Krisenverursachung näher zu erläutern, führt Frau $\mathrm{H}$ aus:

Frau H: Die Kriege, die sie angeführt haben, ich mein die, jetzt mal den Obama rausgehalten, wobei ich den eigentlich noch ganz okay find, aber was damals, äh, der Bush alles so, ich mein, das ist natürlich auch von vielen da die Präsidenten, die da alle waren und die da auch alle mitgetan haben und die ihre Berater hatten und die auch wieder alle.... Ich denk mir, das ist so'n, das hat sich irgendwo aufgebaut und ich... Dass man jedes... Den Krieg und viel Geld für rausgeschmissen worden ist, des, wollen mal sagen, müssen, müssen die sich jetzt da einmischen, des hat mich am meisten, oder, äh, gestört oder stört, na ja, ich weiß nicht, beim Obama ist wohl nicht mehr ganz so, aber dass der Bush sich überall eingemischt hat und da musste ein Krieg geführt werden und da musste da, da wurde das Geld und da wurde... Und wir haben ja, irgendwo waren wir ja auch da dranne dann, also wobei man immer sagen soll, oder so ein Krieg des gilt, aber irgendwas, irgendwo ist was verkehrt gelaufen bei denen. Ich weiß nicht, also von der Wirtschaftsführung, weiß nicht, ob die da so viel Ahnung haben. Wer hat überhaupt Ahnung. 
Interviewer: Ja (lacht).

Frau H: Frag ich mich als Kleiner. Weil zu un-, uns halten`s immer an „Sparen, sparen, sparen“ und man soll sparen und das soll man sparen und eben, ja, und die, die, weiß ich, tun`s rausschmeißen.

Interviewer: Verstehe.

Frau H: Also, ich vermute, es kann auch was Anderes... Kann auch, äh, ich weiß es nicht was, direkt kann ich es Ihnen auch nicht sagen. Daf-, also befasse ich mich, ehrlich gesagt, nicht zu sehr mit. Man unterhält sich im Freundeskreis, im Bekanntenkreis, aber ich denke mir, da st-, blickt keiner durch.

Die aufgrund der Überheblichkeit und Arroganz, der Amerikaner' geführten Kriege haben demzufolge im Zusammenspiel mit Fehlern in der „Wirtschaftsführung“ der USA zur Finanzkrise geführt. Von wirtschaftlichen Belangen, so mutmaßt Frau H, haben die Amerikaner nicht ,,viel Ahnung“. Hierbei ist insbesondere wiederum interessant, dass sie unmittelbar im Anschluss ihre These relativiert und sich wiederum auf die Position der ,Kleinen“ zurückzieht: „Wer hat überhaupt Ahnung? [...] Frag ich mich als Kleiner.“ Zwar ist diese Identifikation als ,Kleine“ auch verknüpft mit einem gewissen Ungerechtigkeitsempfinden bzw. einer Aggression gegen, die da oben“, die „uns“ anhalten, zu „sparen, sparen, sparen“, selbst aber das Geld „rausschmeißen“. Der Ausdruck dieses Ungerechtigkeitsempfindens verläuft aber stets in den engen Grenzen, die Frau H ihrem eigenen Urteilsvermögen setzt: Sie unterhalte sich zwar im „Bekanntenkreis“ über politische Themen, befasse sich aber „nicht zu sehr“ damit. Insgesamt erscheint ihr der gesamte Zusammenhang kaum überschaubar: „da [...] blickt keiner durch.“ Dieses resignierte Interesse an Politik wird in einer folgenden Sequenz noch einmal bekräftigt, in der Frau H sich wiederum mit den „Kleine[n] Leute[n]“ identifiziert:

Frau H: Ja, also ich bin, äh, ich ver-, verfolge, ich bin... Ich kümmere mich nicht so wie andere um die Politik, oder ich verfolge Sachen schon, und ich rede auch mit meinem Partner, wenn mir was unklar ist und frag ihn, äh, wie wie soll ich das jetzt verstehen oder wie, wie muss man das jetzt hier verstehen, was da ist, ich, äh, f-, mein... Sicher verfolge ich des und so weiter, aber des ich jetzt so`n, so`n polit-, so unbedingt mit Politik hab ich`s nicht so im, im im Sinn (lacht), (unverständlich) aber wenn ich irgendwas ungerecht find, dann des jetzt mit den Benzinpreisen (lacht).

Interviewer: Ja, okay, verstehe. 
Frau H: Und ich weiß auch nicht, von wo das kommt, aber ich denk mir, da von den... Wer da auch sich ne lange... Ne goldene Nase verdient, auf alle Fälle nicht wir.

\section{Interviewer: Ja.}

Frau H: Kleine Leute.

Bis hierher konnte gezeigt werden, dass in Frau Hs Rede die Unterscheidung von ,Kleinen“ und ,Großen' einen zentralen Orientierungspunkt bildet. Die Identifikation als ,Kleine“ funktioniert dabei maßgeblich über den Kontrast zu den ,Großen“, deren Rolle mit , den Amerikanern' besetzt wird. In dieser Kontrastierungsfunktion wird dabei eine Ambivalenz zwischen Aggression und Unterordnung erkennbar: Einerseits spricht aus der Darstellung, der Amerikaner' als mächtiger aber inkompetenter ,großer Bruder' sowie aus der Selbstinszenierung als Opfer von dessen Verfehlungen eine protestierende Haltung. Dieser Protest wird aber andererseits dadurch unterlaufen, dass die Selbstinszenierung als ,Kleine“ auch mit einer Infragestellung der eigenen politischen Urteilskraft einhergeht, die den Protest ja gerade erst ermöglicht. Das Amerikabild wird in diesem Zusammenhang gleichsam nur unter Vorbehalt gebraucht, um einen relativ diffusen Unmut gegen , die da oben' auszudrücken. Dieses Aufbegehren gegen „Mr. Big“ (Markovits 2007, S. 32) kann bis hierher kaum als Antiamerikanismus gelten, da die Amerikastereotype lediglich in einem vorsichtig tastenden Modus gebraucht werden und zudem keinen erkennbaren Zusammenhang mit Diskriminierung aufweisen.

Diese Unsicherheit im antiamerikanischen Sprachgebrauch zeigt sich auch in der nachfolgenden Sequenz, in der sich das Interview seinem vermeintlichen Abschluss nähert. Als der Interviewer das Gesprächsende einleitet und sich für das Interview bedankt, beeilt sich Frau $\mathrm{H}$ zu betonen, dass sie nicht ,gegen Amerika“ sei und kehrt ihr positives Obama-Bild heraus, um dies zu bekräftigen.

Frau H: Also, es soll jetzt nicht herauskommen, dass ich gegen Amerika bin, so ist es überhaupt nicht, ne, um Gottes Willen, ich muss... Eigentlich bin ich mehr schon für den Obama, weil der eben so für mich, er hat ja auch nur seine Leute, ähm, auch um... Aber ich denk mir, der Mann hat doch vom Wissen her und, mmm, macht... Er macht bestimmt auch Fehler, das macht jeder, aber eigentlich, denke ich von der Regierung her, ja, finde ich es schon okay und... Wenn ich jetzt, glaube ich, in Amerika leben würd, also ich glaub, ich würde ihn wieder wählen, den Mann.

In dieser Passage wird Frau Hs Ambivalenz gegenüber der eigenen antiamerikanischen Rhetorik explizit. Wenngleich sie in den vorigen Passagen schon ihre Darstellung, der Amerikaner' stets unter dem Vorbehalt ihrer eingeschränkten Urteilsfähigkeit als ,Kleine‘ äußerte, befürchtet sie nun, es könne „herauskommen“, 
dass sie „gegen Amerika“" sei. Ihr vorsichtiges Aufbegehren gegen den ,großen Bruder USA', das ohnehin schon durch eine Ambivalenz von Protest und Unterordnung gekennzeichnet ist, wird ihr an dieser Stelle des Interviews gewissermaßen selbst unheimlich.

Das Unheimliche ihres Sprachgebrauchs kann einerseits dahingehend gedeutet werden, dass sie den Forschungsprozess, an dem Sie teilnimmt, nicht durchschaut und befürchtet, in dessen Verlauf auf eine Seite ihrer ambivalenten Haltung ,festgenagelt‘ zu werden - ein Ausdruck, den sie in einer späteren Interviewsequenz selbst gebraucht. Andererseits kann man, in Anlehnung an Sigmund Freuds Gebrauch des Terminus, demzufolge „das Unheimliche das Heimliche-Heimische ist“ (Freud 1997, S. 268), Frau Hs Sprechen auch insofern als unheimlich interpretieren, dass sie sich im Interviewgespräch ihrer eigenen Ambivalenz gegenüber, den Amerikanern' bewusst wird: Der aggressive Aspekt ihres Amerikabildes, den sie stets zu relativieren und abzumildern bemüht ist, tritt ihr als etwas fremdes und zugleich allzu vertrautes, als irritierender Aspekt ihrer eigenen Identitätskonstruktion gegenüber.

Frau $\mathrm{H}$ ist vertraut mit den ,Standards' antiamerikanischer Identitätskonstruktion und Welterklärung, und diese $\mathrm{zu}$ gebrauchen, liegt im Rahmen der Interviewthematik nahe. Zugleich scheint diese Alternative aber durch das Bedürfnis verbaut, nicht vorurteilig sprechen bzw. nicht „gegen Amerika“ sein zu wollen. Diese Ambivalenz drückt sich auch in ihrer Bezugnahme auf Amerika aus, in der sie sich einerseits als protestierende ,Kleine“ gegen den arroganten Vormund ,USA * wendet, sich aber andererseits qua der selbst zugeschriebenen ,Kleinheit` zugleich die Urteilsfähigkeit abspricht, solchen Protest vorzubringen. Amerikabilder bieten sich für diese paradoxe Form der Selbstinszenierung besonders an: Wer gegen Amerika ist, kann sich als ohnmächtiges Opfer und zugleich als moralisch überlegen inszenieren.

Im weiteren Verlauf des Interviews spitzt sich diese Ambivalenz in Frau Hs Amerikabild weiter zu, was als Fragmentierung des antiamerikanischen Sprechens gedeutet wird. Nachdem sie versichert hat, dass sie nicht „gegen Amerika“ sei, entwickelt sie in zunehmend drastischen Bildern eine ethnozentrische Rhetorik, deren Geschlossenheit die bisherigen Interviewsequenzen bei weitem Übertrifft. Während die bisher analysierten Sprechweisen allenfalls als Grenzfall antiamerikanischen Sprechens eingestuft werden können, konstruiert Frau H im Folgenden eine ethno-nationalistische Wir-Gruppe, die sie gegen die Heterogenität und Ursprungslosigkeit ,der Amerikaner' in Stellung bringt, d.h. antiamerikanisch konturiert. Nachdem sie sich somit aber nicht mehr nur als ,Kleine‘, sondern als Mitglied einer ethno-nationalen Gemeinschaft identifiziert hat, wird sie zum Ende des Gespräches umso nachdrücklicher ihre Position relativieren und ihre neuinszenierte Stärke wieder in Frage stellen. 


\subsubsection{2 „Ein Land, was zusammengewürfelt ist“ - Fragmentierter antiamerikanischer Ethnozentrismus}

Im Anschluss an den vermeintlichen Interviewabschluss entspinnt sich eine längere Gesprächspassage, in der die Teilnehmerin vergleichsweise unvoreingenommen eine ablehnende Haltung gegenüber den USA äußert. Den Einstieg bildet Frau Hs Erläuterung, sie „würde nie nach Amerika fliegen wollen“. Sie begründet diese Abneigung mit den vielen und strengen „Verbote[n]“, die dort herrschen. Als Beispiele führt sie ein übertriebenes Tempolimit und strikte Bekleidungsvorschriften an: „Da muss man ja vorher sich [...] informieren, welche Land reis ich und darf i da mit kurze Hose als Frau gehen“. Im Anschluss daran wendet sich Frau H dem Topos eines ,amerikanischen Einflusses` auf Deutschland zu, dem sie negative Effekte zuschreibt: „Und da das Meiste von Amerika noch mal rüberkommt und vieles abfärbt, ist nicht immer alles so toll.“ Als Beispiel nennt sie eine zunehmende Privatisierung der Krankenversicherung in Deutschland, durch die sie als gesetzlich Versicherte immer häufiger gezwungen sei, Behandlungen und Medikamente zusätzlich zu finanzieren, die ehemals von der Krankenkasse übernommen wurden: ,[...] man zahlt und zahlt und wiederum haben die Kassen, Krankenkassen kein Geld und es ist wie [...] in Amerika praktisch, ne. Kannst hingehen, aber musst alles selber zahlen." Amerika wird in diesem Interviewabschnitt nun also relativ ungebrochen nicht nur als unattraktiv, sondern auch als negativer Einfluss dargestellt (vgl. ähnliche Bilder bei Herrn C, Kap. 7.2.1.1).

Nachdem Frau H von ihrem touristischen Desinteresse an den USA zur Ablehnung eines ,amerikanischen Einflusses` fortgeschritten ist, erweitert sie ihre antiamerikanische Rede relativ plötzlich zu einer ethno-nationalen Rhetorik in der Deutschland und die USA einander in stereotyper Weise gegenübergestellt werden:

Frau H: Ja, ja, die Amis sind schon ein eigenes Volk (lacht), die haben`s halt, ja, aber wenn man denn bedenkt, des des nur... Wenn man sich so ein bisschen mit der Geschichte beschäftigt von denen, äh, irgendwann hab ich mal ... Hab ich irgendwas gesehen im Fernsehen, dann hab ich nachher gesagt: Hallo, die sind ja alle in nur zug-, es sind ja wirklich alle nur von irgendwo, ob von Italien, von China, von weiß ich woher. Des is ja ein Land, was zusammengewürfelt ist, wo man nicht... Die Indianer, die haben, die, die dahin gehören, die haben sie ja dann rausgedrängt aus ihrem Land, aber im Grunde genommen ist des Land zusammengewürfelt aus vielen Kulturen, Nationen, wo ich denk: hallo?

Gegenstand von Frau Hs Empörung ist der ,zusammengewürfelt[e]“ Charakter der USA, die dadurch als „eigenes Volk“ erscheinen. Dass diese Eigenheit der Heterogenität und ,Wurzellosigkeit' für Frau $\mathrm{H}$ negativ konnotiert ist, zeigt sich nicht nur an der Gegenüberstellung mit den „Indianer[n]“, die nach Meinung Frau Hs eigentlich „,dahin gehören“, denen also im Gegensatz zu „den Amis“ ein natürliches Exis- 
tenzrecht auf dem Gebiet der USA zugeschrieben wird. Es zeigt sich auch daran, dass Frau H die ,Wurzellosigkeit' der Amerikaner in Anschlag bringt, um deren vermeintliche Überheblichkeit zu delegitimieren:

Frau H: Und dann, ja, geben sie ein großen Ton an, des is des wo ich sag - äh, na, wer ist jetzt da Ur-, wo is des Urgestein, des waren die Indianer eigentlich da, dafür. Des is des, wo ich denk, ja, da tun sie so und reißen die Klappe auf und, und wollen die Welt bestimmen oder regieren und..., na ja, wollen es nicht, aber so so mächtig, sag ich mal, mächtig tun und des is des, wo ich denk: hallo, wo kommt ihr alle her? Mein sicher, die jetzt da leben, die sind da jetzt geboren und die fühlen sich als Amerikaner, aber wenn man ganz, ganz, ganz weit zurückgeht, dann ... Ja, halt so denk ich dann manchmal, weil... Ja.

Wer seine nationale Identität nicht auf ein ethnisches „Urgestein“ gründen kann, so die Implikation ihres Arguments, sollte auch nicht „mächtig tun“ oder gar „die Welt bestimmen" wollen:

Frau H: Ja, wo ich denk, die reden alle da und tun Wunder, was sie für sich sind und dabei sollen sie erst mal schauen, wo sie alle hergekommen sind und des sind... Es ist nicht negativ gemeint oder soll auch nicht abwerten, aber die sollen einfach, äh, die Kirche im Dorf dann lassen und nicht so meinen, sie sind... Sie haben alles erreicht, dabei sind... Ist da nicht einer, der sagt, wir waren Amerika oder wir sind des und haben des von der Pike auf oder so. Die Indianer, die warn`s! Alle verdrängt aus ihrem eigenen Land dann. Und des is da, wo ich dann manchmal... Da kann... Wenn so bestimmte Sachen sind, dann, wo ich denk - guck an! Des is aber meine eigene, persönliche Meinung.

Diese ethno-nationalistische Rhetorik spitzt sich in den folgenden Sequenzen weiter zu, als Frau H an Stelle „der Indianer“ nun „Deutschland“ als Gegenbild einsetzt. Auf eine Nachfrage des Interviewers, wie der vermeintliche Mangel eines Ursprunges in den USA zu verstehen und auf aktuelle Entwicklungen zu beziehen sei, erläutert sie:

Frau H: Ja, äh, (...) ich mein, alle, die jetzt mit der... (seufzt) Wie soll ich sagen, in Deutschland, also wenn jetzt auch Deutschland sich auch aus einzelnen Bundesländern zusammensetzt. Aber es war... Also ich hätte... Wüsste jetzt nicht, des irgendwo von anderswo - sicher sind da bissel Einschläge drinne überall - aber des da irgendwo, des wir zusammengewürfelt worden sind, ähm. Da war ein Stamm hier, also, jetzt fragen Sie mich nach der Geschichte, wo ich... (unverständlich) Aber des hier, hier war ein Stamm, und der hat sich vermehrt und des, sicher sind die Schweden hier durch und wer weiß wer alles die... So gekommen und haben irgendwo auch ihre Abkömmlinge oder so hiergelassen, aber hier war, hier war der Stamm da und der hat sich dann größer gemacht. Aber so viel wie ich in Amerika, so wie ich das in Erinnerung habe, waren`s da die Indianer, die doch des Land gehabt haben und dann 
sind alle, wenn man so durch die Filme oder so, Dokumentationen, des die alle rüber gewandert sind nach Amerika. Also die meinten, da is des Land... Und durch des Gold. Eigentlich durch des Gold sind die auch nach Amerika gekommen. Und da meinte ich... Und da sind doch alles Mögliche, von allen Ländern sind die damals doch mit den Schiffen rüber nach Amerika, weil sie meinten, da gibt`s Geld. Und da, da, da ist es der Reichtum, da is, durch diese ganzen Bodenschätze auch, und so meinte ich da, außer... Und haben durch des ja auch die Indianer verdrängt, aus ihrem Land raus. Und so meinte ich da, also ich wüsste nicht, wenn des anders wäre, also auf... Dass da irgendwo ein Ursprung, außer die Indianer... So meinte ich des.

In der Parallelisierung von „Deutschland“ mit „,den Indianern“ wird wiederum erkennbar, was in den Kapiteln 4.4 und 7.2 bereits mit Sutterlüty und Neckels Begriff des ,ethnischen Verwandtschaftsglaubens“ beschrieben wurde. Zusammenhalt und Merkmale der nationalen Wir-Gruppe werden nach dem Muster einer Blutsverwandtschaft mit Jahrtausende altem Familienstammbaum vorgestellt, als sei das, was heute als „Deutsch“ verstanden wird, nur eine Variation über eine Gruppenidentität, die schon immer natürlicherweise bestand. Diese ,Blutsgemeinschaft", deren völkisch-familiäre Substanz hier durch den Gebrauch von Begriffen wie „Stamm“, „Abkömmlinge“, ,vermehrt“ unterstrichen wird, steht in scharfem Kontrast zu einem Bild der USA als Gesellschaft, in der zweckrationale Motive dominieren und zur Erlangung von „Gold“, „Reichtum“ und „Bodenschätze[n]“ die Rechte der ,ursprünglichen Völker' missachtet werden.

Bezeichnend ist an den berichteten Sequenzen nun, dass Frau H mit ihrer ethnonationalistischen Rhetorik einen ebenso starken wie politisch anfechtbaren Standpunkt formuliert - ganz im Gegenteil zu ihrer vorigen Identifikation als ohnmächtige ,Normalbürgerin`. Zwar zielt ihr Argument auch hier auf eine Relativierung und Zurückweisung amerikanischer Arroganz und Übermacht, aber die Wir-Gruppe, mit der sich Frau H dieser entgegenstellt, weist dabei weit über die zuvor gesehene politisch-unpolitische Identifikation als ,Kleine“ hinaus. Diese ethnozentrische Selbstinszenierung wird jedoch von Frau $\mathrm{H}$ nicht lange aufrechterhalten. Auf eine Nachfrage des Interviewers nach den aktuellen Bezügen ihres Vergleiches, beginnt sie sich schrittweise auf ihre alte Position der, Unpolitischen“ rück zu besinnen.

Interviewer: Ja. Und da sehen Sie Parallelen heute auch noch, dass das sozusagen um... Also Parallelen zu der amerikanischen Einwanderungsgeschichte, das irgendwo Völker verdrängt werden oder um des Geldes Willen? Oder hab ich Sie jetzt missverstanden?

Frau H: Ja des... Ne, da haben Sie mich jetzt missverstanden. Ne, so meinte ich nicht, dass das dadurch..., ich mein nur, dass die so protzen. Ich meinte nur das Protzen damit, des die so protzen was sie, was sie sind und so und dabei... Des meinte ich. Mehr diese ganzen Ur-ur- 
Urwurzeln nicht da sind eigentlich durch irgendwie, durch zugewandert oder wie auch immer. Ne, mit dem hab... Des meinte ich nicht so eigentlich, so hab ich das gemeint.

Das „Protzen“, das ihre vorige Ablehnung ,der Amerikaner" begründete, steht nun wieder im Zentrum ihrer Argumentation während die fehlenden „Ur-ur-Wurzeln“ nur noch am Rande auftauchen. Die ethno-nationale Identifikation tritt von diesem Punkt an wieder in den Hintergrund und wird durch diejenige der ,Kleinen ‘ ersetzt.

An dieser Stelle läuft das Interviewgespräch bereits gute 40 Minuten und der Interviewer weist Frau H erneut auf die Möglichkeit eines Gesprächsabschlusses hin, worauf Frau $\mathrm{H}$ mit einer Relativierung ihrer Position reagiert und explizit ihre Befürchtungen äußert, ,etwas falsches' gesagt zu haben:

Frau H: Ja, ich möchte mich jetzt auch nicht da um Kopf und Kragen reden, weil (lacht)... Weil, wie gesagt, wie ich Ihnen schon sagte, für mich is, äh, das ganze Thema eigentlich, die Politik, äh, nicht so meins und im Grunde genommen... (schnauft) Vielleicht ist es verkehrt von mir, so zu denken, was der Ami macht ist mir im Grunde genommen egal irgendwie, jetzt kriegen die's ja auch wieder ein bissel aber, aber... Ja, sie sollen ihre Sache machen und sollen schauen, dass sie in ihrem Land alles auf die Reihe kriegen und dann.... Ja. Und wir schauen... Des wir hier, wobei wir gar nix als kleiner Bürger machen können, des sind die Regierungen, die da alles aushandeln und tun.

Interviewer: Ja, nun gut. (...) Dann sage ich noch mal herzlichen Dank für Ihre Zeit und das Gespräch.

Frau H: Bitte, gerne.

Interviewer: Ich wünsch Ihnen noch einen guten Abend.

Frau H: Ja, danke. (lacht) Nageln Sie mich bloß nicht fest mit den Aussagen! Ne, weil ich bin wie gesagt, halt mich eigentlich immer ziemlich zurück (lacht), ne.

Von der nationalistischen Rhetorik ist nun nichts mehr zu vernehmen außer der Befürchtung, sie könne damit einen falschen Eindruck erweckt haben. An die Stelle des Nationalismus treten betonte Indifferenz (,ist mir im Grunde genommen egal“") und Selbstzweifel (,,ich möchte mich [...] nicht um Kopf um Kragen reden“; ,,vielleicht ist es verkehrt von mit, so zu denken“; „Nageln sie mich bloß nicht fest mit den Aussagen!“), und Frau $\mathrm{H}$ zieht sich wieder auf ihre eingangs bezogene Position als „kleiner Bürger“ zurück.

In dieser Schlusssequenz wiederholt sich somit das Unheimliche bzw. die Ambivalenz ihres antiamerikanischen Sprachgebrauches: Frau H greift Bilder eines heterogenen, ,wurzellosen', rein zweckorientierten Amerika auf und stellt diesem die 
naturwüchsig-legitime, harmonische Ordnung homogener ,Völker" gegenüber. Gleich im Anschluss daran, zieht sie sich aber wieder auf eine unpolitische Haltung zurück. Unheimlich scheint (auch für sie selbst) die schlafwandlerische Sicherheit, mit der Frau H die Muster einer ethno-nationalen Identifikation reproduziert, ohne sich mit diesen wirklich identifizieren zu wollen.

\subsubsection{Zusammenfassung Frau $\mathrm{H}$}

Auf Amerikastereotype greift Frau $\mathrm{H}$ zunächst im Rahmen eines relativ diffusen Aufbegehrens gegen , die da Oben` zurück. Dabei zeigt sich eine starke Ambivalenz hinsichtlich dieses Sprachgebrauches: An keiner Stelle des Interviews treten Amerikastereotype als Ausdruck des Protestes oder Erklärung unverständlicher Krisenphänomene auf, ohne dass die damit bezogene Position sogleich wieder relativiert wird. Die Leitunterscheidung zwischen ,Kleinen “ und ,Großen“ scheint dabei paradoxerweise ebenso Ausdruck des Aufbegehrens zu sein, wie auch dessen Widerspruch: Frau H stellt ihre Wir-Gruppe als Opfer einer übermächtigen, zugleich aber inkompetenten und überheblichen Fremdgruppe dar, die als ,amerikanisch ‘ markiert wird. Zugleich ist es aber der Status als ,kleine Normalbürgerin“, der eine selbstsichere antiamerikanische Positionierung verhindert. Die eigene antiamerikanische Positionierung wird von Frau $\mathrm{H}$ dabei als irritierend erlebt: Sie betont explizit, nicht „gegen Amerika“ sein bzw. als antiamerikanisch wahrgenommen werden zu wollen.

Diese Ambivalenz im Amerikabezug Frau Hs zeigt sich nicht nur innerhalb der jeweiligen Sequenzen, in denen Amerikabilder gebraucht werden, sondern auch als Fragmentierung über den gesamten Interviewverlauf. Dies wird insbesondere in der zweiten Hälfte des Gespräches deutlich, in der Frau H, nachdem sie zuvor ihre nicht-antiamerikanische Haltung versichert hat, relativ plötzlich in eine antiamerikanisch-ethnozentrische Argumentation verfällt. Mit einer Rhetorik, die mit derjenigen Herrn Fs, Herrn As oder Herrn Cs vergleichbar ist (vgl. Kap. 7.2 und 7.4), spielt sie nun die vermeintliche ethnische Ursprünglichkeit und Homogenität der deutschen Wir-Gruppe gegen die Heterogenität ,der Amerikaner` aus. Die somit vollzogene ethno-nationalistische Wir-Gruppenkonstruktion tritt allerdings unmittelbar im Anschluss an diesen Interviewabschnitt zugunsten der anfänglichen Identifikation als ohnmächtige ,Kleine“ wieder in den Hintergrund. Das Interview endet daraufhin mit dem expliziten Bemühen Frau Hs, nicht als antiamerikanisch gelten zu wollen bzw. nicht auf die geäußerte Position ,festgenagelt‘ zu werden.

Bemerkenswert ist an diesem geisterhaften Auftreten antiamerikanischer Rhetorik der Kontrast zwischen dem vehementen Abstreiten einer antiamerikanischen Haltung und der geradezu schlafwandlerischen Reproduktion antiamerikanischethnozentrischer Rhetorik. So drastisch Frau Hs ethnonationalistische Rhetorik ist, so stark ist ihr Kontrast zur Identitätskonstruktion der ,Kleinen ', die über weite Tei- 
le des Interviews ihre unsicher tastende Argumentation bestimmt. Diese Inkonsistenz im antiamerikanischen Sprachgebrauch wird hier als Fragmentierung bezeichnet.

Handelt es sich bei Frau Hs Sprachgebrauch also um Antiamerikanismus? Zumindest für Auszüge des analysierten Gespräches wird man dies bestätigen wollen. In diesen werden Stereotype eines übermächtigen und arroganten, zugleich aber inkompetenten und,wurzellosen“ Amerika zur Aufwertung und Konturierung einer ethno-nationalistischen Wir-Gruppenkonstruktion gebraucht. Aber diese Stellen stehen im Kontrast zu jenen Sequenzen, in denen das eigene Unbehagen gegenüber genau dieser Rhetorik explizit gemacht wird und die ethnozentrische WirGruppenkonstruktion, der sie diente, völlig irrelevant erscheint. An dem analysierten Material lässt sich daher in erster Linie die Ungenauigkeit eines Vorurteilskonzeptes veranschaulichen, das seinen Gegenstand als psychische Disposition oder geschlossenes weltanschauliches Denksystem begreift (vgl. Kap. 2.3): Frau H ,ist‘ keine ,Antiamerikanerin', keine ,Nationalistin“ oder ,Rassistin', und dennoch bemüht sie streckenweise antiamerikanische und ethnozentrische Rhetoriken. Antiamerikanismus tritt als Sprechhandeln auf, aber nicht als geschlossene Weltanschauung oder Einstellungsmerkmal. Vielmehr scheinen bestimmte Amerikastereotype und deren antiamerikanische Gebrauchsweisen überindividuell bereit zu stehen, so dass diese auch in fragmentierter Weise reproduziert werden können. Frau Hs ambivalente, teilweise fast erschrockene Reaktion auf ihre eigene Rhetorik veranschaulicht zudem den unheimlichen Charakter, den ein solches rhetorisches Erbe u.U. auch für die Sprechenden selbst hat.

\subsubsection{Falldarstellung Herr I}

Im Gegensatz zur fragmentierten antiamerikanischen Rede des vorigen Falles, zeigt sich im Gespräch mit Herrn I eine weitgehend konsistente Fremdgruppenkonstruktion: ,Die Amerikaner' werden hier als ,integrationsunwillige‘ Fremdgruppe in einem vom Interviewteilnehmer bewohnten Stadtteil dargestellt. Als konturierende Fremdgruppe dienen sie der Konstruktion einer Stadtteilidentität, die für Herrn I als zentraler Orientierungspunkt seines Selbstbildes fungiert. Sein Viertel ,ist alles!“ und wird mit stereotypen Zuschreibungen, die jenen ethnozentrischer Migrationsdiskurse ähneln, gegen ,die Amerikaner‘ abgegrenzt. So gehen diese vermeintlich keiner geregelten Erwerbstätigkeit nach, kommen aber auf dubiose bzw. kriminelle Weise zu Reichtum. Sie weigern sich, die deutsche Sprache zu lernen und „bleiben [...] unter sich“, sind weniger loyal als andere Gruppen in seinem Stadtteil.

Diese quasi-fremdenfeindliche Kennzeichnung der Amerikaner ist besonders bemerkenswert, da Herrn Is Stadtteilidentität von ihm selbst mit einer multikulturalistischen und - im Gegensatz zum ethnozentrischen Multikulturalismus z.B. bei 
Herrn F - ethnisch hybriden Orientierung verknüpft wird. So bezeichnet sich der Teilnehmer etwa selbst als „halb Ausländer“ und betont mehrfach, keinesfalls als rassistisch gelten zu wollen. Und auch die den ,Amerikanern“ zugeschriebene Kriminalität kann vor dem Hintergrund von Herrn Is eigener subkultureller Orientierung kaum als Exklusionsgrund gelten. Mehrfach lässt der Teilnehmer durchblicken, dass er Stolz darauf ist, in einem Viertel zu leben, in dem man ,,alles an jeder Straßenecke“ bekommt (z.B. „Weed“) und in dem „die Leute [...] mit Messern“ oder ,einer Pumpgun rumlaufen“.

Und doch scheint die alternativ-subversiv gefärbte Wir-Gruppenkonstruktion des Teilnehmers eines kategorialen Gegenbildes zu bedürfen. Dass sich hierfür ,die Amerikaner' besonders anbieten, scheint nicht zuletzt vor dem Hintergrund der in Kapitel 7.4 beschriebenen Rechtfertigungsfunktionen von Antiamerikanismus bzgl. rassistischer Positionen naheliegend: Gerade weil , die Amerikaner' nicht als Ethnie oder Rasse vorgestellt werden, eignen sie sich als Fremdbild zu einer explizit nichtethnozentrischen oder nationalistischen Wir-Gruppe. Zugleich ist Herrn I diese Ambivalenz durchaus bewusst, wie an seinen mehrfachen Beteuerungen, nicht als rassistisch gelten zu wollen, sowie an häufigen Relativierungen der eigenen Urteilsfähigkeit erkennbar wird. Ähnlich wie Frau H schwankt er zwischen pauschalisierenden Zuschreibungen gegen , die Amerikaner' und dem Eingeständnis, selbst von amerikanischer Politik und Gesellschaft „keine Ahnung“ zu haben und lediglich „drei, vier Leute“ zu kennen, die er als ,Amerikaner“ einordnet.

Neben dieser Ambivalenz im Gebrauch antiamerikanischer Rhetorik ist es vor allem deren Funktionskontext, der Herrn Is Rede als Beispiel für die unscharfen Ränder des Antiamerikanismusbegriffes relevant macht. In Kapitel 4 wurde nahegelegt, dass Vorurteilskritik zur Bestimmung ihres Gegenstandes kritisch an bestehende Normen gegen Diskriminierung anknüpfen muss. Angesichts der von Herrn I konstruierten Stadtteilidentität bleibt aber gerade deren diskriminierender Effekt fraglich. Zwar werden darin , die Amerikaner' kategorial gegen die Wir-Gruppe abgegrenzt und als nicht-zugehörig ausgeschlossen. Zugleich distanziert sich Herr I aber explizit von ethno-nationalistischen Konstruktionen und betont mehrfach, sich auch mit ,den Amerikanern“ in seinem Viertel arrangiert zu haben.

\subsubsection{1 ,Die Amerikaner' als integrationsunwillige Einwanderer}

Das Interview beginnt mit der Bitte, Herr I möge erläutern warum er in der vorigen Befragung der Aussage ,Mir sind die US-Amerikaner eher unsympathisch“ zugestimmt hat. Seine ersten Assoziationen beziehen sich auf eine kriegerische Haltung der USA, allerdings direkt gefolgt von der Beteuerung, er kenne eigentlich ,direkt keine Amerikaner". 
Herr I: (Räuspert sich) Naja, Amerikaner, was? Naja ä:::h, ja hier, Krieg und so, alles cool, und was soll ich dazu noch sagen, so. Ä:::h, kann ich eigentlich nicht mehr weiter, sie sind mir einfach, äh, unsympathisch. Ich kenne jetzt auch, ähm, direkt keine Amerikaner, und eigentlich nur vom TV oder von den Nachrichten oder so. Und, äh, nee, das ist auf jeden Fall nicht mein Fall. Kann ich aber dazu auch nicht mehr jetzt sagen so.

Das Thema ,Krieg' wird im weiteren Interviewverlauf nur von marginaler Bedeutung sein. Stattdessen tritt auf die Frage, welche alltäglichen Eindrücke er mit ,Amerikanern“ verbinde, ein lokaler Bezug zu dieser Gruppe in den Vordergrund. Obwohl Herr I in der vorigen Sequenz behauptet hat, keine Amerikaner zu kennen, ist der weitere Verlauf des Interviews maßgeblich durch Berichte über , die Amerikaner' in seinem Stadtteil geprägt:

Herr I: Äh:::, m:::h, nee, fällt mir jetzt auch auf die Schnelle nicht ein. Also, hatte auf jeden Fall schon mal ein paar Begegnungen so, mit irgendwelchen Leuten so, j:::a, die sind halt immer zu cool so, für mich. Und zu arrogant. $\mathrm{Zu}$ cool, und denken so, sie sind das Beste, weißt du, leben hier, aber, äh, was in Amerika geht, äh, geht sie nichts an und so. Nee, ja... Kann ich dazu leider nicht, äh, weiter erläutern. Da müsste ich mir (lacht) erst mal Stichpunkte machen, wahrscheinlich.

In dieser Beschreibung der ,Amerikaner'stehen deren ,Arroganz“ und übertriebene ,Coolness‘ sowie deren Desinteresse an ihrem Herkunftsland im Mittelpunkt. Diese Darstellung kann als Variation klassischer Amerikastereotype gelesen werden: So klingen darin die Zuschreibungen von ,Überheblichkeit‘ und ,Egoismus ‘ sowie einer ,Oberflächlichkeit‘ in zwischenmenschlichen Beziehungen an, aber auch eine mangelnde Verbundenheit mit dem ,Herkunftsland“ bzw. eine ,Kultur-' und ,Traditionslosigkeit". Im weiteren Verlauf des Interviews wird Herr I weitere Stereotype bemühen, die aus antiamerikanischen Sprechweisen bekannt sind, wie etwa die vermeintliche Unzuverlässigkeit bzw. Vertrauensunwürdigkeit , der Amerikaner‘. In der vorliegenden Sequenz dreht sich die Beschreibung dieser Gruppe allerdings zunächst um andere, für antiamerikanische Vorurteile eher untypische Bilder:

Interviewer: Sie sprachen gerade von Leuten, die Sie zu cool und zu arrogant finden, oder von Begegnungen mit diesen Leuten, können Sie das ein bisschen näher, können Sie dazu [mehr erzählen]?

Herr I: [Ja, das sind halt], das sind halt so irgendwelche, irgendwelche Schwarzen so... Also was heißt Schwarze, oder so... Also letzte, letztere Umfrage dachte ja schon, ich wäre rassistisch, bla bla bla. So bin ich gar nicht drauf, ja! Also ich habe neunzig Prozent Ausländer als Freunde, so ist es nicht, so. Aber wenn ich dann irgendwelche, mal so einen Schwarzen, dann sind die mit, äh, Käppi... Keine Ahnung, ich weiß nicht, die arbeiten nicht, sind aber immer 
top gestylt, top gekleidet, also die, äh, teuersten Sachen, und sprechen nur englisch, und yeah yo, what's up, what's up, yeah, here, here, da, da, naja, ja, naja, das ist jetzt nicht so mein Fall, also... Keine Ahnung. Nur, ich weiß nicht, woher die ihr Geld beziehen so, aber... Zu cool, dafür, dass die hier in Deutschland leben und kein Deutsch können. Und sich dann auch nicht so ausdrücken können so, naja, ja.

Interviewer: Also auch so eine Art Unangepasstheit, oder sagen wir mal, es ist kein Austausch da, irgendwie.

Herr I: Ja nee, ä:::h, sie sind auch, sind auch nicht bereit irgendwie was anzunehmen. Kaufen sich jede, jede Woche auf jeden Fall eine neue (unverständlich) Käppi so, von New York, aber... Oder bestellen sich Sachen, Alter, die neuesten Schuhe aus New York, keine Ahnung, aber, pf, ja, haben so gesehen nichts drauf, also... In [Stadt 1] überleben sie damit nicht, sage ich mal so.

In dieser Sequenz wird die Gruppe der ,Amerikaner' anhand von drei zentralen Eigenschaften beschrieben: Sie sind (1) unproduktiv, und doch auf mysteriöse Weise (ökonomisch) erfolgreich; sie sprechen (2) die deutsche Sprache nicht, obwohl sie dauerhaft in Deutschland leben; und sie sind (3) auch sonst kulturell unangepasst bzw. nehmen die Umgangsformen ihres Umfeldes nicht an. Vielmehr als den üblichen antiamerikanischen Klischees entspricht diese Darstellung rechtskonservativen bzw. ethnozentrischen Integrationsdiskursen: mangelnde Anpassung an die ,Leitkultur', keine ,ehrliche Arbeit' aber dubioses Einkommen, mangelnde Sprachkenntnisse, etc. In einer späteren Sequenz wird Herr I dieses Bild der ,Amerikaner` zusätzlich um das Motiv einer parasitären Ausnutzung des deutschen Sozialsystems erweitern und es somit Konstruktionen ,integrationsunwilliger Ausländer ' noch weiter annähern. Die obige Sequenz schließt dementsprechend mit dem Urteil: „In [Stadt 1] überleben sie damit nicht", wodurch die Grenzziehung zwischen ,Amerikanern' und der lokalen Wir-Gruppe zusätzlich unterstrichen wird. Die , amerikanische' Fremdgruppe scheint hier also in erster Linie die Funktion einer ethnozentrischen Konturierung der Wir-Gruppe zu übernehmen, wobei allerdings nicht die üblichen ethno-nationalistischen Großgruppen ,Volk', ,Nation“ und ,Staat ' bemüht werden, sondern das Stadtviertel, in dem Herr I sich zu Hause fühlt. Im folgenden Abschnitt 7.5.2.2 wird zusätzlich veranschaulicht, inwiefern der Interviewteilnehmer diese Stadtteilidentität gegen eine ethno-nationalistische explizit abgrenzt.

Zwei weitere Beobachtungen lassen sich an der obigen Sequenz machen, die für die hier entwickelte Deutung relevant sind: Die erste ist, dass Herr I sich präventiv gegen eine Einstufung seiner Argumentation als rassistisch verwehrt. Er verweist darauf dass er ,neunzig Prozent Ausländer als Freunde“ habe und erinnert sich an die ,letztere Umfrage“ (gemeint ist das zum Zeitpunkt des Gespräches ca. zwei Monate zurückliegende Survey-Interview; vgl. Kap. 5.4), bei der er offensichtlich 
bereits ähnliche Bedenken bzgl. seiner Wirkung auf den Interviewer hatte. Bei Terminabsprachen im Vorfeld des hier analysierten Interviews bezeichnete der Teilnehmer die zurückliegende Survey-Untersuchung, die er offenkundig als Überprüfung seiner Einstellungen auf rechtsradikale Tendenzen wahrgenommen hat, als „Nazi-Test“, was auf eine große Sensibilität für mögliche politisch-moralische Sanktionierungen hinweist. Zu Beginn des Interviews betont er, dass der Interviewer mit ihm „keinen Scheiß“ anstellen solle, was ebenfalls im Kontext eines antizipierten Rassismus-Vorwurfs verstanden werden kann. Auch in der nachfolgenden Sequenz wird er sich noch einmal vergewissern, dass ihm vom Interviewer „kein Rassismus“ unterstellt wird. Man kann also sagen, dass sich an dieser Stelle bereits eine ausgeprägte Reflexivität bzgl. der Nähe des eigenen Sprechens zu ethnozentrischen Diskursen zeigt: Es ist Herrn I durchaus bewusst, wenn vielleicht auch auf diffuse Weise, dass seine Darstellung Ähnlichkeiten mit vorurteiligen Fremdgruppenkonstruktionen aufweist oder zumindest Gefahr läuft, von anderen als solche markiert zu werden.

Eine zweite wichtige Beobachtung ist die Vorsicht bzw. Unsicherheit, mit der Herr I seine Beurteilung, der Amerikaner“ vorbringt: er ,kenne jetzt auch [...] direkt keine Amerikaner“, habe sein Wissen über die USA ,eigentlich nur vom TV oder von den Nachrichten“. In einer späteren Sequenz wird er einwerfen, dass es in seinem Viertel „halt keine Amerikaner“ gebe, wenngleich er diese kurz zuvor ausführlich beschrieben hat. Wie in Abschnitt 7.5.2.3 herausgearbeitet wird, dient die antiamerikanische Rhetorik bei Herrn I zwar der Konturierung seiner Stadtteilidentität, bleibt dabei aber selbst vergleichsweise brüchig. Unten werde ich argumentieren, dass diese Brüchigkeit der antiamerikanischen Rhetorik selbst mit einer Widersprüchlichkeit in Herrn Is Wir-Gruppenkonstruktion zusammenhängt, die das antiamerikanische Sprechen aber nicht aufzulösen imstande ist.

Damit sind bereits zu Beginn des Interviews die wesentlichen Momente des hiesigen Funktionskontextes antiamerikanischer Rede versammelt: Eine lokalpatriotische Wir-Gruppenidentität, die in einer Mischung aus Amerikastereotypen und Motiven eines ethnozentrischen Integrationsdiskurses den eigenen Stadtteil gegen, die Amerikaner' konturiert, sowie zugleich ein multikulturalistisches Selbstverständnis, das sich explizit gegen Rassismus abgrenzt. Im darauffolgenden Interviewabschnitt finden sich diese Aspekte noch einmal in komprimierter Form:

Herr I: [...] Also, die Leute, die ich hier kenne, die sprechen nur englisch, direkt, die haben auch kein Bock, Alter, da hier die deutsche Sprache zu lernen. Wie gesagt, die tragen die coolsten Sachen, die Käppis... Ä:::hm, wir sind hier nicht in New York, ja, wir sind hier in [Stadt 1], und ä:::hm... Nee, passt einfach nicht, so. Also dann sollen sie sich dann schon mal, äh, wenn sie hier schon zwanzig Jahre leben, sollten sie dann schon mal, äh, ein, zwei Worte Deutsch können, sage ich mal. (Räuspern) Aber ich, auf jeden Fall, kein Rassismus hier oder 
so, ja? Also, auf gar keinen Fall! (.) Ja, äh, ich kann auf solche Fragen, ich weiß nicht, äh, Sie wollen ja jetzt, das ich was erläutere, aber dazu bin ich jetzt nicht imstande. (Lacht)

Interviewer: Okay. In dieser Aussage ging es ja gerade um amerikanische Kultur. Wenn Sie amerikanische Kultur denken, was fällt Ihnen dabei so ein, also woran denken Sie da?

Herr I: M:::h, da denke ich an KFC, an McDonalds, und an schwarze Leute, die mit einer krassen Käppi und runtergetragenen Hosen rumlaufen. Pf, und die ja, die sprechen halt durchgehend einfach nur englisch "Yo, what's up, what's up", pfpfpfpf, drauf geschissen, ja? Also, sie sagen nicht einmal ja oder nein, sie sagen "Yes, no, no, yes, no" und, naja!

Die Gegenüberstellung von ,Amerikanern“ und Einwohnern seiner Stadt wird von Herrn I noch einmal zugespitzt: ,wir sind hier nicht in New York, [...] wir sind hier in [Stadt 1]“ und das Verhalten der ,Amerikaner" „passt einfach nicht“" in sein Viertel. Direkt darauf folgt wiederum die Beteuerung, er wolle nicht als Rassist gelten. Tatsächlich kann man Herrn Is Rhetorik nicht im engeren Sinne als rassistisch einstufen: Weder die Wir-Gruppe, noch die ,amerikanische“ Fremdgruppe ist hier in einem völkischen oder gar rassischen Sinne als Ethnie markiert. ${ }^{2}$ Dennoch trägt die Grenzziehung zwischen beiden Gruppen ethnozentrische Züge. Dies wird zusätzlich anhand des folgenden Interviewabschnittes deutlich, in dem die Exklusionsrhetorik durch das Motiv einer unproduktiven und parasitären Lebensweise ,der Amerikaner' ergänzt wird:

Interviewer: Sie sprachen eben davon, dass sie in [Stadt 1] so nicht weiterkämen. [Das heißt, da fehlt sozusagen auch ein bisschen...]

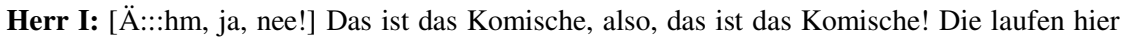
trotzdem... Also, ich kenne keinen... Also die ich jetzt hier getroffen habe, da würde ich mir auf jeden Fall denken, die arbeiten nicht. Ich weiß nicht, woher sie ihr Geld beziehen, also ich weiß es schon, aber das ist auf jeden Fall auf illegale Weise. Aber die, auf jeden Fall tragen die tausendmal teurere Sachen als ich. Und sind immer cool drauf, ja! Und, äh:::, sind auch nicht, sind auch gar nicht so, äh:::, in Zukunft daran zu denken, dass sie irgendwie mal Deutsch lernen oder so. Also die, äh, die ziehen das hier durch so, in ihren afroamerikani-

2 Auffällig ist natürlich, dass Herr I durchwegs nur ,Schwarze“ als ,Amerikaner“ identifiziert. Man könnte vermuten, dass das Attribut ,Amerikaner“ hier als eine Art Chiffre gebraucht wird, um über Schwarze Menschen generell zu sprechen, der Antiamerikanismus von Herrn I also eigentlich ein maskierter Rassismus ist. Anhand des Interviewmaterials lässt sich diese These aber nicht hinreichend belegen. Daraus, dass Herr I ,Schwarze ' und ,Amerikaner" synonym verwendet, kann nicht gefolgert werden, dass für ihn nicht auch noch andere Schwarze existieren, die er nicht als Amerikaner identifiziert. 
schen Shops, Alter, immer Dreads flechten und so, ihre Haare machen, ja, Frauen dicke Ärsche, und das war es, ja.

Die Amerikaner tragen also „tausendmal teurere Sachen“ als Herr I, obwohl sie im Gegensatz zu diesem keiner regulären Arbeit nachgehen. Dass Migrantengruppen eine unproduktive Lebensweise ohne ,ehrliche Arbeit' zugeschrieben wird, häufig mit einem skeptischen Verweis auf vermeintlichen Reichtum trotz mangelnder Produktivität, ist ein etabliertes Stereotyp in fremdenfeindlichen Rhetoriken. Bei Herrn I wird es auf , die Amerikaner' übertragen und in einem späteren Interviewabschnitt auch um das Stereotyp einer parasitären Ausnutzung des deutschen Sozialstaates ergänzt. Das Gespräch war hier zuvor auf Unterschiede zwischen weißen Amerikanern in den USA und den in Herrn Is Viertel lebenden ,Afroamerikanern' gekommen. Herr I betont daraufhin die Schläue der letzteren, die sich in Deutschland angeblich auf Staatskosten ein bequemes Leben machen:

Herr I: Naja, ich... Auf jeden Fall sind sie schlauer, als die Weißen, die dann da, äh, äh, keine Ahnung, ihren Arsch hinhalten. Weil die sind einfach hier in Deutschland, weil die können sich hier durchfressen Alter! (Räuspern) Jo...

Interviewer: Und würden Sie sagen, dass ist auch möglicherweise ein Problem, also dass sie sich hier durchfressen, oder sich hier sozusagen mit...

Herr I: Pf, für mich ist es, für mich ist es kein Problem. Ich bezahle so oder so Alter, so en Masse an Steuern, Alter, das geht gar nicht mehr klar! Und ich weiß, dass ich die finanziere, aber, ähm, ja, das, wie gesagt, das ist mir scheißegal. Weil ich kann daran, ich kann daran so nichts ändern. Wenn ich meine Stimme da abgebe Alter, äh äh, bei irgendwelcher Politik(.)... Es geht ja auch nicht da gegen die Schwarzen, oder die, keine Ahnung, die sich dann durchfressen, da kann man eh nichts machen. (Räuspern) Also die sind auf jeden Fall schlauer, dass sie hier in Deutschland leben anstatt, äh, in Amerika. Weil es da auf jeden Fall, äh ähm, ja da hätten sie auf jeden Fall schlechtere Karten, sage ich mal. Hier sind sie dann doch die Coolen.

Das Bild des schlecht integrierten, parasitären aber auch schlauen, dubiose Geschäfte treibenden Fremden ist damit komplettiert: ,Die Amerikaner' leben von Steuergeldern, die ,Deutsche“ wie Herr I bezahlen. Zugleich ist aber auffällig, wie Herr I auch an dieser Stelle seine Position unmittelbar im Anschluss wieder relativiert bzw. betont, dass die beschriebene parasitäre Existenz für ihn „kein Problem“ sei. Ähnlich wie in den vorigen Beispielen, in denen Herr I zunächst Stereotype ,schlecht integrierter' Einwanderer gebrauchte, um dann jeglichen Rassismus präventiv abzustreiten, wird auch hier zunächst ein Bild des ,parasitären Fremden` gezeichnet, um dieses gleich im Anschluss wider zu entschärfen. Wie in den oben be- 
schriebenen Interviewausschnitten, gebraucht Herr I also einerseits eine bürgerlichkonservative, tendenziell fremdenfeindliche Rhetorik, andererseits grenzt er sich von dieser ab.

Dass ,die Amerikaner' als Kontrastsfolie für die eigene Stadtteilidentität genutzt werden, wird im Folgenden in einen funktionalen Zusammenhang mit der Reflexivität bzgl. vorurteiliger Tendenzen der eigenen Rede gestellt: Weil Herrn I die Nähe seiner eigenen Identitätskonstruktion zu ethnozentrischen Sprechweisen bewusst ist, konstruiert er mit , den Amerikanern' eine Fremdgruppe, deren Exklusion oder Abwertung er für vergleichsweise Konsensfähig hält - insbesondere da es sich bei diesen nicht um eine ,Ethnie“ im völkischen bzw. rassistischen Sinne handelt. Um diese These zu entwickeln, wird im folgenden Abschnitt die Identitätskonstruktion von Herrn I mit ihrer Spannung zwischen rigider, exkludierender Identifikation und multikulturalistisch-inklusiver Offenheit genauer dargestellt.

\subsubsection{2 „Ich habe mir [Stadtteil 1] tätowiert!“ - Eine lokalpatriotische Wir-Gruppenkonstruktion}

Im vorigen Abschnitt wurde dargelegt, wie Herr I , die Amerikaner' als mangelhaft integrierte Fremdgruppe in seinem Stadtteil konstruiert. Im Folgenden sollen nun zentrale Merkmale seiner Wir-Gruppenkonstruktion genauer beleuchtet werden. Hierbei spielen neben einer allgemeinen Glorifizierung der Qualitäten seines Lebensumfeldes vor allem Aspekte der Multikulturalität bzw. ethno-nationalen Hybridität und ein subkultureller Insider-Status eine wichtige Rolle. Auf die Frage, was es für ihn bedeute, in seinem Viertel zu leben, hebt Herr I zu einer emphatischen Glorifizierung seiner Heimatstadt an:

Herr I: Mh, also [Stadt 1] ist, ähm... Sage ich mal so, wenn man die Weltkugel nimmt, würde ich direkt Europa auswählen, wenn man Europa auswählt, würde ich direkt Deutschland auswählen, und in Deutschland würde ich direkt [Stadt 1] nehmen, und in [Stadt 1], da würde ich direkt [Stadtteil 1] nehmen. Also ich wohne genau hier, wo das Perfekteste ist überhaupt! Also ä:::hm... Was war noch mal? Was wollten Sie noch mal?

Interviewer: Was Ihnen das bedeutet, aus [Stadt 1] zu sein, oder [Bewohner von Stadtteil 1] zu sein.

Herr I: Das bedeutet mir... (lacht) Ich habe mir [Stadtteil 1] tätowiert! Äh:::, das ist hier auf jeden Fall... Ja, ich würde, ich mache Urlaub hier bei meinen Eltern drüben auf Balkonien! Ja, das ist [Stadtteil 1], das ist... Also, ich... [Stadt 1] ist alles! [Stadt 1] ist [Stadt1] Nummer eins in ganz Europa. (.) Jo. 
Interviewer: Sie sagten auch gerade... Sie sagten gerade, Sie würden auf jeden Fall Europa wählen, in Europa würden Sie Deutschland wählen, was...

Herr I: Äh:::m, ja, aber an Deutschland würde ich dann auch nur [Stadt 1] wählen, also ganz Deutschland kannste vergessen, äh:::m, oder Sie können das vergessen, äh:::m, ja, nee, fällt mir jetzt auch kein anderes Land ein. Also ich habe auch nur Dänemark, Schweden, Norwegen, Skandinavien, da habe ich mal Urlaub gemacht so, und da mache ich auch gerne Urlaub, weil die sehr, sehr zurückhaltend und neutral sind, und da kann man gut Urlaub machen so. Ansonsten... [Stadt 1], Nummer eins...

An dieser Stelle wird in verdichteter Form die extreme Identifikation Herrn Is mit seinem Stadtteil ausgedrückt. Wie in einer rasenden Kamerafahrt reduziert sich der Fokus seiner Darstellung von der ganzen Welt auf seinen Nahbereich, während alles andere aus dem Sichtfeld verschwindet: Die Welt, Europa, Deutschland sind gleichgültig, denn Herr I wohnt ,genau hier, wo das perfekteste ist überhaupt! [...] [Stadt 1] ist alles!“ Dass er sich den Stadtteilnamen tätowiert, seine Zugehörigkeit sozusagen körperlich eingeschrieben hat, ist zusätzlicher Ausdruck seiner bruchlosen Identifikation mit diesem Ort.

Aus vorurteilskritischer Perspektive ist an dieser Stelle v.a. die Abgrenzung gegenüber Deutschland bzw. gegenüber einer nationalistischen Fundierung seiner Wir-Gruppe interessant. Seine Stadt ist zwar „Nummer eins in ganz Europa“, aber dieses Urteil ist explizit nicht eingebettet in irgendeine Form nationalen Stolzes. Auch an keiner anderen Stelle gibt es Anzeichen dafür, dass sich mit dem Lokalpatriotismus Herrn Is nationalistische oder völkische Ideen verbinden. Im Gegenteil, Herr I fügt ohne Umschweife und ganz beiläufig hinzu, das man ,ganz Deutschland [...] vergessen“ könne. Ähnlich, wie er zuvor das Bild parasitär-ausbeuterischer Einwanderer gebraucht, dann im unmittelbaren Anschluss aber relativiert hatte, schließt er hier an den euphorischen Lokalpatriotismus die Einschränkung an, dass dies mit Deutschland, und also mit Nationalismus, nichts zu tun habe. Darauf, dass eine nationalistische Identifikation Herrn I tatsächlich fern zu liegen scheint, deutet auch der multikulturelle bzw. ethnisch-hybride Gehalt seiner Stadtteil-Identität hin. Im folgenden Interviewausschnitt beschreibt Herr I die verschiedenen ethnischen Hintergründe in der Bevölkerung seines Stadtteils und identifiziert sich selbst als „halb[en] Ausländer":

Herr I: [...] Es gibt halt nur Türken, Jugoslawen, Araber, und mit denen bin ich aufgewachsen. Ich bin zwar Deutscher, aber Sie hören ja schon, wie ich rede. Und ich bin mit denen aufgewachsen, und ich bin so halb, halb Ausländer, (lacht) obwohl ich Deutscher bin.

Anhand dieses Ausschnittes wird der Kontrast von Herrn Is Konstruktion zu nationalistisch-ethnozentrischen Varianten deutlich, wie sie etwa anhand der Beispiele 
von Herrn F oder Herrn A gezeigt wurden (vgl. Kap. 7.2.2 und 7.4.1). Die ethnische Hybridität, die von jenen aus ihrer nationalen Identität ausgeschlossen wird, scheint für Herrn I ein völlig unproblematischer Bestandteil seiner Stadtteilidentität: „Ich bin [...] halb Ausländer, [...] obwohl ich Deutscher bin." Sofern bei Herrn I von ethnozentrischer Identifikation gesprochen werden kann, so bezieht sich diese also nicht auf ethno-nationale, sondern auf seine lokalpatriotische Identität, in der ethnonationale Zuschreibungen kein zentrales Unterscheidungskriterium zu sein scheinen. Während antiamerikanische Rhetorik bspw. bei Herrn A und Herrn F dazu dient, die ethno-nationale Wir-Gruppe zu konturieren und abzusichern bzw. die rassistischen Konsequenzen dieser Identitätskonstruktion zu verdecken, findet sich bei Herrn I keine vergleichbare ethnozentrische bzw. rassistische Funktion. Nichtsdestotrotz werden , die Amerikaner" hier als Kontrastfolie zur Konturierung seiner Stadtteilidentität gebraucht. So betont Herr I im Vorlauf zu dieser Stelle, dass ihm „Türken, Jugoslawen, Araber“" sympathischer seien als ,die Amerikaner“. Im Gegensatz zu jenen erscheinen diese als, gut integrierte" und akzeptable Mitglieder seiner Stadtteilidentität:

Herr I: [...] Also sie [die Amerikaner, F.K.] bleiben auch unter sich! Also wenn ich da komme Alter, da sind, keine Ahnung, ich will von einem Schwarzen was, dann sind da sechs Schwarze, die alle Englisch reden, und, ja, die stimmen dann alle dem zu. Also, die sind nicht ein bisschen, ja? Ich mag auch mehr Türken, Araber, Jugoslawen, das, die mag ich mehr irgendwie als Amerikaner. Abgesehen davon liebe ich auch die Amerikaner, so ist es nicht, also, ich liebe sie nicht, aber ich verstehe mich mit denen trotzdem gut.

Interviewer: Was gefällt Ihnen bei den Türken, Arabern etc. besser?

Herr I: Ä:::h pf, naja, also, ich wohne in [Stadtteil 1]. Ich bin mit denen aufgewachsen, so und, die sind auf jeden Fall... Naja, was soll ich sagen, ich kenne auch Türken, Araber, Jugoslawen, die ich auf jeden Fall schon geschlagen habe oder so. Aber ä:::hm, ja, sind auf jeden Fall loyaler. Die können auf jeden Fall zwei Worte Deutsch mehr als die Schwarzen. Die so „Yeah, Yeah öhöh“ (unverständlich) sie immer „Yes, no, yes, no, blabla, what do you want?““ Ja, die Türken und Araber können wenigstens ,Ja, was ist los digger, blabla“ [...].

Herr I scheint also nicht nur eine multiethnische Zusammensetzung seines Viertels als dessen Charakteristikum anzuerkennen, sondern er begreift sich selbst als „halb Ausländer", und überschreitet mit dieser Hybridität zumindest der Tendenz nach die Grenzen eines ethnozentrischen Multikulturalismus, wie er etwa am Beispiel von Herrn F aufgezeigt wurde. Ebenso betont Herr I in einer vorigen Sequenz, dass er „neunzig Prozent Ausländer als Freunde“ habe und auch in der obenstehenden Interviewpassage wird diese multikulturelle Zusammensetzung seines Stadtteiles als positives Identitätsmerkmal beschrieben. Zwar bleiben ethnische Grenzziehun- 
gen damit in ihrer grundlegenden Form erhalten - seine Freunde, mit denen er im Stadtteil aufgewachsen ist, bleiben „Ausländer“ und er „Deutscher“ trotz ihrer gemeinsamen übergeordneten Gruppenzugehörigkeit. In Deutschland aufgewachsen zu sein macht eine Person demzufolge auch in Herrn Is Konstruktion ebenso wenig zur ,Deutschen', wie die deutsche Staatsbürgerschaft. Dennoch ist Herr I von einem Ideal ethno-nationaler Homogenität und Ursprünglichkeit, wie es bspw. von den oben zitierten Fällen formuliert wird, weit entfernt. Denn Nationalität ist in seiner Konstruktion nicht der entscheidende Aspekt, an dem sich Zugehörigkeit und Ausschluss, Höher- oder Minderwertigkeit festmachen. Nationalität und Ethnizität sind vielmehr nachgeordnete Unterscheidungen innerhalb der Stadtteilidentität.

Auch in seiner Darstellung von Jugendsubkultur und der damit verbundenen Kriminalität ist Herr I weit entfernt von einem traditionalen oder konservativen Verständnis von Zugehörigkeit und Moral. So deutet er an verschiedenen Interviewstellen an, dass er ein gelegentlicher Käufer und Konsument von „Weed“, d.h. Marihuana, sei und betont in der folgenden Passage mit einem gewissen Stolz das gewalttätige Klima seines Stadtteiles, in dem er sich aufgrund seines Insider-Status unbehelligt bewegen könne:

Herr I: Ja, nee, also ich... Hier hat man alles, hier hat man alles, also hier ist auch... Ich bin hier natürlich auch geboren, lebe seit dem Alter in dem gleichen Block, [Stadtteil 1], und... Ja, man hat hier alles. Man hat hier echt alles! Man kriegt alles an jeder Straßenecke, und das ist hier einfach topp! Und hier sind auch auf jeden Fall coolere Leute, äh, als in Amerika. Weil hier laufen die Leute nur mit Messern rum, und da laufen sie mit einer Shotgun rum, also...

Interviewer: Das ist auch schon noch ein bisschen sicherer, sozusagen?

Herr I: Naja, also, ich kenne auch Leute, die hier mit einer Pumpgun rumlaufen, so ist es nicht, aber... Auf jeden Fall ist es hier auf jeden Fall sicherer. Ja, weil, weil, na klar, ich kenne hier auch meine Leute. Also ich kann hier, ich kann hier nackt über [Straße 1] rennen, da würde mir nichts passieren.

Interviewer: Aber man sagt ja schon, das ist eigentlich ein gefährliches Pflaster auch, zumindest in...

Herr I: Auf jeden Fall! Nee, nee, auf jeden Fall, auf jeden Fall, also, äh::.... Ja doch! Wenn man hier seine Leute nicht kennt, dann ist das auf jeden Fall schon heikel. Ja. Als Touri, Alter, äh:::... Ja, man kann hier auch seinen Spaß haben, natürlich! Auf jeden Fall! Aber dann läuft man auch eher an den Ecken rum, da wo die Touris sind. Oder da wo dann Party ist und blablabla, aber läuft dann nicht hier in meiner Ecke rum oder so. 
Im Gegensatz zu „Touris“ und anderen Nicht-Insidern stellt sich Herr I als erfahren im Umgang mit den Unwägbarkeiten seines Viertels dar. Straßengewalt und Drogenhandel in seinem Umfeld sind ihm kein hinzunehmendes Übel sondern fungieren, im Gegenteil, als willkommene, identitätsstiftende Abgrenzung gegenüber AuBenseitern (,Touris“). Und auch die Konturierung dieser Identitätsstiftenden Aspekte mittels des Stereotyps der schießwütigen, antisozialen Amerikaner zielt nicht auf die Konstruktion einer gesetzestreuen, friedlichen Nachbarschaft, sondern vielmehr auf eine Art gemäßigte Ghetto-Atmosphäre.

Die Konturierung bzw. Integration von Herrn Is Wir-Gruppe folgt also zu weiten Teilen nicht den Kriterien traditioneller bürgerlicher Moral oder einem ethnozentrischen Nationalismus: weder ethnische Homogenität, noch konventionelle Vorstellungen von Recht und Ordnung sind positive Kriterien für dessen Identitätskonstruktion.

\subsubsection{Zusammenfassung Herr I}

Vor dem Hintergrund der oben rekonstruierten Wir-Gruppenkonstruktion stellt sich die Frage, warum Herr I sich überhaupt derart pauschalisierend gegen , die Amerikaner' wendet. Wenn ethnische Diversität und Hybridität ein dezidiert positiver Aspekt seiner Stadtteilidentität ist, ebenso wie ein gewisses Ausmaß an Subversivität bzw. Delinquenz (Drogenhandel, Straßengewalt) in seinem Viertel, warum können gerade ,die Amerikaner', im Gegensatz zu vielen anderen Gruppen, nicht Teil der multiethnischen und kulturell hybriden Stadtteilidentität sein? Denn die ihnen zugeschriebenen Merkmale eines dubiosen, illegalen Lebensunterhalts, eines ,Ausnutzens‘ sozialstaatlicher Leistungen, sowie einer kulturellen Devianz (Kleidung, Sprache) scheinen doch mit Herrn Is Wir-Gruppenkonstruktion weitgehend kompatibel zu sein. Dies gilt umso mehr, als der Interviewteilnehmer in einer späteren Sequenz seine Ablehnung des Kleidungsstils ,der Amerikaner“ relativiert und stattdessen eine ausgeprägte Ähnlichkeit zu seinem eigenen „Style“ zugesteht:

Herr I: Also, wenn ich mal rausgehe auf die Straße, und äh, irgendwelche Leute treffe, ä:::hm, dann ist es doch hundert Prozent der Schwarze oder die Amerikaner, die mich einfach angucken, weil ich habe, ich habe halt auch so eine Käppi auf und ein Tuch wie Eminem, und äh, trage meine Hosen auch ein bisschen weiter runter, und, ähm, sehe dann schon aus wie so ein, ähm, black- (.), äh, Street-Style, ja.

Und dennoch fungieren, die Amerikaner" als konturierende Fremdgruppe für Herrn Is Stadtteilidentität. Eine funktionale Deutung für diese Aversion lässt sich anhand des vorliegenden Materials nur ungenau entwickeln. Zwar ließe sich auch hier vermuten, dass - ähnlich wie in den Sprachgebräuchen von Herrn A, Herrn C und Herrn E (vgl. Kap. 7.4) - , die Amerikaner' sich gerade deshalb als Fremd- bzw. 
Feindbild anbieten, weil sie nicht als ,ethnische Gruppe ‘ bzw. ,Rasse“ angesehen werden: Auch Herr I betont schließlich mehrfach, nicht als Rassist gelten zu wollen und kehrt die multiethnische Zusammensetzung seiner Wir-Gruppe hervor. Man kann also annehmen, dass seine Konstruktion ,der Amerikaner' als konturierendes Gegenbild seiner Stadtteilidentität gerade angesichts ihrer multikulturalistischen bzw. anti-rassistischen Implikationen besonders geeignet ist. Dennoch muss diese Konstruktion , der Amerikaner' als Kontrastfolie unter rhetorischen Gesichtspunkten vergleichsweise willkürlich erscheinen. ${ }^{3}$

Zusätzlich lassen sich zur Beantwortung der oben aufgeworfenen Frage zumindest zwei weitere Thesen formulieren, die allerdings weniger auf die rhetorischen Eigenschaften in Herrn Is Rede abzielen: Erstens lässt sich aufgrund des Interviewmaterials annehmen, dass Herr I kränkende persönliche Erfahrungen mit von ihm als ,amerikanisch ‘ markierten Personen gemacht hat. Seine negative Darstellung ,der Amerikaner' könnte demzufolge als ,faulty and inflexible generalization“ (Allport 2003, S. 9) im Sinne des klassischen Vorurteilsbegriffes verstanden werden. Als Bekräftigung dieser These können Interviewpassagen dienen, in denen er davon berichtet, in einem Afro-Shop ausgrenzend und unfreundlich behandelt oder von ,Amerikanern“ beim „Weed“ kaufen , abgezogen“ worden zu sein. ${ }^{4}$

3 Klaus Baethge und KollegInnen sprechen von einer „funktionalen Austauschbarkeit des Antiamerikanismus“ (Baethge et al. 2010, S. 377; vgl. auch Kap. 2.3.3). Auf Herrn Is Antiamerikanismus scheint mir dies in höherem Maße zuzutreffen, als bei den Fällen der vorigen Kapitel. Anhand der Beispiele von Herrn A und Herrn F wurde bspw. argumentiert, dass bestimmte Amerikastereotype, etwa das der Traditions- und Ursprungslosigkeit bzw. der ethnischen Heterogenität, sich für bestimmte Konstruktionen besonders anbieten (antiamerikanische Figur des Dritten, antiamerikanische Rechtfertigung von Rassismus). In Herrn Is Fall ist zwar eine solche Spezifizität des Amerikabildes, wie oben angemerkt, zumindest insofern gegeben, dass ,die Amerikaner' sich als Feindbild besonders demjenigen anbieten, der sich als antirassistisch verstanden wissen möchte. Hierzu kämen allerdings auch andere Gruppen in Frage, wie etwa die Mitglieder benachbarter Stadtteile. Tatsächlich grenzt Herr I seinen Kleidungsstil in einer Interviewstelle gegen denjenigen von Jugendlichen aus einem anderen Stadtteil ab: ,Also ich bin dann doch kein Deutscher aus [Stadtteil 3] oder so, Alter, der dann die Hosen in die Socken steckt und eine Käppi Alter, (lacht) auf das Kleinste stellt und die nur auf dem Kopf trägt, das auf jeden Fall nicht.“

4 Andererseits könnte man einwenden, dass ähnliche schlechte Erfahrungen mit Mitgliedern anderer ,ethnischer' Gruppen nicht zu einer vergleichbaren stereotypen Ablehnung führen. So stellt Herr I vergleichend fest: ,ich kenne auch Türken, Araber, Jugoslawen, die ich auf jeden Fall schon geschlagen habe oder so. Aber äh:::m, ja, sind auf jeden Fall loyaler. Die können auf jeden Fall zwei Worte Deutsch mehr als die Schwarzen.“ 
Zweitens mag sich seine Darstellung der Amerikaner teilweise als Methodeneffekt erklären lassen: Herr I sieht sich im Rahmen des Interviews genötigt, seine vorige negative Darstellung, der Amerikaner' im Survey zu rechtfertigen, und greift dabei auf persönliche Alltagserfahrungen zurück. Er betont während des Interviews mehrfach, dass er sich mit politischen Themen, und insbesondere den USA, eigentlich nicht auskenne, und der Interviewer ihn damit ,,auf den [sic] falschen Fuß“ erwischt habe. Möglicherweise hätte er ,den Amerikanern“ ohne das persistente Nachfragen des Interviewers niemals überhaupt so viel Aufmerksamkeit geschenkt. Andererseits könnte man dieser These entgegenhalten, warum er dann überhaupt, d.h. auch in der vorhergegangenen Survey-Erhebung, eine negative Beurteilung, der Amerikaner' abgegeben hat - immerhin beansprucht Herr I, er habe bei der letzten Befragung ,,so im Endeffekt das gleiche gesagt“ und habe seine „Meinung [...] nicht geändert".

Auffällig ist am Fall von Herrn I aber, dass antiamerikanische Rhetorik hier mit keiner der ideologischen Funktionen verknüpft zu sein scheint, die in den vorigen Abschnitten 7.2 bis 7.4 beschrieben wurden: So finden sich bei Herrn I keine ethnozentrischen oder rassistischen Konstruktionen, keine nationalistische Identifikation, keine antisemitischen oder schuldabwehrenden Rhetoriken. Zwar ähnelt die Rigidität und Glorifikation seiner Stadtteilidentität strukturell den ethnonationalistischen Konstruktionen anderer Teilnehmer - Es handelt sich sozusagen um einen lokalpatriotischen, stadtteilbezogenen Ethnozentrismus. Aber es bleibt doch zweifelhaft, inwiefern angesichts dieses Funktionskontextes von antiamerikanischem Vorurteil gesprochen werden kann.

Hat Herr I also antiamerikanisch gesprochen? Einerseits finden sich semantische und funktionale Ähnlichkeiten, die für ein Bejahen dieser Frage sprechen: Es werden Stereotype arroganter, überheblicher, nicht vertrauenswürdiger Amerikaner reproduziert, die letztendlich zur pauschalisierenden Abwertung einer Personengruppe und der gleichzeitigen Konturierung und relativen Aufwertung der WirGruppenkonstruktion führen. Andererseits fügt sich diese Rhetorik in keine der weithin bekannten Muster von Diskriminierung und Verfolgung: Weder wird eine ethno-nationalistische Identitätskonstruktion reproduziert oder stabilisiert, noch ein Ausschluss nach ethnischen Kriterien legitimiert. Sofern man hier von ethnozentrischer Exklusion sprechen kann - immerhin wird von Herrn I klargestellt, dass , die Amerikaner' nicht in seine Stadt passen bzw. gehören -, handelt es sich um eine mit sehr beschränkter Reichweite. Da unter Gebrauch von Nationalstereotypen eine Personengruppe aus der Stadtteilcommunity ausgeschlossen wird, mag man einen vorurteiligen Effekt dieser Rede annehmen. Ob dieser eine systematische diskriminierende Wirkung zur Folge hat, darf zugleich aber zumindest in Zweifel gezogen werden, solang sich die lokalpatriotische Konstruktion nicht mit ethnonationalistischer Identifikation verbindet. 
Dies gilt umso mehr, als sich bei Herrn I nicht nur der Funktionskontext antiamerikanischer Rhetorik von Nationalismus zu Stadtteilpatriotismus verschiebt, sondern zugleich eine ähnlich starke Ambivalenz bzgl. des Gebrauchs solcher kategorialer Fremdgruppenkonstruktionen zu beobachten ist. Wie im vorigen Beispiel von Frau $\mathrm{H}$, betont Herr I mehrfach nachdrücklich seine eigene Unkenntnis , der Amerikaner': Er kenne nur „drei vier Leute“, die er als ,Amerikaner" kategorisiert und die zudem einer bestimmten Altersgruppe angehörten, so dass sein Wissen kaum zu verallgemeinern sei. Von amerikanischer Politik sowie Politik überhaupt habe er ohnehin ,gar keine Ahnung“, so dass man seine Beurteilung ,der Amerikaner“ „eigentlich auch nicht für ernst nehmen“ könne.

Diese ambivalente Positionierung kann als Widerspruch in seiner Identitätskonstruktion gedeutet werden: Einerseits geht ihm sein Stadtteil ,über alles ', und diese rigide lokalpatriotische Identifikation geht mit dem exkludierenden und abwertenden Gebrauch von Gruppenstereotypen einher. Ihrem Gehalt bzw. Selbstverständnis nach ist seine Wir-Gruppe aber gerade gegen diese Art von ethnozentrischer Grenzziehung gerichtet, wie er anhand seines multiethnischen Freundeskreises und seiner eigenen ethnisch-hybriden Identifikation demonstriert. Auch seine wiederholten Beteuerungen, nicht mit Rassismus in Verbindung gebracht werden zu wollen, können als Ausdruck dieser integrativen Orientierung gelesen werden. Der performative Selbstwiderspruch entsteht hier also durch rigide Identifikation mit einem integrativen Wir-Gruppenmodell - denn es gibt keine starke Identität ohne Ausschluss, auch wenn Pluralismus ein Kernmerkmal der Identitätskonstruktion ist.

Wichtig ist hierbei, dass diese Ambivalenz von Herrn I letztendlich nicht antiamerikanisch oder auf sonstige vorurteilige Weise rhetorisch aufgelöst wird. Er sieht sich vielmehr genötigt, das Dilemma immer wieder explizit zu machen: ,Die Amerikaner' sind eine Problemgruppe, aber eigentlich kennt er kaum welche; sie passen nicht in seinen Stadtteil, aber „,man muss sich nicht anpassen“ und „die können auch weiter so rumlaufen“; der Kleidungsstil ,der Amerikaner" passt ihm nicht, aber zugleich ist er seinem so ähnlich, dass sie ihn auf der Straße unbekannterweise grüßen. Antiamerikanismus ist hier nicht Mittel zur Stabilisierung oder Rechtfertigung rigider Klassifikationen, sondern wird selbst immer wieder in Frage gestellt und hätte sozusagen eine Stabilisierung nötig, die Herrn I aber nicht zur Verfügung zu stehen scheint.

\subsubsection{Zwischenfazit: Ambivalente und fragmentierte Antiamerikanismen}

Der Hauptfokus dieses Kapitels liegt auf den Inkonsistenzen und Ambivalenzen, die sich im antiamerikanischen Sprachgebrauch feststellen lassen. Zwar wurde in den Analysen der drei vorausgegangenen Kapitel auch schon der einzelne Sprech- 
akt bzw. die rhetorische Operation zur Auswertungseinheit genommen, nicht die Person des jeweiligen Interviewpartners, und insofern auch schon ein Schwerpunkt auf die Flexibilität und Situativität antiamerikanischen Sprechens gelegt. Die dabei analysierten Fälle stellten sich hinsichtlich ihrer Amerika-Semantiken und der damit erzielten rhetorischen Wirkungen jedoch als vergleichsweise konsistent dar. Anhand der Fälle von Frau H und Herrn I wurden dagegen dezidiert inkonsistente Antiamerikanismen geschildert. Diese Inkonsistenzen wurden anhand dreier Dimensionen herausgearbeitet: Ambivalenz, Fragmentierung und Verschiebung von Funktionskontexten.

Ambivalent argumentieren sowohl Herr I als auch Frau H hinsichtlich ihres Gebrauchs von Amerikastereotypen. Beide Interviewteilnehmenden sind sich des zumindest potentiellen vorurteiligen Gehalts ihrer Amerikabezüge bewusst und verweisen an mehreren Stellen des Gespräches darauf, nicht „gegen Amerika“ zu sein bzw. betonen, dass ihnen „,kein Rassismus“ unterstellt werden solle. Diese Ambivalenz zeigt sich auch in der mehrfachen expliziten Relativierung der eigenen Urteilsfähigkeit: Herr I stellt fest, von Politik und Amerika eigentlich „,keine Ahnung“ zu haben und im Prinzip auch „,keine Amerikaner“ zu kennen; Frau H betont immer wieder, dass sie sich ,nicht so wie andere um die Politik“ kümmere und im Vergleich zu anderen „Experten“ eigentlich kein zuverlässiges Urteil abgeben könne.

Im Fall von Frau H kombiniert sich diese Ambivalenz im Verlauf des Interviews mit einer Fragmentierung des antiamerikanischen Sprachgebrauchs. An die Stelle der vorsichtig tastenden, ambivalenten antiamerikanischen Rede, die einen Großteil des Interviewgespräches bestimmt, tritt in dessen zweiter Hälfte eine vergleichsweise drastische ethnozentrische Rhetorik, mit der eine nationalistische WirGruppenkonstruktion gegen die ,Wurzellosigkeit‘ und ethnische Heterogenität ,der Amerikaner' abgegrenzt wird. Diese Sprechweise, die mit den in Kapitel 7.2 und 7.4 beschriebenen vergleichbar ist, steht in starkem Kontrast zur vorherigen, ambivalenten Gegenüberstellung von ,protzigem Amerika' und ,kleinen Normalbürgern '. Dieser Konstrast wird Frau H im unmittelbaren Anschluss an ihre nationalistische Konstruktion auch selbst bewusst: Noch deutlicher als zuvor stellt sie ihre eigenen Aussagen in Zweifel und bittet den Interviewer darum, nicht auf die geäußerten Positionen festgelegt zu werden. Gleichzeitig versucht die Teilnehmerin, wieder zu ihrer vorherigen ,kleinen“ Identitätskonstruktion zurückzufinden. Dass dieses plötzliche Auftreten antiamerikanischer Sprechweisen die Teilnehmerin ebenso zu überraschen scheint, wie ihr Gegenüber, wurde mit der Metapher des Unheimlichen bezeichnet: Mit schlafwandlerischer Sicherheit reproduziert Frau H eine Identitätskonstruktion, die ihr schon im nächsten Moment fremd und moralisch problematisch erscheint. Die antiamerikanischen Argumentationsmuster stellen hier ebenso sehr eine etablierte Routine, wie einen irritierenden ,Ausrutscher' dar.

Wenngleich bei Frau H antiamerikanische Sprechweisen einen besonders ambivalenten und fragmentierten Ausdruck finden, so lassen sie sich doch hinsichtlich 
ihrer Funktionalität relativ deutlich dem Kontext nationaler Identifikation zuordnen. Genau diese Zuordnung wird bei Herrn I unscharf, was oben als Verschiebung bzw. Unschärfe des Funktionskontextes bezeichnet wurde. Zwar fungieren ,die Amerikaner' auch hier als Mittel zur Konturierung und relativen Aufwertung der Eigengruppe, jedoch ist diese dezidiert nicht national und nicht ethnisch verfasst: Im Zentrum von Herrn Is Wir-Gruppenkonstruktion steht die Identifikation mit ,seinem“ Großstadtviertel, das ihm ,,alles!“ bedeutet. Diese Stadtteilidentität wird aber in einem positiven Sinne als ethnisch heterogene und hybride Gruppe beschrieben und explizit gegen ,ganz Deutschland“ abgegrenzt, welches man „vergessen“ könne.

Angesichts der explizit multikulturalistischen und antirassistischen Selbstverortung Herrn Is erscheint es einerseits plausibel, dass er als Fremdgruppe ,die Amerikaner" wählt, da diese aufgrund ihres zugeschriebenen nicht-ethnischen Charakters sich als ,antirassistisches' Feindbild besonders eignen. Der Unterschied zu den Rhetoriken von bspw. Herrn C oder Herrn A (vgl. Kap. 7.2 und 7.4) besteht aber darin, dass sich Herr I explizit von ethno-nationaler Identifikation abgrenzt. Diese Verschiebung der Wir-Gruppenkonstruktion von ethno-Nationalismus zu Lokalpatriotismus macht es schwer zu beurteilen, inwiefern Herrn Is Rhetorik überhaupt noch Gegenstand der Vorurteilskritik sein kann. Denn einerseits reproduziert er in Bezug auf ,die Amerikaner' klassische Bilder und Argumentationsmuster eines fremdenfeindlichen Integrationsdiskurses: ,Amerikaner' sind integrationsunwillig, lernen kein Deutsch, gehen keiner geregelten Arbeit nach, leben aber in mysteriösem Reichtum, etc. Andererseits bezieht sich Herr I damit auf eine Gruppe, die üblicherweise in Deutschland nicht zum Opfer ethnozentrischer Exklusion und Diskriminierung wird, und es kann zumindest als fraglich gelten, ob seine Rede als effektiver Bestandteil einer diskriminierenden Praxis gegen ,Amerikaner' aufgefasst werden sollte. Dies gilt umso mehr, als Herr I selbst mehrfach betont, er verstehe sich ,mit denen trotzdem gut“.

Eine weitere mögliche Lesart von Herrn Is Rede besteht darin, seine Identifikation mit seinem Viertel als verschobenen Nationalismus und sein Ablehnung, der Amerikaner' als verschobene Fremdenfeindlichkeit zu deuten. Seine Anfeindung ,der Amerikaner', die er auffälliger weise als Gruppe ausschließlich schwarzer Menschen beschreibt, wäre demnach also als verschobener bzw. (auch vor sich selbst) maskierter Rassismus zu lesen.

Die hier vorgelegte Deutung spricht keiner der geschilderten Möglichkeiten eine klare Präferenz zu. Gerade die Tatsache aber, dass keine solche Entscheidung eindeutig gefällt werden kann, scheint mir bezeichnend für Herrn Is Sprechen zu sein. Weder möchte ich seine Rhetorik in eine Reihe mit den ethnozentrischen Sprechweisen Herrn As oder Es stellen, noch können die ethnozentrischen Züge seiner Fremdgruppenkonstruktion und die verhärtete Glorifizierung seiner lokalen Wir-Gruppe ignoriert werden. Inwiefern sich mit diesen Differenzkonstruktionen 
eine diskriminierende Praxis über den Erhebungskontext hinaus verbindet bzw. ob diese als Camouflage einer rassistischen Handlungsorientierung aufzufassen sind, ist anhand des Interviewmaterials jedenfalls nicht klar zu entscheiden.

Somit kann als zentrales Ergebnis dieses Teilkapitels festgehalten werden, dass antiamerikanische Vorurteile, wie Vorurteile generell, nicht als individuelle psychische Dispositionen oder als geschlossene weltanschauliche Systeme auftreten zumindest nicht nur. Vielmehr scheinen sie Streckenweise eine ,geisterhafte 'Form anzunehmen, so dass ihr Auftreten nicht immer klar einer Kategorie ,Antiamerikanismus', ,Antisemitismus', ,Rassismus' etc. zugeordnet werden kann - was allerdings nicht bedeutet, dass sie als irrelevant aus dem Gegenstandsbereich herausfallen. Amerikastereotype und entsprechende antiamerikanische Argumentationsmuster sind als Diskursfragmente zunächst relativ frei verfügbar. Wozu sie in welchem Kontext eingesetzt werden, ist durch ihren Inhalt und ihre Struktur noch nicht unbedingt entschieden. Und selbst wenn sie, wie etwa von Frau H, in sehr konventionellen rhetorischen Bahnen gebraucht werden, macht dies die Sprecherin noch nicht unbedingt zur ,Antiamerikanerin“. Der auch für sie selbst unheimliche Charakter ihres Sprechens verdeutlicht vielmehr die Unzulänglichkeit eines solcherart personalisierenden Vorurteilsbegriffes. 


\subsection{Zusammenfassung UND DisKussion DER QUALITATIV-EMPIRISCHEN ANALYSEN}

Drei zentrale Fragestellungen haben die hier unternommenen empirischen Analysen angeleitet:

1. Welche Funktionen erfüllen antiamerikanische Sprechakte als Ungleichheitssemantiken?

2. Welcher rhetorische Zusammenhang besteht zwischen Antiamerikanismus und anderen Vorurteilsformen?

3. Wie flexibel und kontextabhängig ist antiamerikanisches Sprechen bzw. lässt es sich als weltanschauliches Phänomen beschreiben?

Die Thesen, die hinsichtlich dieser Fragestellung generiert wurden, sollen nun noch einmal zusammengefasst werden. Hierzu beginne ich mit einer kurzen Rekapitulation der qualitativ-empirischen Ergebnisse, die in den letzten vier Abschnitten dargestellt wurden. Nationalistische, erinnerungspolitische, antisemitische und ethnozentrische Antiamerikanismen werden dabei jeweils überblicksartig zusammengefasst.

Die verschiedenen Realisierungen antiamerikanischer Rhetorik werden im Anschluss daran hinsichtlich der begrifflichen Struktur des performativen Antiamerikanismuskonzeptes betrachtet. Ausgehend vom Begriffsmodell der Familienähnlichkeit wird gezeigt, dass sich die rekonstruierten Rhetoriken als Mitglieder einer Familie antiamerikanischer Sprechweisen ausweisen lassen. Obwohl sich kein Merkmal findet, dass allen darunter befassten Fällen gemeinsam ist, können die verschiedenen rekonstruierten Sprechakte anhand ihrer funktionalen und semantischen Ähnlichkeiten unter einem Begriff zusammengefasst werden. Dieses Antiamerikanismuskonzept zeigt die systematische Ambiguität des Antiamerikanismus, d.h. es veranschaulicht sowohl die Gemeinsamkeiten und Überschneidungen antiamerikanischer Sprechakte als auch deren Kontextabhängigkeit und Flexibilität. Abschließend wird auf jede der drei obengenannten Forschungsfragen eine konzise Antwort formuliert.

\subsection{1 Überblicksdarstellung der Interviewanalysen}

Die folgende Darstellung der qualitativen Ergebnisse dient der Rekapitulation und Zusammenschau der rekonstruierten Antiamerikanismen. Sie erfolgt gegliedert nach Funktionskontexten, indem für jeden Fall zunächst stichwortartig die beobachteten Amerikabilder und deren funktionaler Gebrauch zusammengefasst werden. Anschließend wird die rhetorische Wirkung antiamerikanischen Sprechens für die 
jeweiligen Fallrekonstruktionen überblicksartig dargestellt. Dieses Teilkapitel hat damit vor allem zusammenfassenden Charakter und ist insbesondere dazu geeignet, sich die Ergebnisse der Interviewanalysen in komprimierter Form vor Augen zu führen. Eine stärker synthetisierende Darstellung der Ergebnisse folgt in den Abschnitten 7.6.2 bis 7.6.5.

\subsubsection{Antiamerikanismus und die Konturierung bzw. Stabilisierung nationaler Identität}

\section{- Herr C}

○ Amerikabilder: Arroganz und Überheblichkeit, Einmischung und Weltpolizei, Soziale Ungleichheit, Manipulation öffentlicher Diskurse, Kulturlosigkeit, Amerikanisierung

○ Funktion: Externalisierung von Missständen in der Wir-Gruppe (Armut, Kulturverfall, irrationaler Konsum), Bearbeitung des innerdeutschen Ost-West Konflikts

- Herr F

○ Amerikabilder: Wirtschaftliche Inkompetenz, falsches Wirtschaftssystem, rechtliche Unsicherheit, mangelnde Solidarität, Oberflächlichkeit, Heterogenität, Kulturlosigkeit, Amerikanisierung

○ Funktion: Konturierung und relative Aufwertung der Wir-Gruppe, Stabilisierung der ethno-nationalistischen Weltsicht durch amerikanische Figur des Dritten

Im Funktionskontext nationaler Identifikation konnten zwei Funktionen antiamerikanischer Rhetorik rekonstruiert werden. So dienen Bilder amerikanischer Kulturlosigkeit, sozialer Ungleichheit und Armut, mangelnder Solidarität, etc. einerseits dazu, die Werte und Tugenden der Eigengruppe hervorzuheben bzw. deren negative Anteile als ,amerikanischen Einfluss' zu externalisieren. Diese Funktionen konnten in einer Vielzahl der analysierten Fälle beobachtet werden (vgl. auch Kap. 7.4 zu Ethnozentrismus). Bei Herrn F tritt zusätzlich eine grundlegende Stabilisierungsfunktion hinzu. Bilder eines ethnisch und kulturell heterogenen aber international einflussreichen Amerika werden hier zu einer antiamerikanischen „Figur des Dritten“ (Holz 2010, S. 296; vgl. Kap. 4.6.1) zusammengefügt, die als stabilisierendes Gegenbild nicht nur der deutschen Nationalidentität, sondern der ethno-nationalen Ordnung insgesamt funktioniert. Amerika repräsentiert hier das Andere dieser Ordnung in Form einer Nation, die keine ethnisch homogene ,Wurzel ' aufweist, und dennoch Nation bleibt. Diese aus ethnozentrisch-nationalistischer Perspektive widersprüchliche Konstruktion Amerikas erfüllt die ideologische Funktion, die Kontingenz und mögliche Negation der ethno-nationalen Ordnung latent zu thematisieren und gleichzeitig deren Geltung zu bekräftigen. 
Eine funktional ähnliche ideologische Konstruktion findet sich bei Herrn C: Hier wird das Motiv der ,Amerikanisierung', d.h. eines schädlichen Einflusses amerikanischer Kultur, Wirtschaft und Politik, dazu genutzt, den innerdeutschen Konflikt zwischen Westdeutschland und der ehemaligen DDR zu thematisieren und zugleich als Hindernis einer, gesamtdeutschen“ Nationalidentität zu entschärfen. Aus der Perspektive einer ostdeutschen Subgruppe stellt Herr C , die Wessis ‘ einerseits als überhebliches und ignorantes Gegenüber der , authentischeren“ Ostdeutschen dar. Da er diese Spaltung zugleich aber mit der ,Amerikanisierung ' Westdeutschlands begründet, wird die Ursache des Konflikts auf eine externe Einflussgröße verschoben und die Deutsche Wir-Gruppe somit zugleich wieder versöhnt. Gegen ,Amerika' kann dann in diversen anderen Interviewstellen auch diese ,gesamtdeutsche“ Wir-Gruppe konturiert und aufgewertet werden. Diese Konstruktion dient in ähnlicher Weise, wie bei Herrn F, der Bearbeitung einer Identitätsbedrohung in einem ,ideologisch abgesicherten“ Modus, der eine grundlegende Infragestellung der nationalen Identifikation systematisch vermeidet.

\subsubsection{Erinnerungspolitik, Schuldabwehr und Antisemitismus}

- Herr B

- Amerikabilder: Einmischung und Weltpolizei, Manipulation öffentlicher Diskurse, Unrecht gegen Ureinwohner

- Funktion: Normalisierung der nationalen Wir-Gruppe, latente Relativierung des Holocaust

\section{- Herr D}

- Amerikabilder: Rassismus in den USA, Kriegsverbrechen Hiroshima

○ Funktion: Explizite Normalisierung des Holocaust

- Frau K

- Amerikabilder: Amerikaner sind gewalttätig, Einmischung und Provokation von Kriegen, Krieg als Geschäft, Manipulation der öffentlichen Meinung, USA Instrument jüdischer Herrschaft

- Funktion: Antiamerikanisch-antizionistischer Antisemitismus, Erklärung weltweiter Konflikte und Krisen durch amerikanischen bzw. israelischen Einfluss

Die hier behandelten Fälle stehen im Kontext von Antisemitismus und Schuldabwehr, wobei allein hinsichtlich Frau K von antisemitischer Rhetorik im engeren Sinne gesprochen werden kann. Frau K reproduziert einen ,klassischen“, weltanschaulichen Antisemitismus, in dem amerikanische Politik als Begründung für weltweite Konflikte und Krisen fungiert, deren zerstörerische Kraft wiederum durch den Einfluss ,der Juden“ auf die USA erklärt wird. Dies geschieht unter einer oberflächlichen antizionistischen Camouflage (vgl. Holz 2005, S. 82 ff.), gemäß der niemals von Juden, sondern stets von „Israelis“ die Rede ist. 
Die übrigen präsentierten Fälle können nicht als antisemitisch bezeichnet werden, zeigen jedoch deutliche funktionale und semantische Analogien mit sekundär antisemitischen Argumentationen. Insbesondere Herrn Bs Rhetorik kann als eine antiamerikanische Variante der Schuldabwehr aufgefasst werden, in der Bilder einer amerikanischen ,Weltpolizei“ sowie amerikanischer Medienmanipulation der Opferinszenierung der deutschen Wir-Gruppe dienen. Stereotype eines Genozids an amerikanischen Ureinwohnern werden zur latenten Normalisierung der nationalsozialistischen Judenvernichtung gebraucht. Während bei Herrn B antiamerikanische Rhetorik also kommunikationslatent funktioniert, findet sich bei Herrn D eine explizite Relativierung des nationalsozialistischen Terrors. Auch hier werden Bilder amerikanischer Kriegsverbrechen sowie eines amerikanischen Rassismus gebraucht, um den Holocaust als Hindernis der nationalen Identifikation aus dem Weg zu räumen. Im Gegensatz zu Herrn B geschieht dies allerdings in expliziter Aufrechnung , amerikanischer Taten' gegen deutsche.

Es lässt sich hinsichtlich des Verhältnisses von Antiamerikanismus und Antisemitismus also eine Vielfalt möglicher Verknüpfungen erkennen: Insofern Antisemitismus nach 1945 (zumindest in Deutschland) maßgeblich durch eine Rhetorik der Rechtfertigung geprägt ist, lässt sich eine große funktionale Nähe antiamerikanischer und antisemitischer Sprechweisen ausmachen. Erstere dienen in zwei der hier beschriebenen Fälle einer abschließenden Versöhnung Deutschlands mit seinem nationalsozialistischen Erbe, wobei die Deutschen zum Opfer ,amerikanischer Manipulation“ stilisiert werden. Gegenüber einer sekundär-antisemitischen TäterOpfer Umkehr bietet diese Variante den ,Vorteil', dass nicht antisemitisch gesprochen werden muss, um deutschen Nationalismus zu rehabilitieren.

\subsubsection{Ethnozentrismus und Rassismus}

- Herr A

- Amerikabilder: Rassismus in den USA, Kulturlosigkeit

- Funktion: Latente Abwehr eines Rassismusvorwurfs, ethnozentrische WirGruppenkonstruktion unter egalitärem Vorzeichen, Konturierung und relative Aufwertung der Wir-Gruppe

- Herr E

- Amerikabilder: Rassismus in den USA, Kulturlosigkeit, Oberflächlichkeit, mangelnde Solidarität, wirtschaftliche Inkompetenz, mangelnde Bildung

○ Funktion: Konturierung und relative Aufwertung der Wir-Gruppe, explizite Abwehr eines Rassismusvorwurfs

- Herr C

- Amerikabilder: Rassismus in den USA, Kulturlosigkeit

○ Funktion: Latente Abwehr eines Rassismusvorwurfs, ethnozentrische WirGruppenkonstruktion unter egalitärem Vorzeichen 


\section{- Herr D}

- Amerikabilder: Rassismus in den USA

○ Funktion: Explizite Abwehr eines Rassismusvorwurfs

In allen hier präsentierten Beispielen wird der stereotype Verweis auf amerikanischen Rassismus dazu gebraucht, einen eigenen Rassismus bzw. Ethnozentrismus entweder latent oder explizit zu rechtfertigen und so die eigene Konformität mit egalitären Normen zu demonstrieren. In drei von vier Fällen geht dies einher mit dem Gebrauch von Bildern einer ,Kultur- und Wurzellosigkeit ' der USA, die zur Konturierung und Aufwertung der nationalen Eigengruppe genutzt werden (vgl. Kap. 7.2 zu nationaler Identität). Diese kulturalistische Semantik kann aber zugleich als zusätzliche Unterstützung der antiamerikanischen Rassismus-Abwehr verstanden werden: Ausgehend von der Annahme, dass die Rede von amerikanischer Kulturlosigkeit Ausdruck einer ethnopluralistischen, „Herder'sche[n] Weltsicht“ (Wimmer 2008, S. 60) ist, erscheinen ,die USA“ besonders geeignet, die Rassismus-Problematik zu externalisieren. Denn der ,amerikanische Rassismus' entsteht diesen Konstruktionen zufolge dadurch, dass die ,natürliche" ethno-nationale Ordnung außer Kraft gesetzt ist. Dass ,Amerika' keine Kultur hat, meint dann eigentlich, dass ,die Amerikaner' keine ,Blutsgemeinschaft" bilden. ,Rassismus' ist in dieser Perspektive der Konflikt, der entsteht, wenn in einem nationalen Raum keine ethnisch-essentialistisch begründbare Hegemonie existiert. Gegen ,amerikanischen Rassismus ‘ zu protestieren, wird somit zu einer Bekräftigung rigider ethnonationalistischer Grenzziehungen.

Amerikastereotype können also nicht nur unmittelbar als negative Vergleichsfolie für kulturalistisch-ethnozentrische Identitätskonstruktionen gebraucht werden, sondern sie dienen zugleich dazu, ethnozentrische und rassistische Handlungsorientierungen präventiv gegen antirassistische Sanktionen zu verteidigen bzw. ideologisch mit egalitären Normen in Einklang zu bringen.

\subsubsection{Ambivalenter bzw. fragmentierter Antiamerikanismus und verschobene Funktionskontexte}

\section{- Frau H}

- Amerikabilder: Einmischung und Weltpolizei, Arroganz und Überheblichkeit, Amerikanisierung, falsches Wirtschaftssystem, wirtschaftliche Inkompetenz, Kulturlosigkeit, Heterogenität

○ Rhetorische Funktion: Fragmentierte und ambivalente ethnozentrische Kontu-

- Herr I rierung und Aufwertung der nationalen Wir-Gruppe

- Amerikabilder: Arroganz und Überheblichkeit, Oberflächlichkeit, mangelnde Integration, Aggressivität und Gewalt 
○ Rhetorische Funktion: Ambivalente Konturierung und Aufwertung der lokalpatriotischen Wir-Gruppe

In den vorausgegangenen Analysen konnte hinsichtlich der jeweils aufgezeigten antiamerikanischen Sprechweisen sowie deren funktionalen Kontexten eine relativ große Konsistenz über die jeweiligen Fälle hinweg gezeigt werden. Wenngleich auch dort die Auswertungseinheit grundsätzlich der Sprechakt bzw. eine jeweilige rhetorische Operation ist, und nicht die Interviewteilnehmenden als Personen, konnten doch an den Stellen antiamerikanischer Rhetorik innerhalb eines jeweiligen Falles relativ gleichbleibende Effekte und weltanschauliche Rahmungen festgestellt werden. Um diesen Befund zu kontrastieren und gewissermaßen auch die Randbezirke des hier entwickelten Antiamerikanismusbegriffes zu beleuchten, wurden zusätzlich solche Fälle analysiert, in denen antiamerikanische Rhetorik eine vergleichsweise hohe Inkonsistenz bzw. Ambivalenz aufweist. Hierbei wurden drei Dimensionen dieses Phänomens herausgearbeitet: Ambivalenz, Fragmentierung und eine Verschiebung von Funktionskontexten. So finden sich in beiden analysierten Fällen stark ambivalente Gebräuche antiamerikanischer Muster: Frau $\mathrm{H}$ und Herr I sind sich des (potentiell) vorurteiligen Charakters ihres Sprechens über ,Amerika' durchaus bewusst und betonen mehrfach, nicht als antiamerikanisch gelten zu wollen. Sie tun dies jedoch - im Gegensatz zur Rassismusabwehr der Fälle in Kapitel 7.4 - ohne über eine rhetorische Lösung für dieses Problem zu verfügen. Diese Ambivalenz steigert sich im Fall von Frau H zu einer Fragmentierung antiamerikanischen Sprechens. Während sie sich den größten Teil des Interviews äußerst vorsichtig gegen das ,protzige Amerika“ abgrenzt und sich selbst dabei als bescheidene aber machtlose ,Normalbürgerin“ identifiziert, steigert sich ihre Rhetorik zur Mitte des Gespräches zu einer antiamerikanischen Aufwertung der nun ethnonationalistisch konstruierten Wir-Gruppe. Unmittelbar im Anschluss an diesen Ausbruch zieht sich Frau $\mathrm{H}$ allerdings sogleich wieder auf ihre ambivalente Identifikation als ,kleine Normalbürgerin“ zurück, und beteuert abermals nachdrücklich, nicht als antiamerikanisch wahrgenommen werden zu wollen.

Im Fall von Herrn I lässt sich zwar keine vergleichbare Fragmentierung, aber eine Verschiebung des Funktionskontextes beobachten: Während in allen zuvor besprochenen Fällen nationale und ethnische Identitätskonstruktionen im Zentrum des antiamerikanischen Sprechens standen, dreht sich bei Herrn I alles um eine lokalpatriotische Stadtteilidentität. ,Sein Viertel' bedeutet ihm ,alles‘, und er konturiert diese Wir-Gruppe mittels einer , amerikanischen' Fremdgruppenkonstruktion. Herr I grenzt seine Wir-Gruppe zugleich aber auch explizit gegen deutsch-nationale und ethnozentrische Identitätskonstruktionen ab. Einen Grenzfall der Antiamerikanismuskritik stellt dies deshalb dar, weil hier zwar strukturell rhetorische Muster ethnozentrischer Exklusion reproduziert werden, zugleich aber ungeklärt bleibt, inwie- 
fern deren Performanz als Bestandteil einer diskriminierenden Praxis aufgefasst werden kann.

\subsubsection{Eine Familie antiamerikanischer Sprechakte: Einheit und Flexibilität des Antiamerikanismusbegriffes}

In der letzten der vorigen Kurzdarstellungen wurde die Fragmentiertheit und Ambivalenz antiamerikanischen Sprechens sowie die Flexibilität von dessen Funktionskontexten aufgezeigt. Aber auch diesseits der verschwimmenden Ränder eines performativen Antiamerikanismusbegriffes, d.h. innerhalb der Familie von Sprechweisen, die in Abschnitt 7.2 bis 7.4 klar als antiamerikanisch ausgewiesen wurden, lässt sich eine große Flexibilität von Amerikastereotypen und deren Gebrauch feststellen. Diese Flexibilität sowohl der Amerikabilder als auch der rhetorischen Funktionen wird in Tabelle 14 überblicksartig dargestellt.

Was anhand dieser Darstellung zunächst anschaulich wird, ist die funktionale Flexibilität der Amerika-Semantiken. Neun von zwanzig beobachteten Amerikabildern werden für verschiedene Funktionen gebraucht (in Tabelle 14 grau unterlegt). Dies veranschaulicht die eingangs formulierte These, dass der performative Gehalt antiamerikanischer Sprechweisen nicht aus dem lexikalisch-semantischen Gehalt der gebrauchten Stereotype abgeleitet werden kann.

Zugleich aber wird in der tabellarischen Darstellung erkennbar, dass keineswegs jedes beliebige Amerikabild in jeder Funktion genutzt wird. Betrachtet man das Verhältnis von Semantik und rhetorischer Funktion von der Seite der Funktionen her, d.h. in Tabelle 14: spaltenweise, treten die spezifischen Stereotypen-Komplexe deutlicher hervor: So werden zur Externalisierung als störend empfundener Aspekte der Eigengruppe als , amerikanische Einflüsse (Herr C) oder zur schuldabwehrenden Täter-Opfer Umkehr (Herr B) insbesondere die Motive der ,Amerikanisierung ‘ oder der ,amerikanischen Medienmanipulation“ verwendet. Zur Konturierung und relativen Aufwertung der Eigengruppe oder der Abwehr von Rassismusvorwürfen scheinen hingegen andere Amerikabilder besonders geeignet: ,Rassismus in den USA‘, ,Kulturlosigkeit‘, ,Heterogenität‘ der USA, etc. 
Tabelle 14: Kombinationen von Amerikabildern und rhetorischen Funktionen im antiamerikanischen Sprechen (Datengrundlage sind die Fälle der Detailanalysen ohne Herr I und Frau $H, n=7$ )

\begin{tabular}{|c|c|c|c|c|c|c|c|c|c|}
\hline 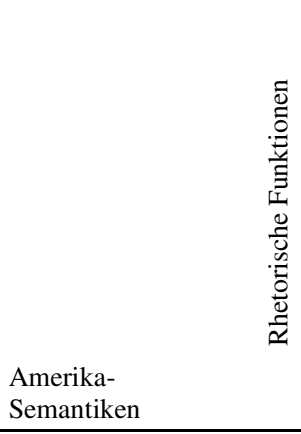 & 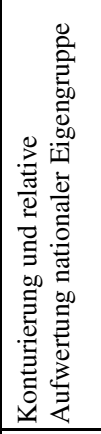 & 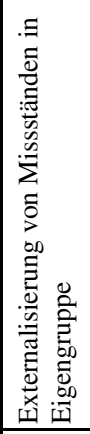 & 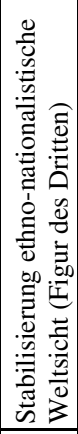 & 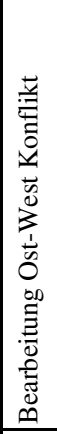 & 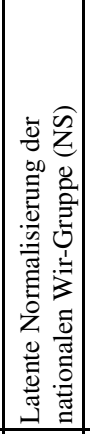 & 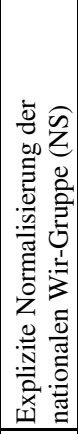 & 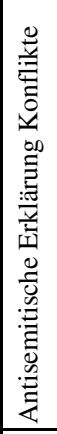 & 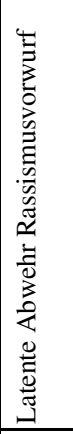 & 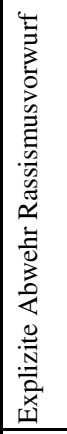 \\
\hline $\begin{array}{l}\text { Arroganz und } \\
\text { Überheblichkeit }\end{array}$ & $\mathrm{C}$ & & & & & & & & \\
\hline $\begin{array}{l}\text { Einmischung und Welt- } \\
\text { polizei }\end{array}$ & & $\mathrm{C}$ & & & B & & K & & \\
\hline Soziale Ungleichheit & $\mathrm{C}$ & $\mathrm{C}$ & & & & & & & \\
\hline \begin{tabular}{|l} 
Manipulation \\
öff. Diskurse
\end{tabular} & & $\mathrm{C}$ & & $\mathrm{C}$ & B & & K & & \\
\hline Amerikanisierung & & $\mathrm{C}$ & $\mathrm{F}$ & $\mathrm{C}$ & & & & & \\
\hline $\begin{array}{l}\text { Wirtschaftliche } \\
\text { Inkompetenz }\end{array}$ & $F, E$ & & & & & & & & \\
\hline \begin{tabular}{|l|} 
falsches \\
Wirtschaftssystem
\end{tabular} & $F$ & & & & & & & & \\
\hline $\begin{array}{l}\text { Rechtliche } \\
\text { Unsicherheit }\end{array}$ & $F$ & & & & & & & & \\
\hline \begin{tabular}{|l|} 
Mangelnde \\
Solidarität \\
\end{tabular} & F, E, D & & & & & & & & \\
\hline Oberflächlichkeit & F, E, D & & & & & & & & \\
\hline Heterogenität & $\mathrm{C}, \mathrm{F}$ & & $\mathrm{F}$ & & & & & & \\
\hline Kulturlosigkeit & $\begin{array}{l}\mathrm{C}, \mathrm{F}, \mathrm{E}, \\
\mathrm{A}\end{array}$ & & $F$ & & & & & $\mathrm{C}, \mathrm{A}$ & \\
\hline \begin{tabular}{|l|} 
Unrecht gegen \\
Ureinwohner
\end{tabular} & & & & & B & & & & \\
\hline \begin{tabular}{|l} 
Rassismus \\
in den USA
\end{tabular} & & & & & & $\mathrm{D}$ & & $\mathrm{C}, \mathrm{A}$ & E, D \\
\hline Amerikaner gewalttätig & $\mathrm{D}$ & & & & & & $\mathrm{K}$ & & \\
\hline Anstiftung Kriege & $E$ & & & & & & $\mathrm{~K}$ & & \\
\hline $\begin{array}{l}\text { Mangelnde } \\
\text { Sittlichkeit }\end{array}$ & $\mathrm{D}, \mathrm{C}$ & & & & & & & & \\
\hline Mangelnde Bildung & $\mathrm{E}$ & & & & & & & & \\
\hline Atombombe & & & & & & $\mathrm{D}$ & & & \\
\hline USA und Israel & & & & & & & K & & \\
\hline
\end{tabular}


Und nicht nur von Seiten der Semantik, auch von der Seite der Funktionen antiamerikanischen Sprechens her betrachtet, ist die Zuordnung nicht eindeutig; d.h. es kann dieselbe rhetorische Funktion über verschiedene Semantiken realisiert werden. Dies zeigt sich am deutlichsten anhand der Spalte ,Konturierung und relative Aufwertung der Eigengruppe‘.

In der Rede von Herrn $\mathrm{C}$ werden hierzu etwa Bilder einer amerikanischen ,Arroganz und Überheblichkeit', ,sozialen Ungleichheit', ,Heterogenität' und ,Kulturlosigkeit' gebraucht, während Herr D auf die Aspekte amerikanischer ,Gewalttätigkeit' und ,Sittlichkeit' rekurriert. Empirische Belege für diese semantische Flexibilität antiamerikanischer Rhetorik beschränken sich in den hier dargestellten Analysen allerdings auf die Funktion der ,Konturierung und relativen Aufwertung ' und sind für die übrigen Funktionen nicht nachzuweisen. ${ }^{1}$ Von einer semantischen Spezifizität dieser übrigen Funktionen im strikten Sinne auszugehen (d.h. dass z.B. eine explizite Normalisierung des NS exklusiv nur mit den Motiven ,Rassismus in den USA ‘ und ,Hiroshima“ realisiert werden kann) scheint dennoch eine höchst riskante Schlussfolgerung. So ist zumindest im Gedankenexperiment plausibel, dass in anderen Redekontexten bspw. die Funktionen einer ,Externalisierung von Missständen' oder einer ,latenten Normalisierung des NS' auch mit anderen Amerikastereotypen realisiert werden könnten.

Es ist also trotz der teilweise beobachteten semantischen und funktionalen Spezifizität insgesamt von einer gewissen „Austauschbarkeit“ (Baethge et al. 2010, 377; vgl. auch Kap. 2.3.3) antiamerikanischer Sprechweisen auszugehen. Diese Flexibilität ist ein entscheidender Grund dafür, gegenüber allgemeinen Definitionen ,des Antiamerikanismus' skeptisch zu sein (vgl. Kap. 2.4 und 3.3). Es scheint weder auf funktionaler noch auf semantischer Ebene ein allgemeines Kriterium verfügbar, an dem man antiamerikanisches Sprechen definitiv festmachen könnte. Zwar lassen sich Funktionskontexte und Stereotypensemantiken antiamerikanischen Sprechens empirisch eingrenzen, wie oben geschehen. Aber aufgrund der rhetorischen Flexibilität innerhalb der so gewonnenen Kategorien können antiamerikanische Akte durch diese nicht abschließend definiert werden. Oder genauer: Man kann zwar antiamerikanischen Sprechakten mit einer Definition exakte Grenzen geben, z.B. als die Disjunktion aller oben genannten Funktionen und Semantiken. Damit würde man aber (1) mögliche andere relevante Formen sowie die flexible Realisierung antiamerikanischer Rede voreilig aus dem Antiamerikanismusbegriff ausschließen. Und man bliebe (2) - mit Wittgenstein gesprochen - ,die Definition der Exaktheit schuldig“ (Wittgenstein 2006, S. 279), d.h. man müsste Gründe für

1 Dies ist auch mangelnden Möglichkeiten des Fallvergleichs bei einem Großteil der beobachteten Funktionen geschuldet: Bei 7 von 9 rekonstruierten Funktionen liegt die Untersuchungseinheit effektiv auf Fallebene, da diese im gesammelten Material nur an einem Fall beobachtet wurden. 
die Entscheidung zu genau jener definitorischen Grenzziehung anführen, die sich in der untersuchten Praxis antiamerikanischen Sprechens selbst nicht finden lassen. ${ }^{2}$ Ich ziehe es daher vor, die oben entwickelte Sammlung antiamerikanischer Funktionen und Semantiken als einen heuristischen Rahmen aufzufassen, innerhalb dessen Sprechakte mit guten gesellschaftstheoretischen Gründen als antiamerikanisch interpretiert werden können.

Die in diesem interpretativen Rahmen realisierte Empirie liefert eine Darstellung zumindest eines Teils der Heterogenität antiamerikanischen Sprechens, die in der standardisierten Empirie unbeobachtet blieb (vgl. Kap. 5.3). In den Interviewanalysen werden die semantische Bandbreite und funktionale Einbettung der rhetorischen Handlungsmuster sichtbar, die das Auftreten von Antiamerikanismus in Deutschland heute kennzeichnen, und die sich mit einer nominalen bzw. operationalen Definition allein nur unzureichend erfassen lassen.

In Kapitel 3.4 der vorliegenden Arbeit wurde als Alternative zu einer nominaldefinitorischen Begriffsbildung das Modell der Familienähnlichkeit vorgeschlagen. Dessen Logik besagt, dass, wenngleich der Sinngehalt eines Begriffes nicht über universelle Merkmale unmittelbar definiert, er doch durch Ähnlichkeiten und Überschneidungen zwischen den Begriffsanwendungen mittelbar bestimmt werden kann. Anhand dieses Modells kann nun gezeigt werden, inwieweit die in den vorausgegangenen Analysen rekonstruierten Sprechweisen als Mitglieder einer Familie antiamerikanischer Sprechakte gefasst werden können, obwohl viele von ihnen keine unmittelbare Übereinstimmung in Semantik oder Funktion aufweisen. ${ }^{3}$

Diese Begriffsstruktur lässt sich anhand von Tabelle 14 nachvollziehen: Alle dort aufgeführten Sprechweisen (d.h. Komplexe von Semantik und Funktion) sind entweder über eine Ähnlichkeit der rhetorischen Funktion oder der gebrauchten Amerika-Semantik mit mindestens einer anderen aufgeführten Sprechweise verbunden. So wird beispielsweise die Funktion der ,Stabilisierung der ethnonationalistischen Weltsicht' bei Herrn F über die Amerikabilder der ,Amerikanisierung', ,Kulturlosigkeit' und ,Heterogenität' realisiert (Tabelle 14: dritte Spalte von

2 Kandidaten für solche Gründe wären etwa forschungspraktische Erwägungen, wie die Handhabbarkeit des Begriffes innerhalb eines bestimmten Forschungsdesigns (z.B. in standardisierter Empirie), oder die theoretische Eingrenzung ex ante auf einen bestimmten Gegenstandsbereich, z.B. Antiamerikanismus und Schuldabwehr.

3 Streng genommen müssen auch diejenigen Sprechweisen, die in Funktion und Semantik unmittelbar übereinstimmen, im Sinne einer Ähnlichkeitsrelation begriffen werden (bspw. die latente Abwehr von Rassismusvorwürfen durch Herrn C und Herrn A; Tabelle 14, zweite Spalte von rechts), da dieselben Merkmale in ihnen wiederum unterschiedlich realisiert werden. Anders gesagt: Die Übereinstimmung der Merkmale zweier verglichener Handlungen ist immer Ergebnis sowohl der Eigenschaften des Verglichenen, wie auch der Tätigkeit des Vergleichens selbst (vgl. Kap. 3.4). 
links). Durch semantische Überschneidungen in den Stereotypen der ,Kulturlosigkeit“ und ,Heterogenität‘ ist diese rhetorische Funktion verknüpft mit denen der ,Konturierung und Aufwertung der Wir-Gruppe“ sowie mit der , latenten Abwehr von Rassismusvorwürfen" bei diversen anderen Interviewteilnehmenden. Ebenso sind die Funktionen einer, latenten Normalisierung ' nationaler Identität bei Herrn B und einer , antiamerikanisch-antisemitischen Welterklärung' bei Frau K über die Stereotype einer , amerikanischen Weltpolizei` sowie der ,Manipulation öffentlicher Diskurse" miteinander und mit der Externalisierungsfunktion bei Herrn $\mathrm{C}$ verknüpft.

Trotz der gezeigten Verknüpfungen innerhalb der Familie antiamerikanischer Sprechakte wäre es aber zumindest ungenau, Antiamerikanismus bspw. als ,Form der Schuldabwehr' oder ,Stabilisierung einer nationalistischen Weltsicht ${ }^{*}$ zu definieren, da somit gerade die gezeigte Flexibilität, Fragmentiertheit und Kontextabhängigkeit antiamerikanischen Sprechens wieder aus dem Blick geriete. Es gibt kein empirisch gehaltvolles Kriterium oder Set von Kriterien, das allen Antiamerikanismen gemein ist. Durch den reflexiven Einbezug der Flexibilität in die Begriffsbildung selbst bietet die Rekonstruktion einer Familie von Sprechakten aber eine theoretisch wohlbegründete Möglichkeit, dennoch von einem Antiamerikanismus zu sprechen.

Zusammenfassend kann festgehalten werden, dass das in diesem Kapitel dargestellte empirisch begründete Modell der Antiamerikanismuskritik drei wesentliche Aspekte beinhaltet: Erstens macht es die semantische und funktionale Flexibilität antiamerikanischer Rhetorik in empirischen Rekonstruktionen nachvollziehbar. Es veranschaulicht die Variabilität im Zusammenspiel rhetorischer Funktionen und Amerika-Semantiken, in dem antiamerikanische Vorurteile erkennbar werden. Zweitens gibt es eine neue Antwort auf die Frage, auf welcher begrifflichen Grundlage trotz dieser Variabilität, d.h. in Abwesenheit eines theoretisch und empirisch gehaltvollen universalen Definiens, die beobachteten flexiblen Gebräuche unter einem Oberbegriff ,Antiamerikanismus` zusammengefasst werden können. Im hier vorgeschlagenen Modell einer Familie antiamerikanischer Sprechakte sind also ohne jeden Anspruch auf Vollständigkeit - Flexibilität und Identität des antiamerikanischen Sprechens, d.h. dessen „systematische Ambiguität“, aufgehoben. Und drittens, so wurde in Kapitel 3 und 4 ausführlich dargelegt, bietet das entwickelte Modell eine neue Perspektive der normativen und gesellschaftstheoretischen Einordnung des Sprechens über Antiamerikanismus. Es leistet eine Reflexion der ,performativ-propositionale[n] Doppelstruktur" (Wellmer 2004, S. 47) der Sprache sowohl in Bezug auf das beobachtete als auch auf das eigene beobachtende Sprechen: Anhand der rekonstruierten Funktionskontexte nationaler Identität, ethnozentrischen und antisemitischen Sprechens macht es nachvollziehbar, inwiefern bestimmte Amerikabezüge einen vorurteiligen performativen Gehalt haben. Zugleich veranschaulicht die familienähnliche Struktur des Begriffes aber, dass die Zusammenfas- 
sung der rekonstruierten Sprechweisen unter einen gemeinsamen Oberbegriff ,Antiamerikanismus' immer auch einen Deutungsakt der Forschenden impliziert. Erst im Rekurs auf das gesellschaftstheoretische Konzept einer ideologisch-rhetorischen Reproduktion von sozialer Ungleichheit und Diskriminierung, werden die beobachteten Sprechakte als Ausdruck eines Antiamerikanismus fassbar, der nicht unmittelbar in diesen nachzuweisen ist.

\subsubsection{Welche Funktionen erfüllen antiamerikanische Konstruktionen als Ungleichheitssemantiken?}

Ungleichheitssemantiken, so wurde in Kapitel 4 erörtert, sind solche Differenzkonstruktionen, die zur Reproduktion und Rechtfertigung verfestigter Strukturen sozialer Ungleichheit gebraucht werden. Mit dieser Konzeption wurde eine Brücke zwischen Vorurteilsbegriff und den Konzepten soziale Ungleichheit und Diskriminierung geschlagen, und somit der Vorurteilskritik eine gesellschaftstheoretische bzw. normative Grundlage gegeben. Stereotype Fremd- und Wir-Gruppenkonstruktionen sind demnach dann als Vorurteile zu kritisieren, wenn sie eine Diskriminierung, Exklusion oder gar Verfolgung bestimmter Personengruppen bedingen oder zumindest begünstigen.

Welche spezifischen rhetorischen Funktionen erfüllen nun aber antiamerikanische Sprachgebräuche in diesem Zusammenhang? Eine Besonderheit des Antiamerikanismus, so eine in der Forschungsliteratur weithin geteilte Einschätzung (vgl. Kap. 2.1 sowie 4.6), besteht zunächst darin, dass er im Gegensatz zu bspw. rassistischen oder fremdenfeindlichen Differenzkonstruktionen keinen unmittelbaren diskriminierenden Effekt hat: Es kann angenommen werden, dass Antiamerikanismus zumindest im Kontext der hier untersuchten Population nicht zu einer Beeinträchtigung der Lebenschancen von Amerikanerinnen und Amerikanern führt - jedenfalls nicht im selben Ausmaß wie etwa fremdenfeindliche Vorurteile in Deutschland zu einer Beeinträchtigung oder Schädigung von Menschen mit Migrationshintergrund bzw. ohne deutsche Staatsbürgerschaft führen. Als Vermittlungsinstanz für den dennoch anzunehmenden diskriminierenden Effekt des Antiamerikanismus wurden nationale Identitätskonstruktionen ausgemacht. Ausgehend von der Annahme, dass Nationalismus systematisch mit der Exklusion und Diskriminierung verschiedener Fremd- und Feindgruppen korrespondiert, rückten Formen einer antiamerikanischen Profilierung, Aufwertung und Stabilisierung nationaler Identität ins Zentrum der empirischen Analysen. In diesem Funktionskontext nationalistischer Identifikation konnten drei wesentliche Formen antiamerikanischer Rhetorik aufgezeigt werden.

Erstens dienen antiamerikanische Sprechweisen als Mittel zur Kontrastierung und relativen Aufwertung nationaler Wir-Gruppenkonstruktionen: Am Beispiel von Herrn C und Herrn F konnte gezeigt werden, wie Bilder einer , amerikanischen Kul- 
turlosigkeit‘ und ,mangelnden Sittlichkeit', einer ,wirtschaftlichen Inkompetenz sowie einer ,fehlenden Solidarität' und ,mangelnden sozialen Sicherheit" dazu gebraucht werden, die Eigengruppe als rationale und zugleich solidarische Kulturgemeinschaft mit einer starken Orientierung auf moralische Werte zu präsentieren. In diesem Zusammenhang tauchen allerdings auch Formen von Antiamerikanismus auf, die als Ausdruck einer unmittelbaren Diskriminierung von ,Amerikanern“ zu verstehenden sind, bspw. in Herrn Ds Bezugnahme auf ,die Amerikaner` als moralisch verderbte, aggressive und gewalttätige Gruppe (vgl. Kap. 7.4.2.3).

Zweitens wurde eine Variante dieser Eigengruppenaufwertung nachgewiesen, in der negative oder bedrohliche Aspekte der Wir-Gruppe als ,amerikanische' bzw. durch ,Amerikanisierung ' erzeugte Phänomene externalisiert werden. Bilder einer irrationalen Konsumkultur sowie einer wachsenden sozialen Ungleichheit werden von Herrn C auf ,amerikanischen Einfluss‘ zurückgeführt und somit effektiv aus dem Verantwortungsbereich der Wir-Gruppe ausgeschlossen.

Als dritte Funktion antiamerikanischen Sprechens lässt sich am vorliegenden Material eine latente Bearbeitung von Kontingenz und inneren Konflikten der nationalen Wir-Gruppe rekonstruieren, die der Stabilisierung einer nationalistischen Weltsicht dient. So konnte am Sprechen von Herrn C gezeigt werden, wie dieser mittels des Stereotyps der ,Amerikanisierung ' eine innere Spaltung der Eigengruppe in Ost- und Westdeutsche thematisieren kann, ohne den damit angesprochenen Konflikt zu einer Bedrohung seiner ,gesamtdeutschen' Identitätskonstruktion werden zu lassen. Dies gelingt dadurch dass der schädliche Einfluss ,Amerikas ‘ gleichzeitig zur Erklärung des innerdeutschen Konfliktes und zur Konturierung eines geeinten Deutschland dient: Gegen ,Amerika‘ zu sein heißt zugleich gegen die ,amerikanisierten Wessis‘ zu polemisieren und die Einigkeit Deutschlands als homogene, ursprüngliche Nation zu bekräftigen.

Bei Herrn F findet sich eine ähnliche Form der latenten Bearbeitung von Identitätsbedrohungen, die in diesem Fall jedoch nicht nur die Einheit und Homogenität der deutschen Nation betrifft, sondern die Struktur der nationalen Weltsicht insgesamt. In Adaption eines Konzeptes aus Klaus Holz' Antisemitismusanalyse wurde hier eine antiamerikanische „Figur des Dritten“ (vgl. Kap. 4.6.2) ausgemacht, in der die Kontingenz der ethno-nationalen Weltordnung symbolisiert und zugleich ausgeklammert wird: In einer Welt, die nach „Herder' sche[m]“ Muster (Wimmer 2008, S. 60) als Summe ethnisch fundierter und eindeutig abgegrenzter Nationen vorgestellt wird, verkörpern die USA die Möglichkeit einer, wurzellosen “ Nation, die nur aus Einwanderern besteht, und dennoch nicht aufhört, Nation zu sein. Da dieses Andere der ethno-nationalen Ordnung somit selbst in Form einer (selbstwidersprüchlichen) Nation vorgestellt wird, kann die Struktur der Ordnung zugleich gesichert werden. Über das, wurzellos-heterogene" Amerika zu sprechen bedeutet somit, die Kontingenz der nationalen Ordnung anzusprechen, und doch deren universelle Geltung zu bestätigen. Im Sinne des in Kapitel 4.5 entwickelten Ideologiebe- 
griffes wird diese Gleichzeitigkeit von Thematisierung und Invisibilisierung einer destabilisierenden Konfliktlage bzw. Kontingenz als ideologische Form der Struktursicherung verstanden.

Die zuletzt erörterten rhetorischen Funktionen nehmen im Rahmen der vorliegenden Arbeit einen besonderen Stellenwert ein, da sie im Gegensatz zu den beiden zuvor genannten Funktionen ein genuin neues Theoriefragment der Antiamerikanismuskritik darstellen.

\subsubsection{Welche Arten des Zusammenspiels mit rassistischen, ethnozentrischen und antisemitischen Differenzkonstruktionen lassen sich feststellen?}

Eine zentrale Teilfrage der vorliegenden Arbeit zielt auf das Verhältnis zwischen Antiamerikanismus und anderen Formen vorurteiliger Differenzkonstruktionen. Im quantitativen Teil des durchgeführten methodenintegrativen Designs wurden deutliche, signifikante Korrelationen zwischen Antiamerikanismus, (antizionistischem) Antisemitismus, Rassismus und Fremdenfeindlichkeit beobachtet. Diese statistischen Befunde bildeten als Explananda einen wichtigen Ausgangspunkt der qualitativen Analysen, in denen Erklärungshypothesen für den beobachteten Zusammenhang entwickelt werden konnten. Die Ergebnisse dieses theoriegenerativen Prozesses lassen sich in drei Thesen formulieren.

Antiamerikanische Rhetorik funktioniert erstens als Rechtfertigung rassistischer bzw. ethnozentrischer Identitätskonstruktionen unter antirassistischen Bedingungen. Unter Rückgriff auf vier Beispiele aus dem Interviewmaterial konnten zwei Varianten dieser Funktion rekonstruiert werden: So werden Topoi eines ,amerikanischen Rassismus ' von Herr E und Herrn D dazu verwendet, die fremdenfeindlichen bzw. rassistischen Aspekte ihrer Darstellung von ,Russen', ,Türken“ und ,Amerikanern ‘ explizit zu relativieren bzw. deren menschenfeindlichen Gehalt abzustreiten. Nachdem jene verschiedenen Outgroups auf stereotype Weise als minderwertig und bedrohlich konstruiert wurden, dienten Stereotype eines rassistischen Amerika dazu, die eigene Konstruktion unter egalitären Vorzeichen zu legitimieren. Neben dieser expliziten Abwehr von Rassismusvorwürfen konnte am Beispiel von Herrn A und Herrn C eine ideologisch verdeckte Variante nachgewiesen werden. Insbesondere in Herrn As Rede bildet die Anklage der ,rassistischen USA ' einen starken Kontrast zu seiner unverblümt ethnozentrischen Konstruktion ,der Türken` bzw. ,der Deutschen': Während die rassistische Anfeindung Barack Obamas in den USA von ihm skandalisiert wird, affirmiert der Teilnehmer nachdrücklich die prinzipielle Unmöglichkeit eines türkischstämmigen Bundeskanzlers aufgrund ethnischer Unterschiede. An keiner Stelle des Interviews findet sich ein Hinweis darauf, dass Herrn A selbst dieser Widerspruch bewusst wird. Stattdessen scheint der Widerspruch im 
antiamerikanischen Sprechen zu einer Art ,praktischen Bewusstseins“ (Giddens 1984, S. 41 ff.) zu gelangen: Die Distanzierung zu ,amerikanischem Rassismus“ ermöglicht es dem rassistisch Sprechenden, die Existenz eines Rassismusproblems generell anzuerkennen und zugleich aus dem Bereich der Eigengruppe auszuklammern.

Die zweite zentrale These betrifft das Zusammenspiel von Antiamerikanismus und Antisemitismus. Am Beispiel von Herrn B konnte ein dem sekundären Antisemitismus analoges Argumentationsmuster rekonstruiert werden, mit dem der Holocaust implizit relativiert und die deutsche Nation hinsichtlich ihres nationalsozialistischen Erbes normalisiert wird. Die Stereotype einer, amerikanischen Manipulation' des europäischen Bildungssystems werden von ihm zunächst dazu gebraucht, jegliche besondere Schuld deutscher Täter bzgl. des Zweiten Weltkrieges als falsche externe Zuschreibung darzustellen. Nachdem diese Täter-Opfer Umkehr den Boden bereitet hat, kann anschließend im Rückgriff auf Bilder eines Genozids an den amerikanischen Ureinwohnern die sich aufdrängende Erinnerung an die Vernichtung der europäischen Juden verdrängt bzw. der Holocaust zu einem Genozid unter vielen normalisiert werden. Die besondere ideologische Funktion dieser antiamerikanischen Form der Schuldabwehr bzw. Normalisierung besteht darin, dass Herr B den Holocaust als Hindernis nationaler Identifikation aus dem Weg räumen kann, ohne ihn jemals explizit benennen zu müssen. Somit hat die Rede von der ,Ausrottung der Indianer' eine doppelte Funktion: Sie erlaubt es, den Holocaust latent anzusprechen und im Vergleich mit , amerikanischen Taten` zu einem Genozid unter vielen zu normalisieren. Jedoch findet sich im Material auch eine weniger ,raffinierte" Variante dieser Normalisierung, die auf eine derartigen Latenzschutz verzichtet. So rechnet Herr D, nachdem er vom Interviewer auf die Geschichte des Nationalsozialismus angesprochen wurde, explizit amerikanische Taten gegen deutsche auf: Der Holocaust erscheint in seiner Darstellung als zu vernachlässigender ,Ausrutscher', dessen herausragende Bedeutsamkeit im Vergleich zum Atombombenabwurf über Hiroshima nivelliert wird.

Als Moment einer klassisch antisemitischen Konstruktion konnte der Amerikabezug von Frau K ausgewiesen werden: In ihrer Darstellung ergänzen sich amerikanische Politik und ,israelischer Einfluss‘ zu einer antisemitischen Erklärung weltweiter Konflikte und Krisen, in der ,jüdische Gier' und ,Streitsucht' als Ursachen bezeichnet werden. Die antisemitische Feindbildkonstruktion wird dabei nur notdürftig durch antizionistische „Camouflage“ (Holz 2005, S. 82 ff.) maskiert und Amerikastereotype nicht als Latenzschutz eingesetzt. Dieser Gebrauch von Amerikastereotypen im Rahmen antisemitischer Alltagstheorien bildet die dritte Erklärungshypothese für den Zusammenhang von Antiamerikanismus mit anderen Vorurteilsformen.

Insgesamt machen die qualitativen Ergebnisse also einen rhetorischen Zusammenhang zwischen Antiamerikanismus, Rassismus, Fremdenfeindlichkeit und Antise- 
mitismus plausibel. Hierbei stehen insbesondere Funktionen der Rechtfertigung und Legitimation vorurteiliger Positionen im Vordergrund. Antiamerikanische Rhetorik dient dazu, rassistische, ethnozentrische und revisionistisch-nationalistische Positionen in Einklang mit egalitären und anti-antisemitischen Normen zu bringen. Dies kann entweder explizit oder kommunikationslatent geschehen, wobei - ähnlich wie im Kontext nationaler Identitätssicherung - der antiamerikanische Latenzschutz als besonders problematische Variante vorurteiligen Sprechens gelten muss. Seine Tragik besteht darin, dass er Reflexion nicht durch Ignoranz, sondern durch eine ideologische Form der Reflexion ersetzt. Er ermöglicht die gleichzeitige Thematisierung und Verdrängung des Widerspruches, den es bedeutet, ethnozentrisch und egalitär bzw. deutsch-national und anti-antisemitisch identifiziert zu sein.

\subsubsection{Ist Antiamerikanismus eine geschlossene Weltanschauung?}

Um eine differenzierte Antwort auf die Frage nach dem weltanschaulichen Charakter des Antiamerikanismus geben zu können, muss das Konzept der, Weltanschaulichkeit ${ }^{4}$ selbst ausdifferenziert werden. In der Antiamerikanismusliteratur ist häufig von der „Completeness of anti-American resentment“ (Friedman 2012, S. 5), der „generalized and comprehensive" Struktur (Markovits 2007, S. 17) antiamerikanischer Vorurteile die Rede. Darunter wird in der Regel verstanden, dass antiamerikanische Äußerungen sich nicht allein gegen einzelne Aspekte der Politik oder Gesellschaft der USA richten, sondern ,,sowohl politische und ökonomische als auch kulturelle Objekte“ betreffen (Beyer 2014, S. 22). Dieser Begriff eines weltanschaulichen Antiamerikanismus wird meist vor dem Hintergrund einer einstellungstheoretischen Vorurteilsdefinition gebraucht. Antiamerikanismus ist demnach eine „Tendenz der Psyche“, die eine „nichtsituative und essenzialistische Bewertung“ der USA zur Folge hat (ebd.).

Für die Zwecke der vorliegenden Ergebnisdarstellung möchte ich eine Differenzierung dieses Konzeptes mittels der Unterscheidung von Amerikabildern und rhetorischen Funktionen vorschlagen. So kann zwischen einer Spannweite der Funktionen von Amerikastereotypen und der Spannweite von Amerikastereotypen selbst unterschieden werden. Beide Dimensionen sind, statistisch gesprochen, zwar korreliert, stehen aber den hier präsentierten Ergebnisse zufolge in einem eher moderaten

4 Ich verwende den Begriff der Weltanschauung hier zunächst im Anschluss an Klaus Holz bzw. Reinhard Rürup, die damit die Funktion antisemitischer Konstruktionen als „Erklärungsmodell für die nicht verstandenen Entwicklungstendenzen der bürgerlichen Gesellschaft“, d.h. als „Zerrbild einer Gesellschaftstheorie“ bezeichnen (Holz 2001, S. 28). In der Antiamerikanismusliteratur wird ein umfassender, welterklärender Charakter antiamerikanischer Konstruktionen zwar regelmäßig festgestellt, jedoch bislang noch nicht unter einem einheitlichen Begriff gefasst (vgl. auch Jaecker 2014, S. 287 ff.). 
Zusammenhang. D.h. es wird zwar immer dann, wenn ein relativ breites Spektrum rhetorischer Funktionen erfüllt wird, auch eine große Zahl verschiedener Amerikastereotype gebraucht. Dieser Zusammenhang gilt aber nicht unbedingt auch umgekehrt: Akteure können ein breit gefächertes Repertoire an Amerikastereotypen bemühen, also zu nahezu jedem Aspekt Amerikas ein stereotypes Bild parat haben, damit aber nur ein und dieselbe Funktion erfüllen (vgl. z.B. Frau K). Psychologisch gesprochen könnte man dies so ausdrücken: Selbst wenn eine Person ein stereotypes Bild der USA insgesamt hat, kann es sein, dass dieses Bild nur in wenigen sozialen Situationen ${ }^{5}$ salient und Handlungsrelevant wird. Nur weil jemand ,alles an Amerika' verabscheut, heißt das noch nicht, dass er oder sie , von Amerika besessen' ist und sich andauernd auf jenes stereotype Bild bezieht. Der Extremfall, dass beide Dimensionen hoch ausgeprägt sind, also ein umfangreiches Set an Amerikastereotypen für ein breites Spektrum an Funktionen gebraucht wird, findet sich im hier analysierten Material sehr selten. Der „kognitive Schematismus“, der in psychologischen Weltanschaulichkeitsbegriffen angenommen wird, impliziert aber immer beides zugleich: Eine umfassende Negativbewertung von allem, was mit ,Amerika' zu tun hat und einen ,obsessiven' Rekurs auf ,Amerika ' in einer Vielzahl sozialer Situationen. Am ehesten könnte diese Art von weltanschaulicher Dichte der Rhetorik von Herrn C zugeschrieben werden. Meine Analyse zählt für diesen Fall neun verschiedene Amerikamotive, die in vier verschiedenen rhetorischen Funktionen gebraucht werden. Wie oben beschrieben, muss diese Form antiamerikanischer Einstellungen aber als Extremfall, nicht als allgemeine Regel antiamerikanischen Sprechens gelten.

Mit der vorgeschlagenen Unterscheidung zwischen semantischer und rhetorischer weltanschaulicher Dichte wird dem gängigen psychologischen Verständnis von Weltanschaulichkeit also eine ,diskursive“ Variante gegenübergestellt: Antiamerikanismus ist dann nicht in erster Linie eine individuelle Disposition, sondern ein umfassendes, überindividuell verfügbares Repertoire von Argumentationsweisen, die von unterschiedlichen Handelnden situativ flexibel und mit unterschiedlicher Dichte aufgegriffen werden können.

Antiamerikanismus ist primär etwas, das man tun kann, und zwar unabhängig davon, wie ,obsessiv‘ man es tut. Die Ergebnisse meiner Analysen legen nahe, dass eine weltanschauliche Geschlossenheit im starken psychologischen Sinne ver-

5 Die verschiedenen rhetorischen Funktionsweisen werden hier als Annäherung an eine Diversität der sozialen Situationen gebraucht, in denen Antiamerikanismus für einen Akteur relevant wird. Eine zentrale Problematik dieser Annahme liegt indessen klar auf der Hand: Tatsächlich sind die verschiedenen Funktionen, die im Material beobachtet wurden, allesamt in der gleichen sozialen Situation (Interviewgespräch) entstanden, und lassen somit keinen direkten Rückschluss auf die tatsächliche Relevanz antiamerikanischen Sprechens im Alltag der Interviewten zu. 
gleichsweise selten zu beobachten ist. Dies bedeutet natürlich nicht, dass es solche ,obsessiven“ Formen von Antiamerikanismus nicht auch gibt. Aber es weist darauf hin, dass ein solcher Schematismus nicht als notwendiges Kriterium allgemeiner Antiamerikanismusdefinitionen gebraucht werden sollte.

Zieht man zudem in Betracht, dass dieser Befund auf der Datengrundlage von auf einer allgemeinen Atiamerikanismusskala hoch-zustimmenden Teilnehmenden gewonnen wurden, so gibt dies zumindest Grund, an der Validität auch umfangreicher ,Antiamerikanismus-Messungen“ bzgl. des Aspektes der Weltanschaulichkeit zu zweifeln: Obwohl interne Konsistenz und externe Validität des SurveyInstrumentes die Annahme eines kognitiven Schematismus stützen, lässt von elf qualitativ untersuchten hoch-zustimmenden Teilnehmenden nur einer eine obsessivweltanschauliche Rhetorik erkennen. ${ }^{6}$ Auch hier wird in den qualitativen Ergebnissen eine Heterogenität der Merkmale antiamerikanischen Sprechens erkennbar, die in den Survey-Daten unbeobachtet blieb. Die faktoranalytisch und korrelativ für die Gesamtpopulation festgestellte Tendenz zu weltanschaulicher Geschlossenheit verweist zwar auf eine Möglichkeit antiamerikanischen Sprechens, droht aber zugleich die Tatsache zu verdecken, dass sich mit einem konsistenten Antwortverhalten auf den erhobenen Skalen auch weniger schematische rhetorische Muster verbinden können.

Ist Antiamerikanismus nun also ein weltanschauliches Vorurteil? In aller Kürze lautet meine Antwort: im psychologischen Sinne, nein; im rhetorisch-diskursiven Sinne, ja. Verstanden als überindividuelles Repertoire vorurteiliger Argumentationsmuster spannt Antiamerikanismus ein breit gefächertes semantisches Feld von Amerikabildern auf (vgl. Kap. 7.1), die zu sehr verschiedenen vorurteiligen Zwecken genutzt werden können. ${ }^{7}$ Einem Großteil der hier rekonstruierten antiamerikanischen Sprachgebräuche kommt zudem eine ideologische Funktion zu. Der Ideo-

6 Ich möchte auf zwei Einschränkungen dieses Arguments hinweisen: Erstens reicht die hier gebrauchte Skala nicht an den semantischen Umfang derjenigen heran, die bspw. Heiko Beyer verwendet (Beyer 2014, S. 143). Zum anderen können aufgrund der ungeklärten Geltungsreichweite der qualitativen Analysen keine sicheren Rückschlüsse auf die Validität der Surveyinstrumente gezogen werden. Hierzu wäre u.a. ein systematischer Vergleich von Teilnehmenden mit hoher und geringer Zustimmung bzw. Ablehnung nötig.

$7 \mathrm{Zu}$ einem ähnlichen Ergebnis kommt Tobias Jaeckers Diskursanalyse von Antiamerikanismus in deutschen Medieninhalten: „Es handelt sich um ein Welterklärungsmuster, das zur Ideologie gerinnen kann. Die in teilen des medialen Diskurses eher fragmentarisch verbreiteten antiamerikanischen Vorurteile oder Ressentiments sind demnach nicht zwangsläufig ideologisch. Sie leisten aber einem Denken Vorschub, das nach einfachen Erklärungen sucht. In bestimmten diskursiven Zusammenhängen können sie sich so zu einer antiamerikanischen Ideologie verdichten.“ (Jaecker 2014, S. 302) 
logiebegriff bezeichnet dabei aber nicht eine schematische Geschlossenheit von Weltanschauung oder psychischer Disposition, wie in vielen Antiamerikanismuskonzeptionen angenommen (vgl. Kap. 2.3.3). Sondern er verweist auf eine bestimmte Form der Reflexion und Bearbeitung von identitätspolitischen Begründungsproblemen: Ideologisch sind solche Argumentations- und Rechtfertigungsmuster, die normative Dilemmata, etwa eine gleichzeitige Orientierung auf ethnische Gleichheit und Ethnozentrismus, latent bearbeiten, sodass der ihnen immanente Widerspruch nicht offen zutage tritt. Betrachtet man Vorurteile als Ungleichheitssemantiken, d.h. als bestimmte Positionen im Streit um die Auslegung der egalitären Norm, dann besteht ihre ideologische Funktion darin, kategorial abgeschlossene Differenzkonstruktionen mit dem prinzipiell unabgeschlossenen Vollzug des Gleichheitsideals in Einklang zu bringen. Ideologische Vorurteile brechen mit der Diskursivität in der Diskursivität, sie sind egalitärer Antiegalitarismus. Dass sich antiamerikanische Vorurteile durch diese tragische Reflexivität vom Rechtfertigungsdruck des egalitären Konfliktdiskurses rhetorisch befreien können, ist ein wichtiger Aspekt ihres weltanschaulichen Charakters. Durch die Kommunikationslatenz ideologischer Argumentationsmuster finden Vorurteile ihren Eingang in die Normalität nicht-vorurteiliger Diskurse; der Ideologiebegriff markiert die Stelle, an dem der Unterschied zwischen Vorurteil und vorurteilsfreiem Sprechen verschwimmt, an dem Vorurteile zu einem akzeptablen Bestandteil alltäglicher Kommunikation werden.

\subsubsection{Exkurs: Widersprüchliche Befunde zu nationaler Identität und Antiamerikanismus in Interview- und Surveydaten}

Ein zentraler Befund der vorgelegten qualitativen Analysen ist, dass antiamerikanische Rhetorik maßgeblich im Kontext nationaler Identifikation funktioniert. Betrachtet man ausgehend von dieser These aber den Zusammenhang von nationaler Identifikation und Antiamerikanismus in den Surveydaten der Hauptstudie, zeigen sich widersprüchliche Ergebnisse. So weist eine im Survey ebenfalls erhobene Skala zu nationaler Identität keine signifikanten Korrelationen mit den ,kulturkonservativen' und , antiimperialistischen' Antiamerikanismusdimensionen auf (vgl. Tabelle 15). ${ }^{8} \mathrm{Zu}$ ähnlichen Ergebnisse kommt auch die Survey-Untersuchung von Heiko Beyer, in der ebenfalls lediglich ein geringfügiger, marginal signifikanter Zusam-

8 Die Skala wurde aus Cohrs 2003 adaptiert und setzt sich aus den folgenden drei Items zusammen, die jeweils auf einer fünfwertigen Likert-Skala $(1=$,stimme überhaupt nicht zu“ bis $5=$,stimme voll und ganz zu“) bewertet werden konnten: „Ich fühle mich als DeutscheR“; „Ich identifiziere mich mit den Deutschen“; „Für mein Selbstbild ist es wesentlich, DeutscheR zu sein“. 
menhang von deutscher Nationalidentität und Antiamerikanismus festgestellt werden kann (vgl. Beyer 2014, S. 182 f.). ${ }^{9}$

\section{Tabelle 15: Korrelationen von Antiamerikanismus und nationaler Identifikation in einer simultanen CFA $(\text { n.s. }=\text { nicht signifikant; } * *=\alpha<, 01)^{10}$}

\begin{tabular}{|l|l|}
\hline & Skala Nationale Identität \\
\hline Antiamerikanismus antiimperialistisch &, 062 n.s. \\
\hline Antiamerikanismus kulturkonservativ &, 036 n.s. \\
\hline Antisemitismus &, $21^{* *}$ \\
\hline Antizionismus &, $168^{* *}$ \\
\hline Islamfeindschaft &, $302^{* *}$ \\
\hline Homophobie &, $228^{* *}$ \\
\hline Fremdenfeindlichkeit &, $373^{* *}$ \\
\hline Etabliertenvorrechte &, $315^{* *}$ \\
\hline Rassismus &, $297^{* *}$ \\
\hline Sexismus &, $154^{* *}$ \\
\hline Abwertung Langzeitarbeitsloser &, $356^{* *}$ \\
\hline
\end{tabular}

Wie kann nun diese Diskrepanz zwischen qualitativen und quantitativen empirischen Ergebnissen erklärt werden? Geht man zunächst davon aus, dass die Deutungen der Interviewanalysen plausibel sind, also die in Kapitel 7.2 bis 7.4 dargestellten Antiamerikanismen tatsächlich im Kontext nationaler Identifikation funktionieren, so kommen für die divergierenden Befunde drei Erklärungen in Frage: Erstens ist es möglich, dass das Survey-Instrument zur Erfassung nationaler Identifikation keinen validen Indikator für die im qualitativen Material beobachteten nationalistischen Motive darstellt. Zweitens könnte die Fallauswahl des qualitativen Samples einen überproportional hohen Anteil nationalistisch identifizierter Teilnehmender beinhalten, so dass die qualitativen Analysen zwar hinsichtlich einer Subpopulation stimmig, nicht aber auf die Survey-Population insgesamt verallgemeinerbar wären. Und drittens schließlich, könnte das Ausbleiben eines signifikanten Zusammenhangs zwischen Nationalismus und Antiamerikanismus auf ein methodisches Problem in den statistischen Analyseverfahren zurückzuführen sein. So können etwa auch dann, wenn in der Gesamtstichprobe zwischen den erhobenen Skalen kein linearer Zusammenhang besteht, dennoch relevante Teilgruppen des Samples einen

9 Zur Abfrage von Nationaler Identifikation wurde dort das Item „Ich identifiziere mich mit Deutschland." mit einer vierstufigen Likert-Skala erhoben (ebd., S. 157 f.).

$10 \mathrm{n}=808 ; \mathrm{Chi}^{2}=76.296 ; \mathrm{df}=24 ; \mathrm{p}<, 0001 ; \mathrm{CFI}=, 969 ;$ RMSEA $=0,052$; SRMR $=, 045$ 
solchen Zusammenhang aufweisen. Ein derartiger bedingter Zusammenhang, demzufolge bestimmte Formen oder Ausdruckskontexte von Antiamerikanismus mit nationaler Identität zusammenhängen, andere aber nicht, kann durch lineare Regressionen bzw. Korrelationen nicht bzw. nur ungenau abgebildet werden. Alle drei Möglichkeiten werden im Folgenden anhand der vorliegenden Daten kurz diskutiert.

Zunächst muss man in Betracht ziehen, dass die Skala zu nationaler Identität einem Forschungszusammenhang entstammt, in dem auf der Grundlage der Theorie sozialer Identität von Henri Tajfel und John C. Turner zwischen nationaler Identifikation und Nationalismus unterschieden wird (Blank und Schmidt 2003; Heyder und Schmidt 2002; Pehrson et al. 2009). Hierbei wird angenommen, dass nationale Identifikation nur die Stärke des individuellen Zugehörigkeitsgefühls zu einer nationalen Gruppe bedeutet, unabhängig von den inhaltlichen Merkmalen dieser WirGruppenkonstruktion. Auf diese Weise kann dann ein selbstkritischer ,konstruktiver Patriotismus ' von einem chauvinistischen Nationalismus unterschieden werden (Blank und Schmidt 2003, S. 291), je nachdem, ob Kriterien ethnischer und kultureller Homogenität bzw. Abstammung oder Kriterien der formalen Staatsbürgerschaft und ökonomischen und politischen Partizipation angelegt werden (vgl. Pehrson et al. 2009, S. 26 ff.). Nationalistischen Nationalidentitäten wird dabei ein positiver Zusammenhang mit Vorurteilen und Diskriminierung unterstellt, patriotischen Nationalidentitäten hingegen ein negativer. Tatsächlich konnte in Surveyuntersuchungen ein solcher gegenläufiger Effekt der beiden Varianten nationaler Identifikation gezeigt werden (vgl. ebd., S. 30; Blank und Schmidt 2003, S. 301; Heyder und Schmidt 2002, S. 78). Geht man gemäß dieser Befunde davon aus, dass die erhobene Skala lediglich eine ,neutrale 'Dimension nationaler Identifikation erfasst, könnte man argumentieren, dass dieses Instrument sozusagen ,by design “ nicht zur Erhebung jener nationalistischen Rhetorik geeignet ist, die in den Interviewanalysen rekonstruiert wurde. Es erfasst nur die allgemeine Grundlage nationaler Identifikation, die nationalistischen sowie patriotischen Wir-Gruppenkonstruktionen gemein ist, und kann daher den Zusammenhang zwischen ersteren und Antiamerikanismus nicht abbilden. Diesem Argument ist aber mit Skepsis zu begegnen, denn es zeigen sich für andere Vorurteilsformen immerhin moderate positive Zusammenhänge mit nationaler Identifikation. Insbesondere Islamfeindschaft $(r=, 302)$, Fremdenfeindlichkeit $(\mathrm{r}=, 373)$, Etabliertenvorrechte $(\mathrm{r}=, 315)$ und die Abwertung Langzeitarbeitsloser $(r=, 356)$ hängen mit der vermeintlich ,neutralen“ Nationalidentität zusammen (vgl. Tabelle 15). Vor diesem Hintergrund erscheint das Konzept eines ,konstruktiven Patriotismus' zumindest fragwürdig.

Wenn also das verwendete Maß für nationale Identität nicht als prinzipiell unabhängig von vorurteiligen Rhetoriken gelten kann, hängt dann nur Antiamerikanismus nicht mit nationaler Identifikation zusammen? Beruhen die qualitativen Ergebnisse also auf einer verzerrten Stichprobe? Betrachtet man das Verhältnis von qualitativen und standardisierten Ergebnissen in den Fällen des Interview-Samples, 
so deutet zunächst einiges auf diese Interpretation hin. ${ }^{11}$ Es finden sich hohe $\mathrm{Zu}$ stimmungswerte für nationale Identität bei fast allen Interviewteilnehmenden, für die im Rahmen der qualitativen Analyse eine nationalis-tische Rhetorik rekonstruiert wurde. Für Herrn I, der hinsichtlich des Funktionskontextes als nichtnationalistisch beurteilt wurde (vgl. Tabelle 16), ist hingegen ein deutlich niedrigerer Wert zu beobachten. Lediglich die eher ablehnende Antworttendenz von Herrn B, dessen Schuldabwehr-Rhetorik dem Funktionskontext nationaler Identifikation zugehört (vgl. Kap. 7.3.1), fällt hier aus dem Rahmen.

Tabelle 16: Rekonstruierte Funktionskontexte und Ausprägungen der Skala nationale Identität im Interview-Sample (höhere Werte bezeichnen stärkere Zustimmung)

\begin{tabular}{|c|c|c|c|c|c|}
\hline & 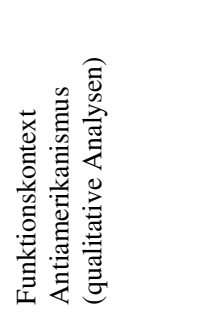 & 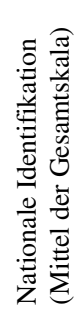 & 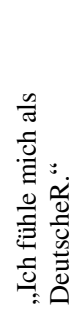 & 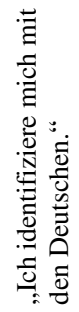 & 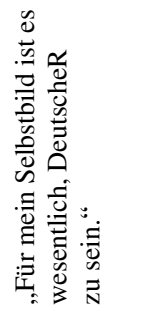 \\
\hline Herr A & Ethnozentrismus & 5 & 5 & 5 & 5 \\
\hline Herr D & Ethnozentrismus & 4,3 & 5 & 5 & 3 \\
\hline Herr E & Ethnozentrismus & - & - & - & 4 (Skala 1-4) \\
\hline Herr B & Schuldabwehr & 2,3 & 3 & 3 & 1 \\
\hline Frau K & Antisemitismus & 5 & 5 & 5 & 5 \\
\hline Herr C & Nationale Ident. & 4,3 & 5 & 5 & 3 \\
\hline Herr I & Inkonsistent & 3,3 & 1 & 4 & 5 \\
\hline Frau $\mathrm{H}$ & Inkonsistent & - & - & - & 2 (Skala 1-4) \\
\hline
\end{tabular}

Betrachtet man diesen Zusammenhang aber auf Ebene der Einzelitems der Identitäts-Skala, so wird die Konsistenz von Interview-Rekonstruktionen und SurveyAntworten wiederum brüchig. Denn hinsichtlich des dritten Items („,Für mein Selbstbild ist es wesentlich, DeutscheR zu sein“) sind nicht nur die Angaben von Herrn B, sondern auch die von Herrn D, Herrn C und Herrn I inkonsistent. Zählt

11 Da nur $\mathrm{n}=6$ der Fälle, anhand derer antiamerikanische Rhetoriken rekonstruiert werden konnten, aus dem Sample der Hauptuntersuchung stammen, ist die Datengrundlage dieses Vergleiches leider sehr begrenzt. 
man die Werte von Herrn $\mathrm{E}$ und Frau $\mathrm{H}$ hinzu ${ }^{12}$, so sind damit schon vier von acht Fällen hinsichtlich der Passung von Identitäts-Skala und qualitativem Befund inkonsistent. Die Items der Identitäts-Skala separat zu betrachten ist deswegen nicht trivial, da insbesondere das besagte dritte Item den Zusammenhang von Vorurteilen und nationaler Identifikation anzutreiben scheint (vgl. Tabelle 17).

Tabelle 17: Produkt-Moment Korrelationen zwischen Einzelitems zu nationaler Identität, Antiamerikanismus und Gruppenbezogener Menschenfeindlichkeit $(n=808 ; * *=\alpha<, 01 ; *=\alpha<, 05 ;$ n.s. $=$ nicht signifikant $)$

\begin{tabular}{|c|c|c|c|}
\hline & $\begin{array}{l}\text { „Ich fühle mich } \\
\text { als DeutscheR“" }\end{array}$ & $\begin{array}{l}\text { „Ich identifiziere } \\
\text { mich mit den } \\
\text { Deutschen“ }\end{array}$ & $\begin{array}{l}\text { „Für mein Selbstbild ist } \\
\text { es wesentlich, DeuscheR } \\
\text { zu sein.“ }\end{array}$ \\
\hline $\begin{array}{l}\text { Antiamerikanismus } \\
\text { kulturkonservativ }\end{array}$ & $\begin{array}{l}-, 03 \text { n.s. } \\
\mathrm{n}=736\end{array}$ & $\begin{array}{l}, 002 \text { n.s. } \\
\mathrm{n}=739\end{array}$ & $\begin{array}{l}, 101 * * \\
\mathrm{n}=734\end{array}$ \\
\hline $\begin{array}{l}\text { Antiamerikanismus } \\
\text { antiimperialistisch }\end{array}$ & $\begin{array}{l}-, 023 \text { n.s. } \\
\mathrm{n}=715\end{array}$ & $\begin{array}{l}\text {,027 n.s. } \\
\mathrm{n}=715\end{array}$ & $\begin{array}{l}, 203 * * \\
\mathrm{n}=710\end{array}$ \\
\hline Antisemitismus & $\begin{array}{l}, 104 * * \\
\mathrm{n}=735\end{array}$ & $\begin{array}{l}, 155^{* *} \\
\mathrm{n}=736\end{array}$ & $\begin{array}{l}, 276 * * \\
\mathrm{n}=731\end{array}$ \\
\hline Antizionismus & $\begin{array}{l}\text {,056 n.s. } \\
\mathrm{n}=657\end{array}$ & $\begin{array}{l}, 056 \text { n.s. } \\
n=659\end{array}$ & $\begin{array}{l}, 186 * * \\
\mathrm{n}=656\end{array}$ \\
\hline Islamfeindschaft & $\begin{array}{l}, 128 * * \\
\mathrm{n}=781\end{array}$ & $\begin{array}{l}192 * * \\
\mathrm{n}=783\end{array}$ & $\begin{array}{l}, 365 * * \\
\mathrm{n}=779\end{array}$ \\
\hline Homophobie & $\begin{array}{l}, 083 * \\
\mathrm{n}=793\end{array}$ & $\begin{array}{l}176^{* *} * \\
\mathrm{n}=794\end{array}$ & $\begin{array}{l}, 257 * * \\
\mathrm{n}=790\end{array}$ \\
\hline Fremdenfeindlichkeit & $\begin{array}{l}, 174 * * \\
\mathrm{n}=787\end{array}$ & $\begin{array}{l}, 246 * * \\
\mathrm{n}=789\end{array}$ & $\begin{array}{l}, 405 * * \\
\mathrm{n}=785\end{array}$ \\
\hline Etabliertenvorrechte & $\begin{array}{l}, 141 * * \\
\mathrm{n}=790\end{array}$ & $\begin{array}{l}183 * * \\
\mathrm{n}=791\end{array}$ & $\begin{array}{l}, 322 * * \\
\mathrm{n}=787\end{array}$ \\
\hline Rassismus & $\begin{array}{l}, 126 * * \\
\mathrm{n}=775\end{array}$ & $\begin{array}{l}, 190 * * \\
\mathrm{n}=777\end{array}$ & $\begin{array}{l}, 375 * * \\
\mathrm{n}=771\end{array}$ \\
\hline Sexismus & $\begin{array}{l}, 057 \mathrm{n} . \mathrm{s} . \\
\mathrm{n}=794\end{array}$ & $\begin{array}{l}, 102 * * \\
\mathrm{n}=797\end{array}$ & $\begin{array}{l}, 210 * * \\
\mathrm{n}=791\end{array}$ \\
\hline $\begin{array}{l}\text { Abwertung } \\
\text { Langzeitarbeitsloser }\end{array}$ & $\begin{array}{l}, 188 * * \\
\mathrm{n}=777\end{array}$ & $\begin{array}{l}, 251 * * \\
\mathrm{n}=778\end{array}$ & $\begin{array}{l}, 354 * * \\
\mathrm{n}=773\end{array}$ \\
\hline
\end{tabular}

Somit finden sich im Material des qualitativen Samples zumindest Indizien dafür, dass hier nicht lediglich eine verzerrte Stichprobe gezogen wurde, sondern dass in-

12 Diese wurden im Rahmen der dritten Pilotstudie ausgewählt. In dem hier zugrundeliegenden Survey wurde allein das dritte Item erhoben, so dass für Gesamtskala zu nationaler Identität keine Werte vorliegen. 
nerhalb der Identitäts-Skala selbst Inkonsistenzen auftreten. ${ }^{13}$ Antiamerikanische Ausdrucksweisen scheinen sowohl mit hohen, als auch mit niedrigen Werten auf der Skala für nationale Identität einhergehen zu können. Betrachtet man das Antwortverhalten mithilfe von Kreuztabellen, so wird dieses Bild auch auf der Ebene der Gesamtstichprobe deutlicher erkennbar. Wie die nicht signifikante Korrelation zwischen Antiamerikanismus und nationaler Identität bereits nahelegt, finden sich jeweils annähernd gleichgroße Zellhäufigkeiten für hoch und niedrig ausgeprägte nationale Identifikation sowohl bei hohen, als auch bei niedrigen Antiamerikanismuswerten (vgl. Tabelle 18 und 19).

Dieses Bild lässt sich zusätzlich veranschaulichen, wenn man die Gruppenmittelwerte für Antiamerikanismus über die Quartile der Identitäts-Skala vergleicht (vgl. Tabelle 20).

Tabelle 18: Absolute Häufigkeiten von antiimperialistischem Antiamerikanisus und nationaler Identität (Skalen in Quartile unterteilt) ${ }^{14}$

\begin{tabular}{|ll|l|l|l|l|l|}
\hline & & \multicolumn{3}{|c|}{ Nationale Identität } & \multirow{2}{*}{} \\
\cline { 3 - 6 } & 1 (niedrig) & 2 & 3 & 4 (hoch) & Gesamt \\
\hline \multirow{4}{*}{ Antiamerikanismus } & 2 & 32 & 33 & 23 & 26 & 114 \\
antiimperialistisch & 3 & 31 & 63 & 51 & 43 & 188 \\
& 4 (hoch) & 51 & 44 & 33 & 21 & 122 \\
\hline Gesamtsumme & 138 & 75 & 80 & 86 & 292 \\
\hline
\end{tabular}

Tabelle 19: Absolute Häufigkeiten von kulturkonservativem Antiamerikanisus und nationaler Identität (Skalen in Quartile unterteilt)

\begin{tabular}{|ll|l|l|l|l|l|}
\hline & & \multicolumn{3}{|c|}{ Nationale Identität } & \multirow{2}{*}{} \\
\cline { 3 - 7 } & & 1 (niedrig) & 2 & 3 & 4 (hoch) & Gesamt \\
\hline \multirow{4}{*}{ Antiamerikanismus } & 2 & 48 & 47 & 31 & 50 & 176 \\
kulturkonservativ & 3 & 31 & 46 & 39 & 24 & 134 \\
& 4 (hoch) & 43 & 69 & 55 & 46 & 201 \\
\hline Gesamt & 147 & 230 & 185 & 177 & 739 \\
\hline
\end{tabular}

13 Tatsächlich wird auch in der Studie von Cohrs, aus der die Identitäts-Items adaptiert wurden, das entsprechende Item faktoranalytisch einer anderen Dimension zugeordnet, als die übrigen beiden (Cohrs 2003, S. 208).

14 Die ungleichen Häufigkeiten in den Quartilen kommen durch Rangbindungen zustande, also solche Werte, die genau auf den errechneten Quartilgrenzen liegen. Solche Fälle wurden jeweils der nächsthöheren Klasse zugewiesen. 
Signifikante Unterschiede treten hier nur für die , antiimperialistische` Antiamerikanismusdimension zwischen den Mittelwerten des zweiten und vierten Quartils ( $\mathrm{p}=$ ,004) sowie des ersten und vierten Quartils $(\mathrm{p}=, 034)$ auf. ${ }^{15}$ Lediglich die hoch national Identifizierte Gruppe unterscheidet sich also hinsichtlich des antiimperialistischen Antiamerikanismus signifikant von den wenig national identifizierten Gruppen. Für die ,kulturkonservative“ Antiamerikanismusdimension lassen sich keinerlei signifikante Differenzen feststellen.

Ein linearer Zusammenhang von Antiamerikanismus und nationaler Identifikation liegt also nicht vor. Die beobachteten Antwortmuster legen hingegen die Vermutung nahe, dass für bestimmte Formen von Antiamerikanismus ein Zusammenhang mit Nationalismus besteht, während für andere Formen dieser Faktor keine oder nur eine geringe Rolle spielt. Auch deutet sich, zumindest für die antiimperialistische Dimension, ein Deckeneffekt an, demzufolge sich nur für extrem hoch national Identifizierte eine signifikant höhere Ausprägung von Antiamerikanismus feststellen lässt.

\section{Tabelle 20: Gruppenmittelwerte der Antiamerikanismusskalen für Quartile der Skala nationale Identität}

\begin{tabular}{|l|l|l|l|l|}
\hline \multirow{2}{*}{} & \multicolumn{4}{|c|}{ Nationale Identität } \\
\cline { 2 - 5 } & 1 (niedrig) & 2 & 3 & 4 (hoch) \\
\hline $\begin{array}{l}\text { Antiamerikanismus } \\
\text { antiimperialistisch }\end{array}$ & 2,413 & 2,377 & 2,564 & 2,750 \\
$\mathrm{n}=182$ & $\mathrm{n}=171$ & $\mathrm{n}=187$ & $\mathrm{n}=176$ \\
\hline $\begin{array}{l}\text { Antiamerikanismus } \\
\text { kulturkonservativ }\end{array}$ & 2,336 & $\begin{array}{l}2,403 \\
\mathrm{n}=197\end{array}$ & $\begin{array}{l}2,471 \\
\mathrm{n}=180\end{array}$ & $\begin{array}{l}2,417 \\
\mathrm{n}=185\end{array}$ \\
\hline
\end{tabular}

Die Surveydaten zeigen also, wenn auch auf der Grundlage eines unzuverlässigen Indikators für Nationalismus, dass unabhängig vom Grad nationaler Identifikation bestimmte Amerikastereotype reproduziert werden. Inwiefern solche stereotypen Amerikabilder mit (nicht-nationalistischem) antiamerikanischem Sprechen einhergehen, lässt sich allein anhand der Surveyitems nicht feststellen, da Hinweise auf alternative rhetorische Funktionskontexte diesen Daten nicht zu entnehmen sind.

Die Frage nach der Geltungsreichweite des qualitativ rekonstruierten Funktionszusammenhangs von Antiamerikanismus und Nationalismus kann also im Rahmen der vorliegenden Studie nicht geklärt werden. Die Prüfung der NationalismusHypothese muss daher als Desiderat für zukünftige Forschung festgehalten werden. Die vorläufigen empirischen Befunde und ex-post Überlegungen dieses Abschnittes verweisen indessen darauf, dass bei solchen Untersuchungen eine angemessen komplexe Operationalisierung von Nationalismus sowie die Möglichkeit verschie-

15 Signifikanz geprüft durch Post-Hoc-Tests mit Bonferroni-Korrektur. 
dener Varianten antiamerikanischen Sprechens berücksichtigt werden sollten. Hierbei wäre wiederum ein methodenintegratives Vorgehen naheliegend, um statistisch identifizierte Subgruppen mit qualitativ-interpretativen Verfahren auf den argumentativen Kontext antiamerikanischer Ausdrücke hin untersuchen zu können. 



\section{Schluss}

In den vorausgegangenen Kapiteln wurde die Frage nach Form und Funktion antiamerikanischer Vorurteile in aktuellen Alltagsdiskursen in der deutschen Bevölkerung behandelt. Im Licht der sprechakttheoretischen Anlage der Arbeit kam diese Frage als eine doppelte Problemstellung in Betracht, die nicht nur die Bedeutung antiamerikanischer, sondern auch diejenige antiamerikanismuskritischer Sprechakte betrifft: Die Frage, was AkteurInnen tun, wenn sie in bestimmten Kontexten bestimmte Amerikastereotype gebrauchen, ist immer auch die Frage, was Forschende tun, die solche Sprachgebräuche als Vorurteile beschreiben.

Dementsprechend lässt sich die Argumentation der vorliegenden Arbeit grob in zwei Teile untergliedern: einen theoretisch-reflexiven und einen empirisch-rekonstruktiven. Im theoretisch-reflexiven Teil wurde zunächst ein Überblick des gegenwärtigen Stands der Antiamerikanismusforschung gegeben, wobei solche Konzepte im Vordergrund standen, denen ein einstellungstheoretischer Begriff des Vorurteils zugrunde liegt (Kap. 2). Ausgehend von den blinden Flecken und theoretischen Engführungen dieser Antiamerikanismusdefinitionen wurde eine sprechakttheoretische bzw. performative Begriffsgrundlage als Alternative vorgeschlagen. Hierbei war das Ziel, die Sensibilität der Vorurteilskritik sowohl für ihre eigenen gesellschaftstheoretischen und normativen Begründungsprobleme, als auch für die flexiblen und fragmentierten Erscheinungsformen ihres Gegenstandes zu steigern (Kap. 3). Auf dieser Grundlage konnte dann im Rückgriff auf Konzepte der Diskriminierungs- und Ungleichheitsforschung ein gesellschaftstheoretischer Rahmen formuliert werden, der die zentralen Bezugspunkte für eine empirische Rekonstruktion antiamerikanischer Vorurteile bereitstellt und zugleich, mittels des Konzepts der „erschließenden Kritik“ (Bonacker 2008, S. 64), normativ abstützt (Kap. 4). Die Brücke hin zum empirisch-rekonstruktiven Teil der Arbeit wurde durch eine Reflexion der sozialwissenschaftlichen Forschungsmethoden geschlagen, mithilfe derer die genannten theoretischen Konzepte für die empirischen Analysen adaptiert wurden. Hierbei standen methodologische Konzepte einer qualitativ-interpretativen 
Hypothesengenerierung sowie der Integration quantitativer und qualitativer Verfahren im Mittelpunkt (Kap. 5).

Surveydaten bildeten den Ausgangspunkt des empirisch-rekonstruktiven Teils der Arbeit, indem sie einerseits einen Überblick über die Verteilung antiamerikanischer Tendenzen in der deutschen Bevölkerung ermöglichten, andererseits aber auch den zentralen Ansatzpunkt für die folgende qualitative Interviewstudie boten (Kap. 6 und 7): Nicht nur konnten über die erhobenen Antiamerikanismus-Skalen gezielt Interviewteilnehmende aus dem Survey-Sample ausgewählt werden, von denen eine hohe Bereitschaft zur Reproduktion antiamerikanischer Rhetoriken erwartet werden durfte. Die statistischen Befunde bzgl. des Zusammenhangs zwischen Antiamerikanismus und anderen Vorurteilsformen bildeten zugleich Explananda für die qualitativen Analysen. Neben der Frage nach dem flexiblen und fragmentierten bzw. weltanschaulichen Charakter antiamerikanischer Alltagskommunikation wurde somit deren Zusammenspiel mit rassistischen, fremdenfeindlichen und antisemitischen Ausdrücken zu einer leitenden Fragestellung der Interviewstudie.

Auf den folgenden Seiten wird dieser argumentative Bogen, von der theoretischen Reflexion über methodologische Überlegungen hin zur empirischen Rekonstruktion, noch einmal in seinen wesentlichen Arbeitsschritten und Ergebnissen zusammengefasst (Kap. 8.1 und 8.2). Anschließend soll auf empirische und theoretische Fragestellungen eingegangen werden, die im Rahmen dieser Untersuchung offen bleiben mussten bzw. naheliegende Anknüpfungspunkte für weitere Forschung bilden (Kap. 8.3 und 8.4). Das Kapitel schließt mit einem Resümee der theoretischempirischen Ergebnisse der Studie.

\subsection{FAZIT DER THEORIEBILDUNG}

Antiamerikanismus, so die grundlegende Annahme der vorliegenden Arbeit, ist in erster Linie als Tätigkeit aufzufassen, als eine Form des Sprechhandelns. Ausdrücke werden nicht dadurch antiamerikanisch, dass sie von antiamerikanisch disponierten Subjekten geäußert werden, sondern dadurch dass sie bestimmte rhetorische Funktionen erfüllen. Diese liegen den zuvor dargestellten empirischen Befunden zufolge maßgeblich im Bereich der Konturierung und Stabilisierung ethnischer und nationaler Identität. ${ }^{1}$

1 Ich lege dabei, im Gegensatz zu einer in der Forschungsliteratur häufig formulierten These, keinen besonderen Schwerpunkt auf die Rolle von Antiamerikanismus bei der Konstruktion einer europäischen Nationalidentität (Markovits 2007, S. 201 ff.; Gulddal 2011, S. 6 ff.). Das heißt nicht, dass die These einer antiamerikanischen Einigung Europas nicht plausibel wäre. Jedoch finden sich in meinem Material keinerlei Hinweise auf einen sol- 
Wie der Verweis auf die rhetorische Praxis bereits nahelegt, lässt sich solches Sprechhandeln nicht anhand von lexikalisch-semantischen oder propositionalen Kriterien definieren. Der antiamerikanische Sprachgebrauch ist nicht anhand des semantischen Sinngehalts bestimmter Amerika-Stereotype oder deren (mangelnder) Korrespondenz mit ,der Realität' Amerikas zu bestimmen. Ein Ausdruck wird nicht dadurch schon antiamerikanisch, dass er bspw. das Klischee der ,schießwütigen Amerikaner' reproduziert. Dies gilt auch dann, wenn die gezeichneten Amerikabilder auf lexikalisch-grammatischer Ebene allgemein als abwertend oder aversiv klassifiziert werden können. Ebenso wenig wird ein Amerikabezug dadurch zum Vorurteil, dass in ihm , die Realität“ der USA falsch oder nicht hinreichend genau abgebildet wird. Ein solcher korrespondenztheoretischer Realismus wäre einerseits reduktionistisch, da er das gesellschaftliche Problem vorurteiliger Rede zu einem kognitiven Fehler verengte. Er wäre darüber hinaus aber auch mit den erkenntnisund sprachtheoretischen Aporien eines ,semantischen und hermeneutischen Objektivismus“ (Wellmer 2004, S. 22) beladen, d.h. er mutete sich selbst letztendlich die Aufgabe zu, ,die Realität' der USA positiv auszuweisen.

Beide Kriterien, lexikalisch-semantische Bedeutung und propositionale Wahrheit, sind in zweifacher Hinsicht zurückgewiesen worden. Nicht nur sind sie nicht hinreichend, um antiamerikanische Vorurteile zu bestimmen, sondern sie sind auch nicht als notwendige Kriterien für antiamerikanische Ausdrücke aufzufassen. Auch mit nicht-feindseligen oder benevolenten sowie propositional wahren Sätzen kann antiamerikanisch gesprochen werden. Zwar mögen die genannten Kriterien in einer großen Zahl antiamerikanischer Ausdrücke gegeben sein; auch die methodenintegrative Empirie der vorliegenden Arbeit liefert hierfür Indizien. ${ }^{2}$ Als Grundlage für eine Definition von Antiamerikanismus sind sie aber nur unter Inkaufnahme erheblicher theoretischer Defizite zu gebrauchen.

In einer sehr ähnlichen Weise sind auch psychologische Vorurteilsdefinitionen problematisch. Deren Rekurs auf psychische Dispositionen, insbesondere Einstellungen als kognitive und affektive Schemata, führt in vergleichbare Probleme, wie die beiden zuvor genannten Kriterien: So können erstens antiamerikanische Äußerungen auch von Personen getätigt werden, deren Handeln ansonsten keinen Anlass zu einer Klassifikation als ,AntiamerikanerInnen“ gibt (vgl. z.B. den fragmentierten

chen paneuropäischen Antiamerikanismus. Im Gegenteil: Die Ergebnisse der qualitativen Empirie deuten darauf hin, dass Antiamerikanismus zumindest gegenwärtig gerade in Bezug auf deutsch-nationale Wir-Gruppenkonstruktionen eine bedeutsame Funktion einnimmt. In Abschnitt 8.3 wird diese Frage noch einmal aufgegriffen.

2 Auch wenn die Validität der Survey-Instrumente anhand des gewählten methodenintegrativen Designs nicht belegt werden kann (vgl. Kap. 5.3), haben sich die Amerika-Items doch immerhin als brauchbares Mittel zur Auswahl antiamerikanisch sprechender Personen erwiesen. 
Sprachgebrauch von Frau H, Kap. 7.5.1). Darüber hinaus muss aber zweitens die einstellungstheoretische Vorurteilsdefinition einen Begriff antiamerikanischen Handelns schon voraussetzen, um die antiamerikanische Subjektpsyche überhaupt bestimmen zu können, und ist insofern reduktionistisch. Zwar kann ein psychologisches Konzept antiamerikanischer Einstellungen Wichtiges zur Erklärung von individuellen Differenzen in antiamerikanischem Handlungen sowie der Persistenz des Phänomens beitragen - nicht zuletzt die Erhebungsinstrumente der hier vorgelegten Survey-Untersuchung beruhen maßgeblich auf der Annahme, dass manche Personen eine Disposition zur relativ situationsunabhängigen Reproduktion gewisser Amerika-Stereotype aufweisen. Als Ausgangs- und Ankerpunkt der Begriffsbildung muss das Einstellungskonzept aber problematisch erscheinen.

Der Begriff antiamerikanischen Handelns, den die Vorurteilspsychologie voraussetzt, scheint in der Forschung bislang vernachlässigt bzw. als selbstevident übergangen worden zu sein. Der sprechakttheoretische Blick dieser Arbeit versteht sich als ein Beitrag zur Füllung dieser Forschungslücke, und zwar in zweifacher Hinsicht: Einerseits rückt mit dieser Perspektive der antiamerikanische Sprachgebrauch in den Fokus, die praktische Bedeutung antiamerikanischen Sprechens und dessen flexible und fragmentierte Ausdrucksweisen. Andererseits fällt mit der performativen Perspektive neues Licht auf den Gebrauchsaspekt des anti-antiamerikanischen Sprechens selbst. Zwar ist in der Literatur verschiedentlich darauf hingewiesen worden, dass das „Definitionsproblem“ (Baethge et al. 2010, S. 367) des Antiamerikanismus vor allem ein Problem der Anwendung von Definitionen sei (z.B. Beyer und Liebe 2014, S. 91; vgl. Kap. 2.2.1) aber diese Theorieperspektive ist bislang kaum systematisch weiterentwickelt worden. Ein performativer Antiamerikanismusbegriff versucht in dreifacher Hinsicht das theoretisch-empirische Potential einer solchen gebrauchssensiblen Begriffsbildung zu entfalten: methodologisch, gesellschaftstheoretisch und normativ.

So erschließt diese Perspektive zunächst in methodologischer Hinsicht ein neues Fundament für die empirisch begründete Rekonstruktion antiamerikanischer Sprachgebräuche. Hierbei bildet das Konzept der Familienähnlichkeit einen zentralen Orientierungspunkt: Wenn nicht nur antiamerikanisches Sprechen sondern auch das begriffliche Sprechen über Antiamerikanismus durch Sozialität, Flexibilität und Normativität gekennzeichnet ist, so muss die Nominaldefinition als ein stark beschränkendes Modell zur Reflexion dieser Sprachpraxis erscheinen. Im Gegensatz $\mathrm{zu}$ solchen kriteriellen Bestimmungen zeichnet sich eine empirisch begründete ,Kartierung' von Ähnlichkeiten und Überschneidungen zwischen antiamerikanischen Sprechweisen vor allem dadurch aus, dass sie das Verhältnis von begrifflichem Sprechen und Gegenstand in die Begriffsbestimmung mit aufnimmt. Natürlich kann der Familienähnlichkeitsbegriff den Regelregress im begrifflichen Sprechen nicht beenden, der sich in der Notwendigkeit ausdrückt, über die praktische Anwendung von Sprachzeichen auch dann noch „Rechenschaft abgeben“ zu müssen 
(Winch 1966, S. 41 f.), wenn deren lexikalisch-semantischer Gehalt bereits definiert wurde. Im Gegensatz zur Nominaldefinition klammert er dieses Gebrauchsproblem aber nicht als philosophische Unannehmlichkeit aus, die um der wissenschaftlichen Exaktheit willen vernachlässigt werden kann. Ein performativer Antiamerikanismusbegriff institutionalisiert gewissermaßen das Gebrauchsproblem als Moment seiner begrifflichen Konstruktionen selbst, und zwingt sich so die stetige Reflexion auf deren Unabgeschlossenheit auf.

Dies findet in den begrifflichen Grundlagen einer Praxistheorie der Bedeutung ebenso Ausdruck, wie in der Methodologie der erschließenden Kritik. Denn es verschiebt sich damit das Kriterium für eine gelingende Verwendung des Antiamerikanismusbegriffes von der Korrespondenz eines lexikalischen Definiens mit dessen außersprachlichem Gegenstand, hin zur Überzeugungskraft der Antiamerikanismuskritik in einem weiteren gesellschaftspolitischen bzw. lebensweltlichen Kontext. Durch die Bestimmung ihres Gegenstands als Rhetorik, wird die Vorurteilsforschung in gewissem Sinne selbst zu Rhetorik. ${ }^{3}$

Dieser Punkt verweist auf die Notwendigkeit einer gesellschaftstheoretischen Verortung des Vorurteilsbegriffes. Antiamerikanische Vorurteile lassen sich ohne ein theoretisches Anknüpfen an die gesellschaftlichen Konflikte und Problemdiskurse, in die sie eingebettet sind, nicht bestimmen. Ohne Berücksichtigung der gesellschaftlichen Machtwirkung antiamerikanischen Sprechens bleibt unklar, inwiefern antiamerikanische Stereotype sich bspw. von solchen über Bahnangestellte unterscheiden lassen, d.h. warum die einen als Vorurteil problematisiert werden, die anderen hingegen nicht. ${ }^{4}$ Die Einbettung des Antiamerikanismus in politische Debatten ist kein hinzutretendes, externes Moment der Vorurteilsproblematik, sondern dessen konstitutiver Bestandteil. Wenn dies zutrifft, muss die theoretische Bestimmung antiamerikanischer Vorurteile maßgeblich in der Rekonstruktion der diskursiven Funktionskontexte bestehen, in die diese rhetorisch eingebunden sind. Im Rahmen dieser Arbeit wurde dies mittels der Konzepte soziale Ungleichheit und

3 Hierbei ist zu berücksichtigen, dass dies nur scheinbar eine Option darstellt: Auch Verweise auf wissenschaftliche Wertneutralität und definitorische Exaktheit sind rhetorische Verweise, nur eben solche, die ihren rhetorischen Charakter - dass sie bei allem Bemühen um exakte Definitionen ,die Definition der Exaktheit schuldig“ bleiben (Wittgenstein 2006, S. 279; vgl. Kap. 3.4) - tendenziell ausblenden.

4 Meines Wissens spricht zumindest in der Forschungsliteratur zu Vorurteilen niemand von ,Anti-Bahnismus‘ o.ä. Damit soll nicht gesagt sein, dass stereotype und abwertende Haltungen gegenüber dem Personal der Deutsche Bahn AG prinzipiell unproblematisch wären. Es zeigt aber, dass der Begriff des Vorurteils mehr umfasst, als das Auftreten von Gruppenstereotypen, negativen Affekten und Verhaltensdispositionen (ein ähnliches Argument macht Anja Weiß bzgl. der theoretischen Bestimmung von Rassismus (Weiß 2001, S. 81; vgl. auch Kap. 4.2). 
Diskriminierung versucht, wobei nationalistische und ethnozentrische Identitätskonstruktionen den Fokus bildeten.

Über gesellschaftliche Diskurse können die Sozialwissenschaften aber nicht sprechen ohne sich zugleich, wie auch immer vermittelt, an diesen zu beteiligen. Diese normative Implikation der Vorurteilskritik wird in bestehenden Forschungsansätzen häufig nur randständig reflektiert oder unter Verweis auf wissenschaftliche Wertneutralität ausgeklammert. Bestehende Vorurteilsdefinitionen, so wurde argumentiert, neigen aber trotz bzw. u.U. gerade wegen ihres wertneutralen Selbstverständnisses zu einer problematischen moralischen Positionierung. Sie tun dies z.B., indem sie feststellen, dass Antiamerikanismus feindselig, hasserfüllt und abwertend sei, und damit zugleich dessen Status als gesellschaftliches Problem bezeichnet wissen wollen, ohne jedoch zu fragen, inwiefern Feindseligkeit, Hass oder Abwertung per se ein ethisches Problem darstellen.

Indem sie über Antiamerikanismus spricht, setzt jede Vorurteilsforschung eine politisch-normative Problembestimmung bereits voraus, da sie ohne eine solche gar keinen Gegenstand zu besprechen hätte. Wertneutrale Positionen betrachten diese Voraussetzung aber als ihrer Theoriebildung externes Phänomen, was letztendlich auf eine stillschweigende bzw. unreflektierte Reproduktion von Common Sense Vorurteilsbegriffen hinausläuft. Ähnliches gilt natürlich auch für solche Auffassungen des Antiamerikanismusproblems, die ihre Bestimmungen mit psychopathologischem Vokabular explizit normativ aufladen. Solche Versuche, die Amerikafeindschaft als ,hysterisch“, ,obsessiv“, ,paranoid“, etc. zu klassifizieren, sind letztendlich in ähnlicher Weise mit den Problemen einer „externen Kritik“ (vgl. Kap. 4.5.3) beladen, wie der Versuch, Vorurteile aus wertneutraler Perspektive in den Blick zu nehmen.

Gegen beide genannten Positionen, die explizit normative und die wertneutrale, wurde hier die Methodologie einer immanenten oder erschließenden Kritik stark gemacht. Diese zeichnet sich dadurch aus, dass sie einerseits ihre normative Komponente anerkennt, andererseits aber eine starke Normativität vermeidet: Vorurteilskritik als „Normative Theorie ohne Normativität“ (Bonacker 2000, S. 13 f.). Eine solche Kritik versteht sich als Teilnehmerin gesellschaftlicher Diskurse, die sie mittels einer spezifischen reflexiven Methodologie neu zu erschließen versucht. Sie deutet stereotypes Sprechen über Amerika hinsichtlich seines performativen Sinngehalts und versucht so, es als Ausdruck von etwas anderem nachvollziehbar zu machen, als es seinem Selbstverständnis nach ist. Was als konstatives Sprechen über, amerikanische Verhältnisse " erscheint, wird als Akt nationalistischer Identitätskonstruktion lesbar. Was sich als moralische Empörung über , amerikanische Menschenrechtsverstöße' präsentiert, wird als Normalisierung der nationalsozialistischen Vergangenheit verstehbar. Als heuristischer Rahmen dieses kritischen Deutungsprozesses wurden hier die Konzepte soziale Ungleichheit und Diskriminierung bzw. die moderne Gleichheitsidee aufgegriffen: Ein stereotypes Sprechen über 
Amerika als Antiamerikanismus zu bestimmen bedeutet demnach, es als rhetorisches Mittel zur Reproduktion kategorialer, diskriminierender Differenzkonstruktionen zu deuten.

Neben diesem Deutungsaspekt ist für die Methodologie erschließender Kritik entscheidend, dass sie ihren eigenen normativ-gesellschaftstheoretischen Ausgangspunkt nicht als absoluten Maßstab richtigen Verhaltens auffassen darf. Die egalitäre Norm bildet nicht das ,gute“ Gegenstück zum ,schlechten`Antiamerikanismus. Vielmehr ist die moderne Gleichheitsidee selbst durch eine immanente Paradoxie von universeller Gleichheit und individuellem Bedürfnis gekennzeichnet (vgl. Menke 2004, S. 28). Der Vollzug dieser Norm, die Gleichberücksichtigung von Personen, besteht in einem prinzipiell unabgeschlossenen Streit konkurrierender Vergleichsmaßstäbe. Dementsprechend geht eine erschließende Vorurteilskritik davon aus, dass es keine strikte Trennlinie zwischen vorurteiligem und vorurteilsfreiem Sprechen gibt und erachtet eine definitive Grenzziehung zwischen Antiamerikanismus und ,Amerikakritik' als theoretisch wenig zielführend. ${ }^{5}$ Anti-egalitär ist nicht nur die Ablehnung etablierter Normauffassungen, z.B. der rechtlichen Gleichbehandlung verschiedener ethnischer Gruppen. Auch eine Gleichheitsauffassung, die eine spezifische Form der Gleichbehandlung solcher Gruppen naturalisierend begründet, d.h. die Kontingenz ihrer eigenen Normauffassung systematisch ausblendet, kann als antiegalitär gelten. Als Beispiel hierfür kann eine ethnopluralistische oder „Herder'sche“ Weltsicht (Wimmer 2008, S. 60) gelten, in der die politische Gleichheit ethnischer Gruppen prinzipiell anerkannt, jedoch mit essentialistischen Vorstellungen von ethnischen Gruppenunterschieden und angestammten ,Lebensräumen“ verknüpft wird. In diesem Sinne nimmt eine erschließende Vorurteilskritik ihren normativen Ausgangspunkt bei der Kontingenz des Vollzuges der Gleichheitsidee. Sie richtet sich gegen antiegalitäre Vollzüge der egalitären Norm.

Dementsprechend wird hier angenommen, dass sowohl das Vorurteil als auch die Vorurteilskritik diese Kontingenz der modernen Gleichheitsidee reflektierend aufgreifen. Der entscheidende Unterschied liegt in der Art der Reflexion. Vorurteile sind demnach weder eine eindeutige moralische Abweichung noch eine individuelle Pathologie, sondern eine Pathologie des Sozialen (vgl. Honneth 2007a, S. 31), genauer: eine Pathologie des egalitären Normvollzuges. Diese soziale Pathologie, zu der kein gesundes Außen abschließend formuliert werden kann, besteht nicht etwa darin, dass sich keine ,gute“ Gleichheitsauffassung formulieren lässt oder das ,richtige' Normverständnis sich nicht durchsetzt. Sie besteht darin, dass sich existierende Gleichheitsauffassungen gegen die Kontingenz ihrer eigenen Setzungen ab-

5 Eine solche Grenzziehung müsste ja bereits über ein entparadoxiertes Kriterium für gelingende Normvollzüge außerhalb des fortlaufenden Konfliktes von Gleichheitsauffassungen verfügen. Damit aber widerspräche sie dem Verständnis der modernen Gleichheitsidee, das sie selbst anlegt. 
schirmen, ihre Gründe naturalisieren und sich so dem Bereich der Rechtfertigung rhetorisch entziehen. Das Problem des egalitären Normvollzuges, das der Vorurteilsbegriff adressiert, besteht in dieser tragischen Reflexivität, durch die innerhalb der egalitären Norm gegen die egalitäre Norm gehandelt wird. In diesem Sinne richtet sich Vorurteilsforschung als „normative Theorie ohne Normativität“ nicht nur kritisch gegen das Problem antiegalitärer Rhetorik, sondern auch gegen die egalitäre Norm selbst: Sie zeigt, dass diese kein prinzipielles Argument gegen Diskriminierung beinhaltet, sondern mit antiegalitären Normvollzügen vereinbar ist. Sofern dieser ideologische Effekt mithilfe von Amerikastereotypen realisiert wird, können solche Sprechweisen als antiamerikanische Vorurteile bezeichnet werden.

Das bedeutet freilich nicht, dass der Vorurteilsbegriff nicht auch Antiamerikanismen trifft, die sich jenseits solcher ideologischer Reflexivität in expliziter Weise gegen ,Amerika' richten. Auch die Anschläge des 11. September 2001 waren antiamerikanische Taten. Um diese als antiamerikanische zu markieren und moralisch zu verurteilen, braucht es aber keine Kritik. Die Terrorakte brechen völlig unideologisch mit etablierten demokratischen Normen und verstoßen überdies gegen geltendes Recht. Der Gegenstandsbereich der Antiamerikanismusforschung beschränkt sich aber nicht auf derartige mörderische Taten, sondern er beinhaltet, ja, er beginnt gewissermaßen erst mit der Rechtfertigung von Diskriminierung, Verfolgung und Mord. ${ }^{6}$ Dass solche Rechtfertigungen innerhalb der existierenden demokratischen Gesellschaftsordnungen möglich sind und regelmäßig auftreten, ist zugleich Gegenstand und Ermöglichungsbedingung von Vorurteilskritik.

Wie aber lässt sich ein solcher kritischer Vorurteilsbegriff konkret auf antiamerikanisches Sprechen anwenden? Welche performativen Wirkungen antiamerikanischer Rhetorik lassen sich empirisch zeigen, und zwar ohne ex ante von einer geschlossenen Feindschaft oder einem kognitiven Schematismus des Vorurteils auszugehen? Die vorliegende Arbeit hat im Rahmen eines sequenziell quantitativqualitativen Forschungsdesigns Hypothesen zur Beantwortung dieser Fragestellung generiert, die im folgenden Abschnitt resümiert werden.

6 Wie bereits in der Einleitung zu dieser Arbeit formuliert, bedeutet das nicht, dass vorurteilige Rechtfertigung und gewalttätige Diskriminierungs- oder Verfolgungspraxen unabhängig voneinander sind. So ist die Billigung oder verschwörungstheoretische Erklärung der Anschläge vom 11. September natürlich deswegen als Vorurteil problematisch, weil bei diesem Ereignis Menschen ermordet wurden. Die Vorurteilsproblematik besteht gerade in diesem Spannungsverhältnis von Gewalttat und diskursiver Rechtfertigung. Dies bezeichnet der Begriff der Performanz. 


\subsection{FAZIT DER METHODENINTEGRATIVEN EMPIRIE}

Ausgangspunkt der empirischen Analysen bildete ein Survey, in dem nach der Methode klassischer Einstellungsmessung die Zustimmung zu stereotypen Amerikabildern erhoben wurde. Die gebrauchte Likert-Skala ließ sich trennscharf in zwei hoch korrelierte $(r=, 773)$ Dimensionen aufteilen, die , antiimperialistische ' und ,kulturkonservative' Stereotype erfassen. Auf der Grundlage der untersuchten Zufallsstichprobe $(\mathrm{N}=808)$ lässt sich somit bei ca. zehn Prozent der deutschen Bevölkerung eine gesteigerte Tendenz zur Reproduktion der erhobenen Amerikastereotype feststellen. ${ }^{7}$ Zudem lassen simultan erhobene Skalen zum Syndrom der „Gruppenbezogenen Menschenfeindlichkeit“ (Zick et al. 2012) Aussagen über den Zusammenhang von Antiamerikanismus und anderen Vorurteilsformen zu. Erhöhte Korrelationen lassen sich mit Antisemitismus $(r=, 452 / r=, 294)$, Antizionismus ( $r$ $=, 486 / \mathrm{r}=, 488)$, Rassismus $(\mathrm{r}=, 546 / \mathrm{r}=, 364)$ und Fremdenfeindlichkeit $(\mathrm{r}=, 434$ / $r=, 247$ ) feststellen. ${ }^{8}$ Diese Zusammenhänge gingen als Explananda in die qualitative Interviewstudie ein.

Die performative Wirkung antiamerikanischen Sprechens, so konnte im Rahmen der qualitativen Analysen gezeigt werden, ist insgesamt im Bereich ethnischer und nationalistischer Identitäts- bzw. Differenzkonstruktionen anzusiedeln. Hier können Amerikastereotype eine Vielzahl rhetorischer Funktionen erfüllen die direkt oder indirekt mit kategorialen und essentialistisch begründeten Gruppenzuschreibungen verknüpft sind. Im Material wurden drei wesentliche Wirkweisen antiamerikanischer Vorurteile nachgezeichnet. An diesen argumentativen Funktionen wurden zugleich Überschneidungen und funktionale Zusammenhänge mit anderen Vorurteilsformen erkennbar.

(1) Ähnlich wie andere Nationalstereotype, können auch Amerikabilder der Konturierung und Aufwertung einer nationalistischen Wir-Gruppenkonstruktion dienen. Anhand der negativen Vergleichsfolie ,Amerika‘ werden die vermeintlichen Vorzüge und besonderen Qualitäten der eigenen Nation sichtbar gemacht bzw. als negativ wahrgenommene Aspekte der Eigengruppe auf ,amerikanischen Einfluss‘ zurückgeführt. Zudem besteht eine besondere Funktion antiamerikanischer Rhetorik darin, dass die USA darin als eine „Figur des Dritten“ (Holz 2010, S. 296) fungieren können, die als ideologische Stabilisierungsinstanz einer ethno-

7 Auf der , antiimperialistischen ‘ Dimension liegen neun Prozent $(n=716)$, auf der ,kulturkonservativen“ fünfzehn Prozent $(n=739)$ der Teilnehmenden höher als eine Standardabweichung über dem Skalenmittelwert. Diese Tendenz ist über verschiedene Teilgruppen der Stichprobe hinweg relativ homogen zu beobachten.

8 Angegeben sind die Faktorkorrelationen in einer simultanen CFA (vgl. Kap. 6.4), jeweils zuerst der Zusammenhang mit der antiimperialistischen und dann mit der kulturkonservativen Dimension. 
nationalistischen Weltanschauung wirkt. ,Amerika' erscheint hier als diejenige Nation, die keinerlei ,Ur-Bevölkerung' aufweist und dennoch Nation bleibt, und ermöglicht so eine latente Bearbeitung der Kontingenz der ethno-nationalen Ordnung. An ,Amerika' kann die Möglichkeit, dass die Welt nicht ethno-nationalistisch verfasst sein könnte, zugleich thematisiert und an einen isolierten Ort ausgelagert werden.

(2) Antiamerikanismus dient als reflexives Vorurteil auch der Rechtfertigung rassistischer oder ethnozentrischer Positionen. So taucht der empörte Verweis auf , amerikanischen Rassismus' gerade in solchen Redekontexten auf, in denen selbst fremdenfeindliche oder rassistische Differenzkonstruktionen reproduziert werden, und wirkt dort als präventive Abwehr von Rassismusvorwürfen. Während dieser rechtfertigende Abgleich eigener und ,amerikanischer' Diskriminierung in manchen Fällen explizit vollzogen wird (z.B. Herr E: „In Deutschland redet man immer von Rassismus [...] aber in Amerika gibt`s den tatsächlich“, vgl. Kap. 7.4.2.1), konnte in anderen eine ideologisch-implizite Variante dieser Rhetorik beobachtet werden. So begibt sich Herr A in einen performativen Widerspruch, indem er die rassistische Diskriminierung, die er an den USA verurteilt (Widerstand gegen einen schwarzen Präsidenten), in Bezug auf die deutsche Wir-Gruppe selbst reproduziert (Cem Özdemir könne aufgrund seiner türkischen Herkunft niemals Bundeskanzler werden). Dieser Widerspruch, die Möglichkeit, dass auch gegenüber seiner WirGruppenkonstruktion ein Rassismusvorwurf erhoben werden könnte, wird aber von ihm an keiner Stelle explizit thematisiert. Mittels antiamerikanischer Rhetorik kann der Teilnehmer rassistisch sprechen und zugleich seine Position mit egalitären Normen in Einklang bringen, indem er das entstehende Rassismusproblem latent (als , amerikanisches') anerkennt, ohne es auf die Eigengruppe anwenden zu müssen.

(3) Eine strukturell ähnliche Form der latenten Bearbeitung von Begründungsproblemen findet sich im Kontext von Erinnerungspolitik und nationaler Identität. So können antiamerikanische Sprechweisen auf doppelte Weise zu einer impliziten Auflösung der „Paradoxie der Normalisierung“ (Holz 2007) des deutschen Nationalismus nach 1945 verhelfen: Mittels des Szenarios einer , amerikanischen Manipulation“ des europäischen Bildungssystems wird eine teilweise Täter-Opfer Umkehr vollzogen, in der , die Deutschen“ als Opfer einer antideutschen Schuld-Kampagne erscheinen. Bilder eines ,amerikanischen Völkermordes ‘ an ,den Indianern“ unterstützen diese revisionistische Versöhnung von NS-TäterInnen und Nachgeborenen, indem sie eine latente Normalisierung des Holocaust ermöglichen. Die nationalsozialistische Judenvernichtung kann angesprochen und zu einem Genozid unter vielen normalisiert werden, ohne den Mord an europäischen Juden und Jüdinnen ein einziges Mal explizit benennen zu müssen. Neben dieser funktionalen Analogie mit sekundär-antisemitischen Rhetoriken lässt sich außerdem ein antiamerikanischantisemitischer Sprachgebrauch beobachten, in dem Amerikastereotype als Moment 
eines ,klassischen“ weltanschaulichen Antisemitismus gebraucht werden. In dieser Variante treten die USA als Instrument bzw. Komplizen der „Israelis“ auf, die „die halbe Welt mit Krieg überziehen“ (Frau K, vgl. Kap. 7.3.2.2), angetrieben durch ,jüdische' Streitlust und Gier.

Anhand der dargestellten Analysen lassen sich insgesamt drei Formen des rhetorischen Zusammenspiels von Antiamerikanismus, Antisemitismus, Rassismus und Fremdenfeindlichkeit ausmachen, die als Erklärungshypothesen auch für die beobachteten statistischen Korrelationen in Betracht kommen:

- Funktionale Analogie bzw. Substitution: Antiamerikanismus erfüllt eine vergleichbare Funktion wie andere nationalistische Fremdgruppenkonstruktionen (Konturierung, relative Aufwertung, Externalisierung) oder sekundär antisemitische Rhetoriken (Täter-Opfer Umkehr, Holocaustrelativierung).

- Rechtfertigung und Latenzschutz: Antiamerikanismus dient der expliziten oder impliziten Abwehr bzw. Vermeidung von Rassismus- oder Revisionismusvorwürfen, bei gleichzeitiger rassistischer oder revisionistischer Kommunikation.

- Wechselseitige Ergänzung von Stereotypien: Antiamerikanismus tritt als ein ergänzendes Motiv in antisemitischer (,jüdisch kontrollierte USA') oder fremdenfeindlicher bzw. rassistischer Rede auf (,liederliche Amerikaner' neben , aggressiven Russen', ,untreuen Türken‘, etc.).

Im Lichte dieser Thesen kann das gemeinsame Auftreten antiamerikanischer, antisemitischer, fremdenfeindlicher und rassistischer Sprechweisen als Ergebnis einer rhetorisch-ideologischen, Arbeitsteilung' begriffen werden. Verschiedene Vorurteilsformen sind demnach nicht nur deshalb miteinander verknüpft, weil sie Ähnlichkeiten hinsichtlich semantischer Struktur oder argumentativer Funktion aufweisen, sondern, weil ihre Kombination bei der Reproduktion rigider Identitätskonstruktionen unter egalitären Vorzeichen einen rhetorischen ,Mehrwert' erzeugt. Das antiamerikanische Vorurteil schützt das rassistische Vorurteil bzw. ein Vorurteil reflektiert auf ideologische Weise die antiegalitären Aspekte des anderen.

Den Rahmen des größten Teils aller beobachteten Antiamerikanismen bilden rigide nationalistische und ethnozentrische Identitätskonstruktionen. Aber bedeutet dies, dass Antiamerikanismus immer als Teil einer geschlossenen völkischnationalen Weltanschauung auftreten muss? Die Ergebnisse der vorliegenden Interviewstudie geben Anlass zur Skepsis gegenüber der These von einer ,,completeness of anti-American resentment" (Friedman 2012, S. 5). So konnten im untersuchten Material zwei Formen der Abweichung von einem weltanschaulich geschlossenen Antiamerikanismus festgestellt werden: eine Fragmentierung des antiamerikanischen Sprachgebrauchs und eine Verschiebung des Funktionskontextes in Bereiche, deren vorurteilskritische Relevanz unklar ist. 
Im ersten Fall treten antiamerikanische Sprechhandlungen mit klarer vorurteiliger Performanz unmittelbar neben solchen auf, die keinerlei vorurteiligen Funktionskontext erkennen lassen oder sogar im Widerspruch zu getätigten antiamerikanischen Ausdrücken stehen. So konnte im Interview mit Frau H ein charakteristisches Schwanken zwischen der Identifikation als unpolitischer ,Normalbürgerin " und einer völkisch-nationalistischen Identifikation mit dem ,ursprünglichen ' Deutschland festgestellt werden. Während erstere Variante sich zwar teilweise gegen das ,protzige" und , arrogante' Amerika richtet, aber nicht mit einer diskriminierenden Differenzkonstruktion zusammenhängt, konturiert die zweite Variante offensiv eine essentialistisch-ethnozentrische Identitätskonstruktion gegen das ,wurzellose“ und ,plutokratische" Amerika. Der Widerspruch zwischen der antiamerikanischen und der , unpolitischen“ Variante ihrer Identitätskonstruktion wird Frau H unterdessen durchaus bewusst. Sie verweist mehrfach darauf, nicht als amerikafeindlich gelten bzw. auf die geäußerten Positionen nicht festgelegt werden zu wollen. Bezeichnend ist dabei die schlafwandlerische Sicherheit, mit der sie einen antiamerikanischen Ethnonationalismus reproduziert, mit dem sie sich dann im nächsten Moment schon nicht mehr identifizieren möchte.

Eine andere Form der Inkonsistenz antiamerikanischen Sprechens zeigt sich in jenem Phänomen, das ich als Verschiebung des Funktionskontextes bezeichnet habe: Antiamerikanische Rhetorik tritt im Beispiel von Herrn I nicht fragmentiert, wie bei Frau H, sondern über das gesamte Interview konsistent auf. Zugleich stellt sich aber angesichts des funktionalen Kontextes die Frage, inwiefern diese Rede überhaupt als antiamerikanisch im Sinne des vorgeschlagenen Vorurteilsbegriffes gelten kann. Die Wir-Gruppenkonstruktion, zu deren Konturierung und Aufwertung negative Amerikastereotype herangezogen werden, beruht auf einer lokalpatriotischen Stadtteilidentität, die von Herr I explizit gegen deutschen Nationalismus abgegrenzt und deren multiethnische Zusammensetzung dezidiert positiv hervorgehoben wird. Angesichts dieser Differenzkonstruktion stellt sich die Frage, inwiefern ihr performativer Sinn als effektiver Beitrag zu gruppenbezogener Diskriminierung gesehen, bzw. inwiefern Herrn Is Sprechen überhaupt als Vorurteil problematisiert werden kann. Es kann vermutet werden, dass die Funktion seiner Differenzkonstruktion gerade darin liegt, die moralischen Untiefen nationaler Identifikation zu vermeiden, und dennoch nicht auf eine starke sozialräumliche Identität verzichten zu müssen. Für die Reproduktion eines solchen Lokalpatriotismus als politisch entschärftem Nationalismus scheinen antiamerikanische Fremdgruppenkonstruktionen besonders geeignet: Wer sich mit ethnischer Diversität identifiziert und gegen die ethnonationalen Engführungen ,Deutschlands' positioniert, kann seine Wir-Gruppe schwerlich gegen ,Ausländer', ,Moslems` oder andere ,klassische' Fremd- und Feindbilder abgrenzen. ,Die Amerikaner' hingegen bieten sich aufgrund ihrer vermeintlichen Distanz zu ethnischen Klassifikationsmustern als ,neutraler', moralisch unbedenklicher Antagonist an. Dennoch bleibt in den Analysen des vorliegenden 
Materials unklar, inwiefern Herrn Is Lokalpatriotismus in einem systematischen Zusammenhang mit Diskriminierung und Verfolgung, d.h. überhaupt als antiamerikanisch, betrachtet werden kann.

Es lassen sich also zwei Formen der Inkonsistenz antiamerikanischen Sprechens beobachten: Fragmentierung und unscharfe Funktionskontexte. ${ }^{9}$ Beide markieren jeweils auch eine Grenze des Sprechens über Antiamerikanismus. Die am Beispiel von Frau $\mathrm{H}$ dargestellte Fragmentierung vorurteiliger Rhetorik verweist auf die Engführungen eines klassischen einstellungstheoretischen Vorurteilskonzeptes, dass den argumentativen und Flexiblen Charakter vorurteiligen Sprechens ausblendet. Am Beispiel von Herrn I wird hingegen eine Problematik des performativen Antiamerikanismusbegriffes erkennbar, nämlich dessen nahtloses Übergehen in nichtvorurteiliges Sprechen. Ausgehend von der in den Kapiteln 3 und 4 explizierten Theorieannahme, dass das diskursive Phänomen ,Vorurteil ‘ sich gerade durch seine fließenden Übergänge zu ,normaler'Alltagskommunikation auszeichnet, kann diese Problematik aber zugleich als theoretischer Zugewinn gelten. Der performative Antiamerikanismusbegriff macht die unscharfen Grenzverläufe zwischen vorurteilsfreier Normalität und vorurteiligem Sprechen sichtbar und erschließt gerade damit theoretisch-empirische Erkenntnismöglichkeiten.

Mittels eines performativen Vorurteilsbegriffs wurden im Rahmen dieser Studie also einerseits wesentliche rhetorische Wirkweisen antiamerikanischen Sprechens rekonstruiert: Antiamerikanische Rhetorik kann als Ausdruck und Stabilisierung ethno-nationalistischer Identitätskonstruktionen verstanden werden. Hierbei können sowohl explizite als auch kommunikationslatente Varianten antiamerikanischer Alltagskommunikation auftreten. Insbesondere letztere können als Erkenntniszugewinn der vorliegenden Arbeit aufgefasst werden, da zu rechtfertigenden Funktionen von Antiamerikanismus im Rahmen von normalisierenden und schuldabwehrenden sowie ethnozentrischen Konstruktionen bislang kaum Forschung existiert.

Andererseits konnte mittels der sprechakttheoretischen Perspektive auch die Unschärfe des Antiamerikanismusbegriffes neu erschlossen werden. Dem vielzitier-

9 Es sei an dieser Stelle ergänzt, dass die genannten Formen der Inkonsistenz nicht gleichbedeutend sind mit dem häufig wiederholten Befund einer Ambivalenz antiamerikanischer Äußerungen: Frau H und Herr I sprechen beide auch ambivalent, d.h. sie kombinieren in ihrem Amerikabild negative und positive Aspekte; es besteht aber ein Unterschied zwischen einem rhetorisch funktionalen Sprechen über Amerika, in dem eine Ambivalenz der Bewertungen erkennbar wird, und einem stereotypen Sprechen über Amerika, das mal vorurteilige Funktionen erfüllt, mal nicht (Fragmentierung) bzw. dessen vorurteilige Funktion nicht klar bestimmt werden kann (Verschiebung des Funktionskontextes). Zwar sind alle drei Aspekte offenbar eng verknüpft mit Fragen der Rechtfertigung vorurteiligen Sprechens (bzw. der Rechtfertigung des eigenen Sprechens als nicht-vorurteilig). Sie sind aber dennoch analytisch zu trennen. 
ten ,Definitionsproblem“ der Antiamerikanismusforschung wird hierbei nicht mit der Formulierung einer verbesserten Definition begegnet, sondern mit einer reflexiven Aufnahme der Unschärfe antiamerikanischen Sprechens in den Antiamerikanismusbegriff selbst. Fasst man Antiamerikanismus als eine Familie von Sprechakten, nicht als individualpsychische Disposition, so befreit man sich einerseits von der Notwendigkeit einer eindeutigen Klassifikation antiamerikanischer Subjekte, so dass fragmentierte Formen vorurteiligen Sprechens begrifflich und empirisch bestimmbar werden. Darüber hinaus ermöglicht die Unterscheidung von Semantik und Gebrauch aber auch eine genauere Beschreibung von Grenzfällen und Grauzonen: So kann etwa, wie im Beispiel von Herrn I, hinsichtlich der stereotypen Semantik eine Überschneidung mit anderen antiamerikanischen Sprechakten bestehen, während deren Gebrauch im jeweiligen Funktionskontext keine klare Zuordnung zu vorurteiligem Sprechen zulässt.

Die sprechakttheoretische Perspektive erschließt so mittels des Konzepts der Familienähnlichkeit zunächst die nötige empirische Offenheit, um die Flexibilität antiamerikanischer Performanzen beobachten zu können. Die begriffliche Geschlossenheit der Analyse muss nicht mehr unmittelbar in den beobachteten antiamerikanischen Ausdrücken gesucht werden, als ein allen klassifizierten Ausdrücken gemeinsames, notwendiges und hinreichendes Set von Kriterien. Sie verschiebt sich stattdessen stärker hin zur Seite der soziologischen Beobachtung, die sich selbstreflexiv darüber Rechenschaft abgeben muss, in welcher theoretischen Hinsicht sie verschiedene amerikabezogene Sprechweisen als antiamerikanische begreifen möchte. Dies ist die zweite Weise, auf die Antiamerikanismus hier als eine Frage des Sprachgebrauches gefasst wird. Das Medium dieser Selbstreflexion ist die soziologische Theoriebildung. Ihr Ergebnis war im Rahmen der vorliegenden Arbeit die Konzentration auf die Begriffe der Ungleichheit und Diskriminierung bzw. der Ungleichheits-Rhetorik im Zusammenhang ethno-nationaler Identitätskonstruktionen. Zusammen mit dem Performativitätsbegriff stellen diese Konzepte eine flexible (weil deutungsabhängige) Einheit des Antiamerikanismusbegriffes her, indem sie als Analyseheuristiken an das empirische Material herangetragen werden. Auf diese Weise nähert sich ein performativer Antiamerikanismusbegriff gleichzeitig von theoretischer und empirischer Seite seinem Gegenstand.

\subsection{MögLICHE THEORETISCHE UND EMPIRISChe PerspektiVEneRWEITERUngen DER ANTIAMERIKANISMUSFORSCHUNG}

Im Rahmen der vorliegenden Analysen wurde der Antiamerikanismusbegriff auf diskriminierende Differenzkonstruktionen im Rahmen nationaler und ethnischer 
Identität, sowie hinsichtlich des Zusammenhangs mit Rassismus, Fremdenfeindlichkeit und Antisemitismus zugespitzt. Zusammen mit dem Bezug auf Diskriminierung bzw. die ,symbolische[n] Ordnung sozialer Ungleichheit“ (Neckel und Sutterlüty 2005, S. 410) ermöglichte dieser konzeptionelle Fokus eine gesellschaftstheoretische Begründung der Antiamerikanismuskritik.

Wie an anderer Stelle betont, ist mit diesem theoretischen Fokus aber kein Anspruch auf Vollständigkeit hinsichtlich der Funktionsweisen und -kontexte antiamerikanischen Sprechens verbunden. Wenngleich sich dieser Schwerpunkt aus den vorgelegten empirischen Rekonstruktionen ergab und insofern nicht als willkürliche theoretische Setzung verstanden werden sollte, ist es doch plausibel, dass Antiamerikanismus auch in anderen Funktionskontexten wirksam werden kann. Im Folgenden sollen daher einige mögliche Anschlussstellen für eine thematische Erweiterung bzw. Vertiefung der Antiamerikanismuskritik angerissen werden, die in der bestehenden Forschungsliteratur teilweise bereits nahegelegt, aber nicht systematisch verfolgt werden.

So wären etwa Studien zu antiamerikanischer Rhetorik im Rahmen von Geschlechterrollen, Sexismus und Heteronormativität ein lohnenswerter Forschungsgegenstand, der bislang nur wenig Aufmerksamkeit erfahren hat (vgl. Diner 2003, S. 29 f.; Roger 2005, S. 20 f.). Die Umkehr traditioneller Geschlechterrollen ist ein klassisches Amerikastereotyp, demzufolge die USA für einen Schwächung männlicher Dominanz bzw. eine quasi-matriarchale Gesellschaftsstruktur stehen (vgl. Markovits 2007, S. 66 f., 76, 100 f.; Diner 2003, S. 83 f.). In diesem Zusammenhang wird mit ,Amerika' häufig auch eine Verrohung oder Aushöhlung romantischer Intimität verknüpft. Analog zum klassischen Stereotyp , amerikanischer Oberflächlichkeit‘ wird ,den Amerikanern“ eine Unfähigkeit zu ,wahrer', tiefempfundener Liebe zugeschrieben. ${ }^{10}$ Zudem gelten die USA gleichzeitig als sexuell pervertiert und moralisch rigide: „too prudish“ und „too pornographic“ (Markovits 2007, S. 24; vgl. auch Jaecker 2014, S. 76). In diesem Zusammenhang wären auch Bezüge zur Heteronormativitätsforschung (vgl. Hartmann 2007) naheliegend, etwa hinsichtlich eines Zusammenhangs mit sexueller Stigmatisierung und Homophobie (vgl. Herek 2007). Es finden sich bspw. in religiös-konservativen Diskursen Stereotype einer ,Verbreitung von Homosexualität“ durch amerikanische Einflussnahme, die zur Konturierung traditioneller Vorstellungen von Moral und ,gesunder' Sexualität genutzt werden und einen diskriminierenden Effekt auf schwule, lesbische, bisexuelle und transgender Personen haben können (vgl. Eleveld 2011; Wahdat-Hagh 2012).

10 Ähnliche Bilder einer ,seelenlosen', gleichsam prostituierten Zwischenmenschlichkeit kennzeichnen nach Ian Buruma und Avishai Margalit, den Westen` in der Perspektive eines ,okzidentalistischen“ Blicks insgesamt (Buruma und Margalit 2005, S. 25 f.). 
Die vermeintliche moralische Rigidität bzw. der Konformismus ,der Amerikaner wird ebenfalls im Rahmen populärer Problematisierungen von demokratischer Öffentlichkeit, Meinungsfreiheit und politischer Willensbildung relevant. So wird die politische Öffentlichkeit der USA immer wieder als ein „demokratischer Faschismus" markiert, in dem Demokratie lediglich als Fassade für die autoritäre Machtpolitik eines Konglomerats von Medienunternehmern, wirtschaftlichen Großkonzernen und politischen Eliten dient (vgl. Jaecker 2014, S. 67 ff.). Auch Diskurse der „Political Correctness“ (vgl. Auer 2002) fallen in diesen Gegenstandsbereich, da diese eine ideologische Funktion erfüllen können, die derjenigen antiamerikanischer Rhetorik verwandt ist: Während sie ihre Positionen als Verteidigung demokratischer Grundrechte gegen ,Meinungsdiktatur' und ,Tugendterror' präsentieren, zielen sie paradoxerweise selbst auf den Abbruch diskursiver Aushandlungsprozesse bzgl. kollektiver Identität, sozialer Ungleichheit, etc.

Gesundheit, Fitness und Körperbewusstsein bilden ein weiteres Themenfeld, in dem Amerikabilder eine erhebliche Rolle spielen können. So wird ,den Amerikanern " bezeichnenderweise sowohl eine übersteigerte Fitness- bzw. Gesundheitsorientierung als auch eine selbstzerstörerische Sucht nach Fastfood und entgrenztem Konsum unterstellt (Jaecker 2014, S. 205 ff.; Markovits 2007, S. 116). Die Vermutung liegt nahe, dass derartige Amerikabilder sich für die rhetorische Bearbeitung der widersprüchlichen Anforderungen anbieten, die eine moderne Konsumgesellschaft an ihre Subjekte stellt: Selbstdisziplinierung, Verantwortung und Fitness einerseits, entgrenzter Konsum und Genuss andererseits (vgl. Bauman 2003, S. 93 ff.; Lamla 2013, S. 14). In antiamerikanischen Rhetoriken könnte ,Amerika' hier als nationalisiertes Außen konstruiert werden, an dem das Dilemma von aktivierender Fitnesskultur und hedonistischem Konsum externalisiert und in ideologisch entschärfter Weise Verhandelt werden kann. An den USA erschiene somit der Widerspruch, den die Subjekte als „Körpermanager“ (Hentschel 2006, S. 120) in ihrer Praxis selbst schon vermittelt haben sollen und daher bzgl. ihrer eigenen Identitätskonstruktionen latent halten: Selbstdisziplinierung als genussvolle Konsumerfahrung.

Die genannten Stereotypien enthalten zwar über die Zuschreibung auf ,Ameri$\mathrm{ka}^{\prime}$ eine nationale Komponente, legen aber dennoch nahe, dass sie der Stabilisierung von Identitäts- bzw. Differenzkonstruktionen auch jenseits nationaler WirGruppen dienen können. Gegen ,die Amerikaner' bzw. ,Amerikanisches' ließen sich etwa auch die Wir-Gruppen der Frauen bzw. Männer, der heterosexuell Begehrenden, der körper- bzw. fitnessbewusst Konsumierenden, oder der konservativen VerteidigerInnen von ,Meinungsfreiheit ${ }^{\star}$ kontrastieren. Auch hinsichtlich dieser Funktionskontexte müsste allerdings, sofern sie als Elemente einer Vorurteilskritik in Betracht kommen sollen, ein Rückbezug auf Prozesse der Diskriminierung und sozialen Stratifizierung hergestellt werden. Denn der Gegenstand der Antiamerikanismusforschung, so wurde in den vorausgegangenen Kapiteln argumentiert, sind 
grundsätzlich nicht amerikabezogene Geschlechter- oder Moralvorstellungen überhaupt, sondern spezifisch solche rhetorischen Konstruktionen, die einen diskriminierenden Effekt haben (vgl. Kap. 2.3 sowie 4.3 bis 4.5).

Aber auch das Verhältnis von nationaler Identität und antiamerikanischem Vorurteil, dem sich diese Arbeit in großer Breite gewidmet hat, gibt weitere Fragen auf. So wurde in Kapitel 7.6.6 auf Diskrepanzen zwischen den Ergebnissen der qualitativen und quantitativen Empirie hingewiesen. Während alle am Interviewmaterial rekonstruierten Antiamerikanismen eine starke argumentative Verbindung zu Nationalismus aufweisen, konnte durch die Surveydaten kein solcher Zusammenhang bestätigt werden. Um die Gründe für dieses Ergebnis genauer untersuchen zu können, wurde einerseits eine komplexere standardisierte Erhebung von Nationalismus, sowie andererseits eine systematisch fallkonstrastierende qualitative Analyse vorgeschlagen. Methodenintegrative Forschungsdesigns bieten sich hier wiederum an, um hinsichtlich des Zusammenhangs von Antiamerikanismus und Nationalismus nach möglichen Subpopulationen zu suchen und diese anschließend mit interpretativen Verfahren auf die jeweils gebrauchten Amerikamotive und rhetorischen Funktionen zu befragen.

Ein ähnliches methodisches Vorgehen könnte auch für eine weiter ausdifferenzierte Analyse des Zusammenhangs von Antiamerikanismus und politischer Orientierung angewandt werden. Es finden sich in der Forschungsliteratur sowohl Vorschläge zur typologischen Unterscheidung von ,rechtem“ und ,linkem“ Antiamerikanismus (Hahn 2003, S. 19; Jarausch 2005, S. 37; Markovits 2007, S. 29), als auch die These einer verschiedene politische Lager übergreifenden antiamerikanischen „Lingua Franca“ (Markovits 2007, S. 11). Die Survey-Ergebnisse der vorliegenden Studie liefern zumindest Indizien dafür, dass beide Thesen ihren Gegenstand zutreffend beschreiben: Antiamerikanismus scheint tatsächlich am rechten und linken Rand des politischen Spektrums jeweils verstärkt aufzutreten, jedoch mit unterschiedlichem Gehalt. Das genaue Verhältnis zwischen solchen Varianten antiamerikanischer Rhetorik wurde bislang nicht systematisch empirisch untersucht. Hierbei wäre insbesondere von Interesse, inwiefern die Rechts-Links Unterscheidung überhaupt sinnvoll zur Rekonstruktion distinkter Antiamerikanismustypen genutzt werden kann, wenn sie nicht ex ante als standardisierte Dimension der Selbstverortung vorgegeben wird. Da im Rahmen der vorliegenden Interviewstudie überwiegend Antiamerikanismen gefunden wurden, die sich einem rechtskonservativen Spektrum zuordnen lassen, erscheint es wünschenswert, mit einem rhetorischfunktionalen Ansatz noch einmal gezielt nach links-identifizierten antiamerikanischen Konstruktionen zu fragen.

Zusätzlich ist festzuhalten, dass die vorliegende Studie mit ihrer Konzentration auf aktuelle Formen von Antiamerikanismus in Deutschland eine relativ eng umgrenzte Population beschreibt. Neben den oben vorgeschlagenen Vertiefungen bzw. Diversifizierungen der Forschungsperspektive innerhalb dieses nationalen Kontex- 
tes wäre daher auch eine Ausweitung von Antiamerikanismusstudien in Richtung internationaler Vergleiche erstrebenswert. ${ }^{11}$ Zieht man in Betracht, wie unterschiedlich die Performanz antiamerikanischer Rhetorik in nationalen Kontexten von bspw. Frankreich über Iran bis Vietnam ausfallen kann, stellt sich die Frage nach der begrifflichen Geltung eines allgemeinen Antiamerikanismuskonzeptes auf besonders nachdrückliche Weise. ${ }^{12}$ In diesen Zusammenhang eine rhetorische Theorieperspektive einzubringen, die nach Familien antiamerikanischen Sprechens auch über nationale Grenzen hinweg fragt, wäre eine hochinteressante, wenngleich forschungspraktisch sehr anspruchsvolle Anschlussmöglichkeit an den hier vorgelegten diskriminierungstheoretischen Ansatz.

Eine stärkere Orientierung auf international vergleichende Forschungsperspektiven ist nicht zuletzt deswegen erstrebenswert, da Antiamerikanismus häufig als wesentlich paneuropäisches Phänomen diskutiert wird (Berman 2008; Gulddal 2011; Markovits 2007). So stellt der Literaturwissenschaftler Jesper Gulddal fest: „Anti-Americanism is a transnational discourse, and can only be studied adequately using a comparative methodology.“ (Gulddal 2011, S. 7) Zwar sei nicht jeder Antiamerikanismus durch eine kontinental-europäische Identität geprägt, jedoch zeigten die von ihm analysierten literarischen Werke, ,that the idea of a transatlantic devide between Europe and the United States must be seen as the master narrative of literary anti-Americanism“ (Gulddal 2011, S. 205). Als weiterer Beleg für einen paneuropäische Identitätsfunktion werden die europaweiten Demonstrationen gegen den Irakkrieg im Februar 2003 angeführt (Markovits 2007, S. 201 ff.).

Inwieweit sich solche antiamerikanischen Einigungsbewegungen $\mathrm{zu}$ einem chauvinistischen „Europeanism“ entwickeln werden, wie ihn Hannah Arendt schon 1954 für möglich hielt, ist schwer abzusehen (vgl. ebd., S. 220 f.). Angesichts der seit 2009 andauernden Krise im europäischen Wirtschafts- und Finanzsystem und der damit einhergehenden Euro-Skepsis, insbesondere rechtskonservativ-nationalistischer Provenienz, scheint die Konstruktion einer paneuropäischen Nationalidentität aktuell jedenfalls eher an Schwung verloren zu haben. In den hier präsentierten Interviewanalysen deutet ebenfalls nichts auf eine spezifisch europäische

11 Ansätze zu einer solchen international vergleichenden Perspektive liegen mit den Monographien von Andrei Markovits, Russel Berman und Jesper Gulddal vor, die Antiamerikanismus als wesentlich europäisches Phänomen betrachten (Berman 2008; Gulddal 2011; Markovits 2007), sowie mit den Sammelbänden von Keohane und Katzenstein (Katzenstein und Keohane 2007a), O’Connor (O'Connor 2007a), Behrends (Behrends 2005) und Rubinstein und Smith (Rubinstein und Smith 1985).

12 Gulddal weist jedoch darauf hin, dass die Bilder und Narrative des Antiamerikanismus, zumindest in dessen literarischen Ausdrucksformen, über verschiedene nationale Kontexte auch außerhalb Europas weitestgehend identisch sind (Gulddal 2011, S. 206 f.). 
Identitätsfunktion antiamerikanischer Rhetorik hin; stattdessen dominieren deutschnationale Konstruktionen.

Nichtsdestotrotz scheint mir die These einer transnationalen Ausrichtung antiamerikanischer Identitätskonstruktionen in einem wichtigen Punkt mit den Ergebnissen der vorliegenden Arbeit zu konvergieren. „European anti-Americanism“, so stellt Gulddal fest, „,can best be described as a form of postnational nationalism“ (Gulddal 2011, S. 206; Herv. F. K.). Damit verbindet sich die Annahme, dass ein antiamerikanischer, Europeanism“ zwar nicht mehr auf einzelstaatliche Identitätskonstruktionen ziele, jedoch "only transcends the nationalist point of view by transplanting nationalisms logic of differentiation from the national to the continental" (ebd., S. 205). Vor dem Hintergrund meiner empirischen Beobachtungen möchte ich hingegen vorschlagen, den ,postnationalen“ Charakter des Antiamerikanismus nicht davon abhängig zu machen, ob die mit ihm konturierte Identitätskonstruktion sich auf einzelne Nationen oder eine, kontinentale' Wir-Gruppe bezieht. Vielmehr würde ich diesen auf die ideologische Funktion einer Äußerung nationalistischer Positionen unter (vermeintlich) postnationalistischen Bedingungen beziehen: In ähnlicher Weise, wie sich Antiamerikanismus zum Ausdruck eines in kultureller Semantik verkleideten Ethnozentrismus und Rassismus anbietet (vgl. Kap. 7.4), kann er dem Ausdruck eines Nationalismus dienen, der sich als postnational, universalistisch und integrativ präsentiert (vgl. Kap. 7.2 und 7.3). Was dabei stabilisiert, konturiert oder aufgewertet wird, ist eine traditionelle nationalistische Ordnung; nur erscheint diese, solang sie in Abgrenzung zu den USA konstruiert wird, nicht als Nationalismus - zumindest nicht im selben Maße wie bspw. antifranzösische Varianten solcher Rhetorik.

Antiamerikanische Vorurteile scheinen also flexibel genug zu sein, um sowohl im Zusammenhang mit paneuropäischen, als auch mit einzelstaatlichen Nationalismen zu funktionieren. Es kann daher nicht davon ausgegangen werden, dass Krisen in der Herausbildung einer transnationalen europäischen Identität automatisch mit einem Rückgang des Antiamerikanismus einhergehen werden. Ebenso wenig wird man aber annehmen können, dass eine gelingende Konsolidierung transnationaler europäischer Identitätskonstruktionen den Antiamerikanismus, der mit diesen wohlmöglich einhergehen würde, von dessen diskriminierender Performanz befreit, nur weil ihm (vermeintlich) keine partikularen Nationalismen mehr zugrunde liegen: Antiamerikanismus wird nicht unproblematisch, nur weil er ggf. im Rahmen eines europäischen Universalismus funktioniert.

Eine genauere Analyse des Verhältnisses von Antiamerikanismus und nationaler Identität sollte sich daher nicht voreilig auf eine der beiden Varianten festlegen (Antiamerikanismus als ,Europäismus‘ vs. Antiamerikanismus als partikularer Nationalismus), sondern die verschiedenen Varianten antiamerikanisch-nationalistischer Identitätskonstruktion einer differenzierten empirischen Beobachtung unterziehen. Hierbei wäre insbesondere auch das Verhältnis von nationalen und trans- 
bzw. supranationalen Identitätskonstruktionen in europäischen Einigungsbewegungen zu beachten (vgl. Habermas 2004).

\subsection{GeltungsReichWeite der ERGEBNisse UND EMPIRISCH-METHODISCHE ANKNÜPFUNGSPUNKTE}

Es sei hier zunächst noch einmal festgehalten, dass die Generalisierbarkeit der entwickelten Hypothesen im Rahmen dieser Studie empirisch weitgehend unbeobachtet verbleibt. Das Bemühen um genetische Plausibilität der Deutungen kann eine gezielte Prüfung der Verbreitung der beschriebenen Rhetoriken nicht ersetzen. Mit dieser Aufgabe, die die Untersuchung großer Stichproben notwendig macht, geht allerdings notgedrungen ein stärker standardisiertes methodisches Vorgehen einher, das mit der sprechakttheoretischen Theoriegrundlage der präsentierten Hypothesen in Konflikt zu geraten droht. Es stellt sich daher die Frage, mit welchen Methoden man sich einer standardisierten ,Messung' der hier beschriebenen Performanzen bzw. rhetorischen Funktionen annähern kann. Weit entfernt davon, eine definitive Antwort auf diese Frage geben zu können, scheinen mir diesbezüglich drei Wege aussichtsreich:

(1) Der Einbezug von Kontextvariablen in die standardisierte Erhebung von Antiamerikanismus: Eine parallele Erhebung theoretisch relevanter Korrelate von Antiamerikanismus könnte stärker in das Design entsprechender Skalen eingebunden werden. In der Logik eines solchen Vorgehens würde eine Skala nur dann als Maß für die Tendenz zu antiamerikanischem Sprechen gelten können, wenn gleichzeitig mit ihr auch Konstrukten wie Nationalismus, Schuldabwehr, oder Ethnozentrismus zugestimmt würde. Eine Antiamerikanismus-Skala müsste in gewisser Weise also mehr als Antiamerikanismus enthalten, um Antiamerikanismus erfassen zu können. Dies kann als messtheoretische Annäherung an die hier vorgeschlagene Unterscheidung von Semantik und Gebrauch verstanden werden, der zufolge die antiamerikanische Bedeutung bestimmter Stereotype (Antiamerikanismus-Items) nicht unabhängig vom Kontext festgestellt werden kann, in dem sie gebrauch werden.

(2) Abgesehen davon, dass sich das zuvor genannte Vorgehen zumindest im Rahmen der Surveyforschung als schwer praktikabel erweisen könnte, deutet die Annahme verschiedener antiamerikanischer Subgruppen auch hinsichtlich der statistischen Analyseverfahren in eine andere Richtung. Die Logik klassenbildender Verfahren, wie etwa Cluster- oder latenter Klassenanalysen, scheint einem an Familienähnlichkeit orientierten Antiamerikanismusbegriff deutlich besser zu entsprechen, als regressions- bzw. faktoranalytische „mindsets“ (Zyphur 2009). Die Annahme, dass dem Antwortverhalten auf einer Vielzahl von AntiamerikanismusItems eine latente kontinuierliche Variable zugrunde liegt, kommt einem nominal- 
definitorischen Begriff entgegen, der allgemeine und hinreichende Kriterien formuliert. Für eine Familienähnlichkeitsperspektive, die auf einen solchen einheitliche Faktor verzichtet, bieten sich hingegen statistische Verfahren an, die nicht Zusammenhänge zwischen Variablen durch latente kontinuierliche Variablen erklären, sondern Muster von Merkmalskombinationen durch latente kategoriale Variablen. Dies eröffnete auch die Möglichkeit, sowohl partielle Überschneidungen zwischen verschiedenen Antiamerikanismus-Klassen zu analysieren, als auch statistisch weitgehend unabhängige Klassen als Ausprägungen desselben Phänomens zu erfassen.

(3) Für eine produktive Anwendung von klassenbildenden Verfahren ist es zudem naheliegend, eine größere Anzahl semantischer Kriterien in standardisierter Form beobachtbar zu machen. Neben komplexeren Likert-skalierten Item-Batterien, wie sie oben angesprochen wurden, wären hierbei auch Erhebungsmethoden sinnvoll einzusetzen, bei denen Daten bspw. mittels Kartensortiertechniken, etwa der Qsort Methode (Müller und Kals 2004), erhoben würden. Damit wäre freilich das Problem des Gebrauchskontextes noch nicht aufgehoben, aber zumindest die semantische Grundlage zur Klassenbildung reichhaltiger angelegt. Im Rahmen solcher Erhebungsverfahren wäre bspw. auch der in Kapitel 7.6.6 problematisierte Zusammenhang von Antiamerikanismus und nationaler Identität statistisch näher zu untersuchen, indem nicht nur verschiedene Amerikabilder, sondern auch verschiedene Typen nationaler Wir-Gruppenkonstruktionen erhoben würden. Für einen Einbezug von Kontextvariablen bei der standardisierten Vorurteilsbeobachtung bieten zudem aktuelle Entwicklungen im Bereich des faktoriellen Survey sowie der Choice Experiments vielversprechende Möglichkeiten (vgl. Beyer und Liebe 2015; Beyer und Liebe 2013).

Schließlich könnten standardisierte klassenbildende Verfahren in methodenintegrativen Designs wiederum produktiv durch qualitative Untersuchungen zum Gebrauchskontext ergänzt werden. Hierbei wäre eine Erweiterung der qualitativen Methoden hin zu stärker an alltäglichen Kommunikationsabläufen orientierten Erhebungsverfahren wünschenswert. So könnten etwa Gruppendiskussionen (vgl. z.B. Baethge et al. 2010; Decker et al. 2013) oder ethnographische Beobachtungen zu einer größeren empirischen Annäherung an die ,natürlichen“ Gebrauchsweisen und -Kontexte von Amerikastereotypen führen, die in der vorliegenden Studie durch die vergleichsweise ,künstliche“ Situation der Interviewgespräche vor allem in Form hypothetischer Schlussfolgerungen ex post möglich war.

\subsection{Resümee und Ausblick}

Ausgangspunkt der vorliegenden Arbeit war die Beobachtung, dass Antiamerikanismus nicht nur ein gesellschaftliches Problem im Sinne von menschfeindlicher 
Gewalt und deren Legitimation darstellt, sondern ebenso ein (alltags-)theoretisches bzw. begriffliches: In öffentlichen Diskursen sowie in der sozialwissenschaftlichen Forschungsliteratur wird der Begriff oftmals mit Verweis auf dessen politische Parteilichkeit zurückgewiesen bzw. eine „more precise definition of the term“ (O’Connor 2007b, S. 6) gefordert.

Ein in der Forschung häufig gewähltes Mittel, um diesem Definitionsproblem bzw. der damit verbundenen Normativitäts-Problematik beizukommen, ist der Rekurs auf etablierte einstellungstheoretische Vorurteilskonzepte. Wenngleich eine stärkere Eingliederung des Antiamerikanismuskonzeptes in den Kanon der Vorurteilforschung generell zu begrüßen ist, führt doch die definitorische Präzision, die solche Konzepte anstreben, selbst zu bestimmten Unschärfen und Leerstellen in Begriffsbildung und Empirie.

Ein Kernargument der vorliegenden Studie ist daher, dass die viel beklagte Unschärfe des Antiamerikanismusbegriffes nicht durch eine präzisere Definition des Konzeptes überwunden werden wird. Dies gilt insbesondere für solche Forschungsansätze, in denen auch die empirische Anwendung des Begriffes in standardisierter Form erfolgt, d.h. durch operationale Definitionen. Der Antiamerikanismusbegriff wird hingegen schärfer gefasst, wenn er Unschärfen zulässt. Und zwar nicht als ,Messfehler', also als zufällige Abweichung von ex ante festgelegten, ,eigentlichen ‘ Kernmerkmalen des Gegenstandes, sondern als zu beobachtendes Element des Gegenstandes selbst. Um Antiamerikanismus theoretisch und empirisch überzeugend beschreiben zu können, muss man mehr beschreiben, als ,reinen“ Antiamerikanismus. Dies ist die Grundannahme des vorgelegten performativen Vorurteilsbegriffes: dass antiamerikanisches Sprechen nur als antiamerikanisch bestimmt werden kann im Rekurs auf dessen Einbettung in einen Funktionskontext, der nicht nur antiamerikanisch ist. Ich kann nicht erst wissen, was Antiamerikanismus ist, und dann fragen, was er tut bzw. in welchen Zusammenhängen er funktioniert. Denn die Tätigkeit antiamerikanischen Sprechens, dessen funktionale Einbettung, ist ein zentraler Bestandteil der theoretischen Beschreibung von Antiamerikanismus.

Diese Tätigkeit, der Gebrauchs- oder Praxisaspekt des Antiamerikanismus, lässt sich aber nicht in definitiven Regeln abbilden. Dies meint die zentrale Einsicht Wittgensteins, dass sich die Regeln sprachlicher Bedeutung prinzipiell nicht in axiomatischen Sätzen erschöpfen: Wir werden immer an den Punkt gelangen, an dem wir über unsere Anwendung der Regel Rechenschaft abgeben müssen (vgl. Winch 1966, S. 41 sowie Kap. 3.4). Der somit drohende Regelregress (jede Regelanwendung wird durch eine weitere Regel begründet, die wiederum hinsichtlich ihrer Anwendung in Frage gestellt werden kann) wird natürlich auch durch einen performativen Antiamerikanismusbegriff nicht aufgelöst. Ein solcher Begriff kann aber, im Gegensatz zu nominaldefinitorischen Konzepten und standardisierter Empirie, die Unschärfen der Regelanwendung in den Begriff selbst aufnehmen, sie gewissermaßen reflexiv mitführen (vgl. Kalthoff 2008, S. 20). Dies ist, wie ich mit 
der vorliegende Studie gezeigt habe, nicht einfach eine erkenntnistheoretische Zusatzleistung, die dem Antiamerikanismusbegriff als methodologisches Extra zur Seite gestellt wird. Sondern, eine gebrauchssensitive Theoriebildung erschließt am Gegenstand selbst neue Aspekte, die ohne eine solche Perspektivverschiebung wahrscheinlich nicht erkennbar gewesen wären. Beispiele hierfür sind das Sichtbarwerden des fragmentierten und flexiblen Charakters sowie der ideologischrechtfertigenden Funktion des Antiamerikanismus.

Auf empirisch-methodischer Seite entspricht diesem Theorieansatz die Rekonstruktion von konkreten, situativ eingebetteten Sprechakten, die je spezifisch hinsichtlich der reproduzierten Amerikabilder und rhetorischen Funktionen untersucht werden. Die begriffliche Struktur der dabei gebildeten Klassen ist die einer Familie, d.h. ein durch die Deutungspraxis der Forschenden vermittelter Zusammenhang von Elementen (Sprechakten), die kein allgemeines hinreichendes Merkmal teilen.

Aber auch eine solche empirisch begründete Rekonstruktion lokal eingebetteter Antiamerikanismen kommt nicht ohne begrifflichen Bezugsrahmen aus, der auf gesellschafts- und handlungstheoretischer Ebene Erwartungen an das beobachteten Phänomen heranträgt und es damit in gewisser Weise als Gegenstand überhaupt erst hervorbringt. Wie ich gezeigt habe, bieten Konzepte aus dem Bereich der Vorurteils- und Diskriminierungsforschung hierzu produktive Ansatzpunkte. Dieser Aspekt unterscheidet meine auf Familienähnlichkeit aufbauende und empirisch begründete Begriffsbildung von induktivistisch-nominalistischen Ansätzen. Trotz des besonderen Fokus auf die flexible, kontextabhängige Realisierung antiamerikanischer Sprechakte, ist Antiamerikanismus hier nicht einfach ein Name, der je nach ,Meinung' der Beobachter auf ganz unterschiedliche Gegenstände referieren kann. Mit einem solchen relativistischen Konzept wäre begrifflich nichts gewonnen. Vielmehr muss auch eine auf Familienähnlichkeit beruhende empirische Begriffsbildung die grundlegende Spannung zwischen kontexttranszendierender Geltung und genetischem Kontextbezug berücksichtigen, die jedes begriffliche Sprechen auszeichnet.

Dieses prekäre Spannungsverhältnis auf theoretisch produktive Weise zu gestalten, stellt den performativen Aspekt der Begriffsbildung dar: was Forschende tun, indem sie einen Begriff gebrauchen. Genau diese Tätigkeit, der Gebrauchsaspekt der Antiamerikanismuskritik, droht durch nominaldefinitorische Konzepte und standardisierte Empirie aber aus der Theoriebildung ausgeklammert zu werden. Eine rekonstruktiv-sinndeutende Empirie und ein performativer Antiamerikanismusbegriff zwingen hingegen stets erneut dazu, auch die Frage der Regelanwendung zu stellen: Ist dieses konkrete Sprechen über Amerika abwertend? Und, wenn ja, inwiefern ist ,Abwertung ' ein Merkmal von Vorurteilen? Und ist es ein notwendiges Merkmal vorurteiligen Sprechens? Und wenn nicht, welche rhetorischen Gebräuche lassen sich alternativ finden? In dieser Weise spinnt sich die doppelte Frage nach der performativen Bedeutung des Antiamerikanismus stetig fort. Zur Ruhe kommt 
die performative Perspektive dabei nicht durch eine saubere axiomatische Theoriekonstruktion mit klar definierten Ableitungsbeziehungen. Sie findet provisorischen Halt in einem theoretischen Gerüst, dessen Fundament nicht fest gegossen ist, dessen Träger und Streben nicht passgenau ineinandergreifen, sondern das eher einer freischwebenden, durch innere Spannungen zusammengehaltenen Konstruktion gleicht.

Dadurch wird eine empirische Vorurteilskritik einerseits gesellschaftstheoretisch sensibel: Die beständige Frage nach der performativen Bedeutung der häufig verworrenen Sprachgebräuche im empirischen Material führte zu der in Kapitel 4 präsentierten soziologischen Rahmung des Vorurteilsbegriffes. Andererseits ist die performative Perspektive aber auch besonders empfindlich für die normativen Aspekte der Vorurteilskritik, denn die Frage, was Forschende Tun, indem sie den Antiamerikanismusbegriff gebrauchen, lässt sich nicht ohne Rekurs auf die funktionale Einbettung ihrer Tätigkeit in den untersuchten gesellschaftlichen Zusammenhang beantworten. Cicourel hat diese Teilnehmerinnenperspektive der Soziologie wie folgt beschrieben:

„Die problematischen Merkmale alltäglichen Lebens können nicht erklärt werden durch formale Logik oder durch irgendein System, das mit seinen Axiomen isomorph ist. Die Sprache, die wir zur Beschreibung der Realitäten des Lebens übernehmen, läuft immer Gefahr, sich mit dem, was wir meinen, zu verheddern. Die Logik alltäglicher Aktivitäten, in die das zu untersuchende Sozialobjekt eingebettet ist, muß in Beziehung gesetzt werden zu der Logik der Theorie des Beobachters, so daß die beiden Systeme sowohl unterschieden als auch und dennoch aufeinander bezogen sind.“ (Cicourel 1974, S. 262)

Ein performativer Antiamerikanismusbegriff ist also nicht zuletzt deswegen theoretisch produktiv, weil er den Bezug zwischen der „Logik alltäglicher Aktivitäten“ und der „Logik der Theorie des Beobachters“ in die Begriffsbildung mit aufnimmt, d.h. gerade auch das „Verheddern“ besagter Logiken zum Gegenstand macht.

Die methodologische Problematik dieses Bezugs kann unter dem Titel der ,Kritik ' verhandelt werden, der in aktuellen soziologischen und sozialphilosophischen Diskursen vermehrt wieder aufgegriffen wird (vgl. Celikates 2009; Jaeggi und Wesche 2009; Lessenich 2014; Vobruba 2013; Wehling 2014). Hierbei wird vor allem der Punkt herausgestellt, dass die Soziologische Beobachtung die Maßstäbe ihrer Kritik nicht extern, sondern durch ein Anknüpfen an die von Laiensoziologen formulierten Problembestimmungen gewinnen muss. In der vorliegenden Arbeit wurde dies versucht, indem der Vorurteilsbegriff an die Ideale der Gleichheit bzw. Gleichberechtigung geknüpft wurde. Vorurteile zu kritisieren bedeutet somit zunächst, Verletzungen etablierter Gleichheitsvorstellungen theoretisch-empirisch zu beschreiben. Da aber weder die kritisierten Vorurteilsäußerungen explizit antiegalitär sind, noch die egalitäre Norm ein geschlossenes Set moralischer Regeln be- 
inhaltet, distanziert sich eine soziologische Vorurteilskritik indem sie gesellschaftlich virulente Maßstäbe der (Ungleichheits-)Kritik aufgreift zugleich von diesen. Das Vorgehen einer soziologischen Kritik ist also dadurch gekennzeichnet, dass sie einerseits die gegen ihren Gegenstand in Stellung gebrachten Normen in diesem Gegenstand (Vorurteil) selbst verortet, und andererseits dadurch die eigene normative Grundlage unterläuft. In diesem Sinne muss eine „kritische Soziologie der Gesellschaft [...] eine Soziologie der Gesellschaftskritik sein, die auch die gesellschaftlich Kritisierenden zur Rechenschaft zieht" (Lessenich 2014, S. 20; vgl. auch Celikates 2009, S. 159 ff.). Vorurteilskritik ist also immer beides zugleich: Kritik von Vorurteilen, d.h. von Verletzungen der egalitären Norm, und Kritik an dieser Norm selbst, deren prinzipielle Vereinbarkeit mit diskriminierenden Differenzkonstruktionen sie am vorurteiligen Sprechen empirisch aufzeigt.

Es wäre wünschenswert, dass in Zukunft eine stärkere Anbindung der Vorurteilsforschung an derartige Konzeptionen sozialwissenschaftlicher Kritik gesucht wird. Nicht zuletzt, weil diese Perspektive, wenn nicht eine Lösung, so doch einen produktiven neuen Blick auf die ,Definitionsprobleme' nicht nur der Antiamerikanismus-, sondern der Vorurteilsforschung insgesamt bietet. Hierin kann die Funktion einer erschließenden Vorurteilskritik gesehen werden: gesellschaftliche Diskurse und Problembestimmungen aufzugreifen und auf solche Art kritisch deutend zu bearbeiten, dass Problemgegenstände in einem neuen Licht erscheinen und festgefahrene Diskurse und Praxen eine neue Dynamik gewinnen. Ob diese neue Dynamik gut oder schlecht, wahr oder falsch ist, lässt sich unabhängig vom Austausch mit den Agierenden im Wissenschaftssystem sowie in anderen gesellschaftlichen Teilbereichen letztendlich nicht bestimmen. Das Gelingen einer solchen kritischen Bearbeitung sozialer Pathologien wird somit stets erneut am „Verschwinden der Frage“ (Adorno 1973a, S. 342) bzw. an deren Verschiebung hin zu neuen Fragen gezeigt werden müssen.

Antiamerikanismus in Deutschland heute ist ein paradigmatisches Beispiel für den Charakter des Vorurteils in einer Zeit, in der essentialistische und exkludierende Unterscheidungen, etwa nach Ethnizität oder Nation, zunehmend in Bedrängnis geraten. So werden im antiamerikanischen Sprechen zwar unmittelbar keine rassischen bzw. ethnischen Zuschreibungen gemacht, aber dennoch, oder vielmehr: gerade deshalb, kann es der Rückversicherung rigider ethno-nationaler Identitätskonstruktionen dort dienen, wo ein Rekurs auf Ethnie und Nation problematisch geworden ist. Es steht zu hoffen, dass die hier vorgeschlagene Theorieperspektive auf antiamerikanische Vorurteile einen dynamisierenden Effekt nicht nur auf die sozialwissenschaftliche Antiamerikanismuskritik, sondern mittelbar auch auf diejenigen rigiden Klassifikationsmuster und Identitätskonstruktionen haben wird, die zu einer Reproduktion diskriminierender gesellschaftlicher Verhältnisse gerade in ihren ideologisch vermittelten, ,demokratischen`Formen beitragen. 



\section{Literatur}

Adorno, Theodor W. (1973a): Die Aktualität der Philosophie. In: Theodor W. Adorno: Gesammelte Schriften. Band 1: Philosophische Frühschriften. Frankfurt a. M.: Suhrkamp, S. 325-344.

Adorno, Theodor W. (1973b): Die Idee der Naturgeschichte. In: Theodor W. Adorno: Gesammelte Schriften. Band 1: Philosophische Frühschriften. Frankfurt a. M.: Suhrkamp, S. 345-365.

Adorno, Theodor W. (1993): Einleitung in die Soziologie. Frankfurt am Main: Suhrkamp.

Adorno, Theodor W. (2003a): Beitrag zur Ideologienlehre. In: Theodor W. Adorno: Soziologische Schriften I. Frankfurt a. M.: Suhrkamp, S. 457-477.

Adorno, Theodor W. (2003b): Einleitung zum „Positivismusstreit in der deutschen Soziologie“. In: Theodor W. Adorno: Soziologische Schriften I. Frankfurt a. M.: Suhrkamp, S. 280-353.

Adorno, Theodor W. (2003c): Erziehung nach Auschwitz. In: Theodor W. Adorno: Kulturkritik und Gesellschaft II. Frankfurt a. M.: Suhrkamp, S. 674-690.

Adorno, Theodor W. (2003d): Was bedeutet: Aufarbeitung der Vergangenheit. In: Theodor W. Adorno: Kulturkritik und Gesellschaft II. Frankfurt a. M.: Suhrkamp, S. 555-572.

Adorno, Theodor W. (2003e): Zur Logik der Sozialwissenschaften. In: Theodor W. Adorno: Soziologische Schriften I. Frankfurt a. M.: Suhrkamp, S. 547-565.

Alloa, Emmanuel; Bedorf, Thomas; Grüny, Christian; Klass, Tobias (2012): Einleitung. In: Emmanuel Alloa, Thomas Bedorf, Christian Grüny und Tobias Klass (Hg.): Leiblichkeit. Geschichte und Aktualität eines Konzepts. Tübingen: Mohr Siebeck, S. 1-4.

Allport, Gordon W. (2003): The nature of prejudice. Cambridge, MA: Perseus Books.

Altvater, Elmar; Ganßmann, Heiner; Heinrich, Michael; Hübner, Kurt; Mahnkopf, Birgit; Messner, Dirk; Wolf, Gerald (1989): Editorial. Aufgeklärte Blindheit. Plädoyer für einen linken Antiamerikanismus. In: Prokla. Zeitschrift für kritische Sozialwissenschaft 19 (1), S. 2-10. 
Arendt, Hannah (1986): Europa und Amerika. Traum und Alptraum. Antiamerikanische Gefühle auf dem Weg zu einem neuen europäischen Ismus. In: Hannah Arendt: Zur Zeit. Politische Essays. Berlin: Rotbuch Verlag.

Auer, Kathrin (2002): „Political Correctness“ - ideologischer Code, Feindbild und Stigmawort der Rechten. In: Österreichische Zeitschrift für Politikwissenschaft 31 (3), S. 291-303.

Austin, John L. (2010): Zur Theorie der Sprechakte. How to do Things with Words. Stuttgart: Reclam.

Baethge, Klaus; Fried, Barbara; Claussen, Detlev; Pielczyk, Bastian; Siems, Siebo (2010): Antiamerikanismus in der Krise. In: Psychoanalyse - Texte zur Sozialforschung 25 (2), S. 366-384.

Bäuerle, Rainer (1995): Proposition. In: Jürgen Mittelstrass, Gereon Wolters, Martin Carrier und Siegfried Blasche (Hg.): Enzyklopädie Philosophie und Wissenschaftstheorie. Stuttgart: J.B. Metzler, S. 364-365.

Bauman, Zygmunt (2003): Flüchtige Moderne. Frankfurt a. M.: Suhrkamp.

Becker, Julia; Wagner, Ulrich; Christ, Oliver (2010): Ursachenzuschreibungen in Krisenzeiten: Auswirkungen auf Antisemitismus und Fremdenfeindlichkeit. In: Wilhelm Heitmeyer (Hg.): Deutsche Zustände. Folge 8. Frankfurt a. M.: Suhrkamp, S. 128-143.

Behrends, Jan C. (Hg.) (2005): Antiamerikanismus im 20. Jahrhundert: Studien zu Ost- und Westeuropa. Bonn: Dietz.

Berger, Peter (1989): Ungleichheitssemantiken: Graduelle Unterschiede und kategoriale Exklusivitäten. In: European Journal of Sociology 30 (1), S. 48-60.

Bergmann, Werner (2007): ,Störenfriede der Erinnerung'. Zum SchuldabwehrAntisemitismus in Deutschland. In: Klaus-Michael Bogdal, Klaus Holz und Matthias N. Lorenz (Hg.): Literarischer Antisemitismus nach Auschwitz. Stuttgart: Metzler, S. 13-35.

Bergmann, Werner; Erb, Rainer (1986): Kommunikationslatenz, Moral und öffentliche Meinung. Theoretische Überlegungen zum Antisemitismus in der Bundesrepublik Deutschland. In: Kölner Zeitschrift für Soziologie und Sozialpsychologie 38 (2), S. 223-246.

Bergmann, Werner; Erb, Rainer (1991): Antisemitismus in der Bundesrepublik Deutschland. Ergebnisse der empirischen Forschung von 1946-1989. Opladen: Leske + Budrich.

Berman, Russell A. (2008): Anti-Americanism in Europe: a cultural problem. Stanford, CA: Hoover Institution Press.

Beyer, Heiko (2014): Soziologie des Antiamerikanismus. Zur Theorie und Wirkmächtigkeit spätmodernen Unbehagens. Frankfurt a. M.: Campus.

Beyer, Heiko; Liebe, Ulf (2010): Antiamerikanimus und Antisemitismus: Zum Verhältnis zweier Ressentiments. In: Zeitschrift für Soziologie 39 (3), S. 215232. 
Beyer, Heiko; Liebe, Ulf (2013): Antisemitismus heute. Zur Messung aktueller Erscheinungsformen von Judenfeindlichkeit mithilfe des faktoriellen Surveys. In: Zeitschrift für Soziologie 42 (3), S. 186-200.

Beyer, Heiko; Liebe, Ulf (2014): Anti-Americanism in Europe: Theoretical Mechanisms and Empirical Evidence. In: European Sociological Review 30 (1), S. 90106.

Beyer, Heiko; Liebe, Ulf (2015): Three experimental approaches to measure the social context dependence of prejudice communication and discriminatory behavior. In: Social science research 49, S. 343-355.

Billig, Michael (1988): Ideological Dilemmas. A Social Psychology of Everyday Thinking. London: Sage.

Billig, Michael (1991): Ideology and Opinions. Studies in Rhetorical Psychology. London: Sage.

Billig, Michael (1997): The dialogic unconscious: Psychoanalysis, discursive psychology and the nature of repression. In: Journal of Social Psychology 36 (2), S. 139-159.

Billig, Michael (2012): The Notion of ,Prejudice': Some Rhetorical and Ideological Aspects. In: John Dixon und Mark Levine (Hg.): Beyond Prejudice. Extending the Social Psychology of Conflict, Inequality and Social Change. Cambridge: Cambridge University Press, S. 139-157.

Birkenkämper, Axel (2006): Gegen Bush oder Amerika? Die transatlantischen Beziehungen und das deutsche Amerikabild. Bonn: Bouvier.

Blank, Thomas; Schmidt, Peter (2003): National Identity in a United Germany: Nationalism or Patriotism? An Empirical Test with Representative Data. In: Political Psychology 24 (2), S. 289-312.

Blumer, Herbert (1971): Social Problems as Collective Behavior. In: Social Problems 18 (3), S. 298-306.

Bonacker, Thorsten (2000): Die normative Kraft der Kontingenz. Nichtessentialistische Gesellschaftskritik nach Weber und Adorno. Frankfurt a. M.: Campus.

Bonacker, Thorsten (2001): Die Selbstreflexivität soziologischer Theorie und die Konsequenzen für ihren Vergleich. In: Ethik und Sozialwissenschaften - Streitforum für Erwägungskultur 12 (4), S. 497-499.

Bonacker, Thorsten (2008): Erschließende Kritik. Über zwei Arten des Umgangs mit der Kontingenz des Verstehens bei Adorno. In: Georg Kohler und Stefan Müller-Doohm (Hg.): Wozu Adorno? Beiträge zur Kritik und zum Fortbestand einer Schlüsseltheorie des 20. Jahrhunderts. Weilerswist: Velbrück, S. 64-82.

Brown, Timothy A. (2006): Confirmatory Factor Analysis for Applied Research. New York: The Guildford Press.

Bude, Heinz (1987): Deutsche Karrieren. Lebenskonstruktionen sozialer Aufsteiger aus der Flakhelfer-Generation. Frankfurt a. M.: Suhrkamp.

Bühner, Markus (2006): Einführung in die Test- und Fragebogenkonstruktion. München: Pearson. 
Buruma, Ian; Margalit, Avishai (2005): Okzidentalismus: der Westen in den Augen seiner Feinde. München: Hanser.

Burzan, Nicole (2011): Soziale Ungleichheit. Wiesbaden: VS Verlag für Sozialwissenschaften.

Butler, Judith (2006): Hass Spricht. Zur Politik des Performativen. Frankfurt a. M.: Suhrkamp.

Butterwegge, Christoph (2011): Rechtsextremismus = Linksextremismus? Über die Konsequenzen einer falschen Gleichsetzung. In: Ursula Birsl (Hg.): Rechtsextremismus und Gender. Opladen: Budrich, S. 29-42.

Ceaser, James W. (1997): Reconstructing America: the symbol of America in modern thought. New Haven: Yale University Press.

Celikates, Robin (2009): Kritik als soziale Praxis. Gesellschaftliche Selbstverständigung und kritische Theorie. Frankfurt a. M.: Campus.

Chiozza, Giacomo (2009): Anti-Americanism and the American world order. Baltimore, MD: Johns Hopkins University Press.

Cicourel, Aaron V. (1974): Methode und Messung in der Soziologie. Frankfurt a. M.: Suhrkamp.

Claussen, Detlev (2010): Der Hund bellt nicht. Deutsche Zustände. Die aktuelle Studie des Bielefelder Soziologen Wilhelm Heitmeyer belegt: Die Krise macht die Deutschen nicht gewalttätiger. In: Die Tageszeitung, 20.02.2010.

Cohrs, Jan C. (2003): Von konstruktiven Patrioten und schwarzen Schafen: Nationale Identifikation und Engagement gegen Fremdenfeindlichkeit. Dissertation. Universität Bielefeld. Fakultät für Psychologie und Sportwissenschaft.

Creswell, John W.; Plano Clark, Vicki L. (2011): Designing and conducting mixed methods research. Los Angeles, CA: Sage.

Crockatt, Richard (2003): America embattled: September 11, anti-Americanism, and the global order. London [u.a.]: Routledge.

Dahl, Gerhardt (2010): Nachträglichkeit, Wiederholungszwang, Symbolisierung. Zur psychoanalytischen Deutung primärprozesshafter Szenen. In: Psyche. Zeitschrift für Psychoanalyse und ihre Anwendungen 64 (5), S. 1-22.

Davidov, Eldad; Thörner, Stefan; Schmidt, Peter; Gosen, Stefanie; Wolf, Carina (2011): Level and change of group-focused enmity in Germany: unconditional and conditional latent growth curve models with four panel waves. In: AStA Advances in Statistical Analysis 95 (4), S. 481-500.

Davidson, Donald (1982): Paradoxes of Irrationality. In: Richard Wollheim und James Hopkins (Hg.): Philosophical Esays on Freud. Cambridge: Cambridge University Press, S. 289-305.

Decker, Oliver; Rothe, Katharina; Weißmann, Marliese; Kiess, Johannes; Brähler, Elmar (2013): Economic Prosperity as „Narcissistic Filling“: A Missing Link Between Political Attitudes and Right-wing Authoritarianism. In: International Journal of conflict and Violence 7 (1), S. 121-134. Online verfügbar unter 
http://www.ijcv.org/index.php/ijcv/article/view/272, zuletzt geprüft am 24.03. 2014.

Decker, Oliver; Weißmann, Marliese; Kiess, Johannes; Brähler, Elmar (2010): Die Mitte in der Krise. Rechtsextreme Einstellungen in Deutschland 2010. Berlin: Friedrich Ebert Stiftung.

Demmerling, Christoph (1994): Sprache und Verdinglichung: Wittgenstein, Adorno und das Projekt einer kritischen Theorie. Frankfurt a. M.: Suhrkamp.

Demmerling, Christoph (2011): Den Leib zur Sprache bringen: Überlegungen zur Leib-Körper-Unterscheidung. In: Allgemeine Zeitschrift für Philosophie 36 (1), S. 7-25.

Diner, Dan (2003): Feindbild Amerika: über die Beständigkeit eines Ressentiments. Berlin: Propyläen Verlag.

Dixon, John; Levine, Mark (Hg.) (2012a): Beyond Prejudice. Extending the Social Psychology of Conflict, Inequality and Social Change. Cambridge: Cambridge University Press.

Dixon, John; Levine, Mark (2012b): Introduction. In: John Dixon und Mark Levine (Hg.): Beyond Prejudice. Extending the Social Psychology of Conflict, Inequality and Social Change. Cambridge: Cambridge University Press, S. 1-23.

Dixon, John; Levine, Mark; Reicher, Steve; Durrheim, Kevin (2012): Beyond prejudice: Are negative evaluations the problem and is getting us to like one another more the solution? In: Behavioral and Brain Sciences 35 (06), S. 411-425.

Dovidio, John F.; Glick, Peter; Rudman, Laurie A. (2005): Introduction: Reflecting on the Nature of Prejudice: Fifty Years after Allport. In: John F. Dovidio, Peter Glick und Laurie A. Rudman (Hg.): On the Nature of Prejudice. Fifty Years After Allport. Malden, MA: Blackwell Publishing, S. 1-15.

Dovidio, John F.; Hewstone, Miles; Glick, Peter; Esses, Victoria M. (2010): Chapter 1: Prejudice, Stereotyping and Discrimination: Theoretical and Empirical Overview. In: John F. Dovidio, Miles Hewstone, Peter Glick und Victoria M. Esses (Hg.): The SAGE Handbook of Prejudice, Stereotyping and Discrimination. London: Sage, S. 3-29.

D'Souza, Dinesh (2008): The enemy at home. The cultural left and its responsibility for 9/11. New York: Broadway Books.

Dunton, Bridget C.; Fazio, Russel H. (1997): An Individual Difference Measure of Motivation to Control Prejudiced Reactions. In: Personality and Social Psychology Bulletin 23 (3), S. 316-326.

Eberle, Thomas (1999): Sinnadäquanz und Kausaladäquanz bei Max Weber und Alfred Schütz. In: Ronald Hitzler, Jo Reichertz und Norbert Schroer (Hg.): Hermeneutische Wissenssoziologie. Standpunkte zur Theorie der Interpretation. Konstanz: UVK, S. 97-119.

Eleveld, Kerry (2011): Right-Wing Group Fuels Homophobia At The UN. Online verfügbar unter http://equalitymatters.org/blog/201105240010, zuletzt geprüft am 17.04.2014. 
F.A.Z. (2001): Der Westen muß sich endlich fragen, was er falsch gemacht hat. Die Schnecke bleibt beharrlich: Ein Gespräch mit Günter Grass über V. S. Naipaul und Arundhati Roy, sein Verhältnis zu Israel und Amerika, das Berliner Wahlergebnis und die PDS. In: Frankfurter Allgemeine Zeitung, 27.10.2001, S. 45.

F.A.Z. (2013): Versuchen wir es doch mit der E-mail made in Germany. Hans-Peter Uhl zum NSA-Skandal. In: Frankfurter Allgemeine Zeitung, 01.11.2013. Online verfügbar unter http://www.faz.net/aktuell/feuilleton/hans-peter-uhl-zum-nsaskandal-versuchen-wir-es-doch-mit-der-e-mail-made-in-germany12643013.html, zuletzt geprüft am 20.02.2014.

Faulbaum, Frank; Prüfer, Peter; Rexroth, Margrit (2009): Was ist eine gute Frage? Die systematische Evaluation der Fragenqualität. Wiesbaden: VS Verlag für Sozialwissenschaften.

Fingerhut, Jörg; Hufendiek, Rebekka; Wild, Markus (2013): Einleitung. In: Jörg Fingerhut (Hg.): Philosophie der Verkörperung. Grundlagentexte zu einer aktuellen Debatte. Berlin: Suhrkamp, S. 9-102.

Flick, Uwe (2007): Qualitative Sozialforschung: eine Einführung. Reinbek bei Hamburg: Rowohlt.

Flick, Uwe; Kardorff, Ernst v.; Steinke, Iris (Hg.) (2012): Qualitative Forschung. Ein Handbuch. Reinbek bei Hamburg: Rowohlt.

Freud, Sigmund (1997): Das Unheimliche. In: Sigmund Freud: Psychologische Schriften. Studienausgabe Bd.4. Frankfurt a. M.: Fischer, S. 242-274.

Fried, Barbara (2014): Antiamerikanismus als kulturalisierende Praxis. Von ,Europäischer Identität‘ und ,amerikanischen Verhältnissen'. Münster: Westfälisches Dampfboot.

Friedman, Max Paul (2012): Rethinking anti-Americanism. The history of an exceptional concept in American foreign relations. Cambridge: Cambridge University Press.

Fuchs, Dieter; Gerhards, Jürgen; Roller, Edeltraud (1993): Wir und die Anderen. Ethnozentrismus in den zwölf Ländern der europäischen Gemeinschaft. In: Kölner Zeitschrift für Soziologie und Sozialpsychologie 45 (2), S. 234-253.

Gabler, Siegfried; Häder, Sabine (1997): Überlegungen zu einem Stichprobendesign für Deutschland. In: ZUMA-Nachrichten (41), S. 7-18.

Giddens, Anthony (1984): The constitution of society. Outline of the theory of structuration. Berkeley, CA: University of California Press.

Giddens, Anthony (1993): New rules of sociological method. A positive critique of interpretative sociologies. Stanford, CA: Stanford University Press.

Giesen, Bernhard (1987): Natürliche Ungleichheit, soziale Ungleichheit, ideale Gleichheit. Zur Evolution von Deutungsmustern sozialer Ungleichheit. In: Bernhard Giesen und Hans Haferkamp (Hg.): Soziologie der sozialen Ungleichheit. Opladen: Westdeutscher Verlag, S. 314-345.

Giesen, Bernhard (1993): Die Intellektuellen und die Nation. Eine deutsche Achsenzeit. Frankfurt a. M.: Suhrkamp. 
Gitlin, Todd (2003): Anti-anti-Americanism. In: Dissent 50 (1), S. 103-104.

Glaser, Barney G.; Strauss, Anselm L. (2010): Grounded theory. Strategien qualitativer Forschung. Bern: Huber.

Glick, Peter; Fiske, Susan T. (2012): An Ambivalent Alliance: Hostile and Benevolent Sexism as Complimentary Justifications for Gender Inequality. In: John Dixon und Mark Levine (Hg.): Beyond Prejudice. Extending the Social Psychology of Conflict, Inequality and Social Change. Cambridge: Cambridge University Press, S. 70-88.

Grass, Günter (2012): Was gesagt werden muss. In: Süddeutsche Zeitung, 04.04.2012, S. 11.

Graumann, Carl Friedrich; Wintermantel, Margret (2007): Diskriminierende Sprechakte. Ein funktionaler Ansatz. In: Steffen Kitty Herrmann, Sybille Krämer und Hannes Kuch (Hg.): Verletzende Worte. Die Grammatik sprachlicher Missachtung. Bielefeld: Transcript, S. 147-178.

Gulddal, Jesper (2011): Anti-Americanism in European literature. New York: Palgrave Macmillan.

Habermas, Jürgen (1973): Erkenntnis und Interesse. Frankfurt a. M.: Suhrkamp.

Habermas, Jürgen (1995): Theorie des kommunikativen Handelns. Band 1. Handlungsrationalität und gesellschaftliche Rationalisierung. Frankfurt a. M.: Suhrkamp.

Habermas, Jürgen (2004): Ist die Herausbildung einer europäischen Identität nötig, und ist sie möglich? In: Der gespaltene Westen. Frankfurt a. M.: Suhrkamp, S. $68-82$.

Hahn, Michael (2003): Vom Keulenschlag zum Schulterklopfen. Einige Erklärungen und Verklärungen von Antiamerikanismus in der Linken. In: Michael Hahn (Hg.): Nichts gegen Amerika. Linker Antiamerikanismus und seine lange Geschichte. Hamburg: Konkret Literatur Verlag, S. 14-24.

Hanson, Norwood Russell (1972): Patterns of discovery. An inquiry into the conceptual foundations of science. Cambridge: Cambridge University Press.

Hartmann, Jutta (2007): Heteronormativität. Empirische Studien zu Geschlecht, Sexualität und Macht. Wiesbaden: VS Verlag für Sozialwissenschaften.

Haury, Thomas (2004): Die "Dollarkönige". Der Antiamerikanismus der DDR. In: Rudolf v. Thadden und Alexandre Escudier (Hg.): Amerika und Europa. Mars und Venus? Das Bild Amerikas in Europa. Göttingen: Wallstein Verlag, S. 6585.

Heitmeyer, Wilhelm (Hg.) (2002a): Deutsche Zustände. Folge 1. Frankfurt a. M.: Suhrkamp.

Heitmeyer, Wilhelm (2002b): Gruppenbezogene Menschenfeindlichkeit. Die theoretische Konzeption und erste empirische Ergebnisse. In: Wilhelm Heitmeyer (Hg.): Deutsche Zustände. Folge 1. Frankfurt a. M.: Suhrkamp, S. 15-36. 
Heitmeyer, Wilhelm (2008): Die Ideologie der Ungleichwertigkeit. Der Kern der Gruppenbezogenen Menschenfeindlichkeit. In: Wilhelm Heitmeyer (Hg.): Deutsche Zustände. Folge 6. Frankfurt a. M.: Suhrkamp, S. 36-44.

Helfferich, Cornelia (2011): Die Qualität qualitativer Daten: Manual für die Durchführung qualitativer Interviews. Wiesbaden: VS Verlag für Sozialwissenschaften.

Hentschel, Christine (2006): Der schlanke Staat und der dicke Konsument. Zur Regierung der Fettleibigkeit. In: Jörn Lamla und Sighard Neckel (Hg.): Politisierter Konsum - konsumierte Politik. Wiesbaden: VS Verlag für Sozialwissenschaften, S. 113-133.

Herek, Gregory M. (2007): Confronting Sexual Stigma and Prejudice: Theory and Practice. In: Journal of Social Issues 63 (4), S. 905-925.

Herrmann, Steffen Kitty; Krämer, Sybille; Kuch, Hannes (Hg.) (2007): Verletzende Worte. Die Grammatik sprachlicher Missachtung. Bielefeld: Transcript Verlag.

Herrmann, Steffen Kitty; Kuch, Hannes (2007): Verletzende Worte. Eine Einleitung. In: Steffen Kitty Herrmann, Sybille Krämer und Hannes Kuch (Hg.): Verletzende Worte. Die Grammatik sprachlicher Missachtung. Bielefeld: Transcript Verlag, S. 7-30.

Heyder, Aribert (2003): Bessere Bildung, bessere Menschen? Genaueres Hinsehen hilft weiter. In: Wilhelm Heitmeyer (Hg.): Deutsche Zustände. Folge 2. Frankfurt a. M.: Suhrkamp, S. 78-99.

Heyder, Aribert; Iser, Julia; Schmidt, Peter (2005): Israelkritik oder Antisemitismus? Meinungsbildung zwischen Öffentlichkeit, Medien und Tabus. In: Wilhelm Heitmeyer (Hg.): Deutsche Zustände. Folge 3. Frankfurt a. M.: Suhrkamp, S. 144-165.

Heyder, Aribert; Schmidt, Peter (2002): Deutscher Stolz. Patriotismus wäre besser. In: Wilhelm Heitmeyer (Hg.): Deutsche Zustände. Folge 1. Frankfurt a. M.: Suhrkamp, S. 71-82.

Hoffmann, Gabriele (1972): NS-Propaganda in den Niederlanden. Organisation und Lenkung der Publizistik unter deutsche Besatzung 1940-1945. MünchenPullach, Berlin: Verlag Dokumentation.

Hollander, Paul (1995): Anti-Americanism: irrational and rational. New Brunswick, NJ: Transaction Publishers.

Hollander, Paul (2004): Understanding anti-Americanism: its origins and impact at home and abroad. Chicago, IL: Ivan R. Dee.

Hollyday, Guy T. (1977): Anti-Americanism in the German novel: 1841 - 1862. Bern [u.a.]: Peter Lang.

Holman, Darryl J. (2004): Unobserved Heterogeneity. In: Michael S. Lewis-Beck, Alan Bryman und Tim Futing Liao (Hg.): The Sage Encyclopedia of Social Science Research Methods. Thousand Oaks, CA: Sage, S. 1160-1162.

Holz, Klaus (2001): Nationaler Antisemitismus: Wissenssoziologie einer Weltanschauung. Hamburg: Hamburger Edition. 
Holz, Klaus (2002): Die Figur des Dritten in der nationalen Ordnung der Welt. In: Soziale Systeme 6 (2), S. 269-290.

Holz, Klaus (2005): Die Gegenwart des Antisemitismus: islamistische, demokratische und antizionistische Judenfeindschaft. Hamburg: Hamburger Edition.

Holz, Klaus (2007): Die Paradoxie der Normalisierung. Drei Gegensatzpaare des Antisemitismus vor und nach Auschwitz. In: Klaus-Michael Bogdal, Klaus Holz und Matthias N. Lorenz (Hg.): Literarischer Antisemitismus nach Auschwitz. Stuttgart: Metzler, S. 37-57.

Holz, Klaus (2010): Der Jude. Dritter der Nationen. In: Eva Eßlinger, Tobias Schlechtriemen, Doris Schweitzer und Alexander Zons (Hg.): Die Figur des Dritten. Ein kulturwissenschaftliches Paradigma. Frankfurt a. M.: Suhrkamp, S. 292-303.

Honneth, Axel (2000): Über die Möglichkeit einer erschließenden Kritik. Die „Dialektik der Aufklärung“ im Horizont gegenwärtiger Debatten über Sozialkritik. In: Das Andere der Gerechtigkeit. Aufsätze zur praktischen Philosophie. Frankfurt a. M.: Suhrkamp, S. 70-87.

Honneth, Axel (2005): Verdinglichung: eine anerkennungstheoretische Studie. Frankfurt a. M.: Suhrkamp.

Honneth, Axel (2007a): Eine soziale Pathologie der Vernunft. Zur intellektuellen Erbschaft der Kritischen Theorie. In: Pathologien der Vernunft. Geschichte und Gegenwart der kritischen Theorie. Frankfurt a. M.: Suhrkamp, S. 28-56.

Honneth, Axel (2007b): Pathologien der Vernunft. Geschichte und Gegenwart der kritischen Theorie. Frankfurt a. M.: Suhrkamp.

Honneth, Axel (2007c): Rekonstruktive Gesellschaftskritik unter genealogischem Vorbehalt. In: Pathologien der Vernunft. Geschichte und Gegenwart der kritischen Theorie. Frankfurt a. M.: Suhrkamp, S. 57-69.

Hopf, Christel (1993): Soziologie und qualitative Sozialforschung. In: Christel Hopf (Hg.): Qualitative Sozialforschung. Stuttgart: Klett-Cotta, S. 11-40.

Hopf, Christel (2012): Qualitative Interviews - ein Überblick. In: Uwe Flick, Ernst v. Kardorff und Iris Steinke (Hg.): Qualitative Forschung. Ein Handbuch. Reinbek bei Hamburg: Rohwolt, S. 349-360.

Horkheimer, Max (1988): Anti-Amerikanismus, Antisemitismus und Demagogie und die Lage der Jugend heute. In: Gesammelte Schriften. Band 14: Nachgelassene Schriften 1949-1972. Frankfurt a. M.: Fischer, S. 408-409.

Horkheimer, Max (1989): Zum gegenwärtigen Antiamerikanismus. In: Gesammelte Schriften. Band 13: Nachgelassene Schriften 1949-1972. Frankfurt a. M.: Fischer, S. 82-83.

Horkheimer, Max (2005): Traditionelle und kritische Theorie. In: Traditionelle und kritische Theorie. Fünf Aufsätze. Frankfurt a. M.: Fischer, S. 205-269.

Horkheimer, Max; Adorno, Theodor W. (2004): Dialektik der Aufklärung. Philosophische Fragmente. Frankfurt a. M.: Fischer. 
Hormel, Ulrike; Scherr, Albert (2006): Ungleichheiten und Diskriminierung. In: Soziologische Basics: Eine Einführung für Pädagogen und Pädagoginnen. Wiesbaden: VS Verlag für Sozialwissenschaften, S. 181-186.

Hormel, Ulrike; Scherr, Albert (Hg.) (2010): Diskriminierung. Grundlagen und Forschungsergebnisse. Wiesbaden: VS Verlag für Sozialwissenschaften.

Höttemann, Michael; Knappertsbusch, Felix; Milbradt, Björn (2010): Transnationale Aspekte in antisemitischen Feind-, Fremd- und Wir-Bildern. In: Wolfgang Benz (Hg.): Jahrbuch für Antisemitismusforschung (19), S. 269-296.

Irvine, Annie; Drew, Paul; Sainsbury, Roy (2013): ,Am I not answering your questions properly?' Clarification, adequacy and responsiveness in semi-structured telephone and face-to-face interviews. In: Qualitative Research 13 (1), S. 87 106.

Jackman, Mary R. (1994): The velvet glove. Paternalism and conflict in gender, class, and race relations. Berkeley, CA: University of California Press.

Jaecker, Tobias (2014): Hass, Neid, Wahn. Antiamerikanismus in den deutschen Medien. Frankfurt a. M.: Campus.

Jaeggi, Rahel (2005a): Entfremdung. Zur Aktualität eines sozialphilosophischen Problems. Frankfurt a. M.: Campus.

Jaeggi, Rahel (2005b): „Kein Einzelner vermag etwas dagegen“. Adornos Minima Moralia als Kritik von Lebensformen. In: Axel Honneth (Hg.): Dialektik der Freiheit. Frankfurter Adorno-Konferenz 2003. Frankfurt a. M.: Suhrkamp, S. 115-141.

Jaeggi, Rahel; Wesche, Tilo (Hg.) (2009): Was ist Kritik? Frankfurt a. M.: Suhrkamp.

Jarausch, Konrad (2005): Missverständnis Amerika: Antiamerikanismus als Projektion. In: Jan C. Behrends (Hg.): Antiamerikanismus im 20. Jahrhundert: Studien zu Ost- und Westeuropa. Bonn: Dietz, S. 34-50.

Joffe, Josef (2006): Die Hypermacht. Warum die USA die Welt beherrschen. Bonn: Bundeszentrale für Politische Bildung.

Joffe, Josef (2012): Der Antisemitismus will raus. In: Zeit Online, 04.04.2012. Online verfügbar unter http://www.zeit.de/politik/ausland/2012-04/guenter-grassgedicht-israel/seite-1, zuletzt geprüft am 10.04.2014.

Johnston, Gregory (2006): Anti-Americanism: An Exploration of a Contested Concept in Western Europe. Dissertation. Louisiana State University. Department of Political Science.

Kalthoff, Herbert (2008): Einleitung: Zur Dialektik von qualitativer Forschung und soziologischer Theoriebildung. In: Herbert Kalthoff, Stefan Hirschauer und Gesa Lindemann (Hg.): Theoretische Empirie. Zur Relevanz qualitativer Forschung. Frankfurt a. M.: Suhrkamp, S. 8-32.

Kalthoff, Herbert; Hirschauer, Stefan; Lindemann, Gesa (Hg.) (2008): Theoretische Empirie. Zur Relevanz qualitativer Forschung. Frankfurt a. M.: Suhrkamp. 
Kambartel, Friedrich; Stekeler-Weithofer, Pirmin (2005): Sprachphilosophie: Probleme und Methoden. Stuttgart: Reclam.

Kane, John (2006): Ambivalent Anti-Americanism. In: Brendon O'Connor und Martin Griffiths (Hg.): The rise of anti-Americanism. London [u.a.]: Routledge, S. 48-67.

Katzenstein, Peter J.; Keohane, Robert O. (Hg.) (2007a): Anti-Americanisms in World Politics. Ithaca, NY: Cornell University Press.

Katzenstein, Peter J.; Keohane, Robert O. (2007b): Varieties of Anti-Americanism: A Framework for Analysis. In: Peter J. Katzenstein und Robert O. Keohane (Hg.): Anti-Americanisms in World Politics. Ithaca, NY: Cornell University Press, S. 9-38.

Kelle, Udo (1997): Empirisch begründete Theoriebildung: zur Logik und Methodologie interpretativer Sozialforschung. Weinheim: Deutscher Studien-Verlag.

Kelle, Udo (2005): „Emergence“ vs. „Forcing“ of Empirical Data? A Crucial Problem of „Grounded Theory“ Reconsidered. In: Forum Qualitative Sozialforschung 6 (2). Online verfügbar unter http://www.qualitativeresearch.net/index.php/fqs/article/view/467, zuletzt geprüft am 10.04.2014.

Kelle, Udo (2008a): Die Integration qualitativer und quantitativer Methoden in der empirischen Sozialforschung: Theoretische Grundlagen und methodologische Konzepte. Wiesbaden: VS Verlag für Sozialwissenschaften.

Kelle, Udo (2008b): Strukturen begrenzter Reichweite und empirisch begründete Theoriebildung. Überlegungen zum Theoriebezug qualitativer Methodologie. In: Herbert Kalthoff, Stefan Hirschauer und Gesa Lindemann (Hg.): Theoretische Empirie. Zur Relevanz qualitativer Forschung. Frankfurt a. M.: Suhrkamp, S. 312-337.

Kelle, Udo; Kluge, Susann (2008): Vom Einzelfall zum Typus: Fallvergleich und Fallkontrastierung in der qualitativen Sozialforschung. Wiesbaden: VS Verlag für Sozialwissenschaften.

Knappertsbusch, Felix (2013): The Meaning of Anti-Americanism: A performative Approach to Anti-American Prejudice. In: International Journal of conflict and Violence 7 (1), S. 91-107. Online verfügbar unter http://www.ijcv.org/index.php/ijcv/article/view/258, zuletzt geprüft am 10.04.2014.

Knappertsbusch, Felix; Kelle, Udo (2010): "Mutterland des nomadisierenden Finanzkapitals" - Zum Verhältnis von Antiamerikanismus und Antisemitismus vor dem Hintergrund der Finanzkrise. In: Wilhelm Heitmeyer (Hg.): Deutsche Zustände. Folge 8. Frankfurt a. M.: Suhrkamp, S. 144-163.

Knappertsbusch, Felix; Milbradt, Björn; Kelle, Udo (2013): Guest Editorial: Qualitative Research on Prejudice. In: International Journal of conflict and Violence 7 (1), S. 50-56. Online verfügbar unter http://www.ijcv.org/ index.php/ijcv/article/view/362, zuletzt geprüft am 10.04.2014. 
Krämer, Sybille (2010): Performanz. In: Hans Jörg Sandkühler (Hg.): Enzyklopädie Philosophie. In drei Bänden. Hamburg: Meiner, S. 1920-1922.

Krauthammer, Charles (2003): To Hell with Sympathy. In: Time Magazine 20 (162), S. 156.

Kreckel, Reinhard (2004): Politische Soziologie der sozialen Ungleichheit. Frankfurt a. M.: Campus.

Kuckartz, Udo (2007): Einführung in die computergestützte Analyse qualitativer Daten. Wiesbaden: VS Verlag für Sozialwissenschaften.

Kuhn, Philip (2013): Dämonisierung mit dem Ziel der Delegitimierung. In: Die Welt, 16.01.2013. Online verfügbar unter http://www.welt.de/politik/ deutschland/article112787522/Daemonisierung-mit-dem-Ziel-der-

Delegitimierung.html, zuletzt geprüft am 05.09.2013.

Küpper, Beate; Zick, Andreas (2011): Gruppenbezogene Menschenfeindlichkeit bei Frauen und Männern. In: Ursula Birsl (Hg.): Rechtsextremismus und Gender. Opladen: Budrich, S. 187-210.

Kvale, Steinar (1995): The Social Construction of Validity. In: Qualitative Inquiry 1 (1), S. 19-40.

Lamla, Jörn (2013): Verbraucherdemokratie. Politische Soziologie der Konsumgesellschaft. Berlin: Suhrkamp.

Lessenich, Stephan (2014): Soziologie - Krise - Kritik. Zu einer kritischen Soziologie der Kritik. In: Soziologie 43 (1), S. 7-24.

Luhmann, Niklas (1980): Gesellschaftsstruktur und Semantik. Studien zur Wissenssoziologie der modernen Gesellschaft. Band 1. Frankfurt a. M.: Suhrkamp.

Luhmann, Niklas (1987a): Soziale Systeme. Grundriss einer allgemeinen Theorie. Frankfurt a. M.: Suhrkamp.

Luhmann, Niklas (1987b): Tautologie und Paradoxie in der Selbstbeschreibung der modernen Gesellschaft. In: Zeitschrift für Soziologie 16 (3), S. 161-174.

Luhmann, Niklas (1990): Paradigm lost - Über die ethische Reflexion der Moral. Rede von Niklas Luhmann anlässlich der Verleihung des Hegel-Preises 1989. Frankfurt a. M.: Suhrkamp.

Mann, Golo (1954): Urteil und Vorurteil. In: Merkur 8 (74), S. 390-394.

Mansel, Jürgen; Spaiser, Viktoria (2012): Antisemitische Einstellungen bei Jugendlichen aus muslimisch geprägten Sozialisationskontexten. Eigene Diskriminierungserfahrungen und transnationale Einflüsse als Hintergrundfaktoren. In: Wilhelm Heitmeyer (Hg.): Deutsche Zustände, Folge 10. Frankfurt a. M.: Suhrkamp, S. 220-244.

Marcuse, Ludwig (1953a): Der Anti-Amerikanische Hexenhammer Anno 1953. In: Neue Schweizerische Rundschau (11), S. 609-614.

Marcuse, Ludwig (1953b): Der europäische Antiamerikanismus. In: Neue Schweizerische Rundschau (1), S. 67-73.

Markovits, Andrei S. (2004): Amerika, dich haßt sich's besser: Antiamerikanismus und Antisemitismus in Europa. Hamburg: Konkret Literatur Verlag. 
Markovits, Andrei S. (2005): Allzeit präsent, doch immer verleugnet. Überlegungen zum europäischen Antiamerikanismus und Antisemitismus. In: Jan C. Behrends (Hg.): Antiamerikanismus im 20. Jahrhundert: Studien zu Ost- und Westeuropa. Bonn: Dietz, S. 320-350.

Markovits, Andrei S. (2007): Uncouth Nation: why Europe dislikes America. Princeton, NJ [u.a.]: Princeton University Press.

Markovits, Andrei S.; Rensmann, Lars (2007): Anti-Americanism in Germany. In: Brendon O'Connor (Hg.): Anti-Americanism: History, Causes, Themes. 4 Bände. Westport, CT: Greenwood World Publishing, S. 155-182.

Martin, Peter (2010): ,I hope I'm not a Racist'. The Investigation of Everyday Racism using Surveys. Dissertation. City University London. Department of Sociology.

Martin, Peter (2013): Racism, Differentialism, and Antiracism in Everyday Ideology: A Mixed-Methods Study in Britain. In: International Journal of conflict and Violence 7 (1), S. 57-73. Online verfügbar unter http://ijcv.org/index.php/ ijcv/article/view/277, zuletzt geprüft am 12.02.2014.

Mayring, Philipp (2010): Qualitative Inhaltsanalyse. Grundlagen und Techniken. Weinheim: Beltz.

Menke, Christoph (1997): Kritische Theorie und tragische Erkenntnis. In: Zeitschrift für Kritische Theorie 3 (5), S. 43-63.

Menke, Christoph (2004): Spiegelungen der Gleichheit. Politische Philosophie nach Adorno und Derrida. Frankfurt a. M.: Suhrkamp.

Menke, Christoph (2012): Zweite Natur. Kritik und Affirmation. In: Malte Völk, Mark Lückhof, David Nax, Oliver Römer, Sebastian Schreull und Christian Spiegelberg (Hg.): ,...wenn die Stunde es zuläßt“. Zur Traditionalität und Aktualität kritischer Theorie. Münster: Westfälisches Dampfboot, S. 154-171.

Milbradt, Björn (2013): Stereotypie - Syndrom - Autoritarismus. Eine sprachtheoretische Untersuchung zum Stereotypiebegriff. Dissertation. PhilippsUniversität Marburg. Institut für Soziologie.

Misik, Robert (2003): Marxismus der dummen Kerls. In: Die Tageszeitung, 25.02.2003. Online verfügbar unter http://www.taz.de/1/archiv/archiv/ ?dig=2003/02/25/a0120, zuletzt geprüft am 10.04.2014.

Müller, Florian; Kals, Elisabeth (2004): Die Q-Methode. Ein innovatives Verfahren zur Erhebung subjektiver Einstellungen und Meinungen. In: Forum Qualitative Sozialforschung 5 (2). Online verfügbar unter http://www.qualitative-research. net/index.php/fqs/article/view/600/1301, zuletzt geprüft am 10.04.2014.

Müller, Jan (2012): Begriffliches Sprechen. Zur sprachphilosophischen Grundkonstellation der frühen kritischen Theorie. In: Malte Völk, Mark Lückhof, David Nax, Oliver Römer, Sebastian Schreull und Christian Spiegelberg (Hg.): „....wenn die Stunde es zuläßt“. Zur Traditionalität und Aktualität kritischer Theorie. Münster: Westfälisches Dampfboot, S. 172-202. 
Nassehi, Armin (1997a): Das stahlharte Gehäuse der Zugehörigkeit. Unschärfen im Diskurs um die ,multikulturelle Gesellschaft“. In: Armin Nassehi (Hg.): Nation, Ethnie, Minderheit. Beiträge zur Aktualität ethnischer Konflikte. Köln: Böhlau, S. 177-208.

Nassehi, Armin (Hg.) (1997b): Nation, Ethnie, Minderheit. Beiträge zur Aktualität ethnischer Konflikte. Köln: Böhlau.

Nassehi, Armin; Richter, Dirk (1996): Die Form „Nation“ und der Einschluss durch Ausschluss. Beobachtungen zur Fremdenfeindlichkeit in Deutschland. In: Sociologica Internationalis 34 (2), S. 151-176.

Neckel, Sighard; Soeffner, Hans-Georg (Hg.) (2008): Mittendrin im Abseits. Ethnische Gruppenbeziehungen im lokalen Kontext. Wiesbaden: VS Verlag für Sozialwissenschaften.

Neckel, Sighard; Sutterlüty, Ferdinand (2005): Negative Klassifikationen. Konflikte um die symbolische Ordnung sozialer Ungleichheit. In: Wilhelm Heitmeyer und Peter Imbusch (Hg.): Integrationspotenziale einer modernen Gesellschaft. Analysen zu gesellschaftlicher Integration und Desintegration. Wiesbaden: VS Verlag für Sozialwissenschaften, S. 409-428.

Nelson, Todd D. (2002): The Psychology of Prejudice. Boston, MA: Allyn und Bacon.

Neubert, Stefan; Roth, Hans-Joachim; Yildiz, Erol (2013): Multikulturalismus - ein umstrittenes Konzept. In: Stefan Neubert, Hans-Joachim Roth und Erol Yildiz (Hg.): Multikulturalität in der Diskussion. Neuere Beiträge zu einem umstrittenen Konzept. 3. Aufl. 2013. Wiesbaden: Springer Fachmedien Wiesbaden; Imprint: Springer VS (Interkulturelle Studien), S. 9-33.

Nohl, Arnd-Michael (2012): Interview und dokumentarische Methode. Anleitungen für die Forschungspraxis. Wiesbaden: VS Verlag für Sozialwissenschaften.

O'Connor, Brendon (2003): A political History of the American Welfare System. When Ideas have Consequences. Lanham, MD: Rowman \& Littlefield.

O'Connor, Brendon (Hg.) (2007a): Anti-Americanism: History, Causes, Themes. 4 Bände. Westport, CT: Greenwood World Publishing.

O'Connor, Brendon (2007b): What is Anti-Americanism? In: Brendon O'Connor (Hg.): Anti-Americanism: History, Causes, Themes. 4 Bände. Westport, CT: Greenwood World Publishing, S. 1-19.

O'Connor, Brendon; Griffiths, Martin (Hg.) (2006): The rise of anti-Americanism. London [u.a.]: Routledge.

Opdenakker, Raymond (2006): Advantages and Disadvantages of Four Interview Techniques. In: Qualitative Research 7 (4), Artikel 11. Online verfügbar unter http://www.qualitative-research.net/index.php/fqs/article/view/175/392, zuletzt geprüft am 16.04.2015.

Özdemir, Cem: Biographie. Online verfügbar unter http://www.oezdemir.de/ biografie.html, zuletzt geprüft am 07.01.2014. 
Pehrson, Samuel; Vignoles, Vivian L.; Brown, Rupert (2009): National Identification and anti-Immigrant Prejudice: Individual and contextual Effects of National Definitions. In: Social Psychology Quarterly 72 (1), S. 24-38.

Plant, Ashby; Devine, Patricia (2009): The active control of prejudice: unpacking the intentions guiding control efforts. In: Journal of personality and social psychology 96 (3), S. 640-652.

Pokatzky, Klaus (2013): Generalsekretär der Evangelischen Akademien in Deutschland spricht von ,pauschaler Keule“. Deutschlandradio Kultur, 03.01.2013. Online verfügbar unter http://www.dradio.de/dkultur/sendungen/thema/1966701/, zuletzt geprüft am 05.09.2013.

Posor, Andrea; Meyer, Christian (2009): Deutschenfeindlichkeit in Schulen. Über die Ursachen einer zunehmenden Tendenz unter türkisch- und arabischstämmigen Jugendlichen. In: BLZ: Mitgliederzeitschrift der GEW Berlin (11). Online verfügbar unter http://www.gew-berlin.de/1297_1485.php, zuletzt geprüft am 05.12.2013.

Postone, Moishe (2005): Antisemitismus und Nationalsozialismus. In: Moishe Postone: Deutschland, die Linke und der Holocaust. Politische Interventionen. Freiburg: Ca Ira, S. 165-194.

Reichertz, Jo (2013): Die Abduktion in der qualitativen Sozialforschung. Über die Entdeckung des Neuen. Wiesbaden: Springer VS.

Reichertz, Jo (2014): Empirische Sozialforschung und soziologische Theorie. In: Nina Baur und Jörg Blasius (Hg.): Handbuch Methoden der empirischen Sozialforschung. Wiesbaden: Springer VS, S. 65-80.

Revel, Jean-Francois (2003): The Anti-American Obsession. In: The New Criterion 22 (2), S. 12-19.

Richter, Dirk (1996): Nation als Form. Opladen: Westdeutscher Verlag.

Richter, Gerhard (2010): Language without soil. Adorno and late philosophical modernity. New York: Fordham University Press.

Rieker, Peter (1997): Ethnozentrismus bei jungen Männern. Fremdenfeindlichkeit und Nationalismus und die Bedingungen ihrer Sozialisation. Weinheim: Juventa.

Roger, Philippe (2005): The American Enemy. The History of French antiAmericanism. Chicago, IL: University of Chicago Press.

Rorty, Richard (1995): Freud und die moralische Reflexion. In: Richard Rorty: Solidarität oder Objektivität? Drei philosophische Essays. Stuttgart: Reclam, S. $38-81$.

Rosch, Eleanor; Mervis, Carolyn B. (1975): Family Resemblances: Studies in the internal Structure of Categories. In: Cognitive Psychology 7 (4), S. 573-605.

Rubinstein, Alvin Z.; Smith, Donald E. (Hg.) (1985): Anti-Americanism in the Third World: Implications for U.S. Foreign Policy. New York [u.a.]: Praeger.

Rudman, Laurie A. (2005): Rejection of Women? Beyond Prejudice as Antipathy. In: John F. Dovidio, Peter Glick und Laurie A. Rudman (Hg.): On the Nature of 
Prejudice. Fifty Years After Allport. Malden, MA: Blackwell Publishing, S. 106-120.

Sablowski, Thomas (2004): ,Antiamerikanismus“ - Ambivalenz eines Kampfbegriffs. In: Das Argument 46 (2), S. 201-206.

Schatz, Holger; Woeldike, Andrea (2001): Freiheit und Wahn deutscher Arbeit. Zur historischen Aktualität einer folgenreichen antisemitischen Projektion. Hamburg: Unrast.

Schäuble, Barbara (2012): „Anders als wir“. Differenzkonstruktionen und Alltagsantisemitismus unter Jugendlichen. Anregungen für die politische Bildung. Berlin: Metropol.

Schedler, Jan; Häusler, Alexander (Hg.) (2011): Autonome Nationalisten. Neonazismus in Bewegung. Wiesbaden: VS Verlag für Sozialwissenschaften.

Scherr, Albert (2008): Diskriminierung - eine eigenständige Kategorie für die soziologische Analyse der (Re-)Produktion sozialer Ungleichheit in der Einwanderungsgesellschaft? In: Karl S. Rehberg (Hg.): Die Natur der Gesellschaft. Verhandlungen des 33. Kongresses der Deutschen Gesellschaft für Soziologie in Kassel 2006. Frankfurt a. M.: Campus, S. 2007-2017.

Scherr, Albert (2010): Diskriminierung und soziale Ungleichheiten. Erfordernisse und Perspektiven einer ungleichheitsanalytischen Fundierung von Diskriminierungsforschung und Antidiskriminierungsstrategien. In: Ulrike Hormel und Albert Scherr (Hg.): Diskriminierung. Grundlagen und Forschungsergebnisse. Wiesbaden: VS Verlag für Sozialwissenschaften, S. 35-60.

Scherr, Albert (2011): Was meint Diskriminierung? Warum es nicht genügt, sich mit Vorurteilen auseinanderzusetzen. In: Sozial Extra 11 (12), S. 34-38.

Scherr, Albert; Schäuble, Barbara (2006): ,Ich habe nichts gegen Juden, aber... ‘ Widersprüche und fragmentarische Formen von Antisemitismus in heterogenen Jugendszenen. In: Fritz Bauer Institut und Jugendbegegnungsstätte Anne Frank (Hg.): Globalisierte Projektionen. Neue Judenfeindschaft? Pädagogische Auseinandersetzungen mit aktuellem Antisemitismus. Frankfurt a. M., S. 51-79.

Schlüter, Elmar; Christ, Oliver (2012): How national identification enhances antiimmigrant prejudice: Development and empirical test of individual-, contextual-, and cross-level explanations. In: Samuel Salzborn, Eldad Davidov und Jost Reinecke (Hg.): Methods, Theories, and Empirical Applications in the Social Sciences. Festschrift for Peter Schmidt. Wiesbaden: Springer VS, S. 291-299.

Schulz, Marlen; Rudat, Michael (2012): „Let's talk about Sex!““ Über die Eignung von Telefoninterviews in der qualitativen Sozialforschung 13 (3). Online verfügbar unter http://www.qualitative-research.net/index.php/fqs/article/view/ 1758/3400, zuletzt geprüft am 16.04.2015.

Schwan, Gesine (1999): Antikommunismus und Antiamerikanismus in Deutschland. Kontinuität und Wandel nach 1945. Baden-Baden: Nomos. 
Schwark, Sebastian (2008): Zur Genealogie des modernen Antiamerikanismus in Deutschland. Baden-Baden: Nomos.

Shoomann, Yasemin (2010): „Deutschenfeindlichkeit“. Zur problematischen Verwendung des Begriffs. In: BLZ: Mitgliederzeitschrift der GEW Berlin (12). Online verfügbar unter http://www.gew-berlin.de/1296_1310.php, zuletzt geprüft am 05.12.2013.

Soeffner, Hans-Georg (2004): Prämissen einer sozialwissenschaftlichen Hermeneutik. In: Auslegung des Alltags - Der Alltag der Auslegung. Zur wissenssoziologischen Konzeption einer sozialwissenschaftlichen Hermeneutik. Konstanz: UTB, S. 78-113.

Sommers, Samuel R.; Norton, Michael I. (2006): Lay Theories About White Racists: What Constitutes Racism (and What Doesn't). In: Group Processes \& Intergroup Relations 9 (1), S. 117-138.

Srp, Uwe (2005): Antiamerikanismus in Deutschland: Theoretische und empirische Analyse basierend auf dem Irakkrieg 2003. Hamburg: Kovac.

Steinke, Ines (2012): Gütekriterien qualitativer Forschung. In: Uwe Flick, Ernst v. Kardorff und Iris Steinke (Hg.): Qualitative Forschung. Ein Handbuch. Reinbek bei Hamburg: Rohwolt, S. 319-331.

Sutterlüty, Ferdinand (2004): Ungleichheitssemantiken und Ungleichheitspragmatiken. Das Beispiel von Deutungskämpfen zwischen der autochthonen Bevölkerung und erfolgreichen Migranten. Unveröffentlichtes Vortragsmanuskript zum 32. Kongress der Deutschen Gesellschaft für Soziologie in München, Sektion Soziale Ungleichheit und Sozialstrukturanalyse.

Sutterlüty, Ferdinand (2008): Ethnischer Verwandtschaftsglaube - ein generatives Klassifikationsprinzip. In: Sighard Neckel und Hans-Georg Soeffner (Hg.): Mittendrin im Abseits. Ethnische Gruppenbeziehungen im lokalen Kontext. Wiesbaden: VS Verlag für Sozialwissenschaften, S. 92-111.

Sutterlüty, Ferdinand (2010): In Sippenhaft. Negative Klassifikationen in ethnischen Konflikten. Frankfurt a. M.: Campus.

Sutterlüty, Ferdinand (2011): Paradoxale Folgen ethnischer Gleichheit. In: West End: Neue Zeitschrift für Sozialforschung 8 (1), S. 103-116.

Sutterlüty, Ferdinand; Neckel, Sighard (2012): Gegen die türkischen Aufsteiger Interethnische Klassifikationen und Ausgrenzungspraktiken. In: Wilhelm Heitmeyer und Peter Imbusch (Hg.): Desintegrationsdynamiken. Integrationsmechanismen auf dem Prüfstand. Dordrecht: Springer, S. 143-170.

Sutterlüty, Ferdinand; Neckel, Sighard; Walter, Ina (2008): Klassifikationen im Kampf um Abgrenzung und Zugehörigkeit. In: Sighard Neckel und Hans-Georg Soeffner (Hg.): Mittendrin im Abseits. Ethnische Gruppenbeziehungen im lokalen Kontext. Wiesbaden: VS Verlag für Sozialwissenschaften, S. 28-89.

Vobruba, Georg (2013): Soziologie und Kritik. Moderne Sozialwissenschaft und Kritik der Gesellschaft. In: Soziologie 42 (2), S. 147-168. 
Wahdat-Hagh, Wahied (2012): „Der Westen wird dasselbe Schicksal erleiden wie Sodom“. Online verfügbar unter http://jungle-world.com/von-tunis-nachteheran/1854/, zuletzt geprüft am 17.04.2014.

Walzer, Michael (2000): Komplexe Gleichheit. In: Angelika Krebs (Hg.): Gleichheit oder Gerechtigkeit. Texte der neuen Egalitarismuskritik. Frankfurt a. M.: Suhrkamp, S. 172-214.

Weber, Max (1988): Soziologische Grundbegriffe. In: Gesammelte Aufsätze zur Wissenschaftslehre. Tübingen: Mohr, S. 541-581.

Wehling, Peter (2014): Soziologische (Selbst-)Kritik und transformative gesellschaftliche Praxis. Kritische Anmerkungen zu Georg Vobruba, ,Soziologie und Kritik'. In: Soziologie 43 (1), S. 25-42.

Weiß, Anja (2001): Rassismus als symbolisch vermittelte Dimension sozialer Ungleichheit. In: Anja Weiß, Cornelia Koppetsch, Albert Scharenberg und Oliver Schmidtke (Hg.): Klasse und Klassifikation. Die symbolische Dimension sozialer Ungleichheit. Wiesbaden: Westdeutscher Verlag, S. 79-108.

Weiß, Anja (2013): Rassismus wider Willen. Ein anderer Blick auf eine Struktur sozialer Ungleichheit. Wiesbaden: Springer VS.

Weiß, Anja; Koppetsch, Cornelia; Scharenberg, Albert; Schmidtke, Oliver (Hg.) (2001): Klasse und Klassifikation. Die symbolische Dimension sozialer Ungleichheit. Wiesbaden: Westdeutscher Verlag.

Wellmer, Albrecht (2004): Sprachphilosophie: Eine Vorlesung. Frankfurt a. M.: Suhrkamp.

Wellmer, Albrecht (2007): Ludwig Wittgenstein. Über die Schwierigkeiten einer Rezeption seiner Philosophie und ihre Stellung zur Philosophie Adornos. In: Wie Worte Sinn machen. Aufsätze zur Sprachphilosophie. Frankfurt a. M.: Suhrkamp, S. 255-265.

Welsch, Wolfgang (2010): Standbeine dürfen nicht zum Klumpfuß werden. In: Musikforum (1), S. 8-12.

Wetherell, Margaret (2012): The Prejudice Problematic. In: John Dixon und Mark Levine (Hg.): Beyond Prejudice. Extending the Social Psychology of Conflict, Inequality and Social Change. Cambridge: Cambridge University Press, S. 158178.

Wetherell, Margaret; Potter, Jonathan (1992): Mapping the Language of Racism. Discourse and the Legitimation of Exploitation. New York [u.a.]: Harvester Wheatsheaf.

Wiggershaus, Rolf (Hg.) (1975): Sprachanalyse und Soziologie. Die sozialwissenschaftliche Relevanz von Wittgensteins Sprachphilosophie. Frankfurt a. M.: Suhrkamp.

Wiggershaus, Rolf (2000): Wittgenstein und Adorno. Zwei Spielarten modernen Philosophierens. Göttingen: Wallstein.

Willis, Gordon B. (2005): Cognitive interviewing. A tool for improving questionnaire design. Thousand Oaks, CA: Sage. 
Wimmer, Andreas (2008): Ethnische Grenzziehungen in der Immigrationsgesellschaft. Jenseits des Herder'schen Commonsense. In: Frank Kalter (Hg.): Migration und Integration. Kölner Zeitschrift für Soziologie und Sozialpsychologie 48 (Sonderheft). Wiesbaden: VS Verlag für Sozialwissenschaften, S. 57-80.

Winch, Peter (1966): Die Idee der Sozialwissenschaft und ihr Verhältnis zur Philosophie. Frankfurt a. M.: Suhrkamp.

Winch, Peter (2008): The Idea of a Social Science and its Relation to Philosophy. London: Routledge.

Wittgenstein, Ludwig (2006): Philosophische Untersuchungen. In: Werkausgabe Band 1. Tractatus logico-philosophicus. Tagebücher 1914-1916. Philosophische Untersuchungen. Frankfurt a. M.: Suhrkamp.

Witzel, Andreas (2000): Das problemzentrierte Interview. In: Forum: Qualitative Sozialforschung 1 (1). Online verfügbar unter http://www.qualitativeresearch.net/index.php/fqs/article/view/1132/2519, zuletzt geprüft am 10.04.2014.

Zahn, Mathias (2013): Verordnete Empörung im Wahlkampf. Online verfügbar unter http://www.tagesschau.de/kommentar/friedrich-nsa100.html, zuletzt geprüft am 23.02.2014.

Zick, Andreas; Hövermann, Andreas; Krause, Daniela (2012): Die Abwertung von Ungleichwertigen. Erklärung und Prüfung eines erweiterten Syndroms der Gruppenbezogenen Menschenfeindlichkeit. In: Wilhelm Heitmeyer ( $\mathrm{Hg}$.): Deutsche Zustände, Folge 10. Frankfurt a. M.: Suhrkamp, S. 64-86.

Zick, Andreas; Wolf, Carina; Küpper, Beate; Davidov, Eldad; Schmidt, Peter; Heitmeyer, Wilhelm (2008): The Syndrome of Group-Focused Enmity: The Interrelation of Prejudices Tested with Multiple Cross-Sectional and Panel Data. In: Journal of Social Issues 64 (2), S. 363-383.

Zyphur, Michael J. (2009): When Mindsets Collide: Switching Analytical Mindsets to Advance Organizational Science. In: Academy of Management Review 34 (4), S. 677-688. 


\section{Kulturen der Gesellschaft}

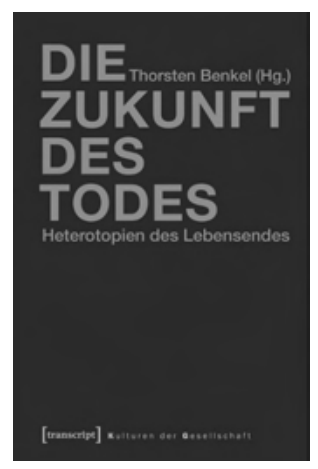

Thorsten Benkel (Hg.)

Die Zukunft des Todes

Heterotopien des Lebensendes

Juli 20I6, ca. 350 Seiten, kart., ca. 32,99€, ISBN 978-3-8376-2992-7

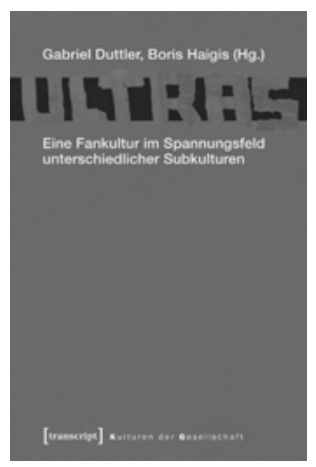

Gabriel Duttler, Boris Haigis (Hg.)

\section{Ultras}

Eine Fankultur im Spannungsfeld unterschiedlicher Subkulturen

April 20I6, ca. 350 Seiten, kart., ca. 29,99€, ISBN 978-3-8376-3060-2

Jens Kersten (Hg.)

Inwastement -

Abfall in Umwelt und Gesellschaft

Abfall in Umwelt und Gesellschaft

Februar 2016, 342 Seiten, kart., 29,99€, ISBN 978-3-8376-3050-3

Leseproben, weitere Informationen und Bestellmöglichkeiten finden Sie unter www.transcript-verlag.de 


\section{Kulturen der Gesellschaft}

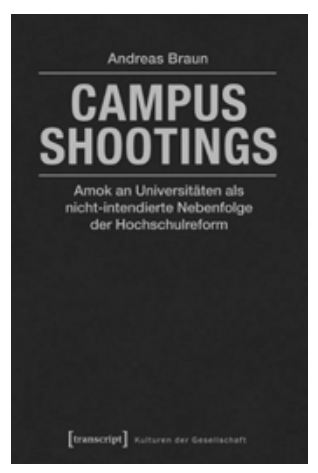

Andreas Braun

Campus Shootings

Amok an Universitäten

als nicht-intendierte Nebenfolge

der Hochschulreform

2015, 408 Seiten, kart., 34,99€,

ISBN 978-3-8376-3I30-2

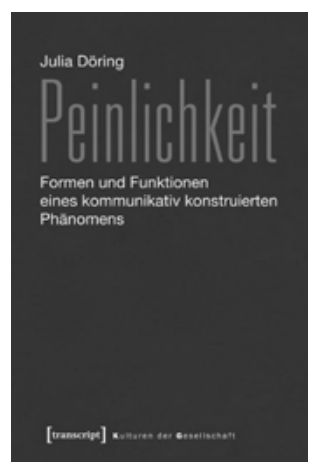

Julia Döring

Peinlichkeit

Formen und Funktionen eines

kommunikativ konstruierten Phänomens

20I5, 268 Seiten, kart., 29,99€,

ISBN 978-3-8376-3I45-6

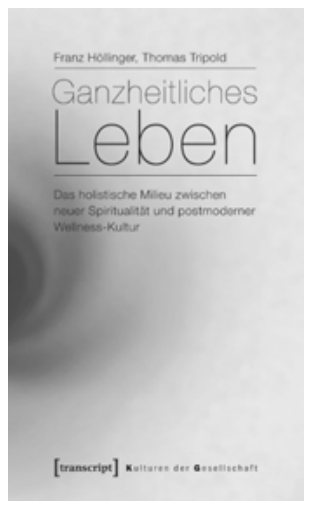

Franz Höllinger, Thomas Tripold

Ganzheitliches Leben

Das holistische Milieu

zwischen neuer Spiritualität

und postmoderner Wellness-Kultur

2012, 302 Seiten, kart., 29,80€,

ISBN 978-3-8376-I895-2

Leseproben, weitere Informationen und Bestellmöglichkeiten finden Sie unter www.transcript-verlag.de 


\section{Kulturen der Gesellschaft}

Robert Schäfer

Tourismus und Authentizität

Zur gesellschaftlichen Organisation

von Außeralltäglichkeit

20I5, 290 Seiten,

kart., zahlr. z.T. farb. Abb., 34,99€,

ISBN 978-3-8376-2744-2

Takemitsu Morikawa

Liebessemantik und Sozialstruktur

Transformationen in Japan

von I600 bis I920

20I5, 320 Seiten, kart., 32,99 €,

ISBN $978-3-8376-2832-6$

Joachim Fischer, Dierk Spreen

Soziologie der Weltraumfahrt

20I4, 208 Seiten, kart., zahlr. Abb., 27,99€,

ISBN 978-3-8376-2775-6

Michael Kauppert, Irene Leser (Hg.)

Hillarys Hand

Zur politischen Ikonographie

der Gegenwart

20I4, 278 Seiten, kart., zahlr. Abb., 29,99 €,

ISBN 978-3-8376-2749-7

Takemitsu Morikawa (Hg.)

Die Welt der Liebe

Liebessemantiken

zwischen Globalität und Lokalität

20I4, 386 Seiten, kart., 34,99 €,

ISBN 978-3-8376-2052-8

Jonas Grauel

Gesundheit, Genuss

und gutes Gewissen

Über Lebensmittelkonsum

und Alltagsmoral

20I3, 330 Seiten, kart., 32,99 €,

ISBN 978-3-8376-2452-6
Sylka Scholz, Karl Lenz,

Sabine Dreßler (Hg.)

In Liebe verbunden

Zweierbeziehungen und

Elternschaft in populären Ratgebern

von den I950ern bis heute

20I3, 378 Seiten, kart., 29,80€,

ISBN 978-3-8376-23I9-2

Cornelia Schadler

Vater, Mutter, Kind werden

Eine posthumanistische Ethnographie

der Schwangerschaft

20I3, 342 Seiten, kart., 32,80€,

ISBN 978-3-8376-2275-I

Thomas Tripold

Die Kontinuität romantischer Ideen

Zu den Überzeugungen

gegenkultureller Bewegungen.

Eine Ideengeschichte

20I2, 362 Seiten, kart., 32,80€,

ISBN 978-3-8376-I996-6

Thomas Lenz

Konsum und Modernisierung

Die Debatte um das Warenhaus

als Diskurs um die Moderne

2OII, 224 Seiten, kart., 23,80€,

ISBN 978-3-8376-I382-7

Stefan Bauernschmidt

Fahrzeuge auf Zelluloid

Fernsehwerbung für Automobile

in der Bundesrepublik

des Wirtschaftswunders.

Ein kultursoziologischer Versuch

20II, 270 Seiten, kart., zahlr. Abb., 28,80€, ISBN 978-3-8376-I706-I 